\title{
UC-NRLF
}

| ||

\$B $34 \quad 304$

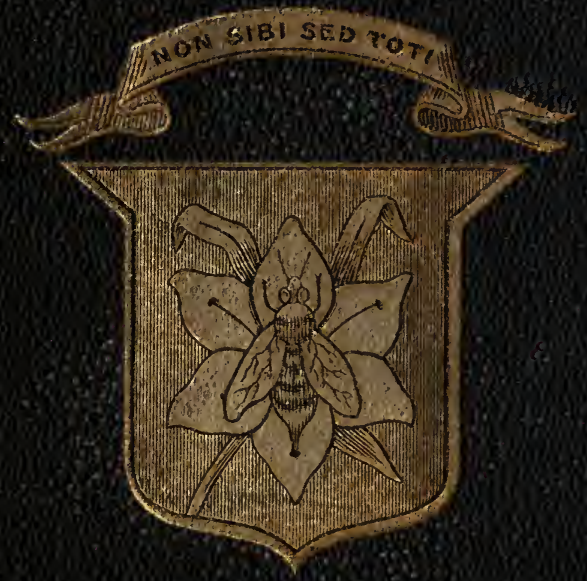

$i 0$
0
0 


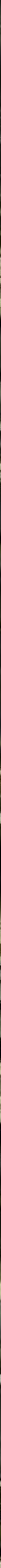




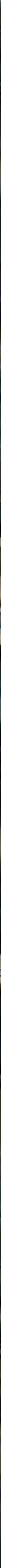







\section{HORSES AND STABLES.}

LIEUT.-GENERAL

SIR FN FITZWYGRAM, BART.

WITH ILLUSTRATIONS.

đfffth exdition (1903).

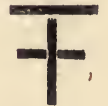

RE-ISSUE.

LONGMANS, GREEN, AND CO.

39 PATERNOSTER ROW, LONDON

NEW YORK, BOMBAY AND CALCUTTA

1911

[All Rights are reserved.] 
Printed by Adlard \& Son, London and Dorking. 


\section{$S F_{2} 85$ F585 1903}

\section{PREFACE TO FIFTH EDITION.}

THE Author desires to acknowledge with very warm thanks the valuable assistance which he has received from V. Colonel J. Drummond-Lambert, C.B., Late Director-General Army Veterinary Department, in bringing this Edition up to date.

'The principal changes in the present (5th) Edition are-

In Chapter 1, on Ventilation, the Air-brick under manger is struck out; it is retained over the manger, page 7. The other means of ventilation remain as before.

Par. 18b, Moss Litter.

Chapter 24, Influenza: Some considerable change has been made in treatment.

Chapter 29, Glanders and Farcy. Do. do.

Chapter 50, Grease and Cracked Heel. Do. do.

Par. 633, Side bones, not caused by calkins.

Par. 876, Aging of Horses: When some teeth show more wear than others, the age is generally gauged by the younger looking teeth.

Par. 931, Dishing: A "dishing" horse usually stands with his Toes turned in. To counteract this, he should be shod, so that during progress he will carry them straight. To this end he should be shod with a shoe quarter of an inch wider than the Crust on the outer quarter; but the shoe on the inside should be made about quarter of an inch narrower than the Crust; and the Crust must be rasped down to fit the shoe. The Clip of the shoe must not be placed in the centre of the front, but about three-quarters of an inch towards the outer side.

Par. 1021, Navicular disease, cause of.

With reference to Mr. Blunt's very interesting letter in the Postscript: Indian experience, I believe, thoroughly supplements his experience. The Arab of the Desert, though thorough-bred on both sides, is not reproduced on either side of the Persian Gulf. The progeny grows 15 to 16 hands high, but loses all the best qualities of the Arab. I had a hope that first-class Arabs brought to this country and kept on dry soil and fed on hard food might have blessed Mr. Blunt's patriotic endeavour to produce the true Arab of greater stature. But it has not been so, and I am sorry for it.

F. W. FITZWYGRAM. 


\section{LIST OF PLATES.}

P.lans of Stables

Paving.

WINDOW, TO DROP BACK

Grasses

HERBAGE

WEEDS .

Hock, BoNes OF

Hock, Conformation OF

Fore-LeG, Bones of

Fore-LEG, CROOKED

Fore-leg, Tendons and Ligaments of Hock-joint, Ligaments of

Knee, Front View of Bones of Off

EYE, THE

TeETh, THE

SkeletoN

Conformation of Various Points

FOOT, THE

Shoms, Fore and Hind .

Tips

TURNED-UP FORE-SHOES .

Hind Shoes for Over-Reach

LAMINITIS

PAGE

$.

$.

\begin{tabular}{l}
$\cdot$ \\
$\cdot$ \\
$\cdot$ \\
$\cdot$ \\
$\cdot$ \\
$\cdot$ \\
$\cdot$ \\
$\cdot$ \\
$\cdot$ \\
$\cdot$ \\
$\cdot$ \\
$\cdot$ \\
$\cdot$ \\
$\cdot$ \\
$\cdot$ \\
\hline
\end{tabular} 


\section{O N T E N T S.}

\section{P A R T I.}

Chapter 1.-Ventilation and Construction of Stables ... 1 Chapter 2.-Improvement of Stables of Faulty Construc$\begin{array}{llllllll}\text { TION } & \ldots & \ldots & \ldots & \ldots & \ldots & \ldots & 19\end{array}$

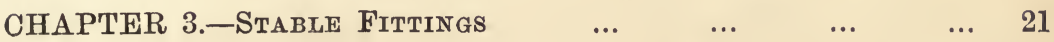

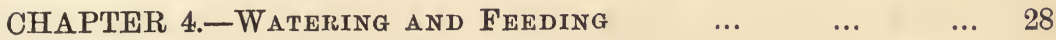

$\begin{array}{llllllll}\text { CHAPTER 5.-FORAGE } & \ldots & \ldots & \ldots & \ldots & \ldots & \ldots & 34\end{array}$

$\begin{array}{llllllll}\text { CHAPTER } & 6 .- \text { GROоMING } & \ldots & \ldots & \ldots & \ldots & \ldots & 66\end{array}$

$\begin{array}{llllllll}\text { CHAPTER } & 7 .- \text { SHOEING... } & \ldots & \ldots & \ldots & \ldots & \ldots & 77\end{array}$

$\begin{array}{llllllll}\text { CHAPTER } & 8 .- \text { EXERCISE } & \ldots & \ldots & \ldots & \ldots & \ldots & 77\end{array}$

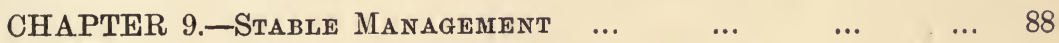

\section{P A R T II.}

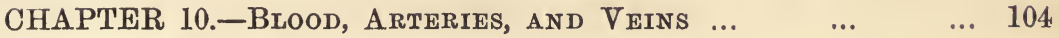

$\begin{array}{lllllllll}\text { CHAPTER } & 11 .- \text { PULSE } & \ldots & \ldots & \ldots & \ldots & \ldots & \ldots & 109\end{array}$

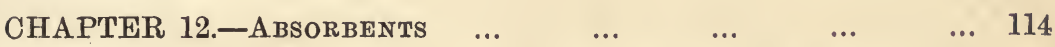

CHAPTER 13.-Structure and Uses of Various Membranes $\begin{array}{llllllll}\text { and Tissues } & \ldots & \ldots & \ldots & \ldots & \ldots & 117\end{array}$

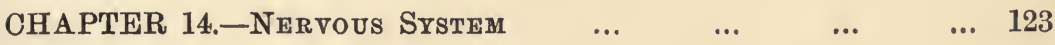

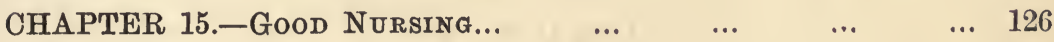

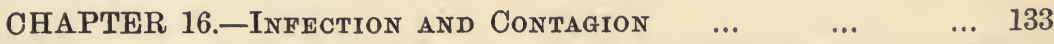

CHAPTER 17.-ACtion and Uses of Medicines $\quad \ldots . \quad \ldots \quad 141$ 
CHAPTER 18.-INFLAMMATION ...

CHAPTER 19.-OF INFLAMMATION, ARTIFICIALLY INDUCED, AS A $\begin{array}{lllllll}\text { Curative Agent } & \ldots & \ldots & \ldots & \ldots & 181\end{array}$

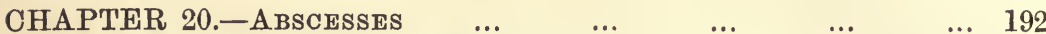

CHAPTER 21.-Ulceratron and Sloughing

\section{P A R T I I.}

CHAPTER 22.-Acute Diseases of the Organs of Respira\begin{tabular}{lllllll} 
TION & $\ldots$ & $\ldots$ & $\ldots$ & $\ldots$ & $\ldots$ & $\ldots$ \\
\hline
\end{tabular} Chapter 23.-Chronic Diseases of the Organs of Respira-

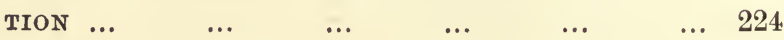

$\begin{array}{lllllll}\text { CHAPTER 24.-INFLUENZA } & \ldots & \ldots & \ldots & \ldots & \ldots & 232\end{array}$

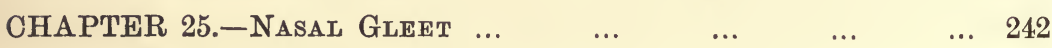

$\begin{array}{lllllll}\text { CHAPTER 26.-STRANGLES } & \ldots & \ldots & \ldots & \ldots & \ldots & 244\end{array}$

$\begin{array}{llllllll}\text { CHAPTER 27.-RhEUMATISM } & \ldots & \ldots & \ldots & \ldots & \ldots & 249\end{array}$

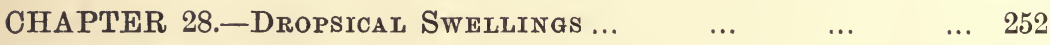

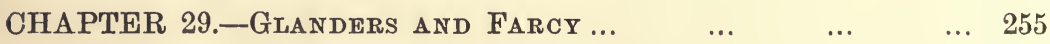

\section{P A R T I V.}

CHAPTER 30.-Colic and Inflammation of the Intestines... 262

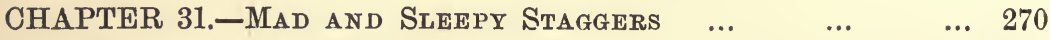

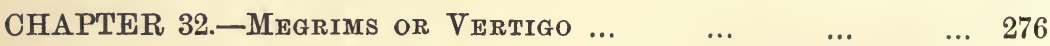
CHAPTER 33.-Tetanus or LockJaw ... $\quad \ldots \quad \ldots \quad \ldots \quad \ldots 278$ $\begin{array}{llllllll}\text { CHAPTER 33A.-PARALYSIS } & \ldots & \ldots & \ldots & \ldots & \ldots & 279\end{array}$ $\begin{array}{llllllll}\text { CHAPTER } 34 .- \text { STRINGHALT } & \ldots & \ldots & \ldots & \ldots & \ldots & 283\end{array}$

\section{PART V.}

Chapter 34a.-Repair of Injuries to Vital Structure $\ldots 284$ CHAPTER 35.-DISEASES OF Bones 


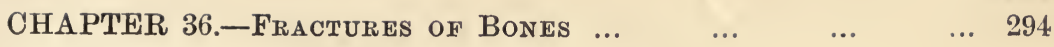

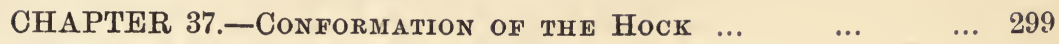

$\begin{array}{lllllllll}\text { CHAPTER } & 38 .- \text { SPAVIN... } & \ldots & \ldots & \ldots & \ldots & \ldots & 301\end{array}$

\begin{tabular}{llllllll} 
CHAPTER & $39 .-$ SPLIN'.. & $\ldots$ & $\ldots$ & $\ldots$ & $\ldots$ & $\ldots$ & \\
\hline
\end{tabular}

CHAPter 40.-Sore Shins, Ring-bone, and Ossified CartiLAGES...

\section{PART VI.}

CHAPTER 41.-BuRsal ENLARgEMENTS

Chapter 42.-Detection of the Seat and Cause of LameNESS ..

CHAPTER 43.-SYMPTOMS OF VARIOUS Diseases AFFECTING THE FEeT ..

CHAPTER 44.-SPRAINS OF Tendons AND Ligaments of THE FORE-LEG

CHAPTER 45.-Sprains of Tendons and Ligaments of the HIND LEG

CHapter 46.-Poll Evil and Fistulous Withers .. $\quad \ldots \quad 351$

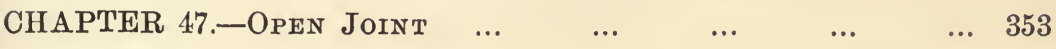

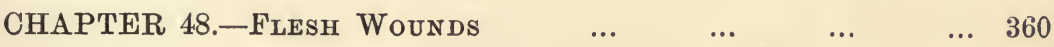
Chapter 49.-Warbles or Shight Tumours ard Sitfasts ... 369

\section{PART VII.}

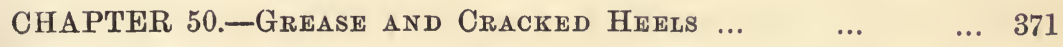

$\begin{array}{llllllll}\text { CHAPTER 51.-MANGE... } & \ldots & \ldots & \ldots & \ldots & \ldots & 374\end{array}$

$\begin{array}{llllllll}\text { CHAPTER } & 52 .- \text { RINGWORM } & \ldots & \ldots & \ldots & \ldots & \ldots & 378\end{array}$

$\begin{array}{lllllllll}\text { CHAPTER 53.-WARTS... } & \ldots & \ldots & \ldots & \ldots & \ldots & 379\end{array}$

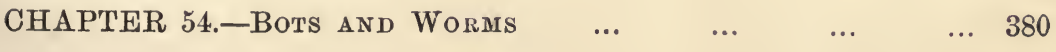




\section{P A RT VIII.}

CHAPTER 55.-Diseases of the Kidneys and Bladder CHAPTER 56.-THE LIVER

PAGE CHAPTER 57.-Diseases of the Eye ...

\section{P A RT IX.}

CHAPTER 58.-Age, AS INdicated BY the TeETh

CHAPTER 59.-LAMPAS

... 426

CHAPTER 60.-CoNFORMATION...

\section{PART X.}

CHAPTER 62.-Principles of Shoeing

... 461

CHAPTER 63.-SHOEING-DetaILS OF ...

... 471

CHAPTER 64.-Shoeing of the Fore-feet

... 489

CHAPTER 65.-Diseases of the Foot

... 492

CHAPter 66.-The Progress of Veterinary Science

... 512

CHAPTER 67.-Origin of Diseases

... 521

CHAPTER 67A.-BACTERIOLOGY

... 526

CHAPTER 68.-PoIsons ANd THEIR ANTIDotes

... 527

CHAPTER 69.-Emergent Cases

... 528

CHAPTER 70.-General SURvey of a Horse...

... 530

CHAPTER 71.-Notes ON DeNTISTRY

... 533

ADDENDA

.. 539 
Plans showing Common and Faulty Modes of Constedction of Stables.
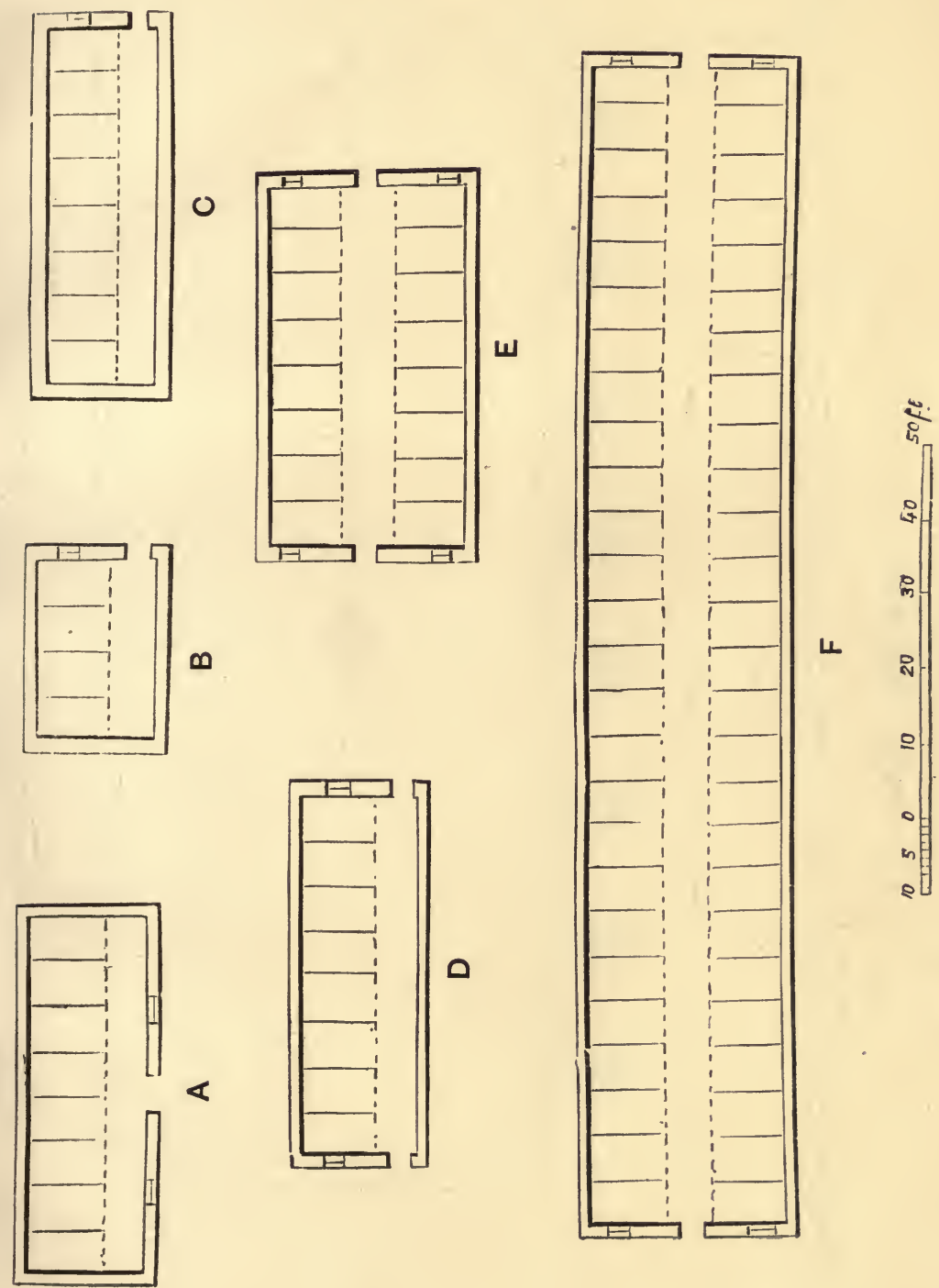


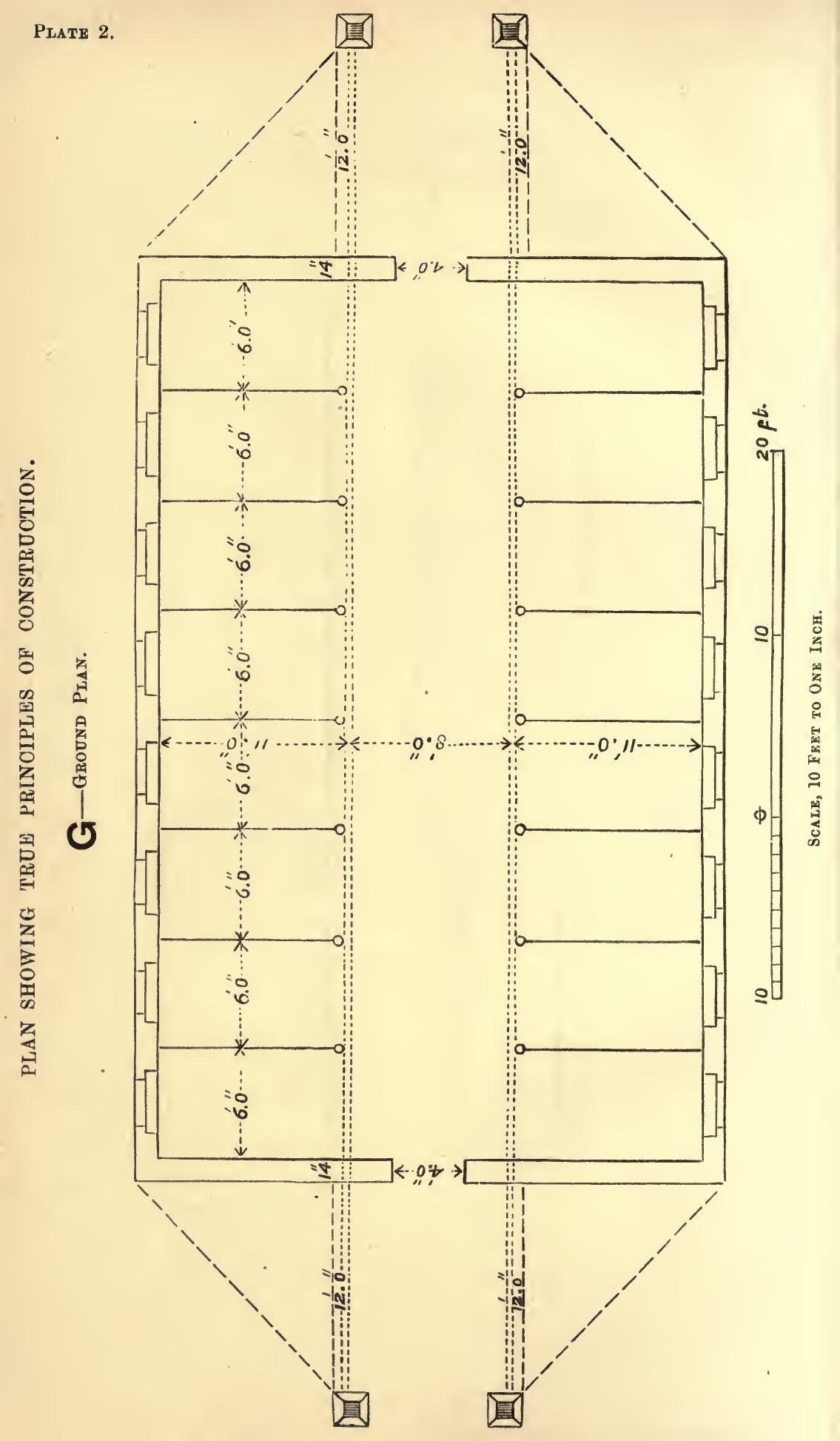


Plate 3.

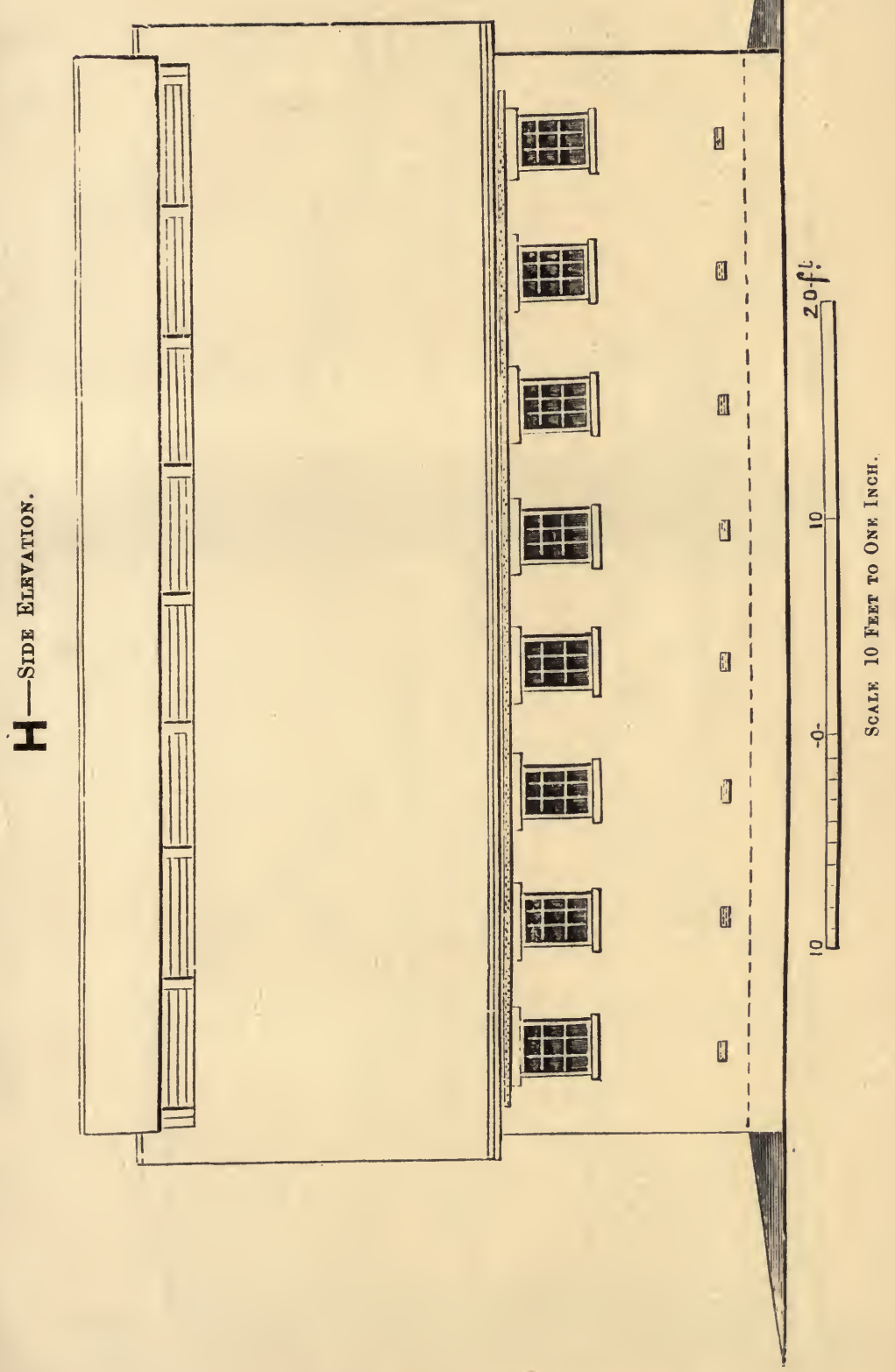



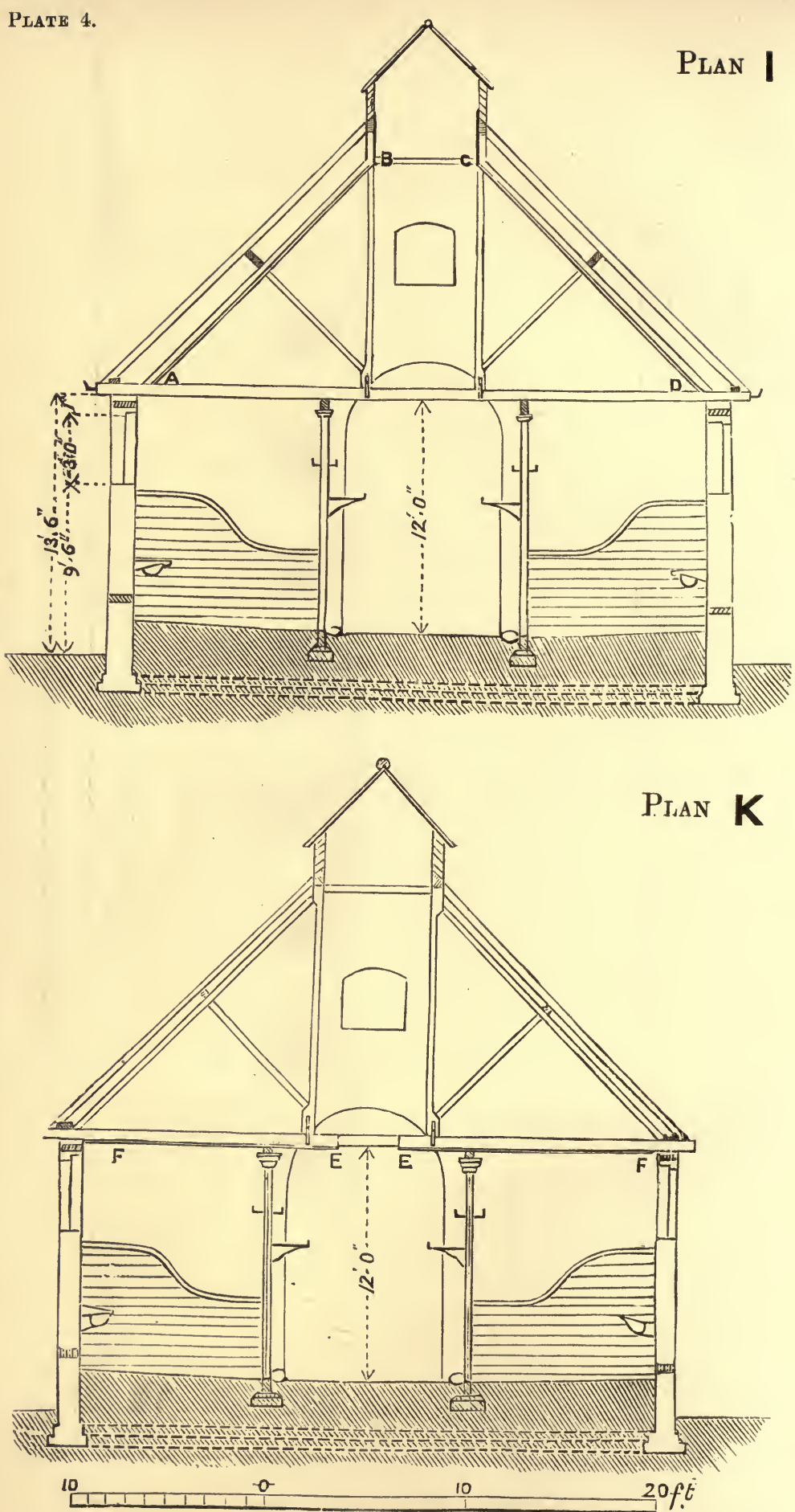

Scat. $\pi, 10$ Feet to ONe INch. 
Plate 5.

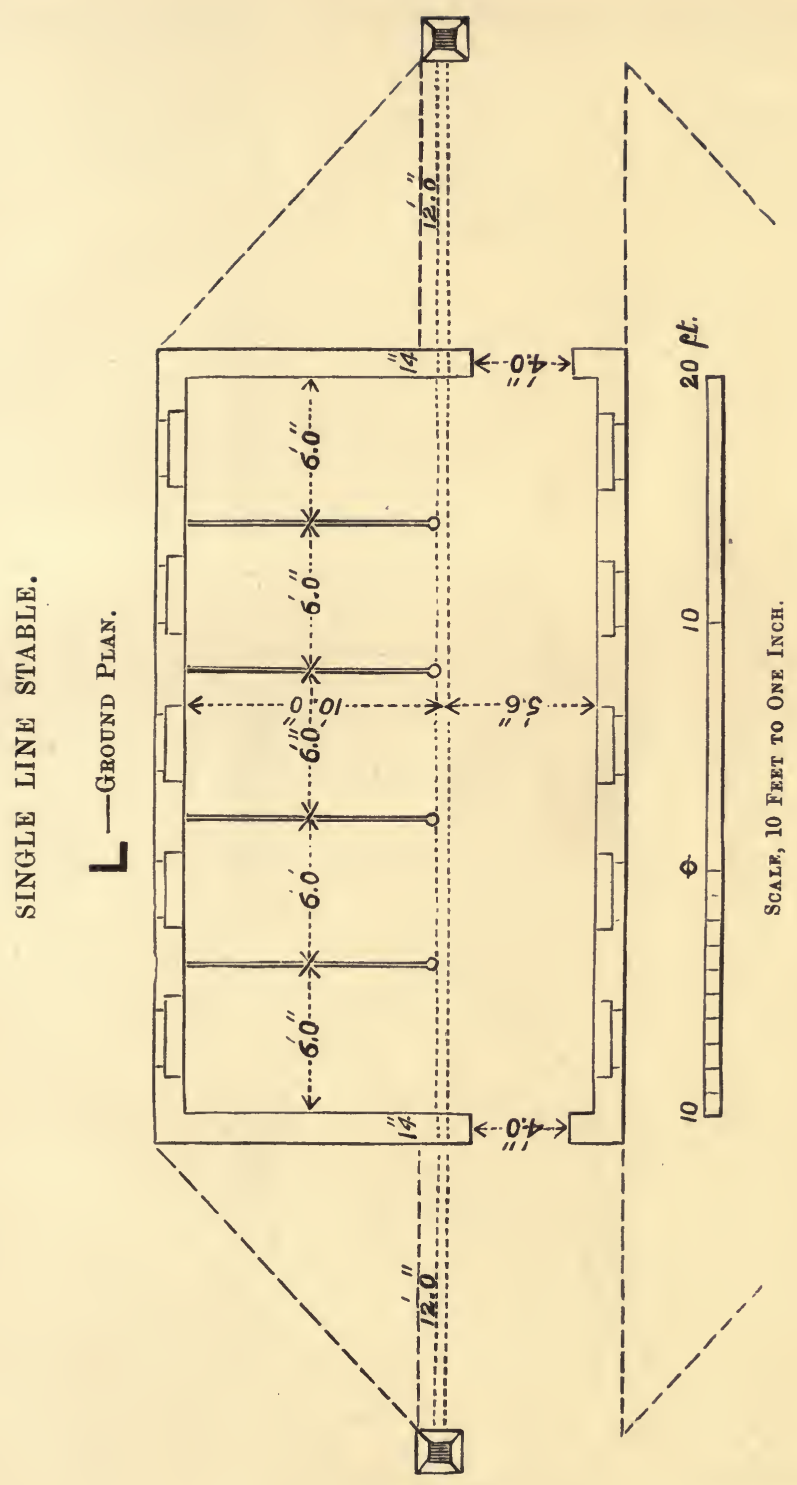




\section{Plate 6.}

\section{Plan M}

Sections to illustrate Ridge Ventilation by means of Louvres.

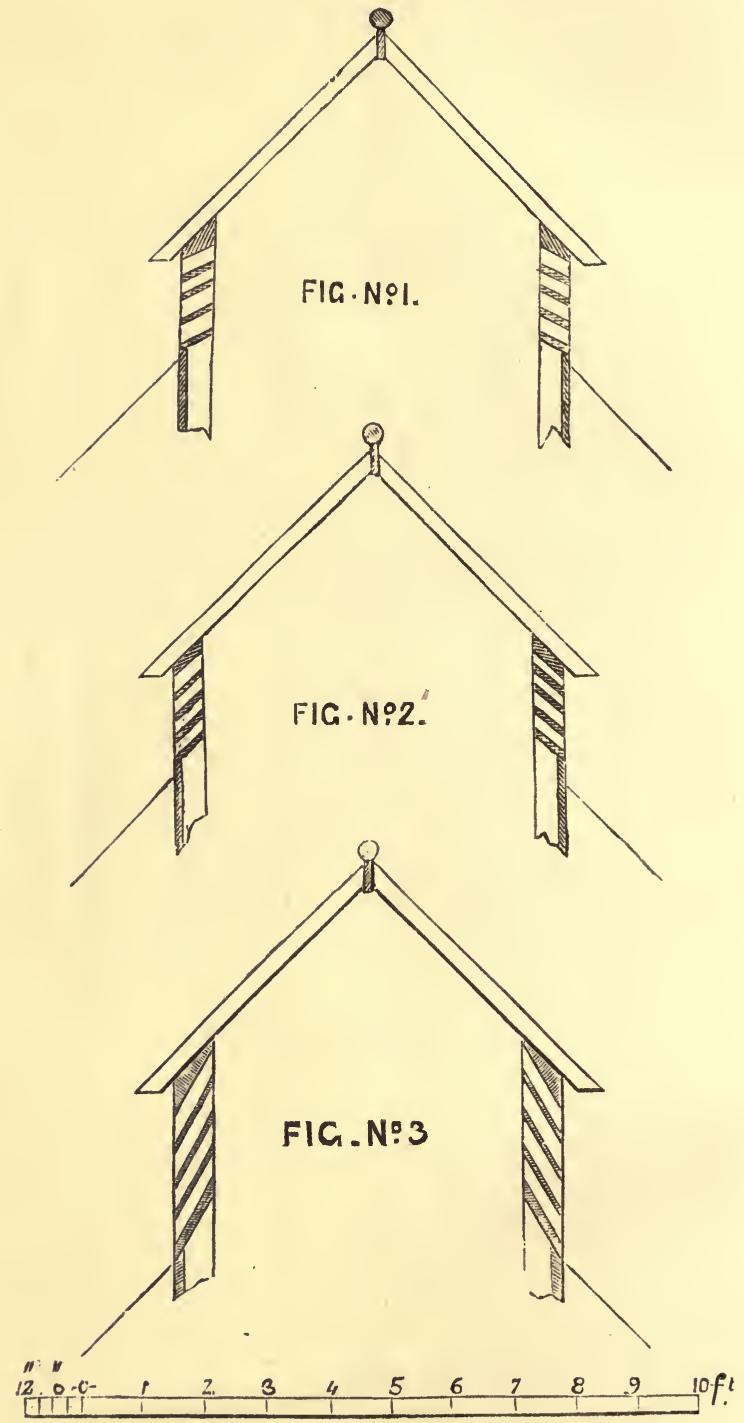

Scalk 4 Fent to ONe Inch. 
PAVING BRICKS.

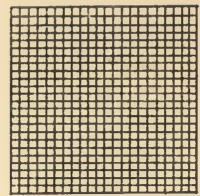

Fig. r.

Cross-cut objecled to (See Para: 16.)

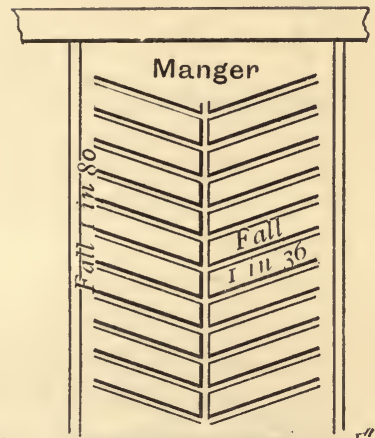

Chantul couns:

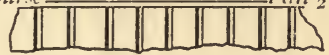

Fig. 3.

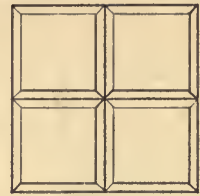

Fig, $\mathbf{I}$.

Enlarged Plan.

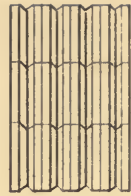

Fig. 2.

Paving .Recommended.

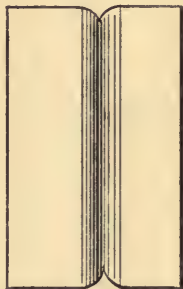

Fig. 2

Single Brick.

Angle of sroove Fig. 2. Section of Brick

PLAN OF STALL WITH CONCRETE PAVING.

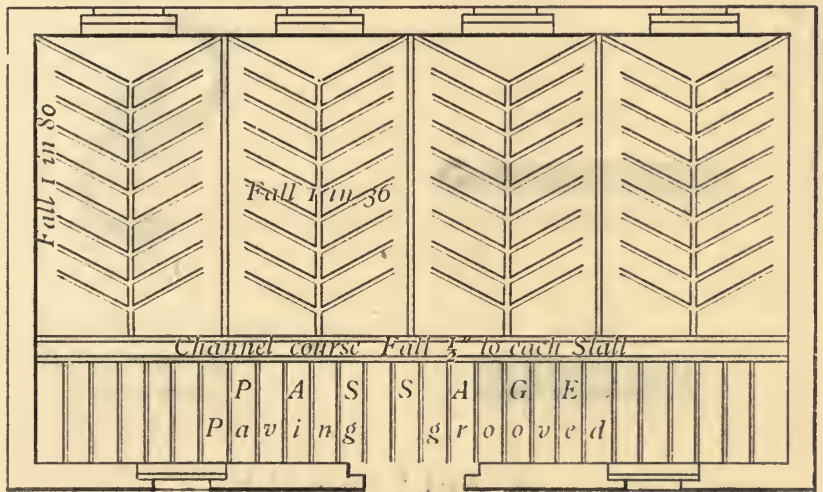

Fig. 4.

PLAN OF 4 STALL STABLE WITH CONCRETE PAVING AND CHANNELS. 


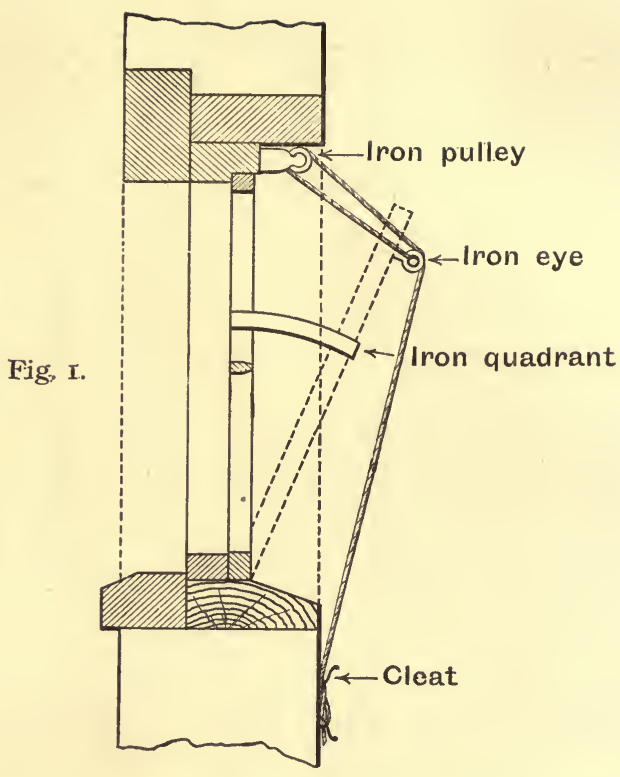

SECTION SHOWING A DROP-BACK WINDOW.

Fig. 2.

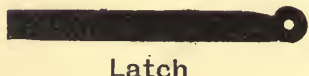

Latch

Fig. 4.

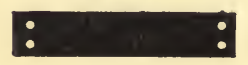

Fig. 4.

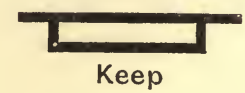

STABLE LATCH. 


\section{HORSES AND STABLES.}

- chapter 1.

VENTILATION AND CONSTRUCTION OF S'TABLES.

1. Importance of pure air. 2. Circulation of the blood. 3. Effect of breath on air. 4. Composition of the air. 5. Circulation of the air. 6. Natural facilities for ventilation. 7. Escape of foul air. 8. How the place of foul air is supplied. 9. Amount of cubical space required by horses in stables. 11. Faulty plans of construction in stables. 12. True principles of construction. 13. Louvre boards. 14. Plans of ceiling. 15. Ventilation of stables with rooms over them. 16. Paving. 16a. Drains and paving. 16b. Litter sheds. 17. Floor of the stable to be higher than the ground outside. 18. Drainage. 18a. Underground drains. $18 b$. Health without drains. 19. Slope of stalls. 20. Site of stables. 21. Aspect. 22. Walls and foundation. 23. Light. 24. Fireplaces. 25. Dimensions and cost. 26. Cheaper construction. 27. Loose boxes. 27a. Ventilation and draughts. Loose boxes and stalls. 27b. Constant attention needed to ventilation. 28. Argument against the need of ventilation. 29. Conclusion.

1. Importance of pure Air.

Pure air is as important to the integrity of the blood as wholesome food to the maintenance of the body.

The importance of pure air can hardly be adequately appreciated without some knowledge of the course of the circulation of the blood and also of the composition of the air.

It is not, however, intended, either in this or any succeeding chapter to enter into any minute descriptions of structures or processes ; but an endeavour will be made to give concisely, and it is hoped sufficiently, broad principles and facts which may enable the non-professional reader to understand the subject referred to.

\section{Circulation of the Blood.}

By each contraction or beat of the heart bright scarlet highly vitalized blood fresh from the lungs is forced through the arteries to all parts of the body. The arteries dividing and subdividing become smaller and 
smaller, and ultimately terminate in very minute hair-like tubes, called capillary vessels or capillaries. These vessels abound in every vascular structure, and from them each structure absorbs those special nutrient particles which are required for its growth or repair. In the capillaries the arterial or outward-bound system of the circulation ends.

In these same capillaries the venous or return circulation commences. Into them also are returned the waste and used-up products of the system. Reversing the previous order the capillary veins now enlarge and coalesce and carry back to the heart dark, purple venous blood, charged with the waste matters of the tissues, and among these with carbonic acid gas.

The impure blood thus brought back by the veins is carried to the right side of the heart, and thence at each contraction or beat of that organ is forced into the lungs.

The lungs contain an infinite number of cells, which through the bronchiæ and windpipe communicate with the outer air. On the outside of these cells the blood-vessels are spread. The blood thus exposed to the air takes up from it a portion of its oxygen, and gives off the carbonic acid gas and various volatile organic matters which have accumulated in it, as described above.

Thus freed from impurity, and containing more oxygen, the blood again becomes bright scarlet and adapted for the nutrition of the body; and in this state it is returned to the left side of the heart for renewed circulation through the frame. From birth to death this process is always going on.

\section{Effect of breath on the air.}

The impurities of the blood are thus transferred to the air. Air, therefore, which has been much breathed in contains too little oxygen and too much carbonic acid gas, and is besides loaded with the organic impurities given off by the lungs and also by the skin. Hence it is obvious that the condition of the blood and the health of the animal depend very much on the purity of the air supplied to the lungs.

\section{Composition of the air.}

Pure air consists of about four-fifths of nitrogen and one-fifth of oxygen with small proportions of carbonic acid gas, aqueous vapour, ammonia, ozone, and other constituents. For the purpose of purifying blood, oxygen is the chief useful part of air. Nitrogen adds largely to its volume and dilutes the oxygen, which would otherwise be much too active. Any excess of carbonic acid gas is unwholesome, and an addition of $\cdot 5$ per cent. is sufficient to render air irrespirable.

\section{Circulation of the air.}

Nature undisturbed takes her own means, into which it is not necessary here to enter, of restoring the purity of the air, or, in other 
words, of maintaining in their due proportion the proper constituents of the air. But in a closed room or stable there are no means by which she can carry on her restorative processes. Hence the need of ventilation. It is absolutely necessary to maintain or restore the proper constituents of the air, if we wish for health for ourselves or our horses.

\section{Natural facilities for ventilation.}

Fortunately the peculiar properties, or rather the state of the gases which respectively constitute foul and pure air, afford great facilities for ventilation. Heat causes all matters to expand, some more and some less; but gases under the influence of heat expand very rapidly, and to a very great degree; and as they expand, they of course become lighter.

As a general rule, foul air in a stable is also heated air. It is only necessary to breathe on the hand to feel that our breath is generally warmer than the air. And besides the breath a certain amount of heat is given off from the bodies of all living animals. Carbonic acid gas, though at equal temperatures heavier, is nevertheless, when heated, as it is when first given off from the lungs, lighter than pure air.

\section{Escape of foul air.}

The lightness of heated foul air at once affords the key for getting rid of it. It is only necessary to provide the means of exit in the highest part of the stable, and it will escape by its own inherent lightness. In fact we may get quit of it without any trouble.

But, on the other hand, supposing that the foul air has no means of escape, what becomes of it? It has risen to the top of the stable, because being heated it is lighter than the surrounding air. It will escape if it can, but if we deny it the opportunity of doing so, it must remain in the stable. It then gradually cools, and as it cools descends and becomes mingled with the air of the stable, and is in due course again presented to the nostrils to be breathed.

Although we cannot see this movement of foul air in a room or stable, it may easily be shown by experiments with coloured gases.

\section{How the place of the foul air is supplied.}

But supposing the foul air to have an exit above, how is its place, how is the vacancy caused by its escape, to be supplied by fresh air?

If there are no apertures except those above, it is clear that by the continued ascent and escape of heated foul air a tendency to a vacuum will be created in the stable. It is well known that the pressure of the atmosphere is equal to $14 \mathrm{lbs}$. per square inch. When, then, even a tendency to a vacuum has been created, the pressure of the air on the outside is sufficient to overcome the upward current of heated air; and cold, fresh air will rush in at intervals to supply the vacancy. When the vacancy is supplied, the upward current and escape of heated air will be resumed until another tendency to a vacuum is created, when a similar 
indraught will occur again. Hence the unpleasant sensation of cold draughts coming down suddenly on the head, so often complained of in rooms ventilated only from above.

To provide against any such sudden change in the direction of the current it is necessary to admit by another and lower series of apertures a certain proportion of the fresh air required.

It is not necessary that the lower apertures should be large enough to admit a volume of air equal to that which is escaping above, because, if the upper apertures are properly constructed, a considerable proportion of air will be constantly and regularly - not in sudden draughts - entering on the windward side, whilst the foul air escapes on the leeward side. In addition to which a certain amount of air comes in through the windows and under the doors, even though closed.

There is, however, confessedly great difficulty in arranging apertures for the admission of fresh air without causing an unpleasant draught in some portion of the room or stable. In this lies the more difficult and more neglected part of ventilation. No one likes the sensation of a cold draught on their own persons, and horses also appear to dislike it almost as much as human beings.

It is well, however, to remember that horses, in this respect, unlike men, rarely suffer in health from cold, unless they are heated at the time, and excepting also those doing very fast work, the pores of whose skins are consequently very open. Their food, however, goes less far, their coats become less sleek, and the highest development of condition cannot be attained when the animals are subjected to such discomforts.

\section{Amount of cubical space required by horses in stables.}

It has not yet been ascertained how much, or rather what is the minimum quantity of fresh air required by horses in stables. In a state of nature the horse, we know, enjoys perfect freedom of air and exercise. $\mathrm{He}$ is, moreover, constantly exposed to all the vicissitudes of weather and climate, for he does not, like many other animals, make cover or shelter for himself. A "mare's nest" has become a proverb.

We may, therefore, assume that in the domesticated state he ought to have an abundant supply of fresh air, with regular exercise ; and further, that he is not likely to suffer from any moderate amount of cold, although no doubt the increased action of the pores of the skin, which results from fast work and grooming, creates an increased degree of susceptibility in these respects.

Unfortunately we have but few statistics to guide us as to the quantity of air required by horses in stables. Some approximate idea may, however, perhaps be gathered from a comparison with that required for human beings.

The Army Sanitary Commission, after much investigation, have recommended that a minimum space of 600 cubic feet should be allowed for each soldier in a barrack room. Now, assuming that the capacity of the lungs of a horse is six times greater than that of a man, we might 
argue that six times greater space, or 3000 cubic feet, would be required for each horse in a stable.

Various circumstances, however, modify this calculation. The horse is not fed on animal food, and therefore the emanations given off from his body are less noxious than those proceeding from human beings; and, again, as he is far less susceptible of injury from draught or cold than man, it is possible to give to stables a greater degree of ventilation than would be tolerable in a room; and lastly, and chiefly, the horse cannot, as men too often do, close the means of ventilation.

Arguing from the experience gained in barrack stables and elsewhere, the author believes that with the concomitants of good ventilation, good drainage and paving, light and cleanliness, 1200 cubic feet, with a ground area of about 87 feet per horse, are sufficient for the maintenance of health. But no amount of cubical space, however great, will secure pure air, unless the plan of the construction of the stable and the ventilation is good. See pars. 11 and 12.

But, in regard to cab-horse stables, it must be remembered that the horses stand in the open nearly half of the twenty-four hours. As a general rule, cab stables are very well ventilated, clean, and well drained. Cab owners have learned by experience to be excessively particular about ventilation, cleanliness, and drainage. In many cab stables which the author has visited the windows have been wholly removed, and the doors are left wide open all night. Of late years there has been a very great and general improvement in the health, condition, and management of cab horses.

In the first edition of this book, the author expressed his opinion that the average duration of the London cab horse, from one cause and another, or probably. from many causes combined, did not exceed two and a half years. He is glad to be able to say, from recent observations, that the present average duration is from $3 \frac{1}{2}$ to 4 years.

\section{Fuulty plans of construction in stables.}

Many stables from their construction are difficult to ventilate properly. In some the construction is such that proper ventilation is impossible. In others ventilation is easy enough, but at the expense of an objectionable degree of draught on the horses. Lastly, be the construction what it may, insufficient cubical space necessitates an amount of fresh air passing through the stable in order to keep it sweet, which must make it cold and draughty.

The six plans annexed will serve to explain our meaning as to faults of construction.

Plan $\mathrm{A}$ is an eight-stall stable of very frequent construction. It has a door and two windows in front. If the windows are large enough, and if the paving and drainage are good and the cubical space sufficient, the construction is not very bad; but it is open to the objection, that it gives no thorough ventilation, and consequently there is no sufficient circulation of air through the stable. The windows and doors are all on 
one side, namely on that furthest from the horses' nostrils. The air enters behind the horses and passes through the stable, and picks up whatever foul emanations may have arisen from the bedding, urine, \&c., before it is presented to the nostrils to be breathed. Again, the horse stands in the portion of the stable in which the air is most stagnant.

We shall make suggestions hereafter for the improvement of these and other stables of defective construction.

Plan B represents a four-stall stable of a construction very common in London. It has only one door and one window at one end. There is no thorough ventilation. The horse nearest to the window may get some pure air, the second must get less, and the evil increases with each succeeding horse. It is impossible to have pure air in a stable of this construction. It is radically bad.

Plan C. The mischief is of course immensely augmented when this plan of construction is applied to a six- or eight-stall stable.

In London of late years the evil of this plan has been greatly diminished by making the skylight at the end, if there is one, to open.

Plan D represents an eight-stall stable having a door and window at each end, with the horses standing in a single row or line.

Plan E represents a stable of similar construction with sixteen stalls, the horses standing in two lines with a passage between them. This was until recent years the ordinary barrack construction.

Both these stables have the great advantage of thorough ventilation. They can therefore be kept pretty sweet, but not without a sensible amount of draught. It is obvious, however, that only the horses next to the windows obtain really pure air. All the rest must imbibe air tainted by the breath of the horses nearer the windows, and by the other emanations of the stable. The evil necessarily increases as the centre of the stable is approached.

Plan $\mathrm{F}$ is a double-line stable of similar construction to $\mathrm{E}$, but with 26 horses on each side-i.e. 52 in all. If there is a window on each side over each horse the stable will be healthy ; or if other buildings interfere with windows, louvre boards running the length of the stable may be substituted.

\section{True principles of construction.}

From the peculiar properties of heated air, as explained in the early part of this chapter, there need be but little difficulty in getting rid of it. The best means of doing so will be detailed hereafter.

The real difficulty lies in providing for the admission of fresh air in quantities sufficient to maintain the purity of the stable without causing in some part or other a sensible and inconvenient draught. This difficulty, however, or, in other words, the need of draught, decreases in proportion as the air has a less distance to travel before it is presented to the nostrils of the horse.

With this view it is essential, as a primary rule, that no more than two horses should be placed between the opposite sources of air. Plan G. 
In all stables the windows should be placed on both sides along the length of the stable. It is then immaterial, as regards ventilation, how many horses the stable is constructed to hold. The air has no greater distance to travel than the breadth of the building. There should be a window over the head of each horse two feet six inches in width and three feet in height. Details as to the best construction of windows and the means of obviating unpleasant draught from them when open will be found under the head of Stable Fittings, in Chapter III. In the plan marked $\mathrm{H}$ the sills of the windows are placed eight feet above the floor.

In single-line stables there should be a row of air-bricks in the front wall about 14 inches above the floor, and a similar row in the back wall above the window. For pattern of air-brick see Plate 8.

By means of the air-bricks there will be a gentle and scarcely perceptible stream of air, permeating the stables, and passing out through the upper apertures.

In double-line stables with drop-back windows on both sides, the maintenance of pure air is not difficult. Windows, however, may require to be closed, and therefore it is desirable to have a row of air-bricks on each side above the windows. The lower ventilation will be best secured by leaving a space of 1 inch between the door and the floor.

The amuunt of air entering under these arrangements will undoubtedly be considerable, but at no one point will it be so great as to create a sensible and unpleasant draught. It will be gradually, gently, and constantly diffused through the whole stable.

Traversed openings are objectionable. They are very apt to get choked, and it is very difficult to clear them out.

If the reader will now kindly turn back to plans A, B, C, D, E, and F, he will readily perceive the points in which those constructions are respectively defective.

Plans G, H, I, and $\mathrm{K}$, show various views of a sixteen-stall stable of the description which the author would recommend.

Though the plans are drawn for a sixteen-stall stable, yet the same construction is equally available and suitable for a less or greater number of horses. Plan L shows a single-line stable for five horses on similar principles, except that there is only one horse instead of two between the opposite sources of air.

\section{Louvre boards.}

For ready means of affording exit for foul air no construction offers so great facilities as an open roof with louvre boards at its ridge running the whole length of the stable. In double-line stables the depth of the louvre should be sixteen inches (plan $\mathrm{H}$ ), which will afford a ventilating outlet of about four feet of each horse. In stables in which the horses stand in a single line or row the depth of the louvre may be reduced one half. For reasons almost similar to those which have been urged in regard to the admission of fresh air, it is very essential that the foul air 
should have an exit along the whole length of the stable instead of merely by holes, pipes, or funnels in one, or two or three places.

Louvre boards are often objected to on account of their admitting rain, wind, and snow. When they admit rain, or an excessive amount of wind, the fault lies in the architect or carpenter. If each board is made wide enough to overlap well the board below, and if the pitch is sufficiently steep, no serious inconvenience will be felt.

The different constructions of louvres shown in plan M will, perhaps, explain our meaning. A louvre constructed as represented in fig. 1 will no doubt admit rain, wind, and snow. Fig. 2 will be pretty safe. Fig. 3 will be quite secure against all but snow, which will find its way into every place which is not perfectly closed. The intervals between each board should be three inches, and the breadth of the boards themselves should be nine inches. The pitch of the boards should form an angle of sixty degrees. In some very exposed situations broader boards and a greater pitch may be required. For reasons connected with good light in the stable, it will hereafter (under the head of Windows and skylights) be recommended that the "boards" be made of thick, rough $\frac{3}{8}$-inch glass.

The pitch of the roof should be somewhat steep. In plan II the height of the roof is one half its span.

\section{$13 a$.}

For cart and other horses doing slow work a raised tile along the apex of the roof is a pretty good and very cheap substitute for louvre boards.

\section{Plans of ceiling.}

Open roofs, notwithstanding the great facilities they afford for ventilation, are often objected to, because the absence of ceiling generally implied in the term "open " roof, is apt to render the stable unduly hot in summer and unduly cold in winter, and especially at night.

This objection, and it is undoubtedly a very serious objection, may be obviated without losing any of the real advantages of an open roof by putting a ceiling on the roof, but at a distance of twelve inches from it. The current of air between the slates and the ceiling will keep the stable cool in summer, whilst the distance between the ceiling and the slates will prevent the cold from striking through in winter or at night. This is a curious, but practical fact.

Some little extra expense will be incurred by placing the ceiling at this distance from the roof, because the depth of the subsidiary rafters usually employed is not above five inches. There is, however, no great difficulty or expense, because the ceiling may be attached to the principal rafters. The detail of the plan of ceiling is shown in Plan I along the lines marked $\mathrm{A} B$ and $\mathrm{C}$ D. It will be observed that the space near the apex of the roof immediately under the louvre boards, shown in the plan by the open lines from $\mathrm{B}$ to $\mathrm{c}$, is not ceiled, so that there may be no interference with the outlet of the foul air. 
Or the stable may be ceiled in the ordinary manner with the exception of an opening of a yard wide in the middle along the whole length of the stable (Plan K). The plan of ceiling is marked $\mathbf{F} \mathbf{E}$ and $\mathbf{E} \mathbf{F}$, the portion between $\mathbf{E}$ and $\mathrm{E}$ being omitted. Though the cubic contents of the stable are much reduced by this plan, yet the horses will derive a considerable amount of advantage from the air circulating between the ceiling and the roof.

With ceilings on either of the above plans, there is no reason why the louvre boards should not be made fixtures, even in stables intended for horses doing very fast work, such as hunting or racing. But if the owner likes to go to the expense, and can trust the discretion of his servants, there is no mechanical difficulty in making the louvre boards to open and shut. Either side may then be closed or left open according to the wind and other circumstances. But, for the ordinary class of horse in ordinary work fixed louvres are to be preferred in most situations. Where, however, stables are built in very exposed or bleak situations, or where there is a strong prevailing wind, it may be necessary to board up one side of the louvre ridge.

Ceilings, such as those proposed, are unquestionably advantageous for all horses, and their adoption or otherwise is simply a question of expense. The increased cost per horse in building a stable will be about $£ 5$.

\section{Ventilation of stables with rooms over them.}

The foregoing suggestions for louvre ventilation have been made on the supposition that there are no rooms or lofts over the stables. If it is desired to have rooms or lofts over the stable, as is generally the case in towns where the ground is valuable, the means of egress for foul air, though it need not be bad, yet must necessarily be inferior to that described above.

Air-shafts lined with zinc and running through the roof into the external air are the best substitutes for louvre ventilation. The openings into the air will require to be protected by a cowl at the top, and a board should be placed about six inches below the bottom of the air-shaft with the view of breaking up and diffusing any occasional downcast draught. There should be one shaft of twenty-four inches in diameter for every two horses.

It is scarcely of much use to make any recommendations as to the position of the air-shafts in a stable, where there are rooms above, because they must necessarily be fixed with reference to the convenience of the inmates of those rooms. If there are only lofts, the shafts may be placed on both sides; or one set of shafts of double size may be placed along the centre. A board should be placed about six inches below the bottom of each air-shaft with the view of breaking and diffusing any occasional downcast current. In other respects the addition of rooms or lofts over the stable need not occasion any alteration in the construction recommended in Plans G, $\mathrm{H}$, and $\mathrm{L}$. 
Neither lofts nor rooms should communicate directly with the stable. If a loft used for storing hay or corn communicates with the stable, the food will become tainted with the emanations rising from below, and the health of the animals will suffer. If rooms communicate with the stable, the health of the inmates, especially children, will suffer.

\section{Paving.}

The material required for really good paving must be non-absorbent, watertight, easily cleaned, durable, and not slippery. It is not, however, easy to find a material which combines all these requirements. Most materials, in proportion as they answer the first-named requirements, fail in the last.

Granite cubes, 6 inches deep are by far the most durable. The first cost, however, is great, and they have the disadvantage of becoming slippery after a time, but at some little expense they can be reroughened by the chisel. As the substance of the stone is homogeneous throughout they will stand re-cutting without injury.

The cavalry stables at Aldershot, which were laid down with granite cubes nearly 40 years ago, are still in use.

Hard-burnt bricks, known by various names in different localities (blue, iron, vitrified, adamantine, clinkers, \&c.), are also much used, and are much cheaper than granite. The best come from Staffordshire. They are very good at first, but it is impossible to bake the brick equally hard throughout; and hence, when the outer face is chipped or otherwise worn through, this sort of paving very rapidly wears into holes.

With the view of diminishing their slipperiness, it is the custom to indent the bricks with transverse as well as longitudinal channels. But this practice is most objectionable because the transverse channels cannot be swept out thoroughly, and consequently they retain a portion of the urine and débris of the dung and bedding. Stalls paved with transverse cut bricks are seldom, if ever, sweet. (Fig. No. 1.)

\section{6a. Drains and Paving.}

If granite cubes are used, the drainage is almost necessarily confined to one drain down the centre of each stall. This is a disadvantage.

If bricks are used, the best results will be gained (in the Author's opinion) by longitudinal drains, one drain in each brick. See Plate 7. Each channel should be $1 \frac{1}{4}$ inches wide, and $\frac{3}{8}$ of an inch deep.

This paving will give sufficient foothold, as the channels are crossways to the horse when he turns round. These longitudinal channels have the advantage that they can be swept perfectly clean without extra trouble to the servant, and they also afford drainage to every portion of the stall.

It will be observed that the channel is formed in the centre of the surface of the brick. The channel must be $\mathrm{V}$-shaped. If round at the bottom the urine will not drain off. 
Great care should be taken to get bricks of the very best quality. The best bricks at a somewhat higher price are cheaper in the end than an inferior article at a lower price.

In order to prevent the percolation of urine through the interstices of the stones or bricks into the ground below, it is essential that all paving should be laid in cement.

Of late years various kinds of Concretes and Cements have been tried for paving. They, as long as they remain perfect, have the great advantage that no urine can percolate through and foul the ground underneath. This advantage is so great and so essential to health, that the author has no hesitation in recommending them.

In all paving, whatever be the material used, the work must be very carefully executed under close supervision by an architect or competent foreman, or the result will be failure.

The cost of making the substructure cannot be stated with any accuracy, as it will vary very widely according to the cost of the necessary material in the neighbourhood.

Care must be taken to get the materials from a thoroughly trustworthy firm.

All paving requires to be laid on a substantial bed of concrete 6 inches thick, and the concrete itself should rest on a bed of broken stones 12 inches deep. No paving will long stand the great moving weight of horses unless it has a sound unyielding substructure.

No paving, whatever the material employed, will be really sweet and dry unless the whole of the bedding is removed from the stable at the morning stable hour and turned outside. The paving must then be swept thoroughly clean and left to the drying and purifying influence of the air until the horses are dressed after their return from the morning exercise, when they may be bedded down again.

Every door and window in the stable should be set open whilst the horses are at exercise.

\section{6b. Litter sheds.}

A shed should be provided for the protection of the litter in wet weather. This shed should be apart from, though near, the stable. If placed against the stable wall the fumes arising from the litter will enter the stable through windows. Again, though this may by care be avoided, the litter generally blocks up the lower ventilating apertures.

In fine weather the litter should be spread out in the open, when it will, if turned over twice during the morning, get thoroughly aired and dried.

17. Floor of the stable to be higher than the ground outside.

The floor of a new stable should be made eight inches higher than the ground outside. We name this considerable elevation, partly because it facilitates natural and surface drainage, and in some degree 
secures the stable from damp, partly on account of the tendency of new floors to sink, and still more on account of the probability of the soil outside becoming higher from constant gravelling or repairs. It is a fact easily to be observed that the floors of most old stables are lower than the ground outside, though it is improbable that such was the original construction. A pavement about 16 feet wide along the front of the stable is a very convenient annex for many purposes and especially for spreading out the bedding.

\section{Drainage.}

Surface drains are the best for stables. Each stall should drain into the main drain, which should run well behind the heel-posts so that the bedding should not get into it.

When the main drain gets outside the stable, it should be continued as a surface drain for ten feet, after which it may be safely discharged into an underground drain.

A considerable amount of space between the stable and the point of underground discharge is desirable in order to prevent any effluvia from the underground drain, which is often more or less choked, from reaching the stable. It is also useful in preventing solid matter from being carried into the underground drain. The distance, in fact, acts as a kind of natural trap.

The channel of the main drain should be open, saucer-shaped, of smooth material, impervious to moisture, and with as few joints as possible. Vitrified tiles, sometimes called gutter bricks, or slabs of stone chiselled to the proper shape, set in cement, or wide open wrought iron conduits answer exceedingly well. Cast iron conduits frequently break under the treading of the horses, and are a constant source of annoyance. Narrow iron pipes, almost closed at the upper side, such as are generally used, do not answer, because they very readily become choked, and in fact require to be cleaned out with a picker every morning, a duty which is apt to be neglected.

For the drain in the stall a fall of 1 in 80 will be required; and the same for the main drain in the rear of the stall. Any collection of débris in the channel, and any consequent tendency of urine or water to lodge, can easily be cleared away by the broom. At its starting-point the level of the main drain should be but very little below the surface of the floor, but its depth must necessarily increase towards the outfall. In long stables undue depth of the main drain may be avoided by making it fall from the centre to both endis of the stable.

\section{8a. Underground drains.}

Of course it is possible to utilise underground drains. But as a practical fact the best plan is to take up the drains, re-make the soil, and adopt surface drainage. 


\section{8b. Health without drains.}

It is a practical fact that stables can be sweet and the horses healthy without any drains at all. From various reasons-level of ground, surrounding buildings, 2 or 3 tiers of horses, etc.-it may be impossible to drain the stables.

The main factor in this system is moss litter aided by abundance of fresh air and cleanliness. Every morning every atom of the bedding, which is wet or otherwise tainted is removed from the stable. The rest is raked to the sides and front of each stall. The floor is then thoroughly swept down and exposed to the air until the horses are bedded down. If the tainted litter is wholly thrown away, $50 \mathrm{lb}$. per horse per week will be required. If the litter is dried and used again, $30 \mathrm{lb}$. to $40 \mathrm{lb}$. may be sufficient. Experience for several years past has abundantly shown that the health of horses can be maintained under this system, if it is thoroughly carried out.

\section{Slope of stalls.}

Horses undoubtedly stand most comfortably on a perfect level, and any slope more than absolutely necessary for drainage purposes is decidedly objectionable. Any great degree of slope is positively injurious, because it throws an undue stress on the hind quarters and also on the flexor tendons of the fore-legs by reason of the toe being more elevated than the heel.

\section{Site of stubles.}

The well-bred horse is a native of a dry country, and loves dryness. In dainp he soon loses all life and spirits, and becomes debilitated. Disease of any sort is very apt to supervene on debility.

The site of every stable should be deeply thorough-drained. The soil selected should, if possible, be gravel. The situation should be moderately high, open, and with facilities for natural drainage. Bleak situations are not desirable. Buildings in the immediate neighbourhood, if high, are objectionable. The ordinary custom of erecting stables and coach-houses round three sides of a square is not the best. The air always hangs more or less in any such almost enclosed space.

\section{Aspect of stables.}

A northern aspect is cold and cheerless, whilst a southern aspect is often unduly hot in summer. In stables with windows on both sides east and west aspects will, as a general rule, be found most advantageous. The one side will have the morning, and the other the afternoon sun. There should be a door at each end or in the middle on each side, as may be most convenient to the particular locality. Either door can then be used according to the circumstances of the weather and wind. If the stable is very large, it is desirable to have doors both at the sides and ends. 


\section{Walls and foundations.}

The material used in building will of course depend on the cost in the particular locality. If the maintenance of an even temperature be an object, the walls ought to be thick, and they may also be plastered on the inside. But, except for such special purpose, nothing answers so well for the inside of the stable as glazed bricks of any neutral tint. If they cannot be procured, the inside walls should be well pointed and neutral-tint washed.

A stable such as that shown in plan G, where the horses stand in double line with a broad passage down the centre, will need walls of fourteen inches thick, if built in brick, on account of the rather wide span and consequent weight of the roof. But single line stables on a similar plan will not require more than a nine-inch wall.

The foundations should be laid on slates, or on two courses of hard bricks set in cement, or in asphalte in order to prevent the damp from rising by capillary attraction. New stables should be well and thoroughly aired and dried before they are inhabited.

\section{Light.}

Ventilation, paving, drainage and sufficient cubical space, such as recommended above, will render it possible to obtain almost perfect purity of air both by day and night. But light and the supervision of the owner are likewise necessary in order to ensure cleanliness, and the best stable management.

Windows, such as those described, will undoubtedly give more light than is found in most stables, and probably sufficient for the maintenance of the health of the eyes. But the best light for the purpose of supervision is that introduced vertically from the roof. It shows the sides and corners of the stable, and enables the cleanliness or otherwise of every part to be seen at once. In unceiled stables, a row of glass "slates" can be introduced without expense in the original construction of the roof; and if placed on the north side will not cause an undue glare. Skylights in other aspects are open to the objection, that during certain hours of the day, especially during summer, they cause an undue glare, and the rays of the sun fall directly on the bodies of the horses. This may be rectified by white-washing the glass. Details as regards various sorts of windows will be given under the head of Stable Fittings, Chapter III.

\section{Open fireplaces.}

The horse in a state of nature attains his highest physical development in a warm dry climate, as in Arabia. In cold climates, in Shetland for instance, the breed dwindles down to a pony. In wet and moderately 
warm pastures, such as Flanders, the horse grows large and coarse. In cold wet climates the horse is not, we believe, found in the wild state.

Warmth and dryness we may therefore assume are needed for the development of the best powers of the animal, though the former is not essential to his health. The Shetland pony is perfectly healthy, hardy, and enduring.

Pure air and freedom from positive damp will be obtained by the plans of building already recommended, and a fairly even temperature by night and day may be maintained, if thick walls and ceilings are also adopted in the construction; but sufficient warmth and perfect dryness will be wanting during many days and nights in the course of the year in this climate. Clothing will do much to supply the animal's body with warmth, exercise and grooming with high feeding will do more; but none of these will raise the temperature of the stable, or get rid of the moisture inherent in the air in this country on certain days and in certain seasons.

If the matter rested here, it would not signify much-the coat might stare a little, the food might be to a certain degree wasted in maintaining the heat of the system instead of producing flesh, and the general condition might be somewhat lower than it would be under perfectly favourable conditions of warmth and dryness.

But the matter does not rest here. The groom will have the stable warm, whilst probably from ignorance he will not object to its being moist or even damp and foul. He will stop the egress of the foul moist heated air produced by respiration, and also the ingress of cold fresh air; and by these means, aided by the caloric loaded with impurities given off by the breath and bodies of the animals, he will raise the air to the desired temperature. In some cases he will crowd an additional number of animals into the stable in winter on the plea that they will keep each other warm. The air, however, will be foul and moist, not pure and dry, such as the well bred horse loves.

As a matter of fact the groom is quite right in desiring warmth for the horses under his charge; and any owner of horses will do well to meet his views by supplying the stable during the latter part of the autumn, winter, and early spring, with heat artificially generated, such as that produced by open fires. Open fires, though somewhat more expensive, are better than stoves or hot air or hot water apparatus, because they assist and promote ventilation. There is really no good reason why the owner of valuable horses should grudge the expense of open fireplaces. A grate is not an expensive article, nor will coals form any material addition to the expense of a hunting or racing establishment. The horses will gain in health and condition far more than is counterbalanced by the trifling extra cost.

\section{Dimensions and cost.}

Six feet is a fair average width for stall, but very large horses require 
an extra foot. The length of the stalls should be 11 feet inclusive of the heel-post.

If the stable be 16 feet, which is a fair average width, it will be best to allot 11 feet to a stall, and $\mathbf{5}$ feet to the passage.

The height of the walls from the floor to the spring of the roof should be twelve feet. In order to give this height in the inside, after allowing for the floor being raised 8 inches above the ground outside, the walls will really require to be 12 feet 8 inches, as shown in plan $H$.

The pitch of the roof should be somewhat steep. A height of one half the breadth gives a fair pitch. Plan $H$. Flattened roofs, though they may cost a little less in the original outlay, are a constant source of trouble and expense.

The dimensions, which are shown in plan $\mathrm{G}$ with an unceiled open roof, will give about 1700 cubic feet per horse. With a ceiling placed close along the roof as in plan I, there will be 1660 cubic feet, and with a ceiling placed as in plan K 1030 cubic feet per horse, exclusive of the air circulating between the ceiling and the roof.

\section{Cheaper construction of stables.}

All horses, even though the commonest, equally need for the maintenance of health the essential requirements of good ventilation, paving, drainage, light, cleanliness, and sufficient cubical space; though they do not equally need warmth and the maintenance of an even temperature.

It becomes, therefore, necessary to consider how the essentials can best be retained, whilst the cost is reduced.

Louvre boards demand a certain amount of extra strength in the roof, and are also in themselves a somewhat considerable item of expense. In lieu of them the crown tile may be simply raised along the whole length of the ridge of the roof. The ventilation, though inferior to that given by louvre boards, will be fairly good, and the plan is much cheaper.

In a stable intended only for cart or other horses doing slow work much expense may be saved by making use of felt instead of slates or tiles for the roof. Good felt properly tarred every third year will last about twenty years. Corrugated iron may also be used. It has the advantage of being incombustible. But on the other hand, it is hot in summer and cold in winter. As the timbers necessary to carry these light materials need not be at all strong, they will require to be supported by posts in the centre. These posts can be furnished with brackets, and thus conveniently made available for hanging up harness.

Again, boarded partitions between stalls are by no means essential. A bale hung by a rope is sufficient. The windows, instead of being hung or made to drop back, can be simply made to open on a pivot in the centre.

Economy may be also practised, according to local circumstances, in the material used for the walls. In some places, where the nature of the soil affords facilities for making it, concrete may be used, and much money saved. 
Good paving, good drainage, and ample light, and ventilation are essentials in stables of any class; and the author thinks that any saving which entailed deficiency in these points would be very ill-judged.

\section{Loose Boxes (see Par. 38).}

\section{7a. Ventilation and Draughts. Loose Boxes and Stalls.}

Whilst a constant supply of fresh air is essential to health, draughts are most objectionable. The question is how to supply a sufficient amount of fresh air without a draught in some part or other of a stall or loose box. This trouble has puzzled all human ingenuity in public halls, where every part of the hall is occupied; and probably the desired end, namely, the admission of fresh air without draught in some part or other of the hall cannot be achieved. There must be a draught; the real question is, how to get out of it? In a stall, where the horse is tied up, and practically in a fixed position, he may not be able to get out of it; but in a loose box the horse can get out of it, and he has instinct enough, or call it sense enough, if you will, to do so (always provided he is not tied up). For this reason, and almost for this reason alone, the author has no hesitation in recommending loose boxes in preference to stalls.

\section{7b. Constant attention needed to Ventilation.}

Our climate is very variable, and therefore the amount of ventilation in a stable requires to be adjusted not once a day, but constantly throughout the day. A good servant will look to this most important point, especially if he find his master takes an interest in it.

\section{Argument against the need of Ventilation, \&c.}

In opposition to the views, which have been expressed above as to the paramount necessity of ventilation, light, cleanliness, drainage, and sufficient cubical space, it is often urged that the great majority of horses get on without them.

To this we reply, first, that the average amount of sickness and mortality among horses is far greater than it need be under more rational treatment and management; and, secondly, that though the horse in common with other animals, and indeed with man, has a certain power of adapting himself to the circunistances in which he may be placed, yet it is evident that the conditions of nature ought to be followed as nearly as possible. Animal life is always most perfectly developed, and its functions best performed by conforming to those conditions. 
29. Conclusion.

Much more, however, than these primary essentials are needed to ensure health and condition in the domesticated horse. Careful attention to diet, grooming, exercise and general good stable management must be added. 


\section{CHAPTER 2.}

\section{IMPROVEMEN'T OF S'TABLES OF FAUL'TY CONS'IRUC'TLN.}

30. Ventilation. 31. Paving. 32. Light. 33. Deficient space. 34. Conclusion.

\section{Ventilation.}

THE recommendations which have been made in the preceding chapter in regard to the construction of new stables would be incomplete without some suggestions for the improvement of defective buildings. In our suggestions we shall endeavour to carry out, as far as circumstances admit, the principles laid down above. For illustrations of plans of bad construction the reader is referred to plans A, B, C, D, E, and F in the preceding chapter.

All such stables, unless surrounding buildings interfere, may be radically improved by making windows on both sides along the whole length, and by making an aperture under each manger, and inserting in it an air brick.

If, however, as is often the case in towns, circumstances, or perhaps the covenants of the lease, even though no buildings interfere, prohibit the making of windows, apertures nine by six inches should be inserted in the wall near the ceiling on both sides; or, if no aperture can be made, air bricks should be inserted in the front wall.

If surrounding buildings or other circumstances prevent the possibility of making apertures along the length of the wall, an air flue with an aperture of four and a half inches by three under the mangers should be carried along the whole length of the stable; and another air flue with apertures of double the size, or nine inches by six, should be carried along close to the ceiling. The size of the outlet air flues must be the sum of the combined areas of the apertures, and will, therefore, vary according to the number of the horses in the stable. It is absolutely necessary that each air flue should open at both ends directly into the external air. The exterior openings must be protected by perforated zinc, to prevent excessive draught.

Ventilation by means of louvre boards along the ridge of the roof should also be provided in every case, where rooms over the stables do not prevent its adoption. Where rooms interfere, air shafts of two feet in diameter, in the proportion of one shaft for every two horses, should be carried up through the ceiling and intervening rooms to the outside of 
the roof. A board should be placed about six inches below the bottom of each air shaft to break and diffuse the draught; and the top of the shaft should be protected by a cowl. When merely a loft intervenes, it should be removed, or at least thrown open in the centre, and proper ventilation and light thus secured through the roof.

If the owner objects to the expense of any such alterations, he may at least have ventilating panes put in the windows and gratings in the doors, or insist on the windows being left partially open both by day and night. Nothing answers better than cutting two inches off the bottom and one inch off the top of the door. The horses' coats may suffer from the amount of air thus rudely introduced by this latter plan, but their health will improve.

\section{Paving.}

Good paving is essential to health. It may always be obtained, even in the oldest stable, at a certain expense. Advantage, unless the stable is very deficient in height, may also be taken of the repaving to raise the floor, and thus secure the possibility of good surface drainage.

\section{Light.}

If the light is deficient, it is very important, both for the sake of cleanliness as well as for the health of the eyes, to improve it. The question of the best means of introducing light is so mixed up with the nature of the surrounding buildings, that it is difficult to make any suggestions which will be practically useful. Vertical light, when it can be obtained, is by far the best.

\section{Deficient space.}

If the cubical space per horse is insufficient, the simple remedy is to diminish the number of horses in the stable. Twelve hundred cubic feet has been already stated to be a sufficient allowance in a well ventilated, well paved, drained, and cleanly kept stable; but if these accessories are.wanting, a much larger amount of space should be allowed.

\section{Conclusion.}

Finally, in every stable, however ill constructed, much may be done by keeping the doors and windows open as much as possible and by scrupulous cleanliness. 
CHAPTER 3.

STABLE FITTINGS.

35. Size of stalls, partitions, \&c. 35a. Breadth of passage behindhorses. 36. Inside walls. 37. Doors. 38. Loose boxes. 39. Latches. 40. Slides or bolts. 41. Hinges. 42. Collar ropes or chains, and logs. 43. Casting in the stall. 44. Head collars and neck straps. 45. Foot-fastenings. 46. Muzzles. 47. Mangers. 48. Hay racks. 49. Forage stores and lofts. 50. Paving, slope of stalls, and drainage. 51. Windows. 52. Slings.

\section{Size of Stalls, Partitions, \&c.}

For stalls divided by partitions a width of six feet is desirable for horses of the ordinary size; whilst for large carriage horses seven feet should be allowed.

The length should be 11 feet including the heel post. The passage behind should be 5 feet. The heel post, into which the partition is inserted, should be rounded off, so as to be as little likely as possible to injure the horse if he kicks against it.

A height of seven feet and a half should be given to the upper end of the partition, in order to prevent the horses from biting at each other, whilst five and a half feet will be sufficient for the remainder. Both in order that the horses may see each other, and that the current of air through the stable may be as little impeded as possible, the extra height of the upper end should be made of open iron-work of any ornamental pattern. Straight iron railings do not answer, as horses are apt to catch at them with their teeth.

The boarding of the partitions should not be continued within 6 inches of the wall. The interval or open space will act beneficially by allowing the air to circulate freely along the back wall of the stable. With a like view to ventilation, and also in order to preserve the woodwork from the injurious effect of damp, an interval of two inches should be left between the bottom of the partition and the floor of the stable.

Oak is the best material for the boarding of partitions, but it is expensive. Good red deal, one and a quarter inch thick, answers very well, and is comparatively cheap.

For stables divided by bales a width of five feet six inches is sufficient, though six feet are preferable. It is essential that the mode of hanging the bale should be such that it may be easily unhooked in case the horse gets cast.

Where each horse is of great value the owner will naturally wish to guard himself against the risk of one horse kicking another by putting 
partitions between the stalls; but in a sanitary point of view bales are preferable, both because they interfere less with the circulation of air through the stable and because the stable is more easily swept out and kept clean. On the other hand, horses lie down much more in boxes than between bales.

\section{5a. Breadth of passage behind Horses.}

Horses are tied to the manger, and cannot get further back than the collar ropes allow. Therefore, if the long partitions recommended above are used, the width of the passage may be reduced to the same extent as the partitions are lengthened. With long partitions five feet will be sufficient breadth for the passage in single-line stables, and eight feet in double. If short partitions are used, six and a half feet will be required in single-line stables and nine feet in double lines.

\section{Inside Walls.}

Glazed bricks are the best material for the inside of walls. They may be obtained in most localities at a price very little exceeding that of ordinary bricks. They have the great advantage of not absorbing the moisture or other emanations of the stable, and may be kept clean and nice-looking for years by simply washing with water.

If ordinary bricks are used for the wall, it will be an advantage to put glazed China tiles over the manger, as that part of the wall otherwise soon looks dirty and black. If the cement with which they are fastened is good they answer well.

If the expense of either such fittings is objected to, a plain well-pointed brick wall, which can be grey-washed as often as need be, answers better than plaster or woodwork. The latter, indeed, is objectionable, especially over the manger, as horses are apt to gnaw it, and dirt and vermin may harbour in and behind it.

\section{Doors.}

The doors of many modern stables are hung on iron bars above, and are made to traverse to the side. In situations where room is an object, this fitting is advantageous; but for ordinary purposes the common door, which is more easily shut and therefore less likely to be left open, is preferable.

Doors should be four and a half feet wide and at least eight feet in height. Horses are apt to be startled on going into or coming out of stables, and then sometimes throw up their heads; and if the door is low may strike them against the lintel, and may in consequence ever after be shy in entering or leaving the stable.

Stable doors which do not traverse should be divided into two equal portions, except in sick boxes, where for reasons given in the next paragraph the height of the lower part should not exceed three feet six inches. As a rule, stable doors should open outwards, and should be 
furnished with a catch in the wall to prevent their swinging to suddenly in windy weather.

\section{Loose Boxes.}

Many modern stables are divided into boxes instead of stalls. The plan has many advantages, principally because the horses can stand out of a draught. Most of us know the extreme discomfort of sitting in draught, and the risk of colds, coughs, and rheumatism. Ten feet six inches square are quite sufficient for stable loose boxes, and the difference of expense in building a stable is but small.

The two end boxes, if more room is thought desirable, can be, without cost, enlarged by taking in the passage at each end.

The doors of loose boxes should always open outwards or traverse to the side. A door fitted with the ordinary latch, if it opens inwards, may occasion a serious accident, such as an injury to the eye, if the horse happens to be standing near it when it is suddenly opened.

But such loose boxes are no substitute for detached loose boxes, which should always be provided for sick horses. Stable boxes share the common air of the stable; but those intended for sick animals require purer air than is commonly found in a stable, and, moreover, they generally need to be kept at a lower temperature than is desirable for horses in full work.

It is not advantageous to make sick boxes over-large. Twelve feet by fourteen with a height of twelve feet is sufficient. In addition to the usual manger and hay rack, loose boxes intended for sick horses should be provided with a staple fixed in the wall about two feet six inches from the ground, on which a pail may be hung. Sick horses carry their heads low and always prefer to feed near the ground.

For sick boxes, when the door is on hinges and divided into two parts, the lower portion should not exceed three feet six inches in height. If higher, a sick horse who stands with his head drooped down may not be able to get it over the door so as to enjoy the fresh air. A bar, however, should be provided to go across the upper half, as otherwise horses, especially young ones, are apt to try and jump out. It is essential that this bar be placed sufficiently high above the half door to allow the horse to get his head in and out easily between it and the door. If the space is narrow, an accident may occur to the animal in drawing back his head, if he happens to get frightened.

If a traversing door is used, three bars will be needed so as to enable it to be left open. For sick boxes, however, the ordinary door divided into two parts is decidedly preferable, because the lower half shelters the patient's legs from draught, whilst he can put his nostrils over it.

\section{Latches.}

All latches are in some degree objectionable. In all, though so rounded off as to reduce the chance of an accident to a minimum, there is a possibility that a rein or stirrup leather may catch in them when the horse is 
Ied in or out of the stable. A pattern of a very cheap but serviceable latch is given in Plate 8.

\section{Slides or Bolts.}

Slides or bolts, if counter-sunk and furnished with a flush-bolt on both sides, are in some respects preferable to the best latches. The groove, however, in which the bolts work, requires to be kept oiled and free from dust and other débris.

\section{Hinges.}

The only really serviceable hinges for large doors are those of the oldfashioned T-pattern, such as until lately were rarely seen except on old church doors. Doors on such hinges will generally hang true for years, whilst the hinge itself adds to the strength of the door by bracing and binding it together.

\section{Collar ropes or chains, and Logs.}

The rope should be just long enough to allow the horse to lie down comfortably. Any greater length is objectionable. As an ordinary rule the log should just reach the ground when the horse is standing near his manger. If longer than this the rope or chain will become slack in the portion between the collar and the manger, and then the horse may get his foot over it. If shorter it will interfere with the convenience of the animal in lying down.

A rather heavy log should be used, which by its weight may assist in keeping the rope in a state of tension. The horse may be relieved of the weight of the log by placing a large ring or $\mathrm{T}$ on the rope immediately above the manger ring. The manger ring should be large, so that the rope may run easily and freely through it. The practice of tying the rope to the ring of the manger is very objectionable, and is a frequent cause of accident.

Chains, though not often used in private stables, are safer than ropes, because their weight, especially when assisted by a rather heavy log, prevents any liability to become slack. The principal objection to chains is the noise made by the animals drawing them through the rings of the manger. Ropes are preferable to leather straps, both because horses are less apt to gnaw them and because being round they run more easily through the manger ring. They are also cheaper.

In some stables the stall is boarded up flush with the front of the manger, and the lower part of the rope then runs behind the boarding. An accident may occasionally be prevented by this arrangement; but the extra boarding seriously interferes with the current of air through the stable, and dirt and dust are apt to accumulate behind the boarding.

Horses, which are given to bite their neighbours, or are apt to turn round in their stalls, should be secured by a rope or chain on both sides of the manger. 


\section{Casting in the stall.}

Casting in the stall generally arises from the animal getting his legs entangled in the rope. This accident will rarely happen, where due care is taken in regard to the length of the rope, and the use of a $\log$ is insisted on. Casting occasionally arises from the horse endeavouring to turn or roll in his stall. In such cases fastening on both sides, as recommended in the previous paragraph, will be found useful. If any particular horse acquires a habit of rolling, and in consequence frequently gets cast, he had better be kept in a loose box.

\section{Head collars and neck strups.}

Some horses are very difficult to secure at night by head collars. All, however, may be effectually fastened by means of a neck strap. A horse cannot slip a neck strap drawn to the proper degree of tightness, because the circle of the strap round his neck is less than that required to go over his head. The objection to neck straps is the injury which they cause to the mane.

Of head collars the best are those which approach most nearly to the principle of a neck strap. The great point in fitting a head collar is to take care that the back strap is long enough to come close up against the throat. Again, the neck strap should not pass over the crown of the head collar, but through a loop attached in rear of it. The strap round the neck will then be so short, without being unduly tight, that the horse cannot easily get it over his head. See Plate 8 .

\section{Foot-fastenings.}

Horses, which break or slip their collars, may all be effectually secured by a strap buckled round one of the fore fetlocks and attached to a peg driven fast into the ground. The strap should be about 12 inches long. It is a practical fact that this fastening will hold almost any horse. A few horses may pull against it for a few days, and perhaps make the fetlock sore. The strap in such case may be shifted to the other fetlock. Almost all horses, however, after a few pulls find themselves powerless, and give up with a good grace the attempt at getting loose.

\section{Muzzles.}

A really good muzzle is yet a desideratum in stable economy. It is difficult to combine free ingress and egress of air with closeness sufficient to prevent a greedy horse sucking in hay and straw.

Wire muzzles interfere but little with the breathing; but some horses break even the best of them, whilst most succeed in sucking in a certain amount of hay and straw through them. Leather muzzles are objectionable, because they interfere with the egress of the air. Those made of straps of leather are less injurious than solid leather with air holes.

A nose band fitted on the collar by closing the mouth answers as well as anything. The horse, it will be remembered, breathes through his 
nostrils. But this contrivance, though effectual as a temporary remedy, would be uncomfortable to the animal for any length of time.

The best mode of tackling a greedy feeder is to bed him down with saw-dust, peat moss, or some material, which he cannot eat.

\section{Mangers.}

Mangers should be made somewhat deeper than the usual pattern, and with a slight lip on the inside, so as to prevent the horse from spilling his corn, which he is apt to do, especially when it is mixed with chaff. A cross bar placed near each end will answer the same purpose; but it is in some degree objectionable, because it interferes with the thorough and easy cleaning of the manger.

Mangers should be made without corners or angles in which dirt can lodge. The material should be non-absorbent. Slabs of glazed fire brick answer well, and in places where the locality affords the material, are very cheap. Iron mangers are used in barracks and answer exceedingly well.

\section{Hay Racks.}

Many in the present day object to the ordinary hay rack placed above the horse's head. It is certainly not the natural position for food, but the low rack has the disadvantage that the horse may injure himself by getting his foot or head into it. To render such an accident as little likely as possible, the low rack should be made shallow and without any projecting rim on the inside of the upper bar. Again, with low racks the horse is apt to pull out all the hay, in order to choose the best locks, and then the remainder gets trodden under his feet. The author is inclined to think that the old is the best.

\section{Forage stores and lofts.}

Forage is best kept in a building detached from, though near to the stable. Where a loft over the stable, as is usually the case in towns, is used for the purpose of storing forage, care should be taken that there is no direct communication between it and the stable. Nothing can well be more objectionable than tainting the food with the emanations of the stable.

\section{Paving, slope of stalls, and drainage.}

These important questions have already been considered at length in the latter part of the first chapter in reference to the construction of stables.

\section{Windows.}

Ample light is essential to the health of the eyes. Light is indeed food and exercise to them. Without ample light the eyes cannot be 
strong. If they are altogether deprived of light, the optic nerve becomes paralysed and blindness is the result.

Again, ample light is essential to the cleanliness of the stable. A dark stable may be dirty without the owner finding it out, and, in good truth, most dark stables are dirty, and a dirty stable must be unhealthy. Both eyes and lungs are especially liable to injury from the gases produced by impurity.

There is an idea that horses put on flesh more rapidly in a dark than in a light stable. It may be so, and it is certain that dealers generally keep their stables somewhat dark. But the main object of the dealer in doing so is, we suspect, to show his horses off to the best advantage to a customer. Horses brought suddenly from comparative darkness into light do not see well at first, and therefore step high in order to avoid possible obstacles in the way. The defective vision so occasioned will scarcely be pleaded as an advantage except for a special purpose such as the above.

Windows, as distinguished from skylights, are intended for purposes of ventilation as well as for giving light. Skylights, however, can be made to open.

Air bricks and ventilating openings are all very well in their way, but for all real freshness in stables there is nothing like windows wide open whenever the weather admits.

Whenever the horses are out at exercise, every door and window should be set wide open.

Four sorts of windows are commonly used in stables of the better class, namely, 1st, the ordinary sash windows, which, if furnished with ropes and pulleys, so as to let down easily from the top, answer well enough. They are, however, open to the objection, that a direct draught may come on the horses, and on this account it is often necessary to close them altogether at night and in cold windy weather. A couple of panes of perforated glass are useful in such windows.

2nd. Windows, which turn on a pirot, in the centre. These may be set open to any required degree. They are the cheapest construction, and answer well enough, especially where many small windows are used; but they are in some degree open to the objection of causing a direct draught on the horses.

3rd. Windows, which do not open wholly, but are furnished with glass louvres, are used in some stables. They are objectionable, inasmuch as they are not calculated to admit a sufficient amount of air.

4 th. Windows working on hinges at the bottom, as shown in the plan annexed, may be made to open to any required degree. They offer every advantage. They afford ample ventilation, and yet do not throw a direct draught on the horses. They should be blocked, so as to prevent their closing within six inches at the top. As no direct draught can come on the horses, when they are closed to this degree, the author thinks that no injurious result can ever arise from their being left open to the above degree at all times and seasons. Plate 8.

When a stable is furnished, as recommended above, with windows on 
both sides, the sort of window to be adopted is not very material, because the requisite amount of fresh air can at all times be obtained from the windows on the lee side without causing an injurious amount of draught.

\section{Slings.}

A set of slings is a useful adjunct in a stable. When due and constant care is used in their adjustment and frequent readjustment, they are calculated to give great relief in some cases of severe injury; but without such care, they often do more harm than good.

\section{CHAPTER 4.}

\section{WATERING AND FEEDING.}

53. Course of the food. 54. Course of water. 55. Small size of stomach. 56. How often is it necessary to feed? 57. Best times for feeding. 58. Regularity desirable in the hours of feeding. 59. Necessity of good forage. 60. Of watering. 61. Quantity of water to be given at one time. 62. Horses to be watered before being fed. 63. No objection to watering horses when warm. 64. Dirty v. clean water. Hard v. soft water. 65. Scouring. 66. Delicate feeders.

\section{Course of the food.}

Ir may be useful in the first instance to trace very briefly the course of food from its reception by the mouth to its final evacuation.

Food is gathered by the lips and front teeth. It is worked about by the tongue and cheeks, and is carried by their action to the back teeth or grinders, which by a lateral and slightly rotatory motion of the lower jaw reduce it to a pulp. During this process it is mixed freely with the saliva and mucous secretions of the glands of the mouth. Saliva is essential to the due preparation of the food for digestion. When it is sufficiently prepared, it is passed on in portions by the action of the muscles of the tongue to the asophagus or gullet, and thence to the stomach.

The stomach is a pouch lined for about one third of its surface with a dense cuticular membrane, and the remaining two thirds is lined with a soft reddish villous mucous membrane.

The muscular coat of the stomach is furnished with three layers of fibres, namely, the circular, longitudinal, and oblique. By the action of 
these three series of muscles the food is rotated over the cuticular and villous linings of the stomach; whilst by the secretions of the softer or villous lining it is supplied with a fluid called the gastric juice, which is essential to the further process of digestion. The food at this stage is called chyme.

The action of the muscular coat producing rotation of the food is due to nervous influence; but the immediate stimulus on the nervous system of the stomach is the food itself. When the stomach is quite empty, the rotatory motion ceases, and the pouch is then in a state of contraction and quiescence.

During the successive rotations such portions of the food, as have become sufficiently soluble, are gradually pressed forward and passed on to the small intestines. In them it is further mixed with the secretions of the pancreas, liver, and intestinal glands. The admixture of these juices completes the preparation of the food, and it is now ready for absorption into the system.

The process of absorption is effected in the following manner. The abdominal veins and the lacteal absorbent vessels of the intestinal linings take up from the food its nutritive parts, which in this state are called chyle. The chyle is carried by the absorbent vessels through the mesenteric glands into the thoracic duct, and by it is ultimately discharged into one of the large blood-vessels on the left side of the neck near the heart.

It is by this constant admixture of material taken up from the food by the absorbents that the necessary supply of blood is maintained. From the blood thus maintained by the food are furnished the materials required for the maintenance and renewal of the body. The food supplies the blood, which in its turn supplies the body.

To revert to the course of the food. When the veins and absorbents of the small intestines have taken up from the food its nutritive parts, the refuse is passed on to the large intestines. In them a further system of absorbents take up from the refuse whatever little nutriment may yet remain in it; and the residuum, along with the waste products of the body excreted into the intestines, is cast forth by the anus as dung. Such is the preparation and course of the food.

\section{Course of water.}

The coursc of water through the body is somewhat different from that of solid food. Water does not lodge in the stomach, but merely passes rapidly through it and the small intestines on its way to the crecum or blind gut, which may be considered as the real water stomach of the horse. The cæcum, we may mention, is one of the large or lower intestines. From the cxcum the water is gradually taken up by the veins and absorbents according to the requirements of the system, and poured into the large blood-vessels in the neighbourhood of the heart.

Eventually, along with the effete or worn out nitrogenous matters and 
certain salts, it is excreted partly from the lungs in the form of aqueous vapour, partly from the skin in the form of perspiration, and in larger and more notable quantities it is discharged from the body as urine through the medium of the kidneys.

\section{Small size of the stomach.}

The capacity of the horse's stomach is small in comparison to his frame. He therefore requires to be fed frequently. In a state of nature the horse is almost constantly browsing, and yet it is rarely so full as to be unable to exert his power of flight. Convenience, however, of servants, and the hour at which we require the domesticated animal for work, must in some degree modify our times of feeding.

\section{How often is it necessary to feed?}

Experience has shown that it is sufficient to feed the horse three times a day. Less frequent feeding is decidedly objectionable. The corn should be divided into three portions, and the hay into two. It is best not to give any hay at the feed preceding the time at which the animal is likely to be required for work. He will do his work easier if his stomach is somewhat empty than if it is distended with hay. Hence, if a horse is used in the morning, the portion of hay should be omitted at the early feed, and reserved for midday and evening. If, on the other hand, he is required for work in the afternoon, he should get his hay in the morning and evening. Hunters, however, whose work occurs about the middle of the day, may with advantage, in the author's opinion, though he is aware it is not the usual practice, be allowed half their usual portion of hay along with their morning feed of corn. The same remark applies to troop horses, whose work generally does not begin before 9 a.m. Cart horses, whose work is always slow, should be fed with hay three times a day.

\section{Best times for feeding.}

Horses should not be fed, when heated, immediately after work. The stomach is not then in a good state for the proper digestion of the food. If the horse is exhausted, as may often occur with hunters after a long day's abstinence, a bucket of warm gruel, which is very easy of digestion, should be given at once; but the corn should be withheld until the animal is cool and has been dressed. By that time, under the influence of the gruel and of the rest, the stomach will probably have recovered its tone.

The best time for feeding as a general rule is at the close of each stable hour. The horse will then feed more quietly, comfortably, and more at his leisure than when servants are bustling about. Besides which many horses, if disturbed whilst feeding, are apt to knock about and spill their corn. 


\section{Regularity desirable in the hours of feeding.}

Regularity in the hours of feeding is a matter of some importance. Over-lengthened abstinence is for the structural reasons explained above in itself injurious; and the mischief is often aggravated by the animal eating to excess when he gets his food. An over-hearty meal is hurtful at any time, but it is especially so when the stomach is weakened by long fasting. Undue pressure and irritation are the result, producing indigestion, and in some cases gastritis, colic, \&c.

\section{Necessity of good forage.}

It is absolutely necessary that the food supplied should be good and sound. Inferior or damaged forage of any sort, such as mouldy hay, damp or kiln-dried oats, or green meat kept till stale, or grazing on fouled ground, very readily produce intestinal disturbance or disease. Besides which we cannot expect to develop the best powers of the animal, unless we supply him liberally with the best nutriment.

\section{Of watering.}

From feeding we pass on to watering. How often should horses be watered, and what quantity should be given at one time?

The anatomical structure of the horse may here guide our practice. The stomach or receptacle for solid food, as has been stated above, is very small, and consequently the horse requires to be fed frequently; but the cæcum or water gut, on the other hand, is very large. It is not uncommon, indeed, to see a horse drink two or even three pails of water at one time, and most of this passes tolerably direct to the cæcum. Hence it is probable that he does not require to be watered often. In a state of nature, though no doubt the succulent nature of the food in part at least supplies the place or want of water, it would be impossible that all the horses on a large plain could be constantly down at the river side.

It has been generally noticed in camps that horses standing in the open air, though fed on dry food, never drink more than twice and often only once in the day. But in stables it is certain that horses drink readily and are refreshed by being watered at least three or four times a day. It is not very difficult to conceive that the difference between the close warm atmosphere of a stable and the cool refreshing air of heaven may sufficiently account for this. Though, for the reasons given above, it is not at all necessary, yet there is no objection to horses having water constantly before them,--provided the water in the trough is wholly drained off and supplied afresh at each stable hour.

\section{Quantity of water to be given at one time.}

Of the quantity of water to be given at one time, the horse himself is in general the best judge. Excepting in a few cases, such as where the horse is excessively hot or exhausted, or has from any cause been kept without water for an undue length of time, or where there is a tendency 
to purgation or diuresis, the horse may safely be allowed to drink as much as he likes.

\section{Horses to be watered before being fed.}

It is a cardinal rule in stable management that horses should be watered before being fed. The contrary practice is exceedingly likely to cause colic, otherwise called gripes. The reason of this is simple enough. Water does not remain in the stomach. It merely passes very rapidly through it on its way to the cæcum. If the stomach is full, the water is very apt to carry with it from the stomach into the small intestines some portions of the food before it is properly prepared for transmission. Now undigested food, though natural to the stomach, in which it ought to be digested and prepared for transmission to the intestines, acts on the latter as a foreign body and produces irritation.

\section{No objection to watering horses when warm.}

It is a somewhat singular fact that horses may be watered with safety almost immediately after their return from work, even though somewhat heated. Probably the friction from grooming, which takes place about the same time, prevents the occurrence of a chill. Many regiments water their horses on their way home from a field day, if a river or troughs are handy, and it is certain that no mischief results from the practice. Probably in this case the further slight exercise in returning home prevents mischief.

There is less risk of chill from drinking cold water, when the body is still actively warm, than when the system has begun to flag. If, however, the horse is thoroughly tired and fagged, the water should be made slightly tepid, or a bucket of warm gruel may be given instead. In such cases there may not be sufficient vitality to raise a large quantity of cold water to the temperature of the body; and hence the animal may become chilled, and his coat will stare, his bowels may become deranged, and further serious consequences may result.

\section{Dirty v. clean water. Hard v. soft water.}

It is very commonly, but erroneously, supposed that horses prefer muddy to clean water. The origin of this idea is the fact that the horse prefers soft to hard water, and will drink indifferent soft in preference to clearer-looking hard water. But he will never drink bad soft in preference to good soft water, nor will he drink bad hard in preference to good hard water, except in so far as all hard water becomes more or less soft by standing and exposure to the air. Where a number of troughs with a stream running through them have been placed in line, the author has often known his horse, though taken to the last, walk to the first in order to get the cleanest water.

Water for the horse should always be drawn fresh. If it is too cold, the chill may be taken off by adding a little warm water. The very ordinary practice of refilling the pails after watering and allowing them 
to stand in the stable until wanted again, in order to take off the chill, is objectionable, because the water so exposed must imbibe some of the deleterious gases present in most stables, and therefore must become tainted.

Hard water, which contains an excess of saline and mineral substances, does not as a general rule agree as well with horses as soft water, such as that obtained from a river or pond. It is apt to produce irritation of the bowels and, as a secondary effect, a staring coat.

The salts contained in hard water may be in a great degree precipitated by boiling, and most waters become softer by being exposed to the air.

Any sudden change in the kind of water supplied to horses is apt to cause derangement and even irritation of the mucous membranes of the bowels, especially a change from soft to hard water. Hence if the water is very hard, it should be boiled before being given to valuable horses, particularly if they are not accustomed to it.

Rain or other soft water stored in tanks soon becomes full of decomposing vegetable matter in hot weather.

\section{Scouring.}

To horses predisposed to scour, water should be given frequently and in reduced quantities, and in winter the chill should be taken off by mixing it with a very little warm water. Perhaps the best plan is to leave water always before such horses, because when so supplied they drink less than when watered at intervals. A diminished quantity of water taken into the system by lessening the secretions of the intestines decreases the tendency to purgation.

If reduction of the quantity of water does not produce the desired effect, it may be mixed with a little wheaten meal, which has a slight astringent effect on the bowels. If further measures are needed, boiled linseed or some such demulcent should be mixed with the oats; and it is as well to bruise the oats, because their ends are liable to cause irritation on an over-sensitive intestinal lining. Horses disposed to scour should be stinted of their water before going to work. Some horses will scour unless a little hay is given to them in the morning before they are watered.

Not infrequently, however, the real cause of scouring will be found in an irritable state of the bowels induced by the presence of various crudities arising from imperfect digestion or previous torpidity. In such cases, if the animal is strong and hearty and not usually predisposed to the complaint, a mild dose of purgative medicine may be beneficially administered, followed by tonics.

Scouring, especially where a tendency to it exists, may readily be brought on by any sort of neglect or bad management, such as by washing the legs and not drying them, by letting the animal stand sweating after exercise without being dried and cleaned, by copious draughts of cold water when the body is heated, or by being watered immediately before fast work. Light-coloured horses, especially if also long in the 
back and slack in the loin and light in the barrel, are predisposed to this affection.

\section{Delicate Feeders.}

Both care and skill are needed in regulating the diet and tempting the appetite of delicate feeders. Some will reject their food altogether if it is given them in large quantities; whilst they will eat it if only a small quantity is offered at a time. Others again will not feed, unless they are allowed frequently to moisten their mouths with water whilst eating. Water should be kept constantly before such animals. Others again, apparently of a nervous or timid disposition, will not feed unless there is a spare stall between them and the next horse. Many horses feed very slowly, and are consequently robbed of half the food by their more voracious neighbours. The remedy is, if possible, to allow a spare stall, or to rack up the neighbouring quick feeder as soon as he has finished his own portion. A little linseed boiled to a jelly and mixed with the corn will induce others to eat more freely. Hay slightly damp and sprinkled with salt is palatable to some horses, who will reject it when dry. A pretty frequent change of food is acceptable to some delicate feeders. A small quantity of beans, for instance, may be added to the oats, which may be given crushed. When the animal has lost its relish for these, barley or pale malt may tempt the palate for a time. A little wet bran with the oats is grateful for a time to some horses. For others carrots or green forage may be substituted for hay, or mixed with the hay.

Delicate feeders will often eat freely during the night, when all is quiet around. Again a very common cause of apparent loss of appetite is some irregularity in the molar teeth, which hinders due mastication. In all cases, therefore, a careful examination of the state of the teeth should be made. In many cases it will be found that the edges of these teeth have become as sharp as razors. The remedy is to file the edges down level.

A good servant will always watch the peculiarities of the appetite of the horse under his charge, and will generally be able to adjust the feeding and tempt the appetite, so as to make the animal carry flesh.

Tonics no doubt increase the appetite, but no servant should be allowed on any pretence whatever to administer them at his own discretion.

\section{CHAPTER 5.}

\section{FORAGE.}

67. Chemical analysis of food. 67a. Division of foods. 68. Oats. 69. Characteristics of good oats. 70. Weight of good and bad oats. 71. Mode of weighing a bushel. 72. Various defects in oats. Kiln drying. Foxy 
oats. Fumigation or bleaching. Damp oats. Softness. Mustiness. Mouldiness. Sprouting, dirt, stones, want of winnowing. 73. Distinction between old and new oats. 73a. Crushed oats. 74. Other grain. 75. Beans. 75a. Peas. 75b. Wheat. 76. Hay. 77. Chopped hay. 78. Waste of hay. 79. Quality and value of hay. 80. Upland, lowland, and water-meadow hay. 81. Distinction between upland, lowland, and watermeadow hay. 82. Characteristics of good upland hay, 83. Characteristics of inferior and bad upland hay. 84. Lowland hay. 85. Grasses which compose good upland hay. 86. Inferior grasses. 87. Very inferior grasses. 88. Bad grisses. 89. Upland herbage. 90. Lowland herbage. 91. Recapitulation. 92. Weeds. 93. Of the time of cutting and saving hay. 94. Of late cut hay. 95. Of saving hay. 96. On makinghay. 97. Mowburnt hay. 98. Dust in hay. 98a. Second crop or aftermath. 98b. Distinction between old and new hay. 98c. New v. old hay, as regards feeding. 98d. Irish hay. 98e. Pressed hay. 88f. Clover hay. 98g. Green forage. 98h. Carrots. 98i. Gruel. 98j. Bran. 98k. Linseed foods. 98l. Boiled foods. 98m. Straw. 98n. Artificial foods. 98o. Concentrated foods.

67. Chemical analyses of food.

$\mathrm{I}_{\mathrm{T}}$ is difficult, if not impossible, to estimate accurately by means of chemical analyses the nutritive value of the various substances used as food. All food must of course contain certain nutritive constituents; but it does not follow that the food which possesses those constituents in the greatest abundance will produce the most beneficial results. Digestibility, readiness of assimilation, absence of unduly heating properties, and many other qualities are needed in order to make a substance possessing the necessary ingredients available as food. Chemistry is a valuable but not an infallible guide, and its indications require to be tempered by the test of experience.

67a. Division of Foods.

The author does not deem it necessary to enter into a ninute description of the chemical elements of foods. It will be sufficient to mention that all nutritive foods are divided into three great principles, viz. nitrogenous, non-nitrogenous, and inorganic.

Nitrogenous elements contain the various forms of albumen, the functions of which are to provide material for the repair and nourishment of the various tissues of the body, namely, bone, muscle, or flesh, \&c.

Nitrogenous elements exist in all animal and in some vegetable foods. They are nearly identical in their chemical composition, whether found in animal or vegetable food. For instance, the albumen, gluten, and legumen of vegetables are composed of the same chemical constituents, and in nearly the same proportion, as the albumen, fibrin, and casein of animal foods. 
Non-nitrogenous elements include starches, sugars, oils, and fat, usually classed under the head of carbonaceous principles. Their functions are to supply materials for the production of animal heat; which is produced by the combustion (in a chemical sense) of the carbon and hydrogen of the food with the oxygen of the air. Secondly, to supply fat, which enters largely into the composition of various substances of the body, and which is stored up or deposited in considerable quantities in different parts of the animal frame. Fat is technically known as adipose tissue.

Fat is not wholly derived from oleaginous materials, but also from the starches and sugars of vegetable foods, being readily formed from these constituents by chemical decomposition in the animal body.

Besides nitrogenous and non-nitrogenous elements there are also certain inorganic principles in foods, consisting of water and saline materials, which are necessary for the purpose of keeping up the supply of similar constituents existing in the various tissues of the body.

From the above description it will be readily understood that horses doing hard and fast work require food containing a large proportion of both Nitrogenous and Non-nitrogenous principles. Not only is the waste of the various tissues accelerated by long-continued exertion, but chemical combustion also takes place more rapidly.

If the nitrogenous elements are not supplied in sufficient quantities to repair the "waste," the animal will fall away in muscle.

If the non-nitrogenous elements are not supplied in quantities sufficient to compensate for the chemical combustion, the fat stored up in various parts of the body will be called upon to supply the deficiency, and the animal will become thin.

\begin{tabular}{|c|c|c|c|c|c|c|c|c|}
\hline & \multirow[b]{2}{*}{$\begin{array}{c}\text { Nitro- } \\
\text { genous. }\end{array}$} & \multicolumn{2}{|c|}{ Non-nitrogenous. } & \multicolumn{2}{|c|}{ Inorganic. } & \multirow[b]{2}{*}{ Water. } \\
\hline & & & & $\begin{array}{c}\text { Starches } \\
\text { and sugar. }\end{array}$ & $\begin{array}{l}\text { Fatty } \\
\text { matter. }\end{array}$ & $\begin{array}{l}\text { Saline and } \\
\text { mineral. }\end{array}$ & $\begin{array}{l}\text { Woody } \\
\text { fibre. }\end{array}$ & \\
\hline Oats & . & . & $12 \cdot 9$ & $53 \cdot 8$ & $6 \cdot 0$ & $3 \cdot 5$ & $10 \cdot 8$ & 130 \\
\hline Beans & . & . & $25 \cdot 5$ & $45 \cdot 9$ & $1 \cdot 6$ & $3 \cdot 1$ & $9 \cdot 4$ & 14.5 \\
\hline Barley & . & . & $10 \cdot 6$ & $63 \cdot 7$ & $2 \cdot 0$ & $2 \cdot 6$ & $7 \cdot 1$ & $14 \cdot 0$ \\
\hline Maize & . & - & $10 \cdot 4$ & 68.5 & $5 \cdot 1$ & $1 \cdot 6$ & $3 \cdot 0$ & $11 \cdot 4$ \\
\hline Bran & . & . & $14 \cdot 2$ & $50 \cdot 4$ & $4 \cdot 2$ & $6 \cdot 1$ & 110 & $14 \cdot 0$ \\
\hline Linseed & . & . & 205 & 196 & $37 \cdot 0$ & $3 \cdot 4$ & $7 \cdot 2$ & $12 \cdot 8$ \\
\hline Grain (not & inclu & ing husks) & $22 \cdot 70$ & $63 \cdot 18$ & $3 \cdot 76$ & $2 \cdot 60$ & - & $11 \cdot 39$ \\
\hline $\begin{array}{l}\text { Kulthee } \\
\text { husks) }\end{array}$ & not & including & $23 \cdot 27$ & $59 \cdot 38$ & $2 \cdot 20$ & $3 \cdot 19$ & - & \\
\hline Hay & . & . & $9 \cdot 7$ & $41 \cdot 0$ & 2.5 & $6 \cdot 2$ & $\overline{26 \cdot 3}$ & $\begin{array}{l}12.03 \\
16.0\end{array}$ \\
\hline Clover ha & & . & 123 & $38 \cdot 2$ & $2 \cdot 2$ & $5 \cdot 3$ & 26.0 & 14.3 \\
\hline Rye-grass & . & . & $3 \cdot 37$ & 12.02 & 0.91 & $2 \cdot 15$ & 0.06 & $71 \cdot 43$ \\
\hline Meadow-g & rrass & . & $3 \cdot 5$ & $9 \cdot 2$ & 0.8 & 20 & 4.5 & $80 \cdot 0$ \\
\hline Lucerne & . & - & $3 \cdot 83$ & $13 \cdot 62$ & 0.82 & $3 \cdot 04$ & $8 \cdot 74$ & $69 \cdot 95$ \\
\hline Clover & . & . & $4 \cdot 27$ & $8 \cdot 45$ & $0 \cdot 69$ & $1 \cdot 82$ & $3 \cdot 76$ & $81 \cdot 01$ \\
\hline Carrots & . & - & $0 \cdot 7$ & $7 \cdot 7$ & $0 \cdot 2$ & 0.9 & 3.5 & 87.0 \\
\hline
\end{tabular}




\section{Oats.}

Of grain for the horse long experience has proved oats to be the best. Of the quantity to be given experience is also our best guide. The regulation cavalry allowance of ten pounds per diem unquestionably is sufficient for horses in ordinary work. This weight is about equivalent to what is usually understood as three feeds.

But where the work is severe, horses should be allowed as much oats as they will eat. Hunters so fed will not consume on the average of the winter more than from fourteen to fifteen pounds or possibly sixteen per diem. The reader may be surprised at the small amount of the average ; but it must be remembered that horses eat but little on the day or days on which they are employed in hunting or other such long work. If an unlimited quantity of oats were given for one day to a horse usually restricted to a small allowance, he would of course eat a great deal more on that day. The author lately selected a horse with a good appetite, whose usual ration was ten pounds, and gave him as much as he liked. Tho first day he ate twenty-two pounds, the second day the same; but on the third day he only consumed eighteen pounds, and for the three succeeding days he averaged seventeen, but on the seventh he ate only sixteen.

At the Newmarket training stables the average quantity consumed by each horse is reckoned at from two and a quarter to two and a half bushels per week; or assuming the oats to weigh $44 \mathrm{lb}$. per bushel, from about fourteen to sixteen pounds per diem. On the other hand, it must be remembered that the oats given by trainers are the very best, and contain a greater amount of nutritive material than those generally supplied by owners to their horses.

Large carriage horses in ordinary gentlemen's work require $14 \mathrm{lb}$. per day. On this allowance they ought to be kept in the best possible condition. It is the amount allowed by one of the principal London firms, when they contract to ration the horses which they let out on job.

Cab horses in London generally eat about from 18 to $20 \mathrm{lb}$. of oats a day. It appears, at first sight, singular that they should eat more than hunters or horses in training. The fact, for it is a fact, may probably be accounted for partly by their being in the air some eight hours a day, partly by the long, fatiguing nature of their work, which causes a great consumption of animal material, and partly by the excellent habit of cabmen of putting on the nose-bag whenever the horse happens to be unemployed on the stand. The cabman is practically aware of the fact that the more he can get his horse to eat the more work he will do. It must also be borne in mind that the oats given by cabmen, though they are sensible enough not to waste their money on a very inferior article, are not the best. The quality of the oat must also be taken into consideration in reckoning the quantity which a horse will eat, or which he requires to keep him in good condition. 


\section{Characteristics of good oats.}

Good oats are clean, hard, dry, sweet, heary, plump, full of flour, and rattle like shot. They have a clean and almost metallic lustre. Each oat in a well-grown sample is nearly of the same size. There are but few small or imperfect grains. The hard pressure of the nail on an oat should leave little or no mark. The kernel, when pressed between the teeth, should chip rather than tear. The skin should be thin. The size of the kernel will be less in proportion as the skin is thick. The colour of the oat is not very material, but white oats are generally thinner in the skin than black. Again, black oats will grow on inferior soils. Short plump oats are preferable to large long grains. Bearded oats must have an excess of husk. Oats are not necessarily bad because they are thickskinned or bearded; but they must contain a less amount of flour per bushel than thin-skinned oats without beards.

Good oats are entirely without smell of any kind, except that of earth in new samples. In testing oats by smell a double handful at least should be taken for the purpose, and not merely a few grains.

The flour should be almost tasteless, except a slight sense of milky sweetness to the palate. In tasting oats the purchaser should put a considerable number into his mouth without looking at them, in order to get a fair average of the grains. If he selects one or two oats to taste, he is sure to choose good grains.

In testing oats for quality it is a good plan to spread out a quantity on a table or sheet of paper. The small and imperfect grains can then readily be detected. Good samples should be free from any admixture of small black seeds. Inferior foreign oats are nearly always so mixedsometimes in great quantities. The small black seeds weigh heavier than oats, and, if numerous, give a deceptively heavy weight to the sample. They consist principally of the seeds of the wild rape, tares, and charlock, or wild mustard.

\section{Weight of good and bad oats.}

Good oats weigh about $42 \mathrm{lb}$. per bushel. Very good samples reach 44 or $45 \mathrm{lb}$., and from a few districts oats as high as 48 or even $49 \mathrm{lb}$. may be obtained in favourable seasons. Fair marketable oats weigh about $39 \mathrm{lb}$. The Government in their contract for oats for the cavalry stipulate for a weight of $38 \mathrm{lb}$. per bushel. Very inferior lots do not weigh above $32 \mathrm{lb}$.

Very dirty oats, sometimes on account of the dirt and sand in them, weigh better before than after they have been cleaned; but as a general rule the effect of cleaning and winnowing a sample is to make it weigh more per bushel. The principal part of the refuse which is thrown out consists of husks and of small, imperfect, or mouldy grains, which are very light in proportion to bulk. 
In some experiments made by a miller for the author he found that a fair sample of oats, per bushel,

$30 \mathrm{lb}$. per bushel yielded Flour, $19 \mathrm{lb} .7 \mathrm{oz} .=155 \mathrm{lb} .8 \mathrm{oz}$. $34 \mathrm{lb} . \quad, \quad, \quad, 22 \mathrm{lb} .5 \mathrm{oz} .=178 \mathrm{lb} .8 \mathrm{oz}$. $38 \mathrm{lb} . \quad$ " $\quad, \quad, \quad 26 \mathrm{lb} .14 \mathrm{oz} .=215 \mathrm{lb}$.

$4.4 \mathrm{lb} . \quad " \quad \quad, \quad, \quad 32 \mathrm{lb} .9 \mathrm{oz} .=260 \mathrm{lb} .8 \mathrm{oz}$.

Another sample

at $32 \mathrm{lb}$. yielded $19 \mathrm{lb} .15 \mathrm{oz}$. of flour, = $159 \mathrm{lb} .8 \mathrm{oz}$. per quarter.

at $38 \mathrm{lb} . \quad, \quad 26 \mathrm{lb} .7 \mathrm{oz} . \quad "=211 \mathrm{lb} .8 \mathrm{oz} . \quad$ "

at $42 \mathrm{lb} . \quad " 30 \mathrm{lb} .14 \mathrm{oz} . \quad "=247 \mathrm{lb}$.

at $44 \mathrm{lb} . \quad " \quad 33 \mathrm{lb} .14 \mathrm{oz} . \quad, \quad=271 \mathrm{lb}$.

Another analysis will be found in the Addendum.

From the above it will readily be seen that good oats, even at a high figure, are cheaper for feeding purposes than inferior samples at a lower price. The increase in weight per bushel is mainly in flour. The husk forms a much larger proportion in light than in heavy oats.

But besides the question of weight, there is the far greater question of the nutritive value of the flour from fully well-grown and well-matured ears over flour from ill-developed ears, the produce of a crop grown on poor soil or under bad climatic conditions. There is no value in any crop except what is extracted from the soil; and if the soil is poor or from bad treatment impoverished, the nutritive value of the produce can be but small.

Dealers often offer to make up the weight of a lot of oats to the stipulated number of pounds per bushel by giving an increased quantity. This practice should not be permitted. Good oats yield more flour per pound than inferior oats. Besides which the flour in light oats is always inferior in quality to that contained in well-grown, fully ripened, and well-developed grains.

$E . g$. a quarter of oats at $32 \mathrm{lb}$. will weigh $256 \mathrm{lb}$. per quarter, and, according to the second of the above tables, contain $159 \mathrm{lb} .8 \mathrm{oz}$. of flour. If $80 \mathrm{lb}$. oats be added in order to bring it up to the weight of a quarter at $42 \mathrm{lb}$., viz. $336 \mathrm{lb}$., there will be an addition of about $6 \frac{1}{4} \mathrm{lb}$. of flour, making the total weight of flour $165 \frac{1}{4} \mathrm{lb}$. ; whilst in a quarter of oats at $42 \mathrm{lb}$. (natural weight) the flour is $242 \mathrm{lb}$. Besides which the difference in the quality of the flour (see above) must be taken into consideration.

\section{Mode of weighing a bushel.}

In the preceding paragraph we have explained that the value of oats is in a great degree dependent on their weight per bushel. In buying oats, it is customary to stipulate that the lot shall weigh so many pounds 
per bushel. In weighing them for this purpose it is of course the object of the seller to get as many oats as possible into the measure, and thus to increase the apparent weight of the sample per bushel; whilst the object of the buyer is to make them weigh as light as he can, or in other words, fill the measure with the least possible quantity of grain.

Tricks are often played on the unwary, and sundry devices are adopted, such as moving the measure once or twice while it is being filled, or shaking it, or knocking against it with the scoop in pouring in the grain, or heaping it over-full, and pressing down the grain, when it is "struck." The effect of these devices is to cause the oats to lie close together, and thus to make the measure hold more than it otherwise would.

But apart from such tricks, which of course are easily seen and checked, a very considerable difference may be produced in the apparent weight of oats according to the way in which the measure is filled.

In the wholesale trade the bushel measure is pushed into a large heap, and turned over gently and struck at once. It is essential that the heap be large, or the measure will not be filled without the aid of a scoop. A good deal of practice is required to do this in a workmanlike way. This gives the true, otherwise called the "natural" or "trade" weight.

In the retail trade some other methods are commonly used. The following are the results of various ways of weighing a bushel of oats, of which the natural or trade weight was $38 \mathrm{lb}$.

Filled quickly from a large shovel, and the strike applied at once, the measure held $38 \frac{1}{2} \mathrm{lb}$. The success of the operation depends on the measure being placed on a firm basis, so that it will not move or shake, and on its being filled quickly. The oats then have not time to run together and consolidate. The measure in consequence holds almost the least possible quantity.

Filled from the mouth of the sack, by allowing the oats to run in freely and quickly, the measure held nearly $38 \frac{3}{4} \mathrm{lb}$., when the operation was neatly and well managed. There is a good deal of knack in getting the oats to run freely. The mouth of the sack must be opened wide, and the sides should be well turned down, so that no interruption may occur in filling the measure. Care must be taken that the mouth of the sack does not touch the measure. With this view, the sack should be placed on a raised platform. The foot-board of the scales will answer for this purpose.

Filled very quickly from a small scoop, the measure held $39 \mathrm{lb}$. Filled somewhat slowly from the same scoop, $39 \frac{1}{2} \mathrm{lb}$.

Filled from a shovel held at the hip, the grain being allowed to flow or trickle in slowly, the measure held $42 \mathrm{lb}$; ; or in other words, the sample was made to appear to weigh $42 \mathrm{lb}$. instead of $38 \mathrm{lb}$., the natural or trade weight. Here both the height from which the grains fell, and the slowness of the operation, combined in causing consolidation.

Different samples, no doubt, will give somewhat varying results according to the greater or less tendency which they may possess for consolidating; but from these details the intending purchaser will readily 
see that, in order to get the article he contracts and pays for, it is necessary that he should know how to weigh a bushel.

The shape of the measure to a certain degree affects the weight of the oats. In a narrow deep measure, the oats will consolidate when poured in, and the apparent weight will be increased. In the bushel legal measure, the depth is not to exceed one half the diameter.

In addition, however, to knowing how to do it, there is a good deal of knack and practice required to fill the bushel properly; and the reader, if he tries the above experiments for himself, will probably at first fail to get the true weight.

The best plan, however, of testing the true weight is by means of a very simple machine, which can easily be made by any carpenter. Make a box 30 inches deep by 12 by 12 inches, which will hold about $1 \frac{1}{2}$ bushels. At the bottom make a hole $4 \frac{1}{2}$ by $4 \frac{1}{2}$ inches, and fit it with a sliding door underneath, which must fit easy, and fill it with oats.

Underneath the box, at a distance of five inches below it, place the bushel measure. Draw back the door, and let the oats run through. When the measure is rather more than full, push back the door. Then "strike" the measure, and weigh the bushel and its contents. Deduct the weight of the measure, and you have the natural or trade weight of the oats.

This is the best and simplest plan, and there can be no mistake.

The box may be placed on a stand, or hung to a bracket fixed at the requisite height in the wall.

The next best plan is to purchase a large scoop, holding rather more than a bushel, and from it to fill the measure at once, and then strike it.

Even, however, with the proper mode of weighing, tricks are sometimes played by dishonest dealers, which affect and increase the weight of a sample. If a sample, for instance, before going to market receives a good shaking, the friction thereby caused will rub off a good many of the awns and asperities of the husks, and the seeds will then flow in more easily into a compact mass, and thus the weight per bushel will be increased; whilst the remainder of the lot, which have not been subjected to the same friction as the sample, will not yield the weight supposed.

Again, certain descriptions of oats give, if we may use the expression, deceptively good weight. Very smooth and well-closed oats, for instance, lie closely together, and leave but little space unoccupied; and therefore, though they may contain but little flour, they may still weigh fairly well. Another sort with really better filled grains, but with rougher coats, may weigh less. Again, some very good-looking smooth large foreign oats give a great weight per bushel on account of the almost woody nature of their husks. Lastly, damp oats, which have not been damp sufficiently long to cause them to swell, may give an unfairly good weight.

The purchaser, therefore, whilst relying on weight as one great, and in most cases the best test, must take care to note well all the other characteristics of the lot he proposes to buy.

In testing samples of oats in the sack it is a common practice in the 
trade to thrust an ordinary smooth walking-stick rapidly into the sack. If the grain is of good quality and condition and free from dirt, \&c., the stick will pass down comparatively easily. If, on the other hand, the oats are damp, badly screened, and otherwise of inferior quality, more difficulty will be experienced in the attempt.

\section{Various defects in oats.}

Kiln drying is a process resorted to in order to get rid either of dampness or softness or of both defects. Oats so dried have a peculiar and easily recognised smell and taste, and in some cases there is a loose and shrivelled appearance about the ends of the husks. This arises from the kernel having swollen when damp, and afterwards contracted in size when the damp was suddenly expelled in the kiln. The colour of the oat is also deepened, and often assumes a reddish hue; but the colour, as will be explained presently, may be got rid of by fumigation.

The process of kiln drying in itself damages the flour to a certain degree; but the great objection to kiln-dried oats arises from the flour having been in most instances, as regards English oats, damaged before they are sent to the kiln. No amount of drying, we need scarcely say, will restore damaged flour to its original condition, or in fact make bad into good flour. An attempt is often made to get rid of the smell by spreading out the oats in thin layers to the action of the air, and then mixing them with new fresh-smelling oats immediately before they are offered for sale. Foreign oats, even though in good condition, are nearly always slightly kiln-dried before being put on board ship to prevent their heating in bulk during the voyage. This process, if the oats are in good condition, as they often are in the finer climates of the Continent, is almost unobjectionable. Oats which have been badly saved, or have become dirty from any cause, are sometimes washed to improve their colour, and are then put in the kiln to be dried.

Very good new oats are occasionally slightly kiln-dried to harden them and make them resemble old oats, and thus increase their value.

Foxy oats are those which have heated from being kept in bulk, when not perfectly dry; and in consequence have undergone to a certain degree a process of fermentation. They are easily recognised by a reddish and sometimes very red colour, and by a peculiar bitterness of smell and taste. They are unfit for horses. The nutritive quality of the flour is in a great measure destroyed. They act injuriously, especially on the kidneys, and produce excessive staling and cause the horse rapidly to lose condition. The red colour is sometimes got rid of by fumigation.

Fumigation or bleaching is a process resorted to in order to get rid of the heightened colour imparted to the oats by the process of kiln-drying or by their having become foxy.

The dark colour is got rid of and an unnaturally white hue is given by subjecting the oats to the fumes of sulphur. This fraud may be detected by taking a handful of oats from the heap and bringing it quickly up to the nose, or by applying the nose directly to a hollow made in the heap. 
When, however, the process is well managed, the smell is exceedingly faint. Several large factories have been erected in various parts of the country, in which the processes of washing, kiln-drying, and fumigating are carried on under the same roof.

Damp oats are objectionable, and should not be taken. Dampness, however, is in some measure a question of degree, and of the length of time during which it has existed. Continued damp, especially when the oats are stored in bulk, soon produces softness, mustiness, or sprouting.

Softness is the first effect produced by damp. The flour, though not in perfectly good condition, may still be wholesome, but any such defect militates against good hard condition in the horse.

Mustiness is a further stage resulting from damp. Musty oats are easily recognised by the smell. They are altogether unfit for food, and are sometimes poisonous, being in an incipient stage of decomposition. When examined under the microscope a fungoid growth may be detected on the inner skin.

Mouldy oats are in a state of positive decomposition, and are obviously unfit for food.

Sprouting is a process of new growth or germination in the oat induced by damp combined with some amount of warmth under certain conditions of the weather. In this respect it will be seen that sprouting differs from mustiness or mouldiness, which are processes of decomposition and death of the grain. Oats, which have sprouted, are quite unfit for food.

Other defects in oats are dirt, stones, and want of proper winnowing. These defects, though they militate against the value, may be remedied by screening and winnowing.

\section{Distinction between old and new oats.}

The chief distinction between new and old oats lies in the smell. New oats smell fresh and of the earth. There is a decided earthy smell about them, which is lost in the old oat. Old oats, if newly thrashed out, may smell fresh, but there is not the earthy smell about them. As a rule, however, they smell rather musty and frequently of rats.

In new oats the outside of the husk in well-saved samples is bright and shining, having almost a glazed appearance, especially in the black variety. In old oats this glazing is lost. The outside, though it may be perfectly clean, is dim and the ends of the husks in white oats, and the point of the kernel in both white and black oats, are always a little darkened. Badly saved new oats may in these respects sometimes resemble old oats ; but in such cases they will probably be distinguished by their softness.

The taste of the new oat is fresh and somewhat milky; and its flour, when moistened in the mouth, readily adheres together. The taste of the old oat is slightly bitter. In the mouth the flour feels dry and is not easily moistened. In the new oat there is a certain degree of juiciness, 
sweetness, and milkiness about its flour. In very dry seasons these distinctions are less observable than in ordinary years.

New oats as a general rule are softer than old; but here again the season, the state of the weather for some time preceding the sample coming to market, and the dampness perhaps of the place in which they have been stored, may cause old oats to handle as soft as new. On the other hand, in very fine seasons new oats may come to market almost as dry and hard as old in average years.

In bearded varieties the beards are well preserved in new samples; but from old oats a considerable proportion of the beards have generally fallen off or been knocked off by friction in carriage, \&c. In all kinds the ends of the grains from the above causes always look shorter and sharper in old than in new samples. The husk also becomes tight and locked round the kernel.

The skin of the kernel of a new oat is covered with a very fine prickly down composed of very minute hairs. In the old oat the kernel appears and feels more smooth. If the husks are stripped off, this distinction will be quite perceptible to the palate in chewing a few grains of each.

All the above distinctions except the first are subject to so many modifications according to varying circumstances, that we must advise the reader, whilst not altogether neglecting them, to form his opinion chiefly by the presence or absence of the earthy smell.

\section{3a. Crushed oats.}

Crushed oats are frequently given with advantage, especially to greedy feeders and animals that bolt their food without sufficiently masticating it. Oats, however, should never be purchased crushed, as inferior grain can easily be, and generally is, substituted for that of better quality.

If crushed oats are used, it is advisable to buy a small hand-mill. The oats can then be crushed as required, and the quality can be ensured.

\section{Other grain. Indian corn, Barley, Gram.}

Indian corn crushed or ground is often used in lieu of oats, when the price happens to be moderate, or the quality of the oat crop is indifferent. It answers very well, and some horses put on flesh better with it than with oats. It should be given mixed with about an equal quantity of bran and chopped hay, the whole being slightly wetted. About the same weight of meal may be given as the horses had been accustomed to of corn.

Many persons prefer giving Indian corn whole after soaking it for some hours. This process softens the grain and causes it to swell. In this condition it is more readily masticated, and is supposed to be more easy of digestion. The author has not tried it in this form, and hesitates to recommend it.

In some foreign countries other grain is substituted for oats, some- 
times because oats cannot be procured, sometimes because those grown in the locality are inferior.

Barley is a common substitute. It is more heating than oats, and is apt to produce constipation, derangement of the bowels, and consequent irritstion of the skin. On this account it is often desirable to combine it with clover, lucerne, grass, or other green meat as a corrective.

The same remarks apply to Gram, a species of pea, which is commonly used in India as a substitute for oats.

When a new description of grain is given in lieu of that to which the horse has been accustomed, it is always desirable to introduce the change gradually if possible.

\section{Beans.}

Beans contain more nutritive material than oats, but if given in excess are heating. Beans are beneficial to horses employed on very hard work, especially to old animals and to those which are a little overtasked.

About two pounds per diem in addition to the usual quantity of oats is a fair allowance, but the amount may be increased or diminished according to circumstances. Beans weigh half as much again as oats, and hence servants in giving them out by measure sometimes allow a good deal more than they intend.

Beans should be hard, dry, sweet, plump, sound, one year old, and should weigh from 60 to $64 \mathrm{lb}$. per bushel. They should invariably be split, as otherwise they are apt to pass whole through the intestines. English beans only should be given. The skins of foreign, especially of Egyptian beans, are often so hard as to render them utterly indigestible in the horse's stomach.

Beans otherwise good are often damaged by an insect, which eats out the kernel. This defect is easily seen. New beans are less nutritious than old, and are moreover apt to produce flatulence and colic.

\section{5a. Peas.}

Peas contain nearly as much nutritive material as beans, and are extensively used in some stables. Like beans they should be given split, and should be plump, dry, sound, and at least one year old.

\section{5b. Wheat.}

Wheat should not be given to horses if any other grain can be procured. It is unsuited to the horse's stomach, and is likely to produce serious intestinal derangements. In cases where no other grain can be procured, wheat may be given if previously parched. The parching process appears to destroy the viscidity of the gluten which causes this grain to be so difficult of digestion in the stomach of the horse. 


\section{Hay.}

For horses in ordinary work the cavalry allowance of twelve pounds per diem is sufficient. It is very commonly thought that horses in hard work should be limited in regard to hay; but if, as has been recommended above, horses in such work are allowed as much oats as they will eat, it is unnecessary and injudicious to put an arbitrary limit on their hay. Practically it will be found that horses, which are not limited in regard to oats, will not usually consume above six pounds of hay per diem; and nobody probably would wish them to have less.

A horse cannot be maintained in health on grain alone. The stomach needs a certain amount of mechanical distension, and without it will not act properly. The same fact is noticed in man, in whom highly concentrated foods, however nutritious, will not maintain health or even life.

\section{Chopped hay.}

Chopped hay has been highly recommended, but except a little for the purpose of mixing with the corn of greedy feeders, the author cannot see any advantage in its use. The argument commonly put forward in its favour, namely, that by chopping the good and bad parts are so nixed that the horse must eat the bad with the good, in his opinion tells seriously against the plan. A horse is better without bad hay in his stomach than with it. Bad forage of any sort is false economy, and the horse in rejecting it shows more sense than his master in trying to force him to eat it. Hay should always be chopped at home, as that sold by dealers is generally made from inferior and damaged growths.

If horses are fed from the nose-bag, as is the practice where the hours of work are long, chopped hay must of course be used.

\section{Waste of hay.}

Great waste of hay is frequently occasioned by careless servants stuffing the rack with perhaps half a hundredweight. Then indeed the horse selects only the very choicest locks, and pulls about and breathes over the remainder and eventually tramples it under his feet. If no more than twelve pounds are given with three feeds of corn, or half that quantity where the horses have an unlimited supply of corn, they will not in general waste or reject much that it would be good for them to eat. With some horses, however, it is necessary, in order to avoid waste, to divide the hay into four instead of the usual two portions during the day.

\section{Quality and value of hay.}

The quality and value of hay depend-

1st. On the grasses and herbage of which it is composed.

2nd. On the soil on which it has been grown.

3rd. On the time at which the grass has been cut.

4 th. On the way in which it has been "saved." 
All these points will be further considered in detail.

N.B.-If in a sample of the hay, a variety of the best grasses, such as rye-grass, meadow fescue, meadow foxtail, cat's-tail, \&c., are found, but attenuated, it is a proof that the soil, though naturally good, is in bad heart, $i . e$. impoverished by over-cropping or want of manure. The hay is worthless. There is no virtue in grass except such as is extracted from the soil. For an illustration, compare No. 3 meadow foxtail and No. 17 slender foxtail. It is true that these are different varieties. But meadow foxtail grown on impoverished, though naturally good soil, will look very much like slender foxtail.

\section{Upland, Lowland, and Water-meadow hay.}

Hay may be broadly distinguished as either upland, lowland, or watermeadow.

Upland is the best. None but upland hay should be used for horses doing fast work. Lowland hay is inferior. Water-meadow hay is altogether unfit for horses.

These terms, which are in common use and generally well understood, are not in all cases strictly accurate, e.g. a low-lying meadow may repose on a dry formation, and in addition may be well drained; and if so, it may grow fine, commonly called upland grasses. On the other hand, a meadow may lie high and yet may be a swamp, and will therefore grow coarse, commonly called lowland or even water-meadow grasses. Still for all practical purposes these expressions may be used, and will be understood by all practical men.

Certain grasses grow only on upland meadows, others only on lowland, whilst others are found only on water-meadows. Some sorts are found both in upland and lowland meadows, whilst others are found both in lowland and water meadows. In short, no very sharp line of demarcation can be drawn between grasses of upland and lowland and watermeadow growth. They shade into each other according to the peculiarities of the soil.

The best upland grasses will, however, be found only in upland meadows, but the inferior upland grasses will be found in moderately dry lowland meadows, and vice versâ, the best sorts of lowland grasses may be found, to a certain extent, on upland meadows.

The same remarks apply to lowland and water-meadow grasses. The inferior lowland grasses may be found in water-meadows, whilst the best water-meadow grasses may be occasionally, though more rarely, found in lowland meadows.

\section{Distinction between upland, lowland, and water-meadow hay.}

Upland hay is known generally by the fineness and firmness of the stalks or stems, and by the narrowness of the leaves of its grasses. Specially, it is recognised by the prevalence of certain grasses (of which hereafter) which do not grow on lowland; and, again, by the prevalence 
of certain sorts of herbage (of which hereafter) which do not grow on lowland.

Lowland hay is known by the coarseness of the stalks and by the broad leaves of its grasses (of which hereafter), and by the absence of good upland herbage. The hay, though coarser, is softer, less firm and crisp than upland hay. The colour is also darker.

Water-meadow hay is at once recognised by its very coarse, broad, often reed-like stalks, and by the very broad, often flag-like leaves of its grasses, and by a large admixture of sedge, and of plants approaching the nature of sedge, and rushes. See No. 19, Rushes, No. 20, Sweetreed grass (Glyceria or Poa aquatica), No. 21, Ribbon-grass (Digraphis arundinacea).

Water-meadow grass is quite unfit for horses, and will be not further alluded to.

The above are only general distinctions. The minuter distinctions, as regards upland and lowland hay, will be detailed below.

\section{Characteristics of good upland hay.}

Good upland hay should be moderately fine, somewhat hard, sweetsmelling, and well saved. The colour should be green, and should convey an idea of newness. Very little heating or fermentation should have taken place in the stack. Some slight heating is, however, almost unavoidable if the crop is cut early, as it ought to be, whilst the juices are still in the grass, or, in other words, before it has run to seed. This slight heating will prevent the best early-cut hay from being very green. A preference has been shown in London of late years for very green hay, arising from the idea that when of this colour, it is most nearly in its natural state; but, for the reason given above, this idea, if carried too far, is a fallacy.

Other causes, such as a shower of rain falling on the grass when nearly ready to be carried, or exposure to a very hot sun, will often cause hay to lose its very green colour, though it may not have suffered any real damage.

The flowering heads of the grasses ought to be present in abundance. Hay, which consists of an undue proportion of leaves, is inferior. Every fibre should be firm and crisp, and should appear distinct. The fibres in good upland hay often lie in one direction. In machine-tossed hay, however, the direction of the fibres is not so well preserved as in that made by the hand-rake. A tangled confusion of the constituents is a sign of badly saved or lowland hay. The perfume of the best upland hay, though not so strong, is very like that of new-mown grass. If masticated it has a mild flavour, whilst lowland and inferior growths have a strong pungent taste.

Hay grown on good soils is also distinguished by the number and variety of the grasses. Horses prefer hay composed of a variety of good grasses to that consisting of only one sort, even though that sort may be the very best. 


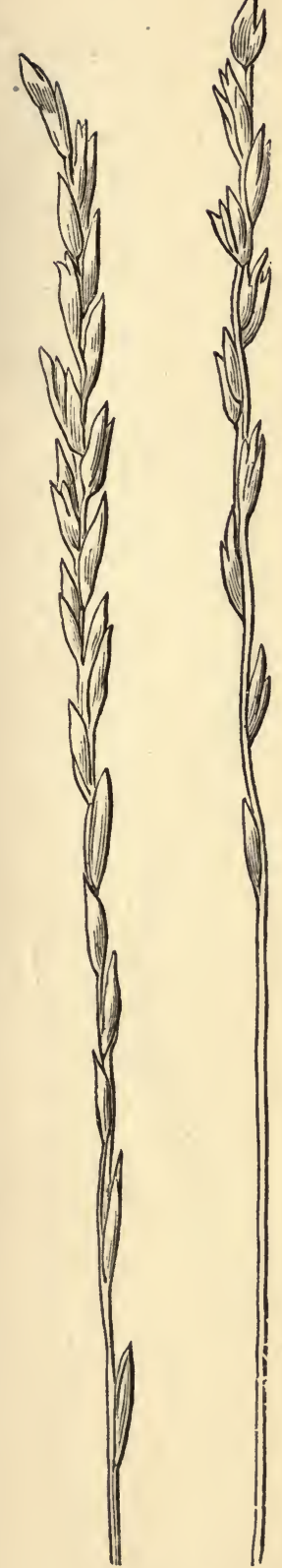

No. 1. Rye Grass. (Lolium perenne.)

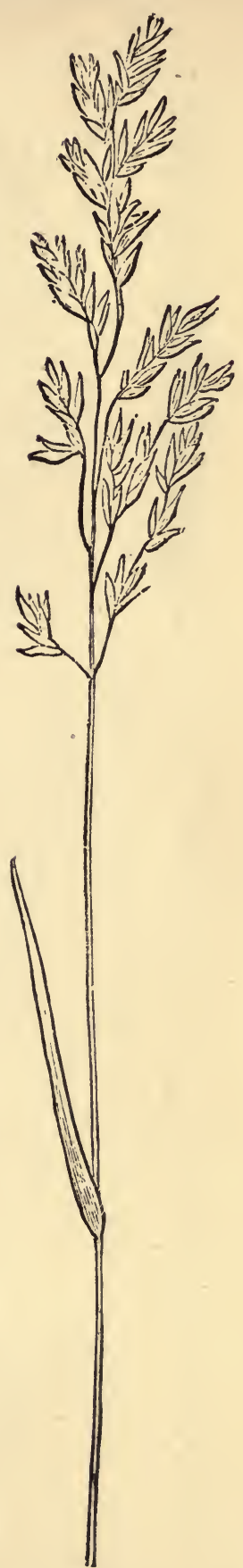

No. 2.

Meadow Fescue.

(Festuca pratensis.)
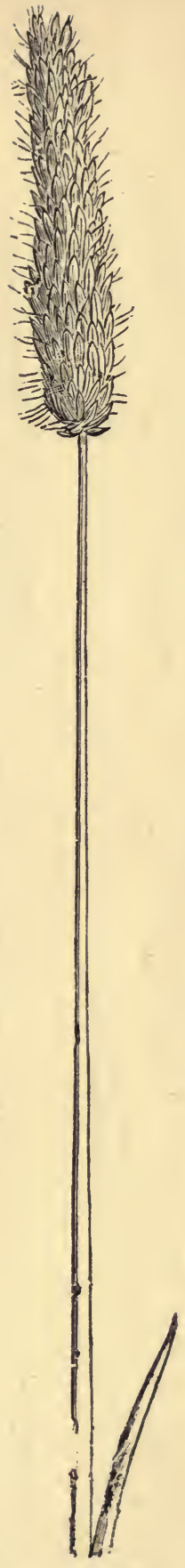

No. 3. 


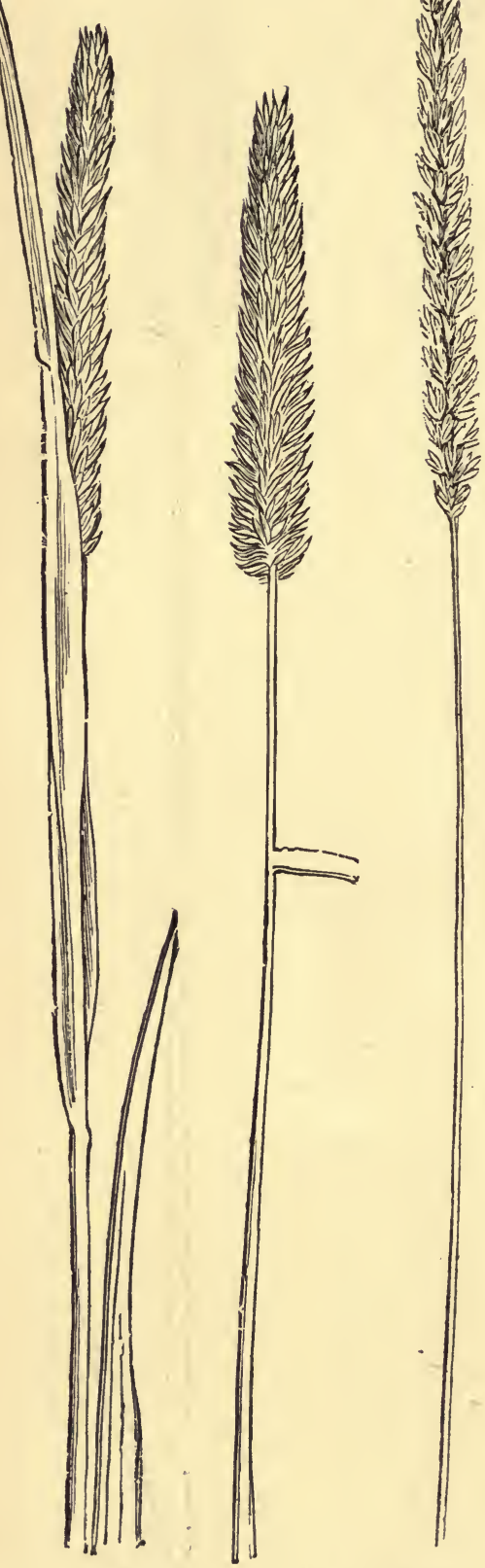

No. 4.

No. 5.
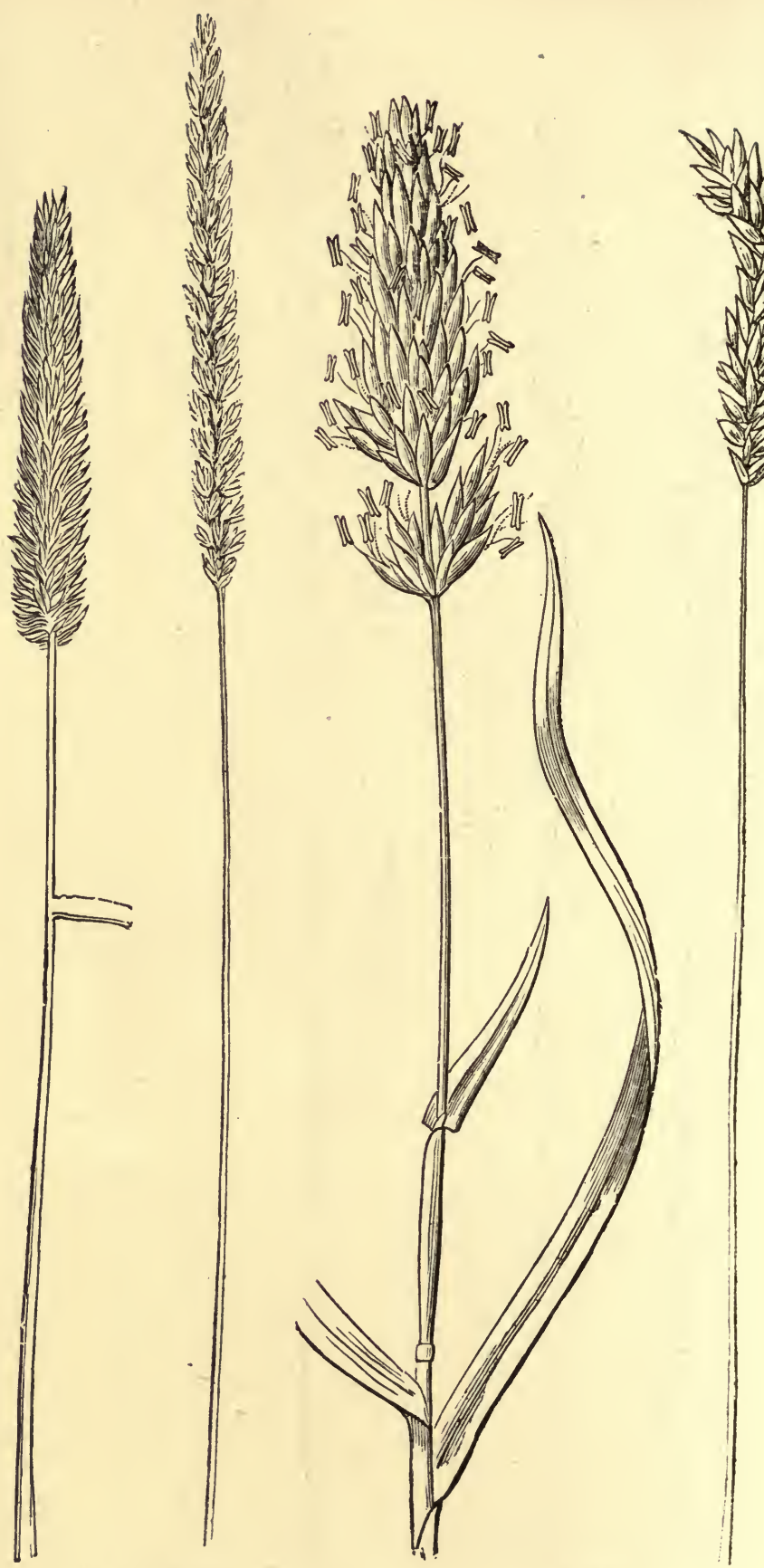

No. 6.

Meadow Cat's-tail or Timothy. Crested Dog's-tail. Sweet Vernal in Flower. Sweet Vernal in Hay (Phleum pratense.) (Cynosurus cristatus.) (Anthoxanthum odoratum.)
(P) 


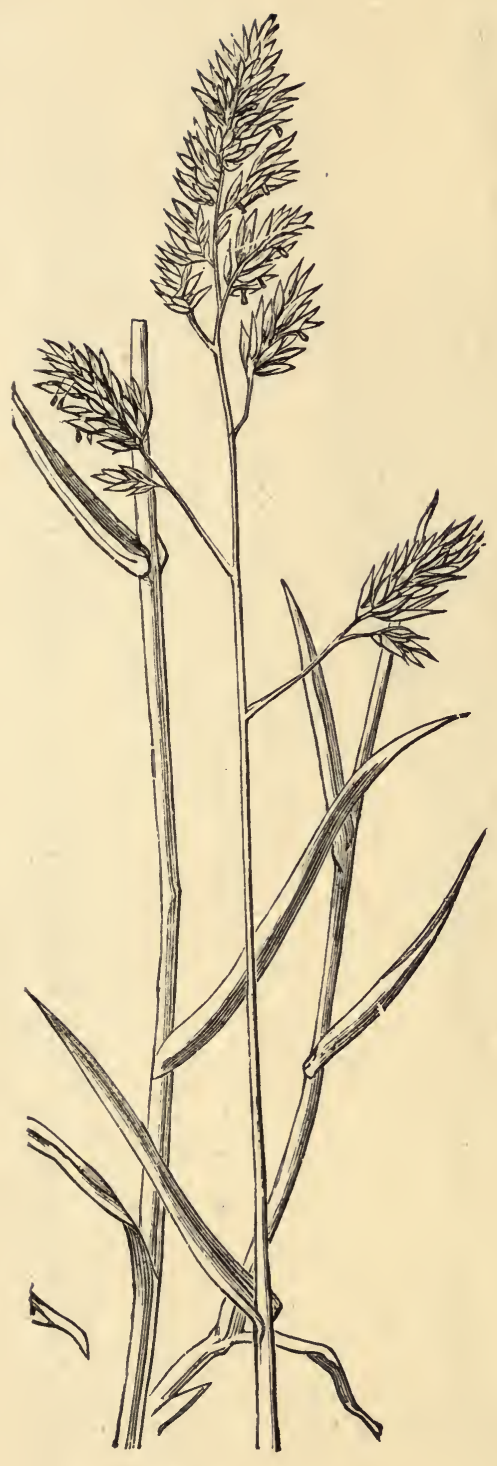

No. 7.

Cocksfoot.

(Dactylis glomerata.)

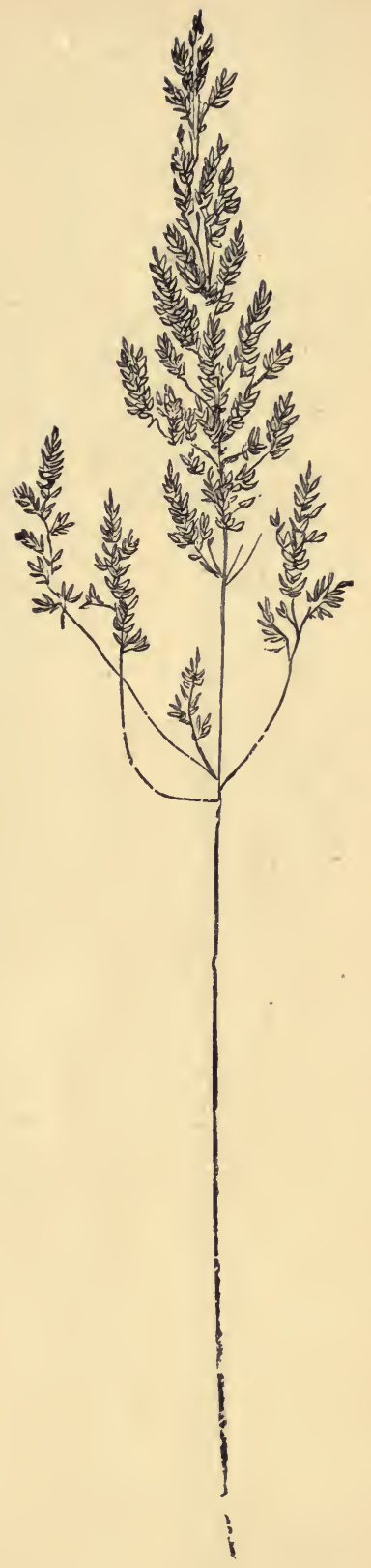

No. 8.

Smooth Meadow Grass. (Poa pratensis.) 


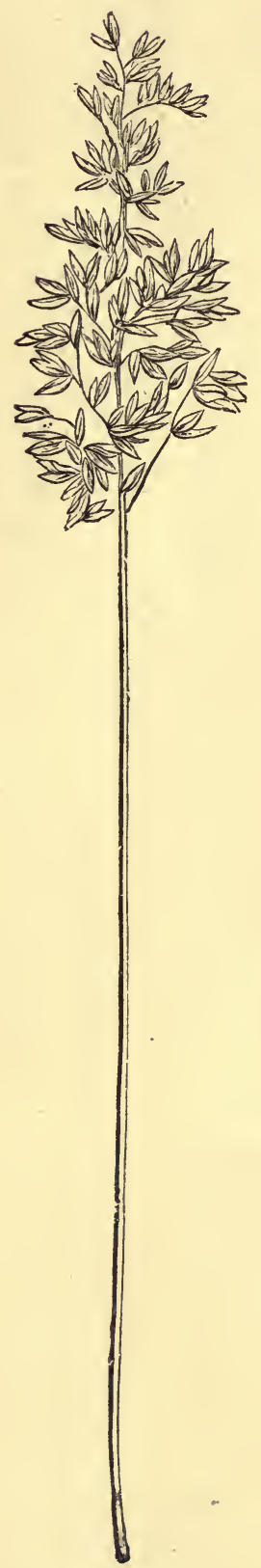

Nก. 9.

Meadow Soft Grass, in very full flower.

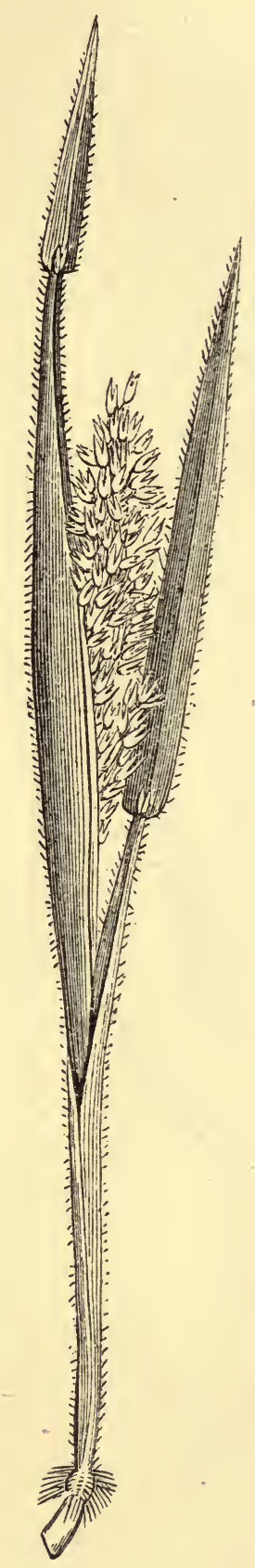

No. $9 a$.

Meadow Soft Grass, in early flower.

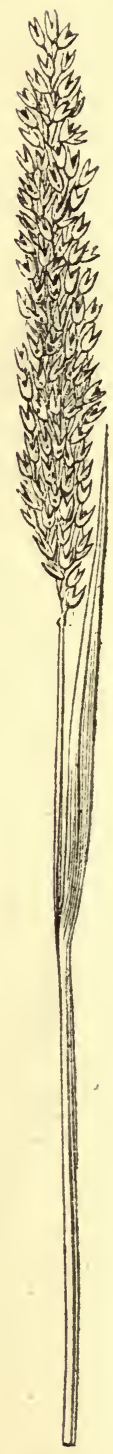

No. 10.

Forkshire Fog, in rather early flower. (Holcus lanatus.) 


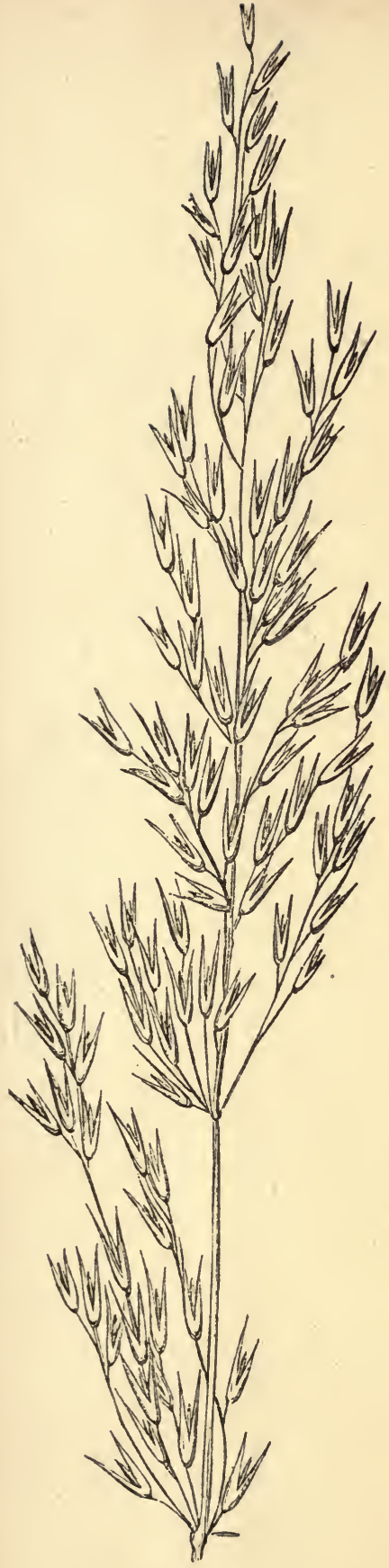

No. 11.

False Oat.

(Avena elatior.)

Flowering head only.

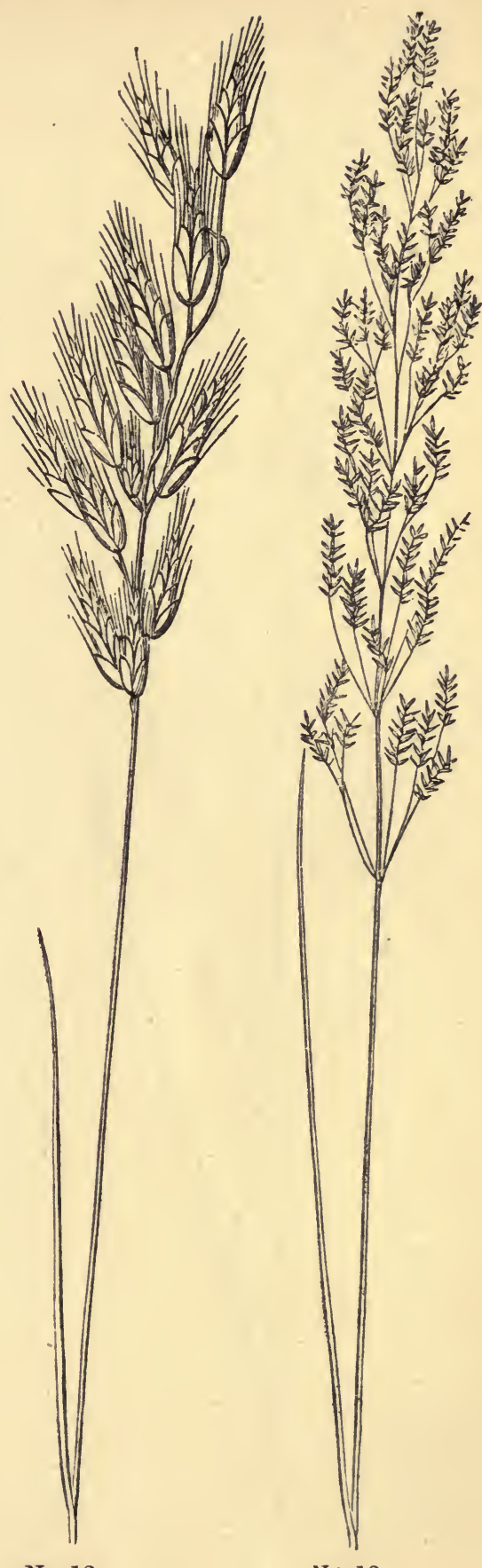

No. 13.

$\begin{array}{cc}\text { Field Brome. } & \text { Fiorin Grass. }\end{array}$ 


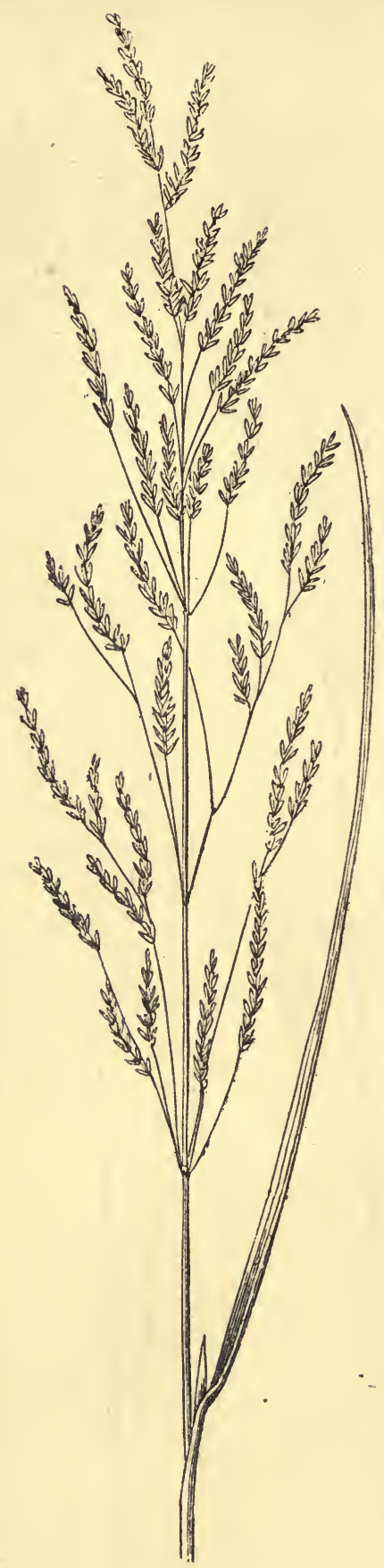

No. 14.

Rough-stalked Meadow Orass. (Poa trivialis.)

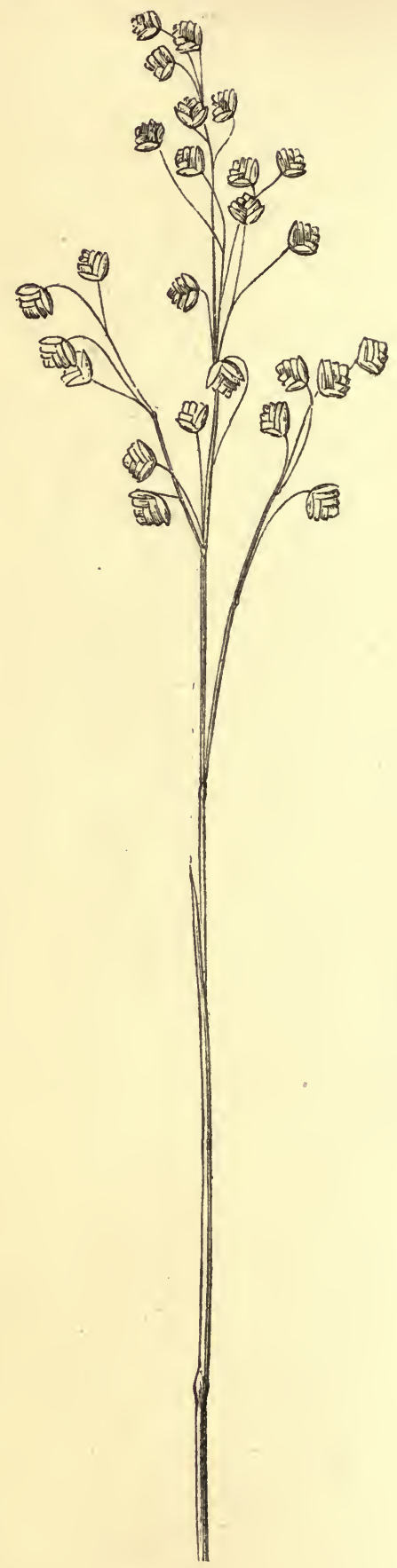

No. 15.

Quaking Grass.

(Briza media.) 


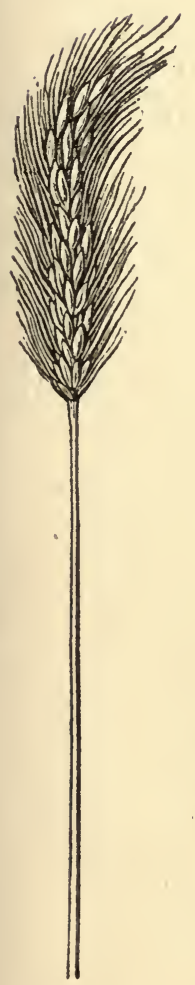

No. 16.

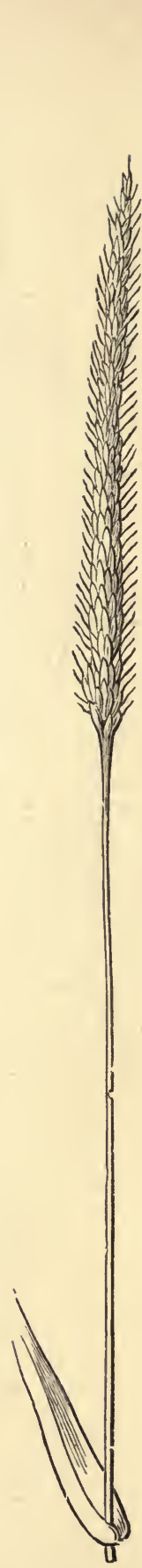

No. 17.

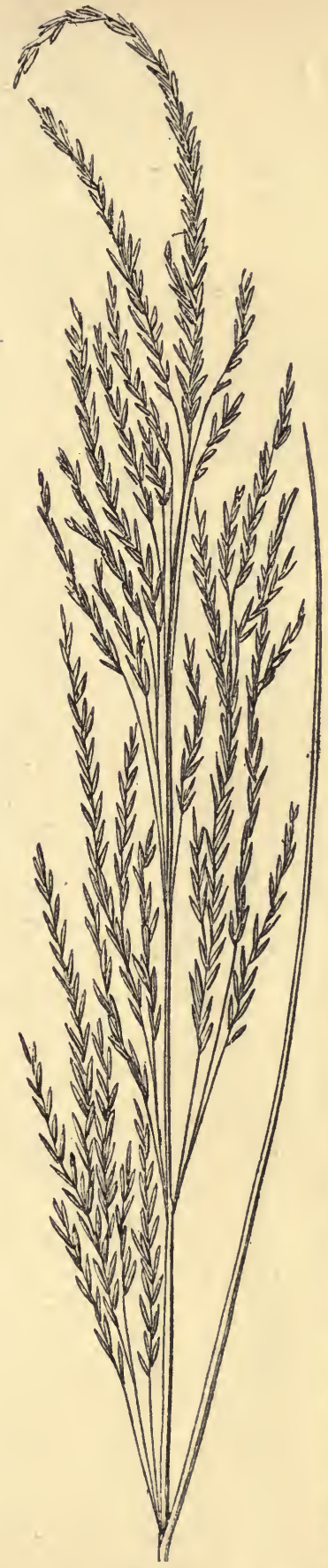

No. 18.

Squirrel-tail,orCom- Slender Fox-tail. mon Meadow Barley. (Alopecurus (Hordeum pratense.) agrestis.)

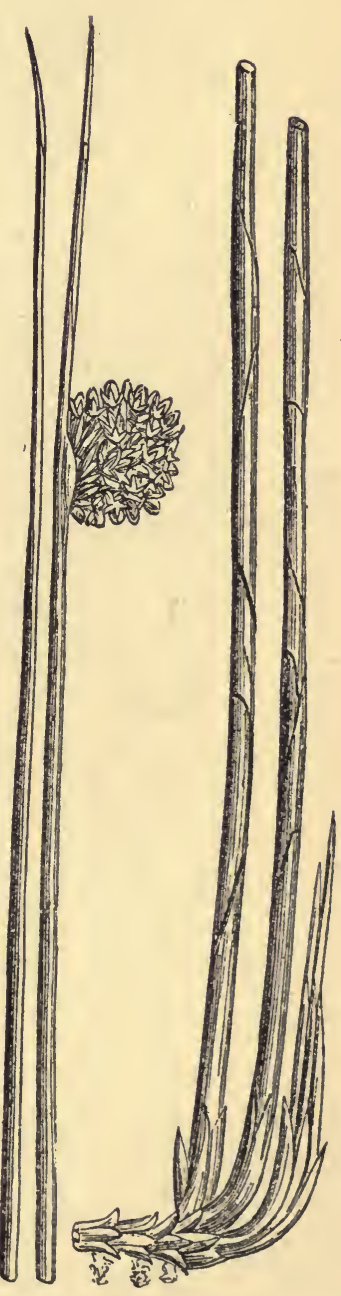

No. 19.

Common Rush.

(Juncus conglomeratus.)
(Aira cæspitosa.)

Flowering head only. 


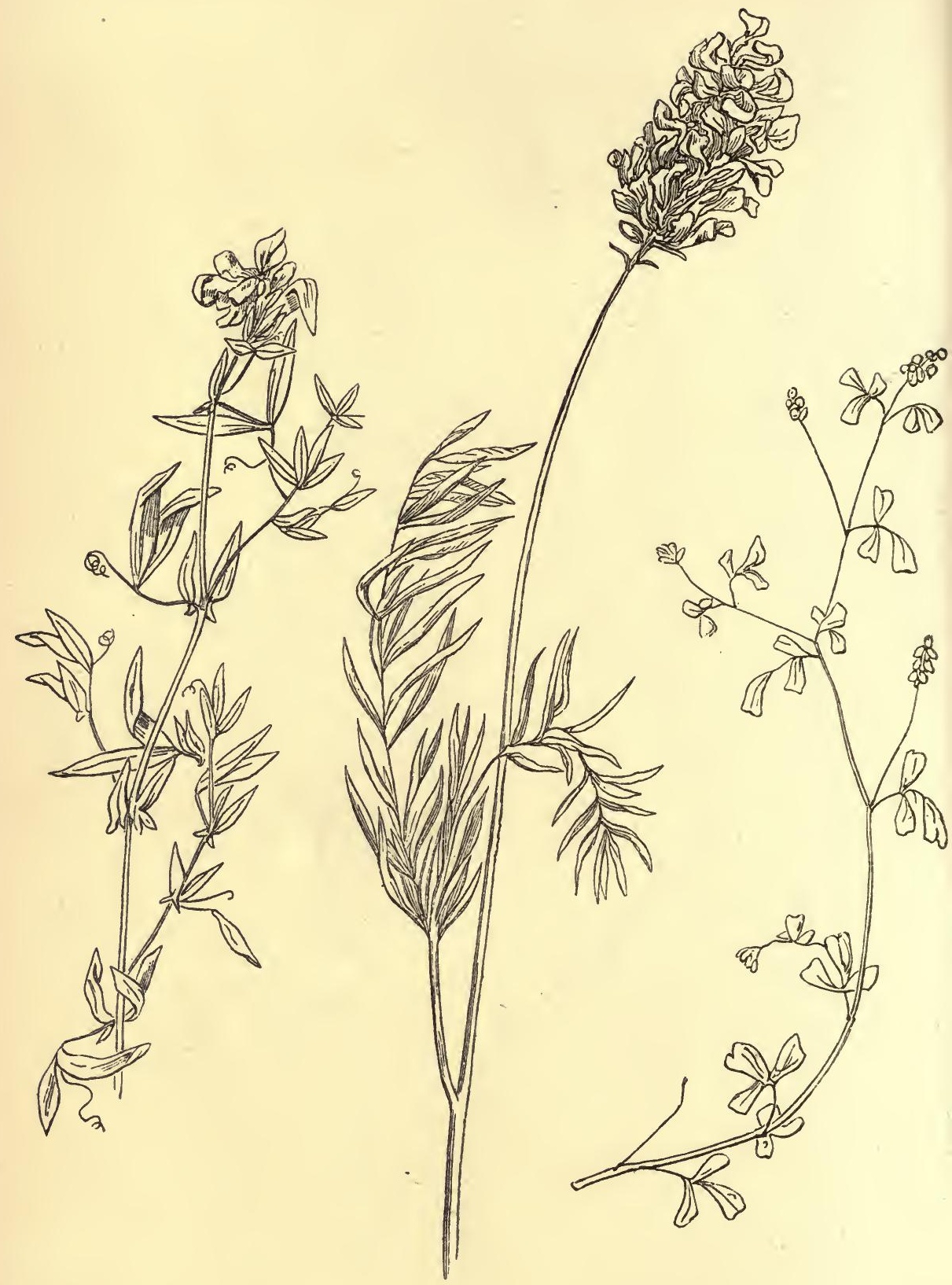

- No. 25.

Little Fellow Vetch.

(Lathyrus pratensis.)
No. 26.

Saintfoin.

(Hedysarum Onobrychis.) (Trifolium procumbens.) 


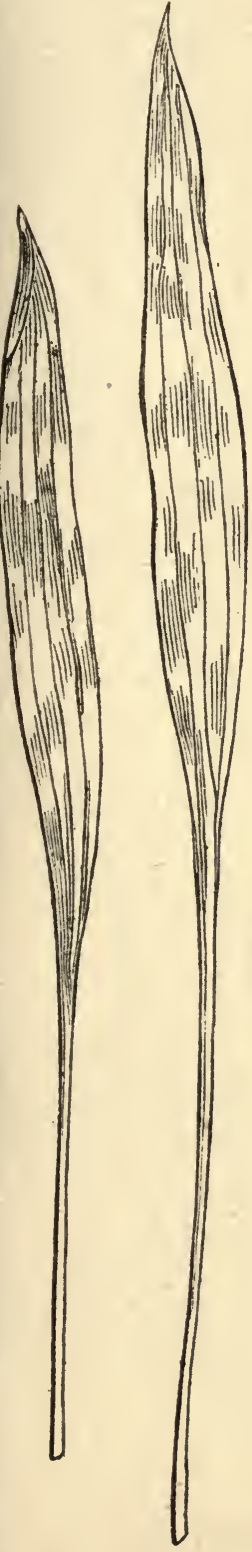

No. 28.

Rib Plantain. (Plantago lanceolata.)

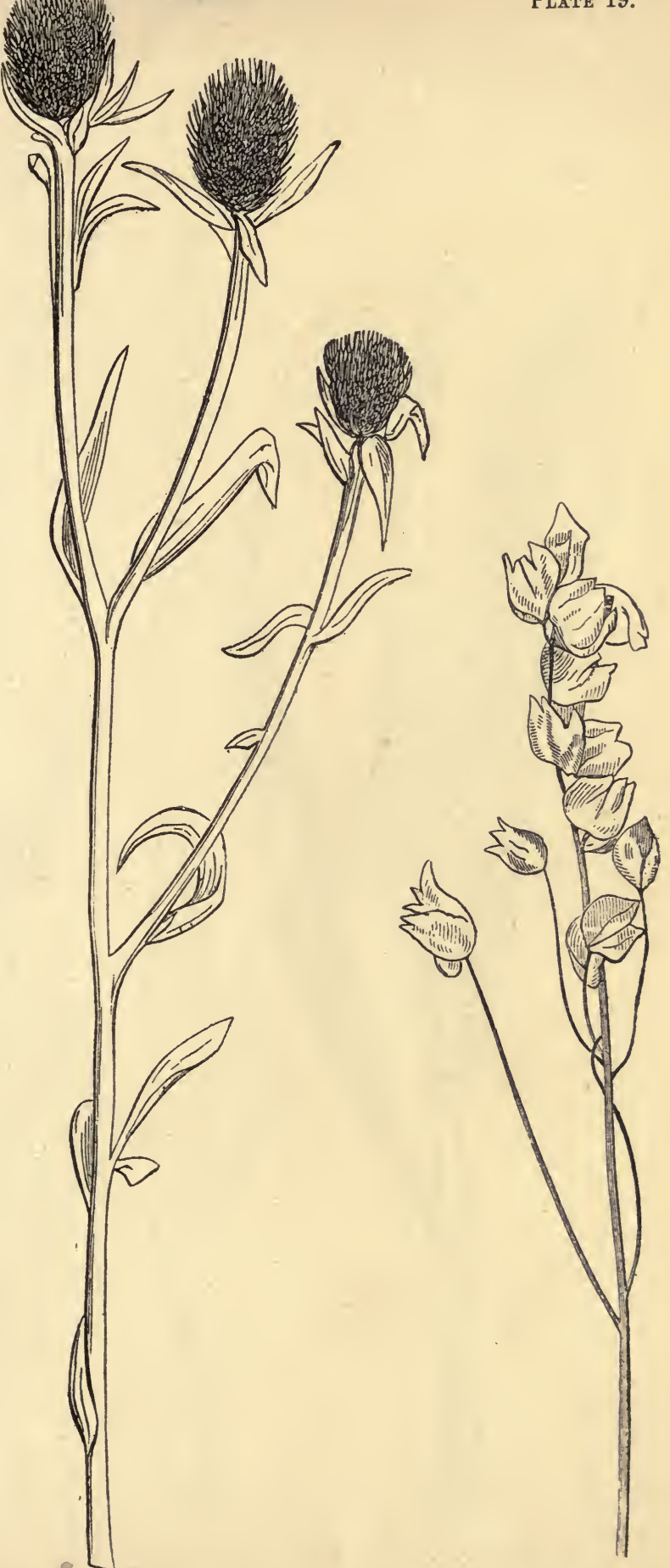

No. 29.

No. 30.

Rattle in Seed.

Hard or Blackheads, or Knapweed. (Centaurea nigra.) 

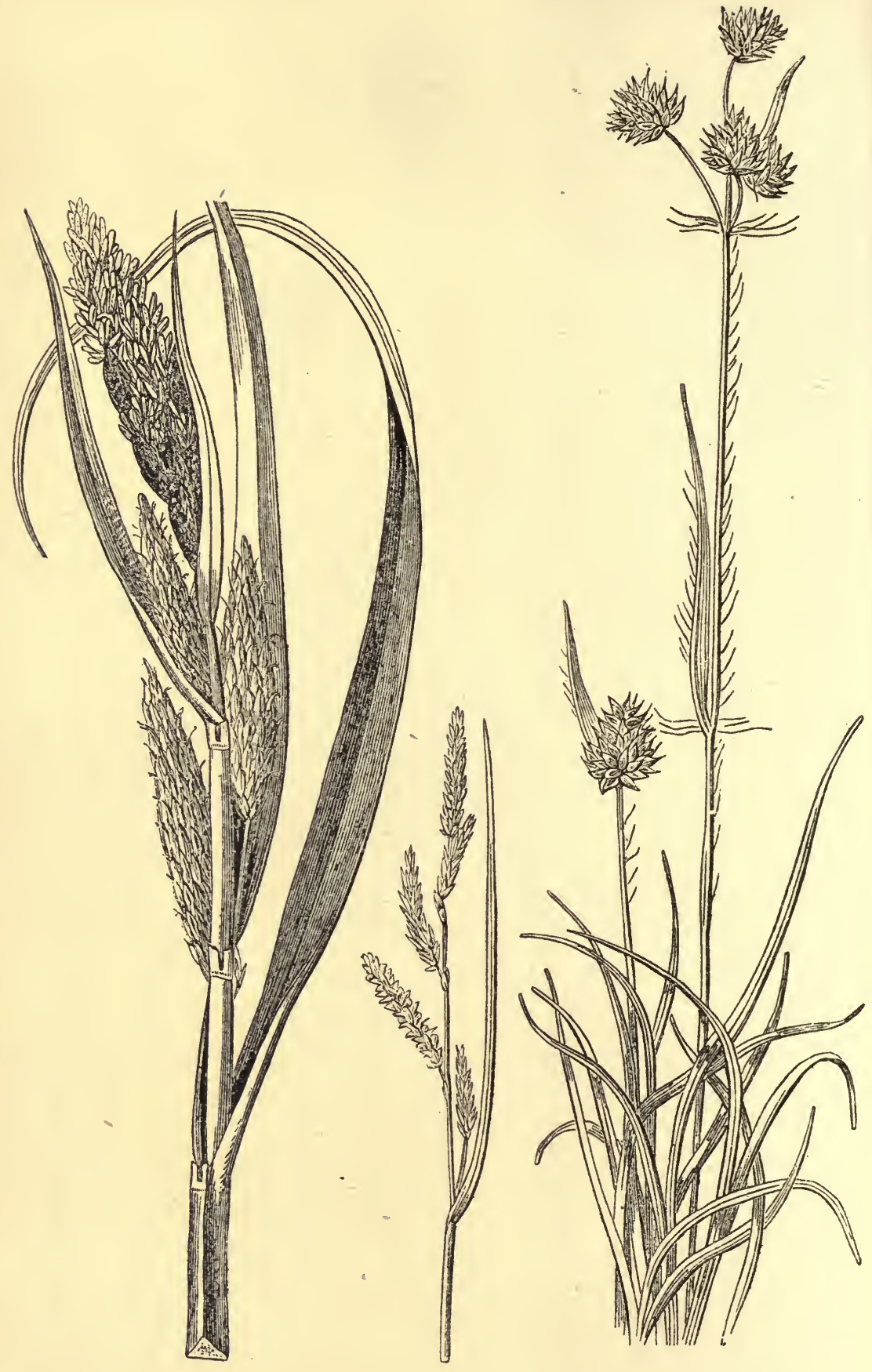

No. 31.

Common Bank Sedge.

(Carex riparia.)

Small Sedge.

No. 32.

Wood Rush.

(Luzula campestris.) 

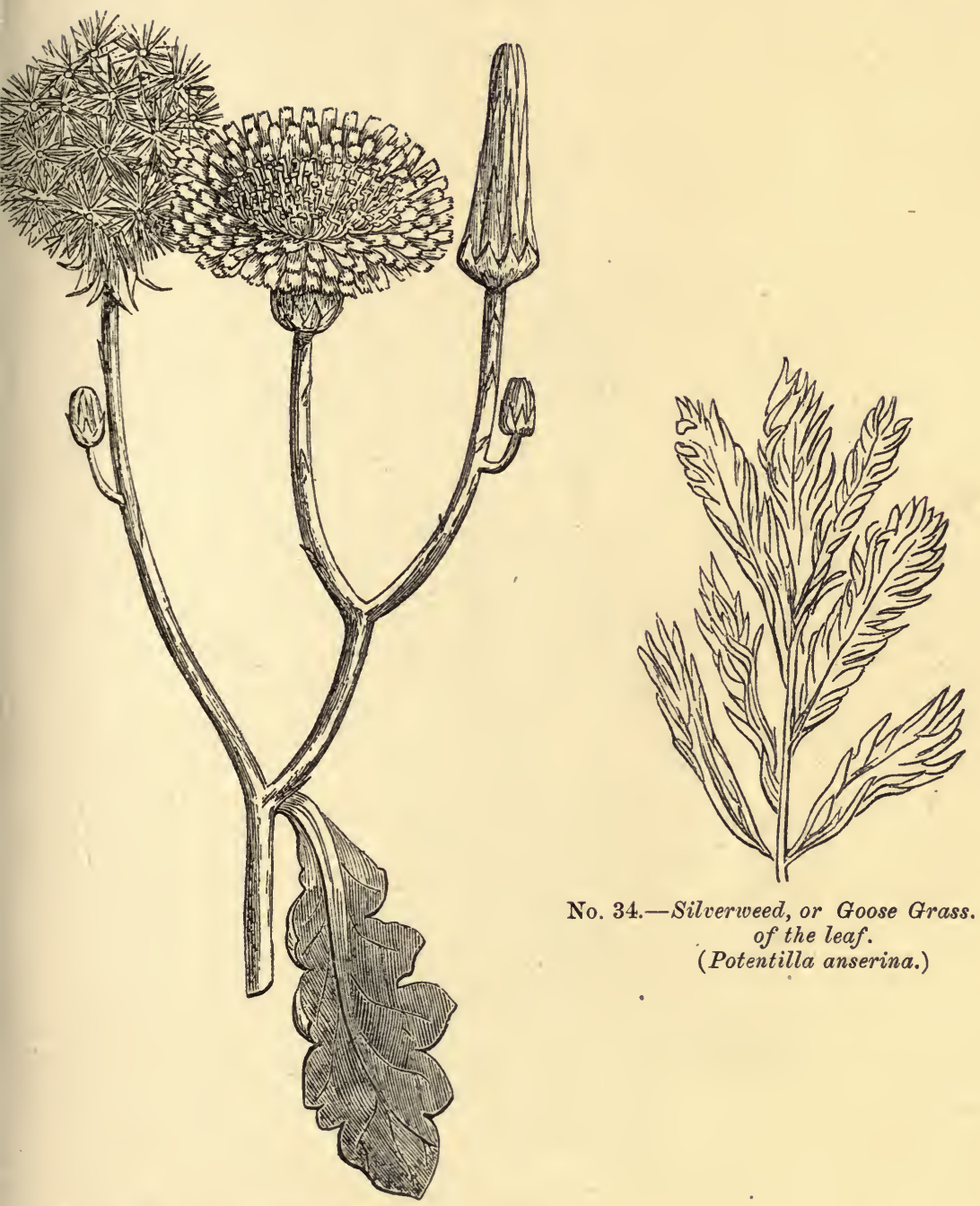

No. 34.-Silverweed, or Goose Grass. Part of the leaf.

(Potentilla anserina.)

No. 33.-Cat's-ear in flower.

(Hypochæris radicata.)

N.B In Hay this weed shrivels up greatly, and the stalks become a mere thread. 


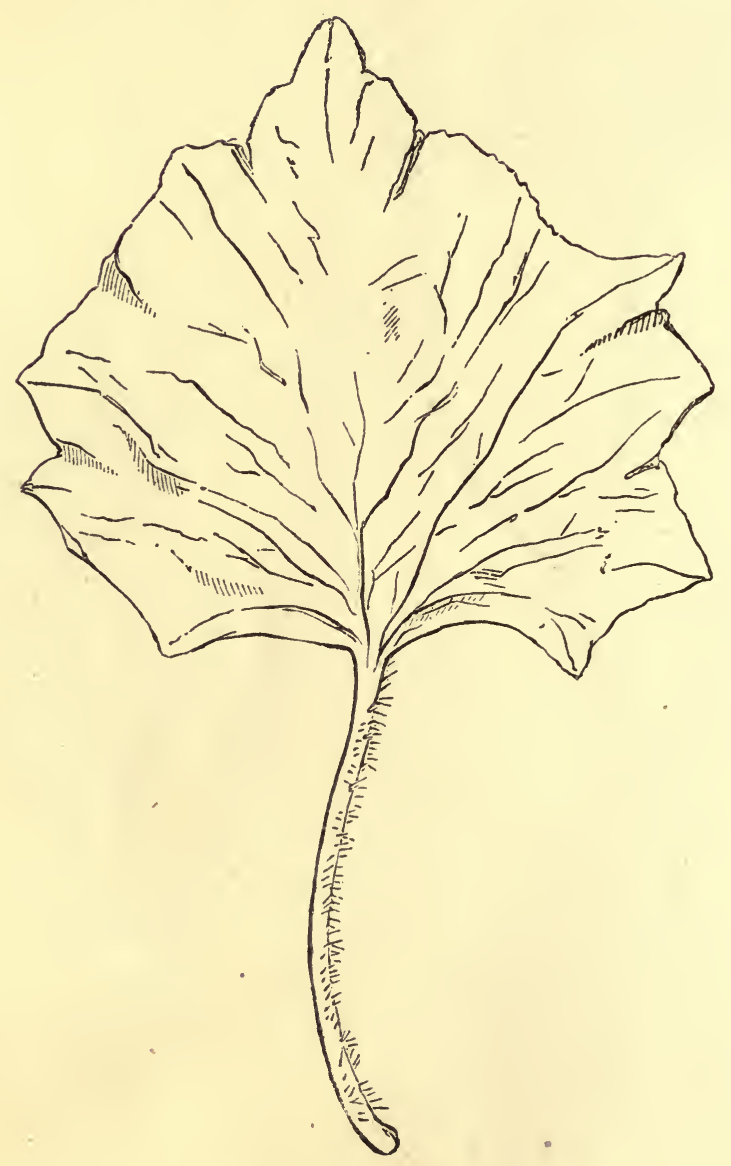

No. 35.-Coltsfoot. Small Leaf. (Tussilago farfara.) 


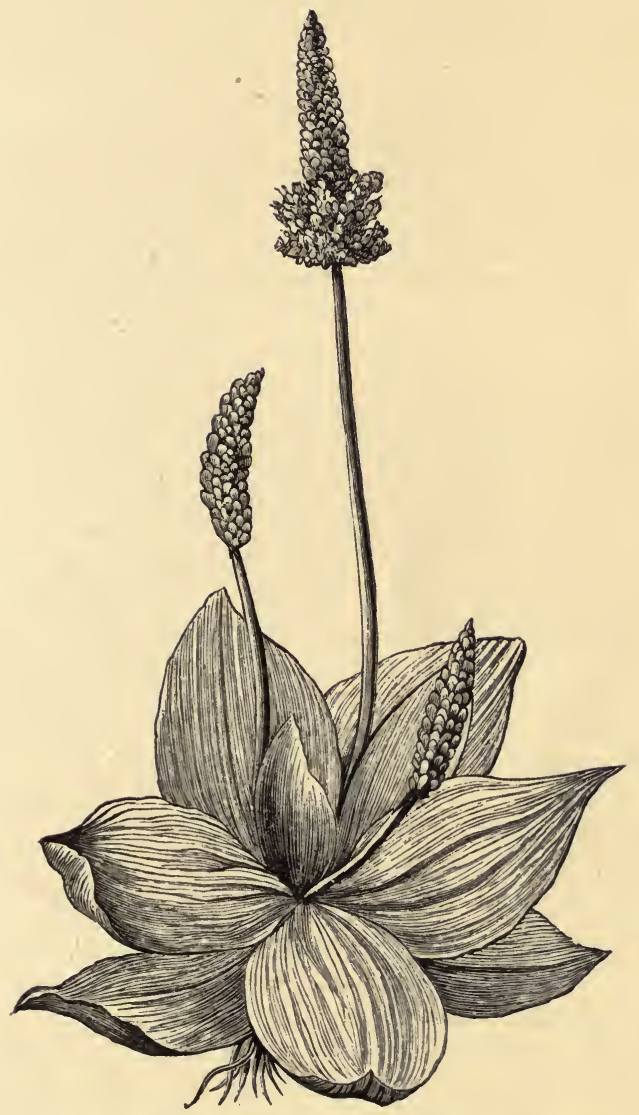

No. 36.-Plantain, a common Weed of no value. 

A proportion of herbage, that is of plants (not weeds) other than grass, is desirable. The different kinds of clover, especially white or Dutch, and the other varieties of trefoils, constitute the great mass of good upland herbage. These plants are generally abundant where the soil on which the crop is grown is good. Herbage makes the hay sweet and palatable. Hay composed only of the best grasses is not relished so well as when mixed with a proportion of herbage.

N.B.-Herbage is a conventional name for plants other than grasses (not weeds) in hay. In a botanical point of view the name is not strictly correct, as all grass is herbage.

A mixture of weeds in hay is objectionable.

The presence of flowers which have not lost their colour, such as buttercups and the flowers of trefoil and clover, is always an item of value in hay, as it shows that the crop has been cut early in the season, before the grasses have lost their juices and nutriment. A similar favourable indication is given by certain early grasses, such as sweet vernal (No. 6), being still in flower, $i$. e. not run to seed.

Hay from artificial grass, if early cut, well made, and not over-heated, is suitable for horses. Most samples are, however, deficient in aroma. Rye-grass is most commonly grown for this purpose; but the farmer, solicitous to obtain quantity, too often delays cutting until the grass is in seed, and the quality of the crop is then reduced.

To recapitulate. The characteristics of the best hay are cleanness, firmness, crispness, and green colour, delicacy in taste, aroma, and appearance, the presence of flowers of their natural colour, the presence of numerous grasses, with sweet vernal and other early grasses in flower, and a proportion of good herbage.

Brightness of colour is an essential requisite as regards market value, but many samples of inferior colour possess no other actual inferiority.

Hay should be one year old. It is then at its best. The author does not believe that hay is improved by keeping for three or four years.

\section{Of inferior and bad upland hay.}

Upland hay, though as a rule superior to lowland hay, may be good, inferior, or bad of the sort.

The best grasses grow only on good soils. The goodness of any soil is, however, largely dependent on manure being duly supplied. The best natural soil will seldom nourish the best grasses year after year without renovation by manure. Without proper dressing, the grasses become poor and thin, or very fine and wanting in firmness. The soil, in fact, has become exhausted, the fibres of its grasses become attenuated, and the hay is soft and silk-like. The herbage also in such cases is generally deficient. Such very fine hay, though perfectly wholesome, is not nutritious, and is therefore unfit for horses doing fast work. The want of herbage is, however, often remedied by sowing clover in the autumn.

Good upland soils, properly cared for, produce the best grasses in the 
best condition. Inferior soils, or even the best natural soils if badly cared for, produce inferior grasses. Hay grown on such soils is usually hard as distinguished from firm, over-dry, and deficient in colour, aroma, nutriment, and herbage.

There are also very poor upland soils, which, especially in dry seasons, grow very little grass. Some are so poor that they will not produce grass sufficient for haymaking.

It must be remembered that there can be no nutriment in grass except what it extracts from the land. Therefore poor land, or land in bad heart, must grow poor innutritious hay.

Some soils produce grass not merely of inferior varieties, but bad of the sort, which is easily recognised in hay by a peculiar sour appearance and taste, and often by a darker colour. The smell, if any, may probably have an odour of turpentine.

Hay grown under trees is readily known by the long, lanky fibres of its grasses, by its lightness, softness, and absence of aroma ; except when grown under fir trees, when a smell of turpentine may be detected. It is very objectionable.

\section{Lowland hay.}

Lowland hay is known-1st. By the coarseness of the stems of its grasses, by the broad leaves of its undergrowth, and by a large admixture of coarse herbage and weeds. 2nd. The direction of the stems and leaves is not well preserved. It is a tangled mass. 3rd. The colour is darker than that of good, well-saved upland hay-though the latter, if heated or badly saved, may be dark. 4th. It has a stronger and less delicate aroma. 5th. The texture is more woolly; and the sample, though each leaf or stem may be coarser, yet feels more soft or less firm. Altogether it lacks the firmness, crispness, cleanliness, freshness of appearance, and delicacy, both of substance and aroma, of good upland hay. Lastly, lowland hay is at once recognised by the absence of the best grasses, which will be presently described as characteristic of upland soils.

\section{Of the grasscs which compose good upland hay.}

The Stems or Flowering heads denote the grasses.

The leaves, which surround those heads, are not easily recognised. Therefore we look to the stems as indicating the grasses. According to the prevalence or otherwise of certain stems, so will be the quality of the hay.

No. 1. Rye-grass (Lolium perenne) grows naturally on most good upland soils. It contains much nutriment. It is also found on poorer soils if dry, but on such it dwindles in size.

It is also extensively cultivated as an artificial grass on lands under rotation. The hay made from it is good for horses. The variety known as Italian is often grown with sewage. Here it becomes coarse, and, though valuable for cows, is unfit for horses. 
No. 2. Meadow Fescue (Festuca pratensis) is a very good upland grass. It forms a considerable bulk of the permanent grass on good upland soils. Its presence denotes good soil. It varies much in its forms, often almost resembling rye-grass, and at other times branching out even more than represented in Fig. 2. There are several other varieties of Festuca, some of which are larger, others smaller than the pratensis.

No. 3. Meadow Foxtail (Alopecurus pratensis) is a very good early grass, and is found on good deep soils. It requires moisture, and therefore will not flourish on light dry soils. It closely resembles cat's tail, but is distinguished from it by long hair-like awns.

No. 4. Meadow Cat's tail, or Timothy (Phleum pratense), is a very good grass, and often forms a considerable bulk of good upland hay. It is, however, best adapted for moist rich soils.

No. 5. Crested Dog's-tail (Cynosurus cristatus) is a very good upland grass. It is well adapted to light and medium soils. Having long roots, it will resist dryness better than most other upland grasses.

No. 6. Sweet-scented Vernal (Anthoxanthum odoratum), though it has no great nutritive value, is very beneficial in hay on account of the fragrance which it imparts. It is a very early grass, and runs early to seed. Hence, if it is found in flower in hay, it is especially favourable as a test that the crop has been cut in good time. If, on the other hand, it has run to seed, it shows that the cutting has been delayed.

The above are the best upland grasses; and in proportion as upland hay contains them, it is good. Some few of them, it will be seen, require that the soil should be moist as well as rich.

\section{Of inferior grasses.}

No. 7. Cock's-foot (Dactylis glomerata) is a somewhat inferior grass. It grows on both good and inferior soils. It also flourishes under the shade and drip of trees. Hence it is sometimes termed Orchard-grass. It is coarse and hard, but as it contains a good deal of nutriment, it is constantly employed as a mixture by agriculturists.

No. 8. Smooth Meadow-grass (Poa pratensis) is inferior, and contains but little nutriment. It grows abundantly on all soils, whether wet or dry. There are numerous varieties of this grass, some fine, some coarse, according as the soil is dry or wet; but they all bear a general resemblance.

No. 9. Soft Meadow-grass (Holcus mollis) is another abundant but inferior grass. It grows on all soils. When dried as hay, it has a soft spengy feel. It contains but little nutriment.

No. $9 a$ shows the same in early flower.

No. 10. As much may be said of Yorkshire fog (Holcus lanatus), which it very closely resembles.

These last two grasses are found to a certain extent in all samples of hay, but in inferior hay they form the great bulk. 


\section{Very inferior grasses.}

No. 11. False Oat (Avena elatior) is a very common class of grass, especially abundant on light and calcareous soils, and often growing on hedgebanks.

No. 12. The Field Brome (Bromus arvensis) is a coarse, common grass. It grows on low-lying ground, and, although not found in water-meadows, will flourish on almost any description of soil.

No. 13. Fiorin grass (Agrostis stolonifera) is an inferior, very plentiful grass, and will grow on any soil. It has, however, been found useful, yielding a weighty crop on salt marshes, reclaimed bogs, and other damp soils, where the better grasses would not thrive.

No. 14. The Rough-stalked Meadow-grass (Poa trivialis) is a common inferior grass, found on all soils, but especially abundant on poor soils, whether wet or dry. Though unsuitable for horses, cattle thrive pretty well on it.

No. 15. Quaking-grass (Briza media) is not abundant, but is found to a certain extent on most poor and low-lying soils. Here and there a few straggling specimens occur on good soils.

\section{Of bad grasses.}

No. 16. Squirrel-tail or Meadow Barley (Hordeum pratense) is a sign of bad and wet land. It has no nutritive value, and is much disliked by horses on account of its bristles, which hurt the gums.

No. 17. Slender Foxtail (Alopecurus agrestis) marks poor land, and is common in waste places and road-sides. It can hardly be distinguished from meadow foxtail, except by its being smaller and much more slender. It has no nutritive value. In some districts a variety of this grass grows very tall and large on wet, undrained land, and is locally known as Black grass.

No. 18. Tufted hair-grass (Aira coespitosa) is very tall, and grows in bunches or large tussocks. It marks very poor soil and low land. Its presence in hay is an invariable sign of worthlessness. The drawing shows the flowering head only.

No. 19. Rushes (Juncus communis), though not grass, may here be mentioned. They are a marked sign of wet, undrained land. They will, however, continue to exist for years in drained land unless well stocked up, though decreasing each year in size and number.

The above are the principal grasses which, according to circumstances, prevail in upland and lowland meadows. A purely upland grass will not be found at all in lowland meadows. Others, however, are common to both, but become ranker and coarser in their stems and leaves in proportion as the soil is wet.

\section{Upland herbage.}

Of the plants constituting good upland herbage, the several varieties of the Trefoil are the most important.

No. 22. White or Dutch Clover (Trifolium repens) flourishes on good upland soils, wherever there is a fair proportion of lime in the soil. 
No. 23. Common Red elover (Trifolium pratense) is found in abundance on most good soils, and to a certain extent on other soils, as long as they are dry.

No. 24. The Little Yellow Clover (Lotus corniculatus) is good herbage, and prevails on most dry upland soils. It varies a good deal in its growth and appearance in different places.

No. 25. The Yellow Vetch (Lathyrus pratensis) is found on soils, whether rich or poor, if dry.

These latter two, as they ripen, are apt to become bitter and unpalatable.

No. 26. Sainfoin (Onobrychis sativa) is found only on fairly good soils.

No. 27. Hop trefoil (Trifolium procumbens) is found on both good and poor soils, if dry.

\section{Lowland herbage.}

Lowland herbage consists of a great variety of plants. It is easily recognised by its broad coarse leaves and general rankness.

\section{Recapitulation.}

Good hay contains a large proportion of the best grasses, along with the trefoils and other good herbage, and only a small proportion of the inferior grasses.

Inferior hay, on the other hand, consists mainly of the inferior grasses, with only a small, or perhaps no admixture of the best grasses, whilst good herbage will be wanting.

Inferior hay generally contains an unduly large proportion of leaves to stems. The absence of a good proportion of stems to leaves is always a sign of inferiority, whether the hay be upland or lowland.

The best upland hay consists mainly of the grasses numbered from 1 to 6 , with almost always some admixture of the rather inferior grasses numbered from 7 to 10 .

Inferior hay will contain but little of the grasses numbered from 1 to 6 , a very large proportion of those numbered from 7 to 10 , and some proportion of those numbered from 11 to 15 .

Very inferior hay will contain none of the grasses numbered from 1 to 6 , and the bulk will consist of those numbered from 7 to 15 , with some of those from 16 to 19 .

The specimens of water-meadow grasses are numbered from 18 to 21 .

\section{Of Weeds.}

The presence of weeds in hay is generally an unfavourable sign. They indicate land either in bad heart, or naturally poor or wet.

Buttercups, however, are often found in considerable quantities on fair moist soils. There are four varieties of buttercups-all more or less acrid. The long-stalked and bulbous varieties are found in considerable quantities on most fair moist soils. The creeping and celery-leaved varieties are found on wet marshy soils. 
Dandelions grow on good soil, but their presence shows that the land has not been kept clean.

Sorrel grows on light soils. It gives a subacid taste to hay. A small quantity is not objectionable.

The Rib Plantain (Plantago lanceolata) is a common weed, growing on all soils. It is $\mathrm{n} t$ objectionable in hay. No. 28.

Hard or Black heads, otherwise called Knapweed (Centaurea nigra), are coarse, tough, and quite indigestible. No. 29.

Rattle (Rhinanthus crista-galli) grows on poor land. Its abundance in any sample of hay is a sure sign of poor land, though a very little is sometimes found on good soils. It is a great nuisance to the farmer. No. 30.

Common Bank Sedge (Carex riparia), if large, indicates very inferior wet soil. Its presence should cause any sample to be rejected. Smaller varieties, some very small, are, however, found on poor upland soils. No. 31 .

Smaller forms of sedge are sometimes found on upland, and are not injurious, though indicating poor soil.

The Wood-rush (Luzula campestris) is very common on upland soils. Its presence in any considerable quantity indicates an inferior quality of hay. No. 32.

Cat's-ear (Hypochoris radicata) is most objectionable. It has a bitter taste, which will cause horses to reject the whole lot of hay, so much do they dislike it. It has a flower somewhat like the dandelion. No. 33.

Silverweed or Goose-grass (Potentilla anserina) is found on clayey sands. No. 34 .

Coltsfoot (Tussilago farfara) abounds in all moist chalky soils and clays. No. 35 .

\section{Of the time of cutting hay and saving hay.}

Hay may be composed only of the best grasses and herbage, and yet may be inferior or bad, because-

1st. It may have been cut too late; or-

2nd. It may have been badly saved.

\section{Of late-cut hay.}

This is a very common evil. The farmer often delays to cut in the hope of obtaining a greater bulk of under grass. This is especially apt to be the case in dry seasons; or, on the other hand, the crop in wet seasons may be left to stand over-long in the hope of finer weather.

The crop should be cut before the grasses have run to seed. The permanent grasses flower and seed every year. In common with all such plants, the nutriment of the plant passes into the seed for the reproduction of its kind in the succeeding year.

We all recognise the effect of seeding on the stem or straw of corn. The straw is almost worthless for feeding, because the nutriment of the plant has passed into the seed. This is also to a great degree the case 
in regard to grass, though not to so great an extent as in corn, as the grass plant does not absolutely die. Still it exhausts the greater part of its nutriment in its efforts for the formation of its seed.

It may be asked, Why should not a horse eat hay seeds as he will eat corn seeds? The Author cannot say, but as a matter of fact the horse will not eat them. Again, the seeds generally fall out when the grass is ripe, and are, therefore, lost.

It is, therefore, essential to good nutritive hay that the crop should have been cut whilst the grasses are yet in flower, i.e. before they have seeded.

Fortunately it is very easy to recognise in hay the grasses which have seeded, and those which have not seeded.

\section{Of saving of hay.}

Again, hay may be composed of only the best grasses and herbage, and may also have been cut in good time, and may yet be inferior, bad, or even worthless, on account of having been badly saved.

This, however, is always a question of degree. No absolute rule can be laid down. A moderate shower of rain, falling on the best upland grass, will cause it to lose its green colour in hay, which yet may be in perfectly good condition, and none the worse as regards real value.

Any considerable degree of wet falling on hay, especially when nearly dry, will cause it to lose its natural bright, clear, healthy appearance, and will make it more or less deficient in aroma, and more or less of its nutritive qualities will be washed out. As stated above, it is a question of degree.

Hay which has long been exposed to the action of rain, wind, and sun, is easily recognised by a ragged, confused, broken, washed-out appearance, and by dinginess of colour.

This subject will be further explained in the succeeding paragraph on making hay.

\section{On making hay.}

The following few remarks on making hay, extracted from a number of the 'North British Agriculturist,' though they may at first sight seem foreign to the scope of this work, will assist the reader in forming a right estimate of its value.

"In the operation great attention and quickness are required in order to retain in the hay all the nutritive qualities of the grass. If the grass can be converted into hay without any alteration in its composition, and with little or no loss of its feeding properties, the water only being extracted, it will then be as well made as possible, and will possess the greatest value. With this view it should not lie long in the field after being cut, but should, if possible, be carried the second or third day. Rain will cause the crop to lose its green colour, but does not of itself really injure the new-mown grass, as is often supposed. Mischief, however, ensues if the grass is injudiciously turned over in wet weather, because the blades become bruised and injured in the process, and then 
the rain washes out the sugar, gum, and other soluble properties. For similar reasons hay ought not to be turned over on damp days, when the air is saturated with moisture."

"It is desirable that a crop be cut as soon as it reaches maturity, before any of the nutritive qualities are gone. It is essential that it be cut before the flowering heads have fully seeded. When the mowing is delayed later, the hay will be deficient in nutriment and aroma, and its constituent fibres will be as dry as straws. In grasses, as in other annual vegetable productions, the process of seeding exhausts the plant, and the stem no longer contains nutriment or moisture."

Hay made from grass which has been purposely left standing until perfectly ripe, with the view of threshing out the seed for sale, is altogether worthless.

\section{Mow-burnt hay.}

Mow-burnt is a name given to hay which has heated in the stack, either-1st, from having been stacked too soon, i.e. before the juices of the grass are sufficiently dried; or 2 nd, from the grass having been stacked when wet from rain or dew.

Mow-burnt hay is easily recognised by its dark colour and high smell. Whether or not it is fit for use is entirely a question of degree. Slightly mow-burnt hay may be used with impunity, especially if given in moderate quantities mixed with sound hay. Horses are fond of it, but it is apt to affect the kidneys.

On the other hand, hay may be so mow-burnt as to be a mere cinder. Such is obviously unfit for use.

\section{Dust in hay.}

Dust in hay commonly arises from the hay having got slightly damp, and having afterwards become quickly dry without passing into the stage of mouldiness. The apparent dust is the débris of the outer coats of the stems and leaves, which decay and fall off in the process of heating, which has taken place as the result of damp.

In different atmospheric conditions, or perhaps in another place of storage, hay not more damp might have become mow-burnt or mouldy.

Dust may also arise from hay having been overdried before being carried, or from having been much exposed to weather. In the first-named case the dust arises from breaking up of the outer coats of the fibres from over-dryness, and in the latter from decomposition owing to exposure.

Dust is occasionally due to a blight having fallen on the crop whilst growing.

Dust, from whatever cause arising, is always an unfavourable feature in hay.

\section{8a. Second crop of hay, or aftermath.}

The second crop of hay, whether of upland or lowland growth, otherwise called the aftermath, is very inferior to the first, and is unfit for 
horses. Its characteristics are softness, absence of stems and flowering heads, and total want of perfume. It consists chiefly of the leaves which grow round the stems of the grasses. The stems, after being cut in the first crop, do not in general grow again during the summer. Such stems as do grow, lack the firm, bright, healthy appearance of the first crop. The colour of the hay is always dark, and the various fibres and leaves lie in confusion.

\section{8b. Distinction between new and old hay.}

In the stack there is seldom any difficulty in determining whether the hay is old or new. The weather-beaten appearance or otherwise of the outside tells its tale pretty clearly. On a single truss, however, apart from the stack, it is very difficult to form a correct opinion. Some London salesmen, whom the Author has consulted on this point, agree in saying that they form their opinion chiefly, if not entirely, on their knowledge of the peculiarities of the growth of the crop in each year in the district from which the market is supplied. (Hay, we may remind the reader, is always drawn from a not very extensive district round the market. It is too bulky to pay for lengthened carriage, except under extraordinary circumstances.) For instance, the crop of one year may be marked by abundance of herbage, that of another year by absence of that feature; or that of one year, as in the hot dry season of 1868, may be distinguished by being universally well saved and also scanty in quantity, whilst in another the crops may be all heavy, or in another year the hay on account of prevailing wet weather may be, as a general rule, badly saved. More than one of these peculiarities may be present in a crop, and may serve to distinguish it very easily from the growth of the previous year. It never happens that the growth in two successive years presents exactly the same features. As hay is not kept above two or, at the outside, three years, the difficulty of bearing in mind the peculiarities of each crop during such very limited period is not great. The wine merchant, who recognises by the bouquet the vintages of many years, has a far more difficult task in his trade. The salesmen appear to prefer this method of distinguishing old from new hay to any of the other distinctions, which the Author will presently endeavour to point out, because it is independent of those changes in colour, smell, softness, dryness, \&c., which are caused by the process of heating or fermentation, to which hay in this country is usually subjected.

At a distance, however, from the district in which the crop is grown, this special knowledge, on which the salesmen seem to rely, would fail. There may have been, for instance, heavy rain in one district at the proper season, and in consequence a heavy crop with abundance of herbage; whilst the crops in another district, from a difference in weather, may be light. Of late years hay has been brought from great distances, and therefore the above hints are not as safe a guide as they were 50 years ago.

To aid the general reader, who cannot be expected to possess the above- 
mentioned special knowledge, we shall endeavour to point out some distinctions, by which in most cases, though perhaps not positively, new and old hay can be distinguished.

Two great difficulties are met with at the outset. Changes are very rapidly produced in new hay by heating or fermentation, which cause it to simulate in almost every respect the appearance of old hay; and secondly, well-saved old hay, which happens not to have heated at all, very closely resembles new hay.

New hay, apart from any change which may be produced in it by heating, is marked by green colour, by the perfect freshness of its perfume, by the sappiness of its fibres, by the preservation of the natural colour of its flowers, and by the absence of consolidation. If, however, no fermentation takes place in the stack, the green colour of the grass, the freshness, though not the perfect freshness, of its perfume, and the natural colour of its flowers, may remain for almost any length of time. The sappiness of its fibres, however, will gradually and sensibly diminish as the year draws on. In some seasons the outside of the fibres may be quite dry in perfectly new hay; but if the outer coat be peeled off, the inner stem will be found to be sappy. In old hay the inside of the fibre will be as dry or nearly as dry as the outside. Sap is retained longest at the knots. Hence in cases of doubt the fibre should always be examined at the knots. If the inside of the knot is dry, it affords some proof that the hay is old.

Old hay is usually marked. by loss of green colour, by absence of fresh perfume, by dryness of its fibres, by loss of colour of its flowers, frequently by greater consolidation, especially towards the centre of the stack, and in some cases by a musty smell. The outer trusses, however, often retain almost all the peculiarities of new hay. Hence it is much more difficult to give an opinion about one truss than about a load.

All the above-mentioned peculiarities of old hay may, however, be found in new hay, when it has been in stack for a couple of months or even less, and has heated. For instance, the green colour of its grasses may be lost by a few days' fermentation, and so likewise the colour of its flowers. The perfume will also change from that of a new-mown grass to the smell (in extreme case) of mow-burnt hay. Again, consolidation is due to heating, not to tile gradual effect of weight and time, as is often supposed. New hay immediately after fermentation will be nearly as much consolidated as it will ever be; whilst a stack, which does not ferment, will scarcely have sunk at all at the end of a couple of years.

Fermentation or heating, we must remark, though a farmer would probably smile at so simple a remark, is not a process continually going on or even going on for any considerable length of time in a stack. Owing to the state of the grasses, aided perhaps by the state of the weather and other circumstances, fermentation takes place, runs its course, and then ceases. If it exists to any great degree, or if it lasts for any considerable length of time, the chances are that the stack catches fire. Stacks of hay do not heat evenly or equally all over. The heating generally commences in the centre, and runs to one side or the other 
according to the wind or other local circumstances at the time. The opposite side may not be affected at all. The outer part is seldom much affected, even on the side to which the heating runs.

Old hay, as a general rule, is harder than new; but in exceptionally dry and hot seasons, the grasses composing new hay may be so dried, and even burnt up, that from the very first they are as hard and dry as the fibres of old hay. On the other hand, a great deal of mow-burnt hay, whether old or new, will handle quite soft. Again, the climate at the particular time at which the stack is cut and brought to market, will affect the moisture and flexibility of the fibres. The Author has known two-year-old hay in hot damp weather handle and twist as flexibly as grass. Further, a stack of old hay, when first opened and cut and thereby exposed to the air, will often sweat in particular states of the weather, and the hay in the trusses will handle like new hay. After a few days, however, the effect of the renewed sweating will go off, and the hay will again handle hard.

The weeds often found in hay generally afford valuable information as to its age. The sap remains longer in their strong and coarse fibres than in the more delicate stems of the grasses.

Of these the Black-head (Centaurea nigra), No. 29, may be taken as an example. Its stalk, but more especially the pods containing the seed, long retain moisture, and may thereby prove the hay to be new, when the state of the grasses might lead a person to think that it was old. The leaves of the Rib-grass (Plantago lanceolata), No. 28, also afford some indication. In new hay they are brown, soft, and flexible, whilst in old hay they are black and friable, $i$. e. break and crumble to pieces on the application of friction. These latter indications may, however, be present in new hay after it has heated.

The degree in which all the above signs respectively exist will obviously vary much according to the month in which the examination is made. They must therefore be applied with discrimination.

These remarks on the distinctive differences between old and new hay may seem at first sight to the reader to be so full of qualifications as to be neither very clear nor explicit. The subject is, in fact, a difficult one, and does not admit of drawing any sharply defined definitions. Apart from a special knowledge of the growth of the year and the preceding year, no rule can be given for distinguishing old from new hay. The Author believes he has laid before the reader all the distinctions, and the necessary qualifications to those distinctions, which exist. The intending purchaser must balance one fact or appearance against another; and with care and practice, and the assistance of the above data, he will probably after a time be able to form a pretty correct opinion. The best means, however, of acquiring a thorough knowledge on this subject is to give up a few mornings to going round a hay market with a respectable and intelligent salesman.

98c. New v. old hay, as regards feeding.

New hay, as is well known, has a tendency to cause scouring; but in 
November well-saved examples are sufficiently dried to render them innocuous in this respect. In the Author's opinion new hay may be given safely after that date to hunters which are not limited in their oats, though he is quite aware that popular opinion is opposed to this view. Hay of one year is desirable, though not essential, to hard condition. After a year and a half, hay, he thinks, loses much of its nutritive qualities. It becomes over-dry and, if the expression may be used, stale. Well-saved samples may retain their perfume for two, or even three or four years ; but, nevertheless, they have lost much of their feeding qualities. Rose leaves and lavender kept in closed jars will retain their scent for twenty years, although so dried up as to crumble to dust in the hand.

\section{8d. Irish hay.}

It is the custom of Irish farmers to leave the hay out in the fields for at least two months in cocks, until it is so thoroughly dried that it does not afterwards heat. Much of the nutriment, however, is extracted out of it, as we might expect, by the effect of the sun, wind, and rain during that long period.

As the hay does not ferment, there is but little difficulty in distinguishing old from new. The state of the weeds generally pretty abundantly found in it affords the best indication of its age. Great reliance may be placed on the state of the Rib-grass (Plantago lanceolata), No. 28. For the first month or so it remains almost green, for the next three months it is brown, for the succeeding three it is black, but pretty flexible. After this time it breaks and crumbles away with a little friction. The Black or Hard-head, No. 29 (Centaurea nigra), a harsh, stubborn weed, retains the moisture in its stalk for the first three months. After that period the moisture will only be found in its knots and in the pods. After six months the moisture has left the knots and remains only in the pods. A bout March the sticky moisture, which has hitherto glued together the seeds in their pod, has dried up, and the seeds are easily separated from each other when the pod is opened. Another plant, known as the Silverweed or Goose-grass (Potentilla anserina), No. 34, affords excellent indications of the age of hay. It is easily recognised by its growing in bunches. In new hay the under side of the leaf is white. An alteration in colour gradually takes place, until at the end of nine months the under side is quite black, and the leaf crumbles to pieces on friction. Coltsfoot, No. 35 (Tussilago farfara), the under side of the leaf, which is at first white, affords indications similar to those given by the silverweed. The Thistle retains something of its green colour and is sappy till spring. In old hay it will be found excessively shrivelled, dry, and brittle. The Dock retains its colour and sap for about four months, and after that period gradually becomes dry, brittle, deep red, and eventually black.

\section{8e. Pressed hay.}

Pressing does not injure hay. But the purchaser must bear in mind that frauds are very possible unless due care is taken. 


\section{8f. Clover hay.}

Clover hay is much relished by horses. It is very useful in putting on flesh, but militates against very hard condition and good wind, and is therefore not recommended for horses doing fast work. The most valuable hay is that made from clover only; but the crop is often-indeed usually, sown with rye-grass, and hence there is frequently, especially in the first cutting, a large admixture of the latter in it.

The produce of the first cutting is the best, that of the second is much coarser. The third growth is not often made into hay. It consists chiefly of leaves, as the stalks do not grow a third time. It is generally fed down.

The most common defect in clover hay is mouldiness or a tendency to it, indicated by loss of colour in the flowers and general blackness. It is, in fact, a difficult crop to save well on account of the great amount of juice in its fibres and leaves, especially in the first cutting of the year.

\section{8g. Green forage.}

Green forage is laxative and cooling, and therefore well suited for sick or young horses, especially when first taken up from grass. The quantity given to the latter should be gradually diminished, as the system becomes accustomed to more stimulating diet and the warmth of stables.

Green forage, if given to horses in fast work, is very liable to cause bowel complaints. From its bulk and laxative action it militates against the hard condition necessary for fast or full work. It is not, however, so objectionable for cart horses, whose work is slow; yet it causes even these to sweat much and easily, and not unfrequently, especially in early spring, brings on bowel complaints.

Green forage of whatever sort should be young and fresh. Grass, ryegrass, lucerne, and sainfoin are to be preferred when they can be obtained. Vetches and clover are also used. Green forage, when old, loses much of its succulence, and vetches in particular become heating. If stale it is apt, from rapid decomposition, to produce colic and intestinal disease.

Clover, vetches, and other plants of the Trifolium variety contain an acrid principle, which is apt to affect the kidneys. Grass, rye-grass, lucerne, and sainfoin are free from this objectionable property, and are therefore more suitable for sick horses than the varieties of Trifolium.

Green forage should always at first be given rather sparingly. Many horses die every spring from neglect of this precaution.

\section{8h. Carrots.}

Carrots are often very acceptable to sick horses, and are especially valuable at those seasons of the year when fresh grass cannot be procured. New carrots are the best. None but sound roots should be selected. They should be sliced longways. If cut transversely they are apt to cause choking. They may be given by themselves or mixed with oats or 
mash. But the sick horse, whose appetite is very capricious, will more often be tempted by the carrot alone.

\section{8i. Gruel.}

Gruel made from oatmeal is palatable and refreshing to a tired horse. The stomach seems to assimilate it more readily than hard corn. The very best fresh coarsely ground oatmeal should be used.

Good gruel is made by putting about a double handful of oatmeal into a pail and pouring on it a little cold water. After being well stirred, a gallon and a half of hot, but not boiling, water must be added, and the whole stirred again. Boiling water should not be used, because it produces a more starchy compound than is suitable for the stomach of the horse in an exhausted condition. The temperature should be reduced to that of new milk before it is given. If the horse is very much overtasked, it may be advisable to add to it a wine-glassful of spirits or a pint of ale.

Gruel may also be made from boiled linseed, and many persons prefer it to oatmeal gruel. It should be prepared by boiling about one pound of linseed in two gallons of water. The fluid should be strained, and forms a nice drink. The residuum may be utilised by mixing it with bran in the form of a mash.

\section{8j. Bran.}

Bran, when fresh ground and wetted, is useful as a laxative. It acts mechanically on the lining membrane of the stomach by causing a slight irritation, which increases the secretions and thereby quickens the passage of the contents of the intestines.

In the cavalry a bran mash is usually substituted for the feed of oats on every Saturday evening, partly because the horses are not exercised on Sundays, and partly as a preventive to constipation, which might otherwise arise from being kept on hard food exclusively year after year.

Whether from this practice or not, it is certain that troop horses do not require those periodical doses of physic which in many stables are supposed to be essential to the maintenance of health.

A bran mash should be made as follows :- The bran should be placed in a clean stable pail, and as much boiling water poured in as the bran will absorb. Half an ounce of salt may be added, and the whole should be covered up to keep in the steam until sufficiently cool. A pound of well-boiled linseed is a valuable addition.

Dry bran in small quantities is said to have an astringent effect. It is often given after physic, if over-active, to stop its further action. A handful of flour, however, in water will answer this purpose better. Bran should invariably be fresh ground.

\section{8k. Linseed.}

Linseed is the seed of the flax plant, and is a valuable food for horses in low or debilitated condition. It is slightly laxative, is soothing to 
excoriater mucous surfaces, and has a marked effect in improving the horse's coat. It may be given boiled either in the form of a mash with the addition of bran, or may be mixed with the oats, or given in the form of gruel.

\section{Boiled foods.}

Boiled foods fatten, but do not give strength and firmness to the muscles. They are, therefore, unsuitable for saddle or carriage horses, though perhaps they may answer for animals in slow work. Even in these, however, they are apt to produce colic, indigestion, and sometimes rupture, probably from the facility with which this description of food may be bolted without due mastication.

\section{$98 m$. Straw.}

Straw must be either wheaten, oaten, or rye, and should be clean, dry, and not much broken in the thrashing. Steam-thrashed straw is inferior to that thrashed by manual labour, inasmuch as it is more broken.

Wheaten is generally preferred to oaten straw, and certainly looks nicer in the stable; but there is no real objection to the latter, except that, when new, horses are apt to eat it. This, however, may be prevented by a proper arrangement of the bedding. Rye straw is very good, but in most localities its cost is a bar to its use.

Barley straw is inadmissible. It is apt to induce disease of the skin.

\section{8n. Artificial foods.}

All food to be useful must supply the special nutrient materials required by the particular animal. For most horses the ordinary articles of food, namely, hay and corn, answer best. Some animals, however, have delicate digestions, others are troubled with want of appetite. Stomachics mixed with the food of the one may assist digestion, whilst tonics may be useful to the latter. Again, in animals, as in men, it sometimes happens that there is some want of nutrition in some part of the system, which must be supplied before the animal will thrive or put on flesh. A harsh coat, for instance, indicates a want of oily material in the system, which may often be beneficially supplied by giving boiled linseed. In other cases the special want may be of fibrinous material in the blood, and then doses of iron will be useful. These instances might easily be multiplied.

After a severe debilitating illness, when the system is thoroughly exhausted, nothing will be found to answer better than a quart of strong beef soup daily, either given as a drink, if the patient will take it in that way, or mixed with corn. The same recipe will, in some cases, but not in all, answer in putting flesh on a horse which, though in good health, remains persistently thin.

Most of the artificial or patent foods advertised in the present day are compounded of a great number of stimulating and fattening ingredients, by means of some one of which the special need of the system may very 
possibly be supplied. But it is as well to remember that most artificial stimulants cease to have any effect after a time.

The chief objection to the use of such foods, even in cases where they act beneficially, consists in the excessive price at which they are sold. The component parts of these foods are easily ascertained by analysis, and, indeed, in most cases are well known. The owner of horses may as well make them for himself as pay a hundred or two hundred per cent. over their value.

On this subject the Author has ventured to extract the following sensible remarks from the valuable work on 'The Horse in the Stable and the Field,' by Stonehenge, pp. 231-2 :

"During the last five or six years various artificially prepared foods have been introduced to the notice of the public, under the names of 'Thorley's Food for Cattle,' 'Henri's Horse and Cattle Food,' \&c. The advertisements of the patentees would lead to the belief that their horse and cattle foods contain more real nourishment than the various kinds of food which have hitherto been given to horses and cattle, but chemical analysis shows the incorrectness of these statements.

"The following observations in the 'Field' of the 18th of February, 1860 , put the matter in its true light, and show that as a mere article of food these preparations are far from economical:

" 'It is not surprising, when artificial foods should thus come to be adopted as so much fattening power, that various mixtures should be employed largely impregnated with stimulating substances. They are thus made extremely palatable to the animal, who naturally enough thrives upon the good things provided for him. We will not now stop to inquire how far this stimulus may be permanently beneficial, even admitting the temporary advantage; our object is simply a cash account. If the price of cake, ranging at about $£ 10$ a ton, forms the limits from which any ordinary return can be expected, how can an article, sold at a price realising from 300 to 400 per cent. on the cost price of the materials of which it is composed, ever bring any return at all?

" 'Such savoury condiments, dished up at from $£ 40$ to $£ 50$ a ton, have no more fattening powers than the ordinary cakes and meal, of which, indeed, their bulk is principally composed. Locust beans, the different oil-cakes, and Indian corn form the basis of these cattle foods so often paraded before the public, with which sundry stimulants, making a kind of curry-powder concoction, are mixed up. This, though it may be highly agreeable, yet at the price above stated forms a most costly addition to the ordinary feeding cost, and an animal once pampered on such material can hardly fall back on ordinary food; hence the price of fattening is greatly enhanced, but without any increase of the saleable carcass, for there is a natural limit in this direction.

" "A compound at $£ 40$ a ton will make no more flesh than oil-cake at $£ 10$; but if the farmer approves of, and will have, the compound, let him simply mix the materials himself. There is no secret in the composition, for the test is at hand in a simple analysis.

" The following is the ordinary formula: 
“To make one ton of meal.

Locust Bean, finely ground, at $£ 6$ a ton cwt. qrs. lbs. \& s. $d$. Indian Corn at $£ 7$ a ton

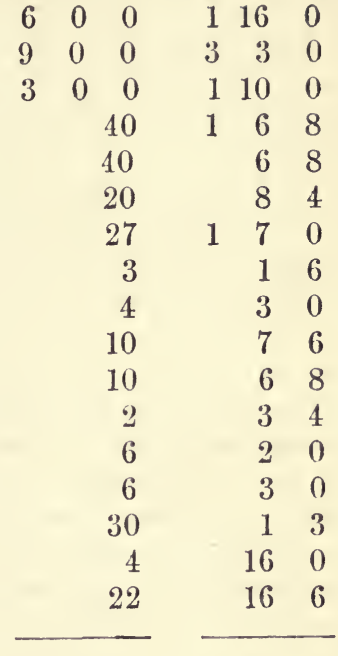

Best Linseed Cake at $£ 10$ a ton . . .

Powdered Turmeric at $8 d$. a $1 \mathrm{~b}$. . . .

Sulphur at $2 d$. a $\mathrm{lb}$.

Saltpetre at $5 d$. a $\mathrm{lb}$.

Liquorice at 1 s. a $\mathrm{lb}$.

Ginger at $6 d$. per $\mathrm{lb}$.

Aniseed at $9 d$. a $\mathrm{lb}$.

Coriander at $9 d$. a $\mathrm{lb}$.

Gentian at $8 d$. a $1 b$.

Cream of Tartar at $1 s .8 d$. a $1 \mathrm{~b}$.

Carbonate of Soda at $4 d$. a lb.

Levigated Antimony at $6 d$. a $\mathrm{lb}$.

Common Salt at $\frac{1}{2} d$. a. Ib.

Peruvian Bark at $4 s$. a $1 \mathrm{~b}$.

Fenugreek at $9 d$. a $1 \mathrm{~b}$.

\section{Total}

$.20 \quad 0 \quad 0$

$1218 \quad 5$

" "Looking at this composition, it will be evident at a glance that the chief ingredients are the ordinary commercial locust-bean, Indian corn, and oil-cakes.

"These form its bulk, and constitute nine tenths of the whole, the remainder being made up of condiments and stimulants, the sulphur and antimony being intended to act upon the skin in the production of a fine coat, and the fenugreek for a kind of mucilage to prevent any ill effects that might arise from the stimulating character of the food.

" "These ingredients have no doubt been selected with skill, and an animal may be expected, and not unreasonably, to thrive upon such savoury substances. For this precious article (which it unquestionably is) the modest sum of about $42 \mathrm{~s}$. a cwt. is demanded, or at the rate of $£ 42$ a ton, or upwards of 300 per cent. on the cost price, even taken at the valuation given above, which for the one tenth or stimulating portion might be considerably reduced, if the several materials were bought at wholesale prices.

" "We prefer, however, to take the ordinary trade valuation, in order to give the widest margin possible for the cost-this, after all, being the simple point at issue. If a farmer wishes for the article, the use of which, containing as it does so much stimulating matter, is very questionable, and chooses to pay from three to four times the intrinsic value, it is of course at his option to do so ; but as the whole question of farming is one of paying, we will put it plainly: Can it pay to feed animals on substances costing from $£ 40$ to $£ 50$ per ton? A knowledge of the constituent elements of these foods may induce a pause before the outlay is made. 
" "Some supposed great secret has no doubt with a few acted as a charm, on the principle of "Omne ignotum pro magnifico;" but the analysis at once dispels this illusion, and nothing remains but the cost and its result, mere matters of ordinary calculation.' "

A small quantity of powdered ginger, or any cheap aromatic spice mixed with the ordinary feed of oats or hay, will often cause a delicate feeder to relish his food, will assist digestion, and will probably answer as well as the highly advertised and very expensive patent foods. Some horses at first object to the taste of spice, and therefore a very small quantity only should be given to begin with. All such artificial aids to digestion should be discontinued as soon as the system recovers tone.

\section{8o. Concentrated foods.}

These foods may perhaps be useful for a few days; for instance, for cavalry employed on a raid in an enemy's country, where supplies cannot be possibly obtained, but they do not answer for ordinary use. The stomach requires a certain amount of mechanical distension to enable it to carry on its digestive operations. Hence, as soon as the stomach becomes really empty, the concentrated food is useless.

\section{CHAPTER 6.}

\section{GROOMING.}

99. Reason of the need of grooming. 100. Structure of the skin. 101. Glands of the skin. 102. Perspiration. 103. Structure of the hair. 104. Shedding of the coat. 105. The Whiskers. 106. Objects gained by grooming. 107. Use of the brush in grooming. 107a. Shampooing. 108. Method of grooming. 108a. Dandy brush. 109. Neglect of grooming. 110. Subsidiary uses of grooming. 111. Improper means used to produce short and glossy coats. 112. Time for grooming. 113. Horses to be groomed immediately after exercise. 114. Danger of allowing a horse, when heated, to sland undried. 115. Cold produced by evaporation. 116. Extremities to be dried first. 117. Special precautions in regard to the back and loins. 118. Of washing the skin. 119. Of drying the legs. 119a. Of washing the legs. Flannel.bandages. 120. Of leaving horses to dry by evaportion. 121. Minor memoranda. 122. Grooming by machinery. 123. Time required to clean a horse. 124. Breaking-out after cleaning. 125. Conclusion.

\section{9, Reason of the need of Grooming.}

The question is often asked, "Why does the stabled horse require constant grooming, whilst the same horse turned out into a field does well enough without it?" 
The question cannot be answered in the form in which it is put. It is not the fact of living under cover, but the active work and the high feeding of the stabled horse, which necessitates grooming. Cavalry horses in camps, for instance, require grooming just as much, and in some respects more than they do in barracks. It is the work and the food, not the shelter, which constitutes the difference between the domesticated animal and the horse in a state of nature.

By work, and especially by fast work, the secretions of the glands of the skin are enormously increased. Furthermore, the horse which is worked hard must be fed on highly nutritious food; and from this cause also the secretions of the skin are largely increased. Nature must be assisted by artificial means to remove these increased secretions, or the pores of the skin will become clogged and the health will be deteriorated.

The greater the action of the skin, the greater must be the attention paid to it. As long as the horse remains in a state of nature, taking only the exercise required for gathering his food, and feeding only on laxative diet, grooming is not needed, because the débris of the food and the excretions of the system are carried off mainly by the action of the bowels and kidneys. The cart horse, whose work is slow, can get on with very little grooming. The hunter and the racehorse, on the other hand, whose whole systems are developed to the utmost, require much more grooming than is necessary for carriage and ordinary riding horses.

Grooming, or in other words, cleanliness of the skin is not, as many suppose, a mere matter of appearance, or of a rough or smooth coat; but it is essential to the general health and condition of the domesticated animal. This fact will become more plain after we have considered the structure of the skin and its glands.

\section{Structure of the Skin.}

The skin is a dense, yet porous, membrane investing the whole body. It is composed of two layers, namely, the outer or upper, called the cuticle or searf skin, which is hard and insensitive, and an under or inner layer called the cutis or true skin, which is sensitive and vascular. These two layers are easily separated, as is seen in cases of slight burns or in the vesicles raised by a blister.

The eutis, or true skin, is thick and full of blood-vessels, nerves, and absorbents. From it the layers of cells which constitute the cuticle, or outer skin, are formed. Each cell is originally round and filled with moisture; but as the moisture evaporates the cells become flattened, and being laid in a series one over the other, they form the cuticle or outer skin.

The outer scales are constantly being cast off in the form of dandriff or scurf, and are as constantly renewed by the secretion of new cells from the true skin below.

The skin varies very much in substance. In parts much exposed, as in front of the knee, it is very thick; in parts less exposed, as behind the knee, it is thin; whilst on the inside of the thigh, where it is not exposed at all, it is very thin. 


\section{Glands of the skin.}

In the skin, having their origin a little below the true skin, are two sets of glands, namely, the "sweat" and the "oil "glands.

The Sweat glands secrete perspiration, and terminate by long-necked tubes on the surface of the skin. Though each gland is minute in itself, yet collectively they form one of the largest secreting organs in the body. Erasmus Wilson, in his work on the skin, says that he has counted as many as three thousand in a square inch of skin taken from the palm of a man's hand. The number of sweat glands, however, varies greatly in different parts of the body.

The Oil glands secrete an oily material. They open, some on the surface, but mostly into the tubes of the hairs. Each hair tube is furnished with one or more of these glands. Wherever there is much friction or motion in the skin, the oil glands are very numerous, as, for example, at the heels, and in the bend of the knee and hock.

\section{Perspiration.}

It has been said, and we believe correctly, that a horse in hard condition and hard work gives off through the pores of the skin, or, in other words, by means of the sweat glands, during the twenty-four hours, an amount equal to that excreted as dung. Perspiration in a greater or lesser degree is always going on, even when the animal is in a quiescent condition. When imperceptible it is called "insensible" perspiration, and when secreted in larger quantities as fluid it is known as "sensible" perspiration.

Excretion of worn-out materials through the skin, of course, goes on in some degree in the horse in a state of nature; but the full development of these glands is only produced by hard work, high feeding, and grooming. They are then excited to a greater degree of energy than exists or is required in a state of nature. Hence, artificial means, or, in other words, means greater than those supplied by nature, must be put in action by man in order to maintain the health of the skin.

The healthy or unhealthy condition of the skin is very readily shown by the appearance of the hair, otherwise called the coat. If the skin is unhealthy, the coat is harsh and dry. Again, if the skin is not properly cleaned, dirt remains, not merely in the coat, as many think, but in the system. A very important set of drains, namely, the glands of the skin, are choked, and the whole system, or in other words, the general health, must in consequence suffer,

The other drains of the body, namely, the lungs, the kidneys, and the bowels, are in action in the horse in a state of nature as much as in the domesticated animal. Hence, they do not, except in disease, require any artificial stimulus.

\section{Structure of the Hair.}

Hair invests every portion of the skin, with a few minor exceptions. It springs from the cellular tissue, on which the true skin rests. Each 
hair-root is enclosed in a distinct sack of its own called a follicle. The base of the sack is supplied with blood-vessels, from which the materials for the formation of the hair are secreted. The manner of the growth of the hair is similar to that of the outer skin, namely, by cells. The cells are pushed up by new cells forming below. They gradually become flattened and elongated into fibres to form the central shaft of the hair, whilst the outer part is covered by flattened cells or scales overlapping each other like slates on the roof of a house. The cells are cemented together by adhesive matter, which is secreted as they grow.

\section{Shedding of the coat.}

Twice in the year, namely, in spring and autumn, the horse sheds his coat. At those seasons the nourishment of the old hair is arrested, the soft pulpy extremities shrink and dry up, and the hair becomes detached and falls off; whilst at the same time a new hair is formed and pushed up by its side.

In autumn longer hairs are supplied as a protection against the cold of winter. In spring these long hairs are cast off, and shorter ones are supplied for summer use. It is not very evident why nature every jear goes through this double course of shedding hair in the horse, when the same object might apparently have been attained by an increased growth of the summer coat at the beginning of winter.

Probably, in order to admit of longer growth, the hairs of the mane and tail are not shed. Their roots are situated more deeply in the subcutaneous tissue.

\section{The Whiskers.}

The whiskers have a similar origin to the hairs of the mane and tail; but being supplied for the purpose of protection they are made stiff, so that whatever is felt at the tip may also be felt at the root. Into the root of each whisker-hair runs the nerve, which supplies it with its delicate power of sensation.

It is the fashion of the day to trim off these whisker-hairs; but it is wrong on principle, though probably the loss is of no great consequence to the domesticated horse.

\section{Objects gained by grooming.}

Grooming answers two principal and several subsidiary ends. First, it removes from the skin those particles of perspiration, dust, and dirt which otherwise would impede and clog the free action of the sweat and oil glands. Secondly, it removes the scurf or worn-out cells which are no longer required on the surface of the skin, and which would, especially when cemented together by particles of sweat, add to the obstruction of the glands. The subsidiary uses of grooming will be adverted to hereafter. 


\section{Use of the Brush in grooming.}

In order that grooming should produce the two above-mentioned principal effects, it is necessary that the skin be cleaned with a good bristle brush, strongly applied and well laid on.

For these purposes rubbing the skin with a wisp or rubber, though it may answer some of the subsidiary uses of grooming, is not sufficient. A wisp, especially a damp wisp, such as is often used, will not clean the skin. It might be supposed rather to plaster in the scurf and dirt. Such rubbing, however, does produce a certain beneficial effect, inasmuch as it is generally laid on with a good deal of force; and the friction has undoubtedly a considerable influence in cleaning the skin.

Against these arguments in favour of the brush it may be urged, that in racing stables the wisp and rubber, though the use of the brush is not altogether neglected, are largely employed. It would be absurd to say that trainers do not understand their business. We think, however, that a distinction may fairly be drawn between thoroughbreds in training and other horses. The skins of the former are finer, their coats are shorter, and they are invariably dried and cleaned immediately after exercise, before the sweat has had time to cake in the pores of the skin or in the coat. Still we must add that we have seen many horses brought to the post from second-rate training stables, whose coats have looked as if they would have been none the worse for a more constant application of the brush.

After the skin has been thoroughly cleaned with the brush, a wisp or rubber may be used with the view of giving it a last polish. It is not, however, at all essential.

\section{7a. Shamponing.}

In India the native groom often cleans his horse by hand-rubbing or shampooing. The practice is good and has an excellent effect on the skin. It would be difficult, probably impossible, to get English grooms to adopt a practice so novel. But in many stables, where a number of young lads are employed, it might be possible to train them, and the Author believes that the practice would be found most beneficial. The action of the hand never irritates the skin, which the brush frequently does, especially the tender skin of young thoroughbreds.

\section{Method of grooming.}

The thorough cleaning of the skin of the horse is an operation requiring both skill and hard labour." To make his labour effective, and to produce the greatest, effect with the least expenditure of power and in the shortest time, the groom should aid his muscular strength with his weight. He should therefore stand well away from the horse, and lean his weight on the brush, which thus used will penetrate the coat more effectually, and with less exertion to the man, than if worked only by his muscular strength. 
The principal working of the brush should follow the natural direction of the hair. It will not penetrate it as deeply and thoroughly when worked against it as with it. To remove, however, external dirt or sweat, which may have caked in the coat, it may sometimes be necessary to brush against the hair.

\section{8a. Dandy Brush.}

Where labour is scarce, as in very many stables, the dandy brush will, in a rough sort of way, do its work in cleaning quicker than the horse brush, and from the friction it produces, it has a very beneficial effect on the skin.

\section{Neglect of grooming.}

When grooming is neglected, the horse, for the reasons already given, soon loses flesh and condition, and generally deteriorates in health; whilst eventually actual disease of the skin may be the result.

Among the more common diseases arising from neglect of grooming are those which are caused by the presence in the skin of parasitical insects, such as mange and lice. The insects inducing these disorders, when not disturbed by the action of the brush, breed rapidly. All such diseases are the sure and certain sign of neglect. These insects will not attempt to obtain a lodging in skin where the pores and glands are in healthy action, and where they are constantly disturbed by the use of the brush.

\section{Subsidiary uses of grooming.}

Whilst good grooming is necessary for the maintenance of the health of the domesticated horse, it is also needed for several subsidiary ends. It is essential to the glossiness, and also to the shortness of the coat, which horsemen so much love to see, and to the development of the highest powers of the animal.

Glossiness of coat is due partly to the absence of dirt, débris of wornout materials, and particles of perspiration among the hairs, partly to the mere mechanical effort of friction in polishing the hair, but mainly to the increased secretion drawn forth from the oil glands of the skin under the friction of good grooming.

Short coats are due partly to the warmth produced in the skin by the frequent friction of grooming, and partly to the maintenance of an even and moderately warm temperature in the stable. Increase in the length of the coat is indeed a provision of nature against cold. If such increase is not required, the winter coat is scarcely longer than that of summer. In some tropical climates, for instance, where the warmth in winter is little less than that in summer, or in deep coal mines where the changes of the season are not felt, or even in well-managed stables, where an equal temperature is maintained and the warmth of the skin is assisted by clothing and good grooming, we find but little difference between the length of the summer and winter coats, 
Different breeds of horses vary very much in the length of their coats. The high-bred horse, which was originally brought from a hot climate, still retains much of the shortness of coat natural to his original habitat. Horses, however, even of the same breed, vary much in the length of their coats, even though placed under exactly similar circumstances. This may probably be accounted for by greater or less strength of circulation in the particular animal. Age has also frequently a great effect on the length of the coat. Old horses, whose circulation is becoming languid, are generally supplied by nature with longer coats than younger animals.

\section{Improper means used to produce sihort and glossy coats.}

Short and glossy coats, as a general rule, indicate good grooming and careful stable management, whilst long dull coats argue the reverse. But we must caution the reader against the practice of some servants of administering tonics and other stimulants, which, by artificially exciting the system, produce temporarily a good external appearance, but in the long run are the fruitful parents of disease.

\section{Time for grooming.}

The highest powers of the horse can only be developed by careful attention, not to one or two great points, but to every point which concerns his health and comfort. Of primary importance, in connection with health and comfort, is the time or times at which the operation of grooming is performed.

Unquestionably the horse ought to be groomed, that is, to have removed from his skin in the morning those insensible emanations of the pores which have accumulated during the night and the latter portion of the previous day. Equally, too, immediately after exercise he needs to have removed from his skin the more sensible emanations of the pores, commonly called sweat.

In most stables, however, it is usual, when the master does not require the horse during the day, to combine these two occasions in one. The horse is taken out to exercise early in the morning, and cleaned afterwards. This plan answers pretty well, but it is undoubtedly inferior to that practised in cavalry and racing stables, where the horses are cleaned in the morning and exercised after breakfast, and cleaned again after exercise. The other plan, however, saves much time and labour.

If the master requires his horses during the day, the animals must, of course, be cleaned in the morning, and again after the ride or drive.

Owners are often very much disappointed that their horses do not improve or thrive as much as they expect, when they use them least. The reason may perhaps be found in some degree in the fact that they are generally least groomed when least used. Every horse should be groomed, or, in other words, have the pores of the skin thoroughly cleansed at least twice in each day.

A horse which has not been exercised during the day, in some respects reqquires more labour to get his skin thoroughly clean than if he had been 
at work. A little gentle perspiration every day, and occasionally a somewhat freer opening of the pores, greatly assist the process of grooming. Indeed, it is very difficult, if not impossible, to keep a horse's skin clean, unless the action of the brush is aided by bringing the glands of the skin into more active use by means of sensible perspiration.

\section{Horses to be groomed immediately after exercise.}

Not only is it necessary that the horse should be groomed after exercise, but it is essential that he should be groomed immediately after exercise. All the pores of the skin are then open, and the brush will more effectually clean the skin than if the operation is delayed until the skin has cooled and its pores have closed, and the perspiration has dried and caked over them.

No horse which is heated, or has been perspiring, should ever be allowed to stand undried one moment longer than is absolutely unavoidable. When a delay cannot be avoided, the evil consequences should be reduced to a minimum by clothing him warmly, and putting flannel bandages on his legs ; or where these advantages are not available, by allowing the saddle or harness to remain on, and by preventing any draught from coming on the animal. In other cases the evil may be mitigated by getting a boy to lead him about briskly, until the servant is ready to attend to him.

\section{Danger of allowing a horse, when heated, to stand undried.}

Neglect of such precautions is likely to end in a chill, which may be followed by serious disease. When a horse is heated, his whole circulation is quickened, and an increased quantity of blood is determined to the surface of the body. A chill will drive this blood suddenly to the inward and vital parts.

Nor is the evil confined to driving to the internal organs the blood, which may happen at the moment to be on the surface. It may be far greater, because, though the horse may be chilled externally, yet the excited state of the circulation continues for some time longer. The heart does not at once accommodate its action to the external change, but continues to send blood rapidly through the system. This continued supply, repelled from the surface, is forced on the already orerloaded internal vesels. Hence may arise serious disease, such as inflammation of the lungs or pluræ, bronchitis, or other inflammatory or congestive affections.

\section{Cold produced by evaporation.}

Many people are not aware of the extreme cold produced by evaporation, such as that resulting from the action of a draught, or of the sun or wind acting on a wet surface, such as the coat of a horse when sweating. On this principle, cooling drinks are made in hot climates by tying a wet flannel round a bottle and hanging it up in the sun or wind.

A long, thick coat, therefore, is no protection to a horse against catch- 
ing cold. On the contrary, for the above reasons, we belicve it increases the liability.

Though it is especially essential, for the reasons given in the preceding paragraph, that horses which are wet from sweating should be dried immediately on their return from work; yet the above remarks, though in a less degree, apply also to all horses which, from any cause, such as rain or the state of the road, return wet to their stables.

\section{Extremities to be dried first.}

It should be a standing rule that the legs should be dried before the body, both because the circulation gets feebler in proportion as the part is distant from the heart, and because all parts which, like the legs in the horse, or like the hands and feet in man, expose a large surface in proportion to their bulk to the action of external cold and evaporation, are peculiarly susceptible of chill. If two horses return from work at the same time, both sweating or wet, in charge of only one servant, the legs of both should be dried and bandaged before the bodies of either are touched; but in such case it is essential that rugs be thrown over the bodies of both horses.

\section{Special precautions in regard to the back and loins.}

Many a cough or cold is produced by injudiciously removing the saddle, and exposing the heated back and loins to the cold, whilst the groom is employed about the extremities. It should be a standing rule not to remove the saddle or harness until the servant is ready to dry the back. In addition to this precaution, if the horse is hot, a rug should during the intervening period be thrown over the loins and back; and if very hot, a second rug should be added across the loins.

\section{Of washing the skin.}

Water has very little effect in cleansing the skin of a horse. The hair acts as a thatch, and water penetrates through it with difficulty, except when it is out of order, and then acts as an irritant. Besides this, it tends to check the action of the oil glands, and to render the coat dry and harsh by removing the oily secretion.

Water, therefore, should not be applied to the coat, except with the view of washing off external mud, and so saving time and trouble to the servant. In all such cases, however, it is necessary that the part be dried immediately, or skin disease, such as cracked heels, grease, and mud fever, will prohably soon appear.

\section{Of drying the legs.}

The legs should not be washed. The mud and dirt should be removed by rubbing the legs with loose wisps of straw and ordinary rubbers. This, though by far the best practice, is troublesome to servants. 


\section{9a. Of washing the legs. Flaninel bandages.}

The ordinary practice is to wash the legs, and wrap them in flannel handages. The groom then cleans the body; and by the time he has done this the legs have probably dried. He should then brush them out, exactly as if they had not been washed-for the water has not cleaned the skin, but has only removed the external mud and dirt. If this is properly done, there is not much objection to washing the legs. But the practice is open to much abuse, and often results in cracked heels, grease, and mud fever.

\section{Of leaving horses to dry by evaporation.}

We cannot close this chapter without warning owners of horses against the common practice of idle servants leaving the horses after exercise in the morning to dry by evaporation, whilst they get their breakfasts and indulge in a pipe afterwards. If horses are exercised in the morning, and the breakfast hour interferes with proper timely attention to them, they should at least be warmly clothed, and have their legs bandaged, before the servant leaves, and the time allowed for breakfast should be reduced to a minimum. Similarly at other times, after the owner has had his horse out, the servant is apt to leave him to dry by evaporation, whilst he cleans the saddle, bit, or harness.

\section{Minor memoranda.}

The nostrils should be earefully sponged out twice a day. The wings of the nostrils should be gently distended by the fingers, and a wellwetted sponge passed into the opening. This will remove the dust from the delicate lining membrane. The dock should be cleaned both morning and evening. The sheath likewise requires to be cleaned occasionally by passing the hand up it, and clearing away any sebaceous matter which may be adherent to it. Many a horse, which has been supposed to be suffering from disease of the kidneys, is merely irritated by a dirty penis, or by a collection of sebaceous matter encrusted on the point of the urethra, which interferes with the free passage of the urine.

White and grey legged horses in dirty weather require to have their legs washed with soap and water in order to make the hair look clean. We have already stated that water has no real effect in cleansing the skin. Especial care should be taken that the legs are dried immediately after the washing. Such horses frequently suffer from cracked heels, grease, and rheumatism from neglect of this precaution.

\section{Grooming by machinery.}

In some large establishments machinery somewhat similar to that used in hair-dresser's' shops for brushing the hair, has lately been set up for grooming horses. It appears to answer extremely well, and certainly saves an immense amount of time and trouble. 
123. Time required to clean a horse.

A good groom ought to be able to clean a horse thoroughly in the morning or after ordinary work, when his coat is short, in half an hour. Fifteen or possibly twenty minutes more may be required after work, if the horse returns very hot or very muddy. If the horse has a very thick or long coat twenty minutes more may be added to the above periods. Not only ought the groom to be able to do it within these periods, but the master ought to insist that he does it thoroughly in that time.

Some exceptions, however, must be made to the above general rules. There are some thick woolly coated animals, which cannot be dried after work in winter by any amount of time or exertion which a servant can be expected to give. Such animals ought, however, to be clipped or singed.

\section{Breaking out after cleaning.}

Some horses break out again and again into a cold sweat after they have been dried and cleaned after exercise. They must be dried again, at least the first and second time, after which it is generally safe to put the clothing on.

Breaking out is usually connected either with a thick woolly coat, or with debility, or perhaps with both combined. The remedy in the first case is removal of the coat, and in the latter it will consist in good feeding, good grooming, and regular exercise in addition to removal of the coat if need be.

\section{Conclusion.}

The effect of daily good grooming is readily recognised in the bright, clean, and healthy appearance of the coat. If the fingers are run through it, no trace of soil will be left on them.

On the other hand, if the skin is not clean, the fingers will be soiled, and white streaks of dirt and dust will be apparent in the parts through which they have passed. Scurf and débris of the perspiration will also be seen about the roots of the hairs. If the groom has absolutely neglected the horse, encrusted sweat and mud from the previous exercise will probably be found on the coat, especially under the belly and between the legs; and the mark of the saddle, on account of the horse having perspired more freely under it than in other parts, may still be apparent; or stains from where the horse has been lying down at night will be left. With a view of testing the cleanliness or otherwise of the skin, the hollow of the side of the hocks, the knees, the points of the hips and shoulder, and the head and neck, may be more particularly examined.

Every owner ought occasionally at least to run his fingers through the coat of his horse before he mounts, or when he visits his stable after the horse has been cleaned on his return from work. He will also do well to see that the feet are properly washed out in the morning or after exercise. It is in vain to expect that servants, however good they may 
be at starting, will long continue to give the time and labour required daily to groom horses, as they ought to be groomed, unless the master is able to and does appreciate the result of their labour.

Horse owners are cautioned against allowing the practice that prevails amongst grooms of forcing off the old coat in the spring, when the process of shedding commences. Nature will complete this process in her own time, and any attempt to hasten it frequently results in leaving the animal bare in patches, and rendering him more susceptible to chills and colds.

\section{CHAPTER 7.}

\section{SHOEING.}

126. In a previous edition the author referred his readers to his treatise, 'Notes on Shoeing,' published by Smith and Co., Waterloo Place; but in the present edition he has reprinted the substance of that work at the end, Chapters 62,63 , and 64 .

The object of putting it at the end, instead of in this, its more proper place, has been to avoid alterations of the numbers of paragraphs, which under this arrangement are the same as in the previous editions.

\section{CHAPTER 8.}

\section{EXERCISE.}

127. Need of exercise. 128. Muscles. 129. Tendons. 130. Ligaments. 131. Lungs and other organs of respiration. 132. Gradual work. 133. Regularity of work. 134. Stage.coach horses. 135. Neglect of exercise. 136. Age, \&c., to be considered in regulating the amount of excrise. 137. Good feeding necessary. 138. Amount of exercise needed. 139. Grass-fed colts. 140. Corn-fed colts. 141. Irish colts. 142. Horses from dealers' stables. 143. Exercise of riding or harness horses. 143a. Exercise in wet weather. 144. Exercise of hunters. 145. Summering of hunters. 146. But will legs and feet stand continual work? 147. Exercising ground in summer. 148. Artificial exercising ground. 149. Temporary ride during a frost. 150. Expense of keeping horses up through the summer. 151. Size of stud required for hunting. 152. Kind of exercise most suitable for hunters in summer. 153. Objections made to harness work. 154. Hunters in 
autumn to be occasionally exercised in deep ground. 155. Hard condition to be antecedent to fast work. 156. Of two hours' so-called exercise. 157. Of exercising in clothing. 157a. Exercise or work in bandages. 158. Time for exercising horses. 159. Training of race horses.

\section{Need of exercise.}

As air is to the lungs or food to the stomach, so is exereise to the due development of the muscles, tendons, ligaments, and respiratory organs.

In the horse, on account of the active exertions which we require from him, we wish to get the muscles as firm, the tendons and ligaments as strong, and the respiratory organs as vigorous as possible. We therefore give exercise, more or less severe according to the use for which the particular horse may at the time be required.

In the ox and sheep, and other animals which are used for food, we wish to have the flesh less firm and more tender; and therefore we give little or no exercise.

\section{Muscles.}

Muscle is simply flesh. Anatomically considered, it is made up of bundles of fibres laid parallel to each other. The tenacity or strength of the fibres depends chiefly on the use to which they are subjected. When disused, they become soft, flaccid, and incapable of sustaining any great strain.

Muscular development is a very important element in the strength of a horse. Muscles under nervous influence possess a power of contraction. By means of this power they act upon and control the tendons, and in fact regulate the movements of the body. Hence in one sense muscles are the real motive power in the animal frame; but it must not be forgotten, that the muscles themselves are set in motion by the action of the nervous system. Hence if a nerve is paralysed, the muscle to which it goes, loses its power of contraction.

Muscles are occusionally ruptured by an over-violent strain; but injury to them commonly consists in some of the fibres being torn across. The blood-vessels, however, which ramify about the fibres, are more frequently ruptured by any such strain than the fibres themselves. This result is marked by extravasation of blood in the part under the skin.

\section{Tendons.}

'T'endons are dense, firm, fibrous, almost inelastic organs. 'They are attached at their upper extremities to the ends of muscles, and at their lower extremities are generally inserted into the eminences of bones. They possess no power of motion or contraction in themselves, but are acted on by the muscles to which they are attached. Tendons are found wherever strength combined with lightness is required, and where muscle on account of its bulk would be inadmissible.

Tendons, like muscles, strengthen and develop, when properly and 
regularly used. They lose in power and firmness when not used. 'They require constant use in order to give them the strength, which is meeded to enable them to sustain the violent usage, to which in the horse they are so often subjected.

The amount of use and strain to which they ought to be subjected, must of course depend on the nature of the work for which the horse is intended. But before we subject any particular horse to hard and severe training, it is always necessary to consider whether his make and shape are such as to fit him for that work.

Harness work causes the least strain, next to it comes ordinary riding, next hunting, whilst racing and steeple chasing occasion the greatest strain. Many a horse, which will not stand the training necessary for racing or steeple chasing, will stand for hunting. Many again, which will not stand the strain of hunting, may answer very well for ordinary riding; whilst others, which are not sound enough for riding, may last for years in harness.

\section{Ligaments.}

Ligaments are of similar structure to tendons. Some ligaments pussess a certain degree of elasticity. The same remarks, however, generally apply to them as to tendons.

Further and more detailed information in regard to the structure and organisation of muscles, tendons, and ligaments will be found in Chapter 13.

\section{Lungs and other organs of respiration.}

The power of the lungs to sustain long and violent exertion is likewise very much a matter of habit. The lungs, unless accustomed to it, cannot sustain the violent work often required of them.

If such work is required of a horse, some fast exercise must of course be given; but the reader will do well to remember that hard condition of the muscles and tendons ought to be antecedent to fast work. When the physical powers are fully developed, when the necessary condition of body is attained, it will not require any great annount of galloping to put the horse " in wind." It is, however, very needful that the owner should take care that the animal, which he intends for fast work, possesses the necessury formation and capacity of chest.

\section{Gradual work.}

Muscles, tendons, ligaments, and the respiratory organs may by patient, constant, and increasing use be gradually brought to perform safely au amount of work and to support a strain which, without such progressive training, they would be wholly unable to stand.

The power of doing work and of sustaining fatigue is, if we may use the expression, cumulative. Provided that the horse be kept in good condition, it increases from day to day and from year to year, until from age the animal powers begin to fail. 


\section{Regularity of work.}

Regularity of exercise is also an important element in the development of the highest powers of the horse. The horse in regular work will suffer less in his legs than another; for he becomes gradually and thoroughly accustomed to what is required of him. The whole living machine accommodates itself to the regular demands on it, the body becomes active and well conditioned without superfluous fat, and the muscles and tendons gradually develop. Horses in regular work are also nearly exempt from the many accidents which arise from over-freshness.

\section{Stage-coach horses.}

As a proof of the value of regular exercise we need only refer to the stage-coach horses of former days. Many of these animals, though by no means of the best physical frame, would trot with a heavy load behind them for eight hours at the rate of ten miles an hour without turning a hair; and this work they would continue to do for years without ever being sick or sorry. Few gentlemen can say as much for their carriage horses. No horses, in fact, were in harder condition.

\section{Neglect of exercise.}

On the other hand, if exercise be neglected, even for a few days in a horse in high condition, he will put on fat. He has been making daily the large amount of material needed to sustain the consumption caused by his work. If that work ceases suddenly, nature will, notwithstanding, continue to supply the new material; and fat, followed by plethora and frequently by disease, will be the speedy consequence.

136. Age, condition, \&c., to be considered in regulating the amount of exercise.

The amount of exercise to be given at any particular time to any particular horse must depend on many considerations, such as his age, feeding, condition, constitution, make and shape, on the state of his legs, on the purpose for which he is intended, and in many cases on the amount of time at disposal for preparation. The art of the groom or trainer is to feel his way in each particular animal up to the fullest development of his powers without over-working or over-straining them.

\section{Good feeding necessary.}

All exercise causes an increased consumption of animal material. This consumption or waste must be repaired by good feeding. If the wear and tear of the body is not sufficiently replaced by new supplies introduced in the shape of food, the horse will obviously lose flesh; and under such circumstances additional exercise, far from producing strength or giving muscle, will cause greater debility. 
Erratum.-Page 80, par. 134, line 4.

For " eight hours" read " one hour." FITZWYGRAM S HORSES AND STABLES. 

138. Amount of exercise needed.

Having laid down the general principles on which we think the amount of exercise ought to be regulated, we shall now endeavour to apply those principles to the various classes of horses.

\section{Grass-fed colts.}

All exercise for a young horse must at first be gentle, and the increase must be gradual. For horses of three or four years old just taken up from grass half an hour's walking exercise is sufficient. In the second month the time may be increased to an hour, and the horse may carry a saddle, and during one fourth of the time he may be quietly lounged.

From the beginning of the third month most young horses may be ridden quietly for an hour, and perhaps trotted with a light weight on them during half that time. From the fourth to the sixth month one hour and a half's ordinary work in the manège may not be too much.

By the end of six months the great majority of young horses, thus gradually and systematically got into condition, should be fit for ordinary work. A few of the weaker and those reduced by strangles or other sickness will require further time and care.

\section{Curn-fed colts.}

Corn-fed colts may be brought into work earlier and quicker than those which have been fed on grass only. High feeding forces and develops the frame and strength, and consequently corn-fed colts are generally as much developed as grass-fed animals a year or two older. Race horses, for instance, are run at very early ages. Thorough-bred animals are supposed to come to maturity sooner than other breeds; but this earlier development is, we believe, merely the result of the high feeding, of which well-bred animals generally have the advantage.

\section{Irish colts.}

In Ireland it is not uncommon to see four and even three year old grass-fed colts in the hunting field. It is impossible that the muscles, tendons, and bones at that early age, except where the system has been forced by high feeding almost from birth, can be sufficiently developed to stand the amount of wear and strain incidental to such violent exercise. It is in fact no rare thing to find horses, which have been so used or rather abused, broken down at five years old. The same unfortunate results are also common enough in England.

\section{[ 142. Horses from dealer's' stables.}

Horses from dealers' stables generally require special care and attention to bring successfully into work. They should, indeed, be treated almost with the precautions recommended above for young horses. They are 
usually very fat and soft. They sweat freely, and in consequence are very liable to chills, coughs and colds, if neglected after exercise. Their respiratory organs also are unused to any violent exertion, and hence are very subject to disease, if injudiciously excited. The digestive powers of their stomachs are also frequently debilitated and deranged by the constant use of tonics.

\section{Exercise of riding or harness horses.}

For horses in ordinary condition, such as those used for riding or driving, two hours' work in the course of the day, provided that in that time a distance of ten miles is traversed, is a fair quantum.

When the owner cannot give this amount of work to his horses, he should insist on his servants exercising them in the morning for such a period as will make up this time and distance each day. There is nothing servants dislike so much as properly exercising horses. It takes up, of course, a good deal of their time, and makes no immediate outward show. Far more horses in gentlemen's stables suffer from too little than from too much regular work.

\section{3a. Eaercise in wet weather.}

When the weather forbids exercise, grooming is the best substitute. The Author particularly calls attention to this, because, where there is no external sign of dirt, servants are very apt to neglect cleaning the pores of the skin.

\section{Exercise of hunters.}

Hunters generally get work enough during the season, but are seldom fit to go till it is half over. We propose to consider, first, why they are not fit to go, and, secondly, how they may be got fit by the beginning of the season.

It will be admitted that hunters are tolerably fit at the end of the season. It has been asserted in these pages, though many for various reasons will question it, that "condition" is cumulative, i.e. goes on and increases with time.

If " condition" is cumulative, why should not a horse be in better form at the beginning of a season than he was at the end of the previous year? Are there any insuperable difficulties in the way? Is the expense too great? Are not the wear and tear and liability to accident far greater in horses that are not fit to go than in those which are thoroughly fit? Is it not a fact, that when a hunter has got thoroughly well seasoned, neither weak nor over fresh, he seldom comes to grief?

It is alleged, however, that there are insuperable difficulties in the way of maintaining hunters in condition through the summer, that legs and feet will not stand continual work, that horses hard wrought in winter require rest in summer, that ground suitable for exercise cannot be found, and, lastly, that keeping horses up through the summer is very expensive.

We will take these objections seriatim. Whilst we fully admit that the highest development of the powers of nature, such as that required 
for racing, cannot be maintained at their utmost for any length of time; yet we cannot see the difficulty of maintaining a horse in condition through the summer, that is, in such condition that no preparation is needed for hunting, except a few gallops to improve the wind, if only the animal be well fed, well groomed, and exercised two hours a day. It is an advantage, or at least more profitable, if the owner can utilise the horse by riding him or working him in harness during the summer months.

Officers' horses in cavalry regiments are so treated, and they are generally in better condition without any preparation at the beginning of the hunting season than the horses of most sporting men after a vast amount of preparation, physic, and work.

\section{5. "Summering" of hunters.}

The so called restorative process of "summering" hunters is open to many objections. The animal after his four months' holiday comes up fat, gross, weak, and out of sorts. He requires physic and sweating to reduce his bulk, extra grooming to bring his skin into order, beans to give firmness to his muscles, and carefully regulated, and relatively to his condition severe exercise to develop his strength and wind, and after all he is generally not half fit to go at the beginning of the season. All this, unless we are in error about officers' horses, is needless waste of time and trouble, and, moreover, a severe and unnecessary trial to the animal's constitution.

Again, if health is to be preserved, horses, which for eight months in the year are accustomed to be groomed, ought to be groomed during the remaining four. It is a fallacy to suppose that the horse, when thrown out of work, does not require to be groomed. In reality he needs it far more for some months, than when at work. The secretions of his body, which have made use of the pores and glands of the skin (vide Chapter 6, on Grooming) as their organs of excretion, continue to do so for some time after those glands have ceased to receive the stimuli, namely, exercise and grooming, which originally brought them into activity. Hence they choke, and in consequence effete matters remain in the system; and in the end the horse requires, as we might expect, two or three doses of physic to clear his system.

Here, then, is a break-down of the theory of summering hunters. The so-called restorative process ends in an amount of constitutional disturbance which requires physic to correct it. This constitutional disturbance, caused by want of proper exercise and grooming during the summer months, has been, we believe, the origin of the three doses of physic traditionally supposed to be essential to getting hunters into condition.

\section{But will legs and feet stand continual work?}

But it may be said,- - granting that a horse may be in better condition from having been worked through the summer, yet his feet and legs will not stand this perpetual strain and hammering.

Feet, we answer, if of good conformation and properly shod, never 
suffer from work. Joints, tendons, and ligaments may suffer, but feet from their construction are not likely to suffer either from age or work. The foot of an old horse is just as sound as that of a young one.

The legs and joints, we admit, do suffer from work, or rather if overworked, fail before other parts of the frame. The question, however, is not whether they suffer from work, but whether they suffer more from regular than from intermittent work. Arguing from the structure of joints, tendons, and ligaments, we should conclude that intermittent, especially severe intermittent work, would affect them more injuriously than continued strong work. The severity of work is comparative to the power of sustaining exertion. Let a man not used to walking take a long walk and he will find it severe work, and his joints next day will be stiff and sore all round. Let another man used to that degree of exercise take the same walk, and he will not find it severe. Severity of work, then, is in a great degree comparative to what the person or horse is accustomed to.

Among the more common effects of work are wind-galls, thorough-pins, and other enlargements about the joints. These all result from increased secretions of synovia thrown out by nature to preserve the joints and tendons from the irritation caused by work. As in the case of the man alluded to above, joints and tendons which are accustomed to the required amount of exertion will be less likely to suffer from irritation than those not accustomed to such exertion.

Sprains, also, which are another occasional effect of severe work, must be less likely to occur when the ligaments and tendons are fully and regularly developed than when they are in a weaker state, as must be the case at the beginning of a hunting season, when the horse has been idle through the summer. The same remarks apply to spavins, splints, and other exostoses, which result from irritation and inflammation in the bony structures.

But it may be asked, "Do not horses, which have suffered from the severity of work during the hunting season, require to be laid up and rested?"

If a tendon or ligament is sprained, the horse must of course be laid up and further treatment will be necessary; or, again, if any disease is set up in the joints, rest and treatment will be required.

But supposing no such accident to have occurred, and supposing that the tendons, ligaments, and joints merely show "work," their recovery will be promoted rather than retarded by fair and reasonable exercise, by good feeding and good grooming during the summer. No doubt a horse which shows "work" requires abstinence for a time from severe work, such as hunting; but we question whether he will be the better for total cessation from work. In all such cases the tone of the system requires to be stimulated rather than let down.

\section{Exercising ground in summer.}

Again, it is alleged that ground suitable for exercise cannot be found in summer. Fairly soft ground may generally, we reply, be found in any 
neighbourhood up to the end of May. In June a newly-mown grass field can always be obtained, the soil of which, having been protected from the sun, will be soft for at least a month after. Some other field, which may have been mown later, will probably bring us to the beginning of August. About this time a new stubble is generally available, and makes good exercising ground.

If, however, in any particular locality it be impossible to find suitable fields, it is better to make artificially an exercising ground rather than run any risk of the horses being insufficiently prepared.

\section{Artificial exercising ground.}

Good exercising ground may be made at no great expense. The first essential of course is drainage, both because all ground on which water has lain becomes very hard when dry ; and because a dry sound bottom is essential to the preservation of the tan, litter, or whatever material may be used as the basis of the artificial ride.

Economy in the cost in the particular locality will necessarily regulate the choice of the material used in forming the ride. A circle of about four hundred yards will be sufficient.

\section{Temporary ride during a frost.}

During a frost a temporary ride sufficient to trot horses round may always be formed by means of refuse litter from the dung heap.

\section{Expense of keeping horses up through the summer.}

Lastly, as regards the expense of keeping hunters up through the summer.-The owner of a large stud may say, "I have too many horses to be able to work them through the summer, and it would cost a fortune to feed them high and keep servants to groom and exercise them."

Our answer is very short. "Keep fewer." It is better to have six horses that can go, than a dozen that can't go ; and not only is it better in point of enjoyment, but it is also cheaper.

\section{Size of stud required for hunting.}

A good horse in good condition ought to go three days a fortnight with hounds in most countries. At this rate only four horses would be required to hunt six days a week. Accidents, however, and illnesses will occur, and it is nicessary to make allowances for these; though much fewer accidents will occur with horses thoroughly in work than with others, and illnesses with good stable management ought to be very rare.

Making all allowances, six hunters and perhaps a hack, if the distances to cover are great, ought to see a hard-riding man through six days a week from the beginning to the end of the season.

If the owner wishes to have a second horse out every day, it may be necessary to add two more to the above number. Masters of hounds, we may observe, very seldom keep more thin the above proportion of horses 
for their huntsmen ; and it is quite certain that gentlemen's horses duriug the day do not generally do more work than the huntsman's.

\section{Kind of exercise most suitable for hunters in summer.}

The system of throwing hunters out of work in summer is, for reasons given above, we believe, little more than a prejudice founded on ignorance, custom, and supposed economy. When the hunting season is over, the kind of exercise best suited to the particular animal should be adopted.

Saddle work may suit some, harness may be better adapted to others, whilst a few may require to be led. We only urge that horses should get sufficient exercise of some sort; but we believe that on the whole light harness work answers the best.

\section{Objections made to harness work.}

Many owners object to saddle horses being put into harness because it is apt, they think, to make them go heavy in hand. Heavy harness work no doubt has this tendency, because horses in drawing large loads lean on the collar in order to assist the draft by their weight; but light harness work is not open to this objection. Nothing, for instance, can be morc suitable for hunters in summer than a pair-horse brougham, provided the coachman has "hands.", Coachmen, however, very generally have heavy "hands," and the complaint of the ill effect of harness work will morc often be found to be due to this cause than to any inherent effect of draft.

\section{Hunters in autumn to be occasionally exercised in deep ground.}

While it is obviously desirable, as a general rule, to select sound ground for exercise, whilst it would probably be injudicious to gallop a horse in a deep ploughed field, yet some exercise in deep ground at a smart trot with or without clothing, according to circumstances, should not be neglected in the preparation of the hunter in autumn. It is as necessary to accustom a horse to the ground in which he will have to go, as it is to accustom him to the pace required of him.

\section{Hard condition to be antecedent to fast work.}

Before quitting this portion of his subject, the Author desires to repeat that horses cannot be galloped into condition. If a horse is weak, fast or severe work will only make him weaker; if he has a big belly, fast work will produce disease ; if he is soft, fast work will make him run up light. Hard condition must be antecedent to galloping; and if the condition is really hard, very little galloping is necessary to put the horse in wind.

\section{Of "two hour's" so-called exercise.}

It has been stated above, that two hours' exercise during the day, provided that in that time a distance of ten miles is traversed, is sufficient 
for the purposes of health and for the maintenance of the condition required for the ordinary purposes of riding and driving.

It is necessary, however, to give a caution against what servants often call two hours' exercise. In most establishments it will be found that it means little more than an hour and a quarter, and all the time at a walk. Servants are generally supposed to go to the stable at six o'clock in the morning, but are usually somewhat later. Sweeping out the stable, watering, feeding, and saddling occupy some twenty minutes, and it may probably be the half-hour before the horses really leave the stable. They are generally brought in again by a quarter to eight, that is, in time to allow the servants to tie them up, unsaddle, and rub down their legs before their breakfast, which is usually at eight o'clock. This is what is called two hours' exercise in most establishments, but a great many do not come up even to this very moderate mark.

\section{Of exercising in clothing.}

$\Lambda$ question is often asked, whether horses ought to be exercised in clothing? In moderate weather it is better that they should be accustomed to go without it. It is false in principle to habituate a horse to the need of an artificial protection, which on other occasions it is impossible to give him. It may indeed be urged, that horses are usually taken to exercise at an earlier and more chilly hour than they are ridden by their owners. On the other hand, it may be replied, that horses at exercise need clothing less than at other times, because they never need and certainly never ought to be kept standing; whereas in the uses to which the owner puts his horses, it must occasionally, if not frequently happen, that they are kept standing for a considerable time, perhaps even when heated. Horses, however, which have been recently clipped or singed, ought to be exercised in clothing. A single rug or hood will be sufficient under ordinary circumstances. More harm than good is caused by exercising in too heavy clothing.

When it is desired to sweat a horse, the question of clothing, or no clothing, or double clothing, will of course depend on the amount of flesh and coat which the particular animal happens to carry.

\section{7a. Exercise or work in bandages.}

When horses are ridden in bandages in deep ground or muddy ground, it sometimes happens that the mud works between the bandage and the skin, and causes excessive irritation and swelling, somewhat resembling mud fever.

\section{Time for exercising horses.}

It is the practice in most stables to exercise the horses in the carly morning, for the servants after exercise to go to breakfast, and for the horses to be cleaned after breakfast. The object of this arrangement is to save the servants the trouble of grooming the horses a second time. 
Apart from any questions connected with grooming, which were discussed in the previous chapter, the practice of exercising horses in the early morning is objectionable. During a great portion of the year the air at that time is generally cold and raw. It is injudicious to pull a horse suddenly out of a warm stable into the chilly air of early morning. Nine o'clock is quite early enough to take the horses out. When they return from exercise, they can then be cleaned at once; whereas if they are taken out in the morning, they are always left to stand for nearly an hour, whilst the servant gets his breakfast. Again in the early morning the owner is seldom up and about, and in consequence the regulated period of exercise is often cut short by one half. Other abuses, such as a resort to the public house and tying the horses up outside, are more likely to occur at an early than at a late hour. On the other hand, when the horses are taken out at nine o'clock, the owner has the opportunity without trouble to himself of checking the time of going out and returning.

\section{Training of race horses.}

The treatment and training of race horses is a somewhat different subject, and one which is beyond the scope of the present treatise. The condition of race horses is not, as in other horses, cumulative. The condition in which they are required for racing is the very highest. The system cannot for long be sustained at an extreme pitch. The object of the trainer is to bring his horse to the very highest pitch of condition on a given day; whilst the object of the owners of hunters and other horses is to have their powers fully developed and sustained for a lengthencd period.

\section{CHAPTER 9.}

\section{STABLE MANAGEMEN'T.}

160. Introduction. 161. Temperature of stables. 162. Artificial warming of stables. 163. Of stables in summer. 164. Registering thermometer. 165. Stables, both cold and close. 166. Damp stables. 167. Change of stables. 168. Horses brought from grass into stables. 168a. Horses from the country. 169. Horses to be cleaned immediately after exercise. 170. Best time for exercise. 171. Of drying horses, when very hot or wet. 172. Warm baths. 173. Artificial removal of coat. 174. Singeing. 175. Clipping. 176. Shaving. 177. Hair not to be removed from legs in rough hunting countries. 178. Manes and tails. 179-180. Bedding. 181. Of horses which eat their bedding. 182. Bedding to be taken outside every 
morning. Litter sheds. 183. Clothing. 184. Hand rubbing the legs. 185. Flannel bandages. 186. Wet linen bandages. 187. Of putting on bandages. 188. Bandages to joints. 189. Persistent coldness of legs. 190. Feet. 191. Arrangement of horses in the stable. 192. Kicking in the stable. 193. Sleeping whilst standing in stable. 194. Weaving. 195. Crib-biting. 196. Wind-sucking. 197. After a hard day's work. 198. Physic. 199. Bran mashes. 199a. Working life of horses in various employments.

\section{Introduction.}

In the preceding chapters an endeavour has been made to lay down the broad principles, which are the basis of good stable management.

These essentials, to recapitulate, are: 1st, an ample supply of pure fresh air at all times in the stable; 2nd, judicious watering and feeding; 3rd, good forage ; 4th, good grooming; 5th, good shoeing; 6th, sufficient and well regulated exercise.

These are no doubt simple recipes for successful stable management,too simple perhaps for many, who believe that there is a mystery in stable management known only to a few. Yet from neglect of these common and obvious requirements, few horses look as well as they ought to do. Many become sick or lame, and thus entail trouble, expense and loss, which might easily have been avoided.

To ensure the highest development of health and strength, not one or two or even three of these essentials are sufficient, but all must be comlined. You cannot have strength in a chain, if any one link be defective.

The present chapter will be devoted to the practical application of the principles already set forth.

\section{Temperature of stables.}

Whilst purity of air in a stable is absolutely essential, the maintenance of an even and moderately warm temperature is also a matter of great importance. The horse is a native of a warm climate, and both thrives and puts up flesh in warmth. His food will go further and his coat will look better in a warm than in a cold stable.

In spring, autumn, and winter a stable should, we think, be kept as comfortably warm as possible without making it close and offensive. Warmth is good for horses, but purity of air is more essential. Good air must never be sacrificed to warmth. Cold air will but produce a staring coat, whilst foul air is the ready parent of disease.

The best test of the purity of air in a stable is the sensation felt on first going into it from the external air. The best time for testing the sufficiency or otherwise of ventilation is the early morning, before the stable has been cleaned and aired.

In a well drained, well paved, well ventilated, and cleanly kept stable the temperature may generally be maintained at from fifty to sixty degrees. Ill drained, ill paved, badly ventilated or dirty stables cannot 
with safety be kept as warm as those of which the sanitary condition is more favourable.

Many varying circumstances, however, of situation, whether bleak or sheltered, of thickness of walls, of ceiling or absence of ceiling, of rooms overhead, of adjacent buildings and such-like considerations, must modify any general rules as to temperature. Some regard too should be paid to the state of the external atmosphere. With the thermometer, for instance, at zero out of doors, a stable would be injudiciously warm at from fifty to sixty degrees, although that temperature may be taken as a fair average for most seasons of the year.

\section{Artificial warming of stables.}

When the weather is cold and more warnth is desired,-instead of shutting up too closely the stable and thereby destroying the purity of the air,-it is better to have recourse to additional clothing or to artificial heating. The latter is very seldom applied to stables, but we feel sure that it would in the long run be much better economy to go to the expense of fires than to run the risk of the many diseases which are generated by foul air. An open fire, though more expensive than a stove, is of far greater service, because, whilst it gives warmth, it also assists the ventilation.

\section{Of stables in summer.}

In summer time stables generally require to be kept as cool as possible. Doors and windows can scarcely be opened too freely. In some cases where the stables have a southern aspect, an awning along the front will be found advantageous.

The question of the best aspect for a stable has been already considered in Chapter 1.

\section{Registering thermometer.}

A registering thermometer to show the extremes of heat and cold is a useful adjunct to a stable. The cost of this instrument is but a few shillings. Servants do not understand the danger of impure air. Frequently of an evening, when they think that there is no fear of the master again visiting the stable, in their ignorant anxiety for the horse's health and for the glossiness of his coat, they stop up every opening through which the pure invigorating air can enter. A registering thermometer is some check on this practice; though of course it is very inferior to an occasional visit from the master in the morning before the stable is opened.

\section{Stables, both cold and close.}

It is quite possible to have a stable both cold and close. Such stables are generally also damp. They are most objectionable, and are the constant source of disease. 


\section{Damp stables.}

The horse in his best and highest form is the native of a dry, warm, sunny country. He loves both warmth and dryness. In damp stables he loses all life and spirit; and debility, generally followed by disease, soon supervenes.

New stables should be thoroughly aired and dried before horses are put into them.

\section{Change of stables.}

Horses rarely suffer in health from a change even suddenly from warm to cold stables, provided they are dry ; but a change from cold to warm stables generally produces coughs and colds.

In like manner horses turned out to grass from warm stables seldom catch cold, whilst those brought into warm stables from the open almost invariably suffer.

\section{Horses brought from grass into stables.}

When horses, which have been lying out at grass or in open yards, are brought into stables, every door and window should for many days be left wide open, and the temperature should only slowly and gradually be increased, and during this transitional period any symptoms of disease should be carefully watched for.

\section{8a. Horses from the country.}

It is the practice among dealers in large towns, especially with horses fresh from the country, to turn them round for some hours on the side reins or pillar chains in inclement or foggy weather. This changes the atmosphere they breathe, which is never so stagnant in the passages or gangways as at their mangers.

\section{Horses to be cleaned immediately after exercise.}

No one point in stable management should be more strongly insisted on, than that the horse be not allowed after exercise, and especially after fast exercise, to stand without being at once rubbed and cleaned. The reasons for this were given in the latter part of Chapter 6, on Grooming.

In private stables, when horses are exercised in the morning, it is the common but injurious practice for servants on their return to tie them up and leave their legs wet, whilst they have their breakfasts. An hour or more is often let slip in this way.

As morning is the most convenient time for exereise, and as servants require breakfast, the evil perhaps eannot be altogether avoided; but it may be much reduced by the master insisting that the legs are dried or bandaged and the horses clothed before the servants leave, and that not more than half an hour is spent at breakfast. 


\section{Best time for exercise.}

Though it is usual to take horses out in the early morning on account of the time and trouble thereby saved, yet the really best time for exercise is after breakfast.

In the morning the servant is often late in starting and in a hurry to get back to his breakfast. Hence the quantum of exercise is cut short. Again, the climate in winter time is less bleak and cold at a later hour, and the servant, having had his breakfast, can at once on his return get to work at his horse. The animal too has then had his morning feed and water some two hours or more, and is therefore more fit for fast exercise, a point of some importance in the preparation of a hunter in the autumn. The servant also has more time to clean out the stable properly in the morning, and the master can better ensure a proper length of exercise. Other reasons specially connected with grooming in favour of exercising after breakfast have been already given in the chapter on that subject. Sce also Chapter 8, on Exercise.

Whilst the horses are at exercise, the doors and windows of the stable should be thrown wide open, so that during that time the interior of the building may get the advantage of a thorough change of air.

\section{Of drying horses, when very hot or wet.}

It is always an object of much importance to get a horse, which returus very hot or very wet after hunting or other severe exercise, dried and cleaned as soon as possible. Two or three men therefore should be set to work at once on him. When the sweat is running off profusely a scraper will answer better than a wisp or cloth.

\section{Warm baths.}

On exceptional occasions, when a horse returns from work more than usually dirty, wet, or tired, there is no objection to washing him all over with warm water, or giving him, as it is termed, a bath. After such washing the horse should be thoroughly dried, and then warmly clothed all over and flannel bandages applied to his legs.

The warm water is probably refreshing at the moment to a tired animal, and also soothing to any little irritation about the joints or other parts; but the chief object of this mode of cleaning off the outside dirt is first to save the servant time and trouble, and secondly to enable the horse to lie down and rest an hour sooner than he otherwise would.

But though under exceptional circumstances such treatment may in the first instance be beneficial, it must be remembered that water does not really clean the skin of the horse. As soon therefore as the animal has sufficiently rested, his skin must be cleaned by the application of the brush in the usual manner. 


\section{Artificial removal of the coat.}

With good grooming, good stables, and the maintenance of an equable temperature, few well-bred horses, except in old age, ought to require the artificial removal of their coats. When, however, it is requisite, there are three means by which it may be effected, namely by singeing, by clipping, and by shaving. Each has its own advantages, according to circumstances.

\section{Singeing.}

Some horses sweat much in autumn, and are worth nothing until their coats are off. Let such be singed. Singeing cannot be begun too early, whilst clipping must not be done until the coat has fully grown and set.

The only real art in singeing is to begin early enough and to remove the fresh growth every week. Gas answers best for the operation.

\section{Clipping.}

Other horses are the better for being worked in autumn in clothing or with their coats on, and will be more fit at the commencement of the hunting season on account of the extra sweating so caused. Let such be clipped or shaved. The horse's coat should be fully set before it is removed by clipping.

\section{Shaving.}

Shaving is a very neat and effectual mode of removing the coat. Some nicety however is required in hitting off the right time for the operation, namely, about a week before the coat sets. If done sooner, the coat grows again, and the horse may require to be singed afterwards. If deferred later, he may be bare all the winter. The part of the back under the saddle should not be shaved, but clipped.

\section{Hair not to be removed from the legs in rough hunting countries.}

In rough hunting countries it is not desirable to remove the hair from the legs of hunters, from the swell of the arm or thigh downwards.

\section{Manes and tails.}

Manes and tails should be brushed, not combed. A comb pulls out the hairs, and will soon make a mane or tail thin. A switched tail may always be produced by combing it at the end.

Almost any mane may be made to lie on the side desired by frequently damping and brushing it, or if need be, by plaiting it with lead. Civilians prefer the mane being laid to the off side. With troop horses it is always laid to the near side, with the view of enabling the dragoon to tr.ke a lock of it in his hand before mounting.

The practice of mounting with a lock of the mane in the bridle hand is good, because it lessens the chance of giving the horse a chuck in the 
mouth from the bit. Most horses which are unsteady on being mounted, have become so from having received such chucks. The saddle also is less likely to shift from its proper position, when the rider is assisted in mounting by having hold of the mane.

\section{9-180. Bedding.}

One great item in a horse's comfort, and consequently in his aptitude to carry flesh, is a good bed. Every horse should be bedded down at midday. Where straw is abundant, there is of course no difficulty in doing this ; but where the allowance of straw, as in troop stables, is limited to eight pounds a day per horse, there is some difficulty in combining daily bedding down with good beds.

As regards economy of straw, it is essential not to give the horse a chance of eating it. With this view no fresh straw should be placed within its reach. The fresh straw should be brought in first, and put not merely at the bottom, but also in rear of the stall ; and then the old litter should be brought in and put at the top and in front. The horse will not readily eat it, and by the following morning the new straw will have become somewhat tainted, and may then be mixed and dried along with the rest. Servants, however, generally prefer to put the new straw on the top, partly because it makes the stable look nicer, and partly because it keeps the clothing cleaner.

Again, great care should be taken in the morning to thoroughly shake up and cleanse the bedding from dung, and any parts which may have become rotten should be thrown out. Good straw rapidly deteriorates if these precautions are not taken. On the other hand, careless servants often throw away along with the bad parts much good bedding, which might be dried and used again.

Bedding should be shaken up and turned over at least twice in each forenoon, so as to expose every part to the drying and purifying influence of the sun and air. It is, however, a mistake to expose it over-much to the action of a very hot sun, as it makes it too dry and brittle.

Every stable ought to be swept out perfectly clean every morning, and all bedding should be removed outside. The paving of the stables will never be perfectly dry and sweet, unless it is exposed to the drying and purifying influence of the air for at least four or five hours each day. The cleanliness and dryness of the floor of the stable are essential items in stable management.

\section{Of horses which eat their bedding.}

Some horses eat their bedding to an extent which is not merely inconvenient on account of the difficulty of maintaining their beds, but which is absolutely injurious to their wind. It is noticeable that horses doing little work and standing idle during the greater part of the day are especially apt thus to gorge themselves. 
When the ordinary devices of muzzling or of giving the horse only the oldest and worst litter for his bed have failed, we know of but one remedy, namely, the substitution for straw of some article which he cannot eat. Sawdust makes an excellent bed, and in many places it may be obtained at half the cost of straw. About $100 \mathrm{lb}$. per week is sufficient to keep up a bed for one horse. Care must, however, be taken to entirely remove and renew the sawdust at least once a week. Sawdust is an absorbent of urine, and also a deodorizer. From this latter quality its impure state is often not recognised. It is not a chemical agent, but only a deodorizer (see par. 323). In Ireland black bog mould is often used. Sea sand, when obtainable, answers very well, and makes a cool and pleasant summer bedding. Of late years moss litter has come into use, and if kept clean and dry answers very well.

\section{Preservation of bedding.}

A shed outside the stable should be provided for the reception of the litter in wet weather (par. 16a). If, however, there is no such convenience, the litter should nevertheless be removed from under the horses and well shaken up and cleansed, and placed temporarily in a spare stall or in the passage, until the horses are cleaned. It had then better be replaced under the horses, because if retained long in a mass it will heat and ferment and deteriorate. Wet weather should not be admitted as an excuse for allowing the bedding to remain in the stalls, or, in other words, for the stalls not being properly swept out and cleansed in the morning.

In no case should the litter be stored under the manger. Strange to say, servants generally do store it under the manger, though the least reflection might convince them that in this position more than any other it must taint the air which the horse has to breathe, whilst the ammonia arising from it must be injurious to his eyes and lungs.

In fine weather the litter should always be placed in the open air rather than under a shed.

\section{Clothing.}

Good large heavy rugs, weighing eight pounds, answer quite as well as what is technically called clothing, and have the advantage of being about half the price. The rug should be hollowed out over the withers, and in addition to the ordinary roller the two ends in front should be brought together and secured by a broad strap and buckle.

For most horses one rug in summer and two in winter are sufficient. old horses, as a general rule, require more clothing than younger animals. Breast-cloths, especially where large rugs secured in front are used, are unnecessary.

All clothing ought to be brushed and exposed to the purifying influence of the sun and air for some hours daily. Advantage may be taken of the period of exercise and grooming for this purpose. The clothing of horses, 
as is the case with the clothes of men, absorbs the emanations of the body, and therefore requires to be frequently cleansed and purified. Separate suits for day and night are very desirable.

In hot summer weather the rug may be taken off, and a linen or calico sheet, chiefly as a protection against flies, may be substituted for it.

If horses are exercised in clothing, a separate suit should be kept for the purpose. It is not desirable that the horse should stand all day in the clothing which has absorbed his perspiration and other emanations whilst at exercise. If, however, separate suits are kept for day and night, this extra suit will not be needed, as the horse may be exercised in the night suit, which can afterwards be dried and aired during the day.

\section{Hand rubbing of the legs.}

Hand rubbing of the legs is very useful in relieving any little fulness arising from over-work, or in other cases from the absence of proper exercise. The pressure and friction thereby given excites the bloodvessels and absorbents to increased action.

\section{Flannel bandages.}

Flannel bandages are useful in several ways. By their pressure they act to a certain degree like hand rubbing; and again by their warmth they operate as a mild fomentation, and thereby reduce heat, swelling, and slight inflammation. Ordinarily they are used as a means of saving the servant the time which would otherwise be required to dry the legs, when wet.

\section{Wet linen bandages.}

Wet linen bandages are useful in reducing the heat of superficial inflamed parts. They do so both by the actual cold of the bandage, and still more by evaporation.

The mode in which warm and cold bandages produce their effects will be described more fully in Chapter 17, under the heads of fomentations and cold applications.

\section{Of putting on bandages.}

Few servants understand how to put on bandages. They need adjustment according to the purpose for which they are required. Those intended to give pressure of course require a certain degree of tightness, whilst those intended for warmth should only be tight enough to prevent their slipping down. Servants, however, nearly always put on bandages too tightly, forgetting or not knowing that each succeeding fold increases the pressure underneath. The bandage should be rolled up before it is applied, and the winding on should begin from the lowest part upwards. 


\section{Bandages to joints.}

It is difficult to bandage any joint, except the fetlock, so as to give pressure or restrain motion. If it be desired to prevent motion, as in some cases of broken knee, the better plan is to apply splints; or to blister lightly the neighbouring parts with a view of making them tender and stiff, so that the patient may be disinclined to move.

As a general rule, where joints are bandaged, it is essential that the horse be tied up by the head to the rack to prevent his lying down. The patient, in the act of lying down or getting up, nearly always bursts a tight bandage.

If the object of the bandage be only to maintain warmth in the part after fomentation, as in cases of sprain in the hock, or on the other hand to reduce the heat of the part, it may be conveniently effected by a covering made of felt or of several plies of flannel cut to the requisite shape and sewn together, with a hole for the point of the os calcis, and fastened in front with a number of straps. This covering may be kept moist with hot or cold water according to circumstances.

\section{Persistent coldness of legs.}

When, in spite of friction and bandages, the legs remain persistently cold, as is often the case in various debilitating diseases, a mustard embrocation or ammonia liniment may be advantageously rubbed on the parts, and the bandages may then be reapplied. Some further directions on this subject, which is connected with disease rather than with stable management, will be found in succeeding chapters.

\section{Feet.}

Feet, if the shoeing is good, as a general rule require nothing but cleanliness to keep them in health. They should be picked out and washed clean every morning and again after exercise.

\section{Arrangement of horses in the stable.}

The arrangement of horses in a stable, especially where bales only are used, is a matter of some importance. Some horses take a special dislike to others, and will constantly bite, kick at, or fight with them; whilst they will stand quiet next to particular animals. A vicious horse should be put in a corner stall, and if possible, should have a spare stall next to him. A horse which is given to bite his neighbours, may, if put in a corner stall, be still further restrained by passing the collar rein through a ring driven into the side wall instead of through the ordinary ring in the centre of the manger. Again, any horse that feeds slowly may advantageously be placed in a corner stall; and his more voracious neighbour should be tied up short as soon as he has done feeding. 


\section{Kicking in the stable.}

Some horses, by kicking in the stable, are constantly laming or distiguring themselves, and endangering the lives or limbs of their attendants or of other horses, besides smashing partitions and walls. Kicking is a very troublesome vice, and many plans may perhaps be tried, before one can be found which will stop it in any particular animal. There is, in fact, no one recipe to stop kicking, but among muny remedies which may be tried, some one will generally be found to be effectual.

When the common remedies, such as a log fastened to the hind leg, or a piece of furze hung up in rear, have failed, it is well to try the effect of a strap connecting one or both hind legs with one fore-leg; or both hind legs may be strapped together, but some horses, notwithstanding their hind legs are tied together, manage to kick by raising both hind legs at the same time. A block of wood or gutta percha, made to fit exactly into the hollow of the heel, and fastened in front by a strap frequently effectually prevents kicking in the stable.

Most horses may be stopped from kicking, when being groomed, by strapping up one fore-leg in the manner recommended some years back by $\mathbf{M r}$. Rarey; but in this case it is essential that a good substantial bed should be kept under the horse, as otherwise he may injure himself by slipping or falling on his knees.

It is not uncommon to find, that horses, which have been stopped from kicking by the use of one of these plans, learn after a time to kick in spite of it. Another plan must then be tried.

In the great majority of cases, however, where horses are vicious, the servants are the real culprits. Ill tempered or idle or even timid servants cause horses to be, or allow them to become vicious. With good servants and gentle treatment very few horses give, or at least long continue to give trouble.

\section{Sleeping, when standing in the stable.}

Some horses sleep when standing and rarely lie down, and seem to do well. It appears to be natural to them. But others, who indulge in this habit, are apt to fall down and cut their fetlocks. In such cases the habit has probably arisen from the horse having, at some time or other, been cast in the stall.

The remedy is of course to induce the horse, if possible, to lie down. A loose box offers the best chance of effecting this object. If this fails, the only preventive to injury is a thick padded boot running completely round the fetlock, in addition to a good substantial bed in front, so that the parts may not be injured, even if the animal falls. It is essential that the boot should go completely round, because a boot covering only the anterior part may slip, and thus leave unprotected the part which needs protection. If the horse suffers in his legs from not lying down, he may be put in slings at night, or a very broad strap may be fastened from one heel post to the other, against which the animal may lean. 
This latter plan gives very little trouble, and often answers exceedingly well.

\section{Weaving.}

Weaving, or constant oscillation from side to side by motion of the fore-legs, accompanied with a corresponding motion of the head from side to side, is a curious and favourite trick of some horses. No particular harm seems to result from it, nor does it appear to be catching among other horses. As a general rule, horses do not weave unless they are tied up, but some will go through the motions even though loose.

The trick arises from nervousness at the approach or presence of any one. Though the animal may appear to be always weaving, yet such is not the fact, as the owner may easily satisfy himself by placing the horse in some stable where he can watch him without being seen or heard.

\section{Crib-biting.}

Crib-biting is a serious evil, and generally increases rather than diminishes with age. Several causes give rise to it. It is sometimes learnt by young horses catching at the manger or at any rail which may be within their reach when they are being groomed. In other cases it may originate in mere playfulness or want of occupation. The use of deal or any unseasoned wood, which horses like to gnaw, for stable fittings is apt to induce the trick. But most commonly crib-biting arises from some acidity or chronic irritability of the stomach, which produces a craving for something to appease it, i.e. to suck in wind.

Crib-biting, if much indulged in, damages the teeth, and is said in some instances to do so to a degree which interferes with feeding. But inasmuch as mastication is performed by the posterior teeth, it is not probable that the domesticated horse can suffer any great inconvenience from injury to the incisor teeth. The office of those teeth is principally to nip off the blades of grass, a duty which is not often required in the stabled animal. Crib-biting, however, from the amount of wind sucked into the stomach often seriously interferes with the digestion, and hence is a common cause of flatulence and colic, whilst, again, by impairing the digestion, it often prevents the horse carrying flesh.

In its incipient stage crib-biting may be retarded, if not arrested, by dressing all the stable fixtures within reach with coal tar, which must be renewed as often as necessary; and it is advisable in all cases, having regard to the disease arising from irritability of the stomach, to keep water always within reach. The use of a wooden bar placed across the mouth, and attached at each end to the head collar has also been recommended. Acting somewhat as a gag, this is said to have a good effect in arresting this tiresome and evil habit.

A strap drawn tightly round the neck is much recommended as a preventive. If sufficiently tight it will prevent the horse from swallowing the air, which is his chief object in cribbing, and on this account it often hinders him from pursuing the habit. It is, however, a question whether 
a strap drawn tight enough to prevent the trick, may not do injury to the muscles of the throat, and thus produce serious mischief. It has also been recommended to place a ball on a strap to give more pressure on the windpipe. The use of a swinging manger in the box, and the absence of any projection likely to be seized by the teeth has been found to prevent this habit. It will, however, probably recur when opportunity offers.

Crib-biting is generally supposed to be very catching. No doubt the trick is sometimes learnt by one horse from another, but inasmuch as it generally arises from derangement of the stomach, this cannot be the case to any great extent. In all cavalry regiments a few crib-biters may be found, but though no trouble is taken to separate them from other horses, it is not found that the habit extends.

The Author has no great confidence in any one of these remedies. It is, however, advisable to try them one after the other, and perhaps one may be found which will be successful with a particular horse.

\section{Wind-sucking.}

Wind-sucking is similar in its causes and effects, and requires the same treatment as crib-biting.

\section{After a hard day's work.}

After a hard day's work the horse should, if possible, be given a loose box. If he seems fatigued or has fasted long, a pailful of gruel given at once, before the operation of cleaning is begun, will be acceptable and easy of digestion. Whilst being cleaned he may be given some hay, of which he will eat a little, and which will revive the powers of his stomach, and get it into a state fit to assimilate the corn. As soon as cleaned, he should have his feed of corn mixed with about a pound of linseed boiled to a jelly, and afterwards his hay as usual.

After he has been thoroughly dressed and cleaned, dry flannel bandages, in lieu of those originally put on after washing or rubbing down his legs, should be applied and left on during the night. The warmth and pressure derived from them will help to reduce any little swelling or effusion or "gumminess" arising from the day's work.

On the following morning, after being thoroughly groomed and his legs hand-rubbed, the horse, if standing in a stall, may be taken out for half an hour's walking exercise ; but if in a loose box the exercise may be dispensed with. At mid-day he should be again thoroughly groomed and his legs hand-rubbed. Nothing refreshes the horse more, or sooner restores the energies of the system, than grooming and hand-rubbing. If the legs continue puffed, the bandages may be reapplied.

A diuretic ball is commonly recommended after a hard day's work as a means of reducing puffiness of the legs and joints. That it will produce this effect the Author does not question, becauss it will excite increased action in the kidneys, and in this way draw off any superfluous secretions from the system. But inasmuch as those secretions remain in 
the system on account of debility or want of tone in the vital powers, it seems to him that the remedy is in a wrong direction. The horse requires not depletion but tone. The vital powers will best recover themselves under the influence of rest, good feeding, good grooming, handrubbing, and pure air and a little walking exercise.

\section{Physic.}

Some few words on Physic can hardly be omitted in a treatise on stable management, though physic will scarcely ever be required, if the management be really good.

Some owners of horses give physic periodically, others only when preparing for fast work a horse that has been out at grass or is from any cause out of condition. Three doses of purgative medicine are by many supposed to be necessary for the preparation of a horse for hunting.

Sensible men do not give physic unless it is needed; and they avoid giving it, when the object sought can be attained by other and less injurious means, such as by an alteration of diet or exercise.

Most physics are poisons more or less strong, and why put ever so small a quantity of poison into the system unnecessarily? It is probable enough that horses do occasionally require medicine; but there is no sense in giving it when not required.

The physic given on these periodical occasions is usually purgative. If the stomach and intestines are healthy and have nothing in them which needs to be forcibly ejected, why disarrange them by thrusting on them medicine?

The old-fashioned answer, we presume, would be "to prevent their getting out of order." How the disturbance of a healthy system can be supposed to effect this, we must leave to others to explain. Few horses on the average enjoy such good health as troop horses, and yet from one year's end to another they never, unless really ill, get physic.

Let medicine then be restricted to those cases in which it is really required, and even then let it be given as sparingly as possible.

If proper and timely notice is taken of the premonitory symptoms of ailments, little active treatment will ever be necessary. Bran mashes instead of corn for a day or two, deprivation of hay, a cooler stable, and above all a loose box, with plenty of pure fresh air will probably do all that is needed, and will do it much better and more safely than physic.

\section{Bran mashes.}

Whilst the periodical administration of purgative medicine is injurious, it is yet good practice to give horses on Saturday evening, if Sunday be a day of rest, a cold bran mash in lieu of the evening feed of corn. Bran mash is cooling and slightly laxative, and therefore a fitting preparation for a day of rest.

A uarm bran mash for a sick horse is made by pouring boiling water on bran in a pail, and covering it with a cloth to retain the steam. A handful of dry bran thrown on the top of the mash will answer the same purpose. 
199a. Working life of horses in various Employments.

Some few statistics may be interesting and valuable. The statistics, however, refer only to the duration of horses in the employments for which they were bought. It does not follow that a horse is worn out, because he is no longer fit for the work for which he was bought. Many, in fact most of them, may be fit for slower or lighter work for many years to come.

The Author desires to return his warm thanks to those, who have so kindly supplied him with the following information.

\begin{tabular}{|c|c|c|c|c|c|c|}
\hline & 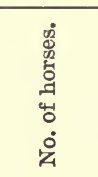 & 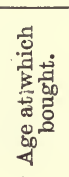 & 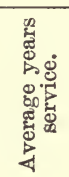 & 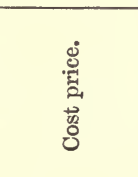 & 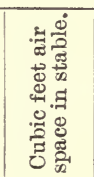 & 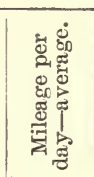 \\
\hline South-Eastern \& Chatham & 1,300 & $5-6$ & $6 \frac{1}{4}$ & $£ 56$ & 1500 & $18-20$ \\
\hline London \& South-Western & 840 & $5-6$ & $6 \frac{1}{2}$ & $£ 59$ & various & - \\
\hline London General Omnibus & 17,000 & $5-6$ & $5-6$ & $£ 43$ & 800 & 13 \\
\hline Road Car ... & 4,284 & $5-6$ & $4 \frac{1}{2}$ & $£ 30$ —40 & 800 & 15 \\
\hline Improved Cab Co. & 1,037 & 6 & $4 \frac{3}{4}$ & $£ 25-£ 30$ & 750 & $20-25$ \\
\hline Carter, Paterson \& Co. ... & 3,000 & - & $6 \frac{1}{2}$ & - & 750 & $12-13$ \\
\hline Cavalry at Home... ... & - & 4 & $8 \frac{3}{4}$ & $£ 40$ & 1200 & 一 \\
\hline
\end{tabular}

The Commissioner of the Metropolitan Police has kindly supplied the Author with the following valuable information:-

313 horses, divided into Patrol and Despatch.

Patrol horses do from four to five hours daily, and the despatch horses 21 miles on week days, and half that distance on Sunday.

Both classes are subject to considerable extra work when occasion requires, and long distances on the road may have to be covered in addition to the duty for which they are required.

\section{Cab horses.}

Cab horses are no criterion. They are bought at all ages. But from the best information which the Author has been able to glean, the average service may be taken at three and a half years. The average distance travelled by the cab appears to be about 20 to 25 miles per day.

\section{Job horses.}

As regards London job carriage horses the Author is inclined to think that in good places the average duration of service may run as high as seven years, whilst in places where they are knocked about, it may not be more than from three to four years or even less.

It may seem impertinent to make a suggestion to job-masters, who of course know their business much better than the Author, but he thinks that their interest in the careful and kindly treatment of the horses would be much better served by charging the full price for the first and 
Addendum to "Cab Horses."-Page 103.

The distances traversed daily by cab horses, oftein above twentyfive miles, may seem excessive. There are, however, many halts during the day, and it must be remembered that horses rest and sleep while standing. 

second years, and an annually decreasing sum for each succeeding year the customer retained the same horse.

In considering the price charged by the job-master the publio must recollect first, the large number of horses which he must keep at his own expense to supply loss from casualties and epizootics occurring, especially in the spring when horses are most in demand. Second, the large number of horses which are returned at the end of the season, which must either be sold at a great sacrifice, or maintained in idleness at a great expense for six months. And third, the very considerable number of horses which after six or more months' training from various causes turn out unfit for London or other carriage work.

The extra number of horses from these causes required to be kept may be set down at 20 per cent. 


\section{PART II.}

CHAPTER 10.

'THE BLOOD, ARTERIES, AND VEINS.

200. The Blood. 201. Serum. 202. Crassamentum. 203. Red Corpuscles. 204. White corpuscles. 205. Coagulation of blood. 206. Arterial and Venous blood. 207. Colour of Blood. 207a. The Heart. 208. Arteries. 209. Veins.

\section{The Blood.}

Blood is essentially the aliment or food of the body. By it all parts are sustained and replenished, whilst from it are drawn all secretions, including all material required for the repair of wounds or injuries. Its specific gravity is about 1.050 in health, but varies in certain diseases. Its ordinary temperature is about $99^{\circ}$ Fahrenheit. In quantity the blood is supposed to amount to about one eighth of the body. It contains a variety of substances, but its ultimate analysis corresponds pretty closely with that of flesh. Throughout life it is always circulating in the heart, arteries and veins. The theory of its circulation has been described above in Chapter 1. Its reaction is constantly alkaline.

Blood consists of a clear fluid, principally composed of water, holding in solution about eight per cent. of albumen and two or three parts in a thousand of the elements of fibrin, with a small quantity of salts of potash and soda, lime, magnesia and other matters. Floating in it also are found red and white corpuscles, the red exceeding the white in number as about three or four hundred to one in health; varying from eight hundred to one during fasting, but in certain diseases of the blood the white corpuscles are greatly increased in number. In addition to these red and white corpuscles, the higher powers of the microscope reveal numerous minute molecules or granules similar to those found in lymph and chyle.

Blood is recruited from supplies of new material furnished by the process of primary digestion in the alimentary tract. It also receives matters from the atmospheric air; and lastly, from the secondary digestion, as that process is called, by which the tissues, which have served their purpose and become effete, are absorbed into the blood before being discharged from the system.

Hence anything which interferes with the process of primary digestion, 
with respiration, or with the excretory organs, and perhaps also anything which disturbs the healthy condition of the nervous system, will affect the composition of the blood. Inflammatory diseases remarkably modify its character.

Blood, when first drawn, appears to be homogeneous; but on cooling it separates into two nearly equal parts, namely a fluid called Serum, and a red solid portion called Crassamentum or clot.

\section{Serum.}

Serum is a thin yellowish or straw coloured fluid, somewhat thicker than water, consisting principally of water with an admixture of albumen and salts.

During life serum, or a fluid very like it, is frequently separated from the blood and effused, whenever the vessels become congested and overdistended.

\section{Crassamentum.}

The Crassamentum or Clot is composed of fibrin holding the red corpuscles in its meshes, caught as they are sinking to the bottom. It owes its colour to the red corpuscles. Fibrin, when deprived of them by washing in cold water, loses its colour and presents an appearance much resembling bleached muscular fibre. Fibrin, when exposed to the air, usually coagulates spontaneously, and it has the power of interlacing its fibres and of contracting on itself. It is soluble in alkalies and acids, but insoluble in water, oil, or spirits. It is a remarkable fact that fibrin as such does not exist in the liquid blood during circulation, but is formed during coagulation by the union of two substances, paraglobulin and fibrinogen, with the aid of a ferment.

\section{The red corpuscles.}

The Red corpuscles are somewhat heavier than the other parts of the blood. In shape they are like flattened discs, and often adhere by their surfaces to each other and form piles like rouleaux of coins, especially in inflammatory blood. Each corpuscle consists of a wall of tough elastic membrane enclosing a substance called Hæmatin, which is the red pigment of blood. One of the component parts of hæmatin is iron.

The main function of the red corpuscles is to act as carriers of oxygen to the tissues. The products generated in the tissues by oxidation are returned in the venous blood in the form of carbonic acid gas, urea, water, and other effete materials. During the oxidizing process caloric is also set free.

Many vessels in a state of health are too small to admit the red corpuscles; but when their coats under the influence of inflammation are distended, they do admit them. Hence a part hitherto devoid of colour may become red. 


\section{The white corpuscles.}

The origin and functions of the white corpuscles are not clearly ascertained. By some they are regarded as identical with lymph and chyle cells, and it is thought that they become changed in the ductless glands and absorbents into red cells or corpuscles. During inflammation they are converted into pus cells, and it is also probable that they may become converted into the cell elements of new tissues. By others the walls of the white corpuscles after rupture are supposed to constitute the fibrin. In many morbid states of the blood of an inflammatory character the microscope shows the white cells to be in excess, and analysis shows that the elements of fibrin are also in excess. They are supposed to be generated either in the blood or in the lymphoid tissues of the body.

\section{Coagulation of blood.}

The spontaneous coagulation of blood after being drawn is caused by the continued power of contraction in the fibrin. It is not completed, when it takes place at all, in less than from twenty to forty hours. The cause of the contraction and solidification of the fibrin in the blood, whether in or out of the body, is not yet positively ascertained. Objections may be made to every theory yet propounded on the subject. Dr. Richardson's idea, that the coagulation is due to or at least attended by loss or evolution of the ammonia contained in the blood was, until lately, generally received; but is now much doubted. A small quantity of ammonia added to blood, when drawn from the body, will certainly prevent its coagulation; whilst, on the other hand, a clot of blood will dissolve, if treated with ammonia. We only know, however, positively, that rest, warmth, free access of air, and multiplication of the points of contact favour coagulation. The withdrawal of the influence of the living vessels is also in all probability largely instrumental in producing this result.

Whatever, however, may be the ultimate cause of coagulation in blood, it is certainly affected by many and various circumstances, such as the rapidity or otherwise with which the blood is drawn, and whether it is taken from a large or small orifice, the temperature of the weather, the amount of fibrin contained in it, the condition of the animal, the amount of exercise he may have had immediately before being bled, the shape of the vessel into which it is drawn, whether shallow, deep, or narrow, \&c.

The older Veterinarians attached much importance to the appearance of the blood, to the presence or absence of a buffy coat, i.e. the absence of red corpuscles from the upper clot, \&c., as indicative of various diseases or stages of disease; but from the above it will be seen that the causes which affect or modify its condition, are so numerous and varied, that but little reliance can be placed on its appearance after it is drawn.

\section{Arterial and Venous blood.}

There are two kinds of blood in the body, namely, Arterial and Venous. Arterial differs from venous blood in the following particulars : 1st, it is 
more scarlet; 2 nd, it has a greater specific gravity ; 3rd, its temperature is slightly higher; 4 th, it contains more fibrin and oxygen, and less carbonic acid gas. It has also a greater capacity for rendering heat latent.

\section{Colour of Blood.}

The colour of blood is not due, as has been often supposed, to the iron which it contains. The colour remains after the iron has been removed. Again the blood of many invertebrate animals contains iron, and yet is colourless. The degree of colour really depends on the gases in the blood. The carbonic acid gas found in venous blood distends the red corpuscles and therefore allows the hæmatin or red pigment contained in them to appear through their coats; whilst oxygen on the contrary shrivels up the corpuscles, and thus gives a light scarlet tint to the blood.

\section{7a. The heart.}

The heart is the great force pump of the body, and may be described as a hollow muscular organ of about $7 \frac{1}{2} \mathrm{lbs}$. weight when the blood is washed out, in a horse of medium size, length about 10 inches and breadth between 5 and 6 inches.

It is in the form of a blunt cone, and is situated almost in the centre of the chest, inclined to the left side, and is suspended from the dorsal vertebræ by the blood-vessels which spring from it.

The heart is enclosed in a distinct sac of its own called the pericardium, a layer of which is reflected over the external surface.

The heart is divided into right and left sides by a longitudinal septum and into auricles and ventricles by a transverse septum, so that it will be seen that this organ has four distinct cavities, two on the right side for the reception of venous blood, and two on the left side for the reception of arterial blood.

The beats of the heart are caused by the contraction of its muscular walls, by which the blood is forced into the lungs for purification and from the lungs through the system generally for the purpose of nutrition.

\section{The Arteries.}

The arteries are elastic tubes formed for the purpose of conveying blood from the heart to all parts of the body. The blood from the left ventricle of the heart passes into the Aorta, and from thence by innumerable channels to all parts of the body. The Pulmonary artery arises from the right ventricle and conveys venous blood to the lungs. The blood after being purified in the lungs by the action of the air is returned by the pulmonary veins to the left auricle of the heart as arterial blood for distribution through the body.

The larger arteries are generally deep seated, and run on the inner rather than on the outer sides of the limbs. So placed. they are better protected from the chance of injury. In passing over joints, however, they. are most commonly found on the side, which is flexed by the motion of the joint. In this situation, any abnormal extension is obviated, and 
thus obstruction to the circulation is guarded against. For somewhat similar reasons arteries, when near the surface, such as those of the lips, ears and nostrils, generally take a serpentine course. The extreme ramifications of the arteries form the arterial capillaries. They are infinitely numerous. In them the outward or arterial circulation ends, and the venous or return circulation commences.

Arteries frequently anastomose with each other. By this provision of nature a part still receives a supply, generally a sufficient supply of blood for its nutriment from the collateral circulation, even though the arteries which more immediately supply it may happen to be divided.

Arteries have three coats, connected together by areolar tissue, all of which are to a certain degree elastic; namely, an outer coat of connective tissue mixed with elastic fibres, a middle muscular and elastic coat, and an inner cuticular coat. On account of the elasticity of its coats an artery expands or contracts according to the amount of blood circulating in it. Hence, in a certain sense an artery may be said to be always full. The coats of the arteries are themselves supplied with blood by a minute system of vessels called the vasa vasorum.

An artery, when opened, generally continues to bleed freely on account of the force of the circulation running through it, and the blood is forced out in jerks at each contraction of the heart. Hence it is difficult to stanch its bleeding. In order to do so, it is often necessary to take it up and apply a ligature at the point of injury, or a compress, or acupressure, or torsion, or styptics. In some cases, where the artery is only partly divided, it may be possible to stop the bleeding by dividing it completely; because when it is cut right across, it contracts and retracts within its sheath on account of the elastic nature of its coats. The Blood which has escaped, forms a clot at the orifice, and another clot is formed inside the vessel extending from the orifice to the next collateral branch. The clot is conical in shape, and acts as a plug in preventing the fluid blood from escaping. Cautery, either actual or potential, is also useful as a means of stopping the flow of blood. There is not, however, much fear of an animal bleeding to death from the effect of even a severe wound of an artery, because the action of the heart is lowered by any considerable escape of blood, and the force of the circulation is thereby diminished. Arterial hæmorrhage causes greater constitutional disturbance than venous.

\section{The Veins.}

The veins are vessels which convey back to the heart the blood distributed by the arteries to different parts of the body. Veins are usually more numerous and larger than their corresponding arteries. In most cases there are as many as three veins to each artery.

Veins are divided into superficial and deep-seated. The former are found immediately below the skin, and hence are sometimes termed subcutaneous; whilst the latter generally accompany the deep-seated arteries. Veins like arteries frequently anastomose. Veins have their 
origin in the capillaries, from whence they gradually increase in size, and run into each other, and form larger and larger veins, and ultimately lead into the heart.

In structure the coats of the veins bear a general resemblance to those of the arteries. They do not, however, possess complete elastic coats. What elastic tissue they have is interwoven in their fibro-cellular tissue, which being in itself extensile and elastic enables them to recover the temporary extensions to which they are liable. The part of their walls which corresponds with the muscular coats of the arteries, is composed of fibres resembling those of fibro-cellular tissue combined with well-marked fibre cells of organic muscle; by the agency of which the veins probably possess some power of independently contracting on their contents. The coats of the veins are supplied with blood by a system of smaller veins called the venæ venarum.

As a substitute for the strongly developed elastic coats of the arteries, valves are placed in all veins, where they are subject to pressure from the muscles between or near to which they run. These valves prevent any return of the blood, which might otherwise arise from such pressure. In parts, which are not subjected to such pressure, there are no valves. In. the foot for instance there are none, and but few in the viscera.

It is probable that the veins are the principal agents in absorbing the waste and excrementitious parts of the body.

The Pulse will form the subject of the next chapter.

\section{CHAPTER 11.}

\section{THE PULSE.}

210. Importance of the indications of the Pulse. 211. Cause of pulsation. 212. Number of pulsations per minute. 213. Taking the pulse. 214. Irregularities of the pulse. 215. Range of pulse in disease. 216. Auscultation as regards the pulse. 217. Action of the heart. 217a. Temperature.

\section{Importance of the indications of the Pulse.}

The Pulse in the horse, as in other animals, is an important guide in determining the healthy state or otherwise of the patient. It indicates the number, force, regularity or otherwise of the heart's action, and the quantity of blood sent forth at each beat.

In examining the pulse, the characters to be especially noticed are its frequency, regularity, and compressibility. As a general rule, the number of the pulse corresponds with the heart's contractions. In certain cases, however, of heart disease, the impulse is not conveyed far on account of the ventricles receiving only a small quantity of blood. 


\section{Cause of Pulsation.}

The pulse is the beating of the arteries produced by the wave of the blood propelled into them by each contraction of the heart. The sensation which the fingers perceive, when placed over a superticial artery, indicates the rapidity, force and regularity of the heart's action, and also the relative quantity of blood flowing through the artery.

As the volume of blood passing through the arteries, when the horse is in a state of good health, is considerable, the pulse is firm and regular. It is, however, greatly increased in frequency during any exertion.

\section{Number of pulsations per minute.}

The range of pulsation per minute in an adult healthy horse, the temperature of the air being $60^{\circ}$, is from thirty-four to thirty-eight; and instances are not wanting of healthy pulses being as low as thirty and as high as forty.

The pulse in young subjects is generally quicker than in aged horses. It is also usually slower in low than in well bred animals.

\section{Taking the Pulse.}

The most convenient places for taking the pulse are the submaxillary, the radial, the temporal, the metatarsal, and the plantar arteries.

The slightest excitement, especially when a horse is sick, will cause an alteration in the pulse. To ascertain, therefore, the true character of the pulse, both with reference to tone and number, the animal should be approached very quietly, and should be soothed for a minute or two, before the finger is applied to the artery.

The fore and middle finger should be placed on the artery in a transverse direction. If it is placed obliquely, the impression will be erroneous as to the true character of the beat.

\section{Irregularities of the Pulse.}

A regular pulse with proportionate fulness is the best criterion of health. Irregularity usually arises from irritability or debility of the system.

A strong and full pulse is present during health under any temporary excitement; but this character is seldom found to accompany any morbid state, into which the animal may fall. The full pulse, which often accompanies disease, has always some vibratory hardness in it.

The intermittent pulse.-A pulse is said to be intermittent, when it beats two, three, or four times regularly, and then ceases for a period of time equal to two or three beats, before it goes again.

Irregularity in strength.-The pulse may beat with natural force two or three times in succession, and then the next beat or two may be feeble, and afterwards it may become strong again, and so on.

Intermittent and irregular. - The pulse may be both intermittent as to time and also irregular as to tone. 
The above changes indicate disease of the heart, either functional or structural, or both conjoined.

Strung and full, or suft and full.-These conditions, though somewhat abnormal, are yet quite consistent with ordınary, though not perhaps with perfect health.

Weak and small.-This condition is indicative of great debility, especially if the pulse is easily extinguished by pressure.

Quick, feeble, futtering, or imperceptible.-This condition is indicative of speedy death.

The wiry pulse.-A hard small pulse, as a wire is hard and small, indicates disease of a sthenic character, and is symptomatic especially of inflammation of the serous membranes and of white fibrous tissue.

The thready pulse.-A pulse which is small and soft, as a thread is small and soft, is termed thready. It indicates great debility.

The oppressed pulse.-The artery is full, but the beat is indistinct. It is indicative of congestion and inflammation of the lungs.

The throbbing pulse.-In the region of any part which is inflamed or congested, or unusually excited from any irritation, the artery will throb more or less violently. The character of the pulse in the vicinity of local disease will indicate its intensity, and in some degree its nature.

A remarkably slow pulse indicates disease or injury of the brain or spinal cord.

The double pulse.-A double beat caused by diminished arterial and increased venous pressure is the result of feeble action of the heart. This pulse is present in many of the septic diseases, such as purpura hæmorrhagica.

\section{Range of the Pulse in disease.}

The number of pulsations per minute under different circumstances in disease vary from twenty to one hundred and twenty or even more.

The pulse may differ slightly on the two sides of the patient. When it is so feeble that it cannot be felt at the near or left submaxillary artery, it may often be detected at the off or right side of the same artery. The pulse may frequently in disease be felt at the arm, when imperceptible at the jaw.

It has been thought by some physiologists that the pulse is always a little stronger on the right than on the left side of the animal.

In treating disease we are not satisfied with reducing the number of pulsations, unless we can also produce a soft pulse. Softening of the pulse is an indication that the nervous irritability is subsiding. This character of softness is present in the decline of all inflammatory affections.

\section{Auscultation as regards the Pulse.}

It is highly important that the beats of the heart should be listened for, as its peculiar action may assist us in interpreting the pulsation of the artery. Again, in some cases, when the pulse is nearly or quite imperceptible to the finger, when, in other words, there is not sufficient 
force in the heart's action to propel forward distinctly a wave of blood, or when the wave of blood which is propelled forward, is too small in quantity to make its passage felt in the artery, we may often gain much information by listening to the beats of the heart.

Auscultation may also enable us to detect either structural or functional disease of the heart. The heart, however, in the horse is but seldom diseased primarily; though it often becomes so, as a sequel of pleurisy or rheumatic affections.

\section{Action of the Heart.}

When the heart is healthy its rhythms are firm and strong, and its beats are as regular as the ticks of a clock, and the pulse is also firm and regular.

In disease the action of the heart may be feeble and even half paralysed, or it may be violent and over-excited. It is not our intention here to enter into any consideration of the diseases or causes of the diseases and affections of the heart. We shall only note its action as regards the indications of the pulse.

If the action of the heart is feeble, the pulse will in consequence be feeble in tone, quick, fluttering, and often intermittent, and the impulse given to the wave of blood in the arteries may be so feeble that the pulse may be extinguished by the slightest pressure of the finger.

The difference between the action of the heart in health and in some debilitating diseases may in many respects be compared with the exertions of a man in swimming. Whilst the man is strong and vigorous his strokes are regular and true; but should he become exhausted and be in danger of being drowned, they become quick, irregular, and feeble.

This comparison may perhaps afford some clue to the treatment required when the pulse is quick, irregular, or feeble. It would be absurd in the case of the drowning man to do anything which might still further paralyse his already flagging muscular energy. It is equally absurd to bleed or lower the horse in a case such as above described.

If we are desirous of rendering assistance, we should not give depressants under such circumstances to either the man or the horse, but rather diffusible stimulants with a view of rousing as far as possible the nervous force, and thereby increasing the muscular energy ; until in the one case the man has reached the shore, and in the other case the heart has kept the horse's blood in circulation, so that it may be revivified and purified by the action of the air in the lungs.

On the other hand, in the earlier stages of inflammatory attacks, especially in those of a sthenic type, or when fever is present, it often happens that the action of the heart is over-excited, and the pulse in consequence is unduly full and strong.

To the inexperienced bleeding and other depletives naturally suggest themselves as the appropriate remedies. Collapse of the power of the nervous system, however, sooner or later always follows excitement. Now if during the period of excitement extreme measures of depletion are re- 
sorted to, there is great reason to fear that the subsequent depression will be excessive ; and prostration of the system and sinking and even death are likely to supervene.

In such cases it is of course needed to reduce, if possible, the overexcited action of the heart; but in lieu of depletives recourse may be had to aconite or some such medicine, which may act directly on the heart and lower its action without taking away any portion of the vital fluid.

No doubt cases do occur, where the pulse is hard or oppressed, when bleeding under certain conditions as to the strength and habit of the patient and the stage and character of the attack will be of benefit; but relief by this means should never be sought except under the advice of a thoroughly competent veterinary surgeon. The owner of a horse will always act wisely and safely in resisting the entreaties of his groom to be allowed to take "only a few quarts of blood."

\section{7a. Temperature.}

The ordinary temperature of the blood has already been stated to be about $99^{\circ}$ Fahrenheit. In diseases of an inflammatory nature or when fever is present the temperature of the blood becomes increased above the normal standard, and is an important guide in determining the condition of the patient.

To ascertain the temperature of a horse a small clinical thermometer is necessary. This is inserted in the rectum, and must be allowed to remain for at least five minutes, when it may be withdrawn, and the index hand will indicate the exact temperature of the patient.

During the prevalence of influenza or other epizootic diseases, it will well pay the owner to employ a veterinary surgeon to take the temperature of his horses every day, as a rise of two or three degrees will be indicated some hours, perhaps two or three days previous to the manifestation of any external symptoms. If the animal is at once taken out of work, the disease will run a milder course. Work in the incipient stage of these diseases often causes them to assume a fatal form.

In influenza the thermometer has recorded $106^{\circ} \mathrm{F}$. in cases that have recovered. The normal temperature of the horse is $100^{\circ}$ or one third more or less.

To obtain an accurate register of temperature it must be taken at the same hours daily. It should not be taken immediately after watering or feeding. Nor should the operator proceed to do so immediately on entering the box, but allow the patient to become tranquil before inserting the thermometer, if at least the animal has been disturbed by his entrance. Moreover, all interference such as dressing, removal of clothes or bandages should be avoided just before the test is applied.

Clinical thermometers by the best makers can alone be relied on. The cheap articles usually sold as clinical thermometers are perfectly unreliable. 
CHAPTER 12.

\section{THE ABSORBEN'TS.}

218. Of the Absorbent system. 219. Structure. 220. Functions of the Absorbents generally. 221. Functions of the lacteals. 222. Functions of the lymphatics. 223. Diseases of the lacteals. 224. Diseases of the lymphatics. 225. Stimulants to the superficial absorbent system. 226. Weed.

\section{The Absorbent system.}

Besides the arteries and veins there is yet another or third system of vessels in the body, called the Absorbents.

Although they play a very important part in the animal economy, yet they are comparatively speaking little thought of or observed,-probably because as a rule they perform their functions so regularly and well, that no disturbance sufficient to call attention to them takes place. When, however, disease does occur in the absorbents, the effect on the constitution as well as on the vessels more immediately affected is not only very marked, but very rapid.

For the purpose of description the absorbents may be separated into two divisions, namely, the Lacteals and the Lymphatics. Each class is further subdivided into vessels and glands. The lacteals are distributed in infinite numbers over the whole of the mucous membrane of the intestines. The lymphatics are found in almost all the structures of the body. The lacteals are merely the lymphatics of the digestive organs.

\section{Structure.}

In structure the Absorbents are very like the veins, a description of which was given in Chapter 10. Their walls have some power of contractility. They are furnished with valves, and in the smaller veins in particular the valves are very numerous. Some peculiarities connected with these valves will be noticed hereafter. The absorbents accompany the veins and arteries, but are more numerous in some than in other parts. They anastomose freely everywhere. Though with difficulty distinguished in the dead animal, they are very readily seen in injected rreparations.

The Lacteals are very minute vessels, having their origin in the innumerable villi of the intestinal mucous membrane. Each villus gives rise to a lacteal. They afterwards unite and form larger vessels, which pass into and through the mesenteric glands, and thence on to the thoracic duct, and ultimately they discharge their contents into one of the large blood-vessels near the heart.

The lacteal glands are situated in the mesentery. Each gland is composed of a plexus of lacteal vessels. The vessels passing out of a gland are less numerous and larger than those entering it. In the glands the 
contents of the ressels, otherwise termed chyle, undergo certain changes in composition.

The Lymphatic vessels are larger than the lacteals. Numerous lymphatic glands are distributed over the body. All lymphatic vessels at various points of their course run through these glands. Like the lacteals they all run into the thoracic duct, and their contents are ultimately discharged into one of the large blood-vessels near the heart.

The structure and uses of the lymphatic glands are similar to those of the lacteal glands.

\section{Functions of the Absorbents generally.}

The function of absorption is necessary both for the purposes of nutrition, and also for carrying off the used up or no longer required or superfluous material of the system. It is by means of absorption that the body is constantly undergoing change, both receiving new material from the food, and eliminating waste products.

It has been generally supposed that the lacteals receive the new material, whilst the lymphatics carry off the waste and effete products. In this latter function the lymphatics are undoubtedly assisted by the veins, which possess considerable powers of absorption. It is now, however, generally believed that the process of absorption of waste material is wholly performed by the veins; and that the lymphatics as well as the lacteals are engaged in absorbing and elaborating organisable principles, which are capable of being still further employed in the animal economy.

\section{Functions of the Lacteals.}

The Lacteals absorb from the food the parts useful for nutrition. They contain a white milky albuminous fluid called chyle, abounding in innumerable particles of oily or fatty matter. In passing through the various lacteal glands, and especially in those situated in the mesentery, the chyle undergoes considerable changes. The quantity of molecular and oily particles diminish; and cells, to which the name of chyle corpuscles is given, are developed in it, and it also acquires the power of coagulating. The chyle, as mentioned above, after passing through the thoracic duct is ultimately discharged into one of the large blood-vessels near the heart.

\section{Functions of the Lymphatics.}

The Lymphatic vessels absorb from the blood those elements which are capable of being again employed in the animal economy. They contain a limpid colourless fluid. As in the case of the lacteals, the fluid, which they absorb, undergoes considerable changes in its composition in passing through the lymphatic glands. After passing through the glands the fluid is carried by the vessels to the thoracic duct, and ultimately discharged into one of the large blood-vessels near the heart. At the period of entering the thoracic duct the lymphatic fluid and chyle appear to be identical except in colour. Chemical analysis fails to detect any difference in their properties or composition. 


\section{Diseases of the Lacteals.}

In some cases the Lacteals appear to suffer from torpidity. The blood in consequence is not properly nourished, and as a result the horse falls off in condition. In other cases the lacteals become the seat of active disease, especially of tubercular degeneration. The glands in the mesentery most often suffer from this cause. After a time the effused tubercular matter destroys their structure, and impedes the passage of the chyle through them. The abdomen in these cases is usually swollen, whilst the other parts of the body are wasted away. Ascites frequently supervenes.

It often happens, however, that there are no outward signs by which we can positively ascertain the existence of any derangement or disease of the lacteal absorbents. We can only surmise that such must be the case when the horse falls off in condition without any other cause adequate to account for the result.

The only treatment we can adopt in any case is attention to the general health, fresh air, good food, and moderate exercise accompanied with the administration of tonics. A run at grass sometimes produces a beneficial effect.

\section{Diseases of the Lymphatics.}

The diseases of the Lymphatics appear to result from a vitiated condition of the blood from which they draw their secretions, rather than from primary affection of the organs themselves. Whether the Lymphatics ever absorb waste material, as a normal duty, may be doubtful ; but it is certain that noxious matters in the blood are readily taken up by them, and when absorbed produce great irritation followed by inflammation and sometimes by total disorganisation of their structure. Virus and pus are also readily taken up by them and carried as far as the nearest Lymphatic Gland. In the gland they occasion inflammation and suppuration, and eventually by this latter action in favourable cases are ejected from the system.

Disease may exist in the superficial lymphatic vessels for a length of time without affecting the deep seated vessels or glands; but when it commences in the deep seated vessels, the superficial are always soon affected. As long as the disease is confined to the vessels, whether superficial or deep seated, there is no reason to fear danger; but when it has involved the glands, it generally proves very intractable.

Having regard to the origin of the disease affecting the Lymphatics, the treatment required appears to consist mainly in attention to the general health and in the very best feeding. Biniodide of copper given internally in doses of one drachm twice a day is also very useful. As a local remedy great benefit is often derived from the application of biniodide of mercury to the surface and around the vessels affected.

To the symptoms and treatment of Farcy, the most serious disease to which the Lymphatics are subject, a separate chapter, No. 29, is devoted, 


\section{Stimulants to the superficial absorbent system.}

Whilst the deep seated Absorbents are difficult to affect by treatment, the superficial absorbents and blood-vessels are easily excited to increased activity. Friction and pressure both excite their action. Hence handrubbing or bandages will often reduce swelled legs. Stimulants of various kinds applied externally and especially biniodide of mercury cause increased absorption. Purgatives by removing the contents of the intestines, and diuretics by increasing the amount of urine, cause the absorbents to set to work to supply the deficiency, and in doing so they remove superfluous fluids from the system.

\section{Lymphangitis or Weed.}

Weed is a very peculiar disease of the superficial absorbents. It is due primarily at least to irritation of the lymphatics of the part affected. Inflammation speedily follows, resulting in a sudden effusion of serum into the limb. The effusion generally arises from a plethoric state of the system induced by high feeding and want of exercise. The absorbents are unable to effect its removal with sufficient rapidity, and in consequence become swollen and congested, often to an enormous size. The case, though it looks ugly, is not so really.

The treatment consists in rousing the absorbents to greater energy. With this view an ordinary dose of medicine may be given, followed by diuretics and tonics. Warm fomentations should be constantly applied to the part. In slight cases a little gentle exercise will often sufficiently arouse the activity of the absorbents.

\section{CHAPTER 13.}

\section{STRUCTURE AND USES OF VARIOUS MEMBRANES AND TISSUES.}

227. Mucous membrane. 228. Villi. 229. Epitheliunı. 230. Serous membrane. 231. Cartilage. 232. Fibro-cartilage. 233. Inter-articular fibro-cartilage. 234. Fibrous tissue. White fibrous and yellow fibrous tissue. 235. Areolar tissue. 236. Fascia. 237. Muscle. 238. Adipose tissue or Fat. 239. Pigments. 240. Glands.

\section{Mucous menibrane.}

Mucous membrane is everywhere continuous with the skin. It also lines all internal parts which communicate either directly or indirectly with the air. It lines for instance the whole alimentary canal from the mouth to the anus, the nasal passages, \&c. It is the medium by which matters are eliminated from the system, or foreign substances are taken up into it.

In structure Mucous membrane much resembles the skin. It varies in thickness in different parts. In the nose, nasal passages, and lungs it 
is very thin, in the mouth it is comparatively thick, whilst in the stomach and intestines it is found in folds. Everywhere it is soft and velvety in texture and abundantly supplied with blood-ressels, nerves, and glands. In the digestive tract and in the spleen, liver, and kidneys it is liberally furnished with absorbents. The secretions from its glands vary according to the part in which they äre situated.

Mucous membrane is everywhere furnished with an external layer of Epithelium, situated on the basement membrane, and beneath this is a structure of vascular tissue of variable thickness, which in different parts presents either outgrowths in the form of papillæ or villi, or depressions and involutions in the form of glands or follicles.

In mucous membrane the tissues essential to the production of a secretion exist in their most simple form, namely a simple membrane having on one surface blood-vessels and on the other a layer of cells. The seoretion of the membrane, called mucus, is elaborated in these cells.

\section{Villi.}

Villi are the eminences seen on mucous membrane, and when magnified appear like the pile of velvet.

Villi are extremely vascular and sensitive, and are largely concerned in the process of absorption.

They are plainly seen on the surface of the tongue.

\section{Epithelium.}

Epithelium consists of a layer of cells arranged in one or in many superposed layers on a basement membrane. The epithelial tissue covers the free surface of the body, i.e. the skin and mucous membrane; and one variety of it is found lining serous and synovial membranes. In these cases it receives the name of Endothelium. The functions of epithelium are secreting, protective, and sensorial. In this membrane the nutrient blood-vessels are contained, whilst in the cells the secretion derived from them is elaborated. There are several varieties of Eplthelium in different parts of the body.

\section{Serous membrane.}

Whilst Mucous Membrane lines all surfaces that communicate directly or indirectly with the air, Serous Membrane on the other hand lines all closed cavities, $i . e$. those excluded from the air, with perhaps one exception, namely, the opening of the Fallopian tube into the abdominal cavity; and it also surrounds or envelopes all organs which move in the performance of their functions. It secretes a halitus or fluid for the purpose of preventing friction between the different parts.

Serous membrane is formed of fibro-cellular tissue, interwoven so as to constitute a membrane ; the free surface of which is covered with a single layer of flattened endothelial cells. It is abundantly supplied with nerves, arteries, and blood-vessels.

Serous membranes are of two kinds, viz, 1st, those which line visceral 
cavities, such as the peritoneal, pericardial, pleural, \&c.; and, 2nd, those called synovial, which line joints and sheaths of tendons, bursæ mucosæ, \&c.

In the first named the fluid secreted is identical in general and chemical characters with the serum of the blood or with very dilute liquor sanguinis. It is probable that it is in great measure separated from the blood by simple transudation through the coats of the vessels.

In the second or synovial membrane the fluid appears to be a process of more elaborate secretion by means of the endothelial cells on its surface. It is dense and viscid, and contains abundance of albumen. It is commonly known as joint oil.

\section{Cartilage.}

Cartilage is a semi-transparent homogeneous substance, possessing very considerable strength and consistency combined with some elasticity. In colour it is pearly white, but turns yellow when dried. It is insensitive and non-vascular. At least no vessels containing red blood can be discovered in it, even by the aid of the microscope. It is, however, covered with a thin film of synovial epithelium, from the blood-vessels of which it is freely supplied with nutriment.

Simple cartilage, such as that which covers the articular surface of bones, consists of numerous granular nuclei embedded in a structureless matrix. This description of cartilage is termed articular, and serves to facilitate the gilding motion of bones, and also acts as a cushion between them, preserving their articular surfaces from attrition and the bones themselves from concussion.

When the articular cartilages of a joint have been eroded or destroyed by inflammation or other disease in the organ, a sort of repair is set up by nature, which consists in the deposit of fibro-cellular tissue in the place of the cartilage. This new material is, however, no sufficient substitute. It generally binds together the ends of the bones, and so prevents further irritation and inflammation, but the joint is stiffened. In other cases this fibro-cellular deposit does not take place, but the exposed surfaces of the bones become soldered together, and the joint is firmly and permanently anchylosed. In other instances condensation appears to take place at the ends of bones, which under the influence of friction subsequently become smooth and polished.

Cartilage is found in various parts of the body, and seems to be employed by nature wherever some degree of elasticity combined with strength is required.

Cartilage may be either temporary or permanent. Temporary cartilage is that which is intended afterwards to be converted into bone. In the early stage of fotal life cartilage exists as the sole foundation of the skeleton, bone being in due time deposited in its meshes and substituted for it. Permanent cartilage in particular parts is sometimes absorbed when the horse grows old, and bone is deposited in its place, as, for instance, between the metacarpal bones. Cartilage once absorbed is never reproduced. 
The disease to which cartilage is most subject is inflammation, which is very readily set up in it by concussion, pressure, or contusion; also by extension to it of inflammation existing in subjacent or neighbouring bone. The result is frequently absorption of the cartilaginous tissue, and the deposit of bone in its place. Cartilage may be broken by an accident. In such cases the reunion, when it takes place, will be by means of osseous deposit, not by any new growth of the cartilage itself.

\section{Fibro-cartilage.}

Fibro-cartilage is intermediate in its structure and uses between cartilage and fibrous tissue. It is found in various parts of the body, and consists of both the white and yellow varieties, the latter being of a very elastic nature. It builds up such organs as the external ears, the nose, larynx, \&c.

\section{Inter-articular fibro-cartilage.}

Inter-articular fibro-cartilage consists of pads and white fibro-cartilage placed between the articular surfaces of certain important joints for the purpose of acting as buffers in preventing concussion.

\section{Fibrous tissue-White and Yellow.}

All ligaments, tendons, fascia, and the meshes of areolar tissue are formed of fibrous tissue. It is of two kinds, namely, White and Yellow.

White fibrous tissue is inelastic. It consists of threads placed parallel to each other, and loosely connected together by areolar tissue. The fibres are exceedingly minute, transparent and undulating. According to their arrangements they compose thin layers of membranes, tendons, or ligaments.

In the membranous form white fibrous tissue is seen in periosteum and in the fascia covering the various organs. In the collected form it is seen in tendons. The fibres are collected into small fasciculi, and thence into larger bundles, generally ranged side by side. The fasciculi are held together by areolar tissue. Ligaments are similar in structure to tendons, but mixed with a certain amount of yellow elastic tissue. Capsular ligaments are similar in structure to the above, although their form is somewhat flatter and more extended. Tendons, being composed wholly of white fibrous tissue, are inelastic, but ligaments and capsular ligaments, on account of the admixture of yellow tissue in their structure, possess a certain amount of elasticity.

Yellow fibrous, otherwise called elastic tissue, is composed of still finer threads, which have a tendency to divide transversely, as if made up of cells. It possesses the valuable property of elasticity. It is so elastic that it may be drawn out to double its natural length without losing its power of returning to its original dimensions. It is found in a small quantity in all ligaments, more largely in the ligamentum nuchæ and between the vertebræ, in the middle coat of the arteries, and in all parts in which much power of motion is required. The fascia of the abdomen, 
for instance, which is very elastic in order to allow of any sudden expansion of the part, is principally composed of it.

\section{Areolar tissue.}

Areolar tissue consists of threads of white and yellow tissue woven inextricably together. It is generated in cells, which elongate and join in lines. It is but very slightly vascular, though many blood-vessels pass through it en route to the skin. Its toughness and elasticity are admirably proportioned to the mobility of each part.

Areolar tisue is the most universal of the constituents of the body. Under the name of superficial fascia, it spreads under the skin and ties it down to the deeper parts, and it also forms a nidus for fat. It separates and yet connects muscles and other parts. Hence it is also called conjunctival or connective tissue. As parenchyma, it constitutes the matrix of the most solid organs, and it forms pads for the protection of and smooth capsules for the motion of such organs as the eye.

The spaces or areolæ, of which it consists, communicate freely with each other. Hence it permits the transmission of air as seen in cases of emphysema, or serum as in cases of anasarca, or blood as in ecchymosis, and other fluids also over a great extent of space. Areolar tissue is sometimes called cellular membrane.

\section{Fascia.}

Fascia is a tendinous expansion, and differs from a tendon only in that the fibres in the latter are in a collected form.

\section{Muscle.}

Muscle or Muscular tissue is what is ordinarily called flesh. It constitutes the chief bulk of the soft external parts of the frame.

Muscle is of two kinds, namely Voluntary and Involuntary. The muscles of organic life, such as those of the digestive tract, the trachea, bronchi, bladder, urethra, \&c., belong to the Involuntary class. They are not so red in colour or so large as the voluntary muscles, nor are they attached to bones. They are further distinguished by being " unstriped," that is, they have not the striped appearance which marks the voluntary class. The Voluntary muscles move all those parts which are under the control of the will. They are larger and redder than the involuntary muscles, and present a striped appearance.

Muscles consist of fibres, which are collected into bundles and are connected together by areolar tissue. Each fibre may be divided lengthwise into fibrillæ. Each fibrilla is made up of a number of square or slightly rounded cells arranged like a string of beads. Each fibre is clothed with a fine transparent sheath called myolemma, and it ends abruptly in a tendinous thread. In the Voluntary class the fibres generally run the whole length of the muscle.

Besides the voluntary and involuntary muscles, there is also another 
set, which are partly dependent on the will and partly involuntary, called Mixed muscles. Such are the diaphragm, pharynx and sphincters.

Nerves are abundant in muscular fibres, and so also is the supply of blood. It courses freely through the blood-vessels which lie parallel to the fibres and through their capillaries. The red colour of muscle is due to the blood in it. The growth of muscle is due to increase in the size, but not in the number of the cells of the fibres.

The function of muscle is its power of contractility. Its contractions are the means by which the various parts of the frame are moved on each other. The entire of a muscle does not move at once, but successive portions contract, whilst the other fibres are at rest. The stimulus to contraction is the impression made on a sensitive nerve, the influence of which is conveyed to a motor nerre. Muscles during contraction become harder, shorter and broader, but do not undergo any change in bulk. What they lose in length, they gain in breadth.

Muscles are connected with bones by means of tendons; or in other words the end of each muscle before its insertion becomes tendinous, and this tendinous end is inserted into a bone. The more fixed end of a muscle is called its origin, and the more moveable its insertion.

Under the influence of strong work combined with good feeding and good health muscular tissue increases in size and hardness. In other words the flesh becomes full and hard. With good feeding without work muscular tissue, though it may increase in size, becomes soft and flabby, being in fact much infiltrated with fat. With bad feeding, especially when combined with hard work, muscle loses its development, and becomes wasted and pale, and its power of contraction is greatly diminished.

\section{Adipose tissue or Fat.}

Adipose tissue or Fat consists of a network of very minute cells, in which is enclosed the oily or fatty matter. The walls of these cells, which are composed of areolar tissue, are exceedingly thin. Capillary vessels, from which the fatty matter is secreted, are looped round each cell.

Adipose tissue is found in almost every part of the body. It is mechanically useful in padding exposed parts. Its particles, though they do not move about among themselves, as has often been supposed, yet yield very readily to pressure; and on this account fat when placed as a cushion under any organ is very useful in obviating the effect of pressure on it. It forms for instance a cushion for the eye and for many joints. It lessens the brittleness of .bones, and also assists in retaining the heat within the body. When an animal is underfed, the system appropriates to its own use the fatty material contained in the cells. Hence under such circumstances a fat horse soon becomes thin.

\section{Pigments.}

The coloring matter of the skin, hair, blood, bile or any other constituent of the body is termed its pigment. 


\section{Glands.}

A gland is an organ composed of blood-vessels, nerves and absorbents, and destined for the secretion or alteration of some particular fluid, as for instance the salivary glands secrete saliva, the lachrymal glands tears, and the sebaceous glands oil.

Secretions are divided into two classes, technically termed recrementitious and excrementitious. The former are those, which after being separated and secreted are returned again to the blood for further employment in the animal economy. The latter are those, which are cast off as superfluous and incapable of administering to nutrition, such for instance as the urine, perspiration, \&c.

Glands are infinite in variety as to size, shape and physical appearance. They all have absorbent vessels. When the secretion of a gland is very large, as in the kidneys and liver, its blood-vessels are also very large. All glands secrete from arterial blood, except the liver, which is able to secrete from both venous and arterial blood. The blood in its passage through a gland is retarded by means of the convolutions of the capillaries about the minute ends of its ducts, and hence time is given for the process of secretion.

As the circulation in a gland is increased, so is its secretion. Thus in the first stage of inflammation a gland secretes more, because the circulation is increased; whilst in the latter stages, when the circulation is stagnant, the secretion decreases. Again in health we easily recognise the effect of strong exercise and consequent increased activity of the circulation in the greater secretion poured forth by the perspiratory glands.

The number of very different secretions made by the glands from the blood must excite our wonder and admiration. How different, for instance, are serum, urine, bile, and saliva. Each gland performs its office in a mysterious manner, elaborating principles which exist in a latent state in the blood.

\section{CHAPTER 14.}

\section{THE NERVOUS SYSTEM.}

241. Plan of the nervous system. 242. '1 he Nerves. 243. Functions of the norvous system. 244. Influence of the nervous system in reference to disease. 245. Medicines acting on the nervous system.

\section{Plan of the nervous system.}

According to Bichat the Nervous system may be separated into two great divisions. The first or Cerebro-spinal system includes the brain and spinal cord and the nerves connected with them and their ganglia. This system is chiefly connected with the processes of animal life. 
The second, or Sympathetic, or Ganglionic system consists of a double chain of ganglia, one on each side, placed along the spinal column from the cranium to the coccyx, and connected to each other by nervous cords. Each ganglion is connected not only with the one immediately before and behind it, but also with the cerebro-spinal system by one or two filaments. From these ganglia the nervous filaments are given off, which pass to the thoracic, abdominal, and pelvic viscera. This system is concerned principally with the processes of organic life.

The separation of the nervous system into two divisions is certainly convenient for the purposes of explanation; but the doctrine implied in it, namely, that there are two distinct nervous systems is objected to by many authors. The pneumogastric nerves, for instance, although belonging to the cerebro-spinal system, which presides over the processes of animal life, are yet associated with some important functions of organic life.

The Cerebro-spinal nerves have a white colour, whilst the Sympathetic are yellowish grey. In them the outer layer of white substance is wanting.

A ganglion is an independent nerve-centre, consisting of vesicular nerve matter traversed by tubular and gelatinous nerve fibres, enclosed in a fine membrane of areolur tissue.

\section{The Nerves.}

Each nerve consists of a bundle of nerve fibres enclosed in a sheath. It is connected at one end, called its origin, either to the cerebro-spinal system or to one of the ganglia of the sympathetic system. The other end is distributed to various parts of the body.

The nerve fibres of both the cerebro-spinal and sympathetic systems convey two kinds of impression, namely sensation and motion. The sensitive nerves convey impressions from their further or peripheral extremities to the nervous centres, and from thence to the brain. The motor nerves, on the other hand, transmit impressions from the nervous centres to the parts to which they are distributed, producing muscular action and influencing various functions of the body. There are no characteristic distinctions between sensitive and motor nerves, except that the tubes of the sensitive are smaller than those of the motor.

Nerves of special sense differ from nerves of common sense only in their functions. Irritation of them does not produce pain, but gives rise to various phenomena peculiar to each.

Nearly all nerves except those of special sense consist of both sensitive and motor filaments. They are distinct only at their origin. Afterwards they mingle together. Reflex action is produced by communication of impressions from sensitive to motor fibres. All reflex actions are involuntary.

A motor fibre can only convey motor impulses, a sensitive fibre only sensation, whilst nerves of special sense can only convey impressions which produce peculiar sensations. In certain parts, however, of their course nerves form plexuses and anastomose with each other and inter- 
change fasciculi. By this means each nerve passing off from the plexus has a wider connection with the spinal cord and more extensive sympathies. Again it is by this means that groups of muscles are associated for combined action.

Nerve-centres have the power of originating the sensitive impulses, by which muscles are excited to action and various functions are performed; but few or no motor impulses proceed spontaneously from nerve-centres. Nerve-centres have also the power of transferring the impressions, which reach them through the centripetal nerve fibres, and thereby of diffusing impressions. Nerve force is by some considered to be allied to electricity.

\section{Functions of the Nervous system.}

The functions of the Nervous System are: 1st, Sensation; 2nd, Voluntary motion; 3rd, Co-ordination of motion; 4th, Reflex action; 5th, the motions connected with the processes of nutrition, secretion, \&c.

Stimuli applied to nerves first increase and then depress their excitability. Narcotics have the power of deadening or of entirely destroying the excitability of the nerves. The action of the nerves is also affected by temperature.

\section{Influence of the Nervous system with reference to disease.}

So far as regards the physiology of the nervous system. Beyond this the medical enquirer is almost lost. Very little is really known of the agencies at work in this system. Nervous influence is the most important and yet the most mysterious influence in life. The nerves themselves we can trace. We know that they are given off from or, as others think, run to the brain and spinal cord from all parts of the body. We know that sensation felt at one extremity of the body is transmitted with more than electrical rapidity to the brain, and thence re-transmitted to the point at which the sensation is felt. The point of the nerve affected has no sensibility except as connected with the brain. Nerves are merely conductors of nervous impressions. They have no power of themselves of generating force. They require a stimulus in order to manifest their functions.

Disease of any part is, we know, connected in some way with disturbance of the nervous system of the part. Yet we cannot, we do not know how to treat the real malady; we treat the effect as we best can. Take, for instance, a simple case of accelerated pulse. The acceleration is doubtless due to nervous disturbance. Yet we cannot treat directly the real cause. We may give cooling drinks, reduced diet, \&c., and so we succeed in lowering the tone of the system. Indirectly and in time our remedies, no doubt, affect the nervous system; but directly we are not able, in the present state of knowledge, to touch the real cause. Besides which there is at all times great difficulty in ascertaining the causes which tend to produce a lowered or excited state of the nervous system. 


\section{Medicines acting on the Nervous System.}

Some medicines, we know, affect and depress the nervous system generally, and in certain cases we can give them with advantage; but we know scarcely any which will act specially in depressing the nerves of a particular part or organ.

Other medicines we know excite the nervous system, and in regard to these our knowledge is a little more extended. We know that certain agents excite the nerves of particular parts. Belladonna, for instance, when applied locally, will affect the nerves of the eyes specially and produce dilatation of the pupil. Strychnia acts powerfully on the nerves of motion, and produces spasms of the voluntary muscles. Strychnia is also a special excitant of reflex action.

As regards external agents acting on the superficial sensitive nerves we are not so much in the dark. We can easily excite or depress them in any particular parts. Blisters, for instance, pressure, pain, \&c., all excite the superficial sensitive nervous system ; whilst opium, cold, ether, chloroform, \&c., have a tendency to allay nervous irritation in the part to which they are applied.

\section{CHAPTER 15.}

\section{GOOD NURSING.}

246. Explanation of the term. 247. Loose boxes and quiet. 248. Draughts. 249. Cleanliness, dryness, and sweetness of stable. 250. Warmth of the body. 251. Clothing. 252. Warmbandages. 253. Coldbandages. 254. Sweating bandage. 254a. Fomenting bandage. 255. Fomentations. 256. Cold bathing of the legs. 257. Removal of the shoes. 258. Water. 259. Food. 260. Horses with free discharge from the nostrils. 261. Utensils to be kept clean. 262. Hand-rubbing, \&c. 263. Beds. 264. Change of box and air. 265. Apparatus for applying a strean of cold water. 266. Instruction of servants in nursing.

\section{Explanation of the term.}

Of primary importance in the treatment of disease is "good nursing." By good nursing we mean an intelligent appreciation of and kind prompt attention to the minuter wants and needs, whatever they may be, of the patient. These wants and needs will not only vary in each case, but they will often vary from hour to hour even in the same case.

Care and kindness, however, are not sufficient. All the care and kindness in the world, if through ignorance misdirected or misapplied, will not aid much in the restoration of health. It is impossible to lay down any exact rules for good nursing, but we hope to be able to give some 
general rules, which, when applied according to the circumstances of each particular case, may be useful in the treatment of sick animals.

\section{Loose boxes and quiet.}

In most cases the first and most important point is to place the patient in a detached, cool, well-ventilated, loose box in a quiet situation. The box should be fitted with a low half door, so that the animal may be able to lean his head over it. This is especially needed in all diseases connected with the respiratory passages.

It is essential that the half door should be low, because sick horses generally droop their heads, and are unable to raise them over high "half" doors. If the patient carries his head very low, the door should be opened altogether, and a bar, gate, or hurdle placed across it. But in ordinary cases it is better to keep the lower half of the door closed, in order to prevent draught and chill about the legs.

In affections of the eyes and nervous system the box should be darkened, and as much isolated as possible from passing traffic.

In some few cases, such as those of wounds, when it is necessary that the horse should be tied up to prevent his biting the injured part, or in other cases where motion is not desirable, a stall will answer well enough; though even in these cases the cooler atmosphere of a detached box is preferable.

\section{Draughts.}

Whilst it is essential that there should be ventilation enough to ensure. purity of air in the box, it is also very important in most, but not in all cases, that no direct draught should come on the patient. As a general rule, sick and debilitated animals are far more susceptible of injury from such causes than horses in health.

In the premonitory and early stage of feverish or inflammatory attacks the slightest draught appears to be most injurious and may bring on a fit of shivering. The access or avoidance of an attack in this very early stage is often determined by care and attention on this point.

When, however, inflammation or fever has developed itself, the horse is less sensitive of draught; and provided he is well clothed, air may be admitted with the utmost freedom.

When the crisis has subsided, the patient is again moderately, but not intensely as in the early stage, sensitive of draught. Much at this time. must be left to the discretion of the attendant. If the animal seems refreshed by more air, he may safely be allowed to have it; but if on the other hand his coat begins to stare, we may be sure that the draught is doing harm.

The above observations, it will be seen, refer to draught, not to temperature. In all cases it is desirable that the temperature should be cool, decidedly cool ; but it is not advisable that it should be positively cold.

249. Cleanliness, dryness, and sweetness of stable.

The box must be kept perfectly clean, dry and sweet. For the latter purpose some disinfectant, such as Macdougall's disinfecting powder, may, 
if necessary, be used. The floor of the box should be kept as dry as possible. The practice of washing the floor is very objectionable, both because it makes the stable damp, and because it induces or at least accelerates decomposition in the débris, which always to a certain extent lodges between the interstices of the paving.

If there are underground drains, water should be poured down thein daily, in order to keep them clear.

\section{Warmth of the body.}

The warmth of the body and especially of the legs must be maintained by warm clothing and bandages, increased or diminished according to the weather and the requirements in each case. Horses which are very weak, we may however remark, cannot bear heavy clothing. Neck and breast cloths, though not necessary or even desirable for horses in health, are sometimes needed for sick animals.

Friction may often be beneficially applied for the purpose of restoring warmth, especially in the legs. In some cases irritants, such as turpentine liniment, mustard, \&c., may be required for the above purpose.

\section{Clothing.}

All clothing should be put on loosely. Not only is greater ease given, but more warmth is obtained from loose than tight clothing. The surcingle especially, if used at all, should be slack. Blankets tied loosely in front and under the belly are however preferable to clothing fastened by the surcingle for sick animals, especially in diseases of the lungs and pleuræ, when the parts involved are liable to suffer from or to be impeded in their free action by even the slightest pressure.

If it can be spared, a second set of clothing should be kept in use; but in any case the clothing should be taken off and brushed twice daily. If the state of the patient renders him very sensitive of any chill, only a portion of the clothing should be removed at a time. In many cases, especially during the stage of recovery, the animal appears to be refreshed in a very marked degree by the admission of fresh air to the skin for two or three minutes at a time. Air under such circumstances no doubt acts as a tonic, and its effects may be compared to those of shower bath on the human frame. With a similar view under careful superintendence a damp hay wisp may be run once or twice over the skin morning and evening.

\section{Warm bandages.}

Bandages intended to give warmth are made of flannel, and should be wrapped loosely round the legs. Tight bandages check the feeble circulation, and moreover the caloric passes more easily through them than through looser folds. It is believed also that there is a stratum of warm air between the folds, which is beneficial. With the view of producing or increasing this stratum, a little hay may be placed loosely round the legs before the bandages are applied. 
Bandages should be about three yards long. The bandage should be rolled up before it is applied, and the winding on should be from the lowest part upwards. The bandages should be taken off two or three times a day, or oftener if the legs are cold, and some friction should be applied to restore warmth. When flannel bandages cannot be obtained, a fair substitute may be extemporised out of hay bands.

\section{Cold bandages.}

Cold bandages are usually made of linen, and must be kept constantly wet with water and be applied with moderate pressure. A chamois leather bandage retains damp longer than any other.

Cold may be conveniently applied to the feet by putting them in a wet bran poultice, or by placing wet swabs round them and felt pads in the soles.

\section{Sweating bandage.}

A sweating bandage is made by covering a wet linen bandage with oilskin. After it has been applied for some days, an ordinary cold bandage should be substituted for it, as it is apt to cause the skin to become scurfy. A sweating bandage has often a powerful effect in reducing enlargements.

\section{4a. Fomenting bandage.}

In cases where it is necessary to apply heat and moisture to any part of the leg below the knee or hock, the following is an excellent bandage to apply after ordinary fomentation. A flannel bandage soaked in hot water should be rolled round the limb. A dry bandage may be then applied over all. By this means heat and moisture will be retained for a long time.

\section{Fomentations.}

A steady man should be placed in charge of the patient. This man should be accommodated with a stool.

The fomentation should be continued for half an hour, and then the part affected should be loosely covered with flannels, and after an interval of an hour the fomentation may be re-applied, and so on according to the requirements of the case. The temperature of the water should not exceed $106^{\circ}$, or hardly as hot as the hand can comfortably bear. The temperature must be kept up to this point by the frequent addition of small quantities of hot water. The sponge or swab should not be allowed to touch the parts affected, but should be applied higher up, so that the water only may trickle down over the inflamed or injured surface. When the fomentation is discontinued, the parts should be loosely covered with flannel in order to obviate the risk of a chill. If flannel is not available, or the part is so situated that it cannot be conveniently applied, ammonia liniment in cases where there is no abrasion of the skin, may be lightly rubbed on.

When a servant cannot be spared for the tedious work of fomenting, a 
fair substitute will be found in wrapping the part round with spongiopiline dipped in warm water. This material, which consists of thick woollen stuff covered with oilskin, will long retain both heat and moisture.

The leg below the knee may be conveniently fomented by putting it in a deep bucket of warm water. In all large establishments it is well worth while to get a bucket made half as deep again as usual for this especial purpose. The water in such cases may require to be put in after the horse's leg is in the bucket.

In most cases three or four fomentations in the course of the twentyfour hours are sufficient.

Where large surfaces such as the chest and sides require to be fomented, woollen blankets are used; but care must be taken, that only a portion of the blanket sufficient to cover the part requiring fomentation, be dipped in the hot water. In most stables an old blanket can be torn up for the purpose. During fomentation a thick rug should be thrown over the fomenting cloth, and removed as soon as the operation is over, as it will unavoidably become damp, and a dry rug must be substituted for it.

\section{Cold bathing of the legs.}

Cold water bathing of the legs is in many cases very beneficial. The cold gives tone to and braces up the structures, which may have become weak or deficient in vital energy. The value of cold, as a tonic, has not been, we think, sufficiently appreciated in such cases. A good jet for this purpose may be made by attaching a gutta-percha or rubber tube to the ordinary water-cock. If the necessary appliances are not available an ordinary watering pot with a rose will answer the purpose fairly well.

\section{Removal of the shoes.}

In most cases of serious illness, especially where fever or inflammation are present, ease and comfort will be given to the patient by removal of all the shoes. Exception however occurs, where horses have flat or pumice feet.

\section{Water.}

Water should always be within reach of the patient, especially in feverish or inflammatory attacks; and it is essential that it should be changed at least three times a day, or oftener in warm weather. A piece of rock salt, which the horse may lick as often as he likes, should also be placed in the manger. Some medicines may be conveniently administered along with the water which the patient drinks.

\section{Food.}

Food suitable to the requirements of each case must be supplied. As the appetite of a sick horse is generally very slight and capricious, only small quantities should be offered at a time; and that which is not eaten 
should be removed after having remained a few minutes before the patient. Sick horses often prefer to feed off the ground.

A little grass or a carrot offered by the hand will often be taken, when a larger quantity put in the manger would be rejected. Sick horses very soon become tired of any particular food, and hence it is desirable to change their diet frequently. Cold bran mash, or warm in catarrhal affections, good sweet hay sprinkled with salt and slightly wetted, grass, carrots cut lengthways to avoid the risk of choking, lucern, bruised oats, malt mashes, linseed tea, linseed boiled to a jelly and added to a bran mash, gruel, and skim-milk are each for a time generally palatable. Boiling water poured on slightly brown hay produces a tea, which is much relished by some animals; and in some diseases the steam arising from it, whilst the infusion is being made, acts beneficially in soothing the inflamed mucous membrane of the nose. Locks of hay after being so treated are also occasionally picked out and eaten. After gastric or bilious ferer stale bread given by the hand will often be taken, when everything else is rejected. After a debilitating disease skim-milk is very beneficial.

During the height of fever the appetite is completely lost; and food, even if taken, could not be digested. A liberal supply of water is grateful in such cases, and may be the means of introducing medicines suitable to the case. There is no use in attempting to force food on a sick horse, until he shows some inclination for it. But as the fever subsides and recovery commences, it is a good plan to tempt the appetite by placing locks or small quantities of different kinds of hay in the corners of the box. This will also induce slight exercise and brighten up the patient.

When there is continued positive inability to swallow, some nutriment may be afforded by frequently giving oatmeal clysters in small quantities.

Linseed oil at the rate of about two cunces in the course of the day mixed in the food is often very useful in improving the condition of debilitated animals. The quantity may be gradually increased up to four ounces, if the patient appears to relish it. In cases of emaciation glycerine at the rate of from four to eight ounces may be given daily.

For reasons explained under the head of Forage, paragraph 98, grass, lucern and carrots are preferable to clover or vetches.

\section{Horses with free discharge from the nostrils.}

A horse with a free discharge from the nostrils should as a general rule be fed from a temporary manger or bucket placed near the ground, as the depending position of the head, whilst the animal is feeding, will facilitate the discharge. A wheel-barrow will serve very well as a makeshift for this purpose. But where the patient shows signs of headache, as is often the case, especially in feverish attacks, this position, which would determine more blood to the head, is very undesirable. Steaming the head is very beneficial in catarrhal affections.

When a horse has a discharge of a suspicious character as to its nature, he should be tied up sufficiently to prevent his throwing it about all parts of the walls of the box. 


\section{Utensils to be kept clean.}

Mangers, buckets and all utensils used in a sick stable or box should be kept scrupulously clean. Particular care should be taken that no sour bran mash be left in the corners of the manger. Hay, on which the patient has been breathing, should be thrown away and not offered to him at another time.

\section{Hand-rubbing, etc.}

Gentle hand-rubbing of the skin and also sponging of the nostrils and dock, and in some cases the whole body, with weak vinegar and water are generally refreshing to sick animals.

The sheath should always be carefully cleaned at the outset of any serious illness, and this operation should be repeated if the case is prolonged.

\section{Beds.}

A good bed is essential to comfort. Fresh clean straw certainly looks nicest, and has undoubtedly the advantages of cleanliness and sweetness; but many practical men prefer a bed made of old litter collected from the dung heap, but of course carefully cleaned and dried. It makes a softer, firmer, and more substantial bed; whilst on the other hand the long hard ends of the new straws, especially wheaten, are apt to irritate and annoy a weakly and sensitive patient. In chest diseases, if the horse is very ill, do not fidget him by over care, as to his bed.

\section{Change of box and air.}

Do not move the patient about, if he is very ill; but if his condition admits of his being moved, it is a good plan to shift him occasionally to a fresh box.

Though a box in a quiet situation is needed for a sick horse, yet as he recovers his strength, he should be moved during the day to a situation where he can see some of the traffic which may be passing by. A little such excitement acts as a stimulant and tonic to the system.

\section{Apparatus for applying a stream of cold water.}

A very convenient india-rubber apparatus is made for the purpose of bringing a constant stream or trickling of cold water on any part which may require such treatment, as, for instance, in some cases of sprains, or of affections of the brain. - In cases of sprain of the tendons or ligaments below the knee or hock, the apparatus must be applied above the joint, and the affected part below covered with a wet linen bandage. The water may be allowed to trickle for two hours at a time, twice or three times during the day. If the weather be cold the water may be made slightly tepid. When a force of cold water from a jet or hose is used, the application should never be continued for more than a few minutes at a time. In both cases the part must be afterwards dried and bandaged. 


\section{Instruction of servants in nursing.}

A good groom to be a really good nurse ought to understand the reason of what he does. The kind of nursing proper at one time and applicable to one phase of symptoms may be inappropriate at another time or under altered circumstances.

He should begin by carefully observing the usual appearance and habits of the horse ; for it is only by being familiar with the appearance and tone of the animal in health that any divergence from the normal condition can be ascertained. The earlier variations symptomatic of some coming change, such, for instance, as a slight pawing or a little increase in the respiration, or a heaving of the flanks, or a want of the usual liveliness or tone, may otherwise pass unnoticed.

Next he should be taught what to observe in the symptoms of a sick horse. Especially he should note the temperature and moisture of the mouth, and the degree of variation which it presents from what has been usual in health; also the warmth or otherwise of the legs and body, and whether there is any variation, and if so, at what times. Irregularity of temperature is a marked sign of disease. The respiration must be carefully observed, and whether it is more affected when the animal lies down. The movements of the flanks generally afford the first indication of quickened breathing. The movements of the nostrils must also be noted. The colour and appearance of the visible mucous membranes will need particular observation.

He should also observe, not merely whether the horse is in pain, but how his feelings are expressed. The nature of the cough, if any, should be particularly noted, and also the part from which it proceeds. In catarrhal affections the degree and nature of the running at the nose and the colour and appearance of the membrane of that organ will need frequent observation.

\section{CHAPTER 16.}

\section{INFECIIION AND CON'TAGION.}

267. Prevention of disease. 268. Erroneous ideas as to the causes of accidents and diseases. 269. Of accidents and diseases, with their ordinary causes. 270. On the propagation of disease by infection and contagion. 271. Prevalent ideas of infection and contagion a source of evil. 272. Diseases seldom transmitted by infection or contagion. 273. Mode of propagation by infection and contagion. 274. Distinction between inoculation, contagion, and infection. 275. Distance at which infectious diseases can be communicated. 276. Sequels of disease. 277. Disinfectants. 278. Ventilation. 279. Sick boxes. 


\section{Prevention of disease.}

As regards successful stable management, the prevention of disease is far more important than its cure.

$N^{\prime}$ o disease occurs without a cause. As a general rule the cause of any disease may be found out; and if ascertained, the disease may in most cases be prevented in future.

It is not possible, however, to prevent the causes of every disease. The climate in which we live, and the nature of the work which we require from horses, oblige us to run some risks; but in every case the risk ought to be reduced to a minimum.

Suppose, for instance, a dog-cart and horse are sent on a cold wet winter's day to a railway station to meet a train. The horse may probably get somewhat hot in the drive over, the train may be late, and waiting at the railway station on such a day is not favorable to the animal's health.

But the risk of injury will be much diminished if the servant has started in good time and driven over slowly; if he has not forgotten to take with him a rug to put on the horse, in case he is kept waiting; or if, when circumstances admit of it, he has kept the horse moving about instead of standing still.

Again, accidents will occur-in the hunting field for example. The nature of the work entails such a liability. But they will be much less likely to occur when the horse is in good working condition of wind and limb, when he is fit to go without being unduly fresh or above himself, when the shoeing, \&c., are good, than when these favorable conditions are reversed.

\section{Erroneous ideas as to the causes of accidents and diseases.}

It is a very common, but very erroneous and mischievous idea, that accidents and diseases spring up spontaneously, that they are necessary black spots in the chapter of life, and that we are powerless to avoid them or to prevent their recurrence. So far from this being the case, almost all accidents and diseases may, if sufficient diligence and perseverance are used in the search, be traced to ascertainable causes; and in the great majority of cases the causes once ascertained may be guarded against and prevented in future.

\section{Of accidents and diseases with their ordinary causes.}

The subjoined list, in whick are grouped together most of the more common diseases and accidents with their ordinary causes, will perhaps make plainer the assertion put forward in the preceding paragraph.

1st. Diseases of the bowels and urinary organs, such as stomach staggers, colic, inflammation of the intestines and kidneys.-Ordinary causes. Bad forage or improper watering and feeding.

2nd. Diseases of the chest, coughs, colds, etc.-Causes. Want of ventilation, overcrowding, exposure, and neglect. 
3rd. Glanders and Farcy are different forms of the same disease. In common with man's other specific disease it is impossible to assign its origin. It is highly contagious. (See Chapter 29.)

4 th. Epizootics, such as influenza and low fever.-Causes. Diseases of this class are generally admitted to be of a specific, contagious, or infectious character, and are popularly supposed to be in a great measure influenced by atmospheric peculiarities, but the precise nature of this is not well understood. This much, however, is certain, that whilst epizootics run almost periodically and with great severity through badly ventilated, ill drained, dirty, badly regulated stables, they seldom seriously affect those where proper sanitary arrangements are enforced and where the stable management is good.

5 th. Diseases of the eyes.-Common ophthalmia generally arises from accidents. Occasionally it is due to an extension to the eye of inflammation already existing in the mucous membrane of the nose. True, or as it is usually termed, Specific ophthalmia arises from constitutional causes, for a detail of which the reader is referred to Chapter 57, on the Eye; and sometimes from hereditary predisposition.

6th. Diseases of the skin, such as mange and ringworm, are generally connected with bad grooming or bad forage, and sometimes with the use of barley straw for bedding. Some skin diseases are occasionally propagated by contagion.

7 th. Cracked heels and grease and canker nearly invariably proceed from neglect or bad management. No doubt certain horses are more predisposed than others to such affections; but these diseases, we believe, will never appear where the stable management is really good. Thrush also is usually a disease of neglect.

8th. Diseases of the feet, such as corns, sandcrack and quittor.-Causes. Bad shoeing and neglect.

9th. Sore backs and broken knees.-Causes. Bad saddling and bad riding, and also as regards broken knees, bad shoeing, defective action and accidents.

10th. Bites, kicks and wounds.-Causes. Carelessness of servants and bad stable gear.

11th. Sprains and diseases of joints.-Causes. Severe work or work for which the animal is physically unfit, or for which he has been insufficiently prepared; and also accidents.

12th. Strangles.-Strangles is a specific disease. At some time or other it appears in most horses; but its development at any particular time appears to be dependent in some cases on atmosphere changes.

13th. Accidents. - Causes may, as a general rule, be summed up under the heads of carelessness and bad management. Some few accidents, however, are confessedly unavoidable.

14th. Laminitis, Weed and some other diseases, though local in their development, usually proceed from constitutional disturbance. Overfeeding and want of exercise in some cases, and the reverse conditions, such as over-severity of work and bad feeding in other cases, are the common causes of the derangement of the general health. 
From this enumeration it will be seen that diseases and accidents mostly proceed from preventable causes. Whenever, therefore, any disease or accident occurs, the causes should be promptly and diligently sought out; and no owner of horses should rest satisfied until he has found it out and has taken measures to prevent it in future.

\section{On the propagation of disease by infection and contagion.}

When a particular disease runs through a stable, it does not by any means follow that it has been introduced or spread by infection or contagion. On the contrary, faulty stable accommodation, or bad ventilation, or bad drainage, or neglect on the part of servants and such-like causes, either collectively or sometimes even singly, are often sufficient to develop wide-spread disease among all the animals subject to the same cause or causes.

When a disease breaks out suddenly in a stable and several animals are attacked at once, it usually depends on their all being subjected to the same noxious influence. In a word, similar causes produce similar effects. The causes, whatever they may be, usually affect first those animals which are weak and predisposed to disease of any sort, afterwards those which are less predisposed, and ultimately may affect all in the stable. The disease is then said to be, and is by many believed to be, infectious or contagious.

The earlier cases in any such attack do not in general arise either from infection or contagion. It must, however, be borne in mind that the vitiated atmosphere produced by the exhalations and secretions of a number of diseased bodies congregated in a badly-ventilated place intensify the original cause and lead to the further reproduction of the disease. The mode of such reproduction will be explained hereafter.

\section{Prevalent ideas of infection and contagion a source of evil.}

The prevalent ideas regarding infection and contagion, though under certain circumstances true, are nevertheless the source of much mischief ; because these agents are often accepted as the adequate and irresistible cause of disease, and therefore no due or sufficiently diligent search is made for the real and active source.

\section{Diseases seldom transmitted by infection or contagion.}

Very few cases of disease either in man or animals are under good sanitary arrangements transmitted by infection or contagion. Certain predisposing conditions are required to enable the poison, whatever it may be, to take effect. It requires, for instance, a certain proximity of the patient, a confined unchanged atmosphere, and as a general rule a delicate, ailing, or otherwise susceptible patient. If these conditions are wanting, diseases seldom spread from one animal to another under ordinary circumstances.

Many complaints, however, which in a clean, well-aired, and welldrained and not over-crowded stable are quite unable to propagate them- 
selves, become infectious or contagious under less favorable circumstances. The emanations from the sick hang thick and noisome in a close, foul, unchanged atmosphere, and by concentration and ferment acquire a positive power of disturbing health and reproducing disease.

\section{Mode of propagation by infection or contagion.}

We have already stated our belief, that the ordinary cause of a disease running through a stable is simply that the same cause, whether it be miasma arising from bad drainage, or foul air arising from want of ventilation or from want of cleanliness or over-crowding, or low sanitary condition arising from bad or insufficient food, or debility caused by overwork or by neglect or any other such-like cause, affects all the animals placed under the same conditions.

We do not, however, deny that diseases under circumstances favorable to their propagation may be communicated by sick to healthy animals, independently of the original cause of the disease. For instance a glandered horse, bought we will suppose at a distant fair and placed among healthy animals, may communicate the disease to them. Water as a vehicle for the carriage of contagion has been hitherto somewhat overlooked. Public water-troughs need the most scrupulous cleaning by the sanitary authorities, or they may become very serious sources for the spread of contagious diseases. With fair care, however, there need be no fear. Public water-troughs are a great public convenience, but they ought to be in the hands of responsible authorities and not in those of an irresponsible association.

The mode in which the propagation of disease occurs is believed to be as follows. In certain diseases there are given off from the patient's body, in his breath, in his perspirations and other secretions, minute but invisible particles or microbes. Although not sufficiently tangible to be examined even by the microscope or to be subjected to analysis by the chemist, yet it is tolerably well ascertained that these particles, which form the matter of infection and contagion, contain, like many other animal products, the four organic elements of carbon, hydrogen, oxygen and nitrogen. In common with such bodies they possess under certain circumstances the power of ferment, and, like the yeast plant, have under favorable conditions remarkable powers of reproduction.

When a sufficient particle of the matter of contagion is either through the lungs or through the skin or otherwise absorbed into a healthy body, it may under circumstances favorable to its development ferment and reproduce itself. This process may occupy, according to the nature of the poison, a few days or several weeks, at the end of which time symptoms of the disease appear.

Each infectious or contagious disease gives rise to a ferment peculiar to itself, which in due time develops symptoms similar to those of the original disease. 


\section{Distinction between inoculation, contagion and infection.}

To ensure the transmission of some diseases a tangible portion of the poisonous matter from a diseased animal requires to be placed on a mucous membrane underneath the skin, or on a fresh wound, or on some delicate absorbing surface.

This is what is called Inoculation. In this way, for instance, smallpox may be produced in the human subject, or glanders and farcy in horses and men. Under circumstances favorable to its development a very small portion of matter is sufficient to reproduce the original disease.

Contagion is but a variety, as it were, of inoculation. In either case the poison is transferred from the sick to the sound. In the case of inoculation the passage of the matter is patent and obvious; whilst in diseases termed contagious it is sufficient that two animals should come in contact. The particles of matter, which pass from one to the other, may be intangible and invisible. The fact that the matter has so passed, though not demonstrable to the eye, is yet proved by the result.

Infection is a term used to denote the spread of a disease by particles of matter floating in the air and absorbed into the system without actual contact of the sick with the healthy animal.

No broad line or distinction can be drawn between inoculation, contagion, and infection. They glide insensibly one into the other. The difference is one of degree, not of kind; for in all cases the poisonous matter is carried from the diseased to the sound animal.

Infection, it will be observed, implies a greater degree of communicability than contagion; and similarly this latter than inoculation.

Many diseases which, under circumstances favorable to health, such as good ventilation, cleanliness and good condition, can only be reproduced by positive inoculation, may under less favorable circumstances be communicated by contagion; and under still less favorable circumstances by infection. On the other hand, diseases which are in their nature highly infectious, often become innocuous and unable to reproduce themselves under good sanitary arrangements.

\section{Distance at which infectious diseases can be communicated.}

The question is often asked, to what distance does the power of infection extend. It is not easy to give a definite answer to this question. The emanations, whether proceeding from the poisonous miasma which originally generated the disease, or from the exhalations or excretions of the bodies of the diseased animals, float through the air much in the same way as the invisible scent of flowers. These emanations may be conveyed a considerable distance in a concentrated and undiluted form under circumstances favorable to their transmission. But, as a general rule, just as scent, when separated from the body which gives it off, soon loses its power, so these morbid emanations in general speedily lose their active qualities and power of evil. A few yards of space, if in a thorough draught, is usually sufficient to ensure such a dilution of the poison as 
will render it innocuous. Fresh air plentifully and frequently renewed is the great antidote to all such poison. It cannot bear dilution without being disarmed of its power and rendered harmless.

As, however, in the case of different scents, some of which after separation retain their powers much longer than others-the fox, for instance, can be traced by the hounds for a considerable time after he has passed, even though a high wind be blowing - so it is probable that the emanations given off by the bodies of animals in certain diseases possess greater stability than others.

\section{Sequels of disease.}

When an animal has suffered from any disease which has greatly lowered the system, it not infrequently happens that he becomes secondarily affected with some other disease of a still lower type. Thus, for instance, glanders or farcy often supervene on an attack of diabetes, and carry off the patient.

Again, when an animal without any positive disease becomes very debilitated, he will very readily take on some disease of a low type, such as low fever, purpura hæmorrhagica, glanders or farcy; and the result is often fatal.

Such cases, it will be readily seen, are not really brought about by infection or contagion, but are simply malignant diseases induced by a low state of the system. When several horses at one time or about the same time are affected in any of these ways, the real cause will probably be found in bad stable management.

\section{Disinfectants and Deodorizers.}

The particles of contagious or infectious matter, like other organic ferments, are very unstable in their composition and are easily acted on by various chemical agents. Such agents are called Disinfectants. They act either by poisoning or killing the ferment; or by abstracting the hydrogen from noxious gases and vapours, they break them up. Chlorine gas, carbonic acid, and many other compounds are commonly used for these purposes. A fuller account of these agents is given towards the end of the next Chapter, on the Action and Uses of Medicines.

Disinfectants, however, and deodorizers, whose action is somewhat similar, though very valuable assistants, should never be allowed to take the place of free ventilation. It is true that they have, as explained above, a very beneficial effect in killing or breaking up the poisonous particles; but they are not sufficient thoroughly to purify the air. Free ventilation, or in other words a real and actual change of air, whether in the stable or in the sick chamber, is absolutely necessary.

It is a well ascertained fact that in hospitals, where much reliance has been placed on the use of disinfectants, disease has often spread with greater rapidity and virulence than in buildings where no such agents have been used, and where in consequence thorough ventilation has been more carefully attended to. Disinfectants and deodorizers are useful auxiliaries, but they must never be regarded as substitutes for ventilation. 
Disinfectants and deodorizers should not be allowed in stables. They are false friends. They are to destroy noxious smells, but they do not touch the source of the foul air, which is rising from inside, or outside, or neighbourhood of the stable.

\section{Ventilation.}

Wherever a number of sick animals are collected under one roof, especial and extraordinary care is needed to prevent the air becoming contaminated. The fetid breath and unhealthy secretions and evacuations of diseased animals require a very large supply of air, in addition to the free use of disinfectants, to dilute and counteract their injurious tendencies.

On the other hand, whenever by imperfect ventilation or over-crowding, by want of cleanliness or by bad drainage, these emanations are allowed to accumulate, concentrate, and ferment, they operate most injuriously not only on the sick animals, but also on healthy horses standing within reach of the poisonous miasma.

Whilst the Author expresses these views with great confidence as regards horses in good health, it must be remembered that all animals, when their systems are from any cause lowered, are prone to take on disease of any kind, especially of that kind, whatever it may be, which is prevalent at the time.

\section{Sick boxes.}

It is never desirable to congregate a number of sick animals under one roof, for reasons which from previous explanations will be at once apparent to the reader.

The door of each box intended for a sick horse should open directly into the air, and the party walls should be carried up completely to the roof, so that no communication may exist between it and the next box.

Sick boxes should be constructed with a view to thorough and easy ventilation. They need more ventilation than might at first sight seem to be required. The system of ventilation and construction recommended for stables in Chapter 1 will be found to answer well.

All boxes used by sick horses should be frequently whitewashed, and every possible means should be adopted to keep them thoroughly clean. But when a box has been occupied by a horse affected with any malignant disease, it is not sufficient to whitewash it. The walls ought to be thoroughly scraped, and then with the paving should be washed with chloride of lime, after which ordinary whitewash may be used.

If the paving is at all defective, and there is reason to think that there has been any soakage of urine or other débris through it into the soil, it should be taken up, and the soil covered with quick lime before it is relaid. The wood work, mangers, and racks should also be washed with soap and water and repainted. Similar precautions should be taken in regard to the buckets and other utensils.

It is well known that, in the wards of hospitals which have been many 
years in use, the walls, unless plastered with non-absorbing cement, often become impregnated with deadly matter; and, under the influence of the emanations given off from them, patients, who might under better sanitary arrangements have recovered, sicken and die. In such cases it has been found necessary to remove the whole of the plaster, to scrape the walls, to remove and renew the whole of the wood work, and to take out all the windows and expose the whole building for a length of time to the purifying influence of the air.

Sick boxes seldom require these extreme measures, because as soon as it is ascertained that a horse is affected with a malignant disease, it is usual to destroy him.

\section{CHAPTER 17.}

\section{ACTION AND USES OF MEDICINES.}

280. Object with which medicine is given. 281. Classification of medicines. 282. Mode in which medicines produce their effect. 283. Purgatives. 284. Horses difficult to affect with purgative medicine. 285. Super-purgation. 286. Purgatives not to be given to a weak horse. 287. Aloes. 288. Aloes in solution. 289. Linseed oil. 289a. Croton farina. 289b. Croton oil. 290. Saline subtances. 291. Clysters or enemata. 292. Diuretics. 293. Diaphoretics. 294. Depressants. 295. Bleeding. 296. Sedatives. 297. Aconite. 298. Digitalis, tartar emetic, hydrocyanic acid, and belladonna. 299. Nauseants. 300. Stimulants and diffusible stimulants. 301. Narcotics. 302. Antispasmodics 303. Anæsthetics. 303a. Chloroform. 304. Tonics, mineral and vegetable. 305. Blisters. 306. Caustics or Escharotics. 307. Astringents. 308. Demulcents. 309. External dressings. 310. Digestive ointment. 311. Diluents. 312. Emollients. 313. Poultices. 314. Fomentations. 315. Spongiopiline. 316. Cold applications. 317. Cooling drinks. 318. Cooling lotions. 319. Alterative balls. 320. Febrifuges. 322. Fever or Cough balls. 323. Disinfectants and Deodorizers. 324. Antiseptics. 325. Mode of delivering a ball. 326. Mode of giving a drench.

280. Object with which medicine is given.

The object with which Medicine is given is to produce an altered-it may be an increased or it may be a diminished-action of some organ of the body or of the system generally.

\section{Classification of medicines.}

Medicines may be roughly classed under the following heads, namely, 1st. Evacuants, which increase the secretions from the bowels, skin, 
or kidneys. They are respectively termed purgatives, diaphoretics, and diuretics.

2nd. Depressants, including sedatives and nauseants, which lower the action of the heart and nervous system.

3rd. Stimulants, which rouse and excite the action of the heart and nervous system.

4th. Narcotics, which exert a primary stimulant, and secondary, but more permanent, sedative effect.

5th. Tonics, which impart tone and vigour to the system.

The above medicines act on the system generally. The following exert chiefly a topical action.

6th. Blisters, which cause irritation of the skin.

7th. Caustics, which decompose solid tissues and fluids.

8th. Astringents, which constringe muscular fibre, repress undue granulations, and cause contraction and condensation in the part to which they are applied. In more familiar language, they dry up sores and induce the formation of a scab.

9th. Demulcents, which act locally by protecting, so far as they reach in an undiluted form, the lining of interior parts.

10th. External dressings, which in cases of abrasions of the skin, wounds, sores, \&c., are useful in protecting exterior parts from the irritating effect of the air and from flies, \&c.

11th. Emollients, which soften and relax the tissues and thereby lessen pain, and allow the blood congested in the part to flow away more easily.

12th. Cold applications, which constringe the structures, abstract heat, and moderate inflammatory action.

\section{Mode in which medicines produce their effects.}

Most medicines which are taken internally are absorbed into the blood and circulation generally. But though absorbed, they do not seem to be assimilated with it or with the structures of the body. On the contrary, they are speedily ejected from the blood by their appropriate excretory organs. This is especially the case with the large class of medicines included under the comprehensive title of evacuants. They seem to produce their principal effect during the process of ejection,- the organ through which they are excreted being excited to increased action.

Medicines, however, do not produce the same effects in all states of the system. Their effects, even if not positively determined, are often much modified by any morbid changes which may have taken place. Some medicines, indeed, are completely changed when introduced into the system. Alkalies, for instance, are neutralised when they meet with the acid of the gastric juice.

Again, most medicines which produce an effect on the skin, act also in a certain degree on the stomach, intestines, or kidneys, because they are more or less absorbed into the system, especially if applied in large quantities. 
Some medicines are believed to produce their effects by acting on the nerves of the part which absorbs or excretes them.

Though we can explain in some degree how medicines produce their effects, yet we cannot explain why particular medicines affect particular organs-why, for instance, aloes acts on the intestines and resin on the kidneys. It is only by continued observations and experiments that these effects have been ascertained to be facts. In applying medicine to the treatment of disease we endeavour to utilise our knowledge of facts, though we cannot always explain the reason of them.

\section{Purgatives.}

Some purgatives seem to act generally on the intestinal canal. The effects of others are confined to the large intestines, but the great majority produce their effect on the small intestines.

Though the immediate action of purgatives consists in causing evacuation of the contents of the intestines, they also produce an effect on other organs; because the intestines when excited to increased action draw off secretions from all parts. Thus a dose of purgative medicine will often reduce swelled legs, because the increased action of the intestines drains off the watery parts of the blood from other portions of the system. Again, they often are useful in carrying off those noxious matters which, from impaired secretion during disease, are apt to accumulate in the blood, and tend, if not removed, to keep up fever and inflammation.

Although the active operation cf purgatives is only temporary, yet their results are often permanent. By their action the intestines are relieved from undigested materials or accumulated fæces, the blood is freed from impurities, and the liver and other excretory organs are roused to healthy action.

Before purgative medicine can be safely given, it is absolutely necessary that the horse should be well "prepared for physic," that is, deprived for at least thirty-six, and if possible forty-eight, hours of all food except cold bran mashes, which are in themselves laxative and tend to assist the action of the medicine. Physic does not take any effect until it is brought into contact with the mucous linings. If the stomach and intestines are full, the purgative may never reach those linings. It may pass through with a mass of food, and its properties may not be extracted, or it may act violently in a mass on the part of the lining which it reaches. On the other hand, when the stomach and intestines are somewhat empty, the medicine is diffused over a large tract of mucous surface, and acts more speedily and more safely.

After the administration of the medicine the patient should be freely supplied with tepid water. If, however, he refuses tepid water, he may be allowed water from which the chill has been removed by allowing it to stand for a few hours in a warm room or kitchen. The diet must be restricted to sloppy warm bran mashes. A little walking exercise or a 
very gentle trot for a few minutes will sometimes also be needed to cause the medicine to operate. With a similar view an enema may be given.

Six or seven evacuations are quite sufficient, though grooms generally like to see a dozen.

So far as the action of the purgative is concerned, a horse moderately purged may generally be put to work in about three days after the physic has ceased to operate, or "set" as it is technically termed.

A dose of physic is very apt to carry off a weakly patient from over. effect; but in some cases of fever attended with great debility it may remain inoperative from want of tone in the system. Balls, which have been given several days previous, are sometimes found whole in the intestines after death.

Some purgatives do not act directly on the intestines, but produce their effects indirectly by exciting organs in connection with them, such as the liver and glandular structures.

The administration of purgatives is always attended with some danger, and therefore it is desirable to use the smallest quantity which will procure the required effect.

\section{Horses difficult to affect with purgative medicine.}

If it be found difficult to move the bowels of any particular horse with medicine, it is a good plan, in addition to the usual preparation, to put him on linseed meal and bran mashes for a further twenty-four hours before the administration of the dose. If in the end the physic does not act, the stinting of the food will probably have done nearly as much good as the medicine would have done. It is a dangerous mistake to give a second dose of aloes at an interval of less than ten days, or to suppose that the medicine will do harm by remaining in the system, if it does not pass off visibly. Its effect is in reality simply negative. In many cases, however, the medicine is passed off by the kidneys.

\section{Super-purgation.}

If the purging continues over long, and wheaten flour mixed with the water fails to stop it, some rice-water gruel, made rather thick, may be given frequently and in small quantities at a time, and also hay and a little bruised corn mixed with dry bran. The patient should be kept very quiet and warm. His legs should be wrapped in flannel bandages, and his body, especially the belly, kept warm with clothing. Astringent and nutritive enemata are often recommended in such cases, but their utility is very doubtful.

\section{Purgatives not to be given to a weak horse.}

Purgatives rapidly reduce the strength-partly by causing the food to pass more quickly through the intestines and thereby giving less time for the absorption of its nutritious parts, partly by the increased secre- 
tions they draw from the system, and partly by the nervous prostration they induce.

Purgatives, therefore, should not be given to a horse in a weak state, because he cannot bear further weakening; nor, except in very reduced quantities and with the greatest caution, in diseases of the lungs or airpassages. In these cases the animal is always weak on account of the blood not being properly purified in the lungs. And, again, on account of the active sympathy existing between the mucous lining of the airpassages and that of the alimentary canal, there is always reason to fear that the inflammation already established in the one may extend to the other. Under such circumstances physic is very likely to cause superpurgation.

\section{Aloes.}

Aloes is by far the best and safest purgative. Cape and East India arc inferior to Barbadoes, chiefly on account of the greater proportion of resinous matter they contain. Aloes is usually and most conveniently given in the solid form as a ball. Four or five drachms are a sufficient dose for most horses, if properly prepared; but large heavy horses may perhaps require five or six. It usually operates in about twenty-four hours.

The following prescriptions for an Aloetic mass are recommended in preference to those made up with oils or other fats :

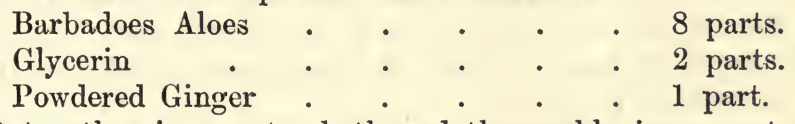

Melt together in a water bath and thoroughly incorporate. Dose from 6 to 8 drachms.

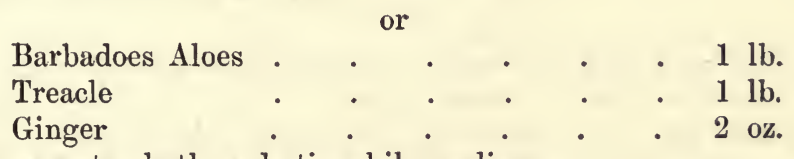

Melt in a water bath and stir while cooling.

Dose from 8 to 12 drachms.

In cases where the use of ginger is considered objectionable, the same quantity of powdered gentian may be substituted. The action of the medicine will be slightly increased.

Aloetic medicine should not be made up in balls until required for use, but should be kept in a mass in a glass-stoppered bottle. When divided into small portions, as in balls, it soon becomes dry and hard, and is then uncertain in its effects. A single ball can be made up by reducing the aloes ( 4 or 5 drachms) to powder in a mortar, and adding 2 drachms of ginger with sufficient treacle to form a soft mass. The ball must then be wrapped in soft paper. 


\section{Aloes in solution.}

Aloes in the solid form contains a resinous principle, and hence is sometimes excreted by the kidneys. In making the solution the resinous matter rises to the top, and may easily be skimmed off. Hence the solution becomes a purer medicine, and may preferably be given in some cases, where the admixture of resin contained in the solid form would be injurious. Its action is also quicker.

The solution is made by dissolving four or five drachms of aloes in a pint of hot water, with two drachms of powdered ginger and an ounce of aromatic spirits of ammonia; or half the above quantity may be dissolved, and half a pint of linseed oil added with two drachms of powdered ginger. The drench should be well shaken before being given.

Practically, however, there is always an objection to giving drenches to the horse when it can be avoided, because an uncertain proportion of the medicine is usually spilt and lost in the administration.

The action of Aloes, whether in the solid or liquid form, may be increased by combining it with gentian. Thus in lieu of five drachms, four drachms of aloes may be given with two drachms of tincture of gentian.

\section{Linseed oil.}

Linseed oil taken internally is a purgative. It is less certain, as a general rule, in its action than aloes; but is preferred in some cases, because it produces less irritation of the intestinal linings than aloes. The dose is from 10 to $30 \mathrm{oz}$.

\section{9a. Croton Farina.}

Croton Farina is a very powerful, but dangerous purgative, and is only given in extreme cases of constipation. It acts rapidly, and causes watery evacuation. It is difficult to stop the purgation induced. It sometimes causes inflammation of the intestines. The dose is from 20 to 30 grains.

\section{9b. Croton oil.}

Croton oil is sometimes administered in cases of obstinate constipation dependent on some functional derangements of the nervous system.

The oil may be given in doses of 15 to 25 minims, either mixed with linseed meal into a bolus, or with olive or linseed oil in a draught. In cases where neither ball nor draught can be given, it may be placed upon the tongue.

Like Croton Farina, this oil is a powerful and dangerous purgative, and should only be administered in extreme cases. 


\section{Saline substances.}

Saline substances, such as Sulphate of Magnesia or Epsom Salts, are also used as purgatives. In addition to their purgative properties, they seem to alter the condition of the blood and to diminish its tendency to coagulation in certain diseases. Hence in fevers they are often administered with benefit; but as a general rule they are neither so safe nor so certain in their action as aloes.

\section{Clysters or Enemata.}

Clysters, otherwise called Enemata, soften and loosen the hardened fæces, and also by mechanically distending the lower gut cause it to evacuate its contents. The excitement of the lower intestines sometimes extends forwards and rouses the small intestines to action. The water should be of the temperature of new milk. The quantity of water thrown up at one time should not exceed quarts. No violence should be used in forcing it up. Whether the instruments used are the ordinary syringe, patent pump, common bladder, or leather bag and funnel pipe, the fluid should invariably be injected gently and gradually. The object of an enema is not to wash out the patient's inside, but simply to rouse the powers of nature to evacuation. Purgative enemata usually consist of warm water only, but if a more stimulating effect is desired, common salt, oil, or solution of aloes or soap may be added. Retention for a few minutes should be ensured by keeping the tail down. A second enema after an interval of half an hour is generally beneficial.

Nutritive enemata, consisting of gruel or rice water, are beneficial in cases where the patient is unable or unwilling to take food by the mouth. They should not exceed a quart in quantity. If larger, they will probably be ejected.

Astringent enemata, made of two drachms each of catechu and opium, or a quart of starch in a gallon of water, are said to be useful in checking diarrhœa.

Sedative enemata are made by adding about two ounces of tincture of opium to the water. They are said to be useful in allaying spasms in the intestines. Their utility is, however, extremely doubtful. Gaseous enemata, consisting of tobacco smoke, are also used for a similar purpose.

Enemata consisting of two ounces of oil of turpentine, diluted with a pint of olive oil, are recommended by some Veterinarians for the purpose of killing worms in the large intestines.

\section{Diuretics.}

Diuretics are medicines which act on the kidneys and cause increased secretion of urine. Like purgatives, they are absorbed in the blood, but not being assimilated, are ejected from it and excreted through the kidneys. During excretion they cause irritation, and hence produce increased secretion. The body should be kept cool during the period of 
their administration. Though the bowels cannot always be acted on, the kidneys are very easily affected.

The diuretics in common use are resin, turpentine, etherous substances, and small doses of nitrate or acetate of potash or other saline matters. The latter, however, if given in large quantities, are excreted by the bowels.

Diuretics, though acting locally on the kidneys, affect the whole system, because the secretions which they induce are drawn from the system generally, as explained under the head of purgatives. Hence they are given in fevers with the view of removing from the blood those deleterious matters which in such cases always accumulate in the system from suspension of the secretory powers. They are also employed to remove from the body excess of fluids or "humours," as they are popularly called, as in cases of swelled legs.

The kidneys themselves are rarely affected primarily. Affections of the urine generally arise from derangement of the digestive organs. If the kidneys get into a chronic state of torpidity the cause will probably be found in want of tone of the system. The true remedy in all such cases lies in good feeding, air, exercise, and proper attention to stable duties rather than in the administration of diuretics.

Diuretic balls are generally made of two drachms each of resin and nitre with one drachm of Venice turpentine, mixed in a mass with soft soap and linseed meal.

\section{Diaphoretics.}

The skin is the channel through which the system excretes a large, though variable, amount of refuse fluid matters, holding in solution various salts and effete organic matters. It has been estimated that as large an amount of matter is passed off through the skin of a horse in high condition and active exercise as by all the other excretory organs. Hence exercise, occasionally at least sufficient to produce a good sweat, is essential to health.

During those diseases in which the functions of the kidneys, lungs, or bowels are more or less disturbed, and when exercise cannot be taken, it is often of great importance to maintain, and if possible increase, the action of the skin, in order to prevent the blood from being poisoned by the accumulation of deleterious matters in it.

Diaphoretics are medicines used to increase the action of the skin by stimulating the cutaneous glands and vessels. They answer well and are frequently used in the human subject; but in the horse, partly on account of the hair with which the skin is covered, and partly on account of the tendency of the medicine to be passed off by the kidneys and bowels, they are not available. The best practical method of causing diaphoresis in the horse is to administer diluents in large quantities, then to apply friction over the body, and to keep the animal well covered with double clothing in a warm atmosphere. A Turkish bath, if available, but this is rarely the case, will produce the desired effect. 


\section{Depressants,}

Depressants proper are those agents which, such as bloodletting, depress the nerve force and system generally. Under the general head of Depressants, however, it is usual to include also Sedatives, which abate the nervous force without causing such positive general depression, and Nauseants, which, as the name expresses, lower the tone of the system by producing nausea.

It will readily be seen that, though a broad distinction may be drawn, yet no sharply defined line divides these agents.

\section{Bleeding.}

Bleeding was some years ago considered to be amongst the most powerful and certain of the depressants, and was much employed by the older practitioners. That it does act as a depressant is beyond doubt, but such action mainly depends upon the weakening effects produced by the sudden reduction of the quantity of blood in the circulation. The idea that bleeding lessens the action of the heart is erroneous, because during the act of bloodletting the heart beats are increased in frequency, but the contractile force of its walls is weakened. Consequently the pulse, although quickened, loses any vibratory hardness it may have, and becomes softer in character.

When it is thought necessary to employ it, blood enough should be taken to produce a marked alteration in the character of the pulse. The blood should be drawn in a full stream, so as to produce the effect as quickly as possible. If bleeding is resorted to at all, it should be in the very early stage of disease, before the strength fails.

Bleeding, however, is not a safe remedy. As a general rule it should be avoided; and if there is any doubt as to its advisability, it is always safer not to bleed. Far more horses are killed than saved by this remedy.

Bleeding is always injurious when the pulse is quick and weak. The prevalent idea that a quick pulse necessarily indicates the presence of inflammation, is wholly erroneous. Such a pulse far more often results from a weak and perverted state of the system, which bleeding will seriously, if not fatally aggravate. Bleeding is especially injurious in the later stages of diseases of the lungs and air-passages, because in them the patient is always weak on account of the blood not being properly purified in the lungs.

\section{Sedatives.}

The term Sedatives is applied to those depressants which abate the nervous force without causing positive general depression. Sedatives may be divided into two classes, namely, those which possess a general, and those which have only a local action. Aconite, which acts by lowering the action of the heart, is an example of the first; whilst warm water, which assuages local pain, may be taken as a type of the latter. 


\section{Aconite.}

Aconite is a prompt and effectual sedative in febrile attacks and in acute inflammation. It moderates and lessens the action of the heart, and hence reduces the quantity of blood which passes in a given time to any part. It has the advantage of not reducing the strength like loss of blood. In a large dose it is highly poisonous; but the tincture may be safely given in doses of from ten to twenty drops frequently until the pulse is relieved.

\section{Digitalis, tartar emetic, hydrocyanic acid, and belladonna.}

Digitalis operates in much the same way as aconite, but is neither so safe nor so certain. In large doses it causes intermittent pulse, and in excess may produce coma and even death. It is apt to accumulate in the system, and symptoms of poisoning may set in after its use has been continued for some time, or even after its administration has ceased. Its action, therefore, should be carefully watched. The usual dose is a scruple three times a day.

Tartarized antimony, otherwise called tartar emetic, though powerful in its effect on the human subject, acts very slightly, if at all, on the horse.

Hydrocyanic acid is also used as a sedative, but is not a safe medicine in inexperienced hands. Half to one drachm is the usual dose.

Extract of Belladonna, in doses of one drachm with one or two drachms of nitrate of potassa, is also employed as a sedative, but in reality its action is narcotic.

\section{Nauseants.}

Although certain peculiarities in the position and structure of the stomach prevent the horse from vomiting except in rare instances, yet nausea sufficient to keep an irritable animal quiet may be produced by giving one drachm of aloes every other day smeared over the molar teeth. In certain cases, such as broken knees, the important object of keeping the patient quiet is sometimes only to be attained in this way.

\section{Stimulxnts and diffusible stimulants.}

Stimulants as external applications will hereafter be treated of specially in the chapter on Irritants. We therefore pass them over in this place.

The internal stimulants used in Veterinary practice are chiefly those known as Diffusible stimulants. They cause rapid, but only temporary excitement of the system. They are very useful in rousing and equalising the circulation, which from any cause may have become languid or even almost paralysed. In shivering fits, for instance, diffusible stimulants may by this action ward off attacks of inflammation. Shivering, which is a marked premonitory symptom of such attacks, is produced by 
the blood being suddenly driven from the surface of the body to the internal organs. They also relieve the congestion of internal organs by exciting the general circulation. Hence they are employed in many diseases, especially in inflammation of the lungs.

Diffusible stimulants are of the highest value in febrile affections, in diseases attended with great depression, during convalescence after serious illness, and in all cases of prostration, \&c.

The ordinary dose consists of

Spirits of Nitrous ether

A • • • • $1 \frac{1}{2}$ oz.

Aromatic Spirits of Ammonia . $\quad \cdot \quad \cdot \frac{1}{2} \mathrm{oz}$.

Water

or

Solution of Acetate of Ammonia

Water

or

Aromatic Spirits of Ammonia

Tincture of Gentian

Water

The Carbonate of Ammonia is a very valuable diffusible stimulant, and may be given either in the form of ball or draught in doses of from 1 to 2 drachms in a pint of water.

\section{Narcotics.}

Narcotics exert a primary stimulant, but more permanent sedative effect on the brain and nervous system. They are given with the view of relieving pain. Combined with other appropriate remedies, they are useful in alleviating spasms and the pain of some wounds and injuries.

Opium, Indian hemp, belladonna, camphor, and tobacco smoke are the narcotics in most common use. Belladonna and camphor and opium are especially valuable in relieving pain.

An ordinary dose may consist of

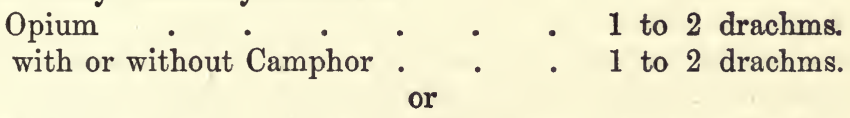

in cases of inflammation of the bowels or liver, the above may be combined with half a drachm of Calomel.

\section{Antispasmodics.}

Antispasmodics are medicines which act upon the brain and nerves, and through them on the system generally. By their action they overcome inordinate muscular action, such as spasms.

They usually consist of a narcotic in combination with a diffusible stimulant and a slight purgative. An antispasmodic draught may be made of-

Spirits of Nitrous ether. . . . . $2 \mathrm{oz}$.

Tincture of Opium . . . . . . 1 oz.

Solution of Aloes . $\quad . \quad$. $\quad . \quad$. 4 to $5 \mathrm{oz}$. 


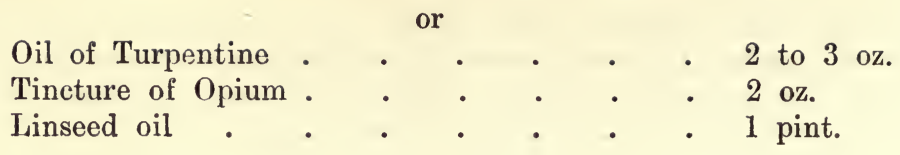

\section{Anæsthetics.}

Anresthetics are now very largely used in veterinary practice and are becoming more and more employed as time goes on.

\section{3a. Chloroform.}

Chloroform ought to be administered in all painful operations, but is not needed in minor cases, such as firing over limited surfaces or castration. The depressing after-effects more than counteract any benefit derived from its operation.

In modern surgery chloroform is administered through both nostrils by means of a ventilated muzzle (Raymond's patent), at the bottom of which a flat sponge saturated with chloroform is inserted, and retained in position by a perforated metal plate.

Many horses become greatly excited after inhaling for a short time. The chloroform in such cases must be administered more rapidly, until the patient becomes still and his eyes open. The eyelids are generally closed until the last. The eyes should be repeatedly examined, and the sponge should be removed before the eye becomes totally insensitive to touch.

If the pupil becomes dilated and insensitive to touch (no matter how small may have been the quantity of chloroform used), its administration must be immediately stopped. But if no such results occur, the administration should be continued until the lid becomes flaccid.

Some horses become unconscious with the administration of 2 oz., while others require $8 \mathrm{oz}$. For veterinary purposes methylated chloroform answers as well as the pure, and is much cheaper.

In all cases it is advisable to ascertain before administration that the heart is free from disease, or a fatal result may be apprehended.

\section{Tonics.}

Tonics are agents which increase the general tone and vigour of the system without producing any sudden reaction. They are supposed, after being first taken into the circulation, to act through the nervous system on the contractile involuntary muscular fibres of the alimentary canal and circulatory system, thereby inducing a more healthy state of primary and secondary nutrition.

They increase the appetite, the fulness and firmness of the pulse, the activity of all bodily functions and muscular power. Preparations of iron appear to be especially useful in improving the condition of the blood by increasing the amount of iron contained in that fluid. 
These beneficial effects, however, are only produced when the system has need of such artificial stimulus. When given to healthy animals tonics are likely to do more harm than good.

They differ from diffusible and other stimulants in that their action is but slowly established, whilst their effects are tolerably permanent, and their administration is not succeeded by subsequent depression.

Tonics, especially mineral tonics, should not be given to horses except under the advice of a well qualified Veterinary surgeon. Even in the human subject great care is required in their administration; but they may be more safely given, because the effect which they are producing can be ascertained daily by inquiry from the patient. In the horse, however, we have not this advantage. We may watch for, but we cannot positively ascertain their effect, until perhaps they have produced a marked result, either for good or for evil.

The medical tonics in ordinary use are divided into the two heads of mineral and vegetable. The first named comprise salts of iron and copper and arsenic. They are generally given with the food. The vegetable tonics in common use are infusions of gentian, quassia, and cinchona (which contains the alkaloid known as quinine). Ginger, aniseed, and other aromatics have also a slight tonic effect. Mineral are far more powerful than vegetable tonics.

The cordial balls so much patronized by grooms generally contain as their principal ingredient some mild tonic, such as gentian, cardamom seeds, \&c.

The really best tonics for the horse, except after seriously debilitating illness, are good fresh cool air, well regulated exercise, good feeding, and good grooming.

Of mineral tonics the ordinary dose may consist ofSulphate of Iron 1 to 2 drachms, with 2 to 4 drachms of Ginger, or

Sulphate of Copper $\frac{1}{2}$ to 1 drachm, with powdered Gentian 2 to 4 drachms, or

Arsenious acid

Though the above are the ordinary doses, yet it must be remembered that Mineral tonics are very powerful, and even dangerous meaicines, unless their effects are closely watched. Hence the amount and frequency of the repetition of the dose may often require to be varied under the ever changing circumstances of the patient.

Of Vegetable tonics the ordinary doses are-

Quinine $\frac{1}{2}$ to 1 drachm, dissolved in a few drops of sulphuric acid and a pint of water,

or

Oak bark 2 to 3 drachms made into a ball with treacle and bran, or

Powdered Gentian root 1 to 2 drachms, or

Tincture of Gentian 1 to 2 ounces in a pint of water.

In some cases the above quantities may be doubled, 
Though in a far less degree than mineral, Vegetable tonics are powerful for good or for evil, and the effects which they are producing require to be carefully watched.

\section{Blisters.}

Blisters, by means of their irritant action, produce infiammation of the true skin, and as a result, effusion of the watery parts of the blood. This effusion appcars in the form of vesicles or blisters, which raise up the cuticle from the skin underneath.

Blisters are used either as local stimulants; or as irritants with a view of causing an altered, and it may be a healthier action; or as counterirritants.

When the first or mere stimulant action is desired, the blistering liquid is applied sparingly. By such stimulation more blood is brought to the part affected, and increased action is the result. With this view blisters are applied to indolent wounds and ulcers, to parts from which the hair has fallen off, and to the coronet in order to stimulate the growth of the hoof. When an irritant effect is desired, as in some cases of sprains of tendons or ligaments, the blistering liquid is applied more freely. When increased irritation is sought for, the liquid is applied freely over a considerable extent of surface.

The agents in use for the purpose of producing stimulation or irritation are of various degrees of severity, from the temporary superficial redness caused by simple friction to the deep and severe action of the actual cautery.

Irritants, under which are included all classes of blisters, are much used in Veterinary practice, and are so important that we deem it necessary to devote a separate chapter to the consideration of their action and uses, - to which the reader is referred for further information on this subject. See Chapter 19.

\section{Caustics or Escharotics.}

Caustics act by chemically decomposing solid tissues and the fluids. This action destroys the vitality of the part. They are therefore much used in cases of unhealthy granulations, otherwise called proud flesh.

Although they destroy the structure with which they come in immediate contact, yet they cause irritation and increased action in the adjacent parts. Hence they are often made use of for the cure of indolent wounds and ulcers.

Some of them possess the property of uniting with albuminous matters, which renders them effectual in coagulating blood and thus stopping hæmorrhage, and likewise in producing an eschar or scab over painful or irritable sores or wounds.

Caustics differ much in intensity. Those in common use are nitrate of silver, otherwise called lunar caustic, bluestone or sulphate of copper, sulphate of iron and zinc, sulphuric and hydrochloric acids, arsenic, corrosive sublimate, terchloride of antimony, and the hot iron or actual 
cautery. These agents are apt to be much abused, being frequently applied in too strong a form or in too great quantities. Inexperienced people in their desire for a decided effect too often forget the delicate nature of the living structures, with which they have to deal, and the pain which such rough treatment gives.

Equable well applied pressure, though not a caustic, deserves to be mentioned in this place as a valuable agent in repressing unhealthy or excessive granulations.

Nitrate of silver is the most convenient application for repressing too luxuriant granulations, or for promoting healthy action in a sore. Corrosive sublimate is frequently used with advantage in quittor to promote healthy action in the sinuses. Red precipitate induces healthy action in a sore. Nitric acid applied by means of a piece of tow at the end of a stick is used in fungus on the sole of the foot.

\section{Astringents.}

Astringents partake, though only in a modified degree, both of the action of caustics and tonics. Like caustics they combine chemically with albuminous and watery matters, whilst like tonics they act on, brace up, and constringe muscular fibre.

When given internally they are useful in arresting excessive secretions of the mucous membranes and in bracing up relaxed parts. Hence they are often given in cases of diarrhœe.

When applied externally, they are beneficial in several ways. They suppress excessive secretions, and hence hasten the formation of healthy cicatrices and promote the process of healing generally. They check the formation of unhealthy granulations; whilst moreover their constringent action renders them serviceable in reducing superficial inflammation, such as that arising from slight contusions, from inflammation of the mucous coat of the eye, \&c.

Internally opium, catechu, sulphate of zinc, acetate of lead, and rice water are administered. In profuse staling iodine has a very marked effect.

For external cases alum, the acetate of lead and zinc, and sulphates of zinc, iron and copper are used. Ice, cold water, and cold generally, though they have no chemical effect, deserve places among astringents by virtue of their action in bracing up muscular fibre. All caustics, if much diluted, have an astringent action.

For an astringent powder equal parts of burnt alum and chalk, or of alum and pipeclay answer particularly well. In cases of indolent sores an ounce of sulphate of copper to a pint of water may be used.

An astringent lotion may be made by dissolving in water as much powdered sulphate of zinc or acetate of lead as it will take up; or equal parts of the above may be dissolved together. The lotion may be reduced in strength by adding water according to the nature of the wound to which it is to be applied. An ounce of salt dissolved in a pint of water also forms a very useful mild astringent lotion. 


\section{Demulcents.}

Demulcents have a purely local action. When taken internally they form a coating, so far as they reach in an undiluted form, to the mucous linings, and protect them from irritation. In sore throat, for instance, in ourselves, we readily recognise the benefits of demulcents in protecting the mucous lining of the throat from the irritating effects of cold raw air. They are also serviceable in preventing acrid secretions from coming in contact with delicate and irritable surfaces. Hence they are given in cases of diarrhœea.

Demulcents are made either of linseed boiled to a jelly and mixed with the food, or by pouring boiling water on the seeds in the proportion of one pint of water to an ounce of seed. The latter must be left to stand till cold, when a thick solution will be obtained.

Another and perhaps better preparation is made by throwing the linseed by a handful at a time into boiling water. Each handful then gets well scalded at once.

\section{External dressings.}

External dressings in cases of wounds are useful in protecting the parts from the irritating effects of the air, of flies, \&c. ; and secondly in lowering the temperature of superficial inflamed parts.

For the first-named purpose cotton wool or strips of cotton dipped in collodion, or a rag wetted with Goulard lotion or cold water answer well. Carbolic acid made into a paste with chalk, or collodion applied over the part with a camel's hair brush will often be found useful in forming an artificial eschar over a sore. For the second-named purpose a rag kept wet with water or with a refrigerating lotion may be used.

To prevent attacks of flies, which in, hot weather are especially apt to be troublesome, the parts may be lightly smeared with spirits of tar, naphtha, petroleum, or diluted carbolic acid. In hot climates much of the success in treatment of wounds and sores depends on keeping off flies. Maggots in a wound will be best got rid of by dressings of equal parts of spirits of turpentine and oil.

Under the head of external dressings are also included the applications used for mange, ringworm, lice, \&c. These will be given under the heads of the diseases to which they respectively refer.

Digestive dressings, for which some recipes will be found in the next paragraph, are also much employed; but the benefit derived from their use is questionable.

\section{Digestive liniments.}

Turpentine Liniment is much employed as a rubefacient, and as a digestive on abraded surfaces. It is usually made as under.

Oil of turpentime .1 part.

Olive oil . : : 4 parts, 
Compound Liniment of Turpentine is used when a more stimulating effect is desired, otherwise called Soap Liniment.

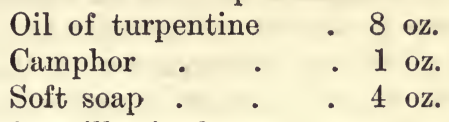

To be shaken together till mixed.

\section{0a. Digestive ointment.}

Common Turpentine . 1 part.

Melt together in a water bath.

Hogs' Lard • • . 4 parts.

\section{Diluents.}

When dissolved in a large amount of water demulcents act as Diluents, which, as their name indicates, dilute the blood and other secretions.

They are useful in certain diseases in diminishing the irritating properties of unhealthy secretions. In irritability of the bladder, for instance, they are serviceable in diluting the urine and thus diminishing irritation in the mucous lining of that organ.

\section{Emollients.}

Fomentations and Poultices, otherwise termed Emollients, by virtue of their heat and moisture soften, relax, and soothe the parts to which they are applied. Hence they are used in cases of recent sprains, in colic or gripes, in enteritis, in bruises, and in all such cases. They are also serviceable in cleansing wounds in which dirt or gravel may have lodged.

But simple as they are, Emollients may be used too freely or for too long, or until they unduly relax the parts, or in the case of wounds induce undue effusion and suppuration, and in some cases excessive granulations.

The lymphy fluid poured out from the adjacent healthy structures is the material intended by nature for the cementing of wounds and for the repair of lacerated structures. From it the muscles, skin, bones, and all other parts are built up, and hence in the treatment of wounds care must be taken not to interfere with the reparative material or ignorantly remove it.

The simple rule appears to be, that Emollients are useful in the first instance in reducing the inflammation, and may in many cases bring about resolution. Or if the progress of inflammation cannot be checked, they may be advantageously continued with the view of bringing on the processes of effusion and suppuration. But as soon as this action has been induced, the emollient should be discontinued, because the object of its application has been attained.

\section{Poultices.}

Poultices intended for the special purpose of giving warmth to a part are usually made of hot bran. Those intended for relaxation may be 
made of equal parts of moist bran, linseed meal, olive oil ; or of boiled carrots or turnips mixed with bran. For ill conditioned sores linseed answers best. If a sore is painful, opium may be added to any of the above. To soften the horn in inflammation of the feet, vinegar may be added to the bran. A poultice may be made an astringent dressing by the addition of sulphate of zinc.

Poultices, though very convenient in the human subject, are not equally applicable in the horse, because they are not easily fixed, except on the feet. A poultice, unless made large, dries too rapidly, and is then apt to cause irritation instead of soothing. On the other hand, if made large it is heavy and difficult to secure. The poultice must not be tied so tight as to arrest the circulation or to leave a mark. With this view, a broad tape or a piece of list should be used instead of a string. An old stocking with part of the foot cut off makes a good poultice bag for the lower part of the leg.

The substance of which the poultice is intended to be made should be steeped in hot water in a cloth. The water must then be permitted to drain off.

\section{Fomentations.}

Warm water makes the best fomentation, and is only open to the objection that its use demands from servants an amount of time and trouble which they are not very willing to give, unless closely superintended. Directions as to the mode of applying fomentations have been given in the chapter on nursing.

\section{Spongiopiline.}

For sprains and bruises, when the skin is not broken, a thick woollen substance covered with oilcloth, called Spongiopiline, which is manufactured for the purpose, forms a good, but still inferior, substitute for the more troublesome operation of fomentation. It should be soaked in hot water, and on account of its thickness and impervious covering will long retain both heat and moisture.

\section{Cold applications.}

Cold applications resemble fomentations in so far as that their action is local, but in other respects their action is diametrically different. They constringe, harden, and brace up the parts to which they are applied. They reduce the calibre and increase the tone of the distended or relaxed superficial blood-vessels, rouse them to increased action, and excite them to absorb the effused products of hyperæmia. They also lower the heat of the part to which they are applied. Hence their value in the treatment of sprains after the first heat and tenderness have passed away, and also in reducing bruises and removing simple superficial circumscribed inflammation.

Of cold applications cold water is the most common and convenient. 
Poured from a height it is sometimes specially effective. Its temperature, if need be, may be lowered by dissolving in it ice and salt, or a mixture of equal weights of common salt, nitre, and muriate of ammonia. Vinegar is sometimes mixed with the water, and is useful where an astringent and refrigerant effect is desired. Powdered ice is also a valuable means of abstracting heat. An ingenious india-rubber apparatus is now made for allowing cold water to trickle down over any required part.

\section{Cooling Drinks.}

Cooling and refrigerant drinks, though less commonly used in Veterinary than in human practice, are refreshing and sometimes palatable to sick animals. They often, also exert a slight tonic action, and generally in addition increase the secretions of the bowels and kidneys.

Cooling drinks are made by dissolving in water saline matters such as 4 drachms of nitre, or cream of tartar, or 4 ounces of the solution of acetate of arnmonia in a gallon of water. Or acids such as 2 or 3 ounces of vinegar, or 1 or 2 drachms of hydrochloric acid may be mixed in the above quantity of water. Many horses, however, will refuse the water when so mixed.

318. Cooling lotions.

Acetate of Ammonia . . . . . 4 oz.

Spirits of wine . . . . . . 4 oz.

Water . . . . . 8 oz.

Mix and keep the part wet with a rag;

or

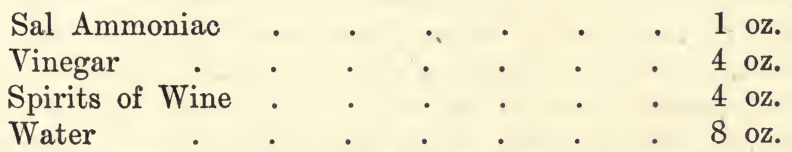

Mix the Sal Ammoniac and Vinegar together, and then add the Spirits of Wine and the water;

\begin{tabular}{|c|c|c|c|c|c|c|c|}
\hline & & & & & & & \\
\hline Sugar of & Lead & - & & - & - & - & $\frac{1}{2}$ oz. \\
\hline Vinegar & . & . & - & . & - & - & $2 \mathrm{oz}$. \\
\hline Water & . & . & . & . & • & . & 1 quart. \\
\hline
\end{tabular}

\section{Alteralive balls.}

By slightly provoking the action of the excretory organs Alteratives are sometimes useful in enabling the system to rid itself of any waste materials or matters, which if retained might cause disturbance of health.

They may be made of-

Nitre, Black Antimony, and Sulphur, 2 drachms each.

Or a mass may be made of Aloes in powder 1 oz., Soft soap $1 \mathrm{oz}$., Linseed meal and treacle $6 \mathrm{oz}$. Dose $1 \mathrm{oz}$. 


\section{Febrifuges.}

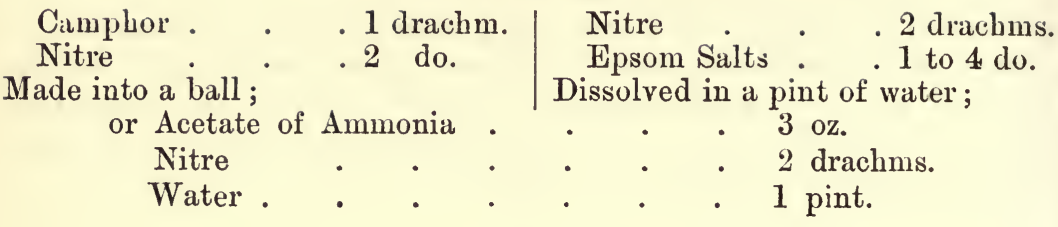

\section{1.}

Infusion of Chiretta in from 2 to $3 \mathrm{oz}$. doses mixed with $1 \mathrm{or} 2 \mathrm{oz}$. of Sal Ammoniac in a pint of water is an excellent febrifuge.

The Chiretta is also an excellent tonic during convalescence from debilitating fevers.

\section{Fever or Cough balls.}

Aloes

Nitrate of Potassa

Extract of Belladonna.

according to the size of the horse. To be nuixed with Stockholm tar into a ball.

\section{Disinfectants and Deodorizers.}

True disinfectants act chemically by decomposing noxious gases and organic matters. Such are chlorine and its compounds, sulphurous acid, Macdougal's disinfectant, Condy's fluid, chloride of lime and soda, carbolic acid, \&c. Their action is produced by their affinity for hydrogen, which is a constituent of most of the deleterious matters found in the stable. They appropriate to themselves this constituent, and by this means break up the poison. Most disinfectants are also deodorizers.

Deodorizers generally, as distinguished from disinfectants, act mechanically. They have an affinity for certain compounds floating in the air, and imbibe and absorb them. Such are sawdust, powdered wood, charcoal, plaster of Paris, sulphate of iron, gravel, sand, and permanganate of potassa.

Deodorizers may under some circumstances become so overcharged with noxious matters, that they may of themselves voluntarily give them off. Earth, for instance, which is a most valuable deodorizer, may become so loaded with impurities as to become stinking. Similarly disinfectants can only combine with a certain proportion of noxious gases or organic matters, and then become inert and valueless.

Along with plenty of fresh air and due regard to cleanliness, disinfectants and deodorizers are useful means of purifying the air of stables and also in neutralising those noxious emanations given off from the bodies and breath of diseased animals, which, if undiluted or undestroyed may become fruitful sources of diseases. It must never, however, be supposed that they supersede or even diminish the necessity for adequate ventilation and scrupulous cleanliness. 


\section{Antiseptics.}

Antiseptics are agents used to prevent or hinder putrefaction. According to modern views, Putrefaction is excited or occasioned by living microscopical animalcules or plants, which, floating in the air, feed upon and decompose dead animals and vegetable substances.

The class of medicines termed antiseptics act as a poison on these bodies and destroy their activity. They check that slow breaking up of organised bodies which is termed putrefaction, by destroying its causes. Sulphurous acid, common salt, salicylic and boracic acids, astringent metallic salts, vegetable substances rich in tannin, sugar, spirits, creasote and pitch oils, and carbolic acid, are the antiseptics in common use.

Antiseptics are used in veterinary practice in the treatment of unhealthy sores and wounds, and occasionally with the view of arresting caries and gangrene.

They are occasionally administered internally in diseases of a septic nature for the purpose of checking the tendency to putrescence. The administration of salicylic acid in doses of from 1 to 2 drachms, in combination with tonics, has been strongly advocated in cases of septicæmia and purpura hæmorrhagica. Carbolic acid is also occasionally given.

\section{Mode of delivering a ball.}

There is a good deal of knack in delivering a ball. It should be delivered by the hand, not at the end of a stick or by a balling gun. The tongue should be slightly drawn forward and turned up within the mouth by the left hand of the operator, but it should not be pulled out of the mouth. The head should be raised while the ball is being put into the mouth, but the moment the ball is at the root of the tongue, the head should be let down level with the body, because it is only in that position that the horse can naturally perform the act of swallowing.

The head should not be let completely down, because in that position the skin and muscles of the neck are so relaxed that the passage of the ball down the throat cannot easily be watched. The downward passage of the ball is best seen on the near side, because the gullet lies towards that side. If the ball does not go down at once, a gulp of water or a handful of grass should be given. The throat must not be rubbed or pressed upon with the view of assisting the passage of the ball. Any such "assistance" will probably induce cough, and cause the ball to be ejected.

To those who have not had much practice a balling iron is useful, because it prevents the possibility of injury to the hand from the horse's teeth. An old kid glove with the fingers cut off will protect the hand from injury from the sharp edges of the molar teeth. 


\section{Mode of giving a drench.}

A proper drenching bottle or horn should be provided. In its absence a soda-water bottle will answer pretty well. The horse's head must be slightly elevated, and then the fluid should be poured down the throat very slowly. The head may, if necessary, be raised by means of a noose in the mouth, attached at its upper end to the prong of a stable fork. At the slightest sign of coughing the head must be released. Many 'drenches, it must be remembered, are of such a nature as to cause great irritation, if even a very small portion goes the wrong way.

A practice existed some years ago, and may perhaps continue even in the present day among farriers, of giving drenches through the nose. It is both injurious and dangerous, and should be strictly prohibited.

\section{CHAPTER 18.}

\section{INFLAMMATION.}

327. Theory of inflammation. 328. Nature of inflammation. 329. Causes of irritation. 330. Effect of irritation on the part affected. 331. Phenomena of inflammation. 332. Arrest of the circulation at the inflamed part. 333. Original seat of the stagnation. 334. Changes which occur in the blood after leaving the seat of inflammation. 335. Effects which result in the neighbouring parts from the stagnation of the circulation at the inflamed part. 336. Effect of inflammation on the general circulation. 337. Fever. 338. Effect of inflammation on the nutrition of the part. 339. Local, diffused, and specific inflammation. 340. Acute, subacute, and chronic inflammation. 341. Signs of inflammation when established. 342. Pain. 343. Redness. 344. Heat. 345. Swelling. 346. Throbbing. 347. Constitutional symptoms. 348. Shivering. 349. Symptoms indicative of the locality of the part attacked. 350. Sthenic and asthenic types of inflammation. 351. Results of inflammation. 352. Resolution. 353. Second result or effusion. 354. Third result or formation of lymph and adhesion. 355. Fourth result or formation of pus, otherwise called suppuration. 356. Fifth result or ulceration and mortification. 357. Treatment of inflammation. 358. Treatment of the primary disease, or disturbance of function in the part affected, otherwise called the inflamed part. 359. Treatment of inflammation when established. 360. Treatment of acute local inflammation. 361. Treatment of subacute local inflammation. 362. Treatment of chronic local inflammation. 363. Treatment of diffused inflammation. 364. Treatment of sthenic inflammation. 365. Treatment of asthenic inflammation. 366. Later stages of sthenic and asthenic inflammation. 367. 
Inflammation seldom fatal. 368. After-effects. 369. Treatment by depletives and violent counter-irritants. 370. Specific inflammations. 371. Curative inflammation.

\section{Theory of inflammation.}

From the very earliest times the subject of Inflammation has occupied the attention and excited the interest of the Medical inquirer; and the treatment of disease in general has always been largely dependent on the views which have been current at the time in regard to this particular affection. The treatment of Inflammation itself has of course followed the ideas entertained as to its nature and causes.

Until within the last sixty years the state known as Inflammation was universally regarded as one of exalted action and increased nutrition of the part affected. Hence depleting remedies were in repute. The seat of the disease was supposed by some to be in the blood, whilst by others the blood was regarded as the food and sustenance of the disease. Hence bloodletting was a favorite practice, whilst in internal attacks violent irritants or blisters to the skin were also freely employed, with the view of withdrawing the blood from the interior to the surface.

These views gradually gave way to the idea that nervous irritation at the part affected was the primary cause; - that collapse of the power of the nervous system of the part rapidly supervened on the previous nervous exaltation; - that then the vessels, deprived of their usual nervous stimulus, lost their contractile energy, and were unable to contract upon and propel forward the current of the blood; - that from this cause stagnation of the blood followed, and congestion was induced;-whilst from the congestion, constantly increased by the fresh supplies of blood propelled into the part by the action of the heart, arose the well-known results of the disease. The vessels became over-loaded and over-distended, and in consequence the watery parts of the blood, followed in some cases by the fibrinous materials, passed out through the coats, rendered thin by over-distension,- - producing, according to circumstances, effusion of serum, exudation of lymph, suppuration, mortification, \&c.

With the occurrence of these views a great change took place in the treatment. Bleeding, strong depletives, and violent irritants or counterirritants fell into disuse; and the object sought was to improve the tone of the system and of the part, with the view of enabling nature to regain her power and restore tone, and thus bring about restoration of the usual healthy current of the circulation. Mild irritants were therefore applied externally to the neighbourhood of the part attacked, and diffusible stimulants were given internally.

These views in regard to the theory at least of the disease have again been of late years modified; but the treatment indicated above is still in a great measure applicable.

Much difference of opinion still prevails as to the exact nature and causes of inflammation, and as to the precise reasons of the various changes which occur in the tissue affected, in the blood, and in the 
neighbouring parts. If the reader wishes to investigate thoroughly this the most debateable subject in medicine, he may consult the learned works of Goodsir, Virchow, Bennett, Lister, Aitken, Paget, and others.

Avoiding as far as possible all minute details and doubtful points, now under eager discussion among medical men, the Author hopes to be able to trace out intelligently, but very briefly, the broad principles and views now generally entertained in regard to Inflammation.

The Vital principle or seat of vital activity was long supposed to reside in some one organ or tissue,-in the brain as some thought, or in the blood as others thought, or in the nervous system or elsewhere. It was supposed that there was some one central point or organ from which all motion, activity, and growth, all life in short, was generated,-that each part derived its vital action from that centre,- that parts or tissues in themselves, as apart from their relation to that centre, possessed no power of motion, activity, growth, or development.

These views have given way to a belief that a vital principle, a power of activity, a power of selecting and adapting the various constituents of the blood for its own use, a power of growth and development, exists inherently in each tissue.

Whether the living power of the tissue resides in its cells, as some think, or in its molecules, as others think, is not necessary to discuss in this place. It is a sufficiently well ascertained fact that a vital power, a power of growth and multiplication, does exist in the ultimate elements of each tissue.

Except as reggards the inherent vitality and power of self-action, there is no great difference between the views now and those formerly entertained as to the growth of new matter and nutrition. By the cells, as is well known, the various tissues of the body are built up and nourished. The blood is the food of the cells. From it in each tissue they extract those special nutrient particles which are essential to their growth, multiplication, development, and life,-much in the same way as the cells of flowers select the colouring matters which they require.

But as regards the nature and treatment of inflammation, the belief now held, that each tissue has in itself a vital power, has led to the modification of many of the ideas formerly entertained as to that disease. It has caused it to be regarded more as a local and specific affection than as a constitutional disturbance. It has likewise enabled several of its phenomena to be accounted for, which were previously inexplicable.

\section{Nature of inflammation.}

Irritation is the starting-point of the state known as Inflammation. From some cause or other the part falls into a state of irritation. Irritation acting on the part, either directly or through the medium of the blood, causes it to undergo alterations as regards the composition, constituents and arrangement of its cells, which enable them to attract to 
themselves and to absorb a larger quantity of matter than usual, and to transform it according to circumstances. It also alters the relations of the cells to the neighbouring parts, whether blood-vessels or other structures.

Inflammation may be said to have begun from the moment that this increased absorption of matters into the tissue takes place, and the further transformation of those matters commences.

\section{Causes of irritation.}

All irritation may in a certain sense be said to be dependent on the nervous system. An external blow, for instance, produces irritation and pain through the medium of the nerves of the part. Nerves may, however, produce irritation and pain from causes other than external.

Hence the irritation in the tissue, which produces its altered vital action, may in general language be said to be due to nervous influences. Much that concerns the nervous system, and the causes and agencies which influence it, is still a sealed book to the medical inquirer. We know, however, that many causes elevate it, whilst others depress it, and some even to the extent of paralysis. We know also that prostration generally supervenes very rapidly on nervous excitement. This latter fact is very important in regard to the nature and treatment of inflammation.

\section{Effect of irritation on the part affected.}

The part directly affected by the irritation is the tissue itself. The blood is only indirectly affected from the changes which occur in the performance of function in the tissue. The cells under the influence of irritation, or in other words under the influence of the disturbance of their normal functions, absorb and appropriate material from the blood in greater quantity and in an altered way to what they would do in health; and again they transform the material so taken up into matters different to what they would do in health. Hence the nutrition of the part is altered,-it may be increased or it may be diminished; and as a further result, the condition of the other tissues connected with the part is also altered.

Among other results of the functional disturbance in the tissue is an alteration in the character of the blood.

\section{Phenomena of inflammation.}

Before proceeding further, we must turn aside for a moment to consider the phenomena of inflammation. The various changes in the circulation of the part are well seen on irritating the transparent vascular membrane of the web of a frog's foot. The first effect is contraction of the channels of the smaller vessels and increased rapidity of the circulation. 2ndly. The same vessels become enlarged, and the current of 
blood is slower, though regular. 3rdly. The flow of blood becomes irregular, and oscillates. 4thly. The current almost ceases, and the ressels are distended with coloured corpuscles. 5thly. If the stagnation be not relieved, the serum will be exuded through the walls of the vessels; and perhaps ultimately, by reason of ruptures occurring in the over-distended coats of the vessels, the red particles of the blood may pass out.

\section{Arrest of the circulation at the inflamed part.}

In the inflamed part the circulation is to a certain degree arrested,to a greater or less degree according to various circumstances. This arrest is due-1st to an altered vital relation between the tissues and the blood; 2nd to increased viscidity or adhesiveness of the blood in the part; 3rd to diminished action of the vessels themselves, owing to nervous prostration, on account of which they cease to assist in the function of circulation; 4 th sometimes to a mechanical impediment, such as agglomeration of the corpuscles, a foreign body, or a clot of fibrin; 5th to a tendency in the vessels themselves to become dilated or varicose at parts and contracted at other parts.

\section{Original seat of the stagnation.}

The various tissues in health derive their nutriment from the blood contained in the capillaries or minute vessels which permeate their structure. Hence in disease the disturbance of the regular functions of the tissue is first felt in those vessels. Hence, again, the blood contained in them is soonest affected and altered in character. Hence the stagnation or "stasis" of the circulation commences in them earlier than in the larger vessels.

\section{4: Changes which occur in the blood after leaving the seat of inflammation.}

There is stagnation and sometimes complete arrest of the blood in the inflamed part. In that part the blood, as stated above, is viscid and altered in its character. It leaves the part but slowly. The change in its character has been produced by the action of the diseased tissue on it. As soon as it gets free from that morbid action, it rapidly regains among the healthy tissues its fluidity and proper consistence. The vital processes by which nature restores the blood in a great degree, but perhaps not entirely, to a healthy condition are difficult to explain. An illustration may serve better than an explanation. If a clear stream runs through a muddy pond, it will issue out from it somewhat disturbed and thick; but after again running a short distance over a gravelly bottom, and exposed also to the wholesome influence of oxydisation from the air, it will soon be as clear as ever. Again it must be remembered that, unless the seat of the inflammation is very extensive, the amount of blood which has become altered in its character from the action of the diseased tissue is very small when again mingled in the mass of the general circulation. 
335. Effects which result in the neighbouring parts from the stagnation of the circulation at the inflamed part.

But around the inflamed part there is an undue and unusual accumulation of blood. This accumulation is not in itself primarily a disease. It is simply the mechanical result of the stagnation of the blood at the inflamed part. The heart continues in its usual state of activity, and propels the blood forward through the various channels of the circulatory system : but the blood, which would in due time come to and pass through the inflamed part, is necessarily arrested by the stagnation and congestion, which has already taken place at the seat of the disease, and consequently the vessels around the stagnation are dilated, and contain more blood than natural. As the current of blood continues to flow into the neighbouring parts, the vessels become more and more overloaded, congested, and dilated. Hence also the strong and heavy throbbing felt in the arteries leading to the part.

It is not, however, to be supposed that there is complete arrest of the circulation in those parts. The vessels surrounding the inflamed part, with their innumerable ramifications, enlarge, and thus permit to pass through them a considerable portion of the blood which in health would pass through the vessels at the original seat of the disease. The vessels on the sides may, however, become so much paralysed from over-distension that their contents also may almost cease to flow, and thus the area of the disease may become extended.

As, however, the seat of the inflammation is usually among the capillaries, which have innumerable ramifications in every direction, the check on the circulation is less than might at first sight have been expected, because collateral circulation is so readily established.

The undue accumulation of blood thus arising we shall hereafter term "Hyperæmia."

\section{Effect of inflammation on the general circulation.}

The general circulation is but little affected. The hyperæmia in the surrounding parts is due to the simple mechanical cause detailed above.

If, however, Fever supervenes, as it usually does in all serious and extensive attacks, the circulation will be quickened, sometimes to an excessive degree.

\section{Fever.}

If the hyperæmia be excessive, or if the pain attending the original attack of inflammation be great, or if the patient be very irritable, or if the part attacked be very sensitive, we may expect symptomatic Fever to set in.

Fever is general nervous irritability, from which arises a quickened state of the circulation. The pulse in consequence is always affected to a greater or less degree, and increased in frequency. The respirations are increased, and so also is the heat of the body. Fever is generally ushered in with shivering and accompanied with thirst. 


\section{Effect of inflammation on the nutrition of the part.}

The effect on the nutrition of the part will be very varied, according to the degree of the disturbance of the functions of the tissue affected, the amount of hyperæmia in the surrounding parts, the health and condition of the patient, and on some other circumstances. The nutrition may be excessive, as indicated in some cases by an over-rapid growth of granulations ; or it may be diminished, sometimes to an excessive degree, as indicated by a tendency to ulceration. Again, the products poured forth may be unhealthy, or they may be available for the repair of lesions. In some cases the disturbance of function in the tissue may be so great as to induce mortification or death of the part.

\section{Local, Diffused, and Specific inflammation.}

Inflammatory attacks are divided into Local or Circumscribed, Diffused, and Specific. The disease is said to be Local when it attacks an organ or definite part of the body. The effects produced on the system will be severe and otherwise according to the importance of the organ attacked and other circumstances. Inflammation is said to be Diffused when it extends over a large tract of tissue, such, for instance, as the cellular tissue, or when it has no tendency to become circumscribed. Constitutional disturbance in a greater or less degree always attends diffused inflammation. Specific inflammation is the term applied to those cases which are caused by animal or blood poisons.

The expression often used of "general" inflammation is not strictly correct. It is simply impossible that all the vessels can at one and the same time contain more than their usual quantity of blood. What is termed general inflammation is in reality fever, attended by a quickened state of the circulation.

\section{Acute, subacute, and chronic inflammation.}

Inflammatory attacks are also usually divided into the three heads of Acute, Subacute, and Chronic.

When the attack is sudden in its origin, violent in its action, rapid in producing its effects, and attended by fever, it is said to be Acute. Acute attacks are seldom of long duration.

It is said to be Subacute when the symptoms mentioned above are less marked. Such attacks are often obstinate and prolonged, and in many cases produce disastrous changes of structure.

Chronic attacks partake of the nature of subacute. The name has reference to the abiding nature of the attack rather than to any other features.

No sharp line of demarcation can, however, be drawn between these degrees of inflammation. They glide insensibly one into the other. 


\section{Signs of inflammation when established.}

From the consideration of the theory and primary stage of inflammation, we now turn to the consideration of the disease when it has established itself in a part.

The principal and usual signs in the part are hyperæmia, pain, redness, heat, swelling, and throbbing. The whole or any part of these symptoms may be present. The first, or hyperæmia, has been already dwelt upon. We therefore pass on to the next, namely Pain.

\section{Pain.}

The pain varies very much in different structures. Some are more sensitive than others, but as a general rule the pain is least where the parts are capable of yielding and swelling; and greatest where they are tense and firm, as in bones, tendons, and ligaments ; or where the part, though soft in itself, is enclosed in unyielding structures, as is the case in regard to the interior parts of the foot. Hence many parts, which are ordinarily insensitive, become exceedingly painful under inflammation, and fever may be expected to supervene when such parts are attacked. The pulse, for instance, is often more affected in laminitis than in many other diseases.

\section{Redness.}

Except in the visible mucous membranes, such as those of the nose, mouth, eyes, \&c., we cannot see the redness on account of the hair with which the skin is covered. The redness is due to the greater quantity of blood contained in the vessels of the part affected, and sometimes also at a later stage to extravasation of the colouring matter of the blood into the neighbouring textures. The redness in some cases remains long after the subsidence of the inflammation, on account of the length of time which the vessels, after having been much over-distended, take to regain their tone, and also because the extravasated material is but slowly absorbed.

\section{Heat.}

The temperature of the part is increased both by the greater quantity of blood present in the congested vessels, and also by an actual increase in the temperature of the blood at the part. There must therefore be generation of heat in the inflamed part. This cannot be wondered at when the great changes which are going on in inflamed structures are taken into consideration.

\section{Swelling.}

Swelling, which is always most appreciable in the soft external structures, is due in the early stage of the attack to the distension of the blood-vessels; and it is also much increased in the latter stages by the effusion and exudation which take place through their coats. 
These products, though of very different kinds, are all derived from the blood. They are, first, serum or the watery part of the blood; secondly, albuminous fluid; thirdly, coagulable lymph; fourthly, the blood itself. The swelling may be hard or may pit on pressure, according to varying circumstances.

Swelling of the part necessarily accompanies every attack of inflammation, but the amount may be so small as to be scarcely appreciable. This apparent absence of swelling is particularly noticeable in bones and other firm substances.

\section{Throbbing.}

Throbbing of the arteries is caused by a sort of regurgitation of the blood, which is partially arrested in its onward course by the congested state of the vessels at the seat of the disease. It is a marked sign of inflammation.

Throbbing is useful in many cases in enabling us to determine with more certainty than we otherwise could the real seat of the disease. For example, inflammation in the interior of the foot is plainly indicated by throbbing of the plantar arteries.

\section{Constitutional symptoms.}

Inflammation, when tolerably severe or extensive, tells of its existence by other signs besides the local symptoms already detailed. It soon causes constitutional disturbance, which is recognised by shivering, cold extremities, dryness of the mouth and nostrils, constipation of the bowels, and diminished action of the skin and kidneys.

When the disease is complicated with or aggravated by fever, as in such cases it usually is, it will be marked by further symptoms, namely, an accelerated pulse, quickened breathing, and irregular temperature of the part at different times.

Though in its origin the disease is always local, yet in some cases the constitutional disturbance may precede the visible manifestation of the local symptoms.

\section{Shivering.}

Shivering is a symptom of the greatest importance. It is generally present in the early stages of all serious attacks of inflammation. It often indicates some important change in the character of the blood, or is due to altered condition of the nervous system, or to the shock of an impending disease. No case in which Shivering is present should be ever neglected for an instant. Although the animal may be shivering, the skin may be hot and burning.

349. Symptoms indicative of the locality of the part attacked.

The symptoms vary very much according to the part attacked. In all serious cases, such as inflammation of the brain, eyes, feet, lungs, or 
bowels, there are special characteristic symptoms which mark each disease. These special symptoms will be noticed hereafter under the heads of those diseases.

\section{Sthenic and Asthenic types of inflammation.}

One more feature, and it is a very important feature in inflammatory attacks, yet remains to be considered.

The attack may be of a "sthenic" or of an "asthenic" type. ( $\Sigma \theta$ '́vos, strength. 'A $\sigma \theta$ '́vos, want of strength, weakness.) This will depend partly on the cause, but mainly on the constitution of the patient. The inflammation will probably be of the sthenic type when it affects a vigorous animal ; whilst it will probably be asthenic if the patient is of weakly. constitution. Sthenic inflammation cannot be produced in a very weakly animal by any degree of nervous exaltation; but the asthenio type may be generated in any animal by causes, such as bad food, malaria, \&c., which lower the system.

The sthenic type is indicated by a quickened, full, and not easily compressible pulse. There is also in general thirst. If an important internal organ is attacked, the appetite is usually lost from the first, the urine is scanty and high coloured, and the frees are hard and knobby. But when the inflammation attacks even important structures remote from the vital organs, the appetite is often for some time less affected. In both cases there is restlessness and discomfort. The skin is hot and dry. The respiration is quickened, and the breath is hotter than usual. Sthenic inflammation may also exist with a full and very slow pulse. In such cases it indicates an affection of the brain. The appetite often remains for some time, and occasionally the patient continues to eat in a half-somnolent state.

In attacks on internal organs the duration of the sthenie stage is often very brief,-after which the disease runs into the asthenic type. The fact has a very important bearing on the treatment to be adopted in such cases. On the other hand, when inflammation of a sthenic type attacks organs, such. as the laminæ, remote from the more important organs, the type may remain unaltered for a length of time.

In the asthenic disease all the vital powers are from the first greatly depressed. The case assumes what is technically called a "low" type. The pulse is soft and compressible, weak and quick, and the volume of hlood flowing through the arteries is comparatively small. The nervous power of the heart is prostrated, and it is unable properly to propel the blood through the system by strong, well-defined rhythms. The patient is weak and downcast. The appetite is impaired, and the animal gradually cares less and less for his food, but it is not completely lost from the first as in the sthenic attack.

Fever may be said to be present in sthenic inflammation, when the pulse, in addition to being quick, full, and not easily compressible, is also bounding; and similarly in the asthenic attack, when, in addition to being soft, compressible, quick, and weak, the pulse becomes very 
quick. The heart appears to be endeavouring to make up for deficiency of power in each stroke by more frequent beats.

Most of the different varieties of inflammation, namely acute, subacute, local, diffused, and specific, may be present with either the sthenic or asthenic type. Chronic inflammation, however, is always, except perhaps quite at first, of an asthenic character.

The Results of Inflammation, which will now be detailed, may ensue equally from the asthenic as from the sthenic attack.

\section{Results of inflammation.}

Inflammation, according to its degree and other attendant circumstances, may result in partial or complete resolution, in effusion of serum, in exudation of fibrinous material, in the formation of lymph and adhesion, in suppuration, in ulceration, or in mortification.

\section{Resolution.}

The most favorable termination of inflammation is resolution, or simple subsidence of the congestion. In this case the blood is again set in more active motion. The cause of this effect is cessation of the irritation producing functional disturbance, and the restoration of the nervous power at the original seat of the disease. The functions of the part being restored, the blood soon again flows in its regular course. The surrounding parts are then speedily relieved, and the abnormal heat, redness, swelling, \&c., disappear.

The effusion is very slight, and is soon taken up by the blood-vessels and absorbents, and the parts regain in all respects their normal condition and integrity. This result is in many cases a spontaneous act of nature, but in other cases it may be brought about, hastened, or assisted by art.

\section{Second result or Effusion.}

The second and very common result, even of mild attacks of inflammation, is effusion of serum or watery part of blood from the overloaded vessels into the textures of the part, producing a soft pitting swelling.

Effusion generally gives relief to the pain and more acute symptoms by unloading the over-distended blood-vessels. In favorable cases the blood-vessels and absorbents soon take up the effusion, and the parts are restored to their normal condition.

This, however, is not always the case. The original disease may continue, and in such cases the undue amount of blood in the part must increase, and the watery effusion will then in consequence be poured out in increased quantities; or under certain circumstances, hereafter to be detailed, exudation of fibrinous material and the formation of lymph may take the place of the watery effusion. 


\section{Third result or formation of Lymph and Adhesion.}

If the distension of the blood-vessels is great, the albuminous parts of the blood may pass out through their coats, and from it fibrin will be formed in the cells of the tissue. The material so generated is known as Lymph. Its more fluid parts are soon absorbed, and the lymph then becomes firm and solid.

Lymph, if due to sthenic inflammation, has a tendency very rapidly to become organised. None of the other fluids derived from the blood under such circumstances are capable of this change. Lymph is the material by which wounds are repaired, broken bones are joined, and new parts of the body are built up.

Hence in some cases lymph may be useful as a means of repair; but in other cases it may be formed in structures where from its adhesive qualities it may be a source of mischief, as, for instance, in the lungs, pleura, and many other parts ; or it may be deposited in excess of the quantity required for repair, and in this way, when consolidated, may be an evil.

Lymph, however, if due to asthenic inflammation, is apt to degenerate.

\section{Fourth result or formation of Pus, otherwise called Suppuration.}

The fourth result of inflammation is the formation of Pus. Pus is formed by the transformation of the cells and nuclei of the areolar tissue into those of pus,- the nutrient matter necessary for their formation being under the diseased action of the tissue exuded from the blood.

The process of the formation of pus is known as suppuration. It is seldom attended with much pain, except when the matter is unable to gain an exit. The time required for the formation of pus is very uncertain. Sometimes it appears a few hours after congestion has set in, sometimes not until after many days, sometimes not at all.

Healthy pus is not offensive, but when the stagnation has proceeded so far as to injure the vitality of the part, the secretion is apt to become thin, acrid, and offensive.

There is a marked difference between pus and lymph. Lymph consolidates, hardens, and builds up the part on which it is deposited; while pus on the other hand diffuses itself through the natural textures, and softens, separates, and breaks them down, and either makes an exit for itself externally, or if confined burrows internally and forms abscesses.

Suppuration frequently supervenes on an undue and excessive formation of lymph. Lymph is apt to be deposited in quantities greater than required for the purposes of repair. From its tendency to accumulate and consolidate, it might, if permitted to remain, fill up and obstruct important organs and passages. Here nature, ever bountiful even in disease, interferes and prevents its undue accumulation by the production of pus, which breaks it up and causes its disintegration and removal. 


\section{Fifth result or Ulceration and Mortification.}

Ulceration generally arises from long-continued or excessive obstruction to the circulation in the part, which in consequence becomes deficient in nutrition and weak. The tissues then become softened, liquefied, and degenerate, and are cast forth as dead in minute particles.

Mortification results from similar causes, but in this case parts visible to the naked eye perish and slough away. It will be seen that the two processes differ in degree rather than in kind.

\section{Treatment of inflammation.}

We shall now endeavour to sketch out the principles on which the state known as Inflammation ought to be treated. Inasmuch, however, as every organ and tissue in the body is liable to take on inflammation, and almost each of them has some speciality in its organisation, which may under varying circumstances demand some modification in the application of any general rules ; inasmuch, too, as inflammation is often complicated with, aggravated or modified by other diseases; and further, inasmuch as inflammation, whether natural or artificially induced, is frequently a means of repair, which needs to be assisted and developed,the reader must not expect to receive sharply-defined instructions, but only a general idea of the sort of treatment necessary under the varying phases and circumstances of the state. At present, however, we shall only treat of inflammation as a disease. Its curative aspect will be considered hereafter.

The cause of inflammation, as stated in the beginning of this Chapter, is irritation of the tissue affected,- of its ultimate elements, -in consequence of which their normal power of selection is destroyed, and that of their attractiveness is increased. The removal of blood by bleeding cannot alter this state of affairs, nor can other lowering remedies, except in so far as that if the inflammation be superficial and circumscribed, local bleeding may relieve the congestion; but if exudation has occurred it cannot relieve this result. The exudation can only be absorbed by undergoing transformation. Now any such process demands strength, and is arrested by weakness.

"The strong pulse, fever, and increased flow of blood in the neighbourhood of the inflamed part are the results, not the causes of inflammation. They may be regarded as agents employed by nature for the restoration of the vital action of the diseased tissue. They may require to be modified, but no attempt must be made to get rid of them by such means as bleeding and depletives." (Abridged from Professor Bennett on the Practice of Medicine.)

In treatment our aim will be, 1st to check or diminish the inflammatory congestion; 2ndly when exudation has taken place, to further its removal; and 3rdly, if this cannot be effected, to render its products as little injurious to the system as possible.

The treatment of inflammation may, we think, be divided into two 
parts, namely, 1st that of the primary disease, or functional disturbance in the tissue; and 2ndly that of the disease after it has established itself.

358. Treatment of the primary disease, or disturbance of function in the part affected, otherwise called the inflamed part.

In the very earliest stages, namely that of irritation in the tissue or organ, the best treatment undoubtedly consists in removal of the cause, if it can be traced and found out.

When the cause is external, such, for instance, as a hay seed lodging in the eye, it is both easy to see it and remove it. With the removal of the cause, the part affected will in general soon recover itself. In other cases we may see and know the cause, such as a blow, but may not be able to remove it. Knowing, however, the cause, we may take measures to lessen its effects. In other cases, such as inflammation of the bowels, though we cannot be perfectly certain of the cause, yet we may pretty safely assume it to be some obstruction in the intestines, and we may accordingly endeavour to effect its removal by suitable means.

In most cases, however, we can neither see the cause nor find it out. Hence, as a general rule, we can do little more than assist nature by placing the patient in the condition most favorable for the restoration of a healthy tone in the system and part.

For this purpose in inflammation of Internal organs recourse should be had in the first instance to natural tonics. Of these the best and chief is cool fresh air in abundance. There is no other restorative at this stage to the tone of the part, to the nervous power, and to the circulation equal to this simple and easily obtained agent. With this view the patient should be promptly removed to a cool loose box, and warmly clothed and his legs bandaged.

As regards feeding, the appetite is the best criterion. In attacks on some internal organs, such as lungs, the appetite is generally lost from the first, but in inflammation of some other organs the patient may be inclined to feed. Corn, however, should be withheld, and food of an easily digested character, such as grass, carrots, or bran mashes, should be substituted for it. When the powers of digestion are enfeebled, as they always are either directly or by sympathy in serious internal attacks, food, if difficult of digestion, will not be assimilated, but will act as a foreign body, and cause further disturbance and increase of the symptoms. Still, so far or as long as the animal is inclined to feed, a fairly liberal diet may be allowed, and indeed is essential to the maintenance or restoration of the tone of the system. Laxative diet is most suitable, and will also be useful in keeping open the bowels, which in all such attacks, probably from want of nervous power, are apt to be constipated.

If by these simple means tone can be restored, and the blood at the inflamed part can again be set in more active motion, the attack may be said to be over; and the temporary congestion of the blood or hyperæmia in the neighbouring part will soon pass away. 
This favorable result, however, does not always ensue. The remedies to which we have had recourse may not succeed in restoring the normal vital functions of the diseased tissue, and the proper flow of the circulation; and we may soon have in the congestion of the blood in the part and neighbouring parts, and in its altered character, a formidable though in reality a secondary disease.

In cases of Superficial inflammation cold applications will be useful in the primary stage in checking the flow of blood into the part by causing the capillary vessels to contract, also in diminishing the congestion, in giving more tone to the tissue, and in rousing its vital powers to healthier action. In severe cases fomentations will be required in order to allay the irritation.

\section{Treatment of inflammation when established.}

In the treatment of inflammation, when established, we shall have to consider 1st whether the attack is local, diffused, or specific; 2ndly whether it is acute, subacute, or chronic ; 3rdly whether it is of a sthenic or asthenic type.

\section{Treatment of acute Local inflammation.}

In the treatment of an acute attack of local inflammation our object is to reduce the violence of the disease.

If the part be superficial and not very extensive, cold water dressings may be applied with the view of reducing the symptoms; but if the attack be severe or deep-seated, it is not probable that we shall be able to effect it sufficiently by such means. Fomentations, which act primarily by allaying irritation in the tissues, and secondarily by relaxing the coats of the vessels and thereby allowing an enlarged passage for the blood, will be needed. If by these means the irritation and subsequent congestion and hyperæmia can be reduced, the tissue affected will in favorable cases gradually recover its normal tone and vital powers, and the part will be restored to a healthy condition. If this effect cannot be produced, we shall have as a result either effusion of serum through the over-distended coats of the vessels, or one of the other results of inflammation mentioned above.

In the treatment of internal local inflammation, the above local remedies cannot be applied; and we shall have to consider whether the type of the disease is sthenic or asthenic. The treatment required will be found further on, under the head of Sthenic and Asthenic inflammation.

\section{Treatment'of subacute Local inflammation.}

Superficial local inflammation is seldom subacute. It is generally either acute or chronic. Subacute attacks are usually deep seated, as in joints, \&c. It is not possible to define any specific treatment for subacute cases. The nature and organisation of the parts must be carefully 
considered. Cold dressings, which might seem to be indicated, will not answer in many cases. In subacute inflammation of the joints, for instance, cold dressings might bring on rheumatism; neither do fomentations answer. Dry warm applications over the region of the part affected seem to answer best as a general rule. If treatment in subacute attacks does not bring about restoration of the parts to health, it is probable that the disease after a time will subside into the chronic form. Subacute inflammation seldom produces direct constitutional symptoms, though indirectly and after a time it may induce them through the medium of the changes which it causes in the structure of organs.

\section{Treatment of chronic Local inflammation.}

Our object in these cases is to raise the tone and vital powers of the part to greater vigour. As a local application a stimulating liniment or a light blister may be rubbed on. Much attention, however, must be paid to improving and strengthening the general health. Good feeding, good grooming, plenty of fresh air, \&c., are especially needed.

Chronic inflammation is not easily amenable to treatment, far less so than the acute attack. The vital power of the diseased tissue appears to be depressed, and unable to rectify the disordered state of its functions. The inflammation is therefore lingering and abiding. It often continues for a length of time without terminating in any result. If any result does occur, it will probably be ulceration.

\section{Treatment of Diffused inflammation.}

Diffused inflammation may be subacute or chronic, but is usually acute. Inasmuch, however, as it generally produces constitutional disturbance, we shall have in regard to treatment mainly to consider the type of the disease,-whether it is of a sthenic or of an asthenic type. The signs by which the sthenic may be distinguished from the asthenic form, have been described above in paragraph 350. The one type will need a very different course of treatment from the other.

We shall therefore divide this subject into the treatment of sthenic and asthenic inflammation,--premising, however, that our remarks also apply to those cases of local inflammation, which produce constitutional disturbance, as noted above in paragraph 360 .

\section{Treatment of Sthenic inflammation.}

In attacks of a sthenic character it is necessary in the first instance to lower the diet,-both on account of the primary disease, and of the constitutional disturbance resulting from it. There is, however, in general but little appetite. Aconite will be found a most valuable medicine in reducing the hardness and quickness of the pulse. It is believed to act by lowering the action of the heart, and in this way it allays the rapidity and force of the circulation, which is always increased in sthenic attacks.

Bleeding and purgatives, which in many respects would appear at first 
sight to be the simplest means of relieving the symptoms, must not be resorted to (unless in very exceptional cases), both because they unduly impair and lower the tone of the system, and because the sthenic stage often so quickly runs into the asthenic.

Extra clothing, bandages to the legs, hand-rubbing and other means of restoring warmth to the extremities have a most beneficial effect in equalising the circulation, the balance of which is disturbed by the congestion of a large quantity of blood in one part. Good nursing in all respects is of primary importance. The need of an abundant supply of cool fresh air cannot be overstated.

Under certain circumstances, which will be detailed more particularly under the heads of various diseases, such as inflammation of the lungs, the application of mild irritants repeated somewhat frequently is useful in giving tone to the parts and in rousing the circulation.

If the bowels are confined, as is frequently the case, a saline draught made of four ounces of acetate of ammonia and four ounces of sulphate of magnesia in a quart of water may be administered in the early stage. A slight effect on the bowels may be looked for in twenty-four hours. If necessary, the dose may be repeated.

When the powers of nature begin to flag, as they generally do after a time, vegetable tonics and diffusible stimulants may be administered with great benefit. When the fever which usually accompanies the attack has subsided, mineral tonics may be given. In the later stages the bowels generally become costive from want of tone. The remedy at this period will be found to consist, not so much in the administration of aperients, as in tonics and nutritious diet, milk, \&c., if the patient can be persuaded to take food.

\section{Treatment of Asthenic inflammation.}

In attacks of an asthenic or low type our chief care must be devoted to sustaining, and, if possible, raising the tone of the system, which throughout is unduly and often excessively depressed. Throughout the attack diffusible stimulants, such as carbonate of ammonia in combination with salines, may be given with the greatest advantage. The mode in which these medicines act in such cases has been explained in Chapter 17 on the actions and uses of medicines.

Every endeavour should be made to induce the patient to feed by tempting his appetite with grass, carrots, skim-milk or whatever he may fancy. Vegetable tonics may be given with great advantage. They give tone and rigour to the system, and often induce the animal to feed, when he would otherwise. refuse all nourishment. If there is no fever, or in other cases when the fever has subsided, vegeto-mineral tonics, such as hydrochloric acid with gentian, may be administered.

Extra clothing, bandages to the legs, friction, and other means of restoring and equalising the circulation, fresh air, and good nursing, are of the utmost importance. Mild irritants, as mentioned in the preceding paragraph, are also sometimes useful. 


\section{Later stages of Sthenic and Asthenic inflammation.}

Throughout the later stages of both the sthenic and asthenic attack our main object is to sustain the strength of the patient, so that he may outlive the course of the disease. For this purpose it is necessary that the powers of nature should be assisted by most careful nursing, good nutritious diet, warm clothing and bandages, and above all by an abundant supply of cool fresh air.

The results which may ensue are the same in all attacks of inflammation which do not end in resolution, namely effusion of serum, formation of lymph, suppuration, ulceration, or even mortification.

\section{Mortality from inflammation.}

Inflammation per se, except that of the bowels, usually terminates favorably. If death eventually ensues, we commonly find that it does not occur for some days or even weeks after the attack has subsided; and even then results from the formation of extensive abscesses, hydrothorax, want of strength, or some such secondary cause.

\section{After-effects.}

A severe attack of inflammation generally leaves behind it some trace of its effects in serous effusion, in the formation of lymph, in exudation, or in ulceration of the parts.

Thus for instance in inflammatory diseases of the lungs and airpassages the effused material may impede the freedom of the respiration; in inflammation of the joints it may become consolidated and organized into bone and produce anchylosis ; in laminitis it may be deposited between the sensitive and insensitive laminæ, and may occasion an alteration of the whole structure of the foot.

The chances of perfect restoration of the parts will very much depend on the strength and general health of the patient after the results of the disease have developed themselves. If the patient has been unduly lowered by depleting measures and violent counter-irritants, it is probable that the system may not have strength and energy enough to take up the effused products, and so bring about complete restoration of the parts. But if on the other hand the strength has been carefully husbanded and sustained, we may fairly hope for a favorable result.

\section{Treatment by Depletives and violent Counter-irritants.}

The Author is aware that the views which he has put forward in regard to the treatment of inflammation, are not those held by the old school.

Violent depletives, such as bleeding, are now abandoned; and violent irritants applied to external parts have well-nigh fallen out of use. As regards the first, it was urged that the system was unable to maintain two violent actions at one and the same time, and that therefore if a sufficient amount of irritation could be established in a safe external 
part such as the skin, the internal inflammation would be reduced and subdued. The rising of a blister was wont to be considered a favorable symptom, being supposed to indicate that the external had vanquished the internal inflammation, and succeeded in drawing the blood from the internal organ to the surface. If on the other hand the blister did not rise, it was supposed that the internal inflammation must be very violent.

It is difficult to conceive that any sensible portion of the blood congested in a large vascular organ, such for instance as the lungs, can really be withdrawn by any such means to the skin.

Strong blisters were also used, not so much with a view to counterirritation, as for the purpose of rousing the diseased parts to renewed activity by sympathy with the effect proauced by the irritant in the neighbouring external part. The more violent the inflammation, the stronger and more extensive, it was argued, ought to be the blister. It is a rule in nature, that if any part can be excited to action, the neighbouring parts sympathise with it and are thereby roused to energy. On this principle it is supposed that the blood which has collected and is stagnating in the inflamed organ, may again be set in more active motion by means of a blister applied to the skin.

From this view the Author only differs as to the means taken to produce or to attempt to produce the desired effect. In his view, whilst a mild irritant repeated somewhat frequently, as recommended above, may be beneficial, a violent blister is more likely to cause paralysis of the functions of the part, than to restore tone and vigor.

Again, any such violent treatment renders the patient uneasy and prevents his resting; and further, the absorption of some part of the irritant into the system, which is very apt to take place, causes great prostration of the vital energies. From such prostration and uneasiness the animal will probably refuse all food.

We do not say, that an animal so treated will necessarily die, but we do say, that he is placed in a far less favorable position for rccovery, than when his strength is husbanded by the avoidance of such violent measures.

\section{Specific inflammations.}

Specific inflammations, namely those attacks which result from the presence of blood or animal poisons, such as glanders, farcy, ophthalmia, \&c., will be treated of under the heads of the diseases to which they refer.

\section{Curative inflammation.}

Hitherto we have spoken of the state known as inflammation as a disease to be combated, rather than as regards its other form, namely as a curative agent.

Inflammation, or in other words an abnormal supply of blood, produced by irritation in the neighbourhood of a part, is necessary for the 
cure of all wounds (except those healed by direct union or adhesion), for the repair of fractures, and for the building up of new material to supply accidental loss of tissue.

The process by which inflammation acts in these cases is as follows: More blood is brought to the part, congestion ensues, and then exudation takes place through the distended coats of the vessels. Lymph is formed from the fibrinous material so exuded from the blood. Lymph, as previously stated, has a remarkable tendency to become organised. It generally partakes, when organised, of the nature of the structure into which it is exuded. Thus if a cavity in the flesh has to be filled up, the lymph when organised will fill it up with a new growth of similar structure, or if the broken ends of a bone have to be united the lymph will knit them together and in due time become bone.

Simple as this process may seem, there are many considerations connected with it, which will be treated of in the next Chapter.

\title{
CHAPTER 19.
}

\author{
OF INFLANMATION, AR'TIFICIALIY INDUCED, AS A CURATIVE \\ AGENT.
}

372. Of inflammation artificially induced as supplemental to reparative action. 373. Of inflammation as a stimulant to parts deficient in vital energy. 374. External stimulation for the relief of inflammation in internal organs. 375. Counter-irritation. 376. Artificial inflammation as an excitant to the absorbent system. 377. Of irritants used to produce Hyperamia or Inflammation. 378. Action of External Stimulants. 379. Friction und heat. 380. Liniment of Ammonia or Turpentine. 381. Tincture of Iodine. 381a. Iodide of Potassium. 382. Cantharides in reduced strength. 383. Mustard. 383a. Ammonia. 384. Biniodide of Mercury (veduced strength). 384a. Perchloride of Mercury. 385. Action of Vesicants. 386. Cantharides. 387. Biniodide of Mercury in full strength. 388. Setons. 389. Punching. 390. Firing. 391. Application of Irritants.

Inflammation, as previously stated, may be either a diseased or a curative action (see para. 371 , in previous Chapter).

In the present Chapter we shall endeavour to explain the advantages and means of inducing inflammation artificially in certain cases.

1st. As supplemental to curative reparative action.

2nd. As a stimulant to parts deficient in vital energy.

$3 \mathrm{rd}$. As a means of producing what is usually termed counter-irritation, but which we think may more properly be regarded as stimulation. 
4th. As a means of exciting the absorbents to greater activity in the removal of newly-formed deposits.

\section{Of inflammation artificially induced as supplemental to reparative action.}

All parts of the body are formed from the blood; the blood is the sustaining and repairing element of the vital frame. From it are drawn the materials needed for the daily sustenance of the frame. From it in cases of injury an increased quantity of reparative material is required to be drawn for the repair of the injured part.

This condition is known as inflammation.

But it often happens that the inflammatory action, though violent, perhaps over-violent at first, becomes slack or subsides before the process of repair is completed.

In such cases it will be necessary to apply Stimulants or Vesicants according to the requirements of each case, to maintain or re-excite the inflammatory action needed to complete the process of repair.

This want is especially apt to be felt in parts of low organisation, i.e. not endued with much nervous power, or many blood-vessels, such as tendons, ligaments, bones, \&c.

Artificial inflammation for the purpose of repair must never be induced until the original inflammation has completely subsided, and the parts have become cool.

\section{Of inflammation as a stimulant to parts deficient in vital energy.}

Inflammation artificially induced is often needed to rouse to new and healthier action parts which, even though highly organised, have become through disease deficient in vital energy; for instance, the healing process in some ulcerative diseases is of so sluggish and languid a nature, that in many cases it is best treated by exciting a mild degree of inflammation (hyperæmia) in the surrounding parts.

Again, it may be sometimes beneficial to bring more blood to parts, which though not diseased, are deficient in vital energy. For instance, if the crust of the foot be weak, much advantage often results from exciting, by means of an irritant, hyperæmia in the coronary substance from which the hoof is secreted.

Furthermore, inflammation artificially induced has often a valuable effect in rousing to a new and healthier action, not merely the part to which it is immediately applied, but also the neighbouring structures.

\section{External stimulation for the relief of inflammation in internal organs.}

In cases where the inflammatory action in internal organs is excessive, i.e. beyond the amount required for the purposes of repair, we can only act on the neighbouring parts, and we must endeavour by mild irritants, more properly called stimulants, to rouse them to increased action; and by their increased action relieve the more important parts unduly affected. 
When so stimulated, the blood-vessels and absorbents of the neighbouring parts will abstract and carry off some portion of the effusion, and other products of the inflammation existing in the internal organ.

With this view, for example in inflammation of the lungs, many practitioners apply a stimulant to the skin of the neighbouring parts. By means of the stimulant the blood-vessels and absorbents of the skin are roused to increased action, and absorb a part at least of the excessive products of the inflammation in the internal organs.

The plan of applying even mild irritants to the skin in cases of lung disease, during the acute stage, is rapidly giving place to the system of treatment by fomentations. Many veterinarians consider that the irritation and nervous excitement frequently set up in a marked degree, and followed by corresponding depression, renders the use of irritants inadmissible in most cases of acute pulmonary disease.

In all such cases the stimulant must be mild. We cannot act by counter-irritation (see next par.). We can only stimulate the neighbouring parts to increased and healthy energy of action. We do not want to create a new disease, such as violent inflammation of the skin.

If produced, it would paralyse for the time at least the power of the blood-vessels and absorbents of the skin. We merely seek to assist nature by stimulating the power of the blood-vessels and absorbents of the skin to increased action.

Again, all parts by constant irritation become exhausted and dormant. Hence it is always better to apply the stimulants at intervals. In the meantime the powers of nature revive, and after an interval the stimulant may be again applied with beneficial effect. Hence in such cases we employ stimulants of a somewhat mild nature. The effect produced is not permanent, and is not intended to be so. The object of each application is to produce a short rally in the powers of the part.

Further, rapidity of action is of great importance in many of these cases. For this reason we employ mustard, or mustard and ammonia in combination, which are very rapid in their action.

\section{Counter-irritation.}

In the old days of medicine it was supposed that inflammation in important internal organs could be relieved by what was known as counterirritation. The idea was:

That nature could not sustain two violent actions in neighbouring parts at one and the same time-that the more violent of the two would exhaust the less violent.

On this idea a strong blister was applied to a safe external part, - i.e. the skin, with the view of abstracting the abnormal quantity of blood, which was occasioning dangerous inflammation in some neighbouring important part, such as the lungs. On this idea it was supposed that in inflammation of the lungs the abnormal quantity of blood in the lungs could be withdrawn by the action of a counter-irritant, from those great and important organs to the skin. 
This idea is now known to be a fallacy, no such abstraction of blood from an internal inflamed organ can take place by means of an irritant applied to an external part. The skin is supplied with blood by superficial vessels. The internal organs are supplied by deep-seated vessels.

We cannot act by counter-irritation in the sense in which that expression was understood in former days. But relief may be given, as explained in the preceding paragraph, by gently stimulating the bloodvessels and absorbents of the neighbouring external parts to increased energy.

\section{Artificial inflammation as an cxcitant to the absorbent system.}

Stimulants are often beneficially applied to newly-formed deposits, with the view of exciting the blood-vessels and absorbents to greater energy in taking up the less solid parts of the new deposit.

All newly-formed growths, and deposits are derived, as the reader is aware, from material exuded from the blood-vessels of the part affected. Before such exudation can take place, there must necessarily be swelling and congestion of the blood-vessels, or what is usually termed inflammatory action. The growth and deposit is at first soft, because the effused material is liquid. In due time the more liquid parts are taken up and carried off by the blood-vessels and absorbents, and then the more solid parts consolidate.

In the treatment of such cases the first object is to check the increased action of the blood-vessels by giving the animal entire rest and by applying cold bandages, \&.c. When the excessive inflammatory action is subdued, the process of absorption is at first generally pretty rapid. After a time, however, the energy of the part in most cases becomes deficient and the residuum of the deposit begins to consolidate. Stimulants may be useful in such cases in reviving the powers of the blood-vessels, but it must be a rule, that the stimulant be not applied until it is required, or in other words until the powers of nature begin to flag. In most cases stimulants may be safely applied immediately after the parts have become thoroughly cool.

All abnormal growths, however, even without any treatment, have a tendency in time to become absorbed.

Hence we frequently find the legs of an old horse almost free from the bony deposits, which disfigured them in the days of his youth.

It will readily be seen, that the application of irritants or stimulants to parts, in which active inflammation is still present, is wholly erroneous. It is simply adding fuel to an existing flame.

Many quack remedies are recommended as specifics for the absorption of bony deposits, tumours, and other new growths. No such specific, however, exists. All we can do is to assist nature to take up the deposit or some part of it.

The advisability or otherwise of attempting to hasten the process of absorption must depend on the ever varying circumstances which surround each particular case. It is impossible to lay down any general 
rule. The Author can only recommend, that, unless the new growth cause lameness or is a great eyesore, the time of absorbing it should be left to nature.

377. Of Irritants used to produced Hyperæmia or inflammation.

Irritants may be divided into two classes.

1st. External Stimulants.

2nd. Vesicants.

\section{Action of External Stimulants.}

External Stimulants, or Rubefacients, are those irritant agents which, when applied to the skin, produce redness and superficial inflammation in a comparatively mild form. By the irritation which they produce, they excite the circulation and cause more blood to be brought to the part. Hence they are useful in some cases in accelerating the repair of injured structures. They also give tone to parts, which from debility or other causes have become deficient in vital energy ; and in cases of newly formed tumours, thickening of the skin, and such like ailments, they are useful in exciting the blood-vessels and absorbents to greater energy in taking up and removing the abnormal growths and deposits.

They are also frequently and beneficially employed on the revulsive principle in hyperæmia or congestion in the internal organs.

A stimulant for instance applied to the sides has often a marked effect in relieving pleurisy.

Friction, heat, liniment of ammonia, or turpentine, tincture of iodine, iodide of potassium, very mild preparations of cantharides and biniodide of mercury, are the stimulants in common use.

\section{Friction and Heat.}

The mildest and one of the most valuable stimulants is friction by the hand. It is especially useful in mild superficial inflammation, e.g. all horsemen are conversant with its beneficial effects in reducing swelled legs after a hard day's work.

The objection to it is that it is troublesome and tedious to servants.

Its effect may be considerably increased by the moderate heat produced by the application of a flannel bandage after the friction.

\section{Liniment of Ammonia or Turpentine.}

A useful stimulating embrocation for application to the skin may be made as follows :

Strong Water of Ammonia . 1 part. Water . . 1 part.

Oil of Turpentine . . . 2 parts. Olive or Linseed 4 parts.

This embrocation may be diluted, if necessary, by adding more oil, or its activity may be increased by the addition of more ammonia.

or Camphor . 1 oz. Rectified Spirits 4 oz.

Olive Oil . 1 pint. Strong Water of Ammonia $2 \mathrm{oz}$ 
Dissolve the camphor in the spirits, and mix the whole together, so as to form a liniment.

380a. Soap Liniment.

Soft Soap - . . 2 oz. Camphor - . . $\frac{1}{2}$ oz.

Proof Spirit . . 1 pint. Solution of Ammonia 5 oz.

Dissolve the soap and camphor in the spirit, then add the solution of ammonia, and filter for use.

\section{0b. Lead Liniment.}

Solution of Sub-acetate of Lead, 1 part. Olive Oil, 4 parts ; mix well.

\section{Tincture of Iodine.}

Tincture of Iodine is sometimes employed as a mild stimulant to promote absorption of effused fluids, or to remove abnormal growths. It should be painted on the part daily until soreness is produced.

Tincture of iodine is prepared as follows :

Iodine . . . 1 part. Rectified Spirits 8 parts. Mix.

The activity of tincture of iodine may be increased by the addition of 1 part of iodide of potassium.

\section{1a. Iodide of Potassium.}

Ointment of Iodide of Potassium composed of one or two parts of lard is a safe and mild stimulant. The mode of application is very similar to that recommended infra for biniodide of mercury in reduced strength. Its use may, if required, be continued for a length of time (see paragraph 384).

\section{Cantharides in reduced strength.}

Although Cantharides is ordinarily used as a vesicant, it is frequently employed in reduced strength as a stimulant for the purpose of rousing the absorbents to increased action.

The preparation is usually made as follows :

Powdered Cantharides . 1 part. Olive Oil . 12 parts.

Digest in a Water bath for 3 hours and filter whilst hot. or Powdered Cantharides . 1 part. Dilute Acetic Acid . 12 parts. For this purpose however biniodide of mercury is to be preferred.

\section{Mustard.}

Mustard is very rapid in its action as a stimulant. It should be moistened by cold water, and then tepid water should be added until it has the consistency of that used for the dinner table. On no account whatever must hot water be used, as it destroys the vesicatory property of mustard. 
Mustard is generally applied by spreading it on whitey-brown paper cut to the required size. The plaster so made is self-adherent. The plaster should not be left on more than 15 minutes. If left on longer, the mustard is apt to be absorbed, and then produces debilitating effects on the system. The plaster may be reapplied at short intervals, say six hours, if needed, two or three times, but not more. The mustard at each application should not be permitted to remain more than 15 minutes on the skin, and should then be washed off.

Plasters are generally used. But the better plan is to take as much of mustard so prepared as a man can hold in the hollow of his hand, and rub it very gently on the part affected until the skin is reached, and then leave it there, unless the symptoms of the case indicate the need of further treatment, in which case it must be washed off before renewed action.

In all cases the action of the mustard requires to be most carefully watched. If the application produces excessive irritation and increased feverishness, it must be at once discontinued. The pulse must be taken from time to time. A marked increase in its beats will tell us plainly that the application is doing harm; whilst on the other hand, if it is relieving the congested condition of the part affected, the pulse improves in tone and becomes more tranquil.

\section{3a. Ammonia.}

On account of its volatile character and severe action, Ammonia is very seldom used alone, but generally in combination with mustard or other agents. One ounce of strong ammonia added to one pound of mustard will considerably increase its activity.

\section{Biniodide of Mercury (reduced strength).}

Biniodide of Mercury in reduced strength, $i$. e. one part of biniodide to twelve of lard, is a very useful stimulant. It is mild in its action, but its effect is tolerably abiding. It is much used to assist nature in taking up newly formed tumours or growths bursal, otherwise called synovial enlargements, and in slight sprains of ligaments and tendons, and in thickening of the periosteum.

If moderately employed, its effect is not so severe as to throw a horse out of work for more than a couple of days. This is a great advantage. It should be reapplied at short intervals, soon after the effect of the previous application has completely passed away. Practically it may generally be reapplied every nine days, until the needed effect is produced.

\section{4a. Perchloride of Mercury.}

A preparation of Perchloride of Mercury, commonly known as corrosive sublimate, is a useful application in cases where actual vesication is 
not required, and is often employed to promote the absorption of abnormal deposit.

The formula for its preparation is :

Perchloride of Mercury $1 \mathrm{drachm}$.

Rectified spirits 1 ounce.

Dissolve the Mercury in the spirits, and apply a moderate quantity with a stiff brush.

\section{Actiun of Vesicants.}

Under the head of Vesicants, otherwise termed Blisters, are included all the applications to the skin, which produce vesicæ or watery effusions from the cutaneous blood-vessels.

Vesicants act much more severe than stimulants, and produce a deeper seated inflammatory action of the true skin. The quantity and rapidity of the watery effusion vary with particular agent employed.

The Vesicants in most common use are Cantharides and Biniodide of Mercury.

Setons and Firing, though they cannot be exactly classed as Vesicants, have a similar action, and may properly be conveniently considered in the Chapter on Irritants (No. 19).

\section{Cantharides.}

The Vesicant in most use is Cantharides or Spanish Fly. It is in general safe and effective, and with proper care does not leave any permanent blemish. The irritation which it produces is abiding, and hence it is much used in cases of injury to parts of low vital or reparative power, such as tendons and ligaments. It has the advantage that if its effects fail before the process of repair is completed it can be repeated.

On the other hand it is open to the objection that, when applied over a large surface, or with too great frequency, or to parts in a weak or inflamed state, it is apt to be absorbed into the system. When so taken up it generally acts on the kidneys and produces great prostration of strength.

Its effects, however, if becoming too severe, may be diminished by dressing the part with liniment of lead; or the blister may be washed off, and the part dressed with oil.

Before the blistering liquid or ointment is applied, the hair of the part should be closely clipped or shaved, and the skin washed to remove grease or scurf.

To prevent the horse from gnawing the blistered part, his head should be tied up for 2 or 3 days, after which a cradle should be put on and the head may be let down.

A blister of Cantharides may be made as under: Cantharides . . 1 part. Olive Oil . . 6 or 8 parts.

To be digested in a water bath and strained through muslin. or Cantharides . 1 part. Lard . . . 6 parts.

Great care should be taken in the purchase of Cantharides, as that sold in inferior shops is frequently adulterated. The Flies should be freshly powdered, and kept in a dark place or in a blue bottle. 


\section{Biniodide of mercury in full strength.}

Biniodide of Mercury in full strength, i.e. 1 part of biniodide to 8 of lard, commonly called "red ointment," is a vesicant.

It is generally supposed to have a specific effect in exciting the action of the absorbents, and is therefore frequently emp'oyed to assist nature in the removal of osseous and other deposits.

It is sharp in its action, but very irritating, especially to nervous and high bred horses; and for this reason should never be used if any fever is present. But for the reduction of indolent swellings it is a valuable remedy.

It is also useful in some cases, where the preparations of Cantharides are inadmissible on account of the facility with which the active principle of the Spanish Fly is liable under certain circumstances (see preceding paragraph) to be absorbed into the system.

\section{Setons.}

Setons in common with other irritants produce hyperæmia in the parts to which they are applied; but the results arising from the hyperæmia are somewhat different from those caused by firing or blisters. Setons act mainly on the deeper seated tissues, and produce their effects by inducing the formation of pus from the lower layer of the skin rather than mere vesication or effusion from the superficial blood-vessels.

By this action they appear to have a powerful effect both in promoting the repair of the deeper seated tissues when injured, and also in removing abnormal deposits.

According to the nature of the material employed setons produce a greater or less amount of irritation and suppuration.

A silk thread for instance will cause but little irritation, whilst a horsehair tape will produce a violent effect. Further, a greater or less effect may be induced according to the size and length of the seton, and the amount of skin detached along its sides. The length will of course depend on the extent, seat, and nature of the lesion.

As compared with other agents, setons have in some cases the advantage of exciting the hyperæmia nearer to the seat of the disease, as for instance in sprains of tendons, and moreover they may be left in for any length of time, and consequently their action may be maintained as long as necessary. These properties are of great value in the treatment of disease or injury to tendons and other parts of low reparative power, and also in some chronic affections. Setons if properly managed leave scarcely any blemish.

Their use, however, is attended with some inconveniences, which will probably prevent their ever becoming a popular remedy. Their management requires great care and attention from stable servants. The seton should be pulled up and down every morning and evening. The matter or pus, which collects in the channel, must on each occasion be thoroughly and carefully pressed out along the whole length, by running 
the fingers firmly but cautiously along the outside; and the orifices themselves must be frequently washed with warm water in order to keep them clean and open. If these details are neglected, the channel and orifices will soon become choked, and the pus will make exits for itself by large irregular holes, and permanent blemishes will probably be the result. In order to secure easy exit for the pus, it is desirable, if the seton exceeds six inches in length, that an intermediate opening should be made with the scissors. The tape should be renewed every ten days, or it will become rotten and may break. It should be secured at both ends by a light piece of stick about three quarters of an inch long, or the two ends may be brought together and knotted.

\section{Punching.}

The old-fashioned operation known as Punching was effected by an instrument closely resembling a saddler's punch, which was driven through the skin and subcutaneous tissues and through the periosteum. Into the hole so made corrosive sublimate or other caustic was in some instances inserted.

Some years ago punching was much recommended as a remedy for spavin, splint, and other such exostoses, but its effects are apt to be violent and uncertain. An undue amount of inflammation is frequently excited, which is likely to aggravate rather than to lessen the predisposition of the part to throw out ossific material, resulting in many instances in a permanent stiff joint. The more familiar remedies of blisters and setons are much safer and more successful.

\section{Firing.}

Firing, otherwise termed the actual cautery, is the most powerful and rapid of all agents used to produce inflammation artificially.

On account of its more energetic action it sometimes succeeds in producing the desired effect, even after other remedies have failed. Firing has also the great collateral advantage of compelling the owner to throw his horse out of work for a considerable length of time. On the other hand, it has some considerable disadvantages. If at all severe, it produces a permanent blemish. Again its effect, though exceedingly violent, is but temporary. Nature, as previously stated, is unable to sustain any very violent action for any great length of time. In consequence it generally becomes necessary after firing to apply a blister to keep up the irritation, and thus afford nature the means and the time needed to complete the process of cure. This is particularly apt to be the case in injuries of tendons and other structures of low reparative power.

We have stated above that only one degree of inflammation, namely, that intermediate between the excessively violent and the torpid stage, is suitable for the purposes of repair. The reader may therefore ask, how does so violent an irritant as the actual cautery answer this end? This apparent contradiction, however, admits of explanation.

In sprains of ligaments and tendons and such like cases we do not, 
and cannot apply the actual cautery to the seat of the disease, but only to a neighbouring part. We produce violent irritation in the outer skin, but the injured part partakes only in a modified degree of the excitement set up in its neighbourhood. Firing is simply the means by which sufficient amount of active inflammation is set up in the injured part to enable nature to complete the process of repair.

An opinion however is prevalent, that much of the benefit of firing in cases of sprains of ligaments and tendons arises from its producing contraction of the skin, and thereby forming a permanent bandage round the injured part. There are great reasons, however, to doubt whether any such permanent contraction of the skin takes place. The vitality of the skin is not destroyed by firing, and living skin is, we know, highly elastic. If the vitality were destroyed by the operation, the dead part would by the ordinary processes of nature be cast off, for no union can exist between a dead and living portion of the body. It is argued, however, that though the vitality of the skin is not destroyed altogether, yet the new skin, which replaces that injured by the firing iron, is not true elastic skin, but a hard fibrous semi-tendinous material incapable of expansion, useful indeed in uniting the edges of the skin, which has been cut through in many places, but differing widely from the original tissue.

Admitting this to be true, we still think that there is an amount of elasticity in the portions of the skin not destroyed by the firing which must prevent its acting as a permanent bandage.

Again the leg, for a long time after the wounds in the skin caused by the operation have completely healed, remains larger than usual.

Now if the vitality of the skin were really destroyed by the firing, the skin would not contract on the leg, as it gradually became finer; and therefore, far from acting as a permanent bandage, it would fit rather loosely round it. We must therefore repeat our belief, that the benefit derived from firing arises simply from its action as an irritant, promising a more than usually lasting effect. Of all notions connected with firing the most absurd is the idea that it may be useful as a preventive against future lameness. There are people who fire, or, as they term it, "just touch with the irons," the inside of the hocks of all their young horses to prevent their having spavins, and also the posterior part of the hocks to prevent their having curbs. What benefit they expect to derive from thus artificially exciting irritation and inflammation in a sound hock, it is hard to say.

Others, with scarcely more reason, fire the hock after curb or spavin has completely formed, although no lameness is caused. There is no sense in this. Curb, though it generally produces lameness during the process of its formation, rarely does so after the parts have consolidated. Again, if a spavin, when completely formed and consolidated, is so placed that it does not interfere with the movements of the joint, the probability is that it will never cause lameness.

Frequently the results occurring from the application of the actual cautery are of a serious character. The shock produced by the violence 
of the "remedy" is not unlikely to cause an excessive amount of irritation, especially if the patient be of a highly nervous tcmperament.

\section{0a. Thermo Cautery.}

Firing by Thermo Cautery is popular in France, being found to give excellent results. In this method of firing the heat is applied to the subcutaneous tissue by means of a platinum tube heated by a spirit lamp at its base. The instrument can be procured from Griallot, 4, Boulevard St. Martin's, Paris (Bourquet's patent).

If properly used very little blemish results. It is most suitable for use in exostoses (bony enlargements) clear of joints or of sufficient size to avoid any risk of penetrating them. It must be confessed, however, that this implement is safe only in the hands of a skilful operator.

\section{Application of Irritants.}

We have described above in general terms the action and mode of the application of the various Irritants commonly used in Veterinary practice.

The important question now arises, namely, what irritant should be employed in each case?

The answer to this question will be found more or less in succeeding Chapters, under the head of the treatment of the various diseases and injuries to which horses are subject.

\section{CHAPTER 20.}

\section{ABSCESSES.}

392. Nature of an Abscess. 393. Hea'thy Pus. 394. Unhealthy Pus. 395. Mode of formation of an Abscess. 396. Treatment. 397. Modes of opening Abscesses. 398. Various kinds of Abscesses. 399. Sinus. 400. Serous Abscesses. 400a. Capped Elbow.

\section{Nature of an Abscess.}

An abscess signifies a collection of pus in any of the tissues or organs of the body. In structure an abscess consists of an accumulation of pus, in the midst of and surrounded by a membranous layer of lymph, which constitutes the walls of the abscess. This wall varies in thickness and consistence, being in some cases scarcely perceptible and in other cases forming the larger part of the abscess. 
Suppuration may occur in any of the tissues of the body, but it is most frequent in the glandular structures, the skin, muscles, and mucous membranes. Cartilage and tendons suppurate only very slowly. Nerve tissues and arteries are but little susceptible of taking on the process of suppuration or of ulceration. Serous membranes, though they may suppurate, yet, more generally, under the influence of inflammation exude serum, or water, or lymph.

Suppuration or the formation of pus may, according to circumstances, be either a healthy or an unhealthy action, though it is in all cases a morbid process. Suppuration may set in for various reasons. It may be a means of removing some poisonous matter from the blood, or some foreign substance impacted in the soft parts of the body. In all such cases it serves a beneficial end, and must then be regarded as a healthy action.

A tendency to suppuration may also be generated by a disordered state of the blood after some lingering and weakening illness, such as fever; or it may be the result of inflammation caused by blows. In other cases the tendency may be a consequence of breathing impure air, or of insufficient or bad food, or of disordered nutrition, or of any such causes which produce impoverishment of the system. Under certain circumstances, hereafter to be described, the suppurative matter forms abscesses.

\section{Healthy Pus.}

Pus is a peculiar fluid, formed under certain diseased conditions of the system. Healthy pus is of a yellowish-white colour, free from offensive smell, and of the consistence of cream. It consists of serum holding a number of globules in suspension. Each globule consists of a cell wall enclosing nuclei, oil globules, and small granules. Healthy pus is occasionally reabsorbed into the system without producing any bad effects. Nature sometimes cures an abscess in this way.

\section{Unhealthy Pus.}

There are several varieties of unhealthy pus. It usually has an offensive smell. It is called sanious, when it contains blood; ichorous, when it is thin and watery; and muco-purulent, when it consists of mucuscontaining cells. Puriform matter is formed by the softening down of a fibrinous exudation without the formation of true pus cells. If suppuration is too profuse it will exhaust the vital powers. Unhealthy pus, if reabsorbed into the system, will produce very injurious results.

\section{Mode of formation of an Abscess.}

The formation of an abscess takes place in the following manner. A part from any cause, we will suppose, has become inflamed. In the centre of the inflamed part the products effused by the process of inflammation begin after a time to break up and liquefy; or, in other words, there are signs of the commencement of the suppurative process. 
If there is a free depending exit for the matter, there is no need of an abscess; but it often happens that there is no such exit, and consequently the matter cannot get out. In such cases nature makes provision for its temporary retention and ultimate expulsion by means of an abscess. If the pus were to float about free among the tissues it might affect them very injuriously, and might act as a poison, or at least as a foreign body.

To obviate this, nature, by means of the fibres of the lymph surrounding the outer circle of the inflamed part, forms a membrane with a smooth, villous, secreting surface. In this sac the pus is retained, instead of floating about among the tissues. The contained pus, however, gradually seeks to reach the surface of the skin or a mucous membrane; and then by means of pressure, which causes ulceration and rupture of the tissues between the cyst and the external air, the pus is evacuated. The submaxillary tumour in strangles is a very good example of an abscess.

Sometimes the abscess is not able thus easily to discharge its contents, but a communication is established with the surface by means of a narrow canal with walls of a membrane similar to that enclosing the abscess. This canal is called a Sinus. When the sinus is constricted at its external orifice, it is called a Fistula. In cases of long standing the walls of the sinus often secrete a thin, serous, and sometimes offensive secretion.

The formation of an abscess, especially if acute, is often accompanied with fever. The part is painful, red, and swollen. Indications of relief are given by the tumour becoming softer and beginning to point; and at the same time fluctuation may be felt in it. Ultimately the integument ulcerates, and the pus is discharged. As soon as suppuration occurs, there is abatement of the fever.

\section{Treatment of an Abscess.}

The treatment required is local. Herein often lies a difficulty. In very many cases we can do nothing, because the part, as for instance in the lungs, cannot be examined. Improvement in the condition of the animal will, however, assist in bringing about the curative process.

When the parts can be reached, the best plan is to open the abscess at its most depending point, as soon as we judge by the softening of the external membrane and by the sensation of pulsation or fluctuation that it is ripe or nearly ready to burst; or in the case of a chronic abscess it may be necessary to open it to the bottom and to apply stimulants. If the abscess is internal, we must wait until by the operation of nature it bursts.

If the suppurative matter has burrowed and formed sinuses, it will be necessary to afford it a free exit; and in very many cases it will be necessary to cut the walls of the sinus completely through to the bottom, so as to convert it into an ordinary incised wound, which may be healed by granulation. 
If the abscess, instead of becoming pyramidal and pointing to a surface, spreads in breadth and circumference, it should be opened at once, because in such case there is no tendency to become encysted or circumscribed. Abscesses under strong fascia should also be opened at once, because that membrane will resist for a length of time the ulcerative process by which the suppurative matter gains its exit, and in consequence a sinus will probably form unless an artificial opening is made. Abscesses which are caused by the presence of irritant fluid should obviously be opened without delay, as well as those in loose areolar tissue, because in such cases there would be an undue tendency to spread. Abscesses in the neighbourhood of joints or of important organs should also be opened early, lest the ulcerative process should affect those structures.

The suppurative process, if it is unduly slow, may be assisted and hastened by the application of fomentations or poultices, or by a light blister; but it is essential that this latter agent should not be applied until the abscess shows signs of coming to a head. Too early an application of such an agent is apt to disperse the matter which is forming or about to form.

For abscesses in internal parts we can do nothing more than place the patient in a condition favorable for their development by good feeding, good care, \&c.

It is hardly ever, we may remark, desirable to check or disperse the matter formed or seeking to form. The tendency to form an abscess is usually an indication that there is something in the system which nature for her own wise reasons wishes to eliminate.

\section{Modes of opening Abscesses.}

An abscess, in parts which can be reached, is usually opened by the knife when the proper time has arrived, i.e. a little before it would burst naturally. Two advantages are gained by opening it artificially, namely, first the opening may be made at the point most favorable for the escape of the pus, and secondly a slighter blemish is made by a clean incision than by the large irregular opening made by nature, i.e. by the process of ulceration of the integuments.

Any pus which remains after opening should as far as possible bo squeezed out gently, and the cyst or sac may be injected with warm water from a syringe twice a day for two or three days, and the edges of the wound must be carefully kept clean. In some cases irritation of the cyst may supervene, with fever and pain and a discharge of sanious pus. To the warm water recommended above some slightly stimulating lotion, such as diluted ammonia, may be added with a view of bringing about a healthier action of the parts. In other cases the presence of a foreign body may prevent the abscess from healing, and possibly a sinus may result. Prior, however, to the formation of a sinus, such cases are best treated by applying stimulants to the surface or by injecting stimulating 
lotion. For the treatment of a sinus the reader is referred to the latter part of this Chapter.

\section{Various kinds of Abscesses.}

Abscesses may be divided into acute, chronic, and specific.

The acute abscess may be taken as a type of the disease under ordinary circumstances. Though often attended with pain and fever, it generally runs its course quickly, and therefore seldom needs any assistance to bring it to a head. Chronic abscesses are those which slowly appear, without any constitutional disturbance except swelling. The cause of their appearance is often not very apparent. They frequently require to be stimulated by a blister in order to hasten on the needful processes. Specific abscesses are those which result directly from some disease, such as strangles.

Abscesses are frequently a result of diffuse and violent inflammation in a part. They also occasionally occur as a consequence of phlebitis or pyæmia. They may occur in various parts of the body, and especially in the mesentery after an attack of strangles, when the tumour has not formed in the regular manner.

\section{Sinus.}

A sinus is a hollow passage lined by a dense fibrous membrane, and usually communicating with a suppurating cavity. This passage always opens at one end on the skin or on some free surface, whilst the other end is at the seat of irritation. The sinus therefore is not the disease itself, but only the tube leading from the diseased part to the external surface. Hence applications to a sinus are of no use unless they reach the bottom of the passage, i.e. to the seat of the disease.

When healthy action has set in at the seat of the disease, it often happens notwithstanding, that the lining membrane of the sinus continues to pour out an exudation. In such cases the only plan is to cut through its walls and to make a complete division. The surfaces must then be prevented from healing too quickly by inserting a pledget of tow between them. An ordinary incised wound will thus have been produced, and nature will then probably heal up the parts by granulation. In minor cases it may be sufficient to inject the sinus with a stimulating or caustic lotion.

\section{Serous Abscesses.}

What is commonly called a Serous abscess is not in reality an abscess, but merely an effusion of serum into the cellular tissue. A true abscess must contain pus. Iodine ointment may be applied, and iodide of potassium may be given internally with a view of promoting absorption. These means often fail. The surest remedy is to freely open the abscess with the knife, taking care to establish a dependent orifice. The wound so caused needs only to be treated as an ordinary incised wound. See par. 754 . 
400a. Capped Elbow.

Capped elbow is a serous abscess of a condensed nature, situated at the point of the ulna and forming a soft fluctuating tumour.

It is generally caused by the heel of the fore shoe in lying down, but may result from any other external injury. Capped elbow rarely produces lameness.

The treatment consists primarily in reducing the inflammation by fomentations; and then as the tumour becomes reduced in size, absorption may be promoted by means of an irritant such as ointment of biniodide of mercury. If the tumour be large and fluctuating, containing a considerable quantity of fluid, the cyst may be freely opened at the most dependent part, and treated as an ordinary serous abscess.

It will be necessary to put on a three quarter shoe or tip to prevent a recurrence of the injury. Occasionally setons are employed with benefit.

CHAPTER 21.

ULCERATION AND SLOUGHING.

401. Definition of Ulceration and Sloughing. 402. Cáuses of Ulceration. 403. Process of Ulceration. 404. Varieties of Ulcers. 405. Treatment. 406. Healing process.

\section{Definition of Ulceration and Sloughing.}

Ulceration is that process of nature by which she separates from the living structures those parts which have lost their vitality. It consists in the progressive softening and disintegration of successive layers of the affected tissue. An ulcer may be défined to be a solution of continuity with loss of substance, owing to some action going on in the part itself, which destroys the tissues. It is attended with the secretion of pus.

Sloughing is the final throwing off of dead tissue from the surrounding structures. Ulceration is the process by which the separation is effected.

\section{Causes of Ulceration.}

The cause may be arrest of nutrition in the part and cessation of the deposition of new material, whilst the old is carried off ; or it may depend on the process of absorption; or it may be an effort of nature for the elimination of dead matter. Again, when from any cause the nutrition of a tissue is altered, and especially if congestion takes place, ulceration is likely to occur. Defective nervous influence is also a predisposing cause. The ulcer always commences where the vitality is least. 
Ulceration is also an occasional sequel of inflammation. When, either by the violence of acute inflammation or by the more gradual effect of chronic inflammation, the nutriment, which ought to be supplied to a part by the free and constant flow of fresh blood through it, is arrested,the tone and vitality of the part is lowered, and it is then in a state on which ulceration is likely to supervene.

Ulceration may, however, occur almost without inflammation if the vitality of the part is sufficiently lowered, as in cases of ulcerated heels arising from horses being exposed to wet and cold. In other cases ulceration is found as a result of a previously existing sore becoming indolent or unhealthy. An ordinary sore for instance forms, and from various causes it may become indolent, and in time the tissues affected lose to a greater or less degree their tone and vital power, and ulceration may follow as a result in the manner described above.

All tissues are liable to ulceration, but blood-vessels and nerves are not so subject to it as other structures. Hence they can often be seen permeating an ulcerating tissue.

\section{Process of Ulceration.}

Ulceration always commences at the surface of the diseased part, or in other words, at the most extreme point of the capillary vessels. Here of course the vitality is least, and therefore that part is the first to get into that low state on which ulceration is likely to supervene.

When the ulcerative process is about to manifest itself on a mucous membrane, there will be observed a red point or two and a few small vesicles on the surface of the part, from under which a watery fluid, or in some cases a thick grey slimy lymph exudes. The ulcerative process has now fairly set in. Particle after particle of the tissue, as each becomes dead, is removed as described above. Each fresh removal adds to the size of the ulcer. As the sore becomes larger, its edges will appear more ragged looking and swollen, and not unfrequently a fungoid kind of flesh will rapidly arise from the sides and bottom of the cavity. The appearance of any such growth is a very unfavorable sign.

\section{Varieties of Ulcers.}

Ulcers, according to the form they take, are described as fistulous, phagedenic, and sloughing.

Fistulous ulcers are those which run deep in various directions, eating their way through and under the surrounding tissues in long narrow channels or fistulæ. Phagedenic or spreading ulcers present to view a round shallow cavity with ragged edges and a disposition to spread superficially. Sloughing ulcers are those in which considerable portions of the tissues come away at one time in flakes.

Ulcers are also classed as healthy, inflamed, weak, or indolent. A liealthy ulcer has smooth edges, and a circular or oval surface studded with florid granulations secreting healthy pus. Such ulcers are prone to 
cicatrise and contract. An inflamed ulcer presents a red surface, and the surrounding parts are hot, swollen, and red. The discharge is sanious and offensive. A weak ulcer has large, pale, flabby granulations, which have but feeble vitality. An indolent ulcer has a flat surface with raised, white, irregular edges and a thin sanious discharge. If granulations are present, they are of a weak character.

\section{Treatment.}

The treatment consists mainly in attention to the general health. The causes, which have been detailed above, show plainly enough that ulceration results from a low state of vitality, either in the system generally or in the part immediately affected. Every means, therefore, such as good feeding, good grooming, plenty of fresh air and the administration of tonics, must be adopted in order to improve the general health. An ulcer seldom refuses to heal, unless the tone of the system is low and deficient.

The best local treatment for a simple ulcer is a plain cold water dressing. The reparative process will not commence until the inflammation in the part is entirely reduced. As a general rule, the ointments are injurious and retard the cure. If, however, the ulcer is indolent, moderate pressure round it will be useful, with the addition, if need be, of a stimulating lotion. If this is not sufficient, a light blister may be applied somewhat frequently round the neighbourhood of the sore, with a view of exciting a healthier action of the parts in its vicinity. If the ulcer is very irritable, a sedative lotion may be substituted for the cold water dressing. Other circumstances may require that the dressing should be of an emollient, an astringent, or caustic character.

If the ulcer arises from a plainly and purely local cause, such as the injury done to the underlying tissues by the pressure of a saddle on the withers, local treatment alone may be sufficient to bring about a healthier action; but in all more serious cases we can only look for the commencement of the curative process by improving the general health and the tone of the system.

\section{Healing process.}

The healing process always begins at the edges of the sore. Its commencement is marked by several changes within the tissues contiguous to the ulcer. In the first place they acquire greater firmness ; 2 ndly the exposed surface of the sore assumes a more healthy character, the edges and the granulations' become more red, the granulations become covered with cuticle commencing from the edges, and thereby general contraction of the size of the sore takes place; 3rdly the discharge which exudes from the sore acquires a greater consistency and becomes of an albuminous character. This healthy secretion gradually spreads over the ulcer, serving a double purpose, namely, it protects the raw surface of the 
sore from external agents, and again it by degrees becomes organised, and by successive layers in due time fills up the cavity.

During the process of healing it, however, often happens that the granulations become too luxuriant; and in such case it will be necessary to check their growth either by pressure or by the application of a caustio dressing. 


\section{PART III.}

\section{CHAPTER 22.}

ACUTE DISEASES OF THE ORGANS OF RESPIRATION.

407. Of the organs of Respiration. 408. Nature of the diseases affecting the organs of Respiration. 409. Causes. 410. Covgrs.-Cause of Coughs. 411. Distinctive signs of different sorts of Cough. 412. CatarRH OR Common Coud. - Nature of Catarrh. 413. Causes. 414. Symptoms. 415. Treatment. 416. Laryngitis and Sore Throat.-Seat and nature. 417. Causes. 418. Symptoms. 419. Treatment. 420. Further treatment. 421. Signs of recovery. 422. After-treatment. 423. BRoNchitis, Pneumonia, Pleuritis, and Pleuro-Pneumonia.-Structure of the organs affected. 424. Structure of the Lungs and Bronchir. 425. Structure of the Pleuræ. 426. Different seats of disease. 427. Certain formations of Chest predisposed to disease. 428. BRONCHITIS.-Nature, seat, and Causes. 429. Treatment. 430. Signs of recovery. 431. Aftertreatment. 432. Pneumonia. - Seat and symptoms. 433. Subsidence of the attack. 434. Increase of the attack. 435. Pleuritis or Pleurisr Nature and seat. 436. Symptoms. 437. Subsidence of attack. 438. Increase of attack. 439. Pleuro-PNeUmonia.-Nature, seat, and causes. 440. Symptoms. 441. Treatment of Pneumonia, Pleuritis, and Pleuro-pneumonia. - Treatment of the premonitory symptoms. 442. Treatment of the attack. 443. Another mode of treatment. 444. Un. favorable terminations. 445. Effusion. 446. Exudation and organisation of Lymph. 447. Suppuration and formation of Abscesses. 448. Gangrene and Mortification. 449. After-treatment.

407. Of the organs of Respiration.

No class of organs in the body is of more importance than those which are connected with the functions of Respiration. None, moreover, are more liable to sudden and serious disease.

The proper breathing organs are the lungs and bronchi. The subsidiary organs are the nasal passages, the larynx, and the trachea. 
408. Nature of the diseases affecting the organs of Respiration.

Most of the diseases of the organs of Respiration are of an inflammatory character. Such, for instance, are Catarrh, Laryngitis, Sore throat, Bronchitis, Pleuritis, Pneumonia, and Pleuro-pneumonia. Other diseases, though not in themselves inflammatory, yet generally result from attacks of inflammation. Such are Broken wind, Thick wind, Chronic cough, Nasal gleet, Roaring, \&c.

\section{Causes of disease of the organs of Respiration.}

Diseases of the organs of Respiration nearly always have their origin in preventible causes, - which may be briefly summed up under the great heads of insufficient ventilation, want of cleanliness in the stable, and bad stable management. Under this latter head we include not only neglect of servants, but also faults of the owner or rider, such as allowing a horse when sweating to stand till chilled, or riding too far or too fast, or working a horse on a full stomach, or when out of condition.

Great and sudden changes of temperature, such as from grass to stables, especially if accompanied by injudiciously sudden alteration of diet from grass to corn, - which is calculated to produce plethora in the system and thereby increased liability to inflammatory attacks,-are also ready and frequent causes. Hence young horses, when first stabled, are apt to suffer.

Some cases of disease no doubt arise from sudden atmospheric changes, but these with good stable management will be rare. Horses standing in town stables are more liable, as we might expect, to suffer from diseases of the respiratory organs than those in country districts.

Diseases of the lungs and air-passages constitute more than half the ailments to which horses are subject. They prevail most during extremes of temperature, whether of heat or of cold, and are frequent in the spring and autumn when the change of coat is taking place.

\section{COUGHS.}

\section{Cause of Cough.}

Cough is a symptom of disease rather than a disease in itself. It arises from irritation existing in some portion of the respiratory structures.

The nature of a cough is a valuable guide as to the part in which the irritation exists, and also as to the degree and stage of the disease from which the irritation arises. By applying the ear to the various parts of the larynx, trachea, front of the chest, or to the sides whilst the animal is coughing, much valuable information may sometimes be gained as to its seat and nature. 


\section{Distinctive signs of different sorts of Cough.}

Coughs may be divided into seven classes, distinguished as under, namely,

1st. The Hard dry cough, which arises from dryness of the membrane of the air-passages. It is found in the early stage of inflammatory attacks.

2nd. The Moist cough, which marks the second stage of an inflammatory attack, when the inflamed membrane has again begun to throw out secretions.

3rd. The Rattling or wheezing cough, which is found when the bronchial tubes are choked with mucus.

4 th. The Soft suppressed cough, which marks the presence of inflammation in the lungs; and a suppressed, but somewhat harder cough, which denotes inflammation in the pleuræ. The peculiar suppressed character of these coughs is due to the pain which the act of coughing produces on account of the inflamed state of the lungs or pleuræe.

5th. The Chronic cough, which is usually dry and short (except when associated with broken wind or roaring), indicates alteration of structure or confirmed irritability of some portions of the respiratory organs.

6th. A Short, hollow, weak, asthmatical cough, which is peculiar to broken wind.

7th. A deep hollow cough, which is frequently found to accompany roaring.

As the peculiarities of the various classes of cough afford very important indications as to the nature and seat of the disease existing in the respiratory organs, it is essential to acquire a knowledge of them. This, however, can only be done by much actual practice.

The treatment which may be required in each case or stage, according to the cause from which the cough proceeds, will be detailed hereafter under the heads of the various diseases affecting the organs of respiration.

\section{CATARRH OR COMMON COLD.}

\section{Nature of Catarrh.}

Catarrh or common cold is acute inflammation of the mucous membrane which lines the nostrils and upper air-passages. It is the same affection as that known in the human subject as Cold in the head. It is attended by mucous or muco-purulent discharge from the nostrils, increased redness of the Schneiderian membrane, oozing of tears from the corners of the eyes, occasionally by swelling of the glands under the jaws, and a snorting cough with or without perceptible febrile disturbance.

\section{Causes.}

Catarrh in adult horses usually arises from some neglect or other in the management of the animal or of the stables,-from what, for the sake 
of brevity, we may call preventible causes,-probably aggravated at the time by sudden atmospheric changes. With young horses first brought into stables catarrh is of very frequent occurrence. It is also occasionally found as a consequence of or accompanying laryngitis or sore throat, because the inflammation set up in that disease very readily extends to the similar continuous membrane of the nostrils.

Catarrh is commonly said to be epizootic; but this result need not be feared, except where predisposing causes, such as neglect and bad ventilation, render the animals susceptible of the disease. It is most frequent, as we might expect, during cold damp weather.

\section{Symptoms.}

The premonitory symptoms are loss of appetite, dulness of the eye, staring of the coat, a tendency to sweat upon slight exertion, and a little watery discharge from the nostrils. These premonitory symptoms are usually followed by slight feverishness, slightly quickened pulse and probably somewhat hurried breathing, and a hot mouth. The bowels are usually constipated. In most cases the throat is more or less sore, and cough may be present.

In the early stage of the feverish symptoms the natural secretions of the part are, as is usual in inflammatory attacks, temporarily arrested; but in the second or moist stage there is an increased discharge from the nostrils.

If the disease runs on, the glands under the jaw become inflamed and swollen from sympathy with the inflammation existing in their neighbourhood. If the throat becomes positively sore, Laryngitis may be said to have supervened.

\section{Treatment.}

The treatment required is simply removal at once to a cool loose box, with abundance of fresh air, extra warm clothing, flannel bandages to the legs, carrots, or green food, warm mashes, and laxative diet instead of corn. With proper care no case of incipient catarrh ought ever to be allowed to develop itself into any serious mischief. A very few days will in general see the patient restored to health.

Catarrh, if neglected, readily runs into laryngitis, bronchitis, pneumonia, or other disease of the respiratory organs. In some few cases it becomes chronic, and is then known as nasal gleet. Good nursing is imperative. The reader is referred to Chapter 15 on Nursing.

\section{LARYNGITIS AND SORE THROAT.}

416. Seat and nature of Laryngitis and Sore throat.

The seat of Laryngitis is in the membrane covering the upper part of the Larynx or box of the windpipe. When the pharynx or back part of the swallow is affected, the disease is termed Sore throat. Both affec- 
tions proceed from inflammation of the mucous membrane of the parts, and as both parts are usually affected at the same time, they generally exist in combination, and we may therefore for practical purposes treat these affections as one disease.

\section{Causes.}

Laryngitis and Sore throat generally have their origin in atmospheric causes. Humidity of the atmosphere is the most common cause; but any sudden change, especially from dry to wet, is apt to bring on these affections. Inasmuch, however, as we seldom find horses at grass affected, it is evident that such changes, though predisposing causes, are rarely sufficient of themselves to induce these diseases. In further confirmation of this view we may remark, that horses turned out to grass from stables even in cold weather rarely suffer from them.

Artificial causes, such as bad ventilation and bad stable management, are needed to aggravate the natural predisposition. The reader will readily understand, that whilst a certain amount of bad air, containing ammonia and other emanations commonly found in badly-kept stables, may not seriously affect the membrane as long as its secretions are sufficient and healthy, yet the same amount of noxious causes may be powerful enough to set up irritation in the part when the membrane and its secretions are even in a slight degree deranged.

Again, neglect on the part of a servant in allowing a horse on his return from work to stand in the stable without being dried at once, or carelessness on the part of the rider in allowing a sweating horse to stand in a draught or in the sun, and all such acts of mismanagement, are apt to bring on these affections, especially at those seasons of the year when, as in spring and autumn, the skin is very sensitive. Horses which are long in the windpipe or which have lost a vein, are predisposed to these diseases.

Horses brought from grass and put into a warm stable are peculiarly liable to be affected in the membrane of the throat, on account of the change from the pure cool air to the heated and often vitiated atmosphere of the stable.

In some very few cases Laryngitis or Sore throat may be caused by the irritation arising from the accidental presence of some foreign body in or about the larynx or pharynx, or from external injuries.

\section{Symptoms.}

The earliest symptoms of Laryngitis combined with Sore throat are cough and difficulty of swallowing solids or even liquids. The mouth is hot and the horse is disinclined to eat, or perhaps "quids" his hay, i.e. lets the masticated hay fall out of his mouth. He only sips his water, or takes it by small mouthfuls. The region of the gullet and fauces is hot and tender, and the least pressure on it often produces a paroxysm of coughing. The salivary glands throughout are swollen and tender. The difficulty in swallowing arises from the irritated state of the mem- 
brane at the back part of the palate, over which the food must pass. The horse also uses much mastication in order to produce an amount of saliva, which may shield the irritated membrane during the passage of the food. Hence we find much slobbering from the mouth, and frequently in bad cases, when the animal drinks, a portion of the water comes back through the nostrils, and occasionally part of the food is returned in the same way. The cough peculiar to this disease is distinguished by its evidently proceeding from the top of the windpipe, and further by its being sharp and troublesome, not suppressed as in pneumonia.

The pulse is quick and the respiration somewhat hurried. If the disease is not checked, the cough will become very hard and harassing, and we may expect increased fever to supervene. Fever, however, is only a concomitant symptom, and our attention must not be diverted to it from the real disease. The fever will subside as soon as the irritation which causes it is removed.

- The further progress of the disease is marked by the mouth becoming dry, the nostrils dilated, the parotid and submaxillary glands more swollen, and the breathing loud and laboured. In severe cases, and especially when the disease is complicated with strangles, the breathing is often accompanied by a roaring noise arising from a thickened state of the membrane, or from some pressure on the larynx caused by the formation of tumours or abscesses in its neighbourhood, and partly also from nervous irritability producing partial spasmodic closure of the glottis.

Laryngitis and Sore throat, when the attack is very severe or long continued, occasionally have an after result in roaring or in chronic cough. The disease is sometimes, though but very rarely fatal, and when such a result occurs, it is often due to neglect or maltreatment. Occasionally, however, a horse may be suffocated in spite of all our efforts to afford relief.

\section{Treatment.}

In the earliest stages the treatment consists in removing the patient to a loose box, with an abundant supply of fresh air. The diet must be restricted to soft food. The horse should be fed from a temporary manger, placed so as to suit the height at which in this disease he generally carries his head. 'Grass is by far the best food; but when it cannot be procured, carrots or bran mash or linseed gruel may be substituted. Hay is wholly inadmissible, as it cannot be properly masticated, and its long dry fibres will be certain to cause irritation in the throat.

When the disease is complicated with strangles, the persistent use of warm fomentations and hot flannels to the throat, and the opening of any tumours or abscesses as soon as they begin to point, will afford immediate relief.

The strength must be supported as much as possible by careful attention to the appetite and good nursing. Grass, carrots, or warm mashes may be offered in very small quantities at a time. Demulcent drinks, such as linseed tea, hay tea, or gruel, are useful and often acceptable. 
Water, in which a drachm and a half of chlorate of potass or half an ounce of nitre should be mixed, should always be within reach.

Steaming of the head with the vapour arising from boiling water poured on hay in a bucket is generally very beneficial. If there is much irritability of the membrane, it will be advisable to sprinkle a little chloroform or ether on the hay. The patient will inhale it along with the steam. In many cases the effect of this treatment in allaying irritation is very marked.

The warmth of the body must be maintained by clothing, and the legs should be wrapped in flannel bandages. At intervals according to the circumstances of the case the bandages should be removed, and handrubbing applied until warmth is restored. Other minutiæ essential to the patient's comfort have been already detailed in Chapter No. 15 on Good Nursing. The great majority of cases will yield to the above treatment.

\section{Further Treatment.}

If the above remedies fail in arresting the attack, it will be advisable to apply a blister of biniodide of mercury over the larynx and extending halfway down the trachea.

In very bad cases the swelling of the parotid glands and the oedema of the rima glottidis is sometimes so great, especially when the disease is complicated with strangles, as to cause imminent danger of suffocation. Relief must then be sought by the operation known as Tracheotomy. If abscesses form and point internally, they may require to be laid open.

\section{Signs of recovery.}

The first sign of recovery is a slight mucous discharge from the nostrils, indicating that the inflammatory action is subsiding. There will also be some slobbering of saliva at the mouth, and the cough will become softer; and the mucus discharged from the inflamed surfaces will be coughed up and got rid of partly by the nose and partly by the mouth, and in due time the cough will cease. The swelling of the parotid glands and of the glands under the jaws will also gradually subside. The concomitant fever mentioned above will cease of itself, along with the irritation which produced it.

\section{After-treatment.}

The after-treatment will need much care and attention. Some deposit on or thickening of the membrane generally remains after the attack has subsided, which may cause the horse to become a roarer; and in order to assist nature to remove it and thereby lessen the chance of any affection of the wind, it is advisable to apply a strong blister of biniodide of mercury, or to insert a seton. The patient should remain in a cool loose box until all irritation has completely passed away.

Again, when the horse is thoroughly convalescent the owner must not be in a hurry to get him into fast work, because the membrane of the 
pharynx and larynx will continue to be for some time very susceptible of irritation and inflammation. Great attention must also be given to the ventilation of the stable.

When the discharge from the nostrils continues for a length of time, even after the horse has in other respects recovered, the case must be treated as one of Nasal Gleet. See Chapter 25.

\section{BRONCHITIS, PNEUMONIA, PLEURITIS, AND PLEURO- PNEUMONIA.}

\section{Structure of the organs affected.}

Before treating of Bronchitis, Pneumonia, Pleuritis, and Pleuro-pneumonia, it will be necessary to glance briefly at the structure of the organs affected in these diseases.

\section{Structure of the Lungs and Bronchix.}

The lungs are contained in the chest or large cavity in the anterior portion of the body. The sides of the cavity are formed by the ribs, its top by the spine or back bone, its front by the sternum or breast bone, whilst posteriorly it is separated from the stomach and intestines by a flexible curtain called the diaphragm. Further protection is afforded to the cavity by the shoulder-blade bones.

The lungs consist of two soft elastic masses, which fill the cavity of the thorax. The right mass of the lungs has four lobules, whilst the left has only three. The interior walls of the cavity and the lungs themselves are covered with a fine serous membrane called the pleura. The lungs are in constant motion during life, enlarging and diminishing during the acts of inspiration and expiration. The mass of the lungs is made of innumerable minute cells, connected together by cellular tissue.

The lungs are connected with the external air by means of the nostrils, larynx, and trachea or windpipe. This latter organ runs at first as a single tube, but after entering the chest it divides into two branches called the Bronchial tubes. They are similar in structure to the windpipe. They divide again and again, and subdivide and ramify through the lungs, gradually becoming more and more minute. They terminate all through the lungs in the minute air cells. Over the surface of these cells the capillary ramifications of the pulmonary arteries are spread in exquisite minuteness, and here the blood imbibes from the air its oxygen. The pulmonary veins receive from the surface of the cells the blood which has been thus oxydised, and return it to the heart.

If the air supplied to the lungs is impure, the oxydising process cannot be efficiently performed. Again, if from disease or other cause the passage of the air through the lungs is impeded, and the supply is thereby lessened, the purification of the blood will be imperfect.

It is chiefly on this latter account that we have so often impressed on the reader the necessity of an ample supply of the best and purest air to 
all horses suffering from diseases of the respiratory organs. A supply which may be quite sufficient in health, when the air has free course through every part of the lungs, may be very insufficient when portions of the respiratory system are impeded.

Each lung, as stated above, is divided into two great divisions or lobes. Disease may exist in one lung or in one lobe without materially affecting the other; but this is very seldom the case in horses, because all inflammatory diseases run their course very rapidly, and therefore in a very short time the whole substance of the lungs is generally involved. Hence it is quite common for horses to die after suffering for only two or three days from diseases of the pleuræ or lungs.

\section{Structure of the pleuræ.}

Every part of the entire substance of the lungs as well as of the cavity of the chest is lined with a fine serous shining lubricating membrane called the Pleura. This membrane prevents the different portions of the lungs from adhering to each other, and also prevents the lungs themselves from adhering to the sides of the cavity of the chest. Thus by means of the Pleuræ their free and easy motion without friction is ensured at each respiration. The portion of the pleura which lines the ribs is termed the pleura costalis, whilst that which invests the lungs is called the pleura pulmonalis.

\section{Different seats of disease.}

Inflammation may attack one or all of these structures, namely the bronchi, the lungs, or the pleuræ. The disease takes its name from the part affected. Thus if the bronchi only are attacked, the disease is called Bronchitis ; if the pleuræ only, Pleuritis ; if the lungs only, Pneumonia; whilst if both lungs and pleuræe are simultaneously attacked, the disease bears the compound name of Pleuro-pneumonia.

Bronchitis is often found as a separate disease, but in bad cases it may become complicated with pneumonia. Pleuritis and pneumonia, though occasionally found as separate diseases, more often occur in conjunction, constituting Pleuro-pneumonia.

\section{Certain formations of Chest predisposed to disease.}

Though we believe, as stated above, that diseases of the respiratory organs generally have their origin in preventible causes, yet we must at the outset admit that certain formations of chest entail a greater liability than others to disease. Even here, however, the owner is mainly responsible. It is his own fault, if he subjects an animal to work and wear for which his physical formation renders him unfit.

A shallow and flat-sided chest, for instance, does not afford sufficient capacity for the lungs to enable the animal to perform fast work. If such work is required of an animal so formed, there will be great liability to disease of the Respiratory organs. 


\section{BRONCHITIS.}

\section{Nature, seat, and causes.}

Bronchitis consists in inflammation of the Bronchial tubes. There are two forms of the disease, namely inflammation of the larger tubes, and 2ndly inflammation of the smaller tubes, called capillary bronchitis. The latter attack is far the more dangerous, because the inflamed and thickened state of the membrane of the minute tubes or the increased secretion of mucus in them prevents the blood from being properly aërated.

Bronchitis usually commences with slight catarrh and cough, and the horse is off his feed and a little feverish. At other times there are no catarrhal symptoms, and the only noticeable sign is feverishness and quickened breathing. This state of the breathing, if not carefully looked for, may easily escape observation. Hence grooms so often declare that the breathing is perfectly regular, whilst the practised eye of a man, who is accustomed to observe, sees at once the mischief, which is going on.

The first positive sign of Bronchitis is indicated by quickened breathing, accompanied with a slight whistling or hissing sound heard on auscultation at the sides of the chest, or else by a deeper and more noisy sound in front of the chest. The whistling sound is technically known as Sibilus, and marks inflammation of the smaller tubes; whilst the deeper sound, which is known as Rhonchus, indicates inflammation of the larger tubes. The peculiarity of these sounds arises from the passage of the air over a dry inflamed membrane in the tubes. During this, or the ${ }^{-7}$ dry stage," the pulse is harder and quicker than natural, and as the disease progresses it becomes quicker and smaller, until in very bad cases it can be no longer felt. The breathing is also much quickened, and the membrane of the nostril is red and inflamed.

About the second day the dry state of the bronchial membrane is succeeded by a moist state, with an increased secretion of mucus accompanied with a suppressed cough. This change, though it has no particular significance, is yet often indicative of relief, inasmuch as it shows that one stage of the inflammation has passed. It is the result of the effusion, which always (except when the attack ends in resolution) takes place in inflammatory attacks when the blood-vessels of a part have become overloaded and over-distended. (See Chapter 18 on Inflammation.) The pulse, which during the dry stage had been harder and quicker than natural, now becomes decreased in volume and increased in frequency. Should the Schneiderian membrane, which had been red and inflamed, become moist, and at the same time the secretion from it of a more natural character, it is a very favorable symptom.

If the mucus which is now secreted is not freely expectorated, it will accumulate either in the larger or smaller tubes, according to the locale of the attack. In the larger tubes it affords considerable impediment to the respiration. The sound of the air passing through them is known as 
the "great" mucous râle. If the smaller tubes are attacked, the sound is more subdued and wheezing-like, and is known as the "small" mucous râle. The distinction between those two sounds will require to be very carefully studied.

Increase of the attack is marked by hurried breathing, dilatation of the nostrils, heaving of the flanks, much fever, a highly inflamed state of the Schneiderian membrane, and rapid prostration of the strength. A peculiarity of the breathing may also be noticed, namely that the act of inspiration is performed with difficulty, whilst that of expiration is effected with comparative ease. The breathing may also be quicker than the pulse.

In pure Bronchitis the throat is not affected. The disease is in the bronchial tubes, either great or small, but not in the larynx or trachea. If, however, bronchitis supervenes on a previous attack of catarrh or sore throat, the larynx and trachea will necessarily be involved.

The causes of Bronchitis are similar to those of catarrh and sore throat.

\section{Treatment.}

At the very earliest symptom the patient should be removed to an airy loose box, warmly clothed, bandages applied to the legs, and his food restricted to grass, carrots, or bran mash. If the legs are unequal in warmth and the coat is inclined to stare, and especially, if there is an inclination to shivering, it will be advisable to give an ounce of spirits of nitric ether with four ounces of acetate of ammonia in eight ounces of water both morning and evening. If these precautions are taken sufficiently early, the threatened attack will probably be averted. A good servant will always notice the slightest deviation from health in the horses under his charge; whilst careless ignorant servants seldom see anything wrong, until disease has fully established itself.

When Bronchitis has unmistakably set in, our efforts must be employed in assisting nature during the progress of the disease, which must run its course, and in attempting to bring about the moist stage as quickly as possible. In the early stages salines may be given, such as half an ounce of the chlorate or nitrate of potass in the water or mash daily.

After a time the pulse usually becomes weak and the patient is prostrated. Diffusible stimulants, such as carbonate of ammonia in doses of one drachm, or sweet spirits of nitre or sulphuric ether in doses of half to one ounce, repeated every four or six hours, are now indicated, and may be continued, if their administration does not distress the patient, until signs of relief are apparent. If the horse is inclined to drink, half an ounce of nitre may be dissolved in each half pailful of water until the kidneys are freely acted on.

If the bowels are constipated, it is better to rely upon the èffect of enemata and laxative food. In some few cases there may be yellowness of the eye and of the membrane of the mouth. This will be found to be caused, not by torpidity of the liver, as might be supposed, but from over-action of that organ, which is sympathetically excited. No treatment is required. 
When, as is often the case, notwithstanding hand-rubbing and bandages, the legs remain persistently cold, the best plan is to apply ammonia liniment to them and then to replace the bandages.

The chest should be well fomented by means of a blanket wrung out of hot water and applied to the sides. This may be covered with a waterproof sheet to keep in the heat and moisture, and after each fomentation the surface should be slightly stimulated with weak ammonia liniment to prevent any untoward action from the effects of cold air on the partially dried parts.

If signs of recovery do not become apparent, the disease will probably extend to the lung tissue or to its covering membrane, and we shall probably have the case complicated with Pneumonia or Pleurisy. A horse may die of pure Bronchitis, but in fatal cases the disease generally runs into pneumonia or pleurisy before death.

\section{Signs of recovery.}

Nature assisted by the above remedies generally brings about a favorable change in a few days. The pulse, although still quick, becomes more distinct, the breathing more tranquil and regular, the feverish symptoms decrease, the cough becomes of a stronger character, and there is a discharge of mucus from the nose. The membrane lining the nostrils assumes a more natural colour, the mouth feels more moist and cooler, the animal lies down comfortably, and the appetite returns.

An early and copious mucous expectoration and a change from the small crepitation to a mucous râle, or in the later stage an abundant muco-purulent expectoration with the return of the natural respiratory murmur in the chest, and a continuance of warmth in the legs are very favorable signs. Sometimes a slight diarrhœa is the turning point of the disease, and it is not advisable to check it unless it becomes severe.

\section{After-treatment.}

When the patient is recovering the nasal discharge may be encouraged by steaming the head. But if such is not the case, the fidgeting and steaming will do more harm than good.

If thorough recovery appears to be retarded by persistent debility, some vegetable tonics may be beneficial in restoring tone to the system. As a rule, however, they are not required after this disease.

\section{1a. Congestion of the Lungs.}

A congested condition of the capillary vessels of the lungs may exist independently of the presence of actual inflammation, or it may accompany Pneumonia, or may be present during the progress of many other inflammatory affections. It is especially prevalent as a result of extreme exertion, such as a hard day's hunting when the animal is not in proper condition.

This state of pulmonary hyperæmia may also be caused by the influence of badly-ventilated and ill-drained stables, confinement on board 
ship, \&c., as the result of actual insufficiency of pure air, producing a partially arrested condition of the function of the lungs.

The symptoms of pulmonary congestion are characterised by an oppressed, almost indistinct pulse, beating with great rapidity and ranging from 80 to 120 beats per minute; the ears and legs are very cold, the patient is much distressed and stands with the fore-legs wide apart and elbows turned outward, the nostrils are distended, the body is covered with cold perspiration, and to these distressing symptoms are added laboured respiration, a wildly-beating heart, and redness of the visible mucous membrane.

431b. Treatment.

The first measure. to be taken is at once to get the patient into a well-ventilated loose box, to clothe the body warmly, and well hand-rub and bandage the legs; if this fails to restore heat to the limbs they must be placed in hot mustard and water or well rubbed with liniment of ammonia and double bandages applied. If you catch the patient in a shivering fit, give at once nitrous ether 3 to 4 ounces-or if that is not at hand 2 ounces of good whiskey.

Hot fomentations should be immediately applied to the chest with pieces of blanket well wrung up (see par. 255). To each bucket of water two ounces of oil of turpentine should be added. When finished, dry gently but thoroughly, and replace the wet by dry blankets.

Diffusible stimulants are indicated in this disease for the purpose of equalising the circulation. No stimulant answers better than a couple of ounces of good whiskey. It should be given at once in a pint of water and repeated in an hour. It has a wonderful restorative effect, if due care is taken that the patient and not his attendant is submitted to its influence. For other diffusible stimulants, if whiskey is not at hand, see par. 300.

At this stage mustard, not very strong, rubbed at both sides of the chest is often beneficial.

Above all, perfect quiet must be observed, the diet should be easy of digestion, light and laxative, such as small mashes, boiled linseed, carrots, or green food, \&c., and a pail of water in which an ounce of nitrate of potass has been dissolved should be within reach.

For obvious reasons, in all diseases of the lungs and in all cases where the breathing is interfered with, the clothing should be put on very loosely (see par. 251).

\section{PNEUMONIA.}

432. Seat and symptoms of Pneumonia.

Pneumonia is inflammation of the substance of the lungs, but generally the bronchiæ are also involved.

The premonitory symptom as in bronchitis is often a slight catarrh. 
Sometimes, however, the attack comes on very suddenly without any observable premonitory symptoms. At other times it starts almost imperceptibly, the animal being only slightly off his feed and his mouth hot. Pneumonia frequently supervenes on bronchitis. It may also supervene on severe catarrh, but does not often do so. If it does, the nasal discharge will be at first arrested and the membrane of the nose will be dry. As long as there is a free discharge from the nostrils in catarrh, there is, we may remark, scarcely any reason to fear Pneumonia. Occasionally pneumonia occurs suddenly as a result of extreme exertion in the hunting-field or under such-like circumstances, and it is then due to the congested state of the blood in the lungs.

The attack itself is generally ushered in by sudden fits of shivering, followed by coldness of the ears and extremities and other usual signs of inflammation and a staring coat. The coldness of the extremities is a marked sign throughout the disease. The horse is evidently uneasy, and turns his head frequently round to his chest. The pulse is oppressed and quick, and generally ranges about sixty beats in the minute at the commencement; but if the attack progresses unfavourably, it will become quicker and may reach a hundred, and will become gradually smaller and smaller in volume. The temperature rises rapidly, frequently to $104^{\circ}$ or $105^{\circ}$ Fahrenheit.

In the early stage the nasal linings are paler than usual, but as the disease progresses, they become purplish and then of a leaden hue. The respiration becomes disturbed, as soon as the disease is established.

A very prominent symptom, which marks this disease, consists in the horse persistently standing with his fore-legs wide apart and his elbows out. He retains this position, because it affords greater expansion to the chest and therefore greater ease than any other position. Horses affected with this disease or with pleuro-pneumonia never lie down, except it be for a moment at a time, or in extremis, when death from suffocation in general rapidly supervenes. The head throughout the attack is inclined downwards, with the nose protruded and the nostrils dilated.

Cough may or may not be present. If present, it is sharp in the first instance ; but as the attack progresses, it becomes of a subdued character, because the act causes pain in the lungs.

With increase of the disease the breathing becomes quicker and more laboured. In proportion as the membrane lining the air tubes and cells becomes thickened, the animal is obliged to breathe more quickly to purify the blood. The breathing is also performed irregularly. The inspirations are delayed in order to prevent the pain consequent on the distension of the inflamed lungs; but the expirations are hurried and laboured in order to get rid of the air, which is causing pain. The legs, ears and muzzle are cold, and in bad cases deadly cold.

If during the early stage of the attack the ear be applied to the chest, a confused humming noise accompanied with a harsh dry murmur instead of the gentle respiratory sound peculiar to health will be heard. The duration of the dry stage is very uncertain. As the inflammation progresses the dry murmur will give way to a moist rattle. This stage may 
last from twenty-four to forty-eight hours, at the end of which time a decided change for better or worse will occur. During this time the breathing will become quicker on account of the increasing congestion in the air cells. The pulse, though still oppressed, will become weaker and quicker.

Pneumonia may attack one lung or one portion of one lung or both lungs. The extent and position of the attack may be ascertained by auscultation.

\section{Subsidence of the attack.}

Subsidence of the attack is indicated by the return of the pulse to something like its normal condition, by restoration and continuance of warmth in the extremities, by a moist state of the nostrils, or the appearance of healthy mucus, and by general relief of the symptoms of inflammation and by a disposition to lie down.

It is necessary, however, to caution the inexperienced against mistaking the earlier symptoms of effusion of serum into the thoracic cavity for those of amendment. The means of distinguishing them will be found further on under thè head of Effusion in paragraph 445 .

\section{Increase of the attack.}

If on the other hand the disease continues to progress, the mouth and nose will become cold, the nostril of a leaden hue, and the pulse fluttering and indistinct. The attack may terminate in effusion of serum, otherwise known as water on the chest, or in exudation of lymph from the pleural surfaces (these, however, are more frequently the result of pleuritis or pleuro-pneumonia) in partial hepatisation of the lungs, or in tubercles, abscesses, gangrene, \&c.

A very unfavorable symptom is afforded by the discharge from the nose becoming of a brownish colour. It indicates a high degree of congestion of the blood-vessels of the lungs. The change of colour proceeds from oozing of the colouring matter of the blood through the over-distended coats of the vessels.

Occasionally the patient dies from congestion of the lungs about the 4 th or 5th day, or even as early as the 2 nd day, before any of the latter described stages are reached.

Horses sometimes die of congestion of the lungs from hard riding or from plethoric state of the system. In these cases the cause of death is sanguineous congestion of the lungs, $i$. $e$. from the blood-vessels pouring out some of the constituents of the blood into the air cells.

We reserve our notice of treatment, and of after-results, until after the consideration of the symptoms of the kindred diseases, Pleuritis and P'leuro-pneumonia. 


\section{PLEURITIS OR PLEURISY.}

\section{Nature and seat of Pleurisy.}

Pleuritis or Pleurisy is inflammation of the pleuræe or delicate serous membrane which forms the covering of the lungs and also lines the cavity of the chest. The disease is generally brought on by the same causes as those which produce other diseases of the respiratory system, and which have been pretty fully detailed above; but sometimes it is occasioned by some abnormal violence to the chest or by its being punctured. In these latter cases the disease will be confined to one side only.

\section{Symptoms.}

A premonitory symptom of approaching disease is given by loss of appetite, by quick short respiration and a quickened pulse; but the first decided symptom of affection of the pleuræ is usually the emission of a sharp clear grunt, when the animal is disturbed or turned round in his stall, or on the application of pressure to his side. The pain, of which this grunt is the expression, is due to the inelastic nature of the pleuræ, which on this account become under inflammation exceedingly sensitive of any motion. If pressure be applied to the intercostal spaces, it causes pain and often produces the peculiar grunt. The pulse is at first about sixty, but soon becomes hard and wiry, and gradually increases to eighty and in bad cases to a hundred beats in the minute or even higher; but it is not so full and oppressed as in pneumonia. On account of the pain in the pleuræ the patient frequently looks round to his sides. Cough is generally present, but it is always of a short suppressed character, because the act of coughing causes pain. The nostrils are dilated to aid the respiration.

The respiration is short and quick, because the horse endeavours to supply his lungs with air with as little expansion of the chest as possible. $\mathrm{He}$ is also very restless, and looks round to his sides with an anxious eye of pain, and frequently paws the ground with his foot. He does not lie down, but often attempts to do so. There are often patches of sweat on the skin over the region of the disease, and the muscles of the part are affected with twitchings. The membrane of the nostrils is not much altered in colour at first, but as the disease progresses, it becomes of a deep red colour.

A further marked sign of the disease is given by a regular elevated line or ridge along the lower border of the ribs from the point of the hip to the lower part of the sternum, caused by the animal employing the muscles of the abdomen instead of those of the ribs to expel the air. The temperature in this disease, like that of pneumonia, rapidly becomes increased.

If the ear be now applied to the sides of the chest, a friction sound, such as that caused by gently rubbing the dry hands together, may be at 
first for a short time detected. This peculiar sound arises from the dry roughened pleura of the lungs grating against the equally dry roughened pleura of the ribs.

Pleuritis is also marked by great irregularity in the temperature of the extremities, portions of which may be cold, whilst other portions are hot, and frequent alterations of temperature occur in the same part.

In a period of time varying from two days to a week in favorable cases the dryness of the pleura is relieved by an effusion of serum from the overloaded vessels. The occurrence of the moist stage has not in itself either a favorable or unfavorable significance. It is merely the course through which every inflammatory attack passes, which does not at once end in resolution. At this the second or moist stage the friction sound, noted above as characteristic of the disease in its first stage, disappears; and the cough becomes loose and moist, and the extremities for a time become warm. The pulse becomes less frequent, smaller and weaker, the breathing less laboured, and the membrane of the nostril loses its redness.

In from about twenty-four to forty-eight hours after the occurrence of the moist stage we may look for a decided change either for better or for worse.

\section{Subsidence of the attack.}

Subsidence of the attack will be indicated by the breathing becoming less hurried, by the pulse becoming softer and more distinct, the temperature becoming lowered, and the cough less frequent, and by the extremities continuing warm. As in most acute diseases recovery, when a favorable change once takes place, is tolerably rapid.

\section{Increase of the attack.}

On the other hand persistence of the attack is indicated by the extremities, which had on the occurrence of the moist stage become warm, again becoming and continuing cold, by a deep scarlet colour of the membrane of the nose, by a discharge of straw-coloured serum from the nostrils, by a thready wiry pulse, and by a rapid increase in the symptoms of inflammation, which will soon terminate either in effusion of serum, otherwise called water on the chest, or in exudation of lymph, causing in some cases extensive adhesion of the pleura of the lungs to the pleura of the ribs; or very frequently in both.

As in pneumonia, it is necessary to caution the inexperienced against mistaking the earlier symptoms of either of these results for those of subsidence of the attack.

We reserve our notice of treatment until after the consideration of the symptoms of Pleuro-pneumonia. 


\section{PLEURO-PNEUMONIA.}

\section{Nature, seat, and causes of Plturo-pneumonia.}

Pleuro-pneumonia is inflammation affecting both the lungs and pleuræ. The disease may attack one lung or one portion of one lung, but it more often attacks both lungs at once. The pleuræ are generally involved to the same extent as the lungs. The position and extent of the disease must be ascertained by auscultation. The causes of pleuro-pneumonia are the same as those of other diseases of the Respiratory System.

\section{Symptoms.}

The symptoms in the early stage are those of pneumonia, with the addition of the friction sound and elevated ridge across the cartilages of the ribs, which were noted above as characteristics of pleuritis. The pulse is more affected than in pneumonia, and less so than in pleuritis, and may probably range about 70 .

In the second or moist and in the later stages the symptoms are also similar to those which have been already detailed under the head of pneumonia and pleuritis, and are in fact, as we might expect, a combination of both. Thus whereas in pleuritis the effusion or exudation is poured out into the cavity of the chest, and in pneumonia the substance of the lungs is affected by the out-poured fluid, in pleuro-pneumonia both results may ensue.

A peculiar low form of pleuro-pneumonia often prevails as an epizootic in large towns, the early symptoms of which are very obscure. The animal merely shows dulness and loss of appetite and increased frequency of pulse. The respiratory movements are at first so little affected, that unless the practitioner is on his guard and tests the state of the lungs by auscultation, the disease may gain a head before its real nature is suspected.

\section{TREATMENT OF PNEUMONIA, PLEURITIS, AND PLEURO- PNEUMONIA.}

\section{Treatment of the Premonitory Symptoms.}

From the details given above, it will have been perceived that these diseases are cognate in their causes and nature. Hence the treatment required is also very similar.

When any of the premonitory symptoms, such as slight catarrh, feverishness, dulness, or loss of appetite, appear, we must at once have recourse to an abundant supply of cool fresh air, abstinence from corn, laxative diet, entire rest, extra clothing, and warm bandages to the legs. In all cases it is desirable that the patient should at once be removed to an airy loose box. Diffusible stimulants are also beneficial. 
If these simple remedies do not altogether avert, or at least bring about subsidence of the attack within a very short time, we must have recourse to medical treatment.

\section{Treatment of the attack.}

Neutral salts dissolved in water have a marked effect in relieving the feverish symptoms. For this purpose two ounces of sulphate of soda or one ounce of nitrate of potassa may be dissolved in a pailful of water, and the patient may be allowed to drink as much as he pleases. If he finishes the pailful, another may be given him. If the bowels are constipated, as is often the case, two ounces of Epsom salts dissolved in water with half an ounce of nitrate of potassa may be administered twice a day. The constipation may, however, be relieved often permanently by repeated enemas of warm soap and water.

If the legs notwithstanding friction and bandages remain persistently cold, a mustard plaster may be applied to them and washed off after fifteen minutes and the bandages reapplied, or they may be rubbed with turpentine liniment.

Diffusible stimulants, which were recommended above during the premonitory symptoms, are not suitable during the dry stage. But when the strength begins to fail, as is often the case after the dry stage has continued for some time, and during the second or moist stage diffusible stimulants such as carbonate of ammonia in doses of from one to two drachms combined with small doses of gentian and ginger once or twice a day, or an ounce of sweet spirits of nitre repeated every four or six hours are very 'beneficial, and may be given from time to time as may be required.

During both the dry and moist stage much relief will be afforded by frequently fomenting the sides with woollen blankets wrung out of hot water and covered with a waterproof sheet, as recommended for Bronchitis. After each fomentation any parts not thoroughly dried may be gently rubbed with liniment of ammonia with the view of preventing the effects of the cold air, and covered with light warm clothing.

The system which was formerly adopted of applying repeated applications of mustard, or mustard and ammonia, to the sides and chest in lung diseases is rapidly becoming discontinued; but as it is still adopted by some practitioners, the Author considers the following remarks with reference to the application of these external stimulants may be useful.

The stimulating effect caused by these agents is produced very rapidly. It will be sufficient to allow them to remain on the skin about ten or fifteen minutes, after which they should be washed off. If the mustard is allowed to remain on longer, it loses its stimulating action and is apt to be absorbed into the system, where it will act injuriously. When the effect of the stimulant has passed off, say in a couple of hours, it may be repeated and again washed off as before. These applications may be used occasionally, if relief appears to be gained by them. If ordinary household mustard, which is usually largely adulterated with flour, be used, half a pound, or about that quantity, will be required at each 
application; but if the mustard seed is purchased whole and then ground, about two thirds of that quantity will be sufficient. In these cases, however, as in most others, much must be left to the discretion of the attendant, who ought to watch the symptoms and the effect produced. The skin of some horses is much more easily acted on than that of others.

As the disease progresses, it is of the utmost consequence to sustain the strength of the patient as far as possible by giving him soft nutritious food, by most attentive nursing, and by warmth applied to the body by means of clothing, \&c.

It is necessary to call the particular attention of the reader to the distinction in regard to diet which exists between the premonitory and the later stages of the attack. In the former the patient must be deprived of all corn and fed on laxative diet. Such timely measures, combined with a loose box, will probably ward off the impending attack, or at least prevent its becoming serious; whilst on the other hand when the disease has fairly established itself, the strength of the patient needs to be sustained in order to enable him to throw it off and survive its debilitating effects. When however the disease has established itself, the appetite always fails and the difficulty is to get the patient to take any nutriment. His appetite must be tempted by whatever may seem at the moment to be palatable. A handful of grass, a carrot or two sliced longways, or a few mouthfuls of bran mash, or of oatmeal gruel made fresh as required, or a few bruised oats may be tried. Skim-milk at this stage will be found very useful in sustaining the strength. In cases where much debility is present, half a drachm of quinine dissolved in an ounce of water and a few drops of sulphuric acid may be given twice daily in a pint of port wine.

As a general rule these diseases terminate quickly and favorably and without any after injurious effects, when treated as recommended above. It is only when the system is unduly lowered, or the fever is aggravated by the use of violent blisters, that we have reason to fear an unfavorable termination.

\section{Another mode of Treatment.}

In the treatment of these diseases it is frequently customary to have recourse to the free use of violent external irritants. The author in previous Chapters on Inflammation and Irritants has given at length his reasons for disapproving of such practice. But inasmuch as the application of these remedies is very common, he deems it right to lay before the reader the usual mode of applying them.

Blisters are generally applied after the more acute febrile symptoms have been somewhat got under. When used earlier, they increase the violence of the symptoms without producing any corresponding advantage as regards the internal inflammation.

In each case care and circumspection are needed to apply the irritant to the proper part. The seat of the attack must be ascertained by auscultation and by taking notice of the other signs detailed above; and 
the blister, seton, or firing iron must then be applied to the neighbourhood of the part affected.

In Bronchitis the throat and windpipe as far down as the chest, in Pneumonia, Pleuritis, and Pleuro-pneumonia both sides and chest, are usually acted on.

The injurious effects likely to result from the application of cantharides over a large surface have been already noticed. In Pleuro-pneumonia, therefore, where the parts affected are very extensive, it is better to use mustard if any such treatment is decided on.

Bleeding, formerly so much in repute in the treatment of these diseases, is now seldom resorted to.

\section{Unfavorable terminations.}

Somè cases however in spite of all our care will terminate unfavorably, and we shall then have to deal with those results which have been mentioned above, namely effusion or water on the chest; exudation of lymph causing either condensation of the connecting tissue of the lungs and also of the air cells, or extensive adhesion of the pleura of the ribs to the pleura of the lungs; or more rarely suppuration and the formation of abscesses; or sometimes gangrene or mortification of the parts attacked; and not uncommonly roaring.

\section{Effusion.}

When Effusion takes place from the overloaded vessels, the acute symptoms are at first greatly diminished, and the inexperienced may be led to think that the patient is going to recover. Warmth returns to the extremities, the pulse though still quick is less frequent and it becomes soft, the appetite partially returns, and the general appearance indicates that the acute pain has subsided. The fact is, that the tension is taken off the coats of the blood-vessels by reason of the effusion, and thus for a time, until the water occupies some considerable space in the chest, the breathing is not so much laboured.

As soon however as that result takes place, the breathing becomes more laboured, and the difficulty increases with the increasing amount of the effusion. The degree to which the water has formed may be ascertained by careful auscultation, as no respiratory sounds will be heard from that part of the lungs which is surrounded by water; whilst above that point the usual sound will be plainly perceptible.

From the commencement of the effusion, although many of the urgent symptoms at first subside, yet others remain throughout, which distinctly negative the idea of a real recovery. The pulse is still quick and wiry, the breathing quick in number, although at first less laboured, the extremities, - which had temporarily regained their warmth, again become cold, the coat is harsh and dry, and there is a want of pliability in the skin. The most marked feature, however, consists in the patient still standing persistently with his fore-legs wide apart.

As soon as the effusion has taken place to any considerable extent, 
there will be in most cases a dropsical swelling beween the fore-legs under the sternum, and the ridge along the abdomen will become more and more distinct, and a straw-coloured serous discharge will be seen from time to time to trickle from the nostrils. The expiration also will be more markedly performed by a double action, i.e. the abdominal muscles will be brought into play to assist in the expiration of the air: As the weakness increases, the hair of the mane and tail will become very loose, and may be easily detached.

All sound of the percolation of the air necessarily ceases below the point to which the serum or water has risen. In some cases the distended vessels continue to pour out serum, until it has risen in the pleural cavities to such an extent as to cause death from suffocation. The water may indeed be drawn off through a tube inserted into the chest, and temporary relief will be gained; but in most cases it quickly re-forms. But in other cases, where the strength has been maintained, permanent relief may sometimes be gained by tapping.

All cases of effusion do not however terminate thus unfavorably. The effusion may be only slight, and in such cases the lower part only of the lungs is pressed upon, whilst sufficient remains for respiration. Nature then by means of the absorbents and blood-vessels takes up the whole or part of the effusion. Any consolidated deposit that may remain, will necessarily more or less impede the freedom of respiration.

The degree in which Nature takes up the effusion, is principally dependent on the tone of the vital powers after the acute attack has passed away. If those powers have been weakened by depletive treatment, by blisters and such-like remedies, or by neglect, Nature may probably be unable to take up the deposit. But if on the other hand by judicious management, good nursing, attention to the appetite, and by the absence of violent remedies those powers have been husbanded and assisted, there is reason to hope that Nature may absorb all the effusion and deposit. In these cases however, her powers will require to be assisted by very careful and well-directed after-treatment.

\section{Exudation and organisation of Lymph, Adhesion, \&c.}

If the attack terminates in Exudation, the Lymph may be deposited either between the lungs and the sides of the cavity of the chest, or in the lungs, or it may affect both parts. Lymph as previously stated, is adhesive in its nature, and has a marked tendency to become consolidated and organised.

In virtue of this property if, as in pleuritis, it is deposited between the pleura of the lungs and the pleura of the ribs, it has, when suffered to remain, a tendency to cause the one part to adhere to the other. This result is known as Adhesion. If the adhesion of the lungs to the ribs affects a large surface, their free motion and expansion is necessarily interfered with, and the horse must ever after be unsound in wind and unfit for fast work.

If as in pure pneumonia the lymph is exuded into the lungs, it will, if 
it becomes organised, consolidate and choke up a portion at least of the air cells and passages, and render the animal unsound. Lymph may be exuded even to such an extent as to cause suffocation.

In Pleuro-pneumonia the exudation may take place either into the substance of the lungs, consolidating their structure and causing them to become hepatised; or between the pleuræe of the lungs and ribs; or it may affect both structures.

In severe cases of Bronchitis lymph is sometimes exuded and deposited in the bronchial tubes; and if it becomes organised, it will produce diminution of those channels and the wind will be affected.

In all the above cases the degree of permanent mischief will depend on the length of time which the lymph remains in the structures affected rather than the amount of the deposit. If the vital powers on the termination of the acute attack are unable to take up and absorb the lymph, it will become consolidated, and it will produce the mischievous effects detailed above. If on the other hand by judicious treatment and nursing Nature is given a fair chance, she will in favorable cases take up the whole or a large portion of the lymph exuded. With a view of stimulating the action of the absorbents small doses of one scruple of iodide of potassium with ginger and gentian may be given with benefit three times a day. Nothing answers better than a pint of good stout daily.

\section{Suppuration and formation of Abscesses.}

In some cases, where the attack, whether arising from pneumonia or pleuro-pneumonia, has been very intense, and especially where in addition the patient has been unduly lowered, suppuration may take place and abscesses will form in the lungs. The presence of an abscess, as soon as it has opened into a bronchial tube, may be detected by those experienced in auscultation on the application of the ear to the chest, either by a rushing sound as the air rushes into the hollow space, or by the absence of any sound of percolation of air through the part, when the abscess, as is often the case, is filled with matter. Even beyond the parts immediately affected and in fact destroyed by the abscesses, it is more than probable that the whole structure of the lungs must be more or less disorganised by the violence of an attack sufficient to induce suppuration.

The formation of abscesses is, however, more easily known by fœtor of the breath and by the animal coughing up muco-purulent matter.

\section{Gangrene or Mortification.}

Gangrene or mortification may occur in any part of the structures which have been subjected to disease. It is in plain language death of the part, and the result is invariably fatal.

\section{After-treatment.}

From what has been stated in reference to the effusion of serum and exudation of lymph, it will readily be seen that the maintenance of the strength is the great object in the after-treatment. Good nursing, good 
fresh air, warm clothing, with the greatest attention to feeding and in some cases the use of stimulants and tonics are necessary. The patient must be kept in a cool loose box, and his appetite, which is generally very capricious, must be tempted with grass, carrots, bran mash mixed with linseed, skim-milk, stale bread, or anything else he will take.

If tonics are required, iodide of iron in doses of a drachm once or twice a day, or sulphate of iron or of copper in drachm doses with two drachms of gentian may be given daily. It is usually advisable to change the tonic after a few doses. Excess or unsuitability of a tonic is indicated by a want or falling off of the appetite. In cases, however, which are progressing favourably, Nature had better be left to herself; and tonics should only be resorted to when the symptoms really indicate the need of them. In some cases medicine may be required to regulate the bowels, but it must be of a very mild character, such as small doses of linseed oil. If much debility remains, a pint and a half of good stout may be given twice daily in addition to the tonics and other dietetic treatment.

As a rule, if the animal can be induced to feed, we may hope for the best. As strength returns, and when the pulse has fallen to its natural level, a little led exercise may be given. Bruised oats, which are easy of digestion, may be allowed in small quantities. If all goes well, we may look for complete convalescence in about six weeks, and the horse may then be gradually brought into work.

The nature of the work, for which he will be fit, will be entirely dependent on the amount, if any, of alteration which has taken place in the structure of the organs. The extent of those alterations may be ascertained partly by auscultation, partly by the movements of the flanks in respiration, partly by the nature and sound of the cough, if any, and lastly by testing the state of the respiratory organs by galloping the animal.

\section{CHAPTER 23.}

\section{CHRONIC DISEASES OF THE ORGANS OF RESPIRATION.}

450. Chronic Covgh.-Nature and seat. 451. Treatment. 452. Thick Wind. - Nature and causes. 453. Treatment. 454. Roaring.Nature and seat. 455. Cauises. 456. The Larynx. 457. Cause of the immoveability of the Arytenoid Cartilage. 458. Other causes of derangement of the Larynx. 459. Treatment. 460. Class of horses predisposed to Roaring. 461. High blowers. 462. Grunting. 463. WhistLing.Nature, seat, and causes. 464. Treatment. 465. Broken Wind.Symptoms and seat. 466. Causes. 467. Emphysema. 468. Treatment. 
469. Class of horses predisposed to Broken Wind. 470. Pulmonary Consumption.

\section{CHRONIC COUGH.}

\section{Nature and seat of Chronic Cough.}

Chronic cough is a very troublesome affection. It may have its seat either in or about the larynx, in the rcspiratory passages, or in the lungs.

It usually arises from morbid sensibility of the nerves of the larynx, or from irritability left in its lining membrane or in the bronchial tubes after pneumonia, bronchitis or influenza. Or it may be connected with indigestion, and indeed it may be said to be a symptom of that affection. An intimate connection, as the reader is aware, exists between the nervous system of the stomach and that of the lungs. Hence any derangement of the former is apt to set up irritation in the latter. Thus horses suffering from worms are often affected with Chronic cough. It also constantly accompanies Broken Wind ; and in some cases it exists without any appreciable cause. In horses subject to this disease very trifling causes, such as the change from the atmosphere of the stable to the open air, or the mere act of eating or of drinking, or a change of weather, or a little unwonted excitement, such as a trot, or a sudden blow, are often sufficient to produce irritation and consequently cough.

Chronic cough, when following bronchitis or influenza, is usually accompanied by an extra secretion of mucus; but we sometimes find it when the membrane is particularly dry.

\section{Treatment.}

The treatment of the malady must depend on the cause from which it proceeds.

When the Cough proceeds from irritability of the larynx, considerable benefit even in cases of some standing will be found to result from the application of external irritation to the throat. Blisters are usually employed for this purpose, but the Author has seen much better results from setons. The action of a seton can be maintained for any length of time, which is an object of great importance in dealing with a chronic affection; and furthermore the horse may be worked as usual, whilst the seton remains in. If setons are objected to on account of the blemish likely to remain, repeated applications of the biniodide of mercury ointment may be beneficially applied. With a view of allaying the irritation which generally accompanies the passage of food down the throat, it is useful to mix boiled linseed with the corn; and five or six pounds of carrots may be given with the other food daily; or to horses in slow work steamed food may be given. The tendency to irritation is diminished by giving food and water often, and in small quantities at a time.

If the cough proceeds from the lungs, or as a sympathetic affection, the real cause, which is usually indigestion, must be treated. Careful 
attention to the diet, abundance of pure air, occasional alterative medicine, general good stable management, and, if need be, tonics, offer the best chance of restoring the digestive powers to a healthy state. The best and most nutritious food only should be given. Any distension of the belly, such as that caused by the use of bulky forage, always affects unfavorably the free movement of the lungs; whilst bad food will be certain to aggravate the indigestion. With a special view of avoiding any undue distension of the stomach, both food and water should be given in small quantities at frequent intervals.

In very many cases, whether the cough arises from irritability of the membrane of the larynx, or from the lungs in sympathy with the digestive organs, much benefit will be derived from the administration of tar, either in water or in balls. For the purpose of impregnating the water, it will be sufficient to pour a quart of the best Archangel tar into a large cask, from which the water may, when required, be drawn; or two drachms of tar may be made up into a ball with gentian, and given daily.

If the Cough has followed bronchitis, pneumonia, or influenza, and is accompanied with an extra secretion of mucus, with occasional discharge from the nose after coughing, or with a wheezing noise,-mineral tonics such as a drachm of sulphate or iodide of copper with two drachms of gentian given daily for a week will be beneficial; the effect produced must, however, be carefully watched. If the cough notwithstanding continues, a change of treatment may be desirable, and the box may be fumigated with tar. This may easily be effected by putting some tar in an iron ladle, and plunging a bar of hot iron into it.

In many cases of Chronic cough arsenic is very beneficial. It may be commenced in doses of two grains twice a day mixed with two drachms each of nitre and sulphur slightly wetted and mixed with the corn. The dose of arsenic may be increased gradually to four grains and continued for a week or so. After which it should be intermitted for ten 'days, when it may be again repeated.

Chronic cough may be, if we may use the expression, intermittent in its character, that is, it may be absent for a time, and then returns as a dry, hacking, half suppressed cough, repeated several times in succession, although the horse may not otherwise be out of health. In such cases a ball made of half a drachm of camphor, one or two drachms of nitre, one scruple to half a drachm of calomel, and one drachm of aloes, with tar and Venice turpentine sufficient to make a ball, will be useful every evening for a few nights, after which it may be discontinued, and repeated after an interval; or the following may be given night and morning for a week with benefit, viz. extract of belladonna and camphor, of each half a drachm, with two drachms of tar, with sufficient linseed meal to make a ball.

Horses affected with Chronic cough, if kept in good condition; often continue for years to perform even moderately fast work; whilst on the other hand, if the condition falls off, the malady always increases and is apt to degenerate into Broken Wind. 
When, however, this affection accompanies or rather is the result of serious derangement of the Pulmonary system, such as Broken Wind, it is obviously incurable, because the cause, from which it proceeds, is incurable.

\section{THICK WIND.}

\section{Nature and causes of Thick Wind.}

Thick Wind generally arises from thickening of the mucous membrane of the finer bronchial tubes and air cells, caused by acute or chronic inflammatory disease either of the bronchial tubes or of the lungs. In the latter case the bronchial tubes are also usually involved. It may also be produced by injudicious and violent exercise after watering, or when the stomach is full, or when the animal has been kept on soft food. It is also found in horses of a pampered plethoric habit. In these cases it is probably due to nervous irritability of the lungs, sympathising, as they readily do, with the condition of the stomach.

On account of the thickening of the mucous membrane the horse labours much in his breathing, especially when the respiration is accelerated by work. The importance or otherwise of this disease mainly depends on the degree of thickening which has taken place and the extent of lung affected. These points can in some measure be ascertained by auscultation over the region of the chest, after the horse has been made to exert himself. This disease is distinguished from Broken Wind by the inspirations and expirations being performed with equal quickness.

\section{Treatment.}

Treatment can only be palliative. Active measures are useless. Good condition, regular work, and very careful watering and feeding will mitigate the evil. When, however, the disease arises from a plethoric state, medicine either purgative or diuretic is useful. Exercise and an occasional sweat will also be needed.

Fat young horses made up for sale are often affected in their breathing to an extent which may easily be mistaken for thick wind; but in such cases moderate diet, exercise, and a course of physic will generally be sufficient in a short time to relieve the symptoms.

\section{ROARING.}

\section{Nature and seat of Roaring.}

Roaring is a very peculiar noise made usually in the act of inspiration, especially when the breathing is accelerated. In some cases it may be made both in expiration and inspiration. The sound is caused by 
obstruction in some part or other of the respiratory passages, and usually in the larynx.

\section{Causes.}

Roaring is very frequently, indeed almost always caused by paralysis of the muscle of the arytenoid cartilage of the Larynx.

This paralysis is due to atrophy of the left recurrent nerve which, if in health, would supply the motor force to the muscle. This force being absent, the muscle loses its power and wastes away. Hence the left half of the arytenoid muscle drops down, and bars the ingress of the air at each inspiration, which therefore strikes violently against the helpless cartilage. Hence the noise we hear.

On the other hand, as the cartilage has been flattened down, the expiration is easily effected. Therefore the roarer makes no noise in expiration.

\section{Treatment.}

Every kind of treatment from firing down the outside of the throat to excision of the muscle has been tried without success.

As, however, in broken wind and chronic cough, hard and regular work with high condition exercise a favorable influence, and may for a length of time render a roarer useful for many purposes; but with all our care the disease, when arising from the above cause, generally inçreases until the animal becomes useless.

\section{7-8. Other Causes. Tight reining up.}

Occasionally the derangement of the Larynx is due to other causes. Among the most common of these is the system of tight reining up. In our endeavour to give an arched appearance to the neck, we sometimes in horses not naturally so formed produce distortion of the larynx, and consequently obstruction to the free ingress of the air. Horses, in which the branches of the lower jaw are not set sufficiently wide apart to allow of the head being freely and easily bent, often make a roaring noise, if the head is reined in, when they are ridden; and a continuance of this forced position may induce thickening of the membrane and ultimately roaring. If taken in time, the remedy is obvious.

\section{Tumour in the Nose.}

A sound somewhat similar to roaring may arise from a tumour in the nose. It may be possible to remove it. Or it may arise from a thickened state of the membrane of the bronchial tubes as sometimes found after catarrh, laryngitis, etc. The usual treatment is blistering.

\section{Class of horse predisposed to Roaring.}

Large horses, especially those which are long in the wind-pipe, are more predisposed to roaring than smaller animals. Ponies are seldom if ever affected. 
Roaring is in some cases hereditary, probably where the make and shape of the sire or dam predispose their progeny to this disease.

\section{High Blowers.}

The noise, which some horses make by flapping the alæ of their nostrils, has occasionally been mistaken by inexperienced people for roaring. It has, however, no connection with disease of any sort. It arises from powerful muscular development in the part. If a horse so formed be pushed to his speed and continued at it for some time, it will be seen that he can intermit the noise at his will; and when he really becomes distressed at the pace, he will have something else to do than to flap about his nostrils, and the sound will then cease altogether.

\section{Grunting.}

Grunts, very similar to those given by roarers when threatened with a blow, are sometimes emitted by horses with big bellies, especially by those just taken up from a straw yard. The cause in such cases may be sudden pressure on the diaphragm from the stomach. Horses also, which have been long in dealers' yards and have been frequently examined as to their wind, will sometimes grunt on being approached, on account of fear of a blow.

Such grunts have often no connection with roaring; but the horses which emit them should be examined as to their wind with more than ordinary care. Grunting and roaring usually go together, though, as above stated, they may be unconnected.

\section{WHISTLING.}

463. Nature, seat, and causes of Whistling.

Whistling is a modification of the noise known as Roaring. The peculiar sound, which is that of air passing through a narrow channel, arises from abnormal contraction in some part of the air passages. The seat of the contraction may be in the larynx, or it may be caused by thickening of the membrane of the windpipe from previous inflammation of that organ. The causes of Whistling are very similar to those of roaring.

\section{Treatment.}

The treatment is similar to that of Roaring.

In some cases a whistler may be capable of more exertion than a roarer; but in other cases an opposite result may be found. The public generally attach less importance to whistling than to roaring. 


\section{BROKEN WIND.}

\section{Symptoms and seat of Broken Wind.}

Broken Wind is indicated by a short weak hacking pretty constant cough, by a very peculiar double action of the flanks, and by a prolonged effort of the abdominal muscles in the act of expiration, by a difficulty in performing the operations of respiration, by a craving after food, by flatulence and a pendulous belly. A mucous râle, caused by an increased secretion from the bronchial tubes, may often be heard, if the ear be applied in front of the chest.

\section{Causes.}

Horses with narrow chests and protuberant bellies, if also gross feeders, are specially subject to this affection. Sometimes it gradually steals on a horse, commencing with chronic cough; whilst at other times it comes on suddenly, perhaps after a hard gallop, when the horse was not fit for it; and sometimes it occurs without any obvious cause.

Broken Wind is found occasionally, though but very rarely, as a sequel of pneumonia and other diseases of the respiratory organs. It more frequently follows on Chronic cough and Chronic indigestion, accompanied by excessive distension of the stomach. In both cases, however, we believe that an impaired condition of the nerves supplying the lungs and air cells is the immediate cause of the affection.

In the one case want of tone of the nervous power in the lungs is simply an after-effect of inflammation in the cellular tissue; whilst in the other it is probably due to the intimate sympathy which exists between the nerves of the digestive organs and those of the lungs.

As regards the effect of inflammatory action on the cellular structure it is probably not necessary to enter into any detail; but the second named cause will need some explanation.

Excessive distension of the stomach and bowels ordinarily arises from the use of either innutritious or of bad forage. In the one case the animal in his endeavour to obtain sufficient nourishment consumes an excessive amount of bulky food. In the other the distension is caused by the generation of gases in the stomach, such as are readily produced by the use of musty or mildewed hay, by damp or sprouting oats, or stale green forage. Indigestion may also arise from bad management, such as working a horse on a full stomach or with his belly full of water. Greedy feeders and horses with a depraved appetite are also specially liable to suffer from indigestion.

When from these or such like causes the nerves of the stomach get out of order, their communications and extensions, which ramify through the cellular structure of the lungs, are also liable to become deranged and in some cases paralysed. From such derangement of the nervous power the coats of the air cells are no longer able to contract upon and expel the air, which at each inspiration enters the cells as usual. Hence 
a larger portion than natural of the air remains in the cells, even after the intercostal muscles have performed their duties in the ordinary course of expiration. In order to expel it, the animal is then obliged to bring into play the abdominal muscles as auxiliaries. Hence arises the prominent sign of Broken Wind, namely a double action of the flanks. These effects ensue equally, whether the paralysis of the nerves be due to previous inflammation of the lungs, or to indigestion.

During catarrhal affections the disease is often temporarily increased and also at sudden changes of the weather, especially during fogs and easterly winds.

In some cases Broken Wind is supposed to arise from a weakened power in the diaphragm, in consequence of which the abdominal muscles are called into play secondarily to assist in the act of expiration.

\section{Emphysema.}

Broken Wind is occasionally complicated with the condition known as Emphysema. It consists in the retention in the inter-lobular cellular tissue of the lungs of a portion of the air, which ought to be completely expelled at each expiration.

By some Veterinarians it has been supposed, that the inability to expel the air is due to rupture of the coats of the air cells, on account of which the air escapes either underneath the pleuræ or into the substance of the lungs. Post-mortem examination, however, generally fails to show any such lesions. The retention of the air is more probably caused by general weakening of the structure, owing to want of nervous power-a result of the later stages of the original disease.

\section{Treatment.}

The peculiar symptom of flatulence, which is present in every brokenwinded horse, shows pretty clearly that in the great majority of cases the disease is due to disordered state of the digestive organs rather than to previous disease of the lungs.

As regards treatment in incipient cases, especially in those which result from derangement of the stomach, there is reason to hope, that removal of the causes and reversal of the conditions, which have induced the malady, may check its progress, although we must not hope altogether to get rid of the disease. Careful feeding and watering and regular exercise are essential.

But when Broken Wind has become chronic, whether it has arisen from inflammatory attacks on the respiratory organs or from indigestion or from emphysema,-where in short any alteration has taken place in the structure of the lungs, - the disease is obviously incurable, and active treatment is worse than useless.

Relief, however, always follows any improvement in the hard condition of the animal for work. But on the other hand it is not easy to get into condition an animal with functional derangement of the lungs, and perhaps a disordered stomach in addition. The best care, the greatest 
attention to diet, grooming, ventilation and exercise are needed. A broken winded horse should never be left idle for a day. Good hard nutritious food is obviously indispensable. Mineral tonics and especially arsenic may be administered with benefit in many cases with the view of restoring tone to the stomach.

With judicious management a horse even with confirmed broken wind, though he will never become sound, may remain for years available for slow work.

469. Class of horses predisposed to Broken Wind.

Broken Wind, though occasionally found in valuable horses, as a sequel of pulmonary disease, is most common among inferior animals, because they are more often subjected to the causes, such as bad or innutritious forage or careless feeding, which so frequently induce it. All horses however are liable to it under the influence of these causes. Hence we often find hunters, which have been summered in a straw yard, affected with this disease.

\section{PULMONARY CONSUMPTION.}

Prolonged disease of any sort, but especially of the liver, or even longcontinued debility, sometimes leads to derangements of the lungs, which ultimately induce Pulmonary Consumption. The disease is the same as Phthisis or Consumption in man. A deep loud cough in the first instance, with falling off in the condition and an unhealthy state of the coat, are marked signs of the disease. In the later stages the hair becomes easily detached, and tubercles form in the lungs.

In Pulmonary Consumption we can hardly hope for much benefit from treatment. Careful feeding, moderate exercise, good grooming, tonics and attention to the general health afford the best chance of arresting the development of the disease; but when tubercles have formed in the lungs, the animals had better be destroyed. Their presence may be judged of from the nature of the discharge, which may be coughed up through the nose, together with rapid falling off of the animal in condition.

Pulmonary Consumption, though not often found in horses in this country, is very common among the stud-bred horses in India in conjunction with liver disease. The "half caste" in India suffers from the same complication of diseases.

CHAPTER 24.

INFLUENZA.

471. Nature of Influenza. 472. Causes. 472 a. Necessity for watching the earliest symptoms. 473. Symptoms. 473 a. Pink-Eye. 474. Conva- 
lescence. 475. Complications. 476. The Liver. 477. Respiratory Mucous membrane. 478. The Lungs. 479. The Alimentary Canal. 480. Bowels. 481. The Kidneys. 482. The Heart. 483. Heat of the Mouth. 484. Fatal terminations of Complications. 485. General Treatment. 486. After-effects.

\section{Nature of Influenza.}

Influenza is a specific disease, characterised by febrile and catarrhal symptoms, accompanied by loss of appetite, great prostration of strength, and often complicated by disease of the liver, lungs and mucous. membranes generally, and sometimes with affection of the heart or bowels. In all cases the nervous system is affected to a great extent, and indeed most of the more prominent symptoms may be regarded mainly as results of depression of the nervous centres. The cause of this depression is the presence of a specific poison in the blood.

\section{Causes.}

Influenza in common with other specific diseases is developed by some peculiar condition of the atmosphere which exercises an injurious influence on the health of animals. Atmospheric causes, though the real agents in developing and spreading specific diseases are unable of themselves to generate them.

Other debilitating or poisoning influences, such as bad ventilation, dirty stables, an insufficient supply of nutritious food, bad forage or debility, or on the other hand an excess of food, even though the quality be good, combined with an insufficient amount of exercise, are needed to aggravate the injurious atmospheric influence. Cold damp seasons, especially in spring and autumn, also adversely affect the general health.

From all or any of these causes the health is lowered. The adverse atmospheric influences, whatever they may be, which tend to propagate and disseminate the disease, under these circumstances find a suitable medium for the development and growth of the specific organic poison which is the active agent in the production of this affection. This is now generally thought to be due to the action of microbes.

Influenza is said to be, and probably is under certain circumstances, infectious. Added to already existing predisposing causes, the effluvium from the body and breath of a horse and still more from the bodies and breath of many horses affected with this or indeed with any other disease, when absorbed into the lungs or deposited on the mucous membranes of other horses, must be a powerful determining cause in all imperfectly ventilated stables.

But the disease can hardly be in reality highly infectious, because we often find its career cut short at a time when many horses are suffering from it-probably from cessation of the original cause.

472 a. Necessity of watching the earliest symptoms.

This is a disease, which above all others requires to be taken in its very earliest stage. The incipient attack can be most readily detected 
by the use of the thermometer in the hand of a competent veterinary surgeon.

The first essential is rest, absolute and complete, a fact, which if it had been appreciated in past outbreaks, would have saved the majority of the horses attacked. Most cases, that are taken in time, run a regular course and terminate favorably. But if work is continued after the time, when the first symptoms ought to have been detected, an unfavorable result will ensue, either death or some other injurious sequel such as roaring, \&c.

No disease lends itself more readily to empiricism. It has many phases, and can only be treated according to the symptoms presented by each case.

\section{Symptoms.}

Influenza in different years and in different places varies much in its intensity and in some of its symptoms. In some seasons it assumes more of an inflammatory character, whilst in others it takes a low form. The description of symptoms given below will have reference to the general type of the disease rather than to the particular features, which may be abnormally present in any particular outbreak.

In mild cases for the first two or three days the horse is observed to be dull, weak and dispirited, generally sweats on exertion, the bowels are slightly constipated, the fæces are paler than usual, and there may be occasionally cough. If the patient is promptly removed to a loose box and carefully treated, these symptoms may pass off (probably in the form of catarrh and a disposition to œdema in the legs) without the necessity for recourse to any active treatment.

More often, however, they are followed by others of a more urgent nature. The horse refuses his food, his coat looks unhealthy, the urine becomes scanty, the frees pale and scanty, the surface of the dung pellets is glazed and perhaps partially coated with mucus, the mouth becomes hot and unnaturally dry, or it may be pasty, particularly at the back of the tongue, and the mucous membrane altogether and especially round the gums is of yellowish red hue, as is also the conjunctival membrane of the eyelids. The temperature rises perhaps to $105^{\circ} \mathrm{F}$. (See par. 217a.) The pulse is quick and oppressed, perhaps 70 per minute, but at the same time feeble, and the breathing is quick. The horse appears to be suffering from intense headache, and if made to move, he staggers in his walk. These symptoms point very clearly to the nervous centres being functionally deranged, especially the brain.

These symptoms may remain much the same for two or three days, except that the pulse may become a little quicker and more feeble, the respirations quicker and shorter, and the temperature higher.

If the horse is well nursed, and proper attention is paid to the rentilation, he will most likely recover without the assistance of medicine.

At other times the disease is ushered in and accompanied by weeping of the eyes, swelling of the eyelids and of the legs and under the belly, and all other usual signs of extreme debility. Even in the very early 
stage the patient may be so prostrated, as to require the assistance of several men to remove him to a loose box.

With care and good nursing the threatened attack may probably pass off in a few days.

The discharge of purulent matter from the nose in the early stage is a good sign, and indicates that the disease is becoming milder. Favorable progress is also marked by the urine being discharged more frequently and in greater quantities and not so highly coloured, and by the dung becoming of a proper consistency and soft, instead of being voided in pellets. A slight tendency to odema in this stage is also a favorable sign. It is one of nature's means of giving relief, and often prevents the occurrence of mischief in important internal organs. But in the later stages it is a symptom of the inability of nature any longer to continue the conflict with the disease.

Should the disease, whether it has commenced in the one way or the other, not take a favorable turn, the mucous membranes will become seriously involved. This will be indicated by the Schneiderian membrane being heightened in colour. The discharge from the nose, instead of being purulent, will be suppressed and seanty, or it may be serous and straw coloured. The throat will become sore, as indicated by a difficulty in swallowing even water. The breathing becomes quickened, and the patient may cough somewhat frequently. The suppressed character of the cough points to the mucous membrane of the bronchiæ being involved.

In other cases an unfavorable turn is indicated by the occurrence of fits of shivering, by the breathing being somewhat embarrassed, by the pulse being increased in frequency and very small in volume. The fits of shivering may or may not recur. Profuse perspiration sometimes supervenes on the rigors, and always temporarily relieves the breathing.

If the patient's constitution is good, a favorable change may be expected.

If the attack at this juncture does not take a farorable turn, the symptoms will probably become more intense, and pneumonic, hepatic, cardiac or enteric complications may set in. The membrane of the nose may become mulberry red, and in very bad cases the discharge may be tinged with streaks of blood. In some cases there may be a discharge of muco-pus from the eyes. The legs often swell, and there may probably be swellings in the sheath and under the belly. A tendency to œdema often exists about the larynx and glottis, and serum may be effused into the air cells or into the parenchymatous structure of the lungs, or along the spinal cord, or in the ventricles of the brain. The animal may wander unconsciously round his box, and look at his sides and paw occasionally with his forefeet as though in pain.

At this stage the disease often assumes an intermittent form, and the patient alternately gains strength for a time and relapses. Eren if the patient survives, chronic cough, defective respiration, skin disease, rheumatism or paralysis are often after-results of such extreme developments of Influenza. 
When a case is about to terminate fatally, the pulse will be found to falter and sink, and as a finale cold sweats will break out. Death generally occurs about the 6th day, but the case may be protracted to about the 14th day.

Throughout the attack it must not be forgotten that the inaction of the bowels is often mainly dependent on want of sufficient nervous tone and energy. There is often no undue hardness of the fæces, but rather the contrary. The proper action of the bowels will best be restored by increasing the vital action by the administration of enemata.

There is sometimes a strong disposition to gangrene in wounds in horses suffering from influenza of a low type. Ulcerous sores or simple wounds take on an unhealthy action from no apparent cause, and this action extends to neighbouring parts, and gangrenous sloughs may result. Great caution should therefore be used in applying strong blisters or setons in influenza, even if for other reasons they were not objectionable.

\section{3 a. Pink eye.}

The term "Pink Eye" has of late years been applied to a particular form of Influenza manifested by symptoms of a peculiarly marked nature, notably that of a remarkably clear pink coloured condition of the conjunctival membrane, accompanied by a swollen or odematous state of the conjunctivæ. From the fact of these features being of so striking a character, the disease has frequently been described as a special affection, but it is now generally recognised as being merely a modification of the catarrhal form of Influenza.

In addition to the conjunctical peculiarities, we find as a rule a considerable amount of general œedema present. The limbs will be swollen from effusion into the connective tissue, and this dropsical condition will frequently be found extending along the course of the abdomen. The violence of the febrile symptoms of course depends upon circumstances, but as a rule the fever runs high, the pulse will range from 60 to 100 , though generally less feeble and of a better tone than it is in the ordinary catarrhal or pneumonic form of the disease. The temperature is generally considerably elevated, often as high as $105^{\circ} \mathrm{F}$., and the respirations are accelerated. A marked stiffness of gait is generally present together with the ordinary catarrhal symptoms in a greater or lesser degree, such as nasal defluxion, cough, \&c., which have already been described.

It may be remarked that in this particular form of Influenza there is a remarkable tendency towards the formation of fibrinous clots or thrombi in the cavities of the heart and in the larger arteries, especially in the pulmonary system. This peculiarity is probably due to either the excess of fibrinogenous matter in the blood, or to the weak action of the heart, or both combined. From this disposition to the formation of thrombi it is not difficult to account for the occasional sudden termination of the disease by death, which frequently occurs in a marked and unexpected manner. 
$473 b$.

The treatment of Pink Eye, like other forms of Influenza, must consist primarily in good nursing, a cool, well ventilated loose box, warm clothing without being heavy, bandages, and such dietetics and general treatment as have already been detailed.

The reader must understand that the disease cannot be cut short by any special mode of treatment; it must run its course, and the general principles laid down for the various modifications of the affection may be followed to the extent indicated by the prevailing symptoms. Purgative medicine is inadmissible, but if much constipation is present ten ounces of linseed oil may be given, but we should rely principally upon laxative diet and enemas to relieve the bowels. Salines as chlorate of potash and nitrate of potash may be given in the drinking water twice a day, but not exceeding one oz. in all.

It is a great mistake to bother a horse with chest disease by giving him medicines. Drenches are specially to be avoided as they generally do more harm than good, and in confirmed cases very serious harm.

\section{Convalescence.}

When a patient is recovering from a severe attack of Influenza, we must not expect any great and rapid amendment. The change will be gradual. We must tax our patience, and be satisfied to look on and seek to aid nature in the gradual restoration of the system. After a bad case there will be during convalescence frequent changes, slight accessions of fever, inequality of heat and cold on the surface of the body and legs and slight shiverings. The appetite will only slowly return and will be capricious in character. It is always a good sign to see the horse lying down and comfortable in that position, especially if the breathing is not accelerated by it.

The treatment during convalescence is simply good nursing, and carefully regulated administrations of tonics.

\section{Complications.}

Attacks of Influenza are often complicated by various other derangements.

The symptoms of the various complications are given in the succeeding paragraphs-but not the treatment. The treatment of each disease will be found under its proper head (see index).

\section{The Liver.}

In most cases the liver is functionally deranged. Of this, the peculiar condition of the visible mucous membranes, the colour and consistency of the fæces and the colour of the urine afford sufficient evidence. In 
decided hepatic complications the mucous membrane has a dirty yellowish-red aspect, the urine is highly coloured and scanty, the fæces are often in a more fluid state than natural and sometimes are offensive in smell. The mouth feels pasty and dry. Constant pawing is also a concomitant symptom. The animal may evince pain on pressure being applied to the region of the liver.

In the early stage, when the liver is simply torpid, half a drachm of calomel will be useful. This may be followed by half a pint of linseed oil. Enemata of tepid water are beneficial in promoting the action of the bowels.

It is not, however, to be supposed, that in all or even in most cases these measures will be successful in relieving the hepatic complications, which often accompany Influenza; but they offer the best chance of relief, and indeed are as strong and active as the animal in his debilitated condition can bear.

Should the horse die under these circumstances, the liver on postmortem examination will be found to be much enlarged, of a dark brown colour, very soft in consistency, friable, granulated and easily broken down by the finger. It may likewise become ruptured, and death may take place from that cause. The spleen and mucous coats of the intestines are usually also involved. The spleen is often found after death to be greatly enlarged and softened.

\section{Respiratory Mucous membrane.}

The Mucous membrane of the air passages is generally more or less affected, and there is a peculiar straw-coloured discharge from the nostrils. This discharge is often apparent, before the breathing has been noticed by the groom to be affected. The breathing, however, is altered and is short and quick. This change, though it may escape observation at the nostrils, is perceptible enough at the flanks. The straw-coloured discharge indicates an inflamed state of the mucous membrane, which is very liable to extend to the ramifications of the bronchiæ. After a time there will be noticed an unusual dilatation of the nostrils, which do not fall to their usual calibre during the act of expiration. As the attack progresses, the breathing will become quicker, and the nostrils more fixed and dilated in order to admit all the air possible.

If the character of the discharge changes to the natural secretion, it is a favorable sign.

\section{The Lungs.}

Influenza very often induces inflammation of the lungs of a subacute kind and also pleuritis. From general debility and want of nervous power there is a peculiar disposition in such cases for the blood-ressels to allow the serum to escape. By the pressure of such effusion the air-cells are diminished in calibre, and hence arises quickened breathing. The pleuræ subsequently become involved, and water or serum collects in the chest. 
On account of this tendency to oedema and outpouring of serum, roaring and thick wind are frequent after-consequences of influenza. We are never certain that a horse, which has been affected with this disease, is not a roarer until we have tested his wind.

The general symptoms attending these pulmonary complications and those indicating relief or increase, are the same as those already described in the Chapter on Diseases of the Organs of Respiration, No. 22. The treatment is also the same, but the reader must bear in mind that the patient is already from other causes in a very debilitated state, and that sedative medicine is inadmissible.

The patient is probably too weak for treatment. He will do better without it. In plain words-don't fidget him.

If the legs are cold or unequal in temperature, as is usually the case, friction and woollen bandages and in some cases stimulating liniments are useful. The temperature of the legs and body is very changeable in this disease.

\section{The Alimentary Canul.}

The Alimentary Canal is always more or less involved in Influenza. In the early stage, disease of the mucous membrane is indicated by constipation of the bowels and a peculiar dry state of the dung pellets, which however in a short time become glazed on their surfaces and partially covered with mucus. This latter sign indicates that the bloodvessels of the intestine are in an inflamed condition, and it warns us of the danger of administering strong purgatives. If this condition of the blood-vessels increases, it is probable that dysentery may supervene.

In this stage the pulse becomes small and very quick, and so feeble that the slightest pressure on the artery seems to extinguish it. The patient will wander round his box and will often exhibit signs of abdominal pain. Death generally follows these latter symptoms.

\section{Bouvels.}

In cases, where the Bowels are especially implicated, the evacuations will probably be offensive and dark coloured, or they may be mixed with blood, and after death blood may be found outpoured. The contents of the intestines, even though the patient may have passed no dung, may be found in a fluid state, and food and medicine balls, which have been taken some days previously, will often be found on post-mortem examination undissolved in the stomach. These symptoms show the extent to which nervous paralysis has affected the system.

\section{The Kidneys.}

The functions of the Kidneys, as indicated by variations in the quantity as well as in the quality of the urine voided during the different stages of the disease, are always more or less affected. At first the secretion is scanty, in a short time it becomes high coloured and gradu- 
ally gets darker. As the disease declines it becomes more copious. If the patient continues to progress favorably, it resumes by degrees its natural character.

\section{The Heart.}

The depression of the power of the nervous centres, which we have noticed above as the main characteristic of Influenza, always affects the action of the Heart.

The heart, in order to perform its functions normally, requires to be supplied with a due amount of nervous force. Its rhythms will then be firm and strong, and its beats as regular as the ticks of a clock; but if the supply of nervous power is deficient and irregular, the action of the heart will be feeble in tone, quick, fluttering, and often intermittent; and the impulse to the wave of blood in the arteries will be so feeble, that the pulse may be extinguished by the slightest pressure of the finger. These symptoms indicate the need of diffusible stimulants rather than of depressants.

Again, having regard to the theory put forward in the early pages of this Chapter, that the original seat of the disease is in the microbe, and that the nervous centres are only secondarily depressed through vitiation of their proper nutritive stimulus, namely the blood, it is obvious that it is of the greatest importance to maintain, as far as possible, the free circulation of the blood-both in order that the vitiated fluid may be purified by the action of the air in the lungs, and also that a better supply of blood may be given to the brain and nervous centres.

Effusion of serum, arising from congestion of the blood in the vessels of the heart, is sometimes found in the pericardium. The congestion is due to want of nervous power in the heart to propel forward the blood. In such cases sudden death may occur when the patient in other respects is doing well.

An intermittent pulse, so long as its beats are fairly strong, is not a bad symptom. It often occurs during convalescence, and may then be taken as an indication of returning health, and that the heart is endeavouring to regain its power-though perhaps somewhat exhausted by the attempt, and hence the occasional intermission of its beat. In the last stages, when the strength is failing, an intermittent pulse is of course a very bad sign.

\section{Temperature.}

During the incubation of the disease the temperature of the body becomes elevated, increasing with the febrile symptoms, but decreasing with the subsidence of the affection. The condition of the temperature is an important item, and should be tested by the clinical thermometer as explained in paragraph $217 a$.

By placing the finger in the mouth increase of heat may be detected. Any sudden marked decrease of temperature is a bad sign. Towards an unfavorable termination of a case, the mouth and also the exhaled breath will feel colder than usual. 
It is always a good sign when the mouth resumes its natural moist feel, and its membrane regains its natural pale rel colour instead of being brown or yellowish brown.

\section{Fatal terminations of Complications.}

Influenza may terminate fatally by affecting some one or other organ principally, or by general affection of nearly all the internal organs. Sometimes the lungs and pleuræ bear the brunt of the disease, and then we have breaking up of these structures. Sometimes the liver is greatly diseased, or the spleen. At other times the bowels only are affected, and their lining membrane is found of a deep mulberry colour in parts, and almost in a state of gangrene in other parts, with a blush of inflammation varying in intensity through the whole canal. Thus in some cases, which appear to be going on favorably as regards the state of the pulse and respirations, the animal suddenly becomes worse and sinks, to the great surprise and mortification of the practitioner.

\section{General Treatmient.}

The treatment has been described along with the various phases of the symptoms and complications. It has to be borne in mind that it is a disease running a regular course. The great aim however must be to support the patient through the disease, and enable nature to get rid of the morbid material engendered in the blood.

Good nursing is the primary requisite. The details of the management included under this head have been already explained in Chapter 15.

The medical treatment consists mainly in the absence of drastic purgatives and strong sedatives.

As the disease abates, the debility, which supervenes, will require the most careful nursing, and if the appetite is capricious some inild tonics may be administered.

In prescribing for the various phases of this disease the Author would observe that the medicinal treatment is suggested for the purpose of counteracting certain symptoms, and should be employed with discrimination. In very many cases more harm than good is done by pouring medicines down horses' throats with the view of checking a disease which nature intends should run a certain course.

\section{After $\cdot$ effects.}

During recovery from Influenza an eruption generally appears on the skin, which may be regarded as precursor of recovery. In chronic cases the cuticle desquamates and leaves as many bare spots as there were lumps, but more often the lumps disappear spontaneously in a short time. No treatment is needed.

Rheumatism is an occasional after-result, as are also roaring, whistling, and chronic cough. Paralysis from the effect of serum effused round the spinal cord, or vertigo from serum effused into the ventricles of the brain, are also found as results of the odematous swellings; but these latter symptoms generally pass off as strength is regained. 


\section{CHAPTER 25.}

\section{NASAL GLEE'I.}

487. Nature and symptoms of Nasal Gleet. 488. Ordinary causes and seat. 489. Treatment. 490. Special causes. 491. Treatment when arising from special causes. 492. Trephining, and after-treatment.

\section{Nature and symptoms of Nasal Gleet.}

Nasal Gleet is of 2 kinds, namely 1st a discharge more or less continuous from one or both nostrils. It arises from inflammation of the lining membrane of the nostrils. Such discharge may be termed "Ordinary Nasal Gleet."

2nd. The discharge may result from inflammation of the lining membrane of one or more sinuses of the head, usually the frontal or superior maxillary. This discharge is technically known as ozena.

488. Ordinary causes and seat of Nasal Gleet.

Common Nasal Gleet is usually a sequel of neglected catarrh or of influenza of a chronic character.

\section{Of Ordinary Nasal Gleet.}

The discharge usually falls freely away from the nostrils, and is not of the glue like adherent character, which is peculiar to glanders. Usually the discharge is from one nostril only. It is sometimes continuous, but more often intermittent.

The discharge may be a sequel of a severe cold, or may result from a blow or other external injury.

In ordinary cases the discharge is white and about the thickness of cream, generally uniform in character, but sometimes curdy, clotty or lumpy, and occasionally it is yellowish in color.

When however, the discharge is connected with disease of the teeth it is generally fetid. The tooth should be drawn. If this cannot be done, an expert veterinary surgeon can generally get it out by opening the maxillary sinus under it.

\section{9 a. Treatment of Ordinary Nasal Gleet.}

This consists mainly of attention to the general health, good care and moderate, not violent exercise.

Mineral and vegetable tonics may indirectly be of benefit by improving the tone of the general health. As a rule the health will be re-established in a fortnight or less.

The nostrils may be syringed with water. 


\section{9 b. Ozena.}

If after 10 days or a fortnight at the utmost the discharge continues and if the teeth are sound, and there is reason to think that the discharge comes from one or more of the sinuses in the forehead, recourse must be had to trephining without any delay.

The maxillary sinus should be attacked first, as it is generally the seat of the discharge; and if so, there is no need of operating on the frontal sinus.

\section{0.}

The operation is perfectly safe. The pus will flow out; but if a portion of it is inspissated, it must be picked out by forceps and fingers. The injection of a stimulant will not remove the hardened pus. It will however cause irritation in the sinus. No injection should be allowed except clean warm water twice a day.

Care should be taken not to allow the skin to close completely the orifice, before the discharge has completely ceased.

\section{1.}

Before the introduction of mallein, many horses were destroyed for glanders, which were only suffering from ozena. No horse ought to be destroyed until it is proved by trephining that the discharge does not proceed from one or other of the sinuses.

Polypi in the nose are best removed by the knife, or ligature - not by torsion.

\section{Trephining and after-treatment.}

The action of the stimulant will at first excite increased discharge, but it will probably become of a more healthy character. If the discharge continues to increase, the stimulant may be discontinued for a few days, and warm water again used.

In many cases the lining membrane of the sinus will be found to be greatly thickened, and perhaps a quantity of inspissated pus may be lodged within it, which will be gradually got rid of by the action- of the injection. Care must be taken not to allow the skin to close completely the orifice, before the discharge has for some days entirely ceased. This may be done by inserting a common cork.

During treatment the patient should be fed well. If the head is hot, it should be frequently bathed with cold water. Mineral tonics should be freely administered throughout. 


\section{CHAPTER 26.}

\section{STRANGLES.}

493. Nature of Strangles. 494. Causes. 495. Symptoms. 496. General treatment. 497. Treatment of the Local swelling. 498. Opening of the Abscess. 499. After-treatment. 500. Treatment by depletives. 501. Is the disease infectious? 502. General remarks.

\section{Nature of Strangles.}

Strangles is a specific disease usually attended with an cruptive fever frequently associated with catarrhal symptoms, generally appearing about the period of adolescence. The local symptoms usually manifest themselves in, or in connection with one or other of the glandular structures. Most commonly the submaxillary and parotid glands become inflamed, and suppuration afterwards takes place in the connecting tissue and its neighbourhood.

In favorable cases the tumour usually occurs in the submaxillary space, and terminates in an abscess in the cellular tissue and textures covering the glands.

When the glands attacked are near the surface of the body, the matter in the abscess, which usually forms, is enabled easily to gain an exit by the ordinary processes of nature; or, if need be, with such assistance as may be given by the lancet, and the system is thus freed without difficulty from the suppurative matter.

If, however, the glands attacked are in the mesentery, or if, as is more rarely the case, abscesses form in the liver, lungs, or kidneys, the matter has no ready means of escape and may become absorbed into the system, where it will act injuriously on the already debilitated system of the patient. When this occurs, the animal often falls into a kind of low fever and generally sinks under its effects.

The first development of the suppurative action is generally, as stated above, around the submaxillary glands; but if checked in that part by improper treatment, abscesses may form elsewhere externally, or in the internal glandular structures. Mischief also sometimes arises even in simple cases, when the animal is too weak or too deficient in vitality to be able. to throw out the eruption.

Strangles, though a debilitating disease, in general leaves no injurious effects. On the contrary the patient usually thrives well afterwards, especially if the suppurative process has gone on favorably. If, however, the eruptive fever is checked by injudicious treatment, or the animal is too weak to throw out the eruption, he will not do well.

\section{Causes.}

There are various theories as to the cause of this disease, but none which satisfactorily account for it. By some it has been thought to be 
generally connected with dentition, by others with atmospheric causes, by others with cessation of the growth of the frame. It is certain, however, that horses occasionally have the disease after the teeth are fully completed; also that in some seasons almost all the young horses in the stable have it, whilst in other seasons almost all escape it; and again three-year-old animals, in whom cessation of the growth of the frame cannot be occurring, most often suffer from it.

Strangles has also been said to be a disease incidental to domestication; but this can scarcely be the case, as wo not unfrequently find horses at grass affected with it. They generally have it in a very mild form. It usually occurs when horses are first brought into stables.

\section{Symptoms.}

The horse is sick and off his feed, and perhaps has a slight catarrh with feverish symptoms. In a day or two the glands under the jaw or behind the ear.begin to swell. Partly from the effect of the fever which accompanies the attack, and partly from sympathy the throat also becomes sore; and hence arises difficulty in swallowing with much slobbering and occasionally some acceleration of the breathing.

When the tumour forms regularly in the submaxillary space, and is of the ordinary size, the abscess generally comes to maturity without much trouble or inconvenience.

If, however, the tumour is situated high up towards the parotid glands, the distress in the breathing will often be very great, and the feverish symptoms will run high. The noisy breathing, which forms so marked a feature in most severe cases, and from which the disease obtains its name, is owing partly to the tumour, formed in the neighbourhood of the parotid glands, pressing on the larynx, and partly also to the inflamed and swollen state of the lining membrane of the larynx, which becomes inflamed by sympathy. The tumour often becomes exceedingly large, and the patient may get excessively weak from being unable to masticate his food. In some cases the animal may be in danger of suffocation from obstruction of the breathing caused by the size and situation of the tumour.

Again from general derangement of the secretions of the body, owing to the eruptive disease existing in one part, the pores of the skin cease to act properly, and in consequence the skin becomes dry and the coat is harsh and staring.

\section{General Treatment.}

As usual with eruptive diseases, Strangles runs a regular course. The great object in treatment is to assist nature to develop the eruption fully and quickly. If the eruption is checked in the external part, in which it usually first appears, it is very apt to fly to another, and perhaps to some internal glandular structure.

Hence, instead of treating this disease with depletives, as some of its symptoms, and especially the fever might seem to indicate, we must endeavour to keep up the strength of the patient.

Herein, however, lies the chief difficulty. The horse is sick and not 
inclined to feed. His throat is sore, and at best he can take nothing but soft food. Hence good nursing becomes the main point in the treatment.

The patient's appetite must be carefully watched and tempted with anything that he will eat. In bad cases grass is not only the best, but is often the only food, that the animal can be tempted to swallow or to attempt to swallow. Carrots cut lengthways are the best substitute, when grass cannot be obtained. Bran mash is sometimes palatable for a day or two, but in general it soon becomes distasteful. Linseed gruel may also be offered. If the patient is able to eat it he should be supplied with corn softened by boiling water being poured over it with the addition of bran and linseed. Whilst it is desirable to give the animal whatever he will take, it is also necessary that the food should be offered him in a softened condition. Hay, put into a bucket and boiling water poured on it, is also palatable. The steam arising from it will also be found to be beneficial by soothing the inflamed surfaces. A little scalded crushed oats, or a small barley or malt mash is often eaten with relish. Stale bread may also be offered.

Warm clothing must be applied to the body, and bandages to the legs. At intervals, if the legs get cold, the bandages should be removed, and the parts rubbed with the hands, until warmth is restored. The patient should be placed in a cool well-ventilated box with abundance of air both day and night. Cool fresh air in this in common with all diseases, in which the respiratory passages are affected, is of the utmost importance. But on no account whatever should the patient be subjected to any cold draught. This caution is needed whenever the respiratory passages are affected. But nevertheless the air in the sick box or stable must be pure and fresh.

If the bowels are constipated, they must be relieved by the use of laxative food, or if need be by injections; but no strong purgative medicine must be given, both for fear of checking the eruption and also on account of its tendency to reduce the strength and perhaps bring on superpurgation. If any medicine is needed, half a pint of linseed oil may be given, and repeated after twenty-four hours if necessary.

The fever which accompanies the eruptive attack will disappear as soon as the disease has run its course. Should it, however, be excessive, it may be advisable to allay it with ordinary febrifuges, but no lowering treatment is admissible.

\section{Treatment of the Local swelling.}

From the general disease we now turn to the Local swelling. Our object must be to induce the process of suppuration or formation of matter. In most cases it will be sufficient to keep the part warm with layers of flannel. But if the suppurative process needs further assistance to bring it to maturity, fomentations followed by a warm poultice of boiled carrots or turnips applied to the part and retained in position by an eight-tailed bandage will be beneficial. The greatest care must be taken in all cases to avoid a chill in the part, which would check the 
formation of matter. Hence fomentations, if applied, must be followed by a poultice.

Blisters have been recommended, but are objectionable in the early stage at least, because they tend to disperse the swelling instead of developing the abscess. When, however, the tumour has begun to soften, a light blister will assist in bringing on the desired action in cases where the progress is unduly tardy.

\section{Opening of the Abscess.}

It has been generally recommended that when an abscess is pointing externally, it should be opened, as soon as it appears ready to burst, at its most depending point, so as to afford the best and freest exit for the matter. If it is determined to adopt this treatment, the incision must be kept open and clean, and the abscess very gently pressed, and occasionally injected with warm water by means of a syringe in order to clear away any matter which may be adhering to its sides. Or a small piece of tow may be put into the opening, and occasionally removed to prevent the wound from closing too soon.

When the abscess is deep-seated, very great caution is needed in the operation for fear of injuring with the lancet any of the blood-vessels in its neighbourhood. Any considerable flow of blood may prove fatal to an animal already in a weak and debilitated state; and again if the lancet should cut through the duct of the salivary gland, we may have a very troublesome fistulous sore, discharging saliva.

It is also urged that an incised opening will heal more rapidly and be less liable to leave a blemish than the irregular opening made by Nature. This is true, but with good care and attention to cleanliness, no blemish ought to result from either.

Again, in opening the abscess by the lancet, there is a danger, and it is a real danger, of opening it before it is really ready to burst. If an abscess is opened immaturely, its natural development will be checked, and it will be very likely to re-form on the mesentery, lungs, or other internal structures, when a fatal result is only too probable.

The better plan, however, is to leave nature alone. Nature will at the right time, neither too soon nor too late, cause the abscess to open. We may assist in developing the process of suppuration; but the time, at which the abscess is fully formed and ready to burst, depends on Nature.

Occasionally it happens that the tumour is so placed on the side of the throat, that by pressing on the windpipe it causes extreme difficulty in breathing. In such cases it may be necessary to open it, even though not fully matured; and if it can be laid well open with safety, the operation will give relief. In extreme cases relief to the breathing can only be obtained by opening the windpipe by the operation known as tracheotomy. This operation is very simple and quite safe in the hands of a Veterinary Surgeon. Though the glands about the head are the usual seat of the tumour, yet abscesses may, as mentioned abore, form in any of the glandular structures. 
If the tumour should form in any of the internal glandular structures, such as the mesentery, liver, or lungs, it will probably be fatal. During life we cannot be certain of its existence in any such situations. We can only surmise it by the symptoms, namely, low fever and emaciation. We must in such cases trust to Nature; but whilst we trust in her, we must do all we can to assist her powers by sustaining the system by generous diet and good nursing; and we must especially avoid any treatment, such as the administration of purgative medicine, which would lower and debilitate the system.

The tumour of Strangles may also form in different parts of the body apart from the glandular structures, as for instance on the shoulders, in front of the chest, \&c.

\section{After-treatment.}

The after-treatment consists simply in the continuance of good nursing and careful attention to appetite, diet, and ventilation, and properly regulated exercise, until the strength is restored. The patient in general recovers rapidly; but if he is much debilitated, vegetable, followed by mineral tonics, will be beneficial.

\section{Treatment by Depletives.}

By some writers depletives and purgative medicines have been recommended in Strangles; but reason and experience alike militate against any such treatment. Depletives will certainly check and perhaps disperse the eruption, which it ought to be our object to develop. The disposition to the eruptive fever will, however, remain, and the animal will not thrive. In other words, the morbid material, which nature has been seeking to get rid of by means of the eruption, will remain in the system, and injuriously affect the general health.

Again, the object of purgative medicine is in general to eliminate from the system certain matters, of which it is desirable to get rid. Why then interfere with the operations of Nature in strangles, when she is striving in her own way, that is, through the medium of the eruption, to free the system from morbid matter?

Nature requires to be assisted, not to be opposed. The great object in treatment is to keep up the strength by nutritious softened diet, and thus to enable Nature to carry out her processes of relief by means of the eruption.

\section{Is this disease infectious?}

This disease is beyond doubt contagious. It is also generally believed to be infectious. It is therefore desirable that any case should be at once separated and isolated. The disease is certainly promoted by cold damp weather. Horses seldom take Strangles a second time; and on the other hand, few horses escape it altogether. 


\section{General remarks.}

Most horses are observed to sicken some days before an attack of Strangles, and some slight fever is also present. The disease itself is always accompanied with more or less febrile symptoms. These are sometimes very slight, and at other times severe.

When Strangles in a healthy animal forms regularly in the submaxillary space, and the tumour is of the ordinary size, the abscess comes to maturity without much inconvenience or trouble to the patient. The throat is of course more or less sore, and there is a nasal discharge. But if the animal is in low condition and the swelling or tumour is situated high up towards the parotid glands, the distress in breathing is often very great and the feverish symptoms will run high.

Cases sometimes occur, which can hardly be recognised as Strangles, though it is probable that they are connected with the disease, but in a very mild form. A young horse for instance becomes slightly feverish, and there is a swelling under the jaws, which in the ordinary course we should expect to develop into the tumour of Strangles. But instead of such regular development there occurs suddenly a profuse discharge from the nostrils; and after a time all appearance of Strangles passes away. The horse has probably gone through the disease in a modified form, or the abscess has burst into the throat.

Many young horses remain for a length of time in a delicate state, and are off and on subject to repeated attacks of catarrh,- until at length the ailments terminate in positive Strangles, - after which in general the animal rapidly gains strength and condition. It would seem as if some morbid matter had been hovering about the system, which is ejected by the eruptive disease.

CHAPTER 27.

RHEUMATISM.

503. Nature of Rheumatism. 504. Seat. 505. Characteristics. 506. Causes. 507. Symptoms. 508. Treatment.

\section{Nature of Rheumatism.}

Rheumatism is inflammation of a peculiar shifting type, usually but not exclusively affecting tissues of low organisation. It may be chronic or it may be acute. The acute attack is usually accompanied by febrile symptoms.

Viewed in its more general aspect, as distinguished from the cause of any particular attack, this disease may be said to be a result of a low or 
impaired state of vitality. Hence its usual seat is in tissues of low organisation.

Some scientists now believe that rheumatism is caused by a microbe, and adduce some strong reasons for their opinion.

\section{Seat.}

The parts usually affected are the white fibrous tissue covering the muscles, the capsules of joints, the tendons and their sheaths, and ligaments. Occasionally the valves of the heart suffer from rheumatism, not indeed directly, but secondarily from deposit of fibrin on them, which impairs their functions; and in some cases the coats of the blood-vessels are affected, and more rarely parts of higher organisation.

\section{Characteristics.}

The chief peculiarities of the disease are the suddenness of its attacks and a very remarkable tendency to shift from one part to another.

Structures, which have been once affected, are very liable to recurrence of the disease, and after a time it may become chronic in such parts. But though it may be chronic, variations in degree will be felt from time to time according to weather, health, and other changing circumstances.

\section{Causes.}

Rheumatism is often caused by neglect. 'It is very readily brought on by exposure to wet and cold, by insufficient diet, by bad stable management, and by all other such causes as lower the general health. Draughts are also a very common cause, especially where due attention is not paid to the regulation of the ventilation. Rheumatism is also a frequent sequel of any debilitating disease, especially of chest affections and influenza. It is said to be hereditary, but this point is very doubtful.

\section{Symptoms.}

A sudden and at first unaccountable stiffness in some part or other is usually the earliest sign. The absence of any external cause sufficient to account for the stiffness or lameness will lead us in such cases to suspect Rheumatism.

This suspicion, if correct, will be confirmed in a few days either by the sudden disappearance of the attack, or by increase in the symptoms, or by its shifting to some other part. For example, if the attack supervenes on influenza, one fore-leg may be found suddenly much inflamed and sore to the touch from the knee downwards along the back tendons, or the seat may be in the knee or any other joint, and may be accompanied by swelling, and the attack will probably be complicated with febrile symptoms and short quick breathing. Under treatment the ailment will probably get better, but suddenly the other fore leg or perhaps a hind leg may be similarly affected. 
If the attack be severe, or if it be continued, the parts affected will soon become hot and swollen. When a part has been frequently attacked, a chronic swelling generally becomes apparent.

When Rheumatism arises from exposure to cold or wet, it generally affects the loins or shoulders.

\section{Treatment.}

For any present attack the best treatment is friction to the part affected, which should afterwards be wrapped in hot flannel. Hot fomentations are also beneficial, but great care must be taken to avoid a chill by applying flannel bandages as soon as the fomentation is discontinued; or, if these are not available, the part should be well dried and then rubbed with ammonia liniment.

In severe or long-continued attacks it is advisable to give an ounce of bicarbonate of potass, followed daily by a dose of half the above amount with half an ounce of nitrate of potass, until relief is obtained. Colchicum in half-drachm doses may be combined with the above. If these remedies fail, two drachms of iodide of potassa may be given in addition.

If the pain is great, in lieu of the above, one drachm of powdered opium and one drachm of aloes with ginger and linseed meal may be given night and morning for three days. The medicine may then be discontinued for a few days, and afterwards repeated. If the pain is very great, one drachm of extract of belladonna may be added to the above dose.

In all cases it is essential to keep the bowels in a loose state. The dose recommended above will probably produce this effect; but if needed, half a pint of linseed oil may be given, and repeated according to circumstances.

If the lameness is persistent after the ordinary means of reducing inflammation have been employed, and when all febrile symptoms have subsided, a blister of biniodide of mercury may be applied to the part, and repeated if necessary.

In good truth, however, in this as in many other diseases prevention is better than cure. Horses in really well-managed stables do not often suffer from Rheumatism.

In animals, which either from previous attacks or constitutionally are predisposed to this disease, the greatest care, in addition to maintaining the system by good feeding, should be taken to have them dried and cleaned immediately after their return from work. The evil effects of allowing horses to stand and get chilled after exercise have been dwelt upon at length in the previous Chapters on grooming and stable management.

Horses predisposed to this disease should never have their legs or feet washed, except when mud necessitates it, and in such cases they must be dried quickly and wrapped in loose flannel bandages. 


\section{CHAPTER 28.}

\section{DROPSICAL SWELLINGS.}

509. Nature of Dropsical Swellings. 510. Seat. 511. Causes of Soft Dropsical Swellings. 512. Causes of Inflammatory Dropsical Swellings. 513. Treatment. 514. Direct removal of the Fluid. 515. Indirect removal of the Fluid. 516. Removal of the causes. 517. Swelled legs.

\section{Nature of Dropsical Swellings.}

The Swellings, recognised as Dropsical, consist of an abnormal quantity of fluid derived from the blood by percolation of its watery parts through the coats of the vessels. The effused fluid consists of serum with a very slight quantity of albumen and wholly free from any admixture of blood or coagulable lymph.

Dropsical Swellings are of two kinds, namely, those which result from venous obstruction or debility, and those which result from inflammation.

The first named are soft and free from heat or tenderness, they pit on pressure and sometimes temporarily disappear either entirely or in a great degree on the application of friction, combined with pressure. The latter are hard, hot, highly sensitive, and often pulsate strongly.

\section{Seat.}

These watery effusions may collect in any of the closed cavities of the body or in any of the loose permeable structures. They bear various names, according to the cavity in which they occur.

They are most common in the legs, constituting the disease known as Edema of the legs; in the peritoneal sac, constituting water on the belly, otherwise called Ascites; or generally under the skin of the belly, sheath, legs, and other dependent parts, being then recognised as Anasarca or general dropsy. Not unfrequently they occur in the chest, as Hydrothorax or Hydrops pericardii; and more rarely in the ventricles of the brain and in the spinal cord as Hydrocephalus, or in the testicle as Hydrocele.

\section{Causes of Soft Dropsical Swellings.}

The effusion of serum which produces the soft pitting swelling may result from a diminished and retarded, or from a retarded though not diminished state of the circulation; or it may result from a poor impoverished condition of the blood; or all these causes, or some of them may exist in combination.

These, however, though the immediate causes, are themselves the result of other affections. Want of tone in the circulation often arises from disease of the heart. If the heart is weak, it is unable to propel the blood onwards as rapidly as it is returned to it by the veins. Hence 
in the larger veins there is a retarded current, which in its turn checks the circulation in the lesser veins. These vessels then become congested. By distension their coats become thin, and ultimately the more fluid parts of the blood percolate through them. Hence may arise Anasarca or general dropsy. Affection of the heart is itself a frequent after-result of influenza, pneumonia, and other debilitating diseases.

Local retardation of the circulation, as indicated by dropsical swellings in particular parts, will generally be found to be due to derangement of the internal organs of the part. Diseases of the liver, spleen, or kidneys, for instance, are apt to hinder the venous circulation of the neighbouring parts, and in this way may become a cause of dropsical swellings in the belly and hind legs. Again, disease of the lungs, when combined with pleuritis, is a frequent cause of water on the chest.

In the above and such like cases the dropsical swelling is further augmented by the accumulation of those fluid particles which are secreted from all structures, and which in health are taken up by the action of the capillaries and absorbents. When, however, these vessels are themselves overcharged, they are obviously unable to absorb the waste fluids.

Dropsical swellings cannot, however, always be traced to actual disease of particular organs. They often depend on a faulty condition of the blood arising from debilitating disease. The blood in such cases having become thin and watery, is then prone to permeate through the walls of the blood-vessels.

Further, when the blood has got into a debilitated condition, it fails to nourish the system properly, and hence again the action of the heart is weakened.

Dropsy may also occur from any cause, such as a sudden chill or exposure, which disturbs or arrests the two processes of exhalation and absorption, natural to all secreting surfaces in health; or from external injury.

\section{Causes of Hard or Inflammatory Dropsical Swellings.}

The second kind of dropsical swellings are distinguished from the foregoing by the symptoms of heat, tenderness, and pain, result from congestion of the blood-vessels under the influence of inflammatory action.

The abnormal disposition to effusion, as the result of congestion, generally arises from a weak or debilitated constitution, or from a circulation which has become deficient in tone and vigour. The attacks of inflammation, which end in dropsical swellings, are generally very acute. The swelling itself in such cases is formed very suddenly and rapidly.

\section{Treatment.}

The treatment, though it will necessarily vary in some degree according to the causes from which the dropsical swelling proceeds, may nevertheless be divided, firstly, into the means of removing the effused fluid, and secondly, the removal of the causes from which the effusion has proceeded. 


\section{Direct removal of the F'luid.}

In very urgent cases removal of the fluid may be effected by mechanical means, such as tapping, and scarification. The operation, however, is not in general of much avail, as the fluid usually forms again. In those cases in which the accumulation is considerable, and from its proximity to important organs is likely to produce a serious result, such as positive obstruction to the respiration, it may be necessary to have recourse to tapping; but except under such circumstances the fluid should not be removed by mechanical means.

\section{Indirect removal of the Fluid.}

Removal of the fluid in less pressing cases may be best effected indirectly by rousing the action of the skin by means of stimulants; whilst at the same time the secretions of the bowels and kidneys may be increased by very mild doses of aperient, or by more active doses of diuretic medicine. Iodide of potassium in doses of half a drachm with two drachms of powdered gentian, and two drachms of ginger twice a day will be found to answer best. Hydrochlorate of ammonia one ounce, and tincture of gentian half an ounce in twelve ounces of water, may be given therewith, on alternate days.

Tonics also, especially sulphates of iron and copper, are very useful in restoring tone to the system. The above medicines may be given in combination. If the symptoms indicate arrest of the secretions of the liver, calomel may be given combined with gentian and ginger.

Friction and pressure to the part, when practicable, are very useful in restoring a healthier and more vigorous tone to the vessels. In slight cases, such as swellings of the legs, these latter remedies together with judicious exercise will generally be found sufficient to cause the outpoured fluid to be reabsorbed, and perhaps also to prevent further effusion.

\section{Removal of the causes.}

Whilst treating the effect, we must not, however, forget to search for and, if possible, remove the cause.

If the dropsical swellings be due to temporary affection of the heart, medicine appropriate to allay the ailment will be required; but if there is chronic disease of that organ, it is hardly worth time and money to treat the case.

If it be an after-result of disease of the lungs and pleuræ, the best remedies are those indicated in the Chapters on diseases of the Respiratory organs. If the cause be traceable to disorder of the kidneys or liver, those organs must be treated. The necessary information will be found in Chapters 55 and 56.

If the cause lie, as is most commonly the case, in general debility, the strength will need to be improved by generous diet, fresh air, decrease of work, moderate exercise, good grooming and tonics. Friction 
and warm clothing will also assist greatly in restoring the functions of the skin, which in all cases of debility are much impaired.

\section{Swelled legs.}

We shall close this Chapter with a few remarks on Swelled Legs, the form in which dropsical effusions are most commonly met with in the horse.

Swelled legs are more often due to debility than to any other cause. The watery fluid collects in these limbs mainly on account of their dependent position, and partly on account of the difficulty which the blood finds in mounting up against gravity, and perhaps in some degree also from the parts being further removed from the centre of circulation. This disease, as we might expect, is most common in underbred horses, because in them the circulation is always less strong than in better bred animals.

Acute cases, in which the legs swell up very suddenly and sometimes to a size several times larger than their normal state, are often traceable to exposure of the animal, especially if exhausted, to wet or cold. Such exposure very readily produces imperfect action of the skin, bowels, and kidneys.

In animals predisposed to this disease, want of exercise, even for a single day, by impairing the tone of the muscles and circulation, and also by decreasing the secretions of the skin, will often bring on an attack.

Hand-rubbing, bandages to the legs, especially in old horses, warm clothing to the body, a little gentle exercise, and in some cases a mild dose of physic constitute the best treatment. Half an ounce of nitre, which will act as a slight diuretic, may be given occasionally with benefit to horses predisposed to this complaint. If the animal is poor, a generous diet is essential. Vegetable and mineral tonics may also be given with advantage. (See par. 304.)

\section{CHAPTER 29.}

\section{GLINDERS AND FARCY.}

518. Intimate connection between Glanders and Farcy. 519. Causes. 520. Propagation of Glanders and Farcy by infection and contagion. 521. Difference in the primary seat of Glanders and Farcy. 521 a. Glanders and Farcy. Acute and Chronic. 522. Symptoms of Farcy. 523. Treatment of Farcy. 524. Diseases sometimes mistaken for Farcy, Lymphangitis or Weed, etc. 525. Symptoms of Glanders. 526. Chancre of Glanders. 527. Treatment of Glanders. 528. Suspicious cases. 529. Diseases some- 
times mistaken for Glanders. 530. Many horses destroyed which are not really affected. 531. Disinfection. 532. Conclusion.

\section{Glanders and Farcy.}

Glanders and Farcy are not, as might be supposed, two distinct and separate affections, but are merely modifications of one and the same disease-the terms being applied to designate the particular situation of the lesions, and the train of symptoms presented. By Glanders we understand that form of the disease where the lesions and symptoms are connected with the mucous membrane lining the nasal chambers, upper air-passages, the neighbouring lymphatic glands, and the lungs. By Farcy we understand the same condition in the superficial lymphatic vessels. In either case the disease is due to the action of the same specific virus or poison.

Both forms of disease may exist in the same animal at the same time, or one may supervene on the other. Inoculation with the matter of Glanders or Farcy may produce either the one or other disease in a sound animal.

\section{Causes.}

We cannot account for the origin of specific diseases. In common with other specific diseases, Glanders and Farcy can only be propagated by contagion, infection, or inoculation-i.e. in other words, by the reception into an animal of the specific virus or poison from one that is diseased.

Common water-troughs are also probably a frequent cause of this disease. They should be placed under the supervision of the police to ensure careful cleansing in the early morn, for it is from horses in night work that contagion is most to be feared.

Diseases which are due to contagion or infection are séldom developed to any serious extent where proper sanitary arrangements are enforced, and where the general health of the animals is ensured by good stable management. But where the reverse is the case and the tone of the system becomes lowered, animals readily yield to any communicable infectious or contagious disease which may be prevailing at the time.

As long as the system is strong and hearty it will often resist malarious and insanitary influences for a length of time; but sooner or later such causes lower the general health, and then animals become predisposed to any prevailing disease.

It is not however to be understood that perfect health and condition give absolute immunity from the attack of any specific virus; but the author wishes to impress on his readers that debilitating influences of any kind will cause animals to be more readily affected.

Bad ventilation, imperfect drainage, insufficient and unsuitable food, dirt and general neglect in the stable management, coupled with defective conformation, are the principal factors in aiding the development of this predisposition. 


\section{Propagation of Glanders and Farcy.}

Very little is known respecting the precise nature of the virus. Suffice it to say that it can be communicated to healthy animals by inoculation or by contagion and probably by infection. Hence, in order to avoid risk, any suspected animal should be removed to an isolated loose box; and all the horses occupying the same stable should be subjected to the closest supervision. The man, who looks after the horse under suspicion should not be allowed to go among the other horses. The whole of the grooming articles, stable equipment, clothing, saddlery etc., must be kept quite distinct. The attendant should be particularly warned, that the disease is communicable to man and fatal.

\section{Difference in the primary seat of Glanders and Farcy.}

Both Glanders and Farcy are diseases of the absorbent system. In veterinary treatises it is commonly said that in glanders the deep-seated absorbents of the anterior extremities are primarily affected; whilst in farcy the superficial absorbents of the hind extremities are the early seat of the disease.

This definition is hardly correct as regards farcy. Farcy is very uncertain in the point of its appearance, and is found almost as frequently in the anterior as in the posterior parts. The outward development of the constitutional disease generally seems to be determined by the occurrence of any abrasion in any part of the body.

The hind legs from kicking, from cracked heels, and from various causes are no doubt more liable to abrasions and superficial inflammation than other parts, and hence perhaps we most frequently find the primary development of farcy in them. In harness horses, however, we often find it on the neck, which is liable to be chafed by the collar, or on the ribs from rubbing of the traces or pole. In all horses it is common on the lips, probably from abrasions or at least irritability of the skin caused by the bit.

Glanders, on the other hand, invariably appears in or about the head, and is primarily indicated by swelling of the glands under the jaw and by a discharge usually from one nostril only in the early stage or during the chronic phase of the disease.

\section{1a. Glanders and Farcy. Acute and Chronic.}

These diseases may be present in an acute or in a chronic form. In veterinary works the symptoms of each are usually described separately. But it will probably be sufficient to give the general features which are most frequently seen, and which are quite enough to enable the reader to recognise the diseases.

\section{Symptoms of Farcy.}

The attack is usually ushered in with febrile disturbance; but at other times this symptom, though probably not altogether absent, may be so 
slight as to escape observation. In most cases the disease itself is indicated by the appearance of a slight, or it may be a considerable swelling of one or more of the superficial absorbents. Before long the vessels become corded, and knots appear at the valves along their line. Each knot breaks out into a very peculiar deep yellow-edged ulcer. The absorbents, we may remark, follow closely the line of the veins. In other cases farcy commences with a very painful œedematous sivelling of the hind leg, and sometimes even before any swelling is perceived, the horse is unaccountably lame. The cause of such lameness really arises from inflammation of the deep-seated absorbents. The swelling, however, soon appears, followed, as described above, by cording of the absorbents. When farcy appears on the lips, face or shoulders, the buds are usually much smaller than when it appears in the hind extremities.

In unfavorable cases the knotting of the absorbents and the formation of ulcers rapidly increase. In some cases the body may be covered with them. Death occurs as soon as the ulceration affects any of the more important internal organs, or the animal may die of exhaustion before this stage is reached. Glanders generally supervenes before death.

In some cases knots only, without any cording, form at the valves of the superficial absorbents. Though this condition may continuc for a time, even for a considerable time, the disease will generally go forward to ulceration, or else will be relieved. There is no real distinction between this and the more usual type of the disease. Among the old school this modification was known as "Button" farcy.

Farcy, however, often appears in a less virulent form. The ulcers may be few, and sometimes the disease seems at a standstill for weeks or months. When the constitution of the patient is good, and other circumstances are favorable, and especially when the disease is confined to the superficial absorbents, the symptoms may subside, and the case apparently yield to treatment.

The matter discharged from a farcy pustule is either like thin pus of a dirty dingy yellow colour or of a glue-like character, and in either case it is offensive; or it may be bloody or ichorous, or like foetid serum. It abrades the surface on which it falls, and hence helps to spread the disease. The pustules sometimes extend into each other, and large unhealthy sores covered with purulent matter are then formed.

During the time of prevalence of Glanders or Farcy among the horses of an establishment there is peculiar disposition in sores of an apparently trivial character, to take on an unhealthy action, exentuating probably in an inflamed condition of the neighbouring absorbents. This disposition tends to show that the blood is in an unhealthy condition.

523. Treatment of Farcy. See 527. 


\section{Diseases sometimes mistaken for Farcy, e.g. Lymphangitis or Wood, \&c.}

Inflammation of the absorbents, vulgarly called Weed, is sometimes mistaken for Farcy. The distinction between the two diseases has been noticed in Chapter 12, on the Absorbents.

Detached swellings about the body arising from suppressed perspiration and other causes are occasionally mistaken for Farcy. These symptoms however generally subside as rapidly as they appear, and do not run, as it were, in chains, but are more or less localised.

Abscesses, often presenting a very unhealthy appearance, may also occur in the hind legs, as the result of local irritation and inflammation caused by kicking in the stable. Here, however, the cause is apparent.

\section{Symptoms of Glanders.}

The appearance of Glanders is primarily indicated by swelling of the Submaxillary Gland. Fever is seldom present to any noticeable extent, except in the acute form of the disease. After a time the characteristic discharge from one or both nostrils, but generally from one only, appears.

The gland on the same side becomes more swollen and painful, but, as a rule, shows no indication to suppurate. A marked symptom in the condition of this gland soon occurs. It becomes hard and firmly adherent to the jaw-bone, and ceases to be painful on the application of pressure. These peculiarities distinguish it from the soft diffused swellings of the glands often found in diseases of the air-passages.

In the early stages of the disease the lining membrane of the nose will assume a heightened colour.

The discharge from the nostrils is at first thin and aqueous, but soon assumes the characteristic glairy condition, and is generally of a strawcolour, but in the very late stages it becomes more purulent in its nature.

The quantity and quality of the discharge varies in different cases; it may be slight or copious, it may be thick or thin; but the one constant feature, which induces us to suspect the nature of the disease, is the gluelike and adhesive nature of the discharge. It clings about the hair round the nostrils, and may even partly close these orifices and cause difficulty in breathing.

The duration of the gleet before further symptoms are developed is extremely variable. It may be only a few days, or it may be weeks or months, depending on the condition and constitution of the animal, the kind of treatment adopted, and also to a great extent upon the mode by which the disease was propagated.

\section{The Chancre of Glanders.}

The Chancre of Glanders is of a peculiarly unhealthy character. It has an elevated circular pinkish border including a base of dingy or faint yellow albuminous matter, which on being touched commences bleeding. 
On the matter being removed, the tissue below will be seen, if the ulcer is deep; or a red spotted foul bleeding bottom will be perceived, if it is superficial. In deep ulcers in the nose, the cartilage will be exposed and even eaten through in bad cases. The extension of the ulcer to the cartilage will also be marked by the discharge assuming a greenish aspect.

These ulcers have no disposition to heal, but rapidly spread and assume an irregular ragged appearance.

527. Treatment of Glanders, Farcy, and suspicious cases.

There is only one treatment, i.e. Mallein test. For Bacteriology and Mallein see Chapter 57, Para. 1056a.

\section{Suspicious cases. See 527.}

\section{Diseases sometimes mistaken for Glanders.}

In some low forms of chronic Catarrh, there is often an irritating discharge, which abrades the surfaces with which it comes in contact, and occasionally produces superficial ulceration. The submaxillary glands also become swollen and painful. The ulcers, however, differ widely from the characteristic chancre of glanders, and the glands are not closely adherent to the jaw-bone.

In certain stages of pneumonia there is occasionally a semi-sanious discharge from the nostrils of a foetid character, and the breath smells offensively. In Glanders neither the discharge nor the breath is offensive, except in the later stages, when the disease in other respects is clearly marked.

In both catarrh and pneumonia the discharge is generally from both nostrils; whilst in the earlier stage of Glanders it usually proceeds from one nostril only. Here also the Mallein test should be employed.

530. Many horses, formerly destroyed, which were not really affected.

In former days many horses were destroyed for Glanders or Farcy, which were not really affected, as proved by the result of post-mortem examination.

The risk, however, both to men or horses standing in the stable or barn was so great, that the owner thought it best to be on the safe side. For Mallein Test, see par. $1056 a$.

\section{Disinfection.}

In both glanders and farcy; in order to guard against the possibility of their reproduction in other horses, it is desirable to burn any articles of clothing, brushes or brooms, to which diseased matter may adhere. The pails and all unpainted woodwork and iron should be thoroughly scoured with hot water and soap, and then whitewashed over three times. Painted woodwork and iron, after being thoroughly cleansed, 
should be repainted. The floors and walls should be scraped and whitewashed three times. Every door and window should be left open for some days, so that the stall and stable may be subjected to the purifying influence of a current of air. Other disinfectants, such as chloride of zinc or MacDougall's disinfecting powder, may also be used.

\section{Conclusion.}

Isolated cases of Glanders or Farcy may occur in any establishment. They may. be propagated by contagion before the nature of the disease is apprehended; but where a proper system of daily inspection of the nostrils and glands of all the animals is carried out, and where due measures of isolation of all suspicious cases are taken, the disease will not be found to spread to any extent.

Glanders or Farcy in an enzootic form in any stable indicates gross mismanagement in some point or points. 


\section{PART IV.}

CHAPTER 30 .

\section{COLIC AND INFLAMMATION OF THE INTESTIINES.}

533. Coats of the Stomach and Intestines. 534. Distinction between Colic and Inflammation of the Intestines. 535. Seat of Colic. 536. Signs of Colic. 537. Distinction in symptoms between Colic and Inflammation of the Intestines. 538. Causes of Colic. 539. Terminations of Colic. 540. Treatment of Colic. 541. Inflammation of the IntesTINes.-Peritonitis and Enteritis. 542. Symptoms. 543. Causes. 544. Treatment. 545. Terminations. 546. After-treatment.

\section{Coats of the Stomach and Intestines.}

The digestive apparatus generally, that is the stomach and intestines, both large and small, is furnished with three coats:

The outer coat is composed of serous membrane, a shining lubricating substance, which is useful in preventing the parts from becoming adherent to each other or to the walls of the cavity of the abdomen. The second or middle coat is muscular. The third or inner lining is composed of mucous membrane. The peculiar arrangement of the mucous membrane of the stomach is described in Chapter 4. All these three coats are more or less vascular, but the great mass of the blood-vessels are situated on the inner surface of the muscular coat immediately under the inner lining membrane.

534. Distinction between Colic and Inflammation of the Intestines.

All those diseases, such as colic or gripes, intussusception, or entanglement of one portion of one gut with another portion, peritonitis or inflammation of the serous membrane, enteritis or inflammation of the muscular and mucous membrane, and other such like affections, though they are known by many names according to the particular part or membrane attacked, may be simply classified under two heads, namely Colic and Inflammation of the Stomach and Intestines.

These two diseases admit of an easy and general definition. Colic is 
spasin of the muscular coat of any part of the intestines; whilst the other is inflammation of the serous or of the muscular and mucous coats.

\section{Seat of Colic.}

When Colic occurs within an hour or so after a full meal, its usual seat is in the small intestines; but at other times it generally arises from impaction of food in the large intestines.

The spasm, which is due to nervous influence, causes sudden contraction of the muscular coat, which necessarily arrests the usual vermicular motion of the part. The spasm causes great pain, which is however only temporary.

In horses which die of colic, not complicated with inflammation of the intestines, the parts affected by the spasm will feel thickened and contracted to about a third or fourth of their original size, and they will also appear whiter than natural. Colic, however, of itself rarely causes death. When a fatal result occurs, we generally find that enteritis or inflammation of the muscular and mucous membrane has supervened on the original disease.

\section{Signs of Colic.}

The early sign of colic is pain, evidently in the region of the intestines, as indicated by the horse looking anxiously round to his flanks. As the pain increases, the patient will scrape with his fore-feet, kick at his belly, walk round his box, or throw himself down and get up again frequently, or roll over, or kick. The nature of the disease is further recognised by the fit soon passing away,-for it is only a spasm. It soon however returns.

There is an absence of fever in this affection, and the pulse is onıy quickened during the spasm, but not oppressed. On the contrary, it is contracted and often hardly perceptible, though perhaps there may not be more than fifty beats in the minute. During the remission of the spasm the pulse is strong. The mouth continues moist, and the mucous membrane of the eye is not affected. During the attack the horse will sometimes pass hard angular dung pellets. This peculiarity of hardness and shape is due to the spasmodic contractions of portions of the guts.

The belly is tense, and sometimes perceptibly swollen, and very tender on pressure. In some cases it is much distended by the generation of gases arising from undigested or improper food. This peculiar condition is known as Flatulent colic. It is most common in farm horses.

From pain and knocking about, the patient generally sweats much, but dries as soon as the spasm has passed away. From the violence with which the horse knocks about, there is some liability to rupture of the diaphragm, especially in the flatulent attack, or if the stomach is distended with food.

If the disease is not soon relieved, the pulse will become very frequent, and contracted to a thread. After about six hours there is ground for apprehension. In protracted cases the result is doubtful. 
Favorable indications are given by an increase in the intervals of time between the attacks, and by each attack becoming slighter. Again, if the patient passes wind freely and soft dung, it is a favorable sign. The increase or decrease of the attack is also indicated by the increasing or decreasing tenseness of the belly.

In pure colic, it is especially to be remarked that the extremities continue warm and the skin remains in its usual state. The symptoms are only those of great spasmodic pain. There is no inflammation present, nor any sign of it.

\section{Distinction in symptoms between Colic and Inflammation of the Intestines.}

Colic is at once distinguished from inflammation of the intestines by the attack being sudden, without any previous inflammatory symptoms, by the pain being intermittent, and by the extremities being warm. The pain is also far more severe than in enteritis. During the intermissions of pain the pulse in colio is strong, whilst in enteritis it continues throughout quick and small.

\section{Causes of Colic.}

The causes of Colic are very various, but by far the most numerous cases arise from some impropriety in the watering or feeding, as already explained in Chapter 4, to which, in order to avoid repetition, we must refer the reader.

Among other common causes are crib-biting, worms, obstructions in the intestinal canal, such as dust balls often found in millers' horses, hair balls, calcareous or other accretions resulting from the use of hard or mineral waters, and also a large draught of cold water taken when the body is warm, which is dangerous, unless the horse is gently led about afterwards for some little time. (See par. 63.)

Colic may also be produced by those causes which induce indigestion generally, such as the mucous coat of the stomach and intestines not furnishing the secretion indispensably necessary for the due conversion of the food into alimentary and fæcal matter; or the mastication may not be properly performed; or the secretions of the salivary glands or those of the liver may be bad or defective; or the peristaltic motion may be sluggish from general debility, or from costiveness. All these causes are, however, aggravated, if not in many cases produced, by improper feeding and watering, aided perhaps by want of due exercise.

Occasionally Colic is due to the effect of purgative medicine. This is especially apt to be the case where the animal has not been properly prepared for physic. At other times it may arise from a sudden chill, such as that caused by allowing a horse in a sweat to stand in a draught. Hernia may also be a cause of colic. In a gelding a dirty sheath froquently causes Colic.

Finally, any sudden change of diet, or bad food of any sort, which is not easily or properly assimilated in the stomach, or an excessive quan- 
tity of food at one time, especially after a long fast, when the stomach is always weak, is apt to produce irritation and spasmodic affections of the intestines. In horses which are predisposed to colic, such as those which are light in the loins or "washy" in colour, very slight causes are sufficient to bring on an attack.

\section{Termination of Colic.}

Colic as a general rule ends favorably after a few hours in resolution; but it may induce intussusception or rupture of the diaphragm, from either of which terminations a fatal result will ensue; or it may continue until inflammation of the muscular and mucous membranes of the intestines, otherwise called enteritis, supervenes ; or in rare cases it may of itself cause death.

\section{Treatmient of Colic.}

Having now considered the nature and causes of the disease, we have obtained some clue to its treatment. In the first place, the cause of the spasmodic attack should, if possible, be ascertained, and every care taken to remove it and prevent its occurrence in future. In the meantime, to alleviate the present symptoms, the belly must be well rubbed. Friction will give relief both by increasing the vermicular motion of the intestines, which is temporarily arrested by spasm, and also by drawing the blood from the interior to the surface. Wisps of fresh clean straw will answer for this purpose. The legs should be well rubbed and wrapped in flannel bandages, and the heat of the body generally must be maintained by warm clothing. Ammonia liniment may also be rubbed on the abdomen.

As regards medicinal treatment, many prescriptions of a varied nature are recommended by different practitioners.

The administration of a diffusible stimulant combined with an anodyne, at the commencement of an attack of colic, will frequently cut it short. Two ounces of the spirit of nitrous ether, with one ounce of tincture of opium, and half an ounce of the aromatic spirit of ammonia, given in a pint of warm water or gruel, makes an excellent colic draught. Or two ounces of oil of turpentine with one ounce of tincture of opium may be given in twelve ounces of linseed oil, or in a pint of thick gruel. Few remedies, however, exceed the sedative effect of camphor combined with nitric ether, a drachm and a half of the former to an ounce of the latter mixed with twelve ounces of water.

The stimulant rouses the bowels to increased action, while the anodyne allays pain, and frequently the spasm is overcome by the combined action of these agents very rapidly.

In Flatulent Colic, $i . e$. where the intestines are distended with gas or "blown out," a draught composed of one drachm each of camphor and powdered opium, with a drachm or drachm and a half of carbonate of ammonia, will be found useful.

Enemata, otherwise called Clysters, should be given in all cases of 
abdominal pain, and repeated at intervals varying from half an hour to an hour. The enema should consist of about two quarts of water, temperature of new milk, with two ounces of linseed oil well shaken together. A quart will be sufficient for succeeding enemata. Every effort should be made to prolong the retention of the enema by depressing the tail for ten minutes at least. The object is to increase the peristaltic (contractive) action of the bowels. But it is not desirable to flood them with water. If more than two enemata are needed in order to produce excretion of the fæecs, some soap may be dissolved in the water with one ounce of linseed or olive oil.

The effect of the enema is not confined to the lower gut, into which it is injected. It is a frequent rule in nature, that if one portion of an organ can be excited to action, other parts of the same organ, i.e. the same intestines, sympathise with it and are also excited to action.

If the foregoing treatment does not afford relief in the course of an hour, a dose of laxative medicine must be given combined with a stimulant, such as four or five drachms of aloes in solution, with one and a half ounces of spirits of nitrous ether, or half an ounce of the aromatic spirits of ammonia, or the stimulants may be given in a pint and a half of linseed oil.

The rubbing of the belly must be continued throughout, and if the animal is in great pain, some walking exercise given at intervals of half an hour will often alleviate the spasms and expedite the action of the medicine. At the end of an hour and a half or two hours, if the spasmodic attacks still continue, hot fomentations must be applied by means of a rug steeped in hot water and held to the belly by a man on each side. To obviate the liability to chill, when the fomentation is discontinued, the belly should be rubbed with ammonia liniment.

Throughout the attack every possible means should be taken, by the assistance of three or more men, to prevent the patient from throwing himself down, as rupture of the diaphragm or entanglement of the guts is likely to result from any such violence. But if the animal prefers to lie down and can be persuaded to keep himself, or can by any moderate restraint be kept in this position, it is as good as any other. During the process of recovery, when the pains become less severe, we generally find the patient inclined to lie down.

In the absence, as may often occur in private establishments, of diffusible stimulants such as nitric ether, any kind of spirit such as gin, rum, or whisky, or aromatics such as pepper and ginger, may be substituted. These all possess antispasmodic properties, and may be found in every house.

Perseverance in these remedies will almost always be found sufficient to bring about subsidence of the attack, although the case may be prolonged for some hours.

This favorable result, however, does not always ensue. Prolonged and especially continuous pain, which may supervene on the earlier spasmodic pain, indicates disease of a very serious nature, and no time should be lost in summoning professional aid. 
It is always advisable, after an attack of colic, to prepare the horse for physic, unless the bowels have been relieved by medicine during the progress of the disease. In all cases there must have been a cause for the disease-sometimes perhaps in the food, which has irritated the intestines, or from various causes there may be a disordered state of the stomach. In many, if not in most cases, the preparation for physic will be sufficient without actually giving the dose. Unless some such precaution is taken, the attack is apt to recur.

Slight cases of colic with intermissions of considerable intervals are sometimes continuous for several days. The bowels do not respond freely to the effect of the cathartic medicine, and slight pains return at intervals. Such cases are always dangerous. They seem to arise from some defect in the biliary secretions. They are best treated by administering one scruple of calomel on the tongue, followed by a pint of linseed oil. On the recurrence of the pains an ounce and a half of nitric ether, or a pint of beer may be given.

If Colic supervenes, as is sometimes the case, on the action of the physic, it will of course be unadvisable to give more cathartics. Small doses of ether and tincture of opium will then be the appropriate treatment.

\section{INFLAMMATION OF THE INTESTINES.}

\section{Peritonitis and Enteritis.}

From Colic we may pass on to Inflammation of the Intestines. This disease may begin in the serous or outer membrane of the intestines, in which case it is known as Peritonitis; or it may have its origin in the muscular and mucous coats, when it takes the name of Enteritis.

Inflammation may also exist in, and be confined to the mucous membrane or internal lining of the intestines, producing the disease known - as dysentery. This disease, though common in man, is very rare in the horse. It is totally distinct in its origin and nature from peritonitis and enteritis, and is easily known by the excessive purging which accompanies it.

Pure Peritonitis, except as the result of an external wound such as that caused by a stake, or by some wound of the peritoneum, or by castration, or by an over-strain in galloping or leaping, is seldom met with. Pure Enteritis is perhaps equally rare. In good truth the serous, muscular, and mucous membranes of the intestines are so intimately connected, that inflammation in the one rapidly involves the other. The principal seat of the inflammation is however always in the muscular rather than in the other membranes, because that coat, as previously stated, is far the most vascular.

\section{Symptoms.}

T'he symptoms of peritonitis and enteritis are much alike; and as the treatment required is the same in either case, the two diseases may, for all practical purposes, be considered as one. 
Unlike colic, which comes on suddenly, these diseases are usually preceded by dulness, want of appetite, and feverishness. The inflammatory attack may commence either in the bowels or in the stomach, but as a general rule it begins in the bowels and usually in the small intestines.

The early symptoms are the same as those of colic, but with this marked distinction, which at once shows the disease, namely the absence of any intervals of ease. The pain, though in general less violent, is continuous throughout, and the puise from first to last is accelerated to a high degree, to double or perhaps treble its usual number, and is wiry in character.

The further symptoms are those usual in inflammatory attacks, namely cold extremities, mouth dry and either unnaturally hot or cold, the respiration hurried and oppressed, visible mucous membrane injected, nostrils unduly dilated, the countenance painfully anxious, the body sometimes bathed in sweat and then cold, or with occasional tremors, and the tail erect and quivering. As in colic the horse looks anxiously round to his flanks. As the disease progresses, the pulse sinks and the legs and ears feel death-like cold. The mouth feels chilly.

\section{Causes.}

Inflammation of the intestines may occur as a sequel of colic, or it may arise from continued constipation, or from any of the many causes which induce indigestion, or from intussusception, calculi, or from the excessive action of a purgative. It may also be brought on by a day's over-hard work, or by exposure to cold when the animal is sweating, or by hernia. Pure peritonitis, as mentioned above, is occasionally caused by any wound of the membrane, and often by castration.

In the great majority of cases, however, this disease is a sequel of other diseases rather than a primary affection; and indigestion, which may itself be produced by very many causes, will generally be found to be the original affection.

\section{Treatment.}

As soon as enteritis declares itself, all irritating food should be withheld, even though the appetite should exist, which, however, is improbable. Forty-eight hours' deprivation of food, or even more will do no serious harm, while it will place the bowels in the much-to-be-desired state of quiescence; and their lining membranes should be soothed, perhaps sheathed by the administration of gelatinised linseed, which can be made the vehicle for necessary medicines. The author is inclined to give the linseed jelly cold, if not iced.

In the usual development of the disease, the treatment may be safely initiated by the administration of the comparatively non-irritant drench of twelve to fifteen ounces of linseed oil with two drachms of opium, which may be dissolved, to ensure diffusion, in about half an ounce of nitric ether. 
The oil will not only act as a demulcent, but will also produce the desired laxation.

One or two drachms of powdered opium with the same amount of extract of belladonna may be given at intervals as indicated by the pain; or Fleming's tincture of aconite in from ten to twenty drop doses, has an excellent effect in some cases.

The persistence and violence of the pain is the best guide as to its repetition, which of course must not be too frequent.

In enteritis, as in other serious diseases, mischief often results from giving too much medicine; but five grains of calomel may be given in the linseed jelly, and repeated at intervals of six to seven hours two or three times. This will promote the flow of bile, and so clear the small intestines.

Enemata of thin linseed jelly, about a quart at a time, are advisable to assist in "unloading" the impacted colon. These should be tepid, not cold, in order to avoid rectal spasms.

It is unwise to check moderate diarrhœa, when it exists, as it is nature's effort at self-relief.

When peritonitis, which is apparent by pain and tenderness on pressure being applied to the abdomen, exists, opium must not be given, but camphor should be substituted.

As in colic, it is advisable to assist the action of the medicine and the removal of the fæces by the frequent injection of small quantities of warm water. Externally, fomentations with hot water, in which some poppy heads have been stewed, will greatly relieve pain; but great precaution must be taken to gently but thoroughly dry the skin at the conclusion of the fomentation, so as to avoid chill, and a dry rug should be put round the belly afterwards.

The body must be carefully clothed, and the rugs should be secured by tying them beneath the belly and across the breast, so as to avoid that pressure which would be given by the roller on the parts affected.

Exercise, though it was recommended in colic as a means of relieving the spasmodic pains, is not advisable in inflammation of the intestines.

\section{Terminations.}

Some cases, properly treated, will terminate quickly and farourably, but the result is always doubtful. If an unfarourable result ensues, it will generally be found that mortification, arising from stoppage of the passage through the intestines, caused by entanglement of the guts, rupture, calculus, or some incurable lesion, has been the immediate cause of death. The duration of an acute attack of inflammation of the intestines is short. If a favourable change does not take place in from twelve to twenty-four hours we may expect death.

In the post-mortem examination of horses which die of this disease, the peritoneal coat is often apparently inflamed; but this is in a great degree illusory, as the effect is produced by the reddened muscular coat shining through the serous outer coat. The parts affected may exhibit any degree of redness from pink to scarlet, to purple, green or black, and 
the intestines often contain blood, and the abdominal cavity a quartity of serum, or sanguineous fluid.

The disease may also terminate in effusion of serum into the abdominal cavity, otherwise called Ascites. This termination will be apparent by a dropsical state of the legs and sheath, as well as by swellings under the belly. There will be tenderness on the application of pressure to the belly, and also a straggling gait of the hind quarters in walking. The breathing will be quickened, short and painful, and the patient may probably lie down at full length and groan. The treatment of such an afterresult will consist in good nursing, in careful and judicious, but not overfeeding, with nutritious diet, and in the administration of tonics. In due time, as strength returns, the absorbents and blood-vessels will take up the effusion.

\section{After-treatment.}

The after-treatment will need great care and attention, especially as regards the diet. The membrane of the intestines will remain for some time in a delicate and susceptible state. Soft food of an easily digested character such as grass, bran mashes, linseed and carrots, should be supplied, for some days or weeks according to circumstances; and when oats are again allowed, they should be bruised, lest their hard ends should cause renewed irritation. It is a good plan to bruise or crush the oats in all cases where they are given after bowel diseases. A second attack supervening on the previous disease will almost certainly be fatal. The other measures required have been already pretty fully described in Chapter 15, on Good Nursing.

\section{CHAPTER 31.}

\section{MAD AND SLEEPY STAGGERS.}

547. Nature of the diseases. 548. Symptoms of derangement of the Brain. 549. Symptoms of Sleepy Staggers or coma arising primarily from affection of the Brain. 550. Symptoms of Sleepy Staggers arising primarily from the Stomach. 551. Connection between the Stomach and the Brain. 552. Symptoms of Mad Staggers, Encephalitis, or Phrenitis. 553. Post-mortem examination. 554. Causes of Sleepy and Mad Staggers. 555. The Brain. 556. Treatment. 557. After-treatment. 558. Aftereffects. 559. Apoplexy. 560:-Treatment.

\section{Nature of the diseases.}

Mad Staggers, otherwise called Encephalitis, Phrenitis, or Brain Fever, - and Sleepy Staggers or Coma, and such like diseases, may be classed under the general head of functional derangement of the Brain. 
These diseases may be primarily affections of the brain; or they may, and frequently do arise from indigestion, and in such cases the brain, though equally affected, is only secondarily diseased.

\section{Symptoms of derangement of the Brain.}

The symptoms of derangement of the functions of the brain vary very much in different cases, according as that organ is, by partial paralysis of its functions, reduced to a comatose or semi-comatose condition, or is by inflammation excited to an over-sensitive state.

The comatose condition is known as Sleepy staggers, whilst the excited state is variously termed Mad staggers, Encephalitis, Phrenitis, or Brain Fever.

549. Symptoms of Sleepy Staggers or Coma arising primarily from affection of the Brain.

In Sleepy Staggers, the horse in the premonitory stage appears dull and listless, careless about his food, stands drowsily with his head in a corner, and sometimes falls asleep, even whilst feeding. He walks with a straggling gait, and has a difficulty in maintaining his balance in turning.

The pulse and respirations in the first instance are always slower than natural. Should the disease increase, the eyes become red, the lids are partially closed, and the pupil is dilated. The urine is scanty and highcoloured, and the bowels are torpid, but neither distended nor tender.

These lethargic symptoms sometimes continue with little intermission for several days, and when depending on a tumour or abscesses in the brain, may last for weeks with occasional attacks of a phrenitic character. If no relief is given by nature or treatment, the case will terminate fatally, either by the lethargic symptoms running on to positive coma, with stertorous breathing, or in some cases apoplexy may supervene; or more generally after the dulness has lasted for a short time, the disease runs into Encephalitis or Mad staggers. As the disease approaches a fatal termination, the pulse becomes quicker and smaller, and at last thready.

In coma, the blood-vessels of the brain are, it is supposed, in a state of congestion. This may increase and end in rupture and extravasation of blood, giving rise to apoplexy and sudden death, even whilst the patient is still in the comatose state. Usually, however coma when a primary affection, runs on to Encephalitis.

550. Symptoms of Sleepy Staggers arising primarily from Stomach.

When the disease arises from a gorged state of the stomach and indigestion, (and the brain is only secondarily affected,) the symptoms are the same as described above,- - except that in addition the stomach is so much distended by an undue quantity of food, probably of not a very digestible character, that it is unable to contract upon it and assimilate it. Hence the food not going through the necessary processes, soon 
decomposes, and gas is quickly formed and evolved. In the early stage this may probably be carbonic acid gas, and in the latter or putrefactive stage, sulphuretted hydrogen.

The pulse in the comatose stage of stomach staggers is below the normal number, sometimes as low as twenty beats in the minute. The respiration is also slower than usual. But when the disease runs on to mad staggers or encephalitis, the pulse and respiration become quickened and excited, as described hereafter.

\section{Connection between the Stomach and the Brain.}

There are two theories as to the reason why indigestion, when accompanied with distension of the stomach, affects the brain.

The branches of the Par vagum or Pneumogastric nerve, ramify over the stomach, lungs and heart. When the stomach is distended, this nerve is unduly and continuously pressed upon, and so gets into a torpid state; and the lethargic symptoms of comatose staggers are supposed to be the result, by reflex nervous action of the brain.

Others think that the distension of the stomach prevents the action of the diaphragm and the proper extension of the chest in inspiration. Hence the blood is insufficiently purified, and the vital fluid supplied to the brain is more or less impure. Hence also there is decreased power and consequent torpidity of circulation; for these results depend on nervous tone and power; and from these causes, it is thought, arises Coma. The former, however, is the more probable explanation.

\section{Symptoms of Mad Staggers, Encephalitis, and Phrenitis.}

Mad Staggers may, as stated above, be a sequel of the comatose state; but occasionally the disease develops itself without any such preliminary sleepy symptoms. Restlessness suddenly appears, followed by a violent state of excitement and delirium. The patient paws with his feet, perspires freely, and stares about with wildness and vacancy of countenance. The respirations are quickened and excited. Febrile symptoms increase. The mouth becomes hot and dry, the nasal and conjunctival membranes are much injected, and the pulse is strong and sharp, often reaching as high as 80 or 90 , or even 120 beats in the minute. The animal throws himself about madly, gets his feet in the manger, tears the rack with his teeth, and breathes stertorously, with his eyes apparently staring out of their sockets. The pupils are fully dilated, no light will affect them, nor is the horse sensible of surrounding objects. Some hard dry dung pellets, or a small quantity of highly coloured urine may be passed. There is spasmodic contraction of the muscles.

Alternately with the violent fits periods of repose and drowsiness often occur, and the animal stands exhausted and sweating at every pore, with his head bored into a corner. During such intervals the pulse is almost in a state of collapse. The violent fits come on more and more quickly, until the animal is in a continuous struggle, panting and perspiring and 
the pulse gradually sinking. If the case terminates unfavorably, death generally occurs during one of these intervals, or apoplexy may supervene.

Some people, who had not previously seen the disease, might think that the horse was actually rabid. In true rabies however the animal is not merely frantic, but positively and wilfully mischievous, and purposely attacks everything dead or living. This is not the case in mad staggers. There is only furious delirium.

\section{Post-mortem examination.}

When animals die in the stage of coma, the vessels of the brain and plexus choroides will probably be found surcharged with blood. An increased quantity of fluid may also be found in the ventricles and under the membrane covering the brain.

In cases of mad staggers, the membrane of the brain will probably be found to have its blood-vessels tinged with blood; and should the patient die in the stage of coma supervening on phrenitis, there will be a considerable effusion of serum into the lateral ventricles, or into the cavities within the olfactory nerves, or under the coverings of the brain. This effusion has caused the pressure and the resulting coma.

The brain itself may in some cases show traces of inflammation by small pin-like heads of blood pervading its structure; or it may appear yellow and discoloured. In some cases an abscess may have formed in the brain, probably induced by a blow, and pus may have formed.

When the disease has arisen from indigestion, the stomach will be found distended with food, and the intestines with fæces, and both with gases.

\section{Causes of Sleepy and Mad Staggers.}

Both Sleepy and Mad staggers commonly have their origin in some derangement of the organs of digestion. The horse has a remarkably small stomach, and from it the food passes on quickly to the intestines. In a state of nature the horse is almost always browsing. A gorged condition of the stomach very readily arises from horses being freely fed after a long fast. When a horse has fasted any considerable time, food should be given him sparingly, and gradually, and at first it should be of an easily digested character, such for instance as oatmeal gruel. Indigestible forage of any sort, and especially stale or old and tough green meat, is also apt to cause derangement of the stomach. Forage to which the stomach is unaccustomed, though it may be good and wholesome of its kind, will also in some cases produce indigestion. It must be borne in mind that the horse cannot, like man or the dog, vomit, and so relieve his stomach. In fact, our means of giving relief in such cases are very circumscribed. From the grcater care, however, of late years bestowed on the method of watering and feeding, Staggers arising from such causes has become comparatively rare.

Both diseases may also arise from pressure on the brain, such as that which may be occasioned by the formation of a tumour or an abscess on the brain or in the lateral ventricles, or by a tumour in the head pressing 
on the brain. Such tumours, as they increase, produce gradually augmenting results either of coma or delirium, or of both at different intervals. Or concussion and pressure, such as that produced by a blow or fall, may bring on similar effects. From such causes the blood-vessels may even give way in the brain, and death may be the immediate result, or sensibility may be lost and a state of perfect coma may ensue.

Sunstroke or the effect of powerful sun and heat, especially on an animal in a plethoric state, may bring on affection (usually comatose) of the brain.

\section{The Brain.}

It is a remarkable fact that the Brain, though it is the seat of all sensation, is yet in itself devoid of all feeling. It may be-laid bare, or a portion of it may be removed or lacerated without causing pain or head symptoms, but the least pressure upon it immediately causes prostration or delirium, and the animal is deprived of sense.

\section{Treatment.}

The disease, namely functional derangement of the brain (from whatever cause proceeding), is the same in both Sleepy and Mad staggers. Hence the treatment will be somewhat similar, though certain variations will be required according to the cause or supposed cause and according to the stage of the disease.

When the comatose attack arises, as it does in the great majority of cases, from indigestion, and especially whilst it is yet in the early stage, nothing answers better than the administration of a large dose of opening medicine. It is most important, if possible, to open the bowels. Relief may be expected if the bowels can be got to act. Large doses of purgative medicine must be employed, because the bowels are always difficult to move when the brain is affected. Enemata of warm water, to which may be added solution of aloes, should also be thrown up. Diffusible stimulants, such as bicarbonate or acetate of ammonia, will also act beneficially in assisting the action of the purgative. With a similar view hand-rubbing and fomentation should be applied to the belly. If the purgative does not act in twenty-four hours it must be repeated.

If the stomach and intestines are distended with gas as mentioned above in par. 550, it will be advisable to give medicine with the view of neutralising it. In the very early stage, when carbonic acid gas is probably evolved, Liquor.Ammoniæ, which will cause carbonate of ammonia to be formed, will answer best; whilst later, when putrefaction of the food has begun and sulphuretted hydrogen is evolved, the chlorinated water of lime, which will cause the formation of muriate of lime, will be required, or the chlorate of potassa may be given.

Turpentine liniment should be rubbed all over the legs. In addition to its action in rousing the secretions of the skin, some portion of the turpentine will be absorbed through the skin into the system, and will there act beneficially by increasing the action of the kidneys. Saline 
draughts will also be useful in exciting the secretions of these latter organs.

When Coma arises from the other causes detailed in the latter part of par. 554, medicinal treatment will not be of much avail.

In Mad staggers, the same course of treatment as has been recommended for the comatose phase is desirable, and should be applied, as far as circumstances may admit, in any particular case. But except in the very early stage or in mild attacks, it is generally almost impossible to apply those remedies on account of the violence of the animal.

As topical relief, both in the comatose and also in the mad stages (if possible) cold wet cloths should be constantly applied to the head, and a stream of cold water should be poured on them from above, or ice may be employed.

Blisters to the head and neck are not advisable during the acute symptoms, whether comatose or phrenitic, as they tend to increase the derangement. But when the acute symptoms have subsided, they may be beneficially applied, or a seton may be inserted. The latter generally answers best. In all cases the patient should be placed in a cool, airy, darkened box.

The duration of the Comatose state is very uncertain. When arising from indigestion, it will probably be over in favorable cases in twentyfour hours; or it will run on into mad staggers with occasional intervals of coma. A decided change for better or worse will probably take place in from one to three days. When the Coma arises from a tumour or abscess on the brain, the case may last for weeks or months if the animal be allowed to live so long. In concussion of the brain the comatose symptoms may last a considerable time, but the patient will not long survive repeated attacks of a violent phase.

In Mad staggers, Encephalitis, Phrenitis, or Brain fever, from whatever cause proceeding, the exhaustion produced by the violence of the disease will probably cause the animal to sink in a few days, unless relief is given.

It will be observed that we have recommended nearly the same treatment both for Sleepy and Mad Staggers. We have done so because we regard the disease, namely functional derangement of the brain, from whatever cause procceding, as the same in both cases. According to circumstances the effect produced may be either coma or inflammation, or both at alternate intervals. But after all the main point is to get the bowels open.

\section{After-treatment.}

When the disease has taken a favourable turn and the patient is recovering, the after-treatment consists in most careful attention to the diet, in good nursing, fresh air, and the administration of tonics, especially of iodide of iron. The feeding should be liberal. The strength of the patient is always greatly reduced by the attack if severe, and especially if prolonged. 


\section{After-effects.}

In some cases partial dulness and even paralysis remain, and convulsions may supervene, and in some cases amaurosis. Blisters and setons may be tried; but as a general rule under such circumstances the best plan is to shoot the animal.

\section{APOPLEXY.}

Horses are sometimes struck down by apoplexy as by a blow, and lose all sense and power of motion, and death quickly ends the scene. Postmortem examination often reveals a congested state of the vessels of the brain and its meninges.

Apoplexy differs from coma and encephalitis in rendering the animal totally unconscious. If relief is obtained, which, however, is rare, the case usually resolves itself into a state of partial coma, more or less intense.

\section{Treatment.}

Bleeding, which was in days past the recognised treatment in apoplexy, both for men and animals, is now abandoned.

In all cases of cerebral disease the first measure to be taken is the immediate removal of pressure, be it from bridle, bearing-rein, harness, collar, or saddle-girth. Next, ice or the coldest water procurable should be applied to the head and along the spine.

- Contrary to experience gained in the human subject, where spirits are expressly forbidden on account of their depressing after-results, a strong diffusible stimulant, such as whiskey and water, has a marvellously revivifying effect; and this should be maintained by brisk friction to the ears and extremities.

\section{CHAPTER 32.}

\section{MEGRLMS OR VERTIGO.}

561. Nature of the disease. 562. Symptoms. 563. Predisposing causes. 564. Trealment.

561. Nature of the disease.

Vertigo, more commonly called Megrims, is an affection of the brain, but the nature of the disease is not well understood. By some Veterinarians it has been defined to be a momentary and passing congestion of the Brain. 


\section{Symptoms.}

The attack is very sudden and peculiar. There are seldom any premonitory symptoms. The animal suddenly shakes and throws up his head, or shakes it violently, or reels, and then stands for a minute or two dull and listless, or runs round and falls to the ground, remaining for $\Omega$ few moments partially insensible or in a state of violent convulsion. The attack rapidly passes away, the horse rises in a minute or two, shakes himself, and proceeds as if nothing had happened, though perhaps he may appear somewhat debilitated. During the fit he may stale or dung insensibly. The attacks are usually periodical, and occur chiefly during hot weather and at severe harness work.

There is seldom any outward sign which indicates liability to this disease. On the contrary the horse looks well, has a good appetite, and shows no spëcial nervousness or dulness. The best Veterinary Surgeon cannot detect a possible liability to this disease, and post-mortem examination also sometimes fails to reveal the cause.

Certain sorts of horses are, however, more liable to it than others; such for instance as those known as star-gazers, with an erect and stiff neck, also those with an awkward protrusion of the nose, with the head so set on that it is difficult to be reined in. It has also been observed to be more common in animals that carry their heads on one side than in others.

\section{Predisposing causes.}

Though we cannot assign the positive causes of this disease, yet it is pretty certain that it is connected with retardation of the flow of blood from the brain. Harness horses are far more subject to it than saddle horses. Many horses, which suffer from it in the collar, are free from it at other times. The collar, probably by retarding the blood returning from the brain, appears specially to predispose to it.

Various other circumstances also appear indirectly to develop the disease, and to increase or diminish the chance of its recurrence. Hot weather, bright sun, and high temper certainly predispose to it. Tight reining up and bearing reins, probably by retarding the return of the blood from the head, develop it. Severe work and bad feeding on the one hand, and high feeding and little work on the other hand, are both apt to bring it on. Fair condition and moderate work diminish the tendency to attacks. Horses, which have lost a vein from the effect of clumsy bleeding, are said to be predisposed to it.

It has been noticed as a practical fact, that horses are more often attacked during the intervals of sunshine, which sometimes occur on hot cloudy days in summer, than at any other time.

\section{Treatment.}

As regards treatment of the actual attack, beyond the free use of cold water douches to the head we have none to recommend. As a preventive we can only advise that the animal be kept in fair, not very high condi- 
tion, and in regular work, with diet sufficiently laxative to ensure his bowels being moderately open. There is, as the reader is aware, an intimate connection between the state of the stomach and the brain.

An overloaded or deranged state of the bowels is apt both in man and beast to affect injuriously the functions of the brain. We are also disposed to recommend the administration of a dose of opening medicine a little before the time when experience in any particular horse may lead us to expect the periodical recurrence of the attack.

A piece of wet sponge secured on the head and along the forehead, or a shade over the eyes, especially in sunny weather, may sometimes prevent attacks. In lieu of a collar for harness work a breast-band should be substituted, and the bearing rein abolished. And the head-gear should be of the lightest possible description, the throat lash being worn extra loose.

If the horse it attacked, when in harness, the collar should at once be pushed up the neck, so as to leave the jugular vein free, and the same also refers to the head collar.

A megrimed horse, however, is not to be depended on - certainly not in harness. We may perhaps ward off attacks by careful attention to diet, regular work, and occasional physic; but with all our care sultry weather, hot sun, or hard work may cause a recurrence of the attack. All kinds of treatment have been tried in vain.

\section{CHAPTER 39.}

TETANUS OR LOCKJAW.

565. Nature of the disease. 566. Symptoms. 567. Immediale cause and seat. 568. Treatment,

565. Nature of the disease.

Tetanus is a persistent contraction without any relaxation or alternation of the voluntary muscles. When the affection is confined to the jaws, it is termed Trismus.

566. Symptoms.

The attack is characterised by closure of the jaws, great difficulty in swallowing, rigidity of the limbs, and extreme difficulty in moving. The animal also pokes his nose, as if suffering from sore throat. As the disease advances, the jaws become so tightly locked that neither food nor medicine can be introduced through them.

Within three or four days, and sometimes earlier, the symptoms reach their height. The ears are erect and turned forwards, the eyes are retracted, and the haw is partially protruded over them. The nostrils are dilated. The animal stands persistently, his legs are stretched wide 
apart and look more like wooden stilts than living structures. The tail is upraised, the belly is tense and tucked up, and the muscles everywhere stand out prominent and rigid.

The Voluntary muscles of the internal structures are similarly affected. The Involuntary muscles of the intestines on the other hand are torpid, because the nervous force seems to be monopolised in the voluntary muscles. Hence arises the obstinate constipation, which forms so marked a feature in this disease.

Notwithstanding the intense contraction and rigidity of the muscles, the patient is highly sensitive, and shrinks from the slightest touch or approach to a touch. The mere fact of entering the animal's box is frequently sufficient to produce violent tetanic convulsions. He sweats profusely and groans from pain. A very marked symptom of the disease consists in rapid protrusion of the haw over the eye, if the horse is touched under the chin, or if his head is elevated.

\section{Immediate cause and seat of this disease.}

Science of late years has made known to us the immediate cause of this terrible disease, namely, a microbe-the tetanus bacillus-which multiplies in wounds or the tissue in their neighbourhood, and generates a poison which is absorbed and exerts its injurious effects on the spinal cord.

That such is really the cause can be proved by inoculating a sound horse with an artificial culture of the bacillus in question, this being followed by the onset of symptoms identical with those seen in an ordinary attack of tetanus.

\section{Treatment.}

Science has taught the cause, an dlet us hope that before long science may find the remedy. There are good hopes.

N.B.-The Author is indebted to Prof. McFadyean, R.V.C., for the latest views on this subject.

\section{CHAPTER 33A.}

\section{PARALYSIS.}

569. Electricity. 569a. Nature of Paralysis. 569b. Classes of Paralysis. 569c. Causes of Hemiplegia. 569d. Symptoms of Hemiplegia. 569e. Treatment. 569f. Symptoms of Paraplegia. 569g. Causes of Paraplegia. 569h. Treatment. 569i. Local Paralysis. 569j. Symptoms. 569k. Treatment.

\section{Electricity.}

With the increase of knowledge in the control of this force, it is becoming more generally used in the treatment of certain diseases as 
a Nerve tonic or restorative, more especially in Paralysis. It is also a stimulus to muscles exhausted by excessivo fatigue.

It has given permanent results in cases of paralysis of the lower lip, arising from injury or head-gear pressure.

But the general use of Electricity in Paralysis has not yet been sufficicntly tested to enable the Author to give any special recommendation in its favour. Still it is probable that in the progress of science much may at no very distant date be hoped from it in the treatment of this disease. Medical authorities tell us that it is an almost certain aid to diagnosis of the exact seat of Paralysis.

Extreme care is needed in its use, which should only be allowed in the hands of an expert professional man, as serious injury may result from its improper or incautious use.

\section{9a. Nature of Paralysis.}

Paralysis can scarcely be described as a disease, for it is in reality only a symptom of certain lesions affecting the nervous system-resulting in loss of motion or in loss of sensation, or both in the part affected,

In the human subject the medical man endeavours to save life, and is often pleased if he can restore his patient to even partial use of his limb, or to power of sensation. The horse, however, is no use to his owner unless he can be restored to full bodily vigor. Hence severe cases of paralysis are seldom treated.

\section{9b. Classes of paralysis.}

As regards the horse, paralysis may be divided into three classes, namely :

1st. Where the paralysis arises from disease of a portion of the brain. This is technically termed hemiplegia.

2nd. Where it arises from affection of the spinal cord, it is technically termed paraplegia.

3rd. Local paralysis.

\section{9c. Causes of Hemiplegia.}

Cerebral congestion, effusion on, or other morbid conditions of the brain are the usual causes.

\section{9d. Symptoms of Hemiplegia.}

Hemiplegia is indicated by loss of power over one half of the body laterally, i.e. the affection is confined to one side of the animal, except as regards the facial muscles.

The muscles are paralysed on the opposite side to which the brain lesions exist. Owing to the paralysed condition of the muscles of the neck and trunk on the opposite side, the animal, when made to move, leans over to the side on which the lesions exist.

But the muscles of the face are affected on the same side as the brain 
lesions. Loss of power of the facial muscles is evinced by a relazed condition of the angles of the mouth, by a pendulous and protruding tongue, and a difficulty in gathering food, and in drinking. It will be noted that, except as regards the facial muscles, the paralysis is confined to one side.

\section{9e. Treatment.}

Treatment has shitherto been considered useless. But of late years Electricity has yielded very good results, especially in facial paralysis and in cases recovering from Paraplegia ; but it ought to be administered by an expert veterinary surgeon.

\section{9f. Symptoms of Paraplegia.}

This form of paralysis arises from affection of the spinal cord. Affection of the spinal cord is indicated by loss of power transversely. It generally affects both hind quarters. It may appear suddenly or may come on gradually (see below). The characteristic symptoms are a recling staggering gait, and inability to turn abruptly or to go back.

\section{9g. Causes of Paraplegia.}

There are two distinct causes of this affection.

1st. Injuries to the spinal column, such as fracture of the vertebræ, disease of the bones of the vertebræ, the formation of an exostosis, or a severe sprain. Such cases are not worth treatment.

2nd. The affection may arise from a disordered condition or actual disease of the respiratory, digestive, or urinary organs, or from irritation of the nerves of the spine arising from cold or wet, by which irritating influences are applied to the terminal extremities of the nerves, and by this means the impression is conveyed to the spinal cord. This form is called reflex paraplegia. These cases are in some degree amenable to treatment.

\section{9h. Treatment.}

The symptoms, as described above, are the same, whether the affection arises from positive injury to the spinal column, or whether it arises from irritation of the terminal extremities of the nerves of the spinal cord.

The reader will naturally ask how to distinguish between cases arising from direct injury to the spinal column, which are not worth treatment, and those arising from diseases more or less connected with the nerves radiating from the spinal column.

The answer to this inquiry is not very satisfactory. If however the horse has sustained an injury, there will of course be reason to fear that the symptoms arise directly from affection of the spinal column. If no such injury is known to have occurred, it is reasonable to hope that the symptom arises from causes only indirectly affecting the spinal cord.

The treatment is the same in either case. The result of the treatment 
will in due time reveal the nature of the affection. The one will not yield to treatment, the other probably will yield.

As a general rule laxatives followed by nerve stimulants are indicated. Nux Vomica may be given powdered, in doses of one drachm twice daily, or, if preferred, its active principle, strychnia, may be given in doses of two or three grains night and morning.

Good nursing, and easily digested food of a nourishing character are imperative, and local applications to the spinal cord, such as fomentations by means of hot blankets, covered with a waterproof sheet or a freshly flayed sheepskin may be applied, and continued as long as necessary. The application of irritants, such as ointment of cantharides, biniodide of mercury, mustard or turpentine liniment, is generally recommended in the subsequent treatment of the disease, but their utility is very doubtful. The real seat of the affection is the brain or spinal cord, and it cannot be reached by such like local applications.

During recovery, however, they may, and doubtless do, assist nature in restoring the nervous tone of the parts affected.

\section{9i. Local Paralysis.}

Local paralysis is not of frequent occurrence in the horse, but it is occasionally seen affecting the facial muscles, especially those of the lips, and is usually the result of some external injury, violence, or pressure applied to one or more of the nerve trunks, such as is produced by the use of heavy or severe bits, especially if the pressure be aggravated by a tight curb chain.

\section{9j. Symptoms.}

The lips will be pendulous and powerless to act as prehensile agents, and the muscles of the mouth generally will be in a relaxed condition. Difficulty is experienced in gathering the food, and mastication is a more or less laboured performance.

\section{9k. Treatment.}

Endeavour must be made to restore nerrous power to the local structure affected. Friction applied by the hand, and the application of stimulants or mild irritants frequently repeated along the course of the nerves, are the most appropriate remedies, accompanied by good nursing, tonics, and nerve stimulants.

In these cases Electricity has yielded the best results. It should be applied for from ten to fifteen minutes daily, until returning sensation indicates its application less frequently. 


\section{CHAPTER 34. \\ S'TRINGHALT.}

\section{Nature of the disease.}

The peculiar twitching, or sudden and convulsive picking up of the leg, known as Stringhalt, is obviously due to some affection of the nerves.

In some cases it may be traced to the pressure of some exostosis on a nerve; but, as a general rule, we are unable to account for the affection, nor does post-mortem examination always show any abnormal state of the nerves.

The disease varies very much in degree or intensity in various cases. It generally affects one or both hind legs, but it is also occasionally noticed in the fore-leg.

In the early stage it is most easily detected, when the animal is first put in motion, and also when he is in the act of turning. The disease generally increases with age, and, though at first it may produce but little or no inconvenience, in the end it generally becomes not only very unsightly, but also seriously interferes with the action.

No treatment, that wo are acquainted with, produces any beneficial effect, but careful attention to the condition of the digestive system has a favorable influence. Something may perhaps be hoped from the newly utilized powers of electricity. 


\title{
P A R T V.
}

\author{
CHAPTER 34A.
}

REPAIR OF INJURIES TO VITAL STRUCTURES.

570a. Preface. 570b. Of repair of Injuries to Vital Structures. $570 c$. How is Nature to be assisted? 570d. Of developing the powers of Nature or assisting Nature in her processes of repair. 570e. Vital Processes. 570f. Repair of Injuries. 570g. Detail of the Process of Repair. 570h. Inflammation. 570i. Need of Treatment. 570j. Of the early stage of the Reparative process. 57Uk. Means of reducing Inflammation. $570 l$. Re-excitement of (curative) Inflammation by artificial means. $570 \mathrm{~m}$. Irritants.

\section{0a. Preface.}

The Author is aware that a considerable amount of repetition of what has been said in the previous Chapters 18 and 19, on Inflammation and Irritants, occurs in this Chapter. He has however thought it advisable to place before the reader in a collected form, and in as clear and consecutive manner as he can, the various processes, which are concerned in the repair of Injuries to Vital Structures, which are treated of in the following Chapters.

570b. Of Repair of Injuries to Vital Structures.

Nature alone, not art, can repair injuries to vital, i. e. living structures. Art alone, not nature, can repair injuries to non-Vital, i.e. inanimate structures.

Art however may assist Nature in the repair of injuries to vital structures.

\section{0 c. How is Nature to be assisted?}

Nature may be assisted-

1st. By mechanical means and appliances.

2nd. By developing the powers of Nature herself.

Of mechanical appliances.-Art for instance may assist Nature in the repair of broken bones, by placing the ends of the bones in apposition. 
Art may further assist Nature by placing the bones, not only in apposition, but by replacing them in their correct, i.e. natural position, and maintaining them in that position by means of splints, or by extension, as may be needed in each case. We cannot bind and nail together broken bones, as we can fractured pieces of non-vital structures, say two pieces of wood. We can only place and maintain the broken bones in such apposition, that Nature, thus assisted, may be able to carry on the process of reunion by her own means.

Again, bones may be placed in apposition. The process of repair may go on favorably for a time; but the powers of Nature may flag before reunion has taken place, $i . e$. before the process of repair is completed.

The same remarks apply to other injuries or wounds. In all cases in the first instance we must place the parts in the best condition for Nature to carry on her processes of repair; second, it may, and pretty generally is necessary to assist Nature in the later stage of the needed repair.

Take for instance sprain of a tendon; 1st, we must place the animal in a state of rest and ease. We may in some cases take the weight off the sprained tendon by the application of a high heeled shoe. Under such favorable circumstances the process of repair by Nature's means will go on favorably; but Nature may require to be assisted in the later stages of repair.

Again in flesh wounds, 1st we assist Nature by removing foreign bodies in the wound, 2nd we bring the parts together, and in some cases according to circumstances keep them together by sutures. Nature will then be in a favorable position to carry on her reparative process. But Nature's power may flag, and re-excitement of her powers by artificial means may be needed.

No two cases in detail are exactly similar. In the above remarks we have merely sketched the broad principles of repair by Nature, assisted by Art.

570d. Of.developing the powers of Nature or assisting Nature in her processes of repair.

All parts of the Body are formed from the Blood. The blood is the sustaining and repairing. element of the vital frame. From it are drawn the materials needed for the daily sustenance of the frame. From it, in cases of injury an increased quantity of reparative material is required to be drawn for the repair of the injured part.

The condition neded to afford this increased quantity of reparative material is that commonly known as inflammation.

\section{0e. Vital Processes.}

There are certain processes of Nature termed Vital processes, which we cannot exactly explain.

We know, for instance, that the material needed for the daily ordinary maintenance of the bodily frame is extracted from the blood.

Wo know again, that each vital structure in the bodily frame extracts 
from the blood the special nutrient material which is needed for its own maintenance or repair. Thus, muscle extracts from the blood the material necessary for the maintenance of muscle. Bone extracts the material necessary for the maintenance of bone. Each hair extracts the material needed for the maintenance and growth of hair.

We cannot explain exactly how the various parts or organs of the body each extracts from the blood its own special nutrient material. But the power to do so is inherent in the tissue or cell element of each part. These are facts which we cannot explain. They are termed Vital processes. These processes are beyond the ken of man.

Having thus premised that the Body in health is sustained by material drawn from the blood, we now come to the repair of injuries by an increased amount of material drawn from the same source, namely, from the blood.

\section{0f. Repair of Injuries.}

When an injury takes place, disturbance of the usual vital processes also takes place. Irritation, nervous irritation, is in consequence set up.

This irritation, though we often do not so recognise it, is the commencement of Nature's system of repair. By irritation, more blood is drawn to the part. We cannot exactly explain why this occurs. It is a fact.

From the presence of more blood, the part becomes hot and perhaps inflamed.

Still, this is a process of repair. The injury cannot be repaired without the presence of an abnormal, $i$. e. greater than usual amount of blood in the part. The usual supply of blood is only sufficient for the maintenance of the part in health. For the purpose of repair more material is needed, and therefore more blood is needed in the part, from which to extract the reparative material.

\section{0g. Detail of the Process of Repair.}

By the nervous irritation caused by the injury, more blood is drawn to the part.

The blood-ressels in the part become overloaded, Nature is unable to pass on this abnormal quantity of blood. The blood-vessels then become distended, and after a time, by over-distension, lose their contractile power. Stagnation of the blood and congestion of the vessels in the part then to a certain degree occur. The coats of the blood-vessels become more and more distended, and thereby become thinner. In this stage of congestion and distension, parts of the blood begin to ooze out through the coats of the blood-vessels. This is the material needed for repair. This is Nature's effort at repair. This stage is known as exudation.

Since Nature thus finds the material needed for the repair of the injury, "what need is there of treatment?" 
But before answering this question, it will be as well very briefly to explain moro accurately the meaning of the term "inflammation."

\section{0h. Inflammation.}

The changes in the condition of the blood-vessels, which have been described above, constitute the processes known as inflammation.

Inflammation cannot, however, technically be said to be present, until the stage of effusion through the coats of blood-vessels has been arrived at. But in common parlance any abnormal amount of blood in a part, especially when the stage of congestion and exudation has been reached, is spoken of as "inflammation."

To recapitulate, the processes which culminate in inflammation are-

1. Nervous irritation.

2. More blood to the part.

3. Stagnation of the blood in the surrounding parts.

4. Effusion through the coats of the over-loaded vessels. This last stage is inflammation properly so called.

The subject of Inflammation has been treated of at some length in Chapter 18 , to which the reader is referred for further information.

\section{0i. Need of Treatment.}

What is the need of treatment, if Nature supplies the remedy?

1st. Because inflammation, Nature's remedy, is generally at the onset over-bountiful, or you may call it over-violent.

It requires to be moderated by art; the effusion poured forth is at first often too great; and second, the quality of the effusion is, from some disturbance of the system, apt to be unhealthy, $i . e$. not quite of the quality best suited for repair.

2nd. Because in the later stages of the curative process, the inflammatory action is apt to subside before the process of repair has bcen thoroughly completed.

\section{0j. Of the early stage of the Reparative process.}

In the early stage of repair, the inflammatory action is apt to be overviolent. In such cases, indeed in most cases of injury, we must endeavour to moderate its violence by Art, i.e. by treatment, but it varies much according to the wascularity and nervous endowment of the part injured, and also especially in regard to the locale of the injury in which the inflammation requires to be reduced.

When, reduced to a moderate state, the blood-vessels exude the requisite quantity of reparative material of a good quality; and Nature may in due time effect the repair.

570k. Means of reducing Inflammation.

Culd applications.-Cold applications reduce inflammation by constringing the coats of the blood-ressels. By this action, first, they reduce 
the quantity of blood entering the part; secondly, by restoring the tone of the contractile powers of the vessels, they enable the vessels to pass off some pertion of the blood which has entered them.

Cold applications answer, where the inflammation is not very violent; and where, in consequence, the contractile powers of the coats of the vessels can be restored. But in severe cases this remedy will be ineffectual.

Warm applications reduce inflammation by the contrary process. First, they soften and expand the coats of the blood-vessels, and thereby enable them to pass off the blood. Secondly, they give relief by increasing the process of effusion through the distended coats of the bloodvessels. Warm applications may be properly applied, when the necessary "checking" effect cannot be obtained by cold applications.

N.B.-Warm applications should never be warmer than the hand and arm up to the elbow can bear comfortably.

\section{0l. Re-excitement of (curative) Inflammation by artificial means.}

It often happens, however, that the inflammatory action, $i . e$. the reparative process, becomes slack, or even ceases before the repair of the injury is effected.

Art must then intervene. Stimulants must be applied to re-excite the amount of inflammatory action needed to complete the process of repair.

According to the circumstances milder or stronger stimulants must be applied.

\section{$570 \mathrm{~m}$. Irritants.}

For the general action, uses, and mode of application of the Irritants best suited to induce artificial inflammation according to the need of each case, the reader is referred to Chapter 19.

In the succeeding chapters, which treat of diseases and fractures of bones, of exostoses, of bursal enlargements, of sprains of tendons and ligaments, flesh wounds, \&c., the irritants best suited to assist the process of repair in each case will be mentioned in detail.

\section{CHAPTER 35.}

DISEASES OF BONES.

571. Structure of Bone. 572. Chemical composition of Bone. 573. Nutrition of Bone. . 574. Development of Bone. 575. Periosteum. 576. Caries. 577 Treatment of Caries. 578. Necrosis. 579. Exfoliation. 580. Inflammation of Bone and Periostcum. 581. Exostoses. 582. Anchylosis. 583. Treatment. 


\section{Structure of Bone.}

Before treating of the diseases it will be necessary to describe very briefly the structure of bone.

Bone appears to be dense and granular; but when viewed under the microscope it is seen to be porous. Some parts are less, some are more porous than others. The less porous part is called the Compact tissue. It forms the outside of all bones. The more porous part is called the Cancellated tissue. It forms the inner structure of long bones, and also enters into the composition of the articular ends of all bones, and into the diploë of flat bones.

These two tissues are similar in structure. The only differences between them are, that the spaces or pores in the Compact are smaller and less numerous than in the Cancellated tissue; whilst the amount of solid matter is greater in the former than in the latter. The compact and cancellated tissues vary in thickness in each particular bone according to the strength, and other qualities required of it. In the interior of all long bones is a hollow space containing the medulla or marrow.

Though bone appears to be very dense, yet it is, even in its compact tissue, sufficiently porous to admit the passage of very numerous small blood-vessels through it. These vessels frequently anastomose with each other.

The outside of every bone (except at its articular extremities which are tipped with cartilage) is covered with a tough fibrous membrane called Periosteum, which conducts the blood-ressels into it. The inside is lined with a thinner and more vascular web, called Endosteum, which supports the medulla in long bones, and the cancelli in spongy bones.

The extremities of long bones are generally expanded and roughened to allow space for the attachment of muscles, ligaments, and tendons.

\section{Chemical composition of Bones.}

Bone is composed of both animal and earthy matter. The animal matter consists of gelatine. It can be removed by heat. The earthy constituents are phosphate of lime, which forms rather more than one half of bone, and small quantities of carbonate of lime, phosphate of magnesia, and fluoride of calcium. Dilute acid will remove the earthy matters, and render the bone flexible and soft.

\section{Nutrition of Bone.}

The nutrition of bone is derived from three sets of arteries. Large arteries enter about the centre of long bones, whilst smaller enter at the articular ends, and very minute vessels enter on the periosteal membrane.

\section{Development of Bone.}

Bone has three stages of development, namely the gelatinous, the cartilaginous, and the osseous. In the earliest stage of fotal life the germ of bone is entirely gelatinous. This is succeeded by temporary 
cartilage, and subsequently bone is gradually deposited in the meshes of the cartilage, and this latter tissue is then absorbed. The points at which bone is deposited are called centres of ossification. Three of these centres are usually found in each bone, viz. one for the shaft and one for each extremity.

\section{Periosteum.}

Periosteum, or the outer covering of bone is composed of dense, tough, inelastic, vascular, white fibrous tissue. Its function is to nourish, strengthen, and protect the bone. It also serves as a medium to conduct the blood-vessels over the surface of the bone. The periosteum is exceedingly strong,--so strong and tough, that in cases of fracture of a bone, it is often enabled to hold together the two parts.

Periostitis or inflammation of the periosteum, may be readily caused by injuries, by exposure to cold, by blood diseases, or by extension of inflammation existing in the bone. The secretion effused from the periosteum during the process of inflammation is very apt to solidify, and in due time to become bone. Hence, we often meet with exostoses as a result of inflammation of the periosteum, or of any of the osseous structures. The great pain produced by inflammation of a bone is due to the very inelastic nature of its outer covering. Nerves are freely distributed to the periosteum, and accompany the arteries into the interior of the bone.

\section{Caries.}

Caries of bone is analogous to ulceration of soft structures, and is the result of a slow inflammatory process causing softening and suppuration.

Caries generally affects the cancellated structure of bones, but the rule is by no means absolute, as the disease frequently exists in the compact tissue.

The primary symptom is apparent swelling of the bone. After a time sinuses form, from which an offensive sanious discharge exudes. If a probe be introduced into one of the sinuses, the interior of the bone will be felt to be soft. As the disease progresses, the part affected assumes a worm-eaten, cxcavated, and broken-up appearance. The many cavities become the seat of various exudations. The cancellated tissue gradually breaks down, and is discharged in minute fragments, along with pus.

The exudation proceeding from caries is distinguished by being thin, acrid, excoriating, sanious, and foul on account of its consisting of the decomposing organic materials of bone. It does not, however, always appear to be thin, because when it afterwards, as is sometimes the case, flows over a mucous membrane, it may become mixed with the secretion of that tissue, and in consequence may assume a clotted appearance.

The periosteum is injuriously affected by the acridity of the discharge, and after a time is destroyed by it. When this result has been produced, the disease proceeds more rapidly, because the carious portion of the bone is now deprived of the nutriment which ought to be supplied to it by the 
periosteum. In this case partial necrosis generally supervenes. No distinct line or margin can be drawn between a carious and a sound part. They glide insensibly into each other. It is remarkable that in caries Nature makes no effort to supply the place of the part which perishes.

\section{Treatment of Caries.}

Caries when fairly established, may be said to be practically incurable. Bone affected by this disease is never restored to its former state. The object of treatment is rather to arrest the progress of an incipient attack, than to attempt a cure.

Having regard to the origin of the disease in want of nutrition of the tissue affected, liberal feeding, with tonics, and attention to the general health, are obviously of primary importance. The part ought to be washed frequently by means of a syringe with warm water, to which may be added a disinfecting lotion, or dilute nitric acid or the actual cautery may be applied.

If these measures fail in arresting the progress of the disease, it will hardly be worth while to go to the expense of further treatment, as restoration of the part cannot be expected. The animal had better be got rid of.

\section{Necrosis.}

Necrosis is death of a bone, or portion of a bone en masse. Caries, on the other hand, is death by gradual decay and absorption of the particles of the structure. Again, necrosis, unlike caries, usually occurs in the Compact tissue.

This disease is often a consequence of inflammation of the bone, which, as the reader is aware, may arise from very many causes. Among other common causes are serere injuries, excessive pressure, contusions, \&c. It may also arise from any causes which affect the due nutrition of bone, such as the removal of its periosteum, or from general debility of the system.

Necrosis is particularly distinguished from caries, by the endeavour which Nature makes to supply the place of the portion which has perished. The periosteum, and healthy structures round the dead bone effuse lymph. This ossifies, and forms a case over the necrosed part. The new bone is therefore always larger, and it is also more spongy in texture, than the original bone. The articular extremities are usually unaffected.

The old bone though dead, is not removed until the new is formed. This is a merciful provision of Nature. The duty of the Veterinary surgeon is to support the strength of the animal whilst the reparative process is going on, and at the proper time to assist in the removal of the necrosed bone. If on introducing through the cloacr, a probe or two probes, one in each hand, a piece of bone is found to be quite loose and separate, it may be removed by the forceps ; or it may be necessary, before removing it, to divide it with a bone-cutting forceps into several pieces, or perhaps to enlarge the opening. Great care and gentleness 
are required in these operations, otherwise a sharp spicula of bone may cause dangerous hæmorrhage by perforating one of the larger arteries in the neighbourhood.

Necrosis, we may add, runs a certain course, and nature endeavours to effect a cure by the formation of new material. Art can only assist by aiding the removal of the old bone at the proper time. If such assistance is not given, Nature will in time effect it by setting up a process of caries and sloughing; but it is desirable to avoid the necessity for this further disease. The pus in necrosis, it is to be observed, is healthy, whilst in caries it is unhealthy.

\section{Exfoliation.}

Exfoliation is simply the separation of a dead from a living portion of bone.

\section{Inflammation of Bone and Periosteum.}

Inflammation is readily set up in bone, or in its periosteum, or in both, by concussion or contusion, or by the extension of inflammation from a neighbouring part.

The processes of inflammation have been already detailed in Chapter 18. They are the same in bone as in the softer tissues. As a result of inflammation, effusion takes place through the overloaded vessels of the part. The effusion may be wholly taken up again by the veins and absorbents. Very generally, however, some portion of it remains between the bone and its periosteum. This deposit in due time, after parting with the more watery portion of its constituents, solidifies, and becomes bone or something like bone. In fact an Exostosis is formed. It is a rule in Nature, as has been previously stated, that deposits resulting from inflammatory effusions, have a tendency, when they become organised, to partake of the nature of the tissue into which the exudation is effused.

\section{Exostoses.}

Exostoses usually arise, as described in the preceding paragraph, from inflammatory action in the bone or periosteum. They may however arise from ossification of a fibrous or cartilaginous tumour on the periosteum. At other times they are formed by abnormal development of any particular part or process of a bone.

The new bone is always more spongy in its texture than the original tissue; but after a time it consolidates in a great degree. It never, however, becomes equal to the old bone in density and strength.

Osseous deposits, though they may seem to disappear, are seldom totally removed. They are only lessened. The absorption of that part, which would be removed in time by the operations of Nature, may be hastened by the application of friction, mercury, iodine, or biniodide of mercury, to the part. 


\section{Anchylosis or Stiff Joint.}

Anchylosis, or stiff joint, is a result of previous disease, rather than a disease in itself. It is occasioned by the presence of deposits, which have resulted from previous inflammation in the structure of, or in the neighbourhood of the joint. It consists in more or less complete consolidation of the parts within or around the articulation.

Anchylosis may arise from thickening and induration of the fibrous capsule, or from the formation of fibroid bands within the joint; or it may be caused by partial or complete erosion of the cartilages and synovial membranes, the material exuded from the bones becoming organised into osseous matter, and firmly cementing the bones of the joint together. This is called true anchylosis. Or it may arise from shortening, contraction, or wasting away of the muscles, which in health would move the joint.

Inflammation in a joint, or even in the neighbourhood of a joint, is always a source of some danger. There is always some reason to fear, lest the deposit resulting from the inflammation should interfere with the free motion of the part, even if it does not produce partial or complete anchylosis.

\section{Treatment.}

For confirmed Anchylosis, arising from permanent alterations, there is no remedy. The previous disease, whatever it may have been, has caused the mischief, and anchylosis is the result. The process of anchylosis may in some cases be hastened by the application of the actual cautery. This is occasionally advisable in the treatment of diseased joints.

For mere stiffness (as distinguished from anchylosis), arising from recent thickenings or deposits in or about the neighbourhood of the joint, the treatment consists in rest; and in the application, as soon as the active inflammation has left the part, of absorbents, such as iodine, or biniodide of mercury. Though we cannot be certain of a favourable result, yet there is reason to hope, that by the use of such means, so much of the thickening or exostosis may be removed, as will at least prevent its interfering with the motion of the joint. With the removal of such interference, the pain and irritation will cease.

In human surgery, operations are sometimes undertaken for the removal of such deposits; but in the horse they do not answer, because there are no means of placing him in such a position as will take the weight off the limb for a sufficient length of time after the operation. 
CHAPTER 36.

\section{FRACTURES OF BONES.}

581. Of Fractures. 585. Causes of Fractures. 586. Symptoms of Fracture. 587. Treatment. 588. Fracture of the Pelvis. 589. Fracture of the Pastern bones. 590. Broken ribs. 591. Fracture of the Nasal bones. 592. Fracture of the Jaw. 593. Partial fracture of the Tibia. 594. Fracture of the Shoulder-blade.

\section{Of Fractures.}

Fractures are termed Simple, when the bone is broken, but the skin is unbroken; Compound, when the fractured ends protrude through the skin; Single, when only one fracture has taken place; Comminuted, when the bone is broken in several parts; and Complicated, when there is laceration of an artery or other additional injury.

In the human subject, the treatment of broken bones is comparatively easy, because the patient can be placed without difficulty or opposition on his part, on his back in bed, the position most favorable for relieving the broken limb of all weight and pressure. Whilst in this position, splints and other restraints can be conveniently imposed, and the patient is blessed with sense enough to induce him to submit to such restraints and to remain quiet.

In the horse, we have none of these advantages. We cannot without hurtful violence throw the animal on his back, nor can we by any persuasion induce him voluntarily to remain in that position. Hence, fractures of important bones are generally incurable. In most cases, therefore, of such injuries it is better to have the animal destroyed at once.

Again, the horse is an animal, whose value as a general rule consists in his power of locomotion. In man on the other hand the surgeon, though he may not be able to make a perfect cure, is often well content if he can produce such reunion of the bones, as may enable the patient, in case of broken leg for instance, to walk about. A horse is of no value unless he can walk, trot, and gallop sound and level. An exception, however, to this general rule occurs in the case of valuable brood mares or stallions.

As regards the reparative powers of Nature, there is no very great difficulty in bringing about reunion even of important bones; but on account of the restlessness of the animal, and from the difficulty of applying restraints and splints, and the further impossibility in many cases of taking all weight off the injured part, it is not probable that the bones will reunite so perfectly evenly as to render the action true and level. 
Lastly, although good union may take place, yet in the outset this is always very doubtful, and therefore when a serious accident. occurs, it is always questionable whether the probability of thorough recovery is great enough to be worth the risk and cost of keep and treatment.

For these reasons we shall not enter into the treatment of the fracture of such important bones as the radius and cannon bone in the fore-leg, or the tibia, femur, or cannon bone of the hind leg. Broken back is obviously incurable.

Fractures, however, of minor bones, or of bones which are so confined by ligaments or muscles, that the fractured parts are little liable to dislocation, even if fractured, are often worth treatment.

\section{Causes of Fracture.}

The causes of Fracture may be included under two heads, namely violence to the bone itself or to some adjacent part, such as occurs in the case of falls or kicks; and less commonly from excessive muscular strain. The sesamoid bones for instance are occasionally broken by the stress thrown on them by the suspensory ligament.

In some horses, as in some men, the bones appear to be abnormally fragile, probably from imperfect nutrition and fatty degeneration. The liability to fracture also increases greatly in old age.

\section{Symptoms of Fracture.}

Fractures are distinguished by some or all of the following symptoms.

1st. The bone is displaced. Pressure or weight thrown on it causes still further displacement. In the case of long bones the broken ends, if the fracture is right across, may pass each other, and thus the limb will be shortened.

2 nd. The fractured limb partially or entirely loses its power of voluntary movement; but by external force it can be moved more readily and in a greater variety of directions than when sound.

3rd. When a broken bone is thus moved, the fractured surfaces may be felt and heard to grate on each other or "crepitate." This crepitation is especially noticeable if the fractured surfaces are rugged, and still more in comminuted fractures. In fractures of an important bone there will also generally be twitching of the neighbouring muscles.

4th. From rupture of the adjacent blood-vessels and consequent escape of blood, or from laceration of the neighbouring soft parts there is usually a considerable swelling about a broken bone. From the same causes the skin, where it is visible, may be discoloured, and the parts hot and tender.

\section{Treatment.}

The first object is to "set" or bring together the broken ends of the bone as soon as possible. When the bones can be properly replaced at once, the fractured surfaces are thereby prevented from grating against 
each other and from irritating or lacerating the adjoining parts; and in such cases there may be no serious amount of swelling to interfere with the due and continued apposition of the parts and the commencement of the process of healing or union.

When the bones are thus adjusted, the next thing, if possible, is to keep them in their places. This is often a very difficult matter, and needs expertness and ingenuity. Splints padded with tow and bandages and strips of adhesive plaster may be used, and in some cases the horse may be slung with the view of taking the weight off the part affected.

The starch bandage is a very useful application. It is formed by soaking in thick starch mucilage strips of linen, which may be placed one over the other in layers, as each dries, until a firm splint is formed. Additional support may be given by a well-adjusted wooden splint outside all. Pads of fine tow will be found useful in preventing undue pressure on particular parts.

Before applying the starch bandage the part should be oiled, and then a piece of tape should be placed longitudinally over the fracture. The end of the tape should be left hanging out, so that if excessive swelling of the limb takes place, the bandage may be ripped open and taken off and dipped in warm water and then reapplied without losing its shape or "mould." Great ease and relief will in such cases be given to the patient by this change. Longitudinal slits in the bandage will also be found to give ease.

Plaster of Paris makes an excellent mould and support in cases of fractured pastern-bones in which great displacement does not exist.

It must be borne in mind that it is not merely a support, but an easy support, which is required. Pressure cannot be borne. Inflammation, but not repair, will follow on uneasiness; and then the patient will be rendered irritable, and by his movements will certainly frustrate all our efforts at cure.

When the parts are much swollen and tender, any undue inflammatory action must, as a preliminary step, be reduced by warm fomentations, as far as possible; or where the mischief is circumscribed or almost superficial, by wet cloths kept constantly moist with cold water or refrigerant lotion.

But practically, except as regards the facial bones, cases, which require such means, cannot as a rule be successfully treated, and the horse may as well be destroyed at once. Generally after all our efforts, and just when we think the case is going on favorably, the horse will by some sudden and unexpected movement cause the fractured ends again to separate.

In compound fractures, $i . \bar{e}$. where the skin is broken and the bone protrudes, and in all comminuted fractures the case is hopeless-at least as regards the horse becoming sound in his action. Facial injuries are, of course, an exception.

Omitting, for the reasons given above, such cases as broken leg or back, we now pass on to the detail of the treatment of those fractures, which under favorable circumstances offer a fair chance of recovery. 


\section{Fracture of the Pelvis.}

Any of the three bones constituting the Pelvis are liable to be broken. The most common and least serious of these injuries is chipping a piece off the spinous process of the ilium, usually from the animal coming in forcible contact with a doorpost or gate. When the observer stands behind, the flatness of the injured side is very perceptible, and in popular language the hip is said to be "down." The piece of bone, when separated, occasions no inconvenience, and after a time becomes enclosed in a cyst. A similar injury sometimes, though much more rarely, occurs to the spinous process of the ischium in the posterior part of the hip. These injuries do not usually cause any permanent unsoundness.

The shaft of the ilium may be broken by a fall. This accident most frequently occurs in heavy draught-horses. On account of the stoutness of the periosteum and the general position of the bone, the broken ends may not be much displaced; but the nature of the accident is apparent from the tenderness of the adjacent parts, and from the swelling and soreness felt when the hand is introduced into the rectum, and also by the crepitation observable, especially when the patient is moved slowly forward, whilst the hand within the rectum is held over the seat of injury. The animal will straddle greatly in his gait.

If the fracture is not extensive and does not involve the hip-joint, and there is not much displacement, and the animal is not irritable, repair may take place. The patient must be restrained from lying down by being placed in slings, and kept as quiet as possible. Nature may, and often does in these cases keep the broken parts in proper apposition, but art cannot from the position of the parts do anything to assist. In favorable cases the bones will have fairly reunited in about three months, and the animal may probably be sound.

Occasionally the fracture is very extensive and involves the hip-joint. More rarely the body of the ischium is broken. In a few cases the symphysis pubis is fractured. All such injuries preclude any hope of recovery.

\section{Fracture of the Pastern bones.}

Fracture of the great pastern bone sometimes occurs, but that of the small pastern or os coronæ is more frequent. It occurs very suddenly, and particularly in horses with high action. Probably the fracture results from the foot coming to the ground in a faulty position, and thus receiving unexpected concussion, whilst the parts of the leg are not in the proper position to receive it.

Fractures of either of these bones are very uncertain as regards the chance of cure. When the horse gets a little better, he is very apt to attempt to more his leg or to place weight on the foot, and then the fractured ends may probably separate again. A simple longitudinal fracture is worth treatment, but a comminuted fracture is not. 
590. Broken ribs.

The Ribs are rather frequently broken; and, if so, the ends generally overlap. It may be possible by manipulation temporarily to readjust the ends, but it is not possible by any mechanical means to retain them in their proper position. No material harm ordinarily results from their overlapping; though in some cases a broken end thoroughly displaced and turning inwards may injure some of the internal organs, and even cause a fatal result. To prevent this, excision of the part may in such cases be necessary. Nature will afterwards fill up the intervening space with callus.

The treatment, in addition to rest, consists in applying a large wide roller or stout webbing over the part, in order to confine the bones in one position as much as possible, and thus prevent undue expansion of the ribs. The roller must be kept in its place by means of straps attached to a collar on the neck.

\section{Fracture of the Nasal Bones.}

Fracture generally produces depression of the bones, and the breathing is then interfered with. The treatment consists in raising the bones with some blunt-pointed instrument to their proper position. To do this it will probably be necessary to make an incision through the skin. The bones must be retained in position, until reunion takes place, by strips of stout plaster, or by any other mechanical contrivance convenient in the particular case. The animal's head should be kept tied up for a considerable time afterwards.

\section{Fracture of the Jaws.}

The lower jaw is liable to be fractured, especially under the molar teeth, where it is very slender. After readjustment, splints and plasters must be applied to retain the bone in its place; and until union has taken place, the animal must be fed on sloppy diet, so that he may require to masticate as little as possible.

\section{Partial Fracture of the Tibia.}

If the Tibia be fractured right across, the case is hopeless ; but when the blow occurs on the outside, where the parts are well protected by muscular, ligamentous, and tendinous tissues, it often happens that the bone is not fractured through; or the fracture may be merely a longitudinal split. In such cases the periosteum may be strong enough to hold the parts together; and if the nature of the injury is discovered at once, the animal will often recover after a few weeks' rest. It very often, however, happens that the real nature of the injury is not suspected, and the horse after a few days' rest is again sent to work, and then the bone at the first strong exertion becomes fractured through. 
594. Fracture of the Shoulder-blade.

This accident is rare. In walking an animal trails the toe along the ground. If, when the foot is brought forward, the hand be placed on the shoulder, a crepitation will probably be felt.

The fracture is usually across the neck; and if so, the case is hopeless. A longitudinal, but not a transverse, fracture in any other part may possibly with rest reunite evenly, and the animal may perhaps become sound.

\section{CHAPTER 37.}

CONFORMATION OF THE HOCK.

595. Importance of Conformation. 596. Structure of the Hock. 597. Peculiarities of a good Hock. 598. Peculiarities of a badly formed Hock. 599. Disease intimately connected with defective Conformation.

\section{Importance of Conformation.}

A good shaped Hock is seldom unsound, whilst one of defective conformation readily becomes diseased if exposed to hard work.

To know a good from a bad, a sound from an unsound hock requires some time, trouble and attention, but not more than it is worth any horseman's while to give. It is good practice to get the bones of a hock to put them together, to examine the formation of each, and to feel them when placed in their natural position; and then to manipulate and compare them with the prominences of the bones in the living animal, especially on the seat of Spavin. With a knowledge of conformation derived from handling the bones, the satisfactory examination of the hock becomes easy.

\section{Structure of the Hock.}

The Hock consists of six bones, namely the astragalus, cuneiform magnum, cuneiform medium, cuneiform parvum, cuboid, and os calcis. The first five of these may be distinguished as weight-bearing bones, whilst the os calcis or bone at the back acts as a lever to the tendons of the leg. See Plate 22.

The true hock-joint, however, is formed by only two bones, namely the tibia or upper bone of the leg, and the astragalus. The other bones, though they possess a limited amount of motion between each other, do not enter into the true hock-joint. 
597. Peculiarities of a good Hock.

The outline should be clean, rigid, and in an adult horse well defined. Any puffiness or swelling is a sign of weakness or disease. The reason of this will be explained hereafter under the head of Bursal enlargements.

The bones should be large and prominent. Large size is essential to strength, and prominence is necessary in order to afford due leverage and attachment to the tendons and ligaments. Large bones are usually accompanied by large and well-developed tendons and ligaments.

The Hock, when viewed from the side, should appear wide both above and below (i.e. from $\mathrm{A}$ to $\mathrm{A}$ and from $\mathrm{B}$ to $\mathrm{B}$, Plate 22). Strength and size both of bones and ligaments are indicated by lateral width.

The hocks should be neither straight (Plate 23, figure 1), nor overmuch bent (figure 2). Undue concussion results from the former, whilst weakness and liability to sprain accompany the latter formation. If the hocks are placed too far behind (figure 3 ) there will be a want of propelling and jumping power.

The hocks should be placed directly under the centre of gravity. Any deviation from the perpendicular line laterally, as is the case when the hocks are inclined too much in (Plate 24, figure 4), or too much out (figure 5), is a source of weakness and therefore of disease.

In order to give due leverage to the muscles of the thigh, it is essential that the tibia should run down well into the hock. A well-developed and prominent os calcis is also essential to the leverage of the tendons of the leg. Figures 6 and 7 .

\section{Peculiarities of a badly formed Hock.}

Badly formed hocks are marked by peculiarities of conformation, the reverse of those we have just described.

\section{Disease intimately connected with defective Conformation.}

The diseases found in the hock generally correspond pretty closely with the points in which the conformation is defective. For instance, in upright hocks we may expect bog spavin and thorough-pin; in over-bent hocks, curb; in narrow hocks, spavin and curb may be looked for; in hocks which bow out, thorough-pin ; whilst in small hocks there is general want of strength and consequent liability to sprain and disease of any sort.

It is not however to be supposed, that horses with defective conformation either in the hocks or elsewhere are useless for any purpose. All that we intend to say is that defective conformation entails a special liability to disease. Again horses, which from defects of conformation may be unfit for one sort of work, may be available for another. A horse for example, whose hocks will not stand the violent exertion of hunting, may last for years for quiet riding or harness work.

Spavin will be treated of in the next Chapter. Thorough-pins and Bog spavins will be considered under the head of Bursal enlargements in Chapter No. 41 ; and Curbs and Sprains under the head of Sprains of the Hind leg in Chapter No. 45. 
SPAVIN.

\title{
CHAPTER 38.
}

\author{
SPAVIN.
}

600. Definition of Spavin. 601. Of the Hock Joint. 602. Formation of Spavin. 603. Liability to Spavin dependent on the conformation of the Hock. 604. Position of Spavin. 605. Importance of Spavin dependent on its position. 606. Peculiarities of Lameness arising from Spavin. 607. Treatment. 608. Active treatment not to be adopted rashly. 609. Of spavins which do not produce lameness. 610. Spavins cannot be removed. 611. Unnerving. 612. Examination of the Hock. 613. Conclusion.

\section{Definition of Spavin.}

By Spavin, when unaccompanied by any prefix, is always meant bonespavin. Bog spavin, though somewhat similar in name and also occurring in the hock, has no connection with this disease.

Sparin is an exostosis or bony enlargement in the region of the hock. It is usually found to involve two or more of the weight-bearing bones. The inner small metatarsal bone of the leg is sometimes, though but seldom, involved. Plate 22.

\section{Of the Hock Joint.}

The conformation of the Hock generally has been dwelt upon in the preceding Chapter. The true hock joint, it will be remembered, consists in the articulation of the tibia and astragalus. The joint is never primarily, and but seldom even ultimately, except as a result of open joint, affected by exostosis.

But besides the true hock joint, there are also joints with a limited amount of motion between each of the other bones, which make up the structure of the hock. Plate 22. The exostosis known as Spavin generally forms between two or more of these bones and interferes with their gliding motion; or it may form on the outside of the bones, or partly on the outside and partly between the bones. As stated above, it very rarely extends to, or implicates the bones of the true hock joint.

\section{Formation of Spavin.}

When from undue concussion, pressure, sprain, or such like causes, irritation is set up either in or in the neighbourhood of the abovementioned bones, it is probable that the irritation will be quickly followed by inflammation, more or less severe according to circumstances, of the periosteum and articular surfaces of the bones implicated. Inflammation will, as usual, probably be followed by effusion from the overloaded blood-vessels of the part. In due time the watery parts of the 
effusion, as has been already explained in the Chapters on Inflammation and Irritants, will be absorbed, and the remainder will solidify. In accordance with the usual rule of Nature the deposition will partake of the character of the part into which it is effused. In short it becomes bone, or in other words a Spavin is formed.

\section{Liability to Spavin dependent on the Conformation of the Hock.}

The probability of the occurrence of Spavin in any particular hock is mainly dependent on its conformation. If the hock is large and strong, and its position is good and true as regards the incidents of the superincumbent weight, it is not probable that it will be injuriously affected either by concussion, weight, or sprain. But if there is any defect either in the conformation, structure, or position, it will probably suffer in some part or other ; and at that point sooner or later, according to the circumstances and nature of the work to which the animal is subjected, we are likely to find disease. (See Plates 23 and 24.)

\section{Position of Spavin.}

It is impossible to define accurately the position of Spavin, but speaking generally it may be described as being situated at the inner and lower part of the hock joints. It varies in some degree according as weak or defective structure, or improper position of the hind legs, or incidence of the line of weight, or sprain of the ligaments, or such like causes may induce pressure or concussion on any particular part. The greatest pressure or concussion, however, are always felt towards the inner side, and hence spavin is always found somewhere on that side. The most common seat is between, and towards the front of the cuneiform bones. See Plate 22.

Spavins may occur on the exterior of the bones. In such cases they are easily seen and felt, and hence are called "detectable;" or they may occur between the bones, in which case there may be little or no external enlargement. These are termed "occult" spavins. During the formation, however, of the exostosis some degree of extra heat and tenderness on pressure may generally be detected. After consolidation, the existence of occult spavins in many cases can only be defined by the nature of the lameness they produce. (For signs of lameness arising from spavin see below, paragraph 606.)

As a general rule exostoses on the exterior of the bones arise from sprains of the ligaments of the hock, whilst those between the bones are produced by pressure and concussion.

\section{4a. Occult Spavins.}

The evidences or symptoms afforded by Occult spavins are inferential or negative rather than positive, and our surest guides to their recognition consist in the continuous and painful lameness, which arises from attrition of the ulcerated surfaces of the bones, and local heat, sometimes 
evanescent; also from the characteristic nature of the lameness, the telltale wear of the toe of the shoe, and the almost perpetual resting of the limb when standing.

\section{Importance of Spavin dependent on its position.}

The importance of a Spavin depends on its position rather than on its size.

If it is situated between the bones, and especially if towards the front, there is always great reason to fear that it may, even though small or very small, interfere with the gliding motion of the weight-bearing bones. Further, any such exostosis, however slight, is likely on account of its interfering with that motion to cause further irritation and inflammation in the part, and ultimately ulcerative disease of the articular cartilages and of the bones themselves.

If, on the other hand, the spavin, even though it be between the bones, is placed far back, it is of less consequence, because there is not much gliding motion in the posterior portion of the hock; and therefore the exostosis, even though large, may not occasion much inconvenience. Indeed, in many old horses we find that positive union has taken place between the posterior portions of the bones without ever having caused any sensible lameness.

Spavins on the external surfaces of the bones, and not between them, are less serious. They may or may not interfere with the action according to their size and position in each particular case. Spavins placed posteriorly and not between the bones, even though large, seldom interfere much with the free motion of the hock.

\section{Peculiarities of lameness arising from Spavin.}

In well-developed cases the lameness arising from Spavin is very peculiar and characteristic. It is caused by imperfect flexion of the hock, and in consequence the toe, instead of being properly raised, is dragged along the ground. Towards the end of the month the toe of the shoe is sensibly worn by this abnormal friction.

In slighter cases some stiffness of the hock and an occasional tripping of the toe may be noticed, and also a sort of vibration in the hock when the toe comes to the ground. These peculiarities will be most observable if the horse is trotted on hard smooth ground. The animal should be especially watched in turning, when a certain degree of flinching or catching up of the leg will be detected. Exercise even for a few minutes greatly diminishes the symptoms; but when the horse after exercise is allowed to stand till cool, the stiffness will recur, probably in an increased degree.

In the stable a horse, though only very slightly lame from spavin, will often drop very much, if made to move in his stall to one side, when the weight comes on the diseased leg. In bad cases, in a state of rest, he will usually keep the leg flexed. 


\section{Treatment.}

The nature of the primary disease, namely irritation and inflammation in some portion of the structure of the hock, caused by some undue concussion or pressure or sprain, gives us at once the clue to its treatment in the early stage, namely rest. Rest is the great essential. Cold applications or fomentations are also useful in reducing the inflammatory action.

Some Veterinary surgeons recommend the application of a threequarter shoe, which they think takes much of the weight and concussion off the part affected. Others prefer a shoe raised on the inside heel, on the plea that it shifts the weight from the inner to the outside quarter. Probably the greatest ease and relief is gained by removing the shoes altogether.

It is a common practice to raise the bed behind, with the view of throwing the weight off the hind on to the fore quarters. The advantage of this practice is very questionable, as the position produced by it has a tendency to bring into closer contact, and thereby cause greater pressure at the seat of the disease, namely the anterior portions of the weightbearing bones. The bed should, we think, be made perfectly level, though in order to counteract the usual slope of the stall to the rear, it will probably require to be made considerably thicker behind than before.

If the work is continued during the formation of a spavin, the inflammation will greatly increase, and an enormous deposit of bone may be the result. Yet, though rest is essential, some slight exercise, such as that which a horse will give himself in a loose box, is beneficial lest the parts should become stiffened by disuse, as well as from the deposit of bone.

If the inflammatory action does not subside after a time under the above simple treatment, and the horse still continues lame, it will be necessary to have recourse to other remedial agents, such as blisters, setons, or firing.

That these agents act beneficially in some cases is beyond question; but whether they produce their effect by irritation or otherwise is a matter in dispute among Veterinarians.

Some think that they act by bringing more blood to the part, or in other words by artificially exciting increased inflammation, and that they thereby hasten the consolidation of the new deposit into bone. Others believe that their beneficial effect is due to decrease in the inflammation already existing in the periosteum and bone, by reason of the irritation excited in the skin by these agents. They believe that by this so-called counter-irritation the growth of the bony deposit is checked and limited, and that the parts are thereby sooner restored to their normal condition. More detailed information regarding the action of Irritants will be found in Chapter 19, Artificial Inflammation as a Curative Agent.

As soon as the process of the deposition is completed, whether on the one hand by hastening its full formation, or on the other by checking and limiting the action-the inflammation and pain, which accompanied the formation of the exostosis will disappear. The horse will then be lame or sound according to the position and amount of the new deposit. 
Firing is undoubtedly the popular remedy for spavin, but it should not be resorted to until fair trial has been made of the other agent mentioned above and infra.

Firing sound hocks to "strengthen" them cannot be too strongly deprecated, not only as inhuman, but as useless.

608. Active treatment not to be adopted rashly.

The owner should not be over-alarmed or tempted too readily into the adoption of active treatment by his horse going lame during the formation of a spavin. Such is the usual case, and it probably arises, not from interference by the exostosis with the bending motion, but simply from the pressure of the new deposit on the inflamed periosteum covering the bone. The pain, and with it the lameness, usually abates as soon as the periosteum has enlarged and accommodated itself to the exostosis; and generally disappears altogether when by rest and other appropriate treatment the inflammation is allayed and the newly formed deposit has consolidated into bone.

In young horses, especially, a lengthened period of rest without any very active measures is always well worthy of a trial. Their bones and ligaments are weak, and their whole frame is often unequal to the work which man demands of them; and in very many cases nothing more than time and the gradual increase of strength resulting from age, good feeding and carefully regulated exercise are needed to give strength and stability to the weaker structures of the frame.

Some very eminent veterinary surgeons think that no time should be lost in attacking the newly-formed bone, and recommend the application of a strong blister of biniodide of mercury at once.

Whichever treatment may have been adopted, rest, followed by light work for some weeks, is essential.

If the treatment, which may have been adopted, is not successful, it may be necessary to resort to firing-and in this case "Point" firing, which will not leave a scar, may be sufficient.

\section{Spavins which do not cause lameness.}

Spavins which when fully formed do not cause lameness should never be subjected to active treatment. Treatment in such cases, far from being advantageous, may only too probably set up renewed inflammation in the part, and may perhaps produce further growth of bone and erentually lameness.

\section{Spavins cannot be removed.}

A Spavin, when once fully formed, cannot be removed by any remedial agents ; though in common with all abnormal growths, exostoses generally become less as age advances. This process of absorption may to a certain degree be assisted and hastened in the case of newly formed deposits by the application of mild blisters or setons; but the more important 
portion, or in other words the consolidated part, of the bony deposit will not yield to any treatment.

\section{Unnerving.}

Division of the nerve has been recommended for lameness arising from spavin with the view of destroying sensation. The operation, however, is useless, because the nerve, which supplies the anterior portion of the hock, is so situated that it cannot be reached and divided. It may perhaps be said that the nerve might be cut higher up; but at that point it is too near the muscle which works the tendon.

In the fore-leg, where the operation of unnerving is often beneficially applied in navicular disease, the position of the nerve and muscle is different.

\section{Examination of the hock.}

In the examination of a hock for spavin, it is necessary in the first place to compare the two hocks together. Any difference in size is very suspicious, especially in the adult horse. A hock, however, which may at first sight appear large on the inside, may on closer examination prove to be exactly similar to the other; and if so, the formation must be regarded as natural, and generally as sound. It is true that there may be spavins in both hocks; but it is very rarely, if ever found, that the two abnormal growths are exactly similar. In long, coarse-coated horses, the hocks should be damped before examination, so as to make the hair lie smooth.

Allowance must be made in certain horses for the shape and prominences of the bones at the inner and posterior part of the hock,which may be due to the line of incidence to the ground. In sicklehocked horses, for instance, there is often an apparent, but natural enlargement of the bones at the inner and posterior part of the hock, which is often mistaken for spavin. In other horses there may be an abnormal prominence of particular bones in both hocks, which, if exactly similar, must be regarded as natural.

Ridges in the centre of the middle and lower tiers of the bones, and a similar development at the head of the inner splint bone, are also sometimes mistaken for spavin. These ridges are in reality eminences for the attachment of the ligaments. They are most fully developed in wellbred horses, whose ligaments are strong and therefore require powerful attachments. They are easily distinguished from spavins by the fact of both hocks being similarly formed; and again by their being in the centre, and not on the edges of the bones as would be the case in a diseased growth; and further by the existence of a similar development in the bones of the knee. Such ridges, far from being a sign of disease, are an indication of strength.

Besides the general examination of both hocks required to ascertain that they are exactly pairs, it is necessary to inspect minutely the inner front and inside of each hock separately from several points of view, in 
order to make quite sure that there is no undue angularity, rigidity, or enlargement on the seat of spavin.

The examiner should first stand in front and view the hock, as seen by looking between the fore-legs. Any enlargement on the inside, especially on the anterior part, will be well seen from this point. Next, he should shift his position a few paces to the side, so as to catch a somewhat side view of the inner front of the structure. In this position any enlargement in front will be easily detected. He should next view the hock from behind, looking between the legs. Any enlargement on the posterior part of the inner side will then be apparent. Lastly, he should move about a couple of paces to the side, and he will notice any undue angularity about the interior edge of the hock.

No enlargement, however, though on the seat of the disease, can safely be said to be spavin, until by manipulation it has been ascertained to be bone. Without such manipulation other enlargements, such as a distended vein, or a thickening of the integuments resulting from a blow, may be mistaken for spavin.

In many cases, however, as has been explained above, there is little or no external enlargement, and we can then only infer the existence of a spavin by the peculiarity of the lameness, or by abnormal heat about the part. In examining a horse suspected of occult spavin, it is a good plan to lift the hind leg and forcibly flex it up to the thigh several times. After this the horse should be trotted slowly, when, if he has a spavin, he will probably show lameness.

The action, the true and perfect flexion or otherwise of the hock, and the level carriage or otherwise of the hips, should be most carefully observed. The action in many of the worst cases of spavin, namely those between the bones, often affords the only indication of the disease. The peculiarities in action caused by spavin have been detailed above.

\section{Conclusion.}

In the adult horse, when we can make sure that he is and has been doing fair work, the existence of a spavin, if it does not cause lameness, need not be a bar to the purchase of an animal otherwise suitable. Lameness does not often recur under such circumstances.

In young horses, the question of the advisability of a purchase must chiefly turn on the conformation of the hocks. If the hocks are good, and especially if the intending purchaser does not require the horse for hard work immediately, a purchase may perhaps be made, though of course at a reduced price. 
CHAPTER 39.

\section{SPLINT.}

614. Of the fore-leg between the Knee and the Fetlock. 615. Nature of Splint. 616. Mode of formation of Splint. 617. Causes of Splint. 618. Position of Splint. 619. Incipient Splints. 620. Fully formed Splints. 621. Treatment. 622. Splints cannot be removed. 623. Of Splints which cause permanent lameness. 624. To detect Splints. 625. Degree of importance to be attached to Splints.

\section{Of the fore-leg between the Knee and the Fetlock.}

As Splint, like spavin, generally arises from or at least is connected with some structural weakness, we propose in the first place briefly to consider the conformation of the fore-leg between the knee and the fetlock.

The fore-leg immediately below the knee is made up, as regards its osseous structures, of three-bones, namely, the great metacarpal, or shank, or cannon bone, and two smaller bones called the splint or small metacarpals. Plate 25.

These bones are not united together, but each of the small bones is attached to the great or shank bone by interosseous ligaments. The object of this sort of attachment appears to be to allow a very limited power of motion or elasticity between the bones. A similar mode of attachment is found in other parts of the body where a certain degree of elasticity is required, as for instance between the bodies of the vertebræ.

In the fore-leg the elasticity conferred by this peculiarity of conformation is useful in diminishing concussion. But this sort of attachment, though useful for the above purpose, gives less strength than absolute union of the bones.

\section{Nature of Splint.}

Splint is an exostosis or deposit of bone, either between one or other of the small bones and the shank, or upon any of the three bones. The cause of the abnormal growth is irritation and inflammation either in the interosseous ligaments, or in the periosteum, or in the bones themselves.

As the greatest strain and concussion always falls on the inside, on account of its being more under the centre of the superincumbent weight, we generally find the exostosis on or towards the inner side,-except in horses which turn their toes in, and thereby throw the greater weight on the outer side.

Splints, for the purpose of explanation, are sometimes divided into two classes, namely, those which arise from sprain and inflammation of the 
interosseous ligaments; and those which arise from irritation and inflammation of the periosteum or of the bone itself. But for practical purposes it is not necessary to maintain this distinction. Indeed, whichever structure be primarily affected, the other also generally becomes more or less involved.

\section{Mode of formation of Splint.}

When inflammation is set up in a bone or in its periosteum, an exostosis is likely to be the result,- unless the action is checked in the very early stage. The mode in which osseous material is effused and consolidated was explained in Chapter 35, par. 581-2. The exostosis or "Splint" will probably unite firmly the small to the great metacarpal bone.

Again, if the inflammation is set up in the interosseous ligaments, it generally results in absorption of the original tissue to a greater or less degree according to circumstances; and in lieu thereof osseous material is deposited, which, when in due time consolidated, unites together the bones between which it is effused. The cause of this peculiar effect of inflammation on fibro-cartilage, of which tissue the interosseous ligaments are mainly composed, is not well ascertained; but its almost invariable occurrence is a well-known fact.

\section{Causes of Splint.}

Though the immediate causes of Splint are irritation and inflammation in the parts affected, yet the occurrence of these causes in any particular horse and at any particular time is mainly dependent on the conformation of the leg, on the work to which the animal is subjected, on the weight he has to carry, and on his age.

If the bones of the leg are small, or if not positively so, are yet small in reference to the carcass; or if there is undue length between the knee and the fetlock; or if the ligaments and tendons are small, or if the legs are crooked, we may be pretty sure that such defects of conformation will probably give rise to irritation and inflammation in the weakest part.

Again if the pasterns are over-long, there will be undue stress on the parts above; or if on the other hand they are very short, there will be excessive concussion. These effects, though arising from defective conformation below, may nevertheless be felt above, notwithstanding the portion of the leg from the fetlock to the knee may be well formed.

Again, if the legs are not placed well and directly under the centre of gravity, or if the incidence of the weight of the body does not fall fair and true on the legs, there will be irritation and inflammation in the part unduly pressed upon. Plate 26.

But no cause of Splint is perhaps more common than the ordinary practice of subjecting young horses to work for which (however good their make and shape may be) their young bones, ligaments and tendons are unfit. Farmers, who breed horses, generally put them to harrow at two years old, they often ride ar drive them at three, and hunting 
men sometimes expect four, and always five year old animals to carry them across country.

Horses at an early age may no doubt do a certain amount of work, and perhaps may be none the worse for it; but the work demanded of them is often in excess of the age and capability of the animal. It is mainly from this cause, as we think, that we see so many horses, whose make and shape are unexceptionable, affected with splints.

The exostosis arising from these and such like causes usually appears about midway between the knee and the fetlock, because the middle is the weakest part in long bones. The reason why it appears on the inside rather than on the outside was explained above in par. 615 .

Defects of conformation are, however, we must remind the reader, in a great degree relative to the work which we require from a horse. Many an animal's legs, for instance, which might stand for years for harness work may be battered to pieces in a short time by hard riding along a road, or strained by hunting in a deep country.

Though some defect in conformation, or sorne excess of work relatively to age and structure, are the ordinary causes of Splint, yet in some cases the exostosis can be traced to no other causes than an hereditary predisposition to throw out ossific material. In such animals we generally find spavins and other exostoses concurrently with splint.

Exostoses, not true splints as defined above, are sometimes found on the outside of the leg, wholly unconnected with any of the above causes, -which arise from inflammation set up in the bone or periosteum from the effect of a blow, such as a servant may give a horse with the handle of a pitchfork, or the animal may give himself accidentally in the hunting-field or when turned out.

\section{Position of Splints.}

In most cases the Splint, for reasons already given, appears on the inside a little above the centre of the bone between the knee and the fetlock. Special circumstances, however, in some degree vary its position. If, for instance, the incidence of the weight does not fall true on the legs, the exostosis will probably form on that part of the bone or bones on which undue pressure comes; or if the leg is crooked, the exostoses will be found at that spot where the malformation causes unusual strain.

Splints, when fully formed and consolidated, do not of themselves, as a rule, cause lameness. They no doubt lessen to a certain degree the elasticity of the tread, but they do not affect the action in any perceptible degree.

The importance of a splint is dependent more on its position in reference to the action of the other leg, or to the passage of the tendons and suspensory ligament, than on its size. If it be so placed that its protuberance is likely to be struck or interfered with by the other leg in action, Splint becomes a serious evil. If it is not so placed, the mere exostosis may be of but little consequence. This question can only be settled by actual experience in the particular horse affected. A splint in one horse from some peculiarity of acțion may be interfered with by the 
movement of the other leg, whilst one in an exactly similar position in another horse may not suffer.

As a general rule, Splints which are well forward are seldom interfered with, whilst those on the side and those situated more posteriorly are oftener struck. Splints, which are high up near the knee, are in every respect in the most objectionable position, both because they are especially apt to be struck by the other leg in action, and because the inflammation arising from such blow or repeated blows is very likely to induce a renewed growth of the exostosis, which may extend to and implicate the bones of the knee.

Splints which are situated far back, are liable to interfere with the free motion of the flexor tendons, or of the suspensory ligament. The former case is exceedingly rare, but the latter is not very unfrequent. As a rule, however, hard parts give way to the softer structures, and hence we generally find that tendons and ligaments after a time succeed in making a free and smooth passage for themselves.

Splints on both sides, exactly opposite to each other, are more liable, as we might expect, than others to interfere with the free motion of the suspensory ligament and occasionally with the flexor tendons. Independently, however, of such interference, the occurrence of exostosis on both sides indicates great general weakness in the structures of the leg.

SPEEDY-CUT. An exostosis, not connected either with the interosseous ligaments or with weakness of conformation, is sometimes found on the inside of the leg near the knee (see Plate $25 \mathrm{X}$ ), which arises from repeated blows on the part by the foot of the other leg. The peculiarity of action, which produces this effect, is known as Speedy-cutting. Horses with this defect should not be purchased. They are dangerous to ride, especially at a fast pace. The pain produced by the blow is sometimes excessive, and may cause the animal to fall at once on his knees. It is always advisable, when inspecting an animal with a view to purchase, to look carefully for the sear which is produced by speedy-cutting.

\section{Incipient Splints.}

Almost all Splints during their formation produce lameness, both because the new deposit causes pressure on the periosteum, and because the periosteum and the bone itself under inflammation are highly sensitive of any concussion, such as that arising from trotting. The degree of lameness is, however, very uncertain, and appears to depend more on the sensitiveness of the parts in the particular animal, than on the amount and size of the deposit. In some cases the lameness is scarcely perceptible and of very short duration, whilst in other cases it is very marked.

\section{$619 a$.}

When the lameness is such as would be caused by Splint, it is more than probable that it is so caused, although offering no evidence to sight or touch. Splints may be and often are so placed as to be invisible; and when fully developed are not sensitive to pressure. In their incipient 
stage, however, which is accompanied by inflammation of the periosteum or skin of the bone, they will generally show tenderness on pressure, and the lameness will be temporarily increased from the pain so caused.

\section{Fully-formed Splints.}

When the Splint has fully formed, and the irritation and inflammation attending its growth have passed away, the horse will generally again go sound.

\section{Treatment.}

The nature and cause of Splint very clearly indicate the treatment required,-namely rest. This powerful sedative may be assisted by theapplication of a cold water bandage round the part affected. A threequarter shoe is also useful in lessening the concussion and the incidence of weight. Further relief may also be giren, if the lameness does not yield to the above treatment, by dividing the periosteum over the newly formed deposit. Leather under the shoe may be useful in diminishing the concussion. And in all cases the animal should be shod in such a way as to allow the frog to come to the ground.

In most cases these remedies will be sufficient. If, however, after an interval of ten days or a fortnight the horse continues lame, and the seat of the splint under manipulation is very sensitive, it may be advisable to apply a blister or seton.

Other Veterinary surgeons think that no time should be lost in attacking the newly formed exostosis. See par. 608 .

If, on the other hand, the horse instead of being rested is kept at work during the formation of a splint, the inflammation will be greatly increased, and an enormous quantity of bone will in consequence be deposited.

If the Splint, when fully formed, is interfered with by the other leg, some alterations in the shoeing will often produce avoidance of the protuberance. The shoe for instance may be kept very close, or underwoven, or the two nails on the inside may be left out, or a three-quarter shoe may be applied according to the requirements of each case. In other cases, an alteration of action sufficient to prevent the evil may be effected by using three-quarter shoes on the outside on both feet. Charlier shoes, if carefully fitted, will occasionally prevent the animal from striking the splint.

If these and such like remedies fail in producing the desired effect, a boot must be placed over the splint, so as to protect it as far as possible. Some horses, however, notwithstanding this protection, strike and bruise the exostosis to such an extent as to cause frequent temporary lameness.

\section{Splints cannot be removed.}

A Splint, when once fully formed into bone, cannot be removed; but Nature in the course of time, in accordance with her usual rule, absorbs 
a portion of the abnormal growth, and hence it is not uncommon to find the legs of old horses free, or nearly free from external exostoses.

The absorption of a portion of the deposit, especially when newly formed, may, however, be assisted and hastened by the use of artificial stimulants. Iodine, mercurials, and various preparations are used for this purpose. The favourite application is biniodide of mercury, in small quantities not sufficient to cause serious inflammation. Blisters and setons are also sometimes employed with a like object. The more consolidated portion of the deposit, however, cannot be removed by any such means.

The Author would earnestly recommend the owner of a horse with a formed splint to let it alone, if it does not cause lameness. The eyesore is not great, and blemishes more serious than the splint are often produced in the attempt to remove it.

\section{Of Splints which cause permanent lameness.}

Permanent lameness from Splint per se is rare. When such does arise, it will generally be found to be caused by the exostosis being so placed as to interfere with the working of the suspensory ligament or of the flexor tendons. As the cause, namely the exostosis or at least that part of it which lies deep-seated and which would interfere with their free passage, is irremovable, a cure is beyond the reach of art; though Nature may in time come to our assistance, partly by the absorption of a portion of the osseous deposit, and partly by the yielding of the hard to the softer tissues. In fact, it not uncommonly happens that, though there may be for a time considerable impediment to the free working of the suspensory ligament or of the tendon, and though these "cords" may be bowed out of the straight line by the deposit, yet in the end nature establishes for them a free or almost free passage.

In other cases the lameness may be caused by the exostosis being so placed, that it is struck so frequently by the other foot in action, notwithstanding the protection given by a boot, that renewed inflammation is set up in it, and lameness results. From the renewed inflammation an increased osseous deposit may take place.

The renewed attack must be treated in the same manner as recommended for the original disease. But if the deposit be increased, the difficulty of preventing collision will be increased, and sometimes there is no resource left, but to put the horse to slow work, when he will be less likely to seriously bruise the splint. Some horses, which, when ridden, hit splints, do not do so in harness, or vice versâ.

\section{To detect Splints.}

Large splints are easily enough both seen and felt, but the detection of an incipient or very small splint is often a matter of nicety.

The signs of splint are lameness accompanied with pain on the application of pressure to the seat of the disease, also heat and throbbing of the arteries of the part, and a marked increase in the lameness at a trot 
over that exhibited at a walk. The lameness produced by an incipient splint is often excessive. In many cases, however, the animal goes sound at a walk, though very lame at a trot. In cases of doubt the horse should be trotted downhill on hard ground, when the increased concussion will cause him to favour the lame leg.

The lameness arising from splint is further distinguished by a very marked dropping of the head when the sound leg comes to the ground, and a corresponding jerking up of the head when the lame leg is brought down. In feeling for splint, the opposite leg should be held up in order to compel the animal to brace up the tendons of the affected leg, when any inequality about the bones will be more easily felt; and secondly, the lame leg should be raised in such a manner as to bring the knee of the horse under the arm of the examiner. The tendons are then fully relaxed, and the bones can be felt to advantage.

In either of these positions the leg is favorably placed for examination; and if the fingers be applied along the leg, and into the channel between the inner small and great bone, the incipient splint will probably be detected by the inequality, if any such yet exists; or by the pain evinced on the application of pressure to the part in which there is inflammation.

In some cases, however, the incipient splint is so small, and possibly the seat of the inflammatory action may at first be so completely in the interosseous ligaments between the bones, that nothing can be felt; and the only indication leading to a suspicion that a splint is forming, consists in the horse going very lame at a trot, whilst sound at a walk. A little extra heat may, however, perhaps be felt on careful examination. The development of a splint may in such cases be expected, and must be carefully watched for. The lameness and heat, if the horse is rested for a few days, will sometimes disappear; but will be again apparent if the animal is worked.

\section{Degree of importance to be attached to Splint.}

Splints, as has been stated, do not usually of themselves produce lameness after they are fully formed. They only become a source of lameness when so situated as to be struck by the other leg in action, or when they interfere with the free passage of the suspensory ligament, or more rarely of the flexor tendons.

In other respects the importance of a splint is chiefly dependent on the make and shape of the legs in reference to the work required of the particular horse.

If the legs are sound and good, and if the action is true and level, the mere fact that certain causes have at some time or other developed an exostosis on the leg, need not deter an intending purchaser. As a practical fact almost all horses have splints ; and they are only of consequence when subject to or arising from the influences enumerated above.

But if the legs are weak or crooked, or if the action is defective, it is probable enough that the same structural weakness or defects, which have at one time developed Splint, may at some futtre time reproduce it or some other disease. 
CHAPTER 40.

SORE SHINS, RING-BONE, AND OSSIFIED CARTILAGES.

626. SORE SHINS. Nature and causes of Sore shins. 627. Treatment. 628. RING-BONE. Nature and seat. 629. Causes. 630. Signs of lameness arising from Ring-bone. 631. Treatment. 632. After-effects. 633. OSSIFIED CARTILAGES. Nature and seat. 634. Causes. 635. Signs of lameness arising from Ossified Cartilages. 636. Treatment.

\section{SORE SHINS.}

626. Nature and Causes of Sore Shins.

The disease known as Sore shins is primarily inflammation of the periosteum of the anterior portion of the metacarpal bones from the knee to the fetlock. It arises from the concussion produced by fast work. Hence it is common in young race-horses, whose frames are not fully formed and consolidated. They not only do very fast work, but they often do it at a season of the year when the ground is apt to be hard.

After a time, from inflammation of the periosteum, ossifio matter is thrown out, which forms in small nodules or in some instances in thin layers on the surface of the bones.

\section{Treatment.}

The treatment in the early stage consists in rest, aided by cold water irrigation at once. In cases where the pain is excessive the application of a decoction of poppy heads or belladonna will be found to have a soothing effect. If the disease is taken in time, these means will probably be sufficient to allay the inflammation, and the horse may shortly resume his work.

As a matter of fact, though it is difficult to account for it in theory, it is generally safe, and often marvellously beneficial in the result, to apply a mild blister at once over the parts affected, without waiting until the active inflammation is reduced. If however work be persisted in, ossific matter will form. The horse must then be laid up, and as soon as the inflammation has been reduced by the usual means, a blister must be applied over the parts, which will in most cases arrest the further progress of the disease.

The occurrence of Sore shins is an indication, either that the trainer has unduly forced the horse in his work, or that his legs are not fit for fast work. 


\section{RING-BONE.}

628. Nature and seat of Ring-bone.

Ring-bone is an exostosis, either on the upper or on the lower pastern bone-affecting in the one case the upper pastern joint, or in the other case the lower pastern or coffin joint around the coronet.

Ring-bone more often affects the hind than the fore fetlocks. The degree of lameness is much greater in the lower than in the upper disease.

False Ring-bone is an exostosis on the bodies of either of the above bones, not affecting or interfering with the joint.

\section{Causes.}

Ring-bone is generally connected either with weakness and consequent sprain of the fibres of the lower divisions of the suspensory ligament, which are inserted into the anterior part of the coronet bone; or with sprain of the articular ligaments of that bone; or it may arise from concussion, or from a blow, tread, or other wound, or from any cause producing undue or unusual strain on the ligaments of or about the fetlock.

From any of these or such like causes inflammation may be set up in one or other or in both pasterns, and an ossific deposit may be the result. In some cases a predisposition to this disease appears to be hereditary.

Ring-bone is common in horses with long pasterns, where there is necessarily a tendency to weakness; and also in animals with unduly short or upright pasterns, in which formation there is a tendency to excessive concussion.

\section{Signs of lameness arising from Ring-bone.}

Lameness arising from Ring-bone (as is usually the case when an osseous structure is affected) is more perceptible on hard than on soft ground. The special peculiarity to be noticed is some stiffness or want of flexion in the fetlock joint, and a consequent snatching up of the foot in action. Some swelling and heat is also in most cases even in the early stage apparent about the fetlock, and in a later stage increased heat will invariably be detected.

\section{Treatment.}

Whatever be the cause,-rest, aided by cold applications, is the primary essential in the treatment. When the active inflammation is reduced, a blister, if the horse continues lame, may, as in other cases of exostosis, be beneficially employed, such as the ointment of biniodide of mercury.

Concussion, and strain on the ligaments, will both be lessened by keeping the toes short, and still more by turning up the shoes at the toe. Leather under the sole is also useful in diminishing concussion. 
If the above is not successful, Point firing may be effective, and it has the great advantage of not disfiguring the horse.

\section{After-effects.}

Ring-bone, when fully formed and consolidated, will produce lameness or not according to the extent, and still more according to the position of the exostosis. If it is so placed as to interfere with the action of the joint, the horse will probably be incurably lame. In slight cases no further mischief occurs than some diminution of the elasticity of the tread. We must, however, warn the reader, that with the renewal of severe work inflammation is apt to be again set up, accompanied with a fresh deposition of bone.

The formation of ring-bone, especially if it appears in more than one fetlock, is generally a sign of constitutional tendency to throw out bony enlargements or of defective formation; and therefore an intending purchaser will do well to think twice before he buys a horse so affected, if he wants him for hard or fast work. But when the exostosis is found on only one fetlock, there is a probability that the inflammation giving rise to the ossific deposit may have originated in a blow or tread, or some such accidental cause.

\section{OSSIFIED CARTILAGES.}

\section{Nature and seat of Ossified Cartilages.}

This disease, otherwise known as Side-bones, consists in ossification of the elastic lateral Cartilages, or wings of the bone of the foot. Nature has substituted cartilage for bone in this part in order to give greater elasticity towards the heels. Any alteration in this structure, such as its conversion into bone, must interfere with the elasticity of the tread, though it may not occasion positive lameness. The bony deposit may however be so extensive, as to materially alter the shape of the coffin bone; and in such cases lameness will be the inevitable result.

Heavy coarse cart-horses are most subject to this disease, and in them the deposit is often very large. In light horses it seldom becomes so large as to be visible to the eye. The change in structure, howerer, is easily ascertained by feeling the wings of the bone of the foot. If they are affected with ossification they will be hard and immoveable instead of elastic. The lameness from side-bones is always more observable in the lighter and better bred than in heavy horses, because the pace at which they travel is faster.

\section{Causes.}

Side-bones are the result of inflammation set up in the lateral cartilages by excessive concussion or by an accidental blow, wound, or tread. The tendency of cartilaginous structures under the influence of inflam- 
mation to become absorbed and replaced by bone has been already noticed.

Side-bones are occasionally found on light horses doing fast work; but much more often on very heavy horses drawing very heavy' loads. The shoes used on these horses usually weigh from 6 to $7 \mathrm{lb}$.

The prevalence of side-bones has often been attributed to high Calkins.

In London, however, though the hind feet are shod with calkins, and the fore are not, yet side-bones are more frequent in the fore than in the hind feet.

In the great towns in the north where calkins are used on both fore and hind feet, side-bones are more frequent in.the fore than hind feet.

It would seem, therefore, that calkins are not the cause of side-bones.

Mr Dollar, V.S., attributes the greater frequency of side-bones on the fore feet to the greater concussion caused by the lifting of the fore feet than on the hind feet in action.

Side-bones, in common with exostoses in other parts, somctimes have their origin in hereditary predisposition. This is especially the case in coarse-bred horses.

\section{Signs of lameness arising from Side-bones.}

As in other cases where the seat of lameness is in the osseous structures or in the foot, the horse will be more lame on hard than on soft ground.

There can hardly be said to be any special peculiarity about the lameness arising from Side-bones, except a certain degree of stiffness of action. When however the above general indications have been given, the immediate seat of disease in the case of Side-bones can always be detected by manipulation.

\section{Treatment.}

When the disease arises from inflammation caused by concussion or accidental wounds, the treatment consists in rest and cold applications.

A bar shoe, so made as to take the pressure off the inside, or off the outside heel, or off both heels, according to the requirements of the particular case, will also be beneficial.

It is seldom possible entirely to arrest the process of ossification, when inflammation is once set up in a cartilaginous structure, but by rest we can sometimes limit its extent. If work is continued during the time the Side-bone is forming, a large exostosis may be the result, though such is but rarely the case.

Side-bones, when once formed, are quite incurable, though in horses with good-shaped feet relief has been afforded by Professor Smith's operation, which consists in two or three longitudinal incisions on each side of the wall, so as to completely divide the horny structure. The resulting expansion adapts itself to the abnormal and hardened projection within. The professor considers prolonged rest necessary, with mild blisters to the coronet, to accelerate the renewal of the horn.

Horses with Side-bones, though after a time they may become unfit for work on hard roads, may be employed and do good work in agriculture 


\section{PART VI.}

\section{CHAP'TER 41.}

\section{BURSAL ENLARGEMENTS.}

637. Nature of Bursal Enlargements. 638. Synovial Membranes. 639. Causes of Bursal Enlargements. 640. Bog Spavin. 641. Thorough-pins. 642. Of Thorough-pins arising from irritation of the true Hock-joint. 643. Of thorough-pins arising from irritation of the Flexor pedis tendon. 644. Windgalls. 645. Treatment of Bursal Enlargements. 645a. Dry pressure bandages. 645b. Further treatment. 64.6. Decrease of Bursal Enlargements in old age. 647. Dealers. 648. Blood Spavin.

\section{Nature of Bursal Enlargements.}

Thorough-pins, Bog Spavins, Windgalls, and such like affections, in whatever part appearing, may all be conveniently classed under the common head of Bursal Enlargements.

Such enlargements, though proceeding from various causes, are in themselves simply distensions of the bursæ or sheaths, which enclose all true joints and certain parts of all tendons and of some ligaments. The enlargement in recent cases arises wholly from an increased secretion of Synovia, otherwise called joint oil; but in cases of long standing it is often much increased by thickening of the synovial fringes, and sometimes also by the products of inflamniatory action in the bursa.

\section{Synovial Membranes.}

Nature has endued these bursa and sheaths with a lining membrane, which secretes Synovia, a fluid resembling oil, for the due lubrication of the parts.

It is not necessary here to enter into the physical structure of Synovial membranes. It niay be sufficient to say that the outer coat of the menbrane is thick, tough, and but slightly sensitive; whilst its inner lining is highly vascular and sensitive. From this inner lining is secreted the clear, bright, glistening, pale straw-coloured sero-albuminous fluid, known as Synovia or joint oil. 


\section{Causes of Bursal Enlargements.}

When any cause, such as over-exertion, produces irritation in the part, the Synovial meembrane is excited by the irritation to throw out an increased secretion of oil. This increased supply must not be regarded as an evil in itself. On the contrary it is useful in lessening the irritation, and is, in fact, a bountiful provision of nature for that purpose. Similarly, when a sprain occurs in the ligaments of a joint or in a tendon, an increased secretion of synovia is poured forth with the same object.

The liability to the occurrence of such causes is, of course, greatly dependent on the conformation of the animal. Upright shoulders, fetlocks or hocks, and all other points of conformation which do not give due elasticity to the frame in action, are liable to cause Bursai Enlargements.

Chronic inflammation of the joints, which is often found as a result of pneumonia, influenza, and sometimes of general debility, is another common cause.

Though overwork, sprain, faulty conformation, or chronic inflammation of the joints may be set down as the usual causes of Bursal Enlargements, yet they sometimes occur without any such violent exciting causes, and can then only be attributed either to a special irritability of the Synovial membrane, on account of which it is excited to increased action on very slight provocation, or to weakness of the coats of the blood-vessels of the membrane, through which an undue effusion takes place.

From these general remarks on the nature of Synovial membranes, and on the causes of Bursal Enlargements, we pass to the consideration of the particular affections, which bear various names according to the part in which they appear.

\section{Bog Spavin.}

Bog Spavin is distension of the bursa of the true hock joint. This joint, as explained in the Chapter on Spavin, No. 38, consists only in the articulation of the tibia and astragalus. The other bones of the hock do not enter into it. The swelling shows itself primarily in front, because in that part the capsule is large and loose, and not bound down by bones or ligaments, and therefore it is easily distended.

Bog Spavin is most frequently found in upright shaped hocks, because that formation induces concussion and irritation. It is also commonly found in weak hocks of any description, because in them any over-exertion is likely to be injuriously felt and therefore is very liable to cause irritation. Such hocks are also more liable to sprain.

Of the treatment of Bog. Spavin we shall speak hereafter in common with that of other Bursal Enlargements.

\section{Thorough-pins.}

Thorough-pin is the name given to a Bursal enlargement, which occurs at the upper and back part of the hock beneath the great extensor pedis tendon. The swelling appears sometimes on one side only, but more frequently on both sides. 
There are two kinds of Thorough-pin, namely those arising from irritation in the true hock joint, and those which are caused by irritation or sprains of the flexor pedis tendon.

\section{Thorough-pins arising from irritation of the true Hock joint.}

Thorough-pin arising from irritation of the true hock joint is in fact only a further development of bog spavin. The increased secretion of synovia, for reasons already given, shows itself primarily in distension of the lower part of the bursa. When this portion is full, any further increase shows itself in the upper part. The swelling appears equally on both sides, and the fluid may by moderate pressure be forced from one side to the other. Hence is derived the name of Thorough-pin, or running " through" from side to side.

\section{Thorough-pins arising from irritation of the Flexor pedis tendon.}

The other and more common description of Thorough-pin is not connected with the true hock joint, but arises from irritation of the Flexor pedis tendon.

This tendon is tightly bound down at its upper part by the ligaments at the back of the tibia, and again below as soon as it reaches the inside of the hock. Hence, any increased secretion of synovia can only lodge in the intervening space, $i . e$. in the hollow of the hock, either on one or both sides.

If the seat of the injury be high up (and it generally does occur, as we might expect, near the bend) we find the enlargement on both sides ; but that on the outside is generally larger than that on the inside. If on the other hand the seat of the injury is lower down, the swelling may, on account of the position of the part of the tendon injured, appear only on the inside; but it more often appears on both sides, or on the outer side only.

Thorough-pins, arising from irritation of the flexor pedis tendon, are at once distinguished from those described in the preceding paragraph, because there is no lower enlargement or bog spavin. It is however very possible that both kinds of Thorough-pin and bog spavin also may be present in the same hock.

Bog spavins and Thorough-pins vary very much in size according to the nature and degree of the particular case. They may be so small as to be scarcely perceptible, or they may be of enormous size.

\section{Windgalls.}

Windgalls are similar enlargements arising from very similar causes in the neighbourhood of the fetlock joints. They seldom however become of any great size. They more commonly arise from over-exertion, concussion and irritation of the parts than from actual sprain. Indeed the fetlock joint is so constructed, that it is very rarely sprained.

Similar enlargements, if any sufficient cause exists, sometimes appear 
in the neighbourhood of other true joints. The hock however and fetlock are the common seat of bursal enlargements.

\section{Treatment of Bursal Enlargements.}

The utility or otherwise of treating a Bursal enlargement depends mainly on the cause, from which the swelling arises in the particular case.

Those which are due to the effect of work, concussion, and such like causes, though they may be temporarily got rid of by the means hereafter detailed, will generally reappear as soon as the horse is again subjected to the causes which originally induced them.

Those, however, which have arisen from the effect of accidental sprains of ligaments of joints, or of tendons are not equally liable to reappear, if they can once be reduced, because the causes are not equally likely to recur.

Rest in either case is the primary requisite. Rest will allay the irritation in the part affected; and with the cessation of the inflammatory action which produced it, the increased secretion will soon cease. Friction and pressure, by rousing the action of the blood-vessels and absorbents of the part, will also assist nature to take up the extra secretion.

A sweating bandage, that is a wet bandage covered with oiled skin, and this again covered with an ordinary flannel bandage, has often a great effect in reducing the enlargement. In the hock and in some other parts, which cannot be conveniently bandaged, pressure may sometimes be successfully applied by means of a carefully adjusted elastic steel truss. This will often answer well for thorough-pin. In cases, however, of bog spavin an india-rubber bandage with a hole in it, through which the joint of the hock may pass or project, will be most convenient. In the case of windgalls, small pads of india-rubber may be placed on the bursæ and pressure applied by wet linen or chamois leather bandages. Horses showing much wear of this kind derive great good from the use of cold water conducted through an india-rubber tube from the tap. If labour can be spared, brisk hand rubbing should follow, and in any case loose woollen bandages should be applied.

\section{5a. Dry pressure bandages.}

"Dry pressure bandages" are applied so as to give pressure on recessed surfaces. The ordinary bandage fails in this respect. For instance, the ordinary bandage round the leg in case of sprain of the Suspensory Ligament, which lies in the-channel formed by the two splint bones, does not give pressure where pressure is really needed. In "dry pressure" bandages these hollows are filled with pledgets of wool or fine tow, and thus pressure is brought to bear on the seat of sprain. These bandages, after brisk hand rubbing, have also an excellent effect in reducing Bursal enlargements and those arising from old sprains, particularly those that fill after work, as more pressure by the pledgets is brought to bear directly on the implicated parts than is the case with the ordinary 
bandage. The Author believes the advantages of this system will be considerably increased by alternation with the cold water jet. These bandages were introduced in England by Mr. W. Hunting, Veterinary Surgeon, of 157, Fulham Road, S.W.

\section{5b. Further treatment.}

Further treatment is often required. If so, bromide of mercury will give the best result.

In rare cases the swelling remains as large as ever, long after all the inflammation has apparently subsided, and notwithstanding the treatment recommended above. If the horse is valuable, it is worth while to try the effect of time and gentle exercise, such as the animal will give himself in a shed with a little yard attached. Nature under such favorable circumstances may bring about a cure.

It has often been recommended in such cases to puncture the sheath or bursa, and so allow the synovia to escape. There is however great danger of violent inflammation setting in on account of the admission of air to the interior of the bursa. If it is decided to try the experiment, the success of which is at least very doubtful, the puncture should be made at the lowest convenient part of the swelling; because the synovia, which will continue to ooze out, will help to exclude the air until the ordinary processes of healing have completely closed the orifice. Even, however, if the operation is so far successful as to be unattended with any injurious consequences, the probability is that the enlargement will soon reappear.

\section{Decrease of Bursal Enlargements in old age.}

Bursal Enlargements have a marked tendency in many cases to decrease in old age, and it is not uncommon to find the legs of an old horse quite or almost quite free from them, although in his younger days he may have been much disfigured. The cause of their disappearance is no doubt due to the generally decreasing energy of the reproductive system in old age.

\section{Dealers.}

Dealers, with whom it is of course a great object to make a horse appear to the best advantage, are great adepts in getting rid temporarily of Bursal Enlargements. The means they adopt are those recommended above, namely friction, pressure, sweating bandages, slight doses of medicine, and laxative diet. The purchaser, however, when he puts the horse to work, will generally find that these enlargements reappear.

\section{Blood Spavin.}

Blood Spavin, though not a Bursal Enlargement, is yet connected with it, and may therefore perhaps be conveniently mentioned in this place. In some cases, when a bog-spavin is large, its protuberance impedes the 
flow of the blood through the vein which passes over it, and renders it varicose. The dilatation of its coats takes place just under the seat of the bog-spavin. There is no direct remedy, but any treatment which lessens the bog-spavin will decrease the tendency to retardation in the upward flow of the blood. No great harm results from the dilatation of the vein. The greater part of the swelling is always due to the Bursal Enlargement-not to the vein.

\section{CHAPTER 42.}

\section{DETECTION OF THE SEAT AND CAUSE OF IAAMENESS.}

649. Introduction. 650. Detection of the seat and Cause of Lameness. 651. Mode of examining a horse. 652. Whether lame before or behind, to be first ascertained. 653. Side, on which the horse is lame, to be next ascertained. 654. If lame before, whether in the foot or elsewhere. 655. If not lame in the foot, and yet more lame on hard than on soft ground an Exostosis may be suspected. 656. Of lameness in the fore-hand, when the horse is more affected on soft than on hard ground. 657. Lameness in the Hind Quarters. 658. Sprains of the Loins and Stringhalt. 659. Rheumatism as a cause of Lameness. 660. Accidents and such like causes of Lameness.

649. Introduction.

Lameness is only a symptom of disease. It may be produced either by pain, by inability, by malformation, or by accident ; or it may arise from disease of the cerebral or nervous system, as in injuries of the spinal cord or in stringhalt.

Lameness is usually, but not invariably a sign of pain. In anchylosis of a joint, for instance, there is decided lameness from mechanical impediment, but no pain.

Again, loss of elasticity of movement, such as is common in old horses or in animals which have done much work, may exist to a degree scarcely distinguishable from lameness.

It might, at first sight, seem a very simple thing to say, whether a horse is lame or not. It is not so, however, in many cases. Old, or hard-worked horses, as just mentioned, sometimes go stiff to a degree, which may easily be mistaken for lameness, unless due allowance is made for age, \&c. Again, some horses, which are very wide in their chests, roll in their action to an excessive degree. Other horses, if constantly driven in harness, acquire a peculiar hitch in their trot, which is not really lameness. If the animal is sound, this will probably disappear when he is trotted slowly in hand with a very loose rein. Others, espe- 
cially young horses, when first put on the bit and from not working properly up to it, go in a peculiar manner, which is sometimes known as "bridle-lameness." If the animal be led with a loose snaffle rein or a halter, on the side opposite to that on which he is bridle lame, the unevenness of gait will disappear.

\section{Detection of the seat and cause of Lameness.}

In some cases the seat and cause of lameness is obvious enough, but not unfrequently it is obscure, sometimes very obscure. Almost every cause of lameness has, however, some peculiarity in its symptoms, by which it may be distinguished.

Occasionally the difficulty of ascertaining the real cause is agrgravated by the existence of inore than one cause sufficient to account for the lameness; or the horse may be lame in more than one place, as for instance in both fore-legs or feet, but perhaps not equally so in each; or in both hind, but not alike in each; or in one hind and one fore leg and so on. In such complicated cases the animal saves the lame leg or legs by throwing his weight on the sound ones in so peculiar a manner, that great and constant practice is needed to form a correct opinion; or again a secondary cause, such as corns, may modify the symptoms of a more serious disease.

In very many, we may say indeed in most cases, the art of the Veterinary Surgeon consists more in rightly discerning the real cause and seat of lameness, than in the treatment of the disease; and it is only by accurate and constant observation and experience that he can acquire this knowledge. The treatment is in general exceedingly simple. Herein the Veterinary differs greatly from the Medical art. In the human subject, the patient is able in most cases to indicate at least the seat of his disease. The horse is incapable of giving this assistance; and we are left to infer, as we best can, the seat and nature of the affection.

We shall now endeavour to give a few general rules, which may assist the reader in forming an opinion as to the seat and cause of lameness in various cases. He must not, however, imagine that a knowledge of this difficult portion of the art of the Veterinarian can be acquired by reading only. Constant practice, keen observation, much trouble and time are also required.

\section{Mode of examining a horse.}

It is essential that the horse should have been in a state of rest for some hours previous to being examined as to soundness. Some ailments are not noticeable, and many ailments are less noticeable after a horse has been a little time in exercise.

Before a horse is brought out for examination, very much is to be gleaned in the stable about his soundness or otherwise by noting the position in which he stands, and whether he bears his weight evenly on all his legs, or whether he points either foot or flexes his fetlock; and as regards his hind quarters, whether he keeps either leg tlexed, or in other 
cases, one before the other. He should be very narrowly watched as he turns in his stall, as any stiffness or irregularity of action is especially noticeable in this preliminary movement.

For examination, the horse should be led out with a long snaffle rein, with his head as loose as possible, at a very slow trot. Slight cases of lameness are more easily detected when a horse is trotted away at once than if previously walked up and down. There should be nothing to excite him. Everything around should be in a state of rest. Lameness may escape detection if the animal is excited. A horse should not be examined in a dealer's yard, except the place is perfectly quiet; nor unless we can be quite certain that he is brought out of the stable without having been previously exercised.

After the horse has been trotted away from the examiner, he should watch him most narrowly, as he turns round. Many defects are more easily seen in the act of turning than at any other time. This is especially the case in stringhalt, spavins, etc.

When the horse is trotted on hard ground, the equal sound or otherwise of the descent of the feet will strike the ear. An inequality of sound may be detected, whilst a slight unevenness of motion may perhaps escape the eye. The sound, one, two, three, four, of the even trot is easily distinguished from irregularity of action.

The horse should then be led at a walk and the examiner should keep his eye on the very first movements, and observe if the animal trips or knuckles, and also how he puts down his feet, whether he uses them both alike, and whether he flexes his hocks equally. All defects and deviations from true and level action are more noticeable in the first step or two than afterwards. Allowance must however be made for the effect of peculiarities of conformation on the action.

A Veterinary Surgeon should be able to determine whether the action is true, or at least conformable to the character of the individual horse or not. A horse, for instance, which is over-wide in front or behind, will necessarily roll to a certain degree; and some clumsy made animals, especially cart-horses, do so to such an extent as to simulate lameness. Others again with very upright shoulders, have naturally short quick action, which must not be confounded with lameness. When a horse has upright shoulders and his fore-legs are rather behind the centre of gravity, he must compensate for this defective shape by short quick action in order to maintain his balance, or else he will be unsafe. The examiner should know the feel of a horse under him,--whether he goes quick and short, or rolls, as a result of natural conformation, or from impairment of structure.

The age, and work which the animal has done, must also be taken into consideration. We do not expect to find an old hunter move in his trot with the elasticity of a four-year-old. There is a gradual impairment of structure always going on in the animal frame with age and work. The excessive degree of stiffness, sometimes observable in old horses, has occasionally led to contradictory decisions among Veterinary Surgeons as to their being lame or sound. 
Again, a horse, when examined, may be lame from some temporary accidental cause, such as picking up a stone, hitting one leg against the other, or from such like causes; and this lameness may disappear the next day or hour. In all doubtful cases, either as to the nature of the lameness, or as to whether the horse is really lame or not, the safer plan is to examine him again the next day before exercise.

If after examination a doubt still exists about the soundness, the horse should be made to undergo some rather severe work, and then be put in a stable; and re-examined two or three hours after, when he is quite cool.

The examiner should endeavour to divest his mind of all prejudice. $\mathrm{He}$ should not in the first instance listen to any remarks or fancied opinions of bystanders on the case. He should set all aside and form his own opinion. Having made up his mind that the horse is lame and where he is lame, he should then make inquiry into the history of the case, and glean all the information he can from the owner and those employed about the animal.

On the other hand, if he decides that the horse is sound at the moment, but learns from the owner that he has frequently gone lame after work or has been intermittently lame, he must adopt further means, such as giving the animal rather severe work, and leaving him to stand in the stable till cool in order to develop the ailment.

Although certain general rules may be given to aid in the detection of the seat and causes of lameness, yet it is quite impossible to give, by any description, rules sufficient to guide the novice in all cases. No attempt will be made to do more than point out the leading peculiarities of disease in various limbs and structures, which may assist the careful and laborious inquirer in gaining the needed practical knowledge. It is possible to lay down broad and general rules; but it is not possible to lay down precise and sharply defined rules, because constantly varying circumstances induce such innumerable modifications of symptoms.

Excluding from present consideration those cases in which an external wound or blow at once indicates the seat and cause of lameness, we proceed to investigate those in which the outward causes are less apparent.

\section{Whether lame before or behind, to be first ascertained.}

The first point is to find out whether the horse is lame before or behind.

The hind quarters should be carefully watched as the horse is led away at a slow trot. Lamèness "behind" will be indicated by an uneven carriage of the hips. The hip on the lame side will be carried higher than the lip on the sound side, for the simple reason that the horse favours the lame side, and throws his weight upon the sound side. The hip on the lame side will also appear straighter, and will be hitched up in action. The examiner should narrowly watch the animal as he turns round after being trotted away. Many defects are more easily seen in the act of turning round than at any other time. This is especially the 
case in spavin and stringhalt. Any sudden "catching up," or "favouring," of a hind leg should be viewed with suspicion.

Lameness "before" is indicated by the uneven carriage of the head. The head will jerk $u p$ when the lame leg comes to the ground, and will drop or nod when the sound leg comes to the ground.

If a horse be lame on both fore legs or feet, it is indicated by a short pottering action.

Lameness in one hind leg often gives rise to all uneven or "rocking" motion, which sometimes leads an inexperienced person to think the horse lame on the opposite side of the fore-hand.

A horse suffering from acute pain in his hind feet will place his forefeet more under him than usual, so as in some degree to take the weight off the part affected; whilst, for a similar reason, in acute pain of the fore-feet he will bring his hind legs more under him.

\section{Side on which the horse is lame to be next ascertained.}

Having ascertained that the horse is lame "before" or "behind," as the case may be, the next point is to find out on which side the lameness exists.

The amateur will probably experience some difficulty at first in ascertaining this, but careful attention to the remarks in the preceding par. (652) will greatly assist him in arriving at a correct conclusion.

\section{If lame before, whether in the foot or elsewhere.}

Supposing the horse to be lame before, the next question is to determine whether the seat of lameness is in the foot, or elsewhere.

The appearance of a horse with foot lameness is usually characteristic. He points his foot at times; the heat in it and round the coronet is more or less increased, and in very acute cases there may be throbbing of the plantar arteries. In his movements the horse treads warily; and in turning he limps móre or less. These symptoms of course vary according to the degree of the disease or injury. In cases of any standing, there is also usually alteration in the structure and size of the foot; and the comparative size of the feet should therefore always be carefully observed.

Foot lameness may be further tested by trotting the horse first on hard, and then on soft ground. If he is lame in the foot, it will be more apparent on the hard than on the soft ground. In doubtful cases he may be trotted down hill on hard ground, or ridden, when the concussion will be greater and the lameness more obvious. If he is lame elsewhere, it will be as apparent and probably more apparent on soft, than on hard ground. An exception to this occurs in the case of splints and other exostoses, the lameness from which is more apparent on hard than on soft ground. Unless the cause of lameness is obvious, the foot should always be examined, before assuming the lameness to be elsewhere.

For the symptoms, which distinguish one disease in the foot from another, the reader is referred to the succeeding chapter on Foot Lameness. 
655. If not lame in the foot, and yet more lame on hard than on soft ground, an Exostosis may be suspected.

If, however, a thorough examination should show that the feet are sound, the symptom, namely, increased lameness on hard ground, will lead us to conclude that the cause may be found in some Exostosis, such as a spavin, splint, ringbone, or sore shins. The peculiarities connected with such lameness and the best means of detecting the seat in each particular case, have been detailed in Chapters Nos. 38 on Spavin, 39 on Splint, and 40 on Sore Shins.

\section{Of lameness in the fore-hand, when the horse is more affected on soft than on hard ground.}

If, however, the lameness being in the fore-hand, the horse is more lame on soft than on hard ground, it is probable that the effect is due to sprain of some muscle, ligament, or tendon.

These causes are so frequent and so important, that the author deems it necessary to devote to their consideration a separate Chapter (No. 44 on Sprains of the Fore Leg).

\section{Lameness in the Hind Quarters.}

We have hitherto supposed the seat of lameness to be in the fore-hand. We must now suppose that, by the rules laid down in paragraph 652 , we have ascertained its seat to be in the Hind Quarters.

With some modifications, the general rules given above for detecting the particular seat of the lameness apply to hind, as well as to fore, quarters.

The level movement or otherwise of the hips is our first and chief guide. If the horse is lame in the hock or below it (and in the great majority of cases the seat of lameness is in the hock), the hip, on the side in which the disease exists, is usually carried somewhat higher than the sound one.

Before trotting the animal, note should be taken of the conformation of the hind quarters. For this purpose the horse ought to be made to stand so as to bear his weight equally on both hind legs. The relative equality of the height of the hips and the development of the muscles on both sides will then be well seen. If the horse is not made to stand well and correctly balanced on his hind legs, an erroneous opinion may easily be arrived at. It not unfrequently happens, that a portion of the projecting part of the bone of the hip has been knocked off. It is important that this accident, if it has occurred, should be noticed before the horse is trotted down; because otherwise the fact of one hip being carried higher than the other would lead the unwary to suspect lameness in the opposite leg, or perhaps to think that the muscles had wasted away from previous disease.

If, on the other hand, the horse should happen to be lane from an injury or sprain above the hock, the hip on the lame side will generally droop somewhat in action. A further peculiarity will be noticed in the 
horse swerving from that side, i.e. not carrying his body in a straight line. In some cases, however, of lameness behind, there is no perceptible difference in the level of the hips in action.

When the horse is trotted down, the examiner should at first stand directly behind him. In this position he will best observe the movements of the hips, and whether the body is carried in a straight line or not. The want of due and equal flexion in the hocks will, however, be seen more plainly by the examiner standing on the side.

Next he must ascertain whether the seat of lameness is in the foot or elsewhere. Lameness, however, in the hind feet is very rare, compared with the many cases in which it occurs in the fore feet.

Hence, if the horse be more lame on hard than on soft ground, we may at once suspect that some exostosis, and probably spavin, is the cause. For further details and special symptoms of such lameness the reader is referred to Chapter No. 38 on Spavin.

If, on the other hand, the horse be more lame on soft, heavy ground than on hard ground, we shall probably find that sprain of some of the ligaments is the cause. But whereas in the fore-leg the sprain usually occurs between the knee and fetlock, in the hind leg the seat of sprain is generally in the hock. Further details, as to the nature of such sprains and their special symptoms, will be found below in Chapter No. 45 on Sprains of the Hind Leg.

In nine cases out of every ten, the cause of lameness in the hind leg will be found in the Hock, - it may be a sprain or it may be an exostosis. The reason of such special liability to disease in the hock has been already explained in the Chapters on the Conformation of the Hock and on Spavin.

\section{Sprains of the Loins and Stringhalt.}

Sprains of the Loins and also incipient Stringhalt are sornetimes not noticeable, so long as the horse moves forward. In every case therefore the animal examined should be "backed," and turned round sharply, when any such defect will be more apparent.

\section{Rheumatism as a cause of Lameness.}

Rheumatism may affect either the fore or hind quarters. The lameness resulting from it very much resembles that arising from violent sprain of a tendon; but it is easily distinguished from it by the lameness appearing and disappearing suddenly, and by its shifting about from place to place. For further details on this subject the reader is referred to Chapter No. 27 on Rheumatism.

\section{Accidents and such like causes of Lameness.}

Besides lamenesses arising from specific aftections of particular muscles, tendons, ligaments, joints, bones, etc., there are very many cases which arise from purely accidental causes, such as blows, fractures, wounds, and sores. Thus a horse may be lame from a blow on the outside of the leg, 
or from a girth gall, or from undue pressure of a saddle on the withers or on some other part, or from cracked heels, or other such causes. The majority of these causes are, however, apparent at first sight.

\section{CHAPTER 43.}

SYMPTOM S OF VARIOUS DISEASES AFFECTING THE FEE'.

661. Examination of the Foot. 662. Symptoms of various diseases in the Feet. 663. Symptoms of Laminitis. 664. Symptoms of Navicular disease. 665. Symptoms of Ossified Cartilages. 666. Symptoms of Thrush. 667. Symptoms of Canker. 668. Symptoms of Corn. 669. Chronic Foot Lameness. 670. Contraction. 671. Influence of Conformation. 672. Temporary causes of Lameness. 672a. Treatment of diseases of the Foot.

\section{Examination of the Foot.}

Having ascertained that the seat of the lameness is in the foot, it will be necessary to examine it minutely. With this view, the foot on the side indicated should be compared as to size and degree of slope and as to depth and breadth at the heel with the opposite one. If the foot is smaller or narrower, it generally indicates that the disease, whatever it may be, is of some standing. If no difference in size is perceptible, it suggests that it is recent.

A further knowledge of the state of the interior of the foot will be gained by feeling it all over, and comparing its temperature carefully at all parts with that of the sound one. Again, if one part is hotter than another, that symptom will at once draw attention and lead to more searching examination of the part indicated. In endeavouring to ascertain whether there is any abnormal heat in the foot or in any part of it, the whole hand, and not merely the tips of the fingers should be applied. Sometimes, although we may not be able to detect any abnormal heat in the foot, we may yet discover an extra fulness of the plantar arteries.

In all cases it must be a constant rule to remove the shoe. Each nail should be drawn separately, and special notice must be taken if the animal flinches at the withdrawal of any particular nail. The foot should afterwards be tapped or pinched all round. Pain, on the application of pressure or of concussion to any part, will lead us to examine that part inore minutely by paring it out. The seat of corn will of course be particularly examined. 


\section{Symptoms of various diseases in the Feet.}

Exc]uding from present consideration temporary causes, such as pricking, tight nailing, bruises to the sole, ete., most of the various diseases which affect the feet present certain special and peculiar symptoms. We shall very briefly note the chief peculiarities.

\section{Symptoms of Laminitis.}

Acute Laminitis, or Fever in the Feet, is at once indicated by great heat in the part, by throbbing of the plantar arteries, and by almost absolute inability of the horse to move. The animal stands with his hind legs drawn up under the body, in order to take the weight off the fore feet. If he is compelled to move, he plants the heels of these feet on the ground and brings the hind legs well forward. Great constitutional disturbance is also present.

Chronic Laminitis-the disease resulting from the acute attack-if severe, is indicated by a wide spreading-out of the erust, and by loss of the concave form of the sole, by wavy circular ridges in the hoof, by an abnormal degree of heat, by a concavity in the front of the wall, by a thickened and elevated condition of the toe and also by the aninual treading as much as possible on his heels in order to avoid giving pain to the sensitive lamina, which are the structures principally affected by the disease.

Subacute Laminitis, common in weak, brittle feet, presents the same symptoms, but in a modified degree. The examiner should carefully watch for any tendency on the part of the horse to plant the heels on the ground before the other parts of the feet.

Wavy circular ridges in the horn are often found in the feet of young horses at grass. In these cases, though they should be viewed with some suspicion, they frequently arise not from disease, but from accelerated or diminished growth of the horn at various times according to the moisture or otherwise of the pastures on which the animals are kept, and on other temporary causes. "Grass rings," as they are termed, differ from laminitis rings by being more regular in character. The latter spread more at the heels, and besides this are associated with other characteristic symptoms.

\section{Symptoms of Navicular disease.}

The symptoms of Navicular disease in confirmed cases are very peculiar. In the stable it is indicated by the horse standing either with his legs straight out and bearing his weight on his toe (the heel being raised off the ground); or by the fetlock being flexed, whilst the toe is drawn back and stuck into the ground. In action it is manifested by the animal treading chiefly on his toes, and consequently digging them in the ground. When the horse has been shod a week, the extra wear thus occasioned will have made itself perceptible on the toe of the shoe. The object of the horse in all these peculiar positions and motions is to avoid putting weight on the back part of the foot, which is the seat of the disease. 
In cases of long standing, the inside quarter of the foot will become straighter, and there will be small circular ridges on that part of the hoof. The horn of the sole will also be found to be increased in quantity, the sole will be more concave than natural, and the feet generally will be more upright, blocky and contracted. From saving of the back part of the foot and consequent absence of pressure on the frog, thrushes will probably make their appearance. Navicular disease may and very often does appear in good open feet, but gradually the above changes will take place. Tenderness will be evinced on the application of concussion to the heels, or at the point of the frog. A further test may be applied by bending up the foot and applying pressure by the thumb to the hollow of the heel. The seat of the disease will be nearly under the thumb.

The lameness is most apparent when the horse first comes out of the stable. It decreases with exercise. Nevertheless, on the day after severe work the horse will be more lame than usual, especially when going down hill. In doubtful cases, therefore, the animal should be subjected to strong work, and examined again after a night's rest.

\section{Symptoms of Ossified Cartilages.}

Ossified Cartilages, commonly called Side bones, are not uncommon in the fore feet, especially in underbred horses. They may occur, though but rarely, in the hind feet. They generally produce a want of elasticity in the tread rather than positive lameness. Their existence is easily detected by feeling the cartilages at each side of the heels. In health they are flexible, but in disease they become more or less ossified and inelastic. See also par. 634 .

\section{Symptoms of Thrush.}

This disease is generally perceptible both to the eyes and the nose. In cases of doubt it is advisable to pare off the outer coat of the frog, as extensive disease may exist under an apparently almost sound exterior.

Thrushes in an otherwise good foot will not cause a horse to go lame unless he happens to tread on a stone, or otherwise bruise the diseased structure.

\section{Symptoms of Canker.}

Canker is a fungoid disease of the sole, commencing generally at the point of the frog, but is not, as a rule, in any way connected with thrush. This fungoid growth exudes a thin, unhealthy discharge, and bursts upon the slightest exciting cause. In the latter stages this diseased condition is apparent enough.

\section{Symptoms of Corn.}

The seat of Corn is at the inner angle of the sole in the space bounded by the crust and its reduplication (the bars). The existence or otherwise of a Corn can always be at once detected by paring off the surface of the sole at the part indicated. See par. 1009 . 


\section{Chronic foot Lameness.}

As a general rule, a diseased foot is for obvious reasons hotter than a sound one; but in some cases of continued lameness and especially in navicular disease, the affected foot may be colder than the other. This peculiarity may be caused partly by the foot having been for a length of time saved or "favored" by the animal; and partly sometimes by the measures taken to reduce the inflammation existing in it. In such cases, however, of long continued disease or disuse the size and form of the foot is always affected; and any such structural alteration will lead us to regard with suspicion a symptom, viz. greater coolness, which otherwise would be indicative of health.

\section{Contraction.}

Contraction is not, as was formerly supposed, a disease in itself, but merely a result of disease or of disuse. This latter cause may, however, arise from circumstances, such as sprains of the tendons of the legs, which are not connected with any disease in the foot itself.

Although not primarily a disease, Contraction may, under certain circumstances become a diseased condition, which will assist in causing lameness.

Feet are not necessarily contracted, because they are small. Small feet are often a natural formation, especially in high bred horses. If the fore feet are small, reference should be made to the hind feet. If the latter are likewise small, we may regard the formation as natural. The objection or otherwise to small feet depends very much on the general conformation of the animal. In a light well bred horse small feet are very much in accordance with the other features of his frame; whilst on the other hand they would be incompatible with, and probably quite insufficient to sustain a large, heavy carcase. Brittle feet are very objectionable. The horn should be tough and sound.

Although as a general rule, the fact of one foot being smaller than the other should be viewed with great suspicion (and a remark should always be made on it by the examiner to an intending purchaser), yet it by no means follows that the horse must necessarily go lame on it. The contraction may have arisen from disuse, caused as mentioned above, by disease quite unconnected with the foot itself. Cases also frequently occur, in which the small foot remains sound and serviceable for years, even although at some previous period it may have been diseased.

\section{Influence of Conformation on the shape and size of the Feet.}

Conformation exercises a great influence on the shape and size of the feet and also on the diseases, to which they are subject. If the horse turns his toes out, the inner quarter will be straight and the horn on that side will be weak; whilst if he turns his toes in, the outer quarter will lose its circularity, and the inner quarter will become more circular. Oblique pasterns cause an open round foot, whilst short pasterns gene- 
rally produce strong upright heels. Highly bred horses have a tendency to small feet, whilst under bred animals generally have large feet. In examining a horse, due allowance should be made for these facts.

672. Temporary causes of Lameness.

Lameness is often caused by pricking, or by tight nailing or sometimes by a bruise of the sole. The seat of injury will be best detected by pinching the foot or tapping it with the hammer. A full examination with the drawing knife must be made of any part, which may appear unduly sensitive under the application of the above tests.

\section{2a. Treatment of diseases of the Foot.}

For the nature and the treatment of the diseases of the Foot, sce Chapter 65.

\section{CHAPTER 44.}

\section{SPRAINS OF TENDONS AND LIGAMENTS OF THE FORE-LEG.}

673. Nature of so-called Sprains. 674. Structure of Tendons and Ligaments. 675. Shortening of Tendons and Ligaments. 676. Duties of Flexor Tendons. 677. Duties and description of Ligaments. 678. Duties of the superior Sesamoideal or true Suspensory Ligament. 679. Duties of Extensor Tendons. 680. Symptoms indicating a sprain,-How to ascertain its seat. 681. Distinction in Symptoms between sprains of the Flexor Tendons, and sprains of the Metacarpal and superior Sesamoideal Ligaments. 682. Sprains of the Flexor Tendons. 683. Sprain of the Metacarpal Ligament. 684. Sprain of the superior Sesamoideal Ligament, commonly called the Suspensory Ligament. 685. Cases of doubt. 686. Treatment of Sprains of Tendons and Ligaments. 687. Detail of Treatment. 688. After-treatment. 689. Biniodide of Mercury. 690. Arnica. 691. Sprains of the Fetlock joint. 692. Injuries of Sheaths of Tendons and Ligaments. 693. To distinguish between sprain of the Sheath of a Tendon or Ligament, and sprain of the Tendon or Ligament itself. 694. Treatment of sprains of Sheaths. 695. Shoulder sprains. 696. Elbow lameness. 697. Rheumatic lameness. 698. Conclusion.

673. Nature of so-called Sprains.

Tendons and Ligaments are often said to be sprained; but the expression is not, as a general rule, strictly correct. Their formation renders such an injury of but rare occurrence. They are dense, firm, nearly 
inelastic, fibrous structures, almost incapable of extension except under strong persistent tension.

The injury, which usually occurs, is inflammation caused by violent usage. Occasionally some of the fibres of the tendon or ligament are ruptured. Cases have indeed occurred, in which these structures have been torn right across. In many cases, on the other hand, the tendon itself is not injured; but its synovial sheath only is sprained, or its bloodvessels may be injured or ruptured.

Among the public, any degree of injury from a slight increase of vascularity in the vessels of the part up to an absolute tear of the fibres right across goes by the common name of "sprain." Having made this explanation, we shall adhere to the ordinary nomenclature, and use the word "sprain" to express any injury short of absolute rupture.

\section{Structure of Tendons and Ligaments.}

Tendons and Ligaments are mairly composed of white fibrous tissue; but in ligaments the material is somewhat less closely put together than in tendons, and it is also intermixed with yellow elastic tissue. See Chapter 13, paragraph 234 .

A chief distinction between tendons and ligaments consists in their attachments. Tendons may be defined as the passive instruments of motion attaching muscles to bones. A tendon is inelastic or nearly so, and is merely the "rope" acted on by muscles, by means of which one bone is moved on another bone. Ligaments, on the other hand, are usually attached to bones at each end, and hold them together. The Metacarpal ligament, however, is inserted into the flexor perforans tendon.

\section{Shortening of Tendons and Ligaments.}

Though tendons and ligaments are never permanently lengthened by so-called sprains, yet they may nevertheless be, and frequently are, in chronic cases after a length of time, shortened by such injuries.

This result is produced partly by the deposit of material effused during the process of inflammation, between the fibres which in consequence are thickened and bowed out, and thereby practically shortened; and partly because the new material supplied for repair is not exactly the same as the tendon or ligament, but a fibro-cellular tissue, which during the healing process, has a peculiar tendency in itself to contract, and also to draw together the edges of the wounded surfaces and structures.

The standing over at the knees and fetlocks so often seen in horses, that have done much work, arises from shortening, induced by frequent sprains, and also from an altered condition of the articular ligaments of the joints.

\section{Duties of Flexor Tendons.}

The Flexor tendons, though exceedingly powerful, being three times as large as the extensors, are nevertheless very subject to sprain. Acted 
on by the muscles above, they are the passive agents or ropes, if we may use the expression, by which the leg is raised, whenever the horse is in motion. From the great stress thrown on them in these duties, we frequently find them sprained in all horses, and especially in those whose work takes place in deep ground. The Flexor tendons are marked A and $B$ in Plate 27.

The seat of sprain and consequent swelling is usually in the lower half towards the fetlock. The injury occurs more often here than in the upper portion, because that part derives strength and assistance from the Metacarpal ligament.

\section{Duties and description of Ligaments.}

The ligaments in the horse may be divided into Connective, Capsular, Amular, and Supporting or Suspensory.

Connective Ligaments unite the extrenities of bones.

Capsular Ligaments confine the joint oil secreted from glands on their internal surface which lubricates the opposing ends of bones.

Annular (or Ring-like) Ligaments bind down tendons that pass over joints for the production or regulation of progression.

Supporting or Suspensory Ligaments are, like the preceding ones, insensitive and do not need the periodical rest which sleep affords to muscles and other structures of higher vitality. They support to a very considerable extent the weight of the body.

\section{Duties of the superior Sesamoideal or true Suspensory Ligament.}

This is the prominent sinew felt through the skin between the cannon or great bone of the leg, and the flexor tendons. It is particularly to be noted that it lies under the flexor tendons (see Plate 27). It starts from the back and uppermost part of the cannon bone, occupying the space between the splint bones. It bifurcates, $i . e$. divides opposite the middle third of the cannon bone, one branch proceeding to the outer side of each sesamoid, with which and the lateral ligaments it is intimately blended, giving off a slip on each side, which proceed downwards and forwards, until inserted into the tendon of the extensor pedis.

We have termed this the true suspensory ligament, because if it be divided in its main trunk, the fetlock will at once come to the ground.

A great part of the weight of the horse is borne by it, when the foot comes to the ground. And on account of the great share which it has in sustaining weight, the suspensory ligament is often sprained, more often indeed than the neighbouring tendons. The swelling and soreness arising therefrom shows itself at the point of its occurrence, i.e. between the shank bone and the flexor tendons. (Please see third sentence, paragraph 684.) On account of its position under the flexor tendons, it is more difficult to apply treatment to it, than to the tendons, which lie over it. Hence it is more difficult of repair.

The superior sesamoideal ligament has the peculiarity of being comparatively elastic, and hence is useful in breaking or diminishing the con- 
cussion, which would otherwise arise from rapid violent motion. It is very liable to suffer from sprains arising from such causes; but more especially in race horses, whose feet in galloping come to the ground with great violence, and also in hunters on landing over fences.

This ligament may be strained in any part. After its division the inner, for obvious reasons, is more often strained than the outer branch. For symptoms of strain of the ligament, see paragraph 684 . For special treatment of severe strains of the ligament, see paragraph 687 , sentence 10.

\section{Duties of Extensor Tendons.}

The Extensor tendons (E) are seldom sprained, because their functions in progression are only secondary. They merely straighten and bring forward the leg, after it has been raised by the action of the flexors.

In the fore leg, we may mention that the Flexors are situated at the back, and the Extensors are in the front of the leg; but in the hind leg there is one Flexor and one Extensor in front, whilst there are two Flexors, one of which is accessory, at the back.

\section{Symptoms indicating a sprain,-How to ascertain its seat.}

We now suppose the reader to have found out by means of the rules given in the last Chapter but one, that the seat of lameness is somewhere in the tendons or ligaments of the fore-leg. We shall endeavour to give the signs, by which the exact position of the sprain may be ascertained.

The slightest sprain produces some lesion, however minute, and this of necessity causes inflammation,-needed indeed to repair the injury. We have, therefore, as a consequence, heat, tenderness, effusion, and lameness. The greater the injury, the greater are these symptoms. On the other hand, the lesion, though sufficient to cause pain and therefore lameness, may be very slight; or it may be deep seated, and the external appearances, though the injury be severe, may still be very slight. Again, in some, and especially in deep-seated sprains, the visible symptoms, on account of the part being closely bound down by other tendons and ligaments, may not appear exactly over the seat of the injury.

681. Distinction in symptoms between sprains of the Flexor Tendons, and sprains of the Metacarpal and superior Sesamoideal Ligaments.

Injury to either of the Flexor tendons is indicated, when the horse is in motion, by want of proper flexion of the knee. There is inability to flex and raise the leg, and consequently a tendency to drag the toe on the ground. But when standing still the horse keeps the knee slightly bent, so as to relax the tendons. In this position, he throws as little weight as possible on the injured part.

On the other hand, in sprains of either the Metacarpal or of the superior Sesamoideal ligament, the leg is raised freely enough, because the tendons, which perform that duty, are not affected; but pain and 
flinching are shown, when the foot comes to the ground, because then the weight comes suddenly on the injured ligament.

\section{Sprains of the Flexor Tendons.}

Assuming that the symptoms indicate that the seat of lameness is in the Flexor tendons, we must apply further tests to ascertain its exact seat.

There are, as the reader is aware, two Flexor tendons, one called the Perforatus, the other called the Perforans. Both originate from the muscles at the back of the leg; but the Perforans terminates at and is inserted into the coronet bone, whilst the Perforans passing through the Perforatus is continued down, and inserted into the inferior part of the coffin bone. Of these two tendons the perforatus is the rearmost and the perforans is the anterior.

Injury to the Perforatus (A, Plate $2 \overline{7}$ ) is indicated by a swelling or curve at the back of the leg, because it lies rearmost and therefore any swelling arising from inflammatory action finds room for expansion posteriorly. Injury to the Perforans (B) on the other hand is indicated by swelling on the sides, because, on account of the perforatus tendon in its rear, it cannot so easily. swell posteriorly. In most cases, however, we generally find both tendons are implicated.

Severe injuries of either of these tendons are easily seen and felt; but in slight cases, although some lameness may be apparent, there is often need of careful and delicate manipulation in order to detect the seat of injury.

Injuries are most easily detected by manipulation, either when the leg is held up and bent back, because in that position the tendons are relaxed and easily got between the fingers and felt; or else by picking up the other leg, when, the animal being compelled to stand on the injured leg, the tendons will be braced up, and any inequality in them will be more readily felt.

When the sound leg is released, it will be noticed that the horse will take the weight off the injured leg as soon as possible.

In either case, pain will be evinced, when pressure is brought to bear on the seat of injury.

\section{Sprain of Metacarpal ligament.}

The symptoms, which distinguish lameness arising from injury of the Metacarpal ligament, in contra-distinction to that caused by sprain of the Flexor tendons, were described in the latter part of the last paragraph but one.

The external signs, however, are not very perceptible. As this ligament (C) lies in front of the Flexor tendons, there is rarely any external swelling, except, and then only to a slight degree, laterally,-and there is but little perceptible heat.

Any injury to it, though not very visible to the eye, may, however, be detected in another way. As the material effused by the process of 
inflammation is in this case necessarily deposited and confined in the interior of the leg, it is certain that pain will be quickly evinced (if the ligament is really injured), when pressure is applied to the seat of injury. With this view the leg should be lifted up and bent back, until the foot nearly touches the knee. In this position the ligament will be most easily felt, because the tendons, which pass over it and bind it down, are then relaxed.

This ligament, it will be recollected, commences at the back of the knee, and is inserted into the Flexor perforans not quite half way between the knee and the fetlock. The seat of sprain is usually either in its upper half $(c)$, or at its junction with the flexor, rather than in the middle.

\section{Sprain of the superior Sesamoideal ligament, or true Suspensory ligament.}

The symptoms of lameness arising from sprain of the superior sesamoideal ligament are similar to those arising from sprain of the Metacarpal ligament.

This ligament (D) lies anterior to the Flexor tendons and to the metacarpal ligament. On this account external signs, though not altogether wanting, are not very apparent. The best mode of detecting any injury is to lift up the leg, and then when the tendons are relaxed, the ligament may be got between the fingers, and if there is any inflammation in it, pain will be evinced on the application of pressure, and some swelling and increased heat will be felt.

There is seldom much external swelling, because the ligament is elosely bound down by the tendons; but in severe cases some enlargement may be noticed on both sides, somewhat anterior to that which arises from injuries of the Flexor tendons. The seat of sprain is usually just above the bifurcation of the ligament. It will be recollected that this ligament commences at the back of the knee, and bifurcates $(d)$ a little above the pasterns, and is inserted into the sesamoid bones (Plate 27).

The branches $(y)$ of the ligament after its bifurcation are apt to be sprained, especially the inner branch. Here of course any injury is apparent to the eye. In old hunters, we often find that the fibres of these branches from repeated strains have become of a semi-cartilaginous nature, and in some instances have been partly converted into bone, and in consequence the parts feel hard and raised.

\section{Cases of doubt.}

In all cases of doubt, as to whether the heat and swelling in any particular case arise from injury of the tendon or ligament, or merely from injury to its sheath, or perhaps only from an ordinary blow or such like cause, the safer plan is to rest the horse and foment the part, until by rapid and complete disappearance of all symptoms of mischief we can be quite sure, that there neither is nor has been injury to any of those important and but slowly repaired structures. 


\section{Treatment of sprains of Tendons and Tigaments.}

From similarity of the cause producing the injury, and likewise from similarity of organisation and structure in all tendons and ligaments, the. treatment, which we are called upon to adopt, is in most cases nearly similar.

The skill of the Veterinary surgeon lies more in detecting the exact seat of injury than in the mode of treatment. The really important point is to determine rightly the part of the leg, to which the treatment ought to be applied. For instance, if a horse is lanre immediately under the knee from sprain of the metacarpal ligament, the treatment, whatever it may be, will obviously require to be applied to a different part than if the superior sesamoideal ligament were sprained near the fetlock. The most prominent symptom, namely flinching, when the leg comes to the ground and weight is suddenly thrown on it, is, it will be remembered, the same in both cases.

Many practitioners however get over this difficulty, and veil their ignorance by blistering, firing, or putting in setons all over the affected leg or legs, - on the ground, we presume, that if the remedy be applied sufficiently extensively, it must somewhere or other hit upon the injured part.

The practice is not only unworthy of an educated man, it is not only cruel ; but in part at least it fails in the attainment of its object. The inflammation excited over a very large surface is too diffused to exert as much influence on the injured part, as when its energy is concentrated on the spot which really needs repair.

We do not say that such treatment is altogether ineffectual. We know that many horses recover and become sound under it,- - though principally, we think, on account of the amount of time and rest which such treatment necessitates. But we do say, that treatment is more effectual, that the animal suffers less, and is sooner restored to work, when the remedy is applied only to the right place.

\section{Detail of Treatment.}

Premising then the necessity of ascertaining the real seat of the injury, we proceed to consider the nature of the treatment to be adopted. This will vary according to the degree, rather than according to the seat of the injury.

Rest, entire rest; and in severe injuries long-continued rest, is always the great desideratum. All treatment without this great natural restorative is useless. Much of the treatment, and indeed all the earlier remedies hereafter recommended, such as cold water bandages, fomentations, high-heeled shoes, and the withdrawal of corn, are but the means by which the part and the system may be placed most completely in a state of rest. In the later stages local stimulants or irritants, such as blisters and firing, which can be applied without removing the part out of a state of rest, may be needed and may be beneficial.

If the injury be slight, a few days' rest aided by the application of a 
cold water bandage to the part, will probably be sufficient to restore it to health.

If the injury be at all severe, our object will be in the first instance to reduce the inflammation. This will be best effected by rest and cold water bandage. Care must be taken, that the bandages are kept thoroughly wet throughout the day. At night the bandages should be taken off. The skin requires rest. The wet bandages should be continued by day, or a jet or hose may be used.

All corn must be withheld, and the horse prepared for physic which may be given or not according to circumstances. If the animal is in high condition, and especially if fever supervenes, it will probably be useful.

With the view of taking the weight off the injured part, a high-heeled or patten shoe should be applied. In some few very severe cases, it may be desirable to put the horse in slings.

As soon as the inflammation is reduced, we shall be able to judge more accurately of the degree of the injury. If it does not appear to be very severe, it is probable that a blister applied over and for some distance round the injured part may be sufficient to restore it to health. If, however, it is very severe, the more powerful remedies of setons or firing may be required in order to make the animal permanently upright.

The modus operandi of these remedies and their comparative advantages and disadvantages, have been already fully dwelt upon in the chapter on Irritants, No. 19 ; but the author does not hesitate again to express his preference for setons, especially in sprains of the Metacarpal or superior Sesamoideal ligament, where the parts are deep-seated.

Adhesion between the tendon and its sheath is a common result of a violent sprain. These structures may become cemented together by the lymph effused during the inflammatory process, if the surplus of that reparative material is not duly taken up and removed by the absorbents and blood-vessels during or after the process of restoration of the injured part. The adhesion causes an obstruction to the free play of the tendon in its sheath, and thereby produces lameness. The inconvenience is most felt when the horse first comes out of his stable, and becomes less when he has been some time at exercise. With a view of preventing this result, it is usual to blister the leg again towards the termination of the reparative process. In favorable cases the blood-vessels and absorbents, being by this means excited to renewed action at this stage, may be able to carry off the effused products of the previous stage. The callosities so often felt in tendons after severe sprains are generally due to the effect of adhesion.

In cases of very serious injuries, such as complete rupture of the Metacarpal or of the superior Sesamoideal ligament, it will be most merciful, and probably cheapest in the end, to destroy the animal at once.

\section{After-treatment.}

When complete restoration has been effected, the patient must be brought only very gradually into work. Even in those cases, where the treatment has been perfectly successful, it must be remembered that all 
tendons and ligaments, not merely the one which has been injured, but all are weak from want of exercise, and are therefore very susceptible of injury. Six months after a severe sprain may be named, as the shortest time at which the horse should again be put to strong exercise preparatory to such work as hunting. If the animal is wanted only for common riding or harness, a less period will suffice.

In "calloused" legs, i. e. sprains, in which the extraneous material has become hardened, great advantage will be derived from standing the horse in a stream of running water, and where the opportunity to do so occurs, advantage should always be taken of it. The new formation may also be further condensed and strengthened by bandages wet with a solution of Tidman's sea salt.

The high-heeled shoe recommended above must not be removed suddenly; but the artificial assistance so given to the tendon or ligament should be gradually reduced until perhaps at the end of one or two months, if the animal is sound, the ordinary shoe may be re-applied. At the same time it must be remembered that the high-heeled shoe must not be allowed to remain on too long, or a permanent shortening of the tendons may be the result.

When in the process of healing, a tendon or ligament has become shortened, it is advisable to apply a shoe with a lengthened toe-piece with the view of gradually counteracting the contraction by the increased stress thereby thrown on the part each time the animal moves. A horse so affected is, however, never likely to be worth much.

Gentle driving in double harness in a light four-wheeled carriage is, perhaps the best sort of exercise to precede regular work after any sprain of tendon or ligament. The danger to be apprehended from the use of a two-wheeled vehicle is that the weight will be thrown on the fore-hand, save in the case of Hansom cabs which are so slung as to hold up even a horse that has practically no fore-legs.

\section{Biniodide of Mercury.}

For slight strains, Biniodide of Mercury gives the best results. It is useful in creating a moderate amount of serous effusion when applied repeatedly; and, if necessary, in increased strength.

\section{Arnica.}

Arnica is a useful application in very slight sprains, and also in many cases which are mistaken for sprains.

It is said to have produced wonderful cures in a very short time, even in cases of severe pain. It is difficult to see how the process of repair, always tedious in parts of low organization,- - such as tendons and ligaments, and which therefore need the assistance of artificially excited inflammation, can be rapidly effected by an agent, whose speciality is the reduction of inflammation by virtue of its action as an astringent on the muscular coats of the blood-vessels. Arnica, however, it may be said, has a secondary action as a stimulant in some cases, by reason of 
its astringent properties. But as a stimulant it is very inferior to an ordinary blister.

We suspect, that, in all such wonderful cases of reputed cure, the symptoms have been mistaken, and that a swelling caused perhaps by the rupture of a few minute blood-vessels and extravasation of hlood under the skin, or by an ordinary blow produced by striking one leg against the other, has been mistaken, as it easily may be in the early stage, for inflammation caused by a real sprain. In most of such cases, we are inclined to think that a cold water application would have answered equally well.

\section{Sprains of the Fetlock Joint.}

The Fetlock joint is occasionally sprained from injury done to its ligamentous and tendinous connections. There is no special sign in the lameness resulting from the injury; but the part feels hot and tender. There is very little, if any, swelling. The treatment required is that usual for sprains.

Repeated sprains, after a time, will cause the tendons and ligaments about the joint to become hard and cartilaginous, and to feel almost like bone. Knuckling over behind and standing over in front are generally caused by sprains of these ligaments and tendons.

\section{Injuries of Sheaths of tendons and ligaments.}

The synovial Sheaths, which enclose all tendons and certain ligaments are subject to injury from the same causes as their tendons and ligaments. But inasmuch as they are less strong, they are more frequently injured. The injury, however, is not very serious, because the Sheaths are not themselves concerned in bearing weight. 'They are not the ropes, to revert to the expression used in the early part of this chapter, but merely the cases in which the ropes work. Again the Sheaths, which are all secreting organs, are more vascular than the dense, firm, fibrous tendons and ligaments which they enclose, and therefore they possess more vitality and more easily repair themselves when injured.

The signs of injury and the mode of detecting the exact seat are the same as those laid down above in regard to tendons and ligaments.

\section{To distinguish betueen sprain of a Sheath of a tendon or ligament, and sprain of the Tendon or Ligament itself.}

The distinction is marked. The swelling is more puffy and diffused than that which accompanies sprain of a tendon or ligament. On the application of pressure to the swelling the tendon or ligament may be felt through it. If the tendon or ligament is of normal size, we may conclude that the injury is confined to the sheath. Again in injuries of sheaths, the horse, though he will be lame at first, will go less tender after a little exercise ; whilst in sprains of tendons and ligaments, the lameness will increase. 


\section{Treatment of sprains of Sheaths.}

Rest and cold lotions will generally he sufficient to restore the parts in a few days. A chamois leather bandage, kept wet either with cold water or refrigerant lotion, will answer well. If such treatment is not effectual it is probable that the tendon or ligament is also implicated,--though the owner may have at first failed to detect the injury. If at seaside, it is a good plan to stand horses twice a day in the sea, as sea water followed by friction by hand-rubbing has a wonderfully recuperative effect on sprained limbs. Where this treatment is adopted, the hoofs should be smeared with Stockholm tar pretty often, as sea water renders the wall, or crust, very brittle.

\section{Shoulder Sprain.}

Obscure cases of lameness in the fore-hand are pretty generally ascribed to the shoulder. But as a matter of fact, the shoulder, except from outside violence, is very rarely the cause.

There are no articular ligaments to the joint, but the bones are held in apposition very firmly by capsular ligaments and muscles, and by the tendon of the muscles, which pass over it.

The point of the shoulder is sometimes injured by accidental causes, such as a blow, a kick, or a wound from a shaft, or from a fall in the act of turning. Such injuries are of course apparent. They may produce violent inflammation of the joint or of the tendon passing over the head of the humerus, or even fracture of the outer head of the bone.

\section{Elbow lameness.}

In Elbow lameness, the horse, when standing, will keep the affected limb pendulous, with the toe only dragging on the ground and drawn under the belly. In action the shoulder is brought well forward (and in this way it is plainly distinguished from shoulder lameness, as described in the preceding paragraph); but when the weight comes on the limb, a sudden giving way and knuckling over at the knee will be noticed. Pain will be evinced when the thumb is pressed close alongside the external lateral ligament of the joint, or at the point of the elbow.

Elbow lameness commonly arises from some injury to the point of the ulna, and occasionally from disease of the joint. The treatment is rest, fomentations, and blisters.

We may remark in passing, that both shoulder and elbow lameness are very rare, though it is common enough to assign to one or other of these causes, most of those cases of lameness in which the real seat of the disease cannot be discovered.

\section{Rheumatic Lameness.}

The Lameness caused by sprain is sometimes very closely simulated, both in tendons and their sheaths and also in ligaments, by that arising from Rheumatism. The means by which the latter may be distinguished 
from the former, have been already explained in Chapter No. 27 on Rheumatism.

\section{Conclusion.}

Tendons and Ligaments, even though but slightly sprained, generally show some trace, and if at all severely sprained, always show considerable trace of the injury, ever after in the way of thickening or shortening. In other words, the products of the original inflammatory action in the part are never completely taken up and removed by the absorbents and bloodvessels, even though the tendon or ligament may be thoroughly repaired and as strong as it ever was. Time and the application of very mild blisters repeated three or four times after recovery, may do much towards removing any such thickening, but still some trace of it will remain. With decrease of the thickening, the apparent shortening will diminish.

Whether a horse with a thickened or contracted tendon or ligament is to be accounted "sound" in the strict sense of the word, supposing of course that no trace of lameness results, is perhaps doubtful. For practical purposes this, like most other questions, is one of degree,-depending first on the amount of injury in each case, secondly on the conformation of the animal and the probability of the recurrence of the lesion as indicated by his make and shape, thirdly on the age, and lastly on the sort of work on which it is intended to employ the horse.

If, for instance, there are indications of a sprain having at some previous time occurred in one of the flexor tendons, and the intending purchaser notices that the horse is long from the knee to the fetlock, he will do well in such case not to conclude the bargain, because the chances are that with such conformation the injury will recur if the animal is put to severe work. On the other hand, if the horse is young and the conformation is good, and if the intending purchaser can afford to lay him up for some time, the probability is that, with the amount of strength gained by increasing age and rest, the injury will not recur; or if the horse is old, and it can be ascertained that he stood sound for a season's hunting since the occurrence of the sprain, a purchase might safely be made. Something, however, would of course in either case be knocked off the price.

Again, much must depend on the price asked, and the use for which the animal is required. A horse may stand sound for hunting, whose legs will not stand training; or another horse may last for years in harness, which would knock up in a single day's hunting. 
CHAPTER 45.

SPRAINS OF TENDONS AND LIGAMENTS OF THE HIND LEG.

699. Sprains of the Hock. 700. Sprain of the Articular ligaments of the hock joint. 701. Treatment. 702. Curb. 703. Treatment. 704. Capped hock. 705. Treatment. 706. Sprains of the ligaments of the Femur. 707. Sprain of the ligaments of, and displacement of the Patella. 708. Sprains of the Fetlock Joint. 709. Sprains of the Loins.

\section{Sprains of the Hock.}

Whilst in the fore-leg the seat of sprain is usually in the tendons or ligaments between the knee and the fetlock, -in the hind leg it is usually in the Hock. The functions of the hock in progression, and the kind of conformation which predisposes to disease, were explained in the Chapters 37 and 38. From the very severe duties which devolve on the hock, we cannot be much surprised that it should be pretty frequently the seat of sprain. See Plates 22, 23, and 24.

\section{Sprain of the articular ligaments of the Hock joint.}

The seat of sprain in the hock is usually in the ligaments, which bind together the various bones of the true and subsidiary joints of the structure. These ligaments, as we might expect in a structure combining so many bones, are numerous. Any one or more may be sprained; or any portion of any of the ligaments may be affected. See Plate 28.

The tendons, which commence at the end of the large muscles of the hind quarters and pass over the hock, are seldom sprained-though such an accident may occur.

\section{Treatment.}

The particular part which is sprained is indicated by heat and swelling and to that part the remedies recommended for sprains in the previous Chapter must, according to the degree and circumstance of each case, be applied.

Very considerable swelling frequently accompanies sprains of the ligaments of the hock; but in all such cases the greater part of the swelling is always due to irritation of the various bursæ of the different parts of the structure, rather than to the inflammation of the sprained ligament itself. These bursal enlargements are, however, in most cases only temporary, and yield to the same treatment as that employed to reduce the inflammation which accompanies the sprain. Should they not do so, a blister may be applied over the part. The detailed treatment of bursal enlargements will be found in Chapter 41. 


\section{Curb.}

Curb may be a sprain of the ligament which connects the os calcis with the cuboid and external metatarsal bones; or it may be sprain of the broad annular (calcaneo-metatarsal) ligament, which passes over and hinds down the tendons in their passage down the back of the hock.

Curb is easily recognised by a protuberance at the back of the hock about five inches below its upper point (A, Plate 29). The examiner should stand exactly at right angles to the line of the back of the leg, when any deviation from the perpendicular line cannot fail to be noticed. If he stands more anteriorly, he may mistake the prominence of one of the bones for Curb; whilst if he stands more to the rear, he may fail to notice the deviation from the straight line.

Over-bent or "sickle-shaped" hocks, and small hocks, are peculiarly liable to Curh.

\section{Treatment of Curb.}

The treatment is the same as that required for any other sprain. The lameness usually subsides as soon as the inflammation is reduced. The strain of the ligament will be lessened by the application of a high-heeled shoe.

Strange as it may seem, the patient, if an aged horse, may generally be put to work again in from ten days to three weeks. But when the sprain occurs in a young horse, whose bones and ligaments are not yet fully grown and developed, rest for a lengthened period is always needed. Nature must be allowed time to strengthen and derelop those structures, which the occurrence of a sprain, such as a curb, have shown not to be equal to what has been required of them. Unless time is given, the ailment will probably recur as soon as the horse is again put to work.

It is seldom advisable either in an old or young horse to resort to any severe treatment in the first instance; but if the lameness recurs, as is frequently the case, when the animal is put to work, it will be advisable to apply ointment of biniodide of mercury, or equal parts of iodine and cantharides ointment to the part; and in some cases ultimately it may be necessary to have recourse to firing in order to produce a permanent cure.

\section{Capped Hock.}

Capped Hock may be simply a serous effusion under the skin at the point of the hock; or the above may be accompanied by thickening of the integuments and inflammation of the bursa, and by deposit of coagulable lymph.

The injury is usually caused by kicking in the stable or in harness. Some horses, however, contrive to injure themselves in the act of lying down or getting up.

In rare cases the enlargement may arise from rupture of the lateral attachment of the perforatus tendon at the apex of the os calcis. The injury will be recognised by a flattened appearance of the point of the 
hock, when the limb is in a state of rest;--which, however, disappears when the hock is flexed.

\section{Treatment.}

The best treatment is to leave it alone. It generally produces no serious effect; but it is unsightly and difficult to get rid of, both because the causes which produce it are apt to recur, and also because active treatment, such as blistering, creates an amount of irritation, which increases the tendency to kick. Treatment by pressure, which would be very beneficial, is difficult to apply to the part.

If it is desired to try active treatment, Biniodide of Mercury should be employed instead of cantharides, as less liable to cause irritation and kicking.

Cases of rupture of the lateral attachments of the perforatus tendon at the apex of the hock, must be treated as recommended for sprains.

In very rare cases, the horse by violent kicking may injure the point of the bone, and caries may supervene, which will render the animal useless.

\section{Sprain of the ligaments of the Femur.}

Sprains of the ligaments of the Femur occur occasionally from any sudden violent exertion or from slipping-up in the stable.

When the injury occurs at the upper end, where the femur articulates with the acetabulum, there is no external sign, for the parts are deepseated ; and the existence of a sprain can only be surmised by the animal straddling and slightly dragging the leg. In such cases rest is the only treatment, for no external topical remedies will reach the parts affected.

At the other, or lower end the ligaments, which really appertain to the femur, are seldom sprained. The external signs, when an injury does occur, are heat, swelling, and tenderness in the part; and the treatment is the same as that which has been already recommended for sprains. Rest, however, in this, as in other cases, is the yreat essential.

\section{Sprain of the ligaments of, and displacement of the Patella.}

Sprain of the ligaments, when the patella is not displaced, is indicated by swelling and heat accompanied with tenderness. In action, the horse carries his leg round instead of raising it properly. The treatment is that usual for sprains.

Displacement of the patella is indicated by the foot being flexed back on the pastern bone, by the hock being straightened, and by inability to advance the leg. If any attempt is made to compel the animil to do so, the pain will be excruciating. The displacement is generally to the outer, and not to the inner side.

Dislocation is most apt to occur in young horses, whose tendons and ligaments have not yet acquired their full strength. It is also sometimes occasioned by undue uprightness of the femur, on account of which the patella slips over the outer condyle of the femur. 
If pushed back, the patella will often slip again into its place. If it does not do so, a rope must be secured round the pastern, and the leg must then be drawn forward by one assistant, whilst another presses on the outer and upper part of the patella, and pushes it in an inward and forward direction.

Its replacement will be indicated by a sudden snap. It will sometimes be found that, as soon as the hand is removed after replacing the bone, it slips out again. When such is the case, the operator should continue his pressure on the part for an hour or longer. The horse must be restrained from lying down for two or three days, and a mild vesicant may be applied to produce soreness of the skin, and thus prevent the animal from moving the leg.

When the patella has once been displaced, there is a tendency for the accident to recur. again and again. In such cases it will be necessary to blister over the part. The effusion and thickening thus produced may exercise, as it were, persistent pressure on the part.

The stifle joint is also subject to general inflammation of its synovial membrane from the effect of injuries.

\section{Sprains of the Fetlock joint.}

The injury is much the same as that which occurs in the similar joint in the fore-leg, mentioned in paragraph 691 in the preceding chapter, and the causes are usually the same. It may, however, arise from repeated sprains of the flexor tendons which pass over the joint.

Knuckling over behind, as distinguished from sprain of the joint, is most frequently caused by spavin, or some other such cause which interferes with the due flexion of the hock ; or excessive work while the tissues are immature.

\section{Sprains of the Loins.}

This injury consists of sprains of the ligaments connecting the dorsal and lumbar vertebræ, or it may be sprain of the psoæ muscles.

Horses so affected roll in their hind quarters and have not proper control over the muscles. The injury generally occurs very suddenly, and is the result of some violent over-exertion. The treatment is long rest and repeated blisters. Adhesive plasters, commonly called charges, have been found beneficial, especially when recovering.

The chance of recovery is very uncertain. If the injury is at all severe, the better plan is to destroy the animal. If the injury is very slight, the animal may move pretty well in a straight direction; but the injury will be detected when the horse is backed or turned round. This trial should never be omitted in the examination of a horse as to soundness. 


\section{CHAPTER 46.}

\section{POLL EVIL AND FISTULOUS WI'IHERS.}

710. Poll Evil. Nature, seat, and causes. 711. Peculiarities arising from the position of the injury. 712. Treatment. 713. Fistulous Withers. Nature, causes, and treatment.

\section{Nature, seat, and causes.}

Poll Evil, as its name imports, occurs on the top of the head, just posterior to the ears. In its earliest stage it is simply a swelling, caused usually by the pressure of the head collar, or sometimes by an accidental blow, such as that which a horse may give himself, especially if frightened, on entering or quitting a stable through a low doorway.

If the cause, whether it be pressure or a blow, be continued or repeated, inflammation will probably set in. As a result of the inflammatory action, the wound or injury frequently suppurates, and after a time abscesses will probably form.

\section{Peculiarities arising from the position of the injury.}

From the peculiar position of the injury, the matter has no depending orifice; and hence it generally happens that, unless artificial assistance by free incision is given for the escape of the matter, it will burrow downwards among and under the ligaments which support the head. Among these it is apt to form large and deep sinuses and fistulæ.

These sinuses often extend down to the bone. The offensive smell of the matter contained in them will indicate this extension. If the matter is suffered to remain long in contact with the bone, it will probably cause caries in that tissue.

\section{Treatment.}

With moderate care and attention, no case of real poll evil ought ever to occur. Timely removal of the exciting cause will always check and prevent its development.

When, however, the disease by neglect and long-continued recurrence of the cause has been suffered to develop itself, the treatment consists in laying the part open with the knife, so as to aftord a depending orifice for the matter.

When the injury is deep seated, it is good practice to assist the escape of the matter by inserting a seton through the sinus, with a view of affording it a depending orifice. The wound itself will require to be treated with a solution of sulphate of zinc in order to excite the parts to increased action, and thus promote the healing process. The best treat- 
ment, however, if in the hands of a competent Veterinary Surgeon, is the knife.

Whatever the treatment may be, if sinuses have formed in different directions (which may be ascertained by the probe), each sinus must be laid open, as far as practicable, from its bottom by the knife, and treated as recommended above. But if the sinuses have been in existence a long time and have become lined with a very low organised membrane, otherwise termed the "core," it may become necessary to cause sloughing of this membrane by the application of a stronger remedy, such as the powder of chloride of zinc, whilst the more external parts may be treated with lunar caustic. A radical cure will not be effected in a sinus so lined, until the core is got rid of.

Great care must be taken to keep the wound open, until it has thoroughly healed from the bottom; and for this purpose it will be necessary to insert into it a pledget of tow covered with digestive ointment. As the ligamentous tissues, among which the sinuses form, are of very low reparative power, the process of cure is generally very tedious.

When the wound is well, great care must be taken to guard against recurrence of the causes which produced it.

In cases, which have been long neglected, caries of the bone occasionally supervenes. From its position and from other causes, this further development is so difficult to treat, and the process of cure is so tedious and uncertain, that the better plan, in the author's opinion, is to accept the loss and to destroy the animal.

\section{FISTULOUS WITHERS.}

\section{Nature, causes, and treatment.}

Fistulous Withers are similar in their nature, and require much the same treatment as Poll Evil. They are nearly always caused by pressure from the saddle, or collar, or by injuries.

In most cases the mischief is at first very slight, and a day or two's alstinence from work with a little alteration of the saddle or collar will generally effect a cure and prevent recurrence. If the skin is tender, a salt and water dressing may be applied.

When, however, the cause is continued or repeated, the tissues under the skin become inflamed, and the spines of the vertebra may be implicated. If such should be the case, fomentations must be applied in the first instance to reduce the inflammation. If these fail, as they often do, in bringing about resolution, matter will probably form under the skin.

Unless a free opening is made for its escape, it will burrow in, under, and among the muscles, tendons, and ligamentous tissues which lie on each side of the spine or withers, and will form sinuses. The treatment in such cases is exactly the same as that of poll evil. The sinuses must be freely opened into a common wound, leaving a depending orifice, if possible. The seton, as recommended above, also answers very well. Carbolic dressings may be applied and the parts must be kept scrupulously clean. 
Caries of the spinous processes of the hones of the rertebra occasionally supervenes. It will be indicated by the offensive smell proceedingr from the sinuses. Unlike the similar occurrence in poll evil, this further development is easily treated; and a radical cure without any injurious result may generally be effected by removing the injured portions of the bone by the bone forceps. The parts, as a general rule, heal over favorably, and nothing more than a slight hollow will be noticed about the withers.

\section{CHAPTER 47.}

\section{OPEN JOINT.}

714. Three sorts of joints. 715. Synovial Joints. 716. True open Joint. 717. Brolien knee. 718. Chief danger in open Joint. 719. Treatment. 720. After-treatment. 722. Old method of treatment. 723. Amount of blemish resulting from Brolien Knee. 724. Wounds or bruises of the Knce not producing open Joint. 725. Injuries of Sheaths of Tendons and Ligaments. 726. Wounds of the Hock Joint. 727. Wounds of the Navicular Joint. 728. Wounds of the Fetlock Joint. 729. Wounds of the Elbow and Shoulder Joint. 730. Wounds of the Stifle Joint.

\section{Three sorts of Joints.}

A joint is the apposition of two or more bones, however united. There are three sorts of joints, namely, 1st. Those which are immoveable, being united together by sutures. Of this class is the union of the bones of the cranium or skull. 2nd. Those in which there is a limited amount of motion, being united by symphysis, but without synovia. Of this class are the pubis and the bodies of the vertebræ. 3rd. Synovial joints united together by ligaments, in which there is full motion. Of this class are the knee and the hock.

\section{Synovial Joints.}

In synovial joints the bones are protected from friction against each other by being tipped by cartilage. The joint itself is enclosed by a sac, technically called a capsular ligament. The inner surface of this sac is lined with a serous covering called synovial membrane, which secretes a clear viscid fluid for the lubrication of the joint.

The bones are kept in apposition, and in fact the joint is maintained by ligaments attached to eminences of the respective bones.

Besides the ligaments properly pertaining to the joint, it often happens that it is strengthened by the passage over it of the large and long 
tendons belonging to the muscles. For instance in the knee, the extensor metacarpi tendon runs over the anterior portion of the joint. These tendons, it is necessary to hear in mind, are furnished with synovial sheaths.

\section{True open Joint.}

True open joint is always marked by the emission of synovia, more commonly called joint oil, from the wound.

It does not however follow, that the joint is really laid open, because there is an emission of synovia from the wound. Synovia, though in less quantity, will be emitted, if the sheath of any tendon, which passes over the joint, is cut through.

If the synovia proceeds only from the sheath of a tendon, the case will probably be neither very serious nor very tedious. If on the other hand the joint is laid open, there is more danger. It is never advisable to explore the wound. Much more injury than good generally results from any such over-anxiety to ascertain the extent of the injury.

All synovial joints are liable to be laid open by external injuries; but the knee for various reasons, which will readily occur to the reader, is far more apt to suffer than any other joint. Principally for this reason, the author proposes to dwell somewhat fully on injuries of the knee, and but slightly on injuries of other true joints. The general principles of treatment are much the same, whichever be the joint injured. The minor differences, arising from difference in position of the various joints, and from the nature of the injuries to which thcy are respectively most liable, will be noticed hereafter.

\section{Broken knee.}

Broken knee is a term used somewhat indiscriminately by the public to express any injury of the knee, whether it be a mere abrasion of the skin, or hair, or a more serious injury, or the true joint be laid open.

We have spoken of the knee hitherto as a true joint, but in reality it consists of three true joints. The different layers of bones form three distinct articulations. Each layer or apposition of bones is furnished with its own capsular ligament. A wound perforating the so-called joint may occur in any of these articulations. Practically, however, we find, that it generally occurs in either of the upper articulations and but rarely in the lowest one.

Non-professional men are apt to think, that the injury occurs in the lowest articulation, because the exterior wound generally appears to be low down. This, however, is caused by a difference in the position of the skin, when the knee is bent and when it is straightened. It is the upper part of the knee, which usually comes in contact with the ground.

The knee, we may remark, corresponds anatomically with the wrist, not with the knee in the human subject. 


\section{Chief danger in open Joint.}

The chief danger in open joint arises from the excessive pain, which is caused by exposure of the synovial membrane to the air. Hence arise fever and constitutional disturbance. In some cases the whole of the membrane may become inflamed, and then the synovial fluid will be altered in character. The ends of the bones may also become inflamed, and abrasion of the articular cartilages, which tip them, may take place. Hence again will arise increased irritability and inflarnmation. Bones, though nearly insensitive in health, are in common with all parts which have no power of swelling, exceedingly sensitive under inflammation.

Violent inflammation in the joint, if continued, will ultimately destroy the articular cartilages, and the bones themselves will then come in contact. In such cases the pain and constitutional disturbance is so great, that either death soon puts an end to the sufferings of the animal, or nature throws out a mass of bone, which causes anchylosis, or stiff joint. The pain ceases when this latter process is completed, but the animal is useless or nearly so.

The supervening of inflammation in excess in the interior is not, however, a necessary consequence, even though the joint may remain open for some days. In healthy subjects with judicious treatment joints have been known to remain open upwards of a week without any such occurrence, and have ultimately healed up satisfactorily.

A favorable opinion may indeed always be entertained of any case, unless or until such inflammation sets in. But when this occurs, the chances of a successful result are very doubtful.

Again, the process of suppuration or formation of pus always supervenes on any considerable amount of inflammation in the part. When this process has once commenced, there is no use in trying to heal the wound by closing the orifice and thereby excluding the air; because pus once formed must have an exit, and, if debarred from it in one place, will make it in other.

\section{Treatment.}

The treatment divides itself into two heads, namely, that of the constitutional disturbance, and that of the local injury.

The first named will be best treated by perfect rest, deprivation of all corn, laxative diet, abundance of fresh air, and by the administration, as soon as the horse is properly prepared, of a mild dose of aloes. Physio in full quantities is apt to produce superpurgation on account of the general irritability of the system.

The treatment of the local injury consists primarily in washing the wound clean. There is no need or advantage in probing it or in attempting to remove every particle of gravel from the interior. Nature by her own processes, and with less irritation to the patient than by the use of any mechanical means, will speedily eject any foreign bodies which may have lodged deeply in the wound. 
Cold water will he useful in assisting the above action for the first twenty-four hours; but should not he continued longer.

The next and nost essential point in treatment is rest, that is, entire absence of motion in the injured part. In the human subject this is easily secured by putting the patient on his back in bed and affixing splints on the injured leg. But in the horse the first of these remedies is not in any degree, and the second is only partially available.

Slings, under very careful management, are useful in giving rest to the patient. They require however great care and some skill in their adjustment, and generally need some little alteration at least once or twice a day. On the one hand the ropes are apt to stretch, and on the other hand the skin often becomes galled in parts from undue pressure. If the patient is turned round in his stall, care must be taken to raise the feeding-box to the level of his head.

Such mishaps ought not to occur.

It is generally recommended to reverse the horse in his stall, both to prevent the chance of his rubbing or knocking his knce against the manger, and also to enable the wound to be examined in good light without disturbing him by turning round.

Some very good horsemen, however, think all this a mistake, and that the patient will be more comfortable by standing in his usual way. The wound does not require much, if any, treatment. If the patient paws about, of course, he must be turned round; but such misbehaviour is not common. Of course the horse must be secured against lying down, and a cradle should be put round his neck so as to hinder his biting the wound; and if he is not turned round in his stall, the edge of the manger should be guarded against by an old sack filled with hay.

The bed should be made level, so that the patient may stand as easily and naturally as possible. If the patient is irritable and knocks about, it is as well to administer some slight doses of opium.

As regards the actual wound, our object is to exclude the air as speedily as possible from the interior of the joint. This will be best effected by placing over the wound a fold of lint kept constantly wet with cold water day and night, and secured lightly both above and below, but in no respect approaching a bandage. The india-rubber apparatus mentioned in par. 265 may be used with good effect. In two or three days' time the cold water dressing may be changed to white lotion, which has a slight astringent effect. If a more astringent action is afterwards desired, a powder made of one ounce of sulphate of copper to a pound of flour may be lightly dusted over the wound with the view of inducing coagulation of the synovia round its edges and assisting in the formation of a scab, which may exclude the air. The clot of synovia, which often forms on the edges of the wound, should not be removed. The wound, however, must heal as all wounds must do, from the bottom by the ordinary processes of nature, that is, by outgrowth of the surrounding parts. As soon as the wound is closed, the recovery is usually rapid.

If the opening into the joint is sinall and the wound is not much lacerated, and if the case is treated before any inflammation has set in, it is 
in greneral safe to attempt to heal it at once by the application of melted shellac and finest tow.

In cases of simple puncture the wound may sometimes be closed at once and induced to heal before any irritation or inflammation sets in by applying over it a bandage or packing of tow or by the insertion of a suture. A light blister round the part will also be useful.

If a case of open joint takes an unfavorable turn, if the inflammation extends to the interior of the joint, if pus begins to be discharged from the wound, and signs of great constitutional disturbance are apparent,treatment will probably be of but little avail. It is useless to attempt to block up under such circumstances the flow of synovia and pus. If we do so, the result will inevitably be increased pain and irritation and the formation of abscesses. The only possible treatment in such ease is to endeavour to reduce the inflammation by constant cold applications. A favorable result can, however, hardly be expected, and the more merciful course is to destroy the patient.

Another very favorite method of treatment is by means of the carbolic spray. One part of earbolic acid is diluted with forty parts of water, and by means of an ingenious little instrument the spray is applied. This should be used several times daily, and in the intervals the part should be covered with lint soaked in the carbolic acid lotion.

Cases of open joint, if promptly, judiciously, and carefully treated, as a rule terminate favorably; but if they are neglected or wrongly treated, there is reason to fear that the inflammation and constitutional disturbance may be so great and extensive as to produce an exostosis in the part, and anchylosis or stiff joint may be the result, or the patient may sink under the pain and irritation.

Some very bad cases occasionally arise from wounds, which though they do not at first penetrate the joint, yet afteruards from the effect of sloughing extend into it. Such after-development, we may broadly say, always arises from improper treatment. If a proper opening is not maintained for the escape of the pus, it may (though in most cases it will make inl exit for itself in some external part) burrow inwards and eventually cause sloughing of the capsular ligament of the joint. The system of tight bandages frequently adopted has a tendency to produce this result, or it may arise from a scab being allowed too early to form over the wound. This latter effect is generally caused by the use of strong astringents. It cannot be too often impressed on the reader, that all lacerated wounds, whether at the knee or elsewhere, can only heal permanently and safely from the bottom. In other cases the tendency on the part of the wound to slough may arise from general debility of the systern of the patient, or from the use of unduly depleting remedies, or more often from both causes combined.

The first point to be attended to in such after-development is to gire a free exit to the pus. Fomentations will be needed for some time to reduce the violent irritation and inflamination, whieh is certain to have resulted from this increase of the mischief. As soon as the inflammation is reduced, the further treatment will be the same as recommended above. 
But the difficulty of cure is very great, because the process of sloughing through the capsular ligament and the surrounding parts must have greatly weakened their reparative powers. A favorable result can hardly be looked for.

\section{After-treatment.}

As soon as possible after convalescence, a little quiet led exercise should be given twice a day; because all joints from disuse, even in health, but especially in disease, are liable to become stiff. Some interval, however, must be permitted to elapse before the horse is again put to work, in order to allow. time for the parts to regain their strength.

Repeated mild blisters are often beneficial and in some cases necessary, to excite the action of the absorbents, to remove any thickening of the parts, which may interfere with the proper motion of the joint. Towards the end of the healing process, the superabundant granulations, which often form round the wound, may require to be cut off with the knife.

\section{Old Method of treatment.}

The old Veterinarians were in the habit of plugging up the wound with wheaten or some such paste, or of applying strong astringents such as sulphate of copper to the part. These remedies are, however, too violent. We cannot heal a wound by art,-we can only assist nature to do so.

\section{Amount of blemish resulting from Broken Knee.}

The amount of blemish resulting from Broken knec will depend on the severity of the injury and on the treatment adopted. If the injury be confined to mere abrasion of the skin, no mark ought to be left. If the skin is cut through, some mark will certainly be apparent, either in displacement of the natural lay of the hair, or in the appearance of white hairs, or in the absence of hair. If the joint be laid open, the blemish will probably be considerable. A light blister over the part offers the best chance of stimulating the growth of the hair; but if the injury has destroyed the roots of the hair, or if any portion of the skin has sloughed away, we nced scarcely say that no treatment will reproduce hair.

\section{Wounds or bruises of the lnee not producing open joint.}

When a horse falls on and injures his knees, it is always advisable, even though the joint may not be laid open, to throw the animal out of work for a few days and to foment his knees. There must be more or less stiffness in the part, which will not be got rid of for some days. If such reasonable precautions are neglected, the owner may not improbably pay the penalty by the horse falling down again, when he goes to work.

\section{Injuries of Sheaths of tendons and ligaments.}

When the Sheath only of a tendon or ligament is injured, the case is less serious, and the wound is in general easily closed and healed. The treatment, however, is the same as that recommended for open joint. 


\section{Wounds of the Hock Joint.}

Next to the knee, the Hock joint is most often injured. From its great extent, injuries of this joint are even more formidable than those of the knee. The general principles of treatment are the same as those recommended for the knee. As, however, the hock cannot be bandaged it clearly cannot be treated on the system of bandages advocated by some Veterinarians for the knee. The patient must of course, be prevented from lying down.

A large proportion of cases of open Hock joint arise from punctures, often caused by the pitchfork, and sometimes by the calkin of the hind shoe of another horse. These, if taken in time, before inflammation has set in, may often, as in similar injuries of the knee, be best treated by the application of collodion or some such pledget or by a suture.

The results of neglect or improper treatment are the same as in the knee, namely violent inflammation and constitutional disturbance, followed probably by either anchylosis, or by death.

\section{Wounds of the Navicular Joint.}

Wounds of the Navicular joint are very rare. They are always punctures arising from a nail running through the Frog or Commissure. If the injury is detected at once, it may be healed by first intention.

If, however, this treatment is not completely successful from the very first, the seat of injury and a very wide circle round $i$. should at once be cleared out, so as to give the freest exit to the joint oil and any product of inflammation which may probably occur.

If this exit is kept open, until nature gradually closes the wound, there is good hope of complete recovery. Nothing further can be done.

\section{Wounds of the Fetlock joint.}

Wounds of the Fetlock joint need the same treatment as those of the knee. As the joint, however, is comparatively small, and there is not much motion in it, these injuries are more amenable to treatment than those of the knee or hock.

\section{Wounds of the Elbow and Shoulder joint.}

The Elbow and Shoulder joint is sometimes, though but rarely penetrated. The wound, which has been generally caused by a shaft or some such injury, is usually of a contused and lacerated character. The flesh wound must be treated as recommended in the succeeding Chapter on Flesh Wounds, whilst that of the joint will need the same treatment as open joint at the knee.

730. Wounds of the Stifle juint.

These are genierally caused by kicks. It is of course inpossible to bandage the part. The treatment is the same as that recommended for the knee. 
CHAP'TER 48.

\section{FLESH WOUNDS.}

731. Definition of a Flesh Wound. 732. Classes of Flesh Wounds. 733. Modes of Healing. 734. Healing by Direct Union. 735. Healing by adhesion, commonly called the First Intention. 736. Healing by Cicatrization or Scabbing. 737. Healing by Granulations. 738. MIode of formation of Granulations. 739. Combination of modes of Union. 740. Recapitulation. 741. Cleansing of Wounds. 742. Stoppage of Hæmorrhage. 743. Dressing for Wounds capable of being healed by Direct Union. 744. Dressing for Wounds intended to be healed by Adhesion. 715. Dressing for Wounds intended to be healed by Granulations. 746. Wounds, healing by Granulations, to fill up from the bottom. 747. Indolent Wounds. 748. Excessive Granulations. 749. Sloughing. 750. Rest. 751. Sutures, Bandages, \&c. 752. Cicatrix. 753. Constitutional effects. 754. Treatment of Incised Wounds. 755. Treatment of Lacerated Wounds. 756. Treatment of Contused Wounds. 757. Treatment of Punctured Wounds. 758. Poisoned and Gunshot Wounds. 758a. Blemishes from Wounds.

\section{Definition of a Flesh Wound.}

A Flesi Wound is a solution of continuity in suft parts, suddenly produced by violence.

\section{Classes of F'lesh Wounds.}

Flesh Wounds may be divided into six classes, namely 1st, Incised, Znd, Lacernted, 3rd, Punctured, 4th, Contused, 5th, Poisoned, and 6th, Gun-shot.

\section{Modes. of Healing.}

Wounds are healed either 1st, by Direct union, or 2ndly, by Adhesion, otherwise called the First Intention, or 3rd, by Cicatrization, vulgarly called Scabbing, or 4 th, by Granulations.

\section{4. 'Healing by Direct Union.}

Direct union, or the direct and inmediate growing together of the opposite surfaces is the most favorable mode of healing; and therefore it should, if possible, be brought about. It is however only obtainable in incised wounds, and even then only under very favorable circunstances.

It is necessary, that we should be able to check the bleeding, to remove all foreign bodies, to bring the divided parts together in their natural 
position, and further, to retain them in union. There must also be entire absence of inflammation. The surface of the wound must be excluded from the air, and cold must be applied to prevent the setting in of inflammation. If these conditions are attainable, direct or immediate union may probably be procured, if in addition the constitution of the animal be good.

\section{Healing by Adhesion, commonly called the First Intention.}

The 2nd mode of union is by Adhesion, commonly called the First Intention. It consists in the effusion of Lymph between the opposed surfaces. In this mode there is slight inflammation of the parts, but not of a destructive character. In direct union the absence of all inflammation is.necessary. In other respects the same conditions are required as for direct union, namely absence of bleeding and of foreign bodies, direct apposition of the sides of the wound, and exclusion of the air. Healing by Adhesion is the most common mode of union.

\section{Healing by Cicatrization or Scabbing.}

The 3rd mode of union is by Cicatrization, commonly calleci Scabbing. In it the wound is excluded from the air by some substance, such as hair, blood, etc., under cover of which the union takes place. This mode of union is sometimes brought about artificially by covering the wound with collodion, etc. The absence of inflammation is necessary.

\section{Healing by Granulations.}

The 4 th mode of union is by Granulations. This is otherwise termed union by Second Intention. It takes place, whenever any of the conditions necessary for direct union, or for adhesion are not fulfilled.

Union by Second Intention consists in the effusion of lymph from the over-loaded vessels of the part under the influence of active, but not cxcessive inflammation. The lymph becomes vascular, and from it Granulations are formed. All lacerated and some incised wounds are healed by this mode. Though simple incised wounds may be closed and healed in farorable cases by direct union or by adhesion, yct loss of structure camnot be repaired or cavities filled up, except by material effused from the blood.

\section{Mode of formation of Granulations.}

The Lympl, spoken of in the preceding paragraph, in a short time after its exudation coagulates. lied streaks soon appear in it, which are incipient blood-vessels formed from, allid continuous with the ressels of the adjacent parts. In this way the lymph is formed intu a definite structure and becomes a living constituent jart of the body. In it there next appear little eminences, each containing a cell. These eminences are called Granulations. They secrete healthy pus. The upper layers gradually become converted into cpithelium, whilst the lower layers are 
converted into connective tissue. The lymph thus organised always partakes more or less of the structure, into which it is exuded. The deposition of lymph will continue under favorable circumstances, until the chasm is filed up to a level with or above the surrounding parts.

Good lymph, it will be remembered, is only secreted in the moderate or "active" stage of inflammation. It is not secreted in the acute or chronic stages. In most injuries the degree of inflammation is at first excessive. Hence in the treatment of wounds our first object generally is to reduce the inflammation by means of cold applications or fomentations. When this has been done, the probability is that good lymph will be exuded. Nature, not art, conducts the bealing process. All that man can do is to get the part into a state favorable for the operations of nature ; and if the patient is healthy and other circumstances connected with the particular case are favorable, she will soon complete the cure.

In some cases however it happens, and especially where the constitution is weak and unhealthy, or where the part injured is of low organisation, that the inflammatory process becomes torpid, before sufficient lymph has been exuded. It may then becoine necessary to stimulate the part to renewed activity by the application of irritants.

On the other hand, if the local inflammation continues for too great a time, the lymph will soften into pus.

\section{Combination of modes of Union.}

In a wound of considerable extent, several of the above modes of union may often be seen in operation in different parts at the same time, as for instance the 1st, 2nd, and 4th.

There is a greater disposition in the horse than in man to suppurative action. Hence wounds of any extent seldom heal completely in the horse by direct union or by adhesion. These modes should, however, be sought for and obtained as far as possible in each case, with the view of reducing the size of the part requiring to be filled up by granulations.

\section{Recapitulation.}

Such are the various modes of healing wounds, and like all nature's processes they are simple enough. In practice, however, innumerable modifications occur, arising from the nature of the wound, the degree and seat of the injury, the presence or otherwise of foreign bodies in the injured part, the amount of hæmorrhage, the health of the patient, and degree of irritability peculiar to his system. In short, no two cases are exactly alike.

Details connected with these varying circumstances will now demand our attention.

\section{Cleansing of Wounds.}

All foreign bodies in a wound should at once be removed, as far as possible, by allowing lukewarm water to fall in a stream over it from the mouth of a vessel. Or a sponge or a piece of fine tow may be pressed on 
sume part above, from whence the water may gently trickle over the wound; but the abraded surface itself should never be touched. Any large particles of gravel or dirt may be carefully removed by the furceps. It is, however, a mistake to irritate a wound by over-anxiety to cleanse it thoroughly. Nature will by her own processes remove, with less irritation than man can do, any foreign matters which will not come away by the simple means recommended above.

\section{Accidental Hæmorrhage.}

Accidental Hæmorrhage arises from violence of any kind, frequently self inflicted. It is either arterial or venous or both. If the blood is of a bright scarlet colour spurting out, we know it is Arterial; if of a dull red colour flowing in a steady stream, we conclude it is Venous; if mixed we know that both kinds of blood-vessels are injured.

To arrest the Hæmorrhage three things are necessary: 1st, careful, very careful removal of foreign material. More harm than good is often ignorantly done by probing the wound in search of such material. 2nd, the application of pressure. 3rd, copious application of cold water or ice.

To arrest arterial bleeding in the legs, the pressure must be applied above the wound, whilst in venous bleeding it must be applied below, as in the one case the blood is being carried from the heart, whilst in the other case it is returning to the heart, $i . e$. flowing in opposite directions.

As a matter of fact ordinary hxmorrhage in the extremities, can after cleansing be arrested by the application of a plug of wood wool, or lint (not linen) on fine tow, around the fibres of which the blond speedily clots. The plug must be kept in position by a clean linen bandage, and orer the whole a continuous stream of cold water should be played. For more serious bleeding as from the groin, the jugulars, etc., the prompt attendance of the Veterinary Surgeon is an absolute necessity. In the meantime treat as above.

Bandages and compresses must be removed or loosened, when the bleeding is arrested. Erysipelas may follow from neglect of this attention.

\section{Dressing fur Wounds capable of being healed by Direct Union.}

The best dressing for wounds, which comply with the conditions required for direct union, is carbolic acid paste spread on tow. It effectually excludes the air, and is supposed to destroy those atmospheric germs which hinder the healing process. (See Disinfectants and Deodorizcrs, par. 277, Chapter 16.) Scarcely any suppuration takes place in wounds when this disinfectant is employed under the above favorable circumstances. Hence direct union, or at least union by adhesion, is likely to occur. The bandages which retain the dressing should not be removed for some days. The dressing of course must not be applied until the bleeding has ceased and the wound has been cleansed. It will be necessary to remove the hair round the part before the dressing is applied. 


\section{Dressing for Wounds intended to be healed by Adhesion.}

For wounds capable of being healed by adhesion, lint steeped in Friar's balsam or collodion may be applied. Where collodion is used, the hair about the part must be removed. Or glue, or shellac plaster may be applied to keep the edges of the wound in apposition after removing hair from the edges of the wound.

\section{Dressing for Wounds intended to be healed by Granulations.}

For wounds intended to be healed by Granulations, there is no better dressing than lint steeped in cold water. Care must be taken to keep the lint moist, and for this purpose it may be covered with oil-skin or gutta-percha. Or carbolised oil may be applied with a feather. The carbolic spray, as recommended for open joints, will be found very useful in cases of extensive granulating wounds. These means will be found far preferable and more effectual than the Digestives used in olden time, when Surgery was in its infancy. Nature alone can heal. We only assist her by preventing the interference of retarding influences.

\section{Wounds, healing by Granulations, to fill up from the bottom.}

All wounds healing by granulations must fill up gradually from the buttom. It must be remembered that there is a greater tendency to union in the edges of the skin and in parts near the skin than in deeper tissues. Hence, all deep wounds require to be kept open, until we are assured that the healing process is fully completed from the lowest part. This object may generally be obtained by inserting a piece of dry lint between the edges of the wound.

The formation of a slight scab over the exterior of the wound is useful in many cases as a protection against the irritating effects of the air and accidental abrasion; but no dense firm unyielding scab should be permitted to form or remain, because it will unduly check the natural exudation of the matter, which in such wounds always forms. The - matter, if confined, will collect until at last it bursts out by some large irregular opening, or, if unable to obtain an exit, will burrow in the deep-seated tissues and cause extensive mischief.

\section{Indolent Wounds.}

If a wound, which is healing either by scabbing or by granulations, becomes indolent, and the healing process is slow and imperfect, it may be necessary to rouse the parts to more energetic action. If the wound is merely in the skin, the edgres of it may be removed with the knife, and the cut surfaces brought into contact and kept together by sutures. In other cases caustic may be applied to the wound, or the neighbouring parts may be lightly blistered.

Indolence in the healing process is a sign of constitutional debility. Hence, in addition to local measures, the gencral health should be carefully attended to. 


\section{Fxcessive Granulations.}

In some indolent wounds and especially in those over the cornnet, there is often a disposition to excessive and unhealthy granulations, otherwise called proud flesh. This disposition must be kept in check by the application of some astringent or caustic, such as sulphate of copper or zinc, nitrate of silver, or alum, and in some cases, where it can be conveniently applied, by pressure. When granulations form in masses, matter will often be found under them, which is apt to burrow in sinuses, unless an opening be made for it.

\section{Sloughing.}

Sloughing is death of a part, produced by disease or injury. The circulation is obstructed and the part undergoes decomposition. Sloughing is apt to take place whenever a part has been much lacerated or bruised. The slough may be superficial or deep. When the slough has separated, repair takes place by granulations. 'The extent of a slough depends on the nature of the injury and on its situation. The parts most liable to slough are those that have only a small supply of blood. Vaseular parts are not so liable to take on this action.

\section{Rest.}

In all wounds it is an object of much importance to keep the part in a state of rest. In some parts a certain degree of motion cannot be avoided, but an endeavour should be made to lessen it as far as possible. For instance, if the jaw be injured it is desirable to place the patient on sloppy diet, which will not require much mastication. In wounds of the leg, advantage may be taken of particular kinds of shoes, such as those raised at the heels or at the toes; according to the circumstances of the particular case. In some cases the patient will require to be tied up to prevent his moving about, whilst in other cases a cradle will be needed to prevent his gnawing the wound with his teeth.

\section{Sutures, Bandages, \&c.}

Sutures are useful in bringing together the eages of the skin in parts where there is but little flesh, such as on the forehead, the nose, and eyelids; but they do not answer in fleshy parts, because the weight of the flesh and the swelling arising from the attendant inflammation generally bursts them. In such cases the needful apposition of the parts is best promoted and maintained by bandages. Again, sutures are not advisable where the edges of the wound are much torn, or where there are foreign bodies lodged in it, because the inflammation and suppuration, which ensues in such cases, is aggravated by the confinement of the matter, and in the end the sutures generally break away.

Sutures are best applied by means of a curred needle. Interrupted sutures answer better than continuous, because the process of healing by direct union or by adhesion is seldom complete in the horse for reasous 
already mentioned, and hence the matter which forms needs frequent means of escape. The twisted suture made by two needles and a skein of tow or silk twisted over them answers very well in a small incised wound, such as that caused by bleeding in the neck.

In extensive wounds a flexible silver wire suture should be used in preference to silk, because it does not absorb the cfiused matters, and hence also is less likely to slough out. In extensive flesh wounds, however, especially when large portions are pendulous, sutures do not answer. Bandages applied, if possible, from below upwards should be used.

A bandage should be adjusted very evenly, and not so tight as to obstruct the circulation or to cause pain. When circumstances admit of it, the bandage should be applied above and below, but not over the wound. This arrangement will enable the dressing to be easily changed without the necessity of removing the bandage each time. Plasters are frequently used to keep the edges of wounds together. They are made by dipping strips of canvas or linen in glue or shellac.

\section{Cicatrix.}

True skin, when once destroyed, is never reproduced. Its place is supplied by a cicatrix which is formed of fibro-cellular tissue covered by epithelium. A cicatrix differs from true skin mainly in not containing hair or glands.

\section{Constitutional Effects.}

The constitutional effects of such wounds, as it is worth our while to treat in the horse, are in general not very serious. Traumatic fever sometimes ensues, but usually subsides in a few days. Temporary debility may follow any excessire loss of blood from an incised wound, but nature soon repairs the loss.

\section{Treatment of Incised Wounds.}

In favorable cases Incised wounds may be healed by direct union. If any of the conditions necessary to that mode of union are wanting, it may probably be possible to obtain union by adhesion. Of late years considerable advantage has been derived from the application of medicated wool kept in position with a bandage, and constantly wet with cold water, or, as it is called "irrigation." Medicated wool possesses the advantage of excluding the air. In some cases it may be necessary to have recourse to union by scabbing or by granulations. As incised wounds are generally simple in their character, the details, which have already been given, will probably be sufficient as a guide to their treatment.

\section{Treatment of Lacerated Wounds.}

In Lacerated Wounds some of the conditions necessary for direct union are wanting. Some degree of inflammation is always present, and 
again the parts cannot be brought into perfect apposition. Healing by direct union is therefore out of the question. Under favorable circumstances we may perhaps obtain the conditions necessary for healing a portion of the wound by adhesion. Usually however these wounds require to be healed by the more tedious process of granulation.

Laccrated wounds seldom bleed much, even though some of the arteries may be divided, because the vessels are torn, and in consequence contract and retract within their sheaths; and again, the torn filaments favour the formation of an external clot by entangling small particles of the fibrin of the blood.

The parts must be brought as nearly as possible into apposition. From the nature of the wound it is not probable that the edges can be made to meet. It is seldom advisable to cut off any portion of the skin, even though it may be detached. Isolated pieces of skin, which may be left in parts, should be permitted to remain. They may become points of connection, and so reduce the size of the cicatrix. True skin, it must be remembered, is never reproduced.

If violent inflammation sets in, fomentations and poultices must be applied to reduce it. If this unfavorable symptom is not present, the wound can be treated as recommended in paragraph 754. If the wound subsequently becomes unhealthy or indolent, or if excessive granulations appear, the measures recommended above for such cases must be resorted to. Sutures are seldom of much use or even available in these cases. A depending orifice must be secured. The wound must be frequently cleansed, and the carbolic spray as recommended for open joint may be used with advantage.

In those cases, where from pain and irritation traumatic fever sets in, sedatives and a mild dose of physic will probably be needed. As a preventive, it is always advisable to lower the diet of the patient for a few days after the occurrence of the injury. Afterwards a liberal diet is essential, or the powers of nature will not be able to carry on the process of repair. The chief danger to be apprehended in Jacerated wounds is the occurrence of tetanus, or lockjaw. (For Lockjaw see Chap. 33.)

\section{Treatment of Contused Wounds.}

By Contused Wounds are meant injuries inflicted by bruising the skin and subcutaneous tissues without any absolute breach of the skin. Such wounds generally contain serum, or a inixture of blood and serum under the skin. In the progress of any serious contused wound there are two distinct periods, namely the separation of the slough produced by the contusion, and that of the repair of the chasm by granulations. If the parts around are much bruised, superficial slough may ensue to a considerable extent. Before healthy granulations can form, the wound must discharge itself of all dead matter. Minor contused wounds do not generally run to sloughing.

The great principle in the treatment of contused wounds is to render them of a simple character by giving to the confined matter and extravasated blood a free exit by making an incision at the lowest part. All 
contused wounds, however, do not require to be opened, because the effect of the fomentations and stimulating liniments, which may be applied, are often sufficient to rouse the blood-vessels and absorbents to remove the effused fluids. In all contused wounds, whether great or sniall, there is always, it must be remembered, some destruction, though it may be very slight, of the subcutaneous tissues, or muscles. The products resulting from such causes must be removed. If the powers of nature are not sufficient, their more speedy removal must be assisted by art.

As in lacerated wounds, the violent inflammation at first existing in the contused and neighbouring parts must be reduced by general and topical measures before the healing process will coinmence.

During the healing process serum is very apt to collect in cavities in the wound. Though punctured, the sacs are apt to fill and refill, and sometimes there is a good deal of trouble in getting rid of them. They are best treated by being freely laid open and injected with a diluterl solution of zinc or copper, or a seton may be passed through them.

\section{Treatment of Punctured Wounds.}

Punctured Wounds, if the puncture does not extend into a joint or through the sheath of a tendon, are best treated by being laid open and converted into ordinary incised wounds.

Unless this course is taken much pain will ensue, because the deeper tissues, which have been injured and which will become inflamed, have otherwise no room to swell. Again unless a free opening is made, the matter, which is sure to arise from the inflammatory action, will burrow and form abscesses and sinuses. The opening must be kept clean by frequent washing and dressing; and in some cases it may be advisable to insert a pledget of tow smeared with ointment in order to ensure the maintenance of the opening.

If there is good reason to think, that the puncture has penetrated a joint or the sheath of a tendon, the case must be treated as one of open joint,-for the treatment of which the reader is referred to the preceding chapter.

\section{Poisoned and Gunshot Wounds.}

Poisoned and Gunshot Wounds are of very rare occurrence in the horse. The Author has therefore decided to omit all notice of them, though the subjects in themselves are interesting.

\section{8a. Blemishes from Wounds.}

Some degree of blemish will always result, where the skin is cut through, but the extent thereof will be lessened if due care is taken to avoid injuring the new skin with caustics, though it may be necessary to keep the granulations, or as they are popularly called "proud flesh," under control.

These growths will probably require reduction from time to time, but the caustic must be applied only to their central portions, so that no 
injury may be done to the gradually increasing formation of new skin, which eommenced its growth on the outer edges of the wound and indicates itself by its shining or opalescent edges.

\section{CHAPTER 49.}

\section{WARBLES OR SIIGH'T TUMOURS AND SITFASTS.}

759. Warbles or slight tumours. 760. Sitfasts. 760a. Melanosis. 760b. Scirrhous Cord.

\section{Warbles or slight tumours.}

Warbles are recent soft swellings or tumours arising from inflammation of the skin, generally caused by friction or undue pressure of the saddle, girth, or collar on the part affected, or sometimes by bad saddling, or bad riding, even though the saddle fit perfectly. "The swelling itself is due to a slight effusion of serum, or lymph, or of both, produced by the inflammation.

The first essential in treatment is to remove the cause of the irritation. In addition the horse should, if possible, be spared from work for a day or two. The stuffing and fitting of the saddle or other article of equipment should be looked to and, if necessary, altered. In some cases a chamber must be made over the part affected.

The Warble itself will be best treated by a solution of salt and water. It is not advisable to foment the part, because hot water has a tendency to make it tender and unduly sensitive of future injury. If the part really requires fomentation and is likely to suppurate, the injury is beyond what is usually called a Warble, and must be treated according to its nature and degree, as a contused wound.

Troublesome fluctuating Warbles sometimes require to be laid open through the centre from end to end. The interior must then be touched with caustic, and cold water dressings may afterwards be applied.

\section{9a. Other small tumours.}

These are generally caused by insects or flies, which burrow into the skin and deposit their larva in it. The tumours are not serious. They can ensily be got rid of by squeezing the little lump between the thumb of each himd.

\section{Sitfasts.}

When a swelling, such as described in the preceding paragraph, either by neglect or by repeated recurrence of the cause has become hard and 
insensible, and the skin is permanently injured,-it is no longer termed a warble, but is known as a Sitfast. The skin becomes thickened and half dead, and is often adherent to the bottom of the sore and kept alive by blood at its root. The Sitfast will frequently be found to be partially separated all round from the living skin.

The best treatment is to cut it out; but should its adherence to the underlying tissue be too extensive, a day or two's poulticing will facilitate its separation. Lunar caustic should then be applied with a view of producing a fresh active healthy sore, which may with care be induced to heal up properly.

True elastic skin of the original quality is never reproduced, when once destroyed, either in the case of Sitfasts or of any other injuries. But a substitute for it will be produced, which will answer sufficiently well in most cases; and the skin all round will contract in such a way, as to leave but little mark.

\section{0a. Melanosis.}

Melanosis occurs in the form of numerous tumours, usually where the skin is thin and denuded of hair, containing a black pigment. It affects horses of light colour, especially greys and washy chestnuts, usually in aged animals, though the disease is recorded as having occurred as early as five years old.

The cause is obscure. In some few cases the tumours reach a great size, but in most cases they are not sufficiently developed to incommode the animal. For small tumours no treatment is needed or advisable, but in large tumours the knife may be resorted to; but as the tumours appear to be constitutional, any beneficial result is doubtful.

\section{0b. Scirrhous Cord.}

This is an unfavorable result of Castration, causing a more or less extensive and indurated swelling at the end of the divided cord, and a conspicuous enlargement of the scrotal bag or sack. The only treatment is excision by a Veterinary Surgeon. 


\section{PART VII.}

CHAPTER 50.

\section{GREASE AND CRACKED HEELS.}

761. Nature of Grease and Cracked Heels. 762. Causes. 763. Signs of Grease. 764. Treatment. 765. Signs of Cracked Heels. 765a. Causes. 766. Treatment. 767. Conclusion. 767a. Mud Fever.

\section{Nature of Grease and Cracked Heels.}

Grease and Cracked Heels, though cognate in their cause and treatment, are separate diseases.

\section{Causes.}

Both are due to bad stable management. They are not due to humors, as idle grooms often represent to their employers, but mainly to neglect in not drying the heels, when wet; and sometimes to allowing dirty, wet bedding to hang about the heels.

Some horses are no doubt more predisposed than others to these diseases; but nevertheless the immediate causes may be summed up under the general heads of neglect and bad management.

The Author however must admit that some years ago he had a horse whose heels used at times to give him considerable anxiety.

Low-bred horses are more liable than others to these affections, partly because they are seldom well groomed, and partly because their circulation is not so strong as that of high-bred animals, and therefore the action of the vessels of the skin is more likely to be injuriously affected by external causes.

Light "washy" coloured animals are always weak in their circulation and therefore very liable to either grease or cracked heels. Both for this cause and because it is more frequently washed, a white heel is oftener attacked than a dark one.

The common practice of clipping the hair off the back part of the fetlock and heels is another frequent cause, especially in underbred animals. Though long hair about the heels is objectionable on account of the extra trouble it gives to servants, yet some moderate amount of hair is needed as a protection to the skin against chill, cold, wet, dirt and sand, and also against excessive evaporation, especially in those breeds to which such long hair is natural. 


\section{Signs of Giease.}

The earliest signs are a slight tendency of the hairs on the inside of the heels to stand up, and very shortly after to show very minute spots of oil on the hairs.

\section{Treatment.}

No case of Grease ought ever to be allowed to get further than this. With ordinary care on the part of a stableman, no case of Grease ought to escape notice on the first day of its appearance-certainly not later than the second day.

The treatment of this disease, if taken in time, is very simple. Wash the greasy heel with soap and warm water well. Then dry it and put on oxide of zinc, 1 part zinc to 8 of lard. If the greasy heel is not well on the following morning, repeat the ointment. In most cases the horse will be fit for work on the second or third day.

In neglected cases, if the disease has been suffered to run on to the ulcerative stage, the sores will require to be dressed with caustic applications, until a healthy action is established. If, however, grapes have formed, the excrescences will need to be cut off, and the parts must then be cauterised.

When the sores begin to heal, they are very apt to itch, and the horse may probably, unless prevented by a cradle or by tying up his head, gnaw them. Exercise, though in some respects it might be beneficial, yet, whilst the sores are open, generally seems to aggravate the disease. As soon as the sores are healed, regular walking exercise on dry ground should be given.

In cases of chronic greasy discharge of a virulent nature, a lotion of a stronger character than that recommended above will be required, such as an ounce of sulphate of copper dissolved in a pint of water.

Grease is neither infectious nor contagious. It often appears among many horses in a stable or at about the same time, because similar causes produce similar effects.

\section{CRACKED HEELS. \\ 765. Signs of Cracked Heels.}

'The Heel becomes hot, tender, and swollen, and the skin cracks in various places. The horse, when first brought out of the stable, is quite lame, but after a little exercise the lameness goes oft. In bad cases the heel and the part of the lèg immediately above may become so swollen and tender, that the act of bending occasions great pain; and a very little blood may perhaps ooze out of the cracks. Where this occurs, it shows, as a general rule, reprehensible neglect. 


\section{Treatment.}

If the case is taken in its incipient state, the treatment is the same as that reeommended for grease. After which put on a poultice made up of warm water and the soft part of a good white loaf. After the poultice has been on the heel for a day and night, and if the poultice has had due effect, then wash and dry the heel, and put on the ointment of oxide of zinc as recommended for grease. If another poultice seems necessary, put on a fresh made poultice, made as above.

Another good plan of treating cracked heels is after thoroughly washing and drying the heels to apply a dressing composed of carbolic acid one part, glycerine or oil twenty parts, with a feather, cover with lint, and carefully roll a soft, narrow bandage round the pastern and heel. This not only protects the part from cold and wet, but to a certain extent prevents the heel from being flexed, and allows the cracks to heal more rapidly.

If the case has been neglected, or if the cracks do not readily heal under the above treatment, a weak solution of nitrate of silver may be applied. If the edges look indolent, it will be advisable to stimulate the parts with turpentine liniment and to touch them occasionally with sulphate of copper or nitrate of silver. In cases where the heels are much inflamed, an ointment made of acetate of lead or of oxide of zinc with lard or vaseline may be used with advantage.

Though this disease is usually associated with neglect and debility, yet we occasionally find it arising from a plethoric condition combined with want of proper exercise. Horses, for instance, in high condition, such as hunters thrown out of work by a frost, are sometimes afiected if not well looked after.

Race horses, though well groomed and excrcised, occasionally suffer from Greasy or Cracked Heels. The process of sweating induces the affection. The sweat runs down into the hollow of the heel, and this part is often not covered, as it ought to be, with the bandages after work; and then the sudden evaporation of the perspiration, strongly impregnated as it is with the salts of the blood, leads to disease.

\section{Conclusion.}

Horses, which have ever been affected with either of these diseases, are more liable to them again than other animals. Hence in the future management more than ordinary care will be required.

\section{7a. Mud Fever.}

The somewhat inelegant term Mud Fever is applied to a form of erythema or superficial inflammation of the skin of the legs, and frequently of the surface of the abdomen.

It is generally supposed to be caused by the irritating effect of wet and dirt, and some particular kinds of clay are believed to hare a peculiar effect in producing this affection, and in these localities washing the 
legs on return from work, should be strictly forbidden. The mud should be allowed to dry on the legs and subsequently washed off.

That these ideas are erroneous is proved by the fact that the disease is almost unknown amongst cavalry troop horses, and hunters whose legs are unclipped, and where the system of washing is not allowed. The causes of mud fever may be said to be from washing and insufficiently drying the legs, especially in cases where warm water is used; the circulation, which has been excited by the warm water becomes suddenly checked by the effects of the cold air, the vessels become congested, and superficial inflammation follows. One of the principal predisposing causes of this affection is the system of clipping hunters' legs, whereby the skin is more liable to become affected by any external irritating influences.

The reader is referred to paragraphs 116 to 120 , also 177 on this subject in the Chapter on Stable Management.

The prominent symptoms of mud fever are swelling of the limbs, heat, and tenderness of the skin, more or less lameness the result of irritation and occasional constitutional disturbance. An eruption of vesicles occurs in patches on the legs, and along the surface of the abdomen, and after a time the hair falls off, and frequently desquamation of the cuticle also takes place to a considerable extent. These symptoms are accompanied by a staring coat and general falling off in condition.

The treatment of mud fever consists in placing the patient in a cool, well-ventilated box, and by administering a mild dose of aperient medicine. The diet should be laxative in character with green food or carrots. The skin of the affected parts should be well washed and carefully dried with soft flannels, and may then be dressed daily with a liniment composed of equal parts of lime water and linseed oil well shaken together. Or a dressing of one ounce of liquor plumbi subacetatis to half a pint of olive oil may be applied. This treatment, with good stable management, walking exercise, and gradually increasing the oat ration, will generally be found sufficient in ordinary cases.

CHAPTER 51.

MANGE.

768. Nature of Mange. 769. Mange, a sure sign of neglect or mismanagement. 770. Mange, not contagious among healthy well groomed horses. 771. Signs of Mange. 772. Treatment. 773. Clothing need not be destroyed. 774. Itchiness of the skin. 774a. Lice. 774b. Treatment.

768. Nature of Mange.

The disease known as Scabies, or Mange, results directly from the attack of a parasitical insect which burrows beneath the epidermis or 
searf-skin. The acari which are the active agents in the production of this disease, are of two kinds, called respectively, the Sarcoptes and Dermodectes equi. The latter parasite is the more common; but, as the ravages caused by both are similar, further description is unnecessary. The insects are so small, that they cannot be seen ly the naked eye, but they may be discovered by the aid of the microscope or even of the pocket lens. The attacks of these animalculi cause irritation and itching of the skin; and, as a result, the hair falls off in patches.

It is important to bear in mind, first, that Mange is not primarily a skin disease, but the result of insects being allowed to lodge in the skin; and, secondly, that the skin, either from want of grooming, or from poverty of the blood or system, or from the effect of unsuitable food, or from some or all of these causes, is generally, and perhaps we might safely say, must be in an unhealthy state, before it is in a condition suitable for these parasites to live in and breed.

Young horses taken up from grass, especially if poor, are sometimes found to be affected with the mange insect, but more commonly with lice.

\section{Mange, a sure sign of neglect or mismanagement.}

Mange never occurs in healthy, well gioomed, well fed horses. It is a sure sign of neglect and dirt, or of injudicious feeding, or of bad management of some sort. The owner will do well to change his servants, whenever this disease appears in his stable.

\section{Mange, not contagious among healthy, well groomed horses.}

Mange is not contagious among healthy and well groomed horses. It is very possible, that some of the insects may find their way from a diseased to a neighbouring healthy horse. But they will not remain, they will not lodge permanently, still less will they breed, in a skin to which the brush is well applied and in which they are in consequence disturbed two or three times a day.

Horses, however, in a debilitated or neglected state are very susceptible to this disease, and among such it is very readily transmitted from one to another. Hence, when circumstances, which are more or less common to all the animals in a stable or camp, engender this disease in one horse, it is necessary that he should at once be separated from the others. The brushes and clothing must also be kept separate.

\section{Signs of Mange.}

Mange usually commences at the roots of the hair of the mane and tail. As stated above, it is caused by the presence of insects. Multitudes of minute pustules appear, whose summits gradually expand into vesicles, which burst and coalesce with one another, and by their united discharges form patches of encrustation upon the skin. At these patches the hair loosens at its roots, and either falls out, or it rubbed of from time to time, and at length the place is left bare. The follicles of the hair desquamate in the form of bran-like scales or meal dust. 
Upon these patches small red spots may frequently be seen, owing to the crust being rubbed off the pustules, and consequent exposure of the inflamed cutis.

The skin loses its elasticity, and becomes corrugated in harsh aricl folds, especially about the neck and sides. Sometimes blood oozes from the bare places. The disease is accompanied with intolerable itching.

\section{Treatment.}

The treatment of Mange, so far as killing the insects, is very simple. The coat, if long, should be removed by clipping, and the skin must be thoroughly washed with warm soft water and soap, and after being carefully dried may be dressed with the following liniments. Oil of tar four ounces, common oil one pint, powdered sulphur four ounces. Mix and apply to every part of the skin with a soft brush. The dressing may he repeated on the following day, and allowed to remain on for three or four days, when it may be thoroughly washed off. Any slight irritation that may remain can be allayed by bathing the part with a lotion composed of sulphuric acid two drachms, water one pint. If the skin is inclined to crack or become rough it should be lubricated with a little vaseline or glycerine.

Many practitioners advocate a strong infusion of tobacco with the addition of glycerine as a mange dressing, while others recommend a lotion composed of one part of carbolic acid to twenty parts of water.

Some of the patent sheep dipping preparations also are very effectual.

The animal's head must be tied up to prevent his biting himself.

After washing the skin, if clothing is worn, a linen sheet must be placed under the rugs to prevent irritation.

In slight and recent cases the skin will soon recover its tone, when the insects are got rid of, and in most cases the hair will grow again. But when the disease is of long standing, or has been engendered, as is usually the case, by neglect, bad grooming, bad feeding, or poverty, or at least is complicated with low condition arising from these causes,--the skin is not easily restored to a healthy condition, even though the insects have been got rid of.

Besides the above local remedies, it will be necessary to act on the constitution by invigorating it in every way by the best food and tonics. A change of diet is always very desirable. Green meat, which by reason of its laxative qualities lessens the irritability of the skin, should always be given if procurable. Pale malt (except when the animal has been previously kept on barley, or boiled linseed answers well.

Horses are often a long-time before they recover their condition after an attack of mange; but this, is quite as much due to the fact that the animals had been neglected and were probably in a dehilitated state before they were attacked, as to the effect of the disease.

Though the disease is not contagious among well-cared-for horses, yet it runs quickly through those, which are out oi condition, ill-fed and weak. 


\section{Clothing need not be destronged.}

There is no need to destroy the clothing of horses affecterl with Mange. It is sufticient to bake or boil it thoroughly.

Servant's clothing should be baked or boiled if it will not be so spoiled.

\section{Itchiness of the skin.}

Horses, especially in hot countries, are frequently subject to itchiness of the skin. The symptoms very closely resemble those of Mange. The head, neck, and shoulders are mostly affected. From the intense itching the animal will often rub off large patches of hair.

The local treatment consists in shaving off the hair, and dressing the skin with equal parts of mercurial ointment and soft soap made into a lather with hot water and applied by means of an old brush. The new hair will grow rapidly after this application.

Change of diet and laxative food will also be needed for a time. Boiled linseed is very beneficial. Horses, which are kept on barley, are very liable to this affection.

In some horses the skin is so exceedingly irritable (without any positive disease) that the animal cannot bear the friction of the ordinary saddle lined with flannel on his back. A linen cloth carefully and sinoothly laid under the saddle will often in such cases give relief.

Other horses are affected with a skin disease, resembling mange, but not produced by the attacks of parasitical insects, about the head and face or under the brow band. The mercurial ointment recommended above will generally effect a cure.

\section{4a. Lice.}

There are many varieties of Lice, but only two which need mention as regards horses, viz. : 1st, the common house louse; and 2nd, the poultry louse.

The first-named usually attack old and ill-fed horses; and also not uncommonly young at grass.

The second sort, the poultry louse, attack horses in fair condition, and generally select the best fed.

In both cases the ravages of the parasite produce the same effects, viz. extreme itchiness, accompanied by an eruption of vesicles.

\section{4b. Treatment.}

The horse's coat should be removed by clipping, and the skin should then be well washed, and the liniment recommended for Mange or any of the parasiticides should be applied. One dressing probably will be sufficient. In all cases the stable must be thoroughly cleansed and whitewashed.

The causc-overfeeding in the one case, nr want of feeding in the other-must he guarded against. 


\title{
CHAPTER 52.
}

\author{
RINGWORM.
}

775. Nature of Ringworm. 776. Causes. 777. Treatment.

\section{Nature of Ringworm.}

Ringwory is not connected, as the name might lead us to suppose, with the presence of an insect. It is due to a parasitic growth of fungus made up of organic cells, which affects more especially the hair follicles on the surface of the skin. The disease may commence in any part. The premonitory symptom is usually an unthrifty look about the coat. A white scaly scurf accompanied with staring of the hairs in the parts affected is the first positive indication, followed by a thickened scurf with raised eminences. This spreads rapidly in blotches over the neighbouring parts, generally assuming the form of rings, and the hair falls off. The appearance is so peculiar, that the disease cannot be mistaken by any one who has ever seen a case.

\section{Causes.}

Ringworm usually results from an unhealthy condition of the skin,in most cases produced by neglect of grooming, or by bad food, or by any sudden change of diet, even from bad to good. Occasionally, however, it appears in stables, where both the grooming and the food are unquestionably good.

Damaged oats or hay are very ready causes of this disease. In every case, therefore, the food should be very carefully examined. The oats, in addition to being inspected externally, should be stripped of their husks with the view of ascertaining, whether they have become mildewed under the surface; and their state should be further tested by smelling and chewing the grains. The hay should also be looked to, especially with the view of ascertaining whether it is mildewed.

Young horses on first coming into stables are sometimes affected, probably from change of diet. Horses recovering from fever occasionally suffer from this disease. In this latter case, it seems to arise from an impoverished state of the blood.

Ringworm, it is said, can be produced in healthy horses by inserting under the skin a scale of the cuticle from one of the blotches of a diseased horse. In ordinary cases the disease is not very contagious, though generally supposed to be so. It frequently, however, runs through stables, much in the same way as influenza and other discases, because similar causes produce similar effects. 


\title{
777. Treatment.
}

If any positive cause, such as bad forage or neglect of grooming can be ascertained to have existed, measures must of course be taken to rectify it. Without such amendment local treatment will not be of much avail. If, as is often the case, debility is also a symptom, care must be taken to improve the tone of the system by good feeding and good grooming.

As regards Local treatment, scrape each spot well with a spatula, not roughly, but sufficiently to clear off the fungus, and also clean off the hair for half an inch round the spot.

When the fungus has been remored, the spot will become red and moist, but not bleeding.

Wash well with warm water and soap, and then dry it; and then pass very quickly over it a stick of nitrate of silver; and also very lightly over the hair on the margin of the spot.

It is not necessary to keep the horse off his work, unless there are any spots under some part of the harness.

\section{CHAPTER 53.}

\author{
WARTS.
}

778. Situation and size of Warts. 779. Causes. 780. Treatment.

\section{Situation and size of Warts.}

A WART is an extra secretion of cuticle from the papillæ of the dermis. Warts are of rather common occurrence in the horse. They appear on the thin and more delicate portions of the skin, as for instance on the sheath, the inner surfaces of the hind limbs; the abdomen, the eyelids, and the sides of the nose. They scldom appear on the back, hind quarters, sides, or outer surfaces of the limbs. They are sometimes found on the neck, where the skin has. been injured by the collar.

They vary in size from that of a pea to that of a large potato. The wart commences as a small round substance, and gradually increases. As it increases, it becomes divided into clefts and fissures, from which the blood occasionally exudes.

779. Causes.

The precise causes of these excrescences are not known; but they probably arise from some peculiar derangement of the nutritive vessels, 
which secrete the skin. Others think that they originate in undue rascularity of the true skin, hy means of which an abnormal growth is generated. It is certain that after removal they are apt to recur.

\section{Treatment.}

Warts should always be removed whilst yet small. The more common practice is arsenic and lard in the proportion of one drachm of arsenic to one ounce of lard. Two scratches should be made on the wart and a small quantity of arsenic paste applied to the scratches. The wart will fall out in a few days.

Another good practice is to scrape the surface, and then dress with chloride of lime.

Some of our best Veterinary Surgeons prefer the knife in all cases, but in some cases there is danger of cutting an artery.

In some cases, when warts, without any appreciable base exist in parts of the body causing them to interfere with the saddlery or harness, it may be necessary to slough them out.

A thin paste consisting of sulphuric acid and sulphur, spread over the wart will produce the necessary sloughing process in the course of a few days. The part must be afterwards treated as a simple wound.

\section{CHAPTER 54.}

\section{BOTS AND WORMS.}

\section{Buts. 782. Intestinal Worms. 783. Treatment. 784. Worm in the Eye.}

\section{Bots.}

Bots are the larvæ or grubs of the Estrus or Gad-fly. The eggs are deposited on the legs, arms, knees, or body of the horse during the autumn, and are licked off by the animal and hatched in the stomachto the cuticular coat of which they cling by two strong hooks or tenacula. Their heads, which are situated between these hooks, are buried in the lining of the stomach. They often adhere so tenaciously, that their bodies may be broken, before they will quit their hold. They are sometimes found in the villous coat, and they but rarely extend into the duodenum. The mucus of the stomach seems to be their food.

About June or July the bots are often voided in the dung, and they then assume the chrysalis or grub form, and remain so for a few weeks, when the case opens, and the fly takes wing. Bots, when being voided, 
often adhere by their tenacula to the fundament. There are several species, but it is not necessary here to describe them.

Their presence does not seem usually to act injuriously on the health of the horse, though occasionally the stomach is eroded by them. When they are seen in the dung they are usually undergoing the natural process of being voided before their transformation; and if we have patience, nature will quietly expel them without our aid. At this period, a dose of physic may perhaps hasten the loosening of their hold; but we cannot make them quit their tenement much before nature disposes them to do so, inasmuch as their bodies are hard and insensible to the action of any medicine, and their heads are enveloped in the lining of the stomach.

\section{Intestinal Worms.}

The cause of the production of these parasites in the body is enveloped in mystery. Poverty of the system, pasturing in marshy or wet ground, or the usc of stagnant waters are undoubtedly predisposing agents. Joung animals are more subject to them than aged, and weakly than stronger subjects. They are however often found in horses to which none of these conditions apply.

Worms derive their nutriment by suction from the intestinal secretions. They die, if the animal dies; or if voided, they perish immediately.

Two kinds of worms are commonly found in the horse, namely, first the Ascaris megalocephala, or long round worm, which we frequently discover in the dung. They inhabit the small intestines, and are sometimes twelve inches long. Secondly, the Oxyuris curvula, a small needle-like lively worm found in great numbers in the large intestines and rectum. This worm is usually white in colour, and about half an inch long.

In some cases the presence of Worms may be detected by their being excreted along with the dung, whilst in other cases their presence can only be suspected by a peculiar hard, dry, unthrifty appearance of the coat, or at other times by frequent whisking of the tail and by some dry brownish matter adhering around the anus. Worms may also exist for a length of time without presenting any outward appearance which might lead to their detection.

In some cases they injuriously affect the health of the horse, whilst in others they seem to do no harm. We are as little able to explain this difference in effect, as to explain the cause of their existence.

As a general rule, when a horse has worms, his system is out of order -possibly not on account of the worms, but perhaps the worms find at suitable tenement in his intestines, because they are out of order-just as the mange insect will lodge in an unhealthy in preference to a healthy skin.

\section{Treatment.}

Previous to the alministration of medicine the horse should be kept without food for at least twelve hours. A dose of two ounces of turpentine giren in a pint of linseed vil, with half an ounce of tincture of opium 
to prevent griping, will effect a temporary clearance. Or a drachm of tartarised antimony may be given for six consecutive mornings before the horse is fed, followed on the seventh day by a dose of physic. A drachm of calomel for two or three consecutive nights, followed by a dose of physic given on the third morning fasting will also answer. The small worms, which inhabit the rectum, may sometimes be cleared away by injections of a weak solution of salt, or of turpentine and linseed oil, or infusion of quassia.

A change of diet is desirable. Salt in the manger is beneficial. Mineral and vegetable tonics are useful in improving the condition. Worms, however, notwithstanding the temporary clcarance effected by medicine, are apt to reappear after a time.

\section{Worm in the Eye.}

In India a worm is occasionally found floating in the aqueous humour. The treatment consists in puncturing the cornea at its upper inner margin. The humour will then escape, and will carry with it the worm. The humour soon re-forms, the wound readily heals, and in general no after-injurious result ensues. The inner margin is selected for the operation because the cornea at that part is least dense; and the upper instead of the lower margin, because the aqueous humour, which gradually reforms, will be less likely to again escape (whilst the wound is healing) than if the incision has been made at the lower part; and the resulting cicatrix on the cornea is less likely to interfere with the vision. 


\section{PART VIII.}

CHAPTER 55.

\section{DISEASES OF THE KIDNEYS AND BLADDER.}

785. Use and action of the Kidneys. 786. Inflammation of the Kidneys, or Nephritis. 787. Symptoms. 788. Treatment. 789. Irritation of the Bladder, and its causes. 790. Symptoms. 791. Treatment. 792. Inflammation of the bladder, or Cystitis. 793. Symptoms. 794. Treatment. 795. Inflammation of the Neck of the Bladder. 796. Retention of the Urine. 797. Symptoms. 798. Treatment. 799. After-treatment. 800. Bloody Urine. 801. Diuresis, or Excessive Staling. 802. Symptoms. 803. Causes. 804. Treatment.

\section{Use and action of the Kidneys.}

BY the action of the kidneys, the superfluous fluid, which contains in solution various saline and nitrogenous substances, is removed from the system.

The quantity of urine secreted by the kidneys is very variable, even in health; being affected by the quantity of fluid imbibed, by the succulence or otherwise of the food, and by the activity of the skin and the amount of perspiration. In some diseases, as for instance in fever, the secretion is very scanty in quantity, acrid in quality, and high coloured; whilst in some other maladies, as in diuresis, it is excessive, and very clear and almost colourless.

The kidneys may be excited to increased action by various saline, etherous, and resinous substances. Such agents are termed Diuretics. Cantharides has also a similar effect.

786. Inflammation of the Kidneys, or Nephritis.

Inflammation of the substance of the Kidneys, otherwise called Nephritis, is fortunately rather rare. Its causes will generally be found in prolonged or severe work; or in exposure to wet and cold, producing derangement of the secretions of the skin; or in over-viulent or too frequent doses of diuretic medicine ; or in mow-burnt hay, kiln-dried oats, or other irritating food. It may also be brought on by sprain of the jisoie 
muscles, or in other cases by the presence of calcareous matter's in the kidneys.

Occasionally Nephritis occurs as a sequel to bronchitis, pneumonia, influenza, or laminitis-probably owing to the secretions of the body, which had been arrested during the acute attack, being afterwards discharged in over-large quantities through the kidneys. It is also found as a sequel of rheumatic affections. Sometimes it is induced by the absorption of the active principle of cantharides from a surface, to which that substance has been applied. Inflammation of the bladder may also extend along the ureters to the kidneys.

\section{Symploms.}

The horse is feverish, restless, and uneasy, and perspires freely. Ho often lies down cautiously and rises up again, as if suffering from colic ; but the abdomen, instead of being hard and distended as in that disease, is tucked up. He moves with caution and experiences temporary relief from lying down, but is not relieved by hand-rubbing. Owing to the pressure of the psox muscles on the inflamed kidneys he is unwilling to move-he stands with his hind legs wide apart, crouches and straddles in his gait, and groans if turned sharply round. Tenderness and wincing are evinced on the application of pressure to the loins. At frequent intervals he stretches himself cautiously as if about to stale, but passes no urine, or only a small quantity, highly coloured and often tinged with blood. In very acute attacks, the horse will sit on his haunches, groan, and look round to his flanks. The bowels are usually constipated, and the pulse is accelerated and soon becomes very quick and weak.

Inflammation of the kidneys is distinguished from a similar affection of the bladder by the secretion being very small and emitted with much groaning and effort, whilst in the latter disease the urine is secreted freely and ejected almost as soon as secreted. In both diseases the bladder is empty.

It may also be distinguished by examination of the bladder by the hand through the anus. If the disease is confined to the kidneys, the bladder, when it can be felt (but it is not easy to find it, inasmuch as it is empty) will not feel warmer or more tender than usual; but if the bladder is the seat of inflammation, it will be very hot and tender. The kidneys themselves may be felt; and if inflamed, they are hot and painful.

When the inflanmation is caused by the presence of calcareous substances in the kidneys, a very marked symptom is afforded by the penis hanging pendulous and a.constant dripping of urine, often tinged with blood. If the patient be a stallion, the testicles are retracted. The thigh on the side of the inflamed kidney, if only one be affected, is generally benumbed. If the disease is not relieved, the strength fails rapidly, and from retention of the constituents of urine in the system the skin often acquires a urinous smell. The retention of these matters in the blood exerts a poisonous influence on the system, and often produces conal and paralysis. 


\section{Treatment.}

The depressing and destructive influence of the arrested urinary secretions must be diminished, as much as possible, by exciting the activity of the skin and bowels. Flannel cloths steeped in very warm water should be at once applied to the loins, and covered with some waterproof material to keep in the heat and moisture. A pint of oil with a scruple of calomel may be given, and warm enemas should be administered. After forty-eight hours the dose of oil may be repeated, if needed, in order to produce moderate purgation; but it is not probable that it will be required. When the purgation has ceased, the calomel may be advantageously repeated in half-drachm doses with one drachm of opium in a ball night and morning for three or four successive days. Aloes should not be given, as it is apt to cause increased irritation in the kidneys. Saline purgatives are also inadmissible.

If the pain and straining are great, belladonna and camphor, in doses of one drachm, or combined with opium, or opium alone may be given twice a day for a period not exceeding two days.

The functions of the skin should be stimulated by warm elothing and hand-rubbing. Woollen cloths wrung out of very hot water and covered with a waterproof sheet and a dry rug to delay evaporation may be applied to the loins. The skin of a newly-flayed sheep with the flesh side inwards, and changed for a fresh one every second day, will also be beneficial. Care must be taken to avoid the occurrence of a chill, when the cloths or skin are removed. With this view the parts may be rubbed with an embrocation made of six ounces of oil, one ounce of the strong solution of ammonia, and two ounces of tincture of opium.

Mucilaginous drinks, such as linseed tea, hay tea, etc., should be offered; but if the animal will not take them, he should be supplied with slightly tepid water, mildly acidulated by some mineral acid. The food, which must be sparingly given, should consist of grass, carrots, or lucern. Clover, vetches, and all varieties of the trifolium species are objectionable, because they contain an acrid principle, which injuriously affects the urinary organs.

Irritants and counter-irritants, such as cantharides and turpentine, are wholly inadmissible, because they are apt to become absorbed and to exert an injurious effect on the kidneys. Clysters, however, of warm water are useful, both in relieving the bowels and in acting as fomentations to the inflamed organ.

As soon as the congestion is relieved by these measures, the kidncys will again begin to resume their secreting functions. The urine, however, at first secreted is always very acrid, and therefore causes great irritation in the organ. In order to diminish this effect, every endeavour must be made throughout the attack to get the horse to take mucilaginous drinks or even water. Half an ounce of bicarbonate of soda given two or three times a day in the drink will act very beneficially at this period in lessening the acidity of the urine. If there is much pain, a drachn of powdered opium with half a drachm of camphor may be given in a ball, and repeated once or twice if necessary, at intervals of three hours. 
If the disease terminates in suppuration, it will be indicated by pus being mingled with the urine, which will continue for some time during the period of convalescence.

In fatal cases, the kidneys, if the disease has been of any standing, will be found to be very much enlarged and softened; and in some cases disorganisation of the structure may have taken place.

\section{Irritation of the Bladder and its causes.}

Irritation of the Bladder may arise from excessive doses of diuretic medicine, from absorption of eantharides too freely applied for blistering purposes, from sympathy with inflammation of the kidneys, from overlong retention of urine, from calculi, from strain of the psoæ muscles affecting the kidneys and the bladder by sympathy, from a sudden check to the cutaneous perspiration by exposure to cold when the animal is hot, or from bad or irritating food.

If the case is of a persistent nature, the state of the bladder should be examined through the anus, to ascertain if there be a calculus in it.

\section{Symptoms.}

Irritation of the Bladder is indicated by restlessness, frequent straining, protruded penis, and by the passing at short intervals of small quantities of urine. If the symptoms are more grave than the above, it is probable that the disease has passed from the stage of irritation into that of inflammation of the organ. The bladder on examination through the anus will be found either shrivelled up and empty, or hot and tender.

\section{Treatment.}

The cause in the particular instance must be sought for, and if possible, removed.

To relieve the symptoms, many of which depend on the acidity and scantiness of the urine, the patient should be encouraged to drink plenty of water and mucilaginous fluids, in which may be given half an ounce of bicarbonate of soda and potash. The food should consist of mashes and hay with but very little corn. Grass, carrots, and lucern are very beneficial; but clover and other plants of the trifolium variety are for reasons already given objectionable.

Rest is indispensable. Some laxative medicine, such as a pint of linseed oil, is useful in unloading the bowels. Warm rugs should be placed over the loins, and clysters may be freely thrown up. The warm water will exereise a soothing influence on the irritated membrane. The effect, if need be, may be increased by adding to each clyster an ounce of laudanum or a drachm of extract of belladonna, and to insure its being retained the clyster should not exceed two pints. If the animal is debilitated, and especially if the irritation apprars to proceed from weakness of the bladder, vegetable tonics may be given with benefit. 


\section{Inflammation of the Bladder, or Cystitis.}

Inflammation of the Bladder itself is very seldom met with. When it occurs, it is generally consecutive on irritation of that organ, or it may be induced by sympathy with inflammation existing in the kidneys.

\section{Symptoms.}

Inflammation of the Bladder is indicated by the same symptoms as irritation of that organ, but they appear in an aggravated degree. Considerable fever is present, indicated by a quickened pulse, injected visible mucous membrane, and a high temperature. There is restlessness with arching of the back, whisking of the tail, frequent straining, and a protruded penis. At short intervals a few drops of urine, which is generally thick, high coloured, and mixed with ropy mucus and pus, will be passed with difficulty. In some instances, blood may even be voided. In pro. tracted cases the skin of the neighbouring parts becomes scalded by the continued dribbling of the urine. Occasionally the animal lies down, as if suffering from colic. If the hand be introduced into the rectum, the bladder will be found shrivelled up and empty, and oftentimes hot and tender; and upon the application of pressure to it, the patient will wince and strain violently. During the voiding of the urine, some few dung: pellets may be passed. The skin is hot and dry, and the animal often looks at his flanks.

If the disease is not relieved, the walls of the bladder will lose their contractile power; and in such cases the bladder may be found full, but this would only occur in the last stage. The bladder may be ruptured through over-distension.

\section{Treatment.}

The treatment in most respects is the same as that recommended for nephritis. The case is quite as urgent, and every precaution pointed out in that disease should be adopted in this.

The condition of the bladder should be ascertained at an early stage of the disease. If much distended, gentle manipulation and pressure per rectum may evacuate it, if there be no obstruction from calculus, or unless the neck of the cyst is inflamed or spasmodically contracted. If this fails the fluid must be evacuated by means of the catheter. If the disease be due to the presence of calculi, nothing but an operation promptly performed can give relief.

\section{Inflammation of the Neck of the Bladder.}

Inflammation of the neck is more common than inflammation of the body of the bladder. Its prominent symptom is retention of the urine on account of the inflamed condition of the orifice through which it ought to pass. Though the neck is principally concerned, yet the inflammation affects more or less the remainder of the organ.

The treatment of the inflammatory attack is much the sime as has 
been detailed above in reference to nephritis. But in addition to such treatment, it will probably be necessary to relieve the retention of the urine by other means. Those means and also the chief signs of retention of the urine will be detailed in the succeeding paragraphs.

\section{Retention of the Urine.}

In the majority of colic cases the patient suffers temporarily from retention of the urine, owing to spasm of the neck of the bladder. But, otherwise, the disease is not common in the horse.

It may, however, arise from inflammation of the neck of the bladder, or from calculi in some of the urinary passages, or from want of tone, or from the bladder becoming over-distended with urine, or from any cause producing functional derangement of the nerves supplying the muscular coat of the bladder with nervous force, as may sometimes happen when horses are driven a long distance without stopping, sometimes from fatigue-as in hunters, or in the case of animals which will not stale out of their own stables. Retention may also take place in peritonitis, on account of the pain which it gives the animal to use the abdominal muscles in expelling the urine, and also in tetanus. In some cases, especially in prolonged diseases, retention is caused by an accumulation of débris and dirt about the orifice of the urethra.

\section{Symptoms.}

The symptoms of retention of the urine are great uneasiness, distress and anxicty of countenance, colic pains and straining. The pulse is not at first much affected; but if relief is not soon obtained, it becomes quick and hard, and ultimately imperceptible. The patient will frequently stand stretched out as in the act of straining to void urine. He will lie down and rise frequently. Clammy sweats will break out over him. In the last stage the pulse will entirely sink, and the animal may have a little ease before dissolution takes place.

In the early stage any doubt as to the nature of the affection may be removed by putting the hand up the rectum and feeling the bladder.

\section{Treatment.}

The making up of the bedding and shaking about fresh straw often creates a desire and attempt to pass urine, and the effort may be successful. The steady pressure of the hand passed through the anus on the fundus of the bladder will often cause the urine to be discharged. Clysters will often assist in producing this effect. Hand rubbing of the belly is also beneficial. In those cases, which arise from an accumulation of dirt and débris about the orifice of the urethra, a thorough washing will often be found sufficient.

If these means are not successful in producing evacuation of the contents of the bladder, a catheter must be used, or the animal may die from irritation, or the bladder may burst. In a mare the catheter is easily passed, but in the horse the operation requires care and dexterity. The 
penis will usually be found retracted. The hand, being well oiled, must first he passed up the sheath, and the penis must be grasped and gradually brought forward, and held by an assistant. A flexible catheter, well oiled, should then be introduced and gradually pushed forward, and, when its point reaches the perineum, it should be guided forward and inwards by gentle pressure with the fingers.

If an obstruction, such as a calculus exists, it must, if possible, be removed by gentle manipulation. An endeavour made to direct it into the urethra and to guide it forward. If very small, it may perhaps be expelled, by the force of the urine, or it may be gradually manipulated forward, and then possibly extracted with a small forceps from the point of the penis. If, however, it is of any size, it will not pass the curvature of the urethra, and then can only be removed by an operation. Hydrochloric acid given twice a day in doses of two drachms in a pint of water will in some cases, where the calculus is small or in small fragments, or where no urgent symptoms are present, be successful in dissolving the concretion.

\section{After-treatment.}

In all the above cases, the after-treatment consists in careful aroidance of the causes, which may have induced the attack, in good nursing, spare diet, and the administration of tonics. Especial care must be taken that the animal be not subjected, for some time at least, to exposure or overhard work.

\section{Bloody Urine.}

Bloody Urine may arise from inflammation of the mucous lining of the kidneys, ureters, bladder, or urethral canal; or from sympathy with inflammation arising from sprain of the muscles in the neighbourhood of the kidneys. It may also be due to an escape of the colouring matter of the blood, without any inflammation being present. Careful chemical and microscopical examination of the urine will assist in correctly diagnosing these obscure cases.

The general treatment in such cases is rest and laxative diet, especially grass. Linseed tea should also be given.

More rarely this disease arises from weakness of the urinary organs, and must then be treated by the administration of tonics. Half a drachm each of nitric and muriatic acid with half an ounce to one ounce of the tincture of gentian, or half a pint of the infusion daily will answer exceedingly well. Some Veterinarians prefer to give diluted sulphuric acid in doses of a drachm three times a day.

Bloody Urine is a somewhat uncommon disease in the horse. Covering stallions, however, sometimes suffer from it, probably on account of the amount of stimulants often given them by their care-takers.

In hot countries, it is very common among horses in high condition for the urine to be deeply stained. This is not due to the presence of blood, but to an excess of colouring matter, the result of functional derangement of the liver. A simple laxative will in such cases invariably effect a cure. 


\section{Diuresis, or Fxcessive Slaling.}

For the sake of convenience we have grouped this affection along with diseases of the Kidneys and Bladder; but in diuresis the urinary apparatus is not in reality disensed; there is only excessive action of the organs, due to derangement of the digestive functions, or to an abnormal condition of the blood.

Diuresis, or excessive staling, of very clear urine, produces great prostration of strength, and may, if neglected, end fatally. More often, however, if not relieved, it brings on such a deteriorated state of the system that some acute disease supervenes and carries off the patient.

\section{Symptoms.}

The principal symptom, other than excessive staling, is extreme thirst. The horse drinks readily and greedily, and if he be not indulged will refuse his food. The skin is dry, and the coat is rough and staring. The digestion is generally out of order, and the bowels are torpid. The appetite is capricious, depraved and impaired. From the prostration induced the horse sweats easily and is incapable of much exertion, and falls away rapidly in condition.

\section{Causes.}

The causes of this disease are various. Most frequently they are connected with the use of bad forage. Mow-burnt or mouldy hay, and kilndried oats are especially apt to produce it by reason of their diuretic effect on the kidneys. The water in particular localities sometimes also affects these organs. More rarely it occurs as a sequel of any glandular disease such as strangles, or of any derangement of the organs of digestion.

In some cases it may be traced to the frequent use of "condition balls," a main constituent of which is often nitre or turpentine, which act as stimulants on the kidneys, and by their irritating action cause continual and excessive function of those organs.

Diuresis must not be confounded with that simple augmentation in the amount of urine, which may arise from a multitude of causes, some of them alimentary, and others of a nervous character. Such augmentation when only temporary, must not be viewed in the light of disease. Change in the food, for instance, often affects the secretion. Thus, if a horse be put on tares, the urine will not only be increased, but will become whitish and show a great deal of sediment.

\section{Treatment.}

The treatment must necessarily vary according to the cause from which the disease proceeds in each particular instance.

If the forage is in fault, it will probably be sufficient to change it. In all cases, however, a change of food is beneficial. Grass, whenever it can be procured, should be given. 
If, in addition to the causes described above, the organs of digestion, as is frequently the case, are also out of order, laxative diet, with linseed tea, in lieu of water, and a slight dose of linseed oil, will be useful. If the animal will not take linseed tea freely, he must be allowed water. If the water which he has been drinking is hard, it should be exposed to the sun and air for a considerable period, or boiled. Clay mixed with the water given to drink sometimes acts most beneficially.

Iodide of potassium and iodine have a very marked and beneficial effect in this disease. Of the former one drachm, or of the latter half $\Omega$ drachm, may be given daily. Iodide of iron in doses of one drachm daily also answers well. Iodine and its compounds should be given between meals. If given immediately before or after a meal, it combines with the starchy matters of the food, and is rendered comparatively inert. Lastly, if the horse has been dosed with condition balls, they must be discontinued.

As great prostration accompanies this disease, a liberal diet should be allowed. In addition to good sweet oats pale malt and boiled peas may be given. High dried malt is very objectionable, as it acts on the urinary organs. If the disease continues for a length of time, the patient will lose condition, and in such cases vegetable and mineral tonics will be needed.

In most cases, with proper management and attention, the attack will pass off in a few days; but great care must be taken to guard against recurrence of the cause which produced it. The disease in general is only serious when neglected.

\section{CHAPTER 56.}

\section{THE LIVER.}

805. Situation and Functions of the Liver. 806. Diseases of the Liver. 807. Causes of temporary Functional derangements. 808. Symptoms of slight derangements. 809. Treatment. 810. Congestion of the Liver. 811. Treatment. 812. Inflammation of the Liver. Acute Hepatitis. 813. Treatment. 814. Organic disease of the Liver. 815. Treatment.

\section{Situation and Functions of the Liver.}

The Liver is the largest gland in the body. The greater part of it is situated within the short ribs on the right side. A small portion lies on the left side, and also in the epigastrium. The outer covering of the liver is derived from the peritoneum, within which is a cellulo-vascular lining, called the capsule of Glisson.

The chief function of the Liver is the secretion of bile, a yellow, alkn- 
line, soapy fluid. From the liver the bile passes directly into the intestines. The horse is not furnished, as are many other animals, with a gall-bladder.

Unlike most secretions, bile is elaborated chiefly from the venous blood. Mixing with the partially digested food, it hastens its solution, and adapts it for absorption into the system. By some it is thought also to stimulate the intestinal linings to increased secretion of their solvent fluids. The bile poured into the intestines is nearly all taken up again by the absorbents before the frecs arrive at the anus.

The secretion of the Liver is increased by rich abundant food, by indolence, by heated stables, also by mercury, any preparation of ammonia, mineral acids, and by purgatives generally. Conversely it is diminished by light diet, strong exercise in the open air, cool stables, compounds of iodine administered internally, and by carbonate of soda given whilst the process of digestion is going on.

\section{Diseases of the Liver.}

The Liver, though subject to frequent derangement in man and also in some of the lower animals, is comparatively seldom diseased functionally or organically in the horse.

Its diseases may be divided into two classes, namely, temporary functional derangements, such as inactivity, congestion, and inflammation; and secondly, organic structural changes, such as enlargement, atrophy, softening, and induration. The first named ordinarily result from preventible causes, such as excess of food, want of proper exercise, or exposure to vicissitudes of temperature or weather. The latter are seldom primary affections; but as a general rule result from other diseases, such as influenza, inflammation of the lungs and pleuræ, etc.

\section{Causes of temporary Functional Derangements.}

Inactivity, often followed by. congestion, is frequently caused by excess of food, especially if it be of a stimulating character combined with insufficient exercise. The liver becomes loaded with bile, and this condition is afterwards succeeded by a diminution of the quantity of this secretion formed in the hepatio cells. This is in conformity with the usual rule of nature that, when any organ is put to excessive use for a time, reaction follows. The horse then becomes hide-bound and debilitated. In many cases the appetite falls off, but in others the patient may feed even ravenously. He will not however thrive until the organ again resumes its normal function. Congestion may also be brought on by a sudden chill or exposure. In London and other large towns it is very prevalent in densely foggy. weather, owing to the systemic depression thereby produced and the impurity of the blood from its imperfect revivification in the lungs.

A state of passive congestion may exist for a length of time without any very noticeable symptoms. On the other hand inflammation may supervene on the congestion, whether arising from previous inactivity, or 
from chill, or exposure. In very acute cases the period of congestion may be so short as to escape notice.

\section{Symptoms of slight derangements.}

Slight derangement of the Liver is often indicated by irregularity of the appetite. The animal feeds well one day and will not feed the next. The skin is rough, dry, harsh, and itchy, and the mucous inembranes are yellowish in colour, owing to retention in the blood of the material which should have been formed into bile, or from re-absorption of the bile due to some obstruction in its proper channel.

\section{Treatment.}

A little saline medicine, or some slight purgative followed by more careful feeding and proper exercise, or half a drachm of calomel with a little ginger every day for three or four days, will generally effect a cure. The derangement is often spontaneously relieved by a slight attack of diarrhœa.

\section{Congestion of the Liver.}

If the slight symptoms indicated above are neglected, and the derangement is allowed to continue for a length of time,-or in other cases without any such premonitory symptoms, Congestion (often followed by inflammation) may take place in the organ.

The attack, however, generally comes on gradually. The animal is dull and indisposed to move; the appetite fails and the bowels become disordered; the eye and mucous membranes assume a more decidedly yellowish tint; and the fæces are hard, scanty, light coloured, and fotid. Great uneasiness is evinced on the application of pressure to the right hypochondriac region. The breathing in general is not much affected, but there are frequent fits of blowing, and there is also a hollow cough. The pulse is full, soft, and compressible. The tenderness arising from a diseased state of the liver often causes the animal to favour his right fore-leg in action.

\section{Treatment.}

In Congestion of the liver, the bowels must be acted on from time to time, according to the strength of the patient, by purgatives; and such agents should be used as will in addition specially affect the liver, and cause an increased flow of bile. With this view saline purgatives, such as four ounces of Epsom salts, may be administered once or twice a day ; or calomel may be given in doses of thirty grains with two drachms of extract of gentian daily, until the congestion is relieved. Fomentations followed by mustard rubbed occasionally over the region of the liver have often a marked effect in relieving the congestion. The diet should be sparing in quantity, easy of digestion, and somewhat laxative.

In the later stages, when the strength begins to fail, tonics may be 
given. None answer better than hulf a drachm each of nitric and hydrochloric acid in a pint of water with one ounce of tincture of gentian, or half a pint of the infusion.

\section{Inflammation of the Liver. Acute Hepatitis.}

If the congestion runs into Inflammation, the pulse will become hard, quick, and small, and the usual symptoms of fever will be present. Pain will be felt, if pressure be applied to the right side just behind the saddle place, but the pain is not great, because the parts are soft and capable of swelling.

If the attack is not checked, the freces usually become clay-like in colour and consistency. The dryness, itchiness, and yellow tint of the skin increase, and the unhealthy, rough, and staring appearance of the coat is more marked. The glands about the throat and other parts of the body sometimes become enlarged. The animal rapidly loses condition. Occasionally severe diarrhœa supervenes and complicates the symptoms. Ascites, or dropsy of the belly, is a common sequel of the attack.

The liver is also occasionally, though but rarely, subject to sudden acute attacks of Inflammation. This disease is known as Acute Hepatitis.

The horse becomes dull and moping, and probably coughs occasionally. He hangs his head, his eye droops, and he loathes his food. He seems to suffer from inward pain, but not of a severe kind. He has not lain down during the previous night, the dung balls are small and dark coloured, the urine is scanty, the mouth is hot, and the animal is feverish. The fever runs on, and the inner side of the lips, cheeks, tongue, and the mucous membranes of the nose and eyes are tinged with yellow colour accompanied with a pasty state of the mouth with a rather sour smell. If blood be abstracted, the serum will be of a golden hue. The dung balls are tinged or perhaps deeply stained with bile, and often encased in viscid mucous matter. The urine is of a yellow colour with a copious sediment. The patient lies down occasionally, looks at his side, rises again, and occasionally walks round the box in a circle to the right. This is a common symptom in acute hepatitis. If the right side be pressed upon, he will flinch, or perhaps bite, and show signs of tenderness.

The pulse becomes quick, strong, and bounding, the breathing is disturbed and short. The patient appears dull and stupid and often sinks into a lethargic state, or he may stagger in his walk.

In either of these attacks, if the symptoms are not soon relieved, the case may end in rupture of the liver.

\section{Treatment.}

Both in Inflammation of the liver and in the cognate affection Acute Hepatitis, no time must be lost in attacking the disease. In most cases in the early stage a dose of aloes should be administered. By this cathartic the overloaded condition of the bowels will be relieved. Warm fomentations should be applied to the region of the liver, as recommended 
for acute nephritis, followed hy ammonia liniment or an application of mustard. The diet should consist of grass, carrots, hran mashes, etc.

As snon as the more acute symptoms are abated iodide of potassium may be given in one drachm doses daily, combined with gentian and ginger. The effect of this medicine is to diminish the action of the liver. During the acute attack calomel should not be administered, because it is an excitant to the glandular structures. In the after, or chronic stage, it is highly useful, and tends again to excite the organ to proper secretion.

\section{Organic diseases of the Liver.}

Organic disease of the Liver rarely occurs as a primary affection. It is usually a sequel of other diseases, especially of any diseases which prevent the free circulation of the blood through it.

A state of hyperæmial congestion, or undue accumulation of blood in the capillary vessels, is the usual commencement of almost all structural disease. This congestion may arise from any affection which interferes with the passage of the blood into the pulmonary artery, such, for instance, as inflammation of the lungs and pleura, influenza, peritonitis, any violent visceral inflammation, valvular disease of the heart, or disease of the pericardium. Enlargement of the liver to a great size, and softening of its structure, often follows. low typhoid affections. It is also common in old cart horses.

On the other hand, atrophy sometimes occurs, and the organ dwindles down to half its proper size.

In some cases the Liver takes on a scirrhous or indurated state, and ceases in a great measure to perform its functions.

Ordinary congestion of the liver, especially when it has become chronic, sometimes leads to enlargement and softening of the organ, known as hypertrophy of the Liver. It is most often seen in very fat horses, such for instance as brewers' and millers', or in pampered animals, such as gentlemen's carriage horses, which have not sufficient exercise. The liver slowly and gradually augments in size, sometimes with no sign of ill health about the animal, until it suddenly bursts its capsule, and death soon follows.

The liver may also become the seat of tubercular and cancerous deposit. The bile ducts may likewise be obstructed by calculi, when the same symptoms are evinced as in congestion and inflammation.

The existence of any such organic change, though its exact nature may not be discoverable during life, is indicated-but often only very obscurely -by the same symptoms as those previously described under the head of temporary functional derangements.

Accidents, such as a heavy fall on one side, may occasion rupture of the organ, when death will rapidly ensue.

\section{Treatment.}

In the early stages of organic disease of the Liver, there is often great difficulty in diagnosing it. There is frequently only a passive state of 
congestion. If diagnosed, the treatment will be the same as that recommended for congestion. In extreme cases of hypertrophy, an external enlargement is not unfrequently observed. Percussion may aid in forming a correct opinion. In many cases however the disease creeps on insensibly to a very serious extent without any well-marked symptoms.

When any change of structure has taken place complete restoration. is not to be expected; but the further progress of the disease may often be checked for a length of time by keeping the bowels moderately open by means of saline laxatives, careful feeding, and exercise. The iodide of potassium and carbonate of soda are useful in reducing the excessive action of the organ. Tonics are also beneficial in assisting it to regain its tone.

\section{CHAPTER 57.}

\section{DISEASES OF THE EYE.}

816. Introduction. 817. Shape and size of the Eye. 818. Outer coverings or Coats. 819. Cornea. 820. Sclerotic or outer Coat. 821. Choroid or middle Coat. 822. Retina or inner lining. 823. Conjunctival Membrane. 824. Interior structures of the Eye. 825. Aqueous humor. 826. Vitreous Humor. 827. Crystalline Lens. 828. Iris. 829. Corpora Nigra. 830. Optic nerve. 831. Other nerves of the Eye. 832. Arteries of the Eye. 833. Appendages of the Eye. 834. Eyelids. 835. Eye-lashes. 836. Tears. 837. Aruscles of the Eye. The Retractor oculi. 838. Membrana Nictitans or Haw. 839. Nature and seat of the Diseases of the Eye. 840. Common Ophthalmia. 841. Symptoms. 842. Treatment. 843. Specific Ophthalmia. 844. Nature of Specific Ophthalmia. 815. Causes. 846. Treatment. 847. Cataracts. 848. Examination of the Eye for Cataract. 849. Lenticular Cataract. 850. Capsular Cataract. 851. Capsulolenticular or Interstitial Cataract. 852. Absorption of Cataracts. 853. Degree of injury to vision caused by true Cataract. 854. No cure for true Cataract. 855. Spurious Cataracts. 856. Amaurosis. 857. Causes. 858. Treatment. 859. Gutta Serena. 860. Minor diseases of the Eye and its appendages. 86i. Lacerations of the Eyelids. 862. Diseases of the Lachrymal passages. 8.63. Shying. 863a. Worm in the Eye.

\section{Introduction.}

Before treating of the diseases of the Eye it will be necessary to give some slight description of the principal structures of the organ and of their functions. Without such description it would be scarcely possible to make intelligible to the unprofessional reader the diseases of the Eye 
and their causes, or the treatment required in the various cases. $\Delta \mathrm{s}$ far as possible all minute anatomical description will be avoided.

\section{Shape and size of the Eye.}

The Eye is nearly globular, except at its anterior part, which, probably for the purpose of better converging the rays of light, is more convex.

The size of the eye is nearly the same in all horses. Any apparent difference arises chiefly from the depth at which it is placed in its socket in different animals.

\section{Outer coverings or Coats.}

The outer surface of the anterior portion of the eye is formed by the Cormea. The remainder of the globe is invested by three coats,- - namely the Sclerotic or fibrous outer coat, the Choroid or vascular middle coat, and the nervous or inner lining called the Retina.

\section{The Cornea.}

The cornea covers about one fifth of the globe of the eye. It is firm in substance, elastic, and capable of resisting considerable pressure, and therefore well calculated to protect the eye from external injury; whilst its perfect transparency allows the free passage of light through it to the interior. In form it is convex, so as to act as a lens for transmitting the rays of light.

The cornea consists of two layers, but is denser in the centre than on the sides. By this arrangement greater converging power is gained, and better protection is also afforded to the more exposed parts. Its structure is laminated, and its anterior surface is covered with the epithelial part of the conjunctival membrane. There are no blood vessels in the cornea itself, only nutrient canals; - but the conjunctival layer under inflammation becomes very vascular. This is the only layer of the Cornea which is sensitive. The posterior or inner layer is epithelial.

\section{The Sclerotic or outer coat.}

The Sclerotic or outer coat is composed of white fibrous tissue interwoven in every direction. Its use is to give strength to the globe, and it also serves to give attachment to the various muscles which move the eyeball. It is itself loosely invested by a very fine tunic called the vaginalis, which allows the eye more easily to glide over the soft cushion of fat on which it rests.

\section{The Choroid or middle coat.}

The Choroid or middle coat is highly vascular and supplies the nutriment required by the internal structures. It is covered with a brown pigment, except at its upper back part, which is invested by a bright green pigment, termed the tapetum lucidum. This peculiarity is found in all animals intended to see in a diminished light. 


\section{The Retina or inner lining.}

The Retina or inner lining is mostly composed of a soft pulpy expansion of the optic nerve, covering the interior surface of the globe. It is the essential part of the organ of vision. The nerve enters by a foramen at the inner and posterior part of the eye. The principal artery, which supplies the internal parts of the eye, also enters through the same foramen.

\section{The Conjunctival Membrane.}

To the above three coats may be added a fourth, called the Conjunctiva, which has been alluded to above. It is a thin delicate mucous membrane covering the anterior portion of the sclerotic coat, the inner surface of the eyelids, and the margins of the cornea. Its epithelial layer is continued over the rest of the cornea. Its name is derived from its connecting the exterior parts of the eye and the eyelids.

\section{Interior Structures of the Eye.}

The interior structures of the eye consist of three humors, namely the Aqueous, Vitreous, and Crystalline.

\section{The Aqueous Humor.}

The Aqueous humor consists of clear slightly saline watery fluid which fills up the space between the cornea and the crystalline lens. In this humor the free border of the Iris floats. The space occupied by the aqueous humor in front of the iris is termed the anterior, while that in the rear of it is termed the posterior chamber of the eye. This humor is secreted by an extremely fine membrane, which everywhere lines the wall of these chambers. It forms a liquid medium in which the iris can float and carry on its peculiar duties, hereafter to be detailed. It also assists in maintaining the convexity of the globe, whilst by its transparency it readily permits the passage of the rays of light to the retina.

\section{The Vitreous humor.}

The Vitreous humor is a transparent fluid contained in imnumerable cells, formed by the hyaloid nembrane. In appearance it resembles jelly. It lies posterior to the aqueous humor and crystalline lens, and fills up the remainder or about four fifths of the bulk of the ocular globe.

\section{The Crystalline Lens.}

The Crystalline humor or Lens, so called from its form and high refracting power is a circular biconvex body, having its greater convexity on the posterior side, highly transparent and of firm consistence, imbedded behind the iris and inmediately between the aqueous and vitreous humors. It is enclosed within a capsule of its own, and is connected with 
it by a fine tissue, which quickly undergoes decomposition after death and forms the liquor Morgagni.

It is held in its situation by attachments formed from the circumference of its capsule to the zonula ciliaris, which latter is the thin membrane prolonged from the vascular portion of the retina. It is supported in its position anteriorly by the aqueous humor, and posteriorly by the vitreous humor, contained within the hyaloid membrane. The exceedingly thin membrane at the anterior surface of the lenticular capsule is a part of the membrane that secretes the aqueous humor.

In structure the Lens is rather soft externally, but increases in density towards its centre. It is composed of concentric lamellæ, which can be easily separated from each other by immersion in boiling water or alcohol. These lamellæ, when separating, split into three portions on the back and front; and the edge of the line of junction is serrated. The Lens is supposed to be nourished on the principle of endosmose and exosmose through these serrated edges. The structure of the capsule of the Lens is identical with that of the cornea elastica ; and like that membrane, it rolls up upon itself, when a portion of it is removed. It retains its transparency when immersed in spirit or macerated. It is composed of chondrine, a substance almost analogous to cartilage.

From its shape, density, and perfect transparency, the Crystalline Lens acts on the rays of light entering the eye in the same manner as an ordinary artificial lens. It is the chief agent in producing the impression of an object on the retina, or expansion of the optic nerve.

The question of the passage and refraction of light through various media is in itself exceedingly interesting; but any detailed consideration of this subject would be foreign to the scope of this work. The reader, if he wishes to pursue the inquiry, will find every information in works on the human eye.

No blood-vessels, nerves, or arteries have as yet been discovered in the lens. Yet we know that it must be organized, because it undergoes the phenomena of growth and morbid changes. The manner in which it is supposed to be nourished has been stated abore. The Lens does not, however, appear to have any diseases of its own; but it suffers from diseases of neighbouring structures in various ways, as will be hereafter described.

\section{The Iris.}

The Iris is a loose movalble curtain floating in the aqueous humor. In structure it is muscular and vascular. It is attached at its outer margin only to the sclerotic coat and cornea by the ciliary ligament. As mentioned above, it divides the space containing the aqueous humor into two portions or chambers. The action of the muscular fibres of the Iris is involuntary. The agent which controls and affects its nerves, and through them its muscles, is Light. In a strong light the pupillary opening is more or less diminished through contraction of the circular order of the fibres of the Iris. When the stimulus of light is remored, the muscles of the radiating order of fibres again come into play, and then 
according to these circumstances the pupillary opening is proportionately enlarged.

The opening in the centre of the Iris is called the pupil. Though circular in man, it is transversely oblong in the horse and in many other animals intended to seek safety in flight. The diameter of the pupil, or opening formed by the iris, varies, as explained above, in an inverse ratio to the amount of light to which the eye is exposed.

The colour of the iris varies in different horses, but it is always brilliant. Its posterior surface, called the uvea, is in most cases brown or nearly black. In wall-eyed horses this pigment is partly wanting, whilst in albino or cream-coloured animals it is altogether absent.

The iris is highly endued with nerves, in order to give it due susceptibility to the ever-varying degrees of light to which the eye is subject. It is also furnished with arteries, veins, and absorbents.

From its situation, structure, and office of regulating the amount of light admitted to the retina, from its connections with most of the operations of the organ of vision, and from its diseases, the iris is a structure of great importance.

\section{The Corpora nigra.}

The Corpora nigra are little black pigmentary globular bodies, belonging to the uvea or posterior lining of the iris and attached to its margin, to which they form a kind of fringe. Three or four hang down from the upper border of the iris, and usually one or two are attached to the lower margin. Their use, as indicated by their colour, appears to be to absorb and modify the rays of light entering the eye. They may be said to be auxiliaries to the iris to some extent, and perhaps partly supply the want of eyebrows in the horse.

\section{The Optic nerve.}

The Optic nerve, which is given off directly from the brain, enters the eye by a round cribriform aperture at the inner inferior and posterior part of the globe. Its expansion forms the chief part of the retina.

\section{Other nerves of the Eye.}

The various structures of the eye are, as we might suppose, very highly endued with nervous power. The chief peculiarity of its nervous system is the intimate connection between the two eyes. Lach part of each eye is supplied with branches of the nerve which supplies the corresponding part of the other eye. Hence in amaurosis in one eye the pupil may contract, when the other eye," which is not so affected, is exposed to a strong light. The retina of the blind eye of course does not feel the effect of the light, but its iris is moved in connection with the motion of the iris of the other eye, which does feel the effect of the light, but not quite to the same extent. Ifence also discase of the internal structures, such as specific ophthalmia in one eye, is apt to affect the other eye; and 
to a lesser degree, even in affections arising from external causes, one eye generally sympathises to a certain extent with the other.

\section{Arteries of the Eye.}

The internal structures of the eye are supplied with blood by the ophthalmic artery, which enters by a foramen at the back of the globe.

From the fact that the internal structures of the eye are wholly supplied by a deep-seated artery entering at its posterior part, it is plain that local bleeding can have little or no effect in specific ophthalmia and other diseases of the internal structures.

\section{Appendages of the Eye.}

The principal appendages of the eye are the eyelids; the lachrymal glands, which secrete fluid for its lubrication; the lachrymal ducts, which carry off these secretions; the muscles which move the eye and its various appendages ; the nerves, which affect those muscles; a mass or cushion of adipose membrane or fat, on which the globe of the eye rests ; and lastly, the membrana nictitans or haw.

\section{The Eyelids.}

The Eyelids form a sort of curtain, by means of which the horse closes at will the anterior aperture of the orbit. They are made up of skin, muscular fibre, cartilage, mucous membrane, and glands. The corners of the eyelids, where they meet, are termed canthi.

The skin of the eyelid is peculiarly thin and delicate. The interior is lined with conjunctival membrane. Its glands, termed the meibomian, are very numerous, and secrete an oily material which prevents the lids from adhering to each other or to the cornea. The size of the aperture between the eyelids varies in different horses. In some a greater, in others a less portion of the globe is exposed to view.

\section{The Eye-lashes.}

The Eye-lashes grow from the anterior margins of the lids. A distinct branch of the nerve is supplied to each bulb, from which a hair grows. Hence the eye-lashes are exceedingly sensitive.

\section{The Tears.}

The Lachrymal glands are situated in a depression in the outer and upper angle of the orbit. Under certain circumstances, such as the irritation of foreign bodies, various deep-seated inflammatory affections, or recent inflammation of the conjunctival membrane or of any of the external tunics, the glands are excited to increased action, and the surface of the eye is washed by a more than usually copious amount of saline watery secretion. When the ordinary channel is unable to carry off this secretion fast enough, it is poured over the lower lid and is then recognised as tears. 
In a state of health there is always a slight secretion from the lachrymal glands, which is carried along and conveyed away by two small canals into the lachrymal sac at the inner canthus of the eye, and thence by means of a duct into the nose. This duct has heen sometimes mistaken for the ulcer of glanders.

\section{Muscles of the Eye. The Retractor oculi.}

The muscles of the eye, as we might expect in a part so sensitive and so rapid in its motions, are both numerous and powerful. None however call for any special remark, except the Retractor oculi. Owing to the great strength of this muscle the horse possesses in a peculiar degree the power of withdrawing at will the eye into its orbit.

This power is greatly assisted by the fact of the eye resting posteriorly on the cushion or bed of semi-fluid fat mentioned above, which on the application of pressure yields very rapidly and thereby admits of easy retraction of the eye. The displacement of this body also causes the haw or membrana nictitans to come forward over the eye.

\section{The Membrana nictitans or Haw.}

The Membrana nictitans or Haw, which is situated in the inner corner of the eye, constitutes a very marked peculiarity of that organ in the horse. The haw has two principal uses, first, by moving backwards and forwards it wipes off the dust or other extraneous particles which may lodge on the surface of the eye; and, secondly, by protruding forward when the eye is drawn back on the approach of danger, it guards the cornea to a certain degree from any accidental blow. Its motion may be said to be involuntary, because it is forced over the eye mainly by the withdrawal of that organ into its socket.

This peculiarity of structure renders it very difficult to perform on the eye of the horse many of those delicate operations which are so useful in human surgery for the relief of various ocular diseases. With some trouble however the eye may be got at. The operator must frequently touch or threaten to touch the eye; and though for some time it will be drawn back at each threat, yet at last the retractor muscle will be wearied out and certain operations may then be performed. This practice is adopted with success in India in cases of worm in the eye. Of late years chloroform and cocaine have been used in operations on the eye.

\section{Nature and seat of the Diseases of the Eye.}

By the nature of its organisation, by its office and situation, and by its connections with other parts of the system, the eye is exposed to numerous external "and internal causes of disease.

The diseases of the eye may be divided into two great classes ; namely, those which result from external influences, and those arising from constitutional causes. Most, but not all of the diseases of the eye, whether resulting from the one or the other classes of causes, are of an inflammatory character. 
840. HAIV, COMMON OPHTHALMIA, AND CONJUNCTIVITIS.

Of diseases resulting from external causes common Ophthalmia or inflammation of the conjunctiva is the most frequent. It usually has its origin in some casual injury, or from the presence of some foreign body.

Atmospheric causes are an occasional but not very common source of this disease. Most of those cases, which may seem at first sight to arise from atmospheric causes, will be found to be merely an extension to the eye of inflammation already existing in the membrane of the nose.

\section{Symptoms.}

The first noticeable symptom is the closing of the eye, accompanied by a profusion of tears. Unless the seat of injury is wholly external, and therefore at once apparent, the eye should be examined. Here however we at once meet with some difficulty. The animal closes his eyelids firmly. He is impatient of light. As soon as we attempt to separate the lids he withdraws his eye into the socket, and the haw is thereby pushed forwards and the tears flow profusely. A sharp rap of the hand on the neck will sometimes cause the animal to open his eye, and an opportunity to examine it will then be afforded. If this device fails, the hand should be laid steadily on the brow with the thumb resting on the margin of the upper lid. The thumb must be kept quietly and firmly on the lid, until the retractor muscle ceases to act violently, and then the lid should be gently pushed upwards, and the index finger of tho other hand may at the same time draw down the lower lid.

A disturbed state of the blood-vessels and a reddened hue of the conjunctival membrane will probably be noticed. Possibly on further examination we may detect a wound of the cornea, such as that inflicted by a whip or by a bite from another, horse. If however there is no such wound, the chances are that some foreign body, such as a hay seed, has lodged on the eye. The seat of such lodgment is generally under the upper eyelid. In such cases the removal of the foreign body is of course the primary requisite. The upper eyelid is easily everted with a little tact by pressing against its outer surface with a blunt probe or some such instrument, and turning the margin of the eyelid upwards and inwards at the same time. Foreign bodies seldom lodge on the cornea, because the action of the haw, aided by the flow of tears which are at once effused, speedily carries them away.

Although blows over the eye or upon it are not usually productive of dangerous symptoms, yet we occasionally find disastrous results. Concussion of the retina may take place from the effect of a violent blow on the eye, and may be followed by temporary or permanent amaurosis. Again, the humors of the eye may be lost; or the rupture may be internal, and we may then have an escape of blood into the anterior chamber of the eye ; or the ciliary margin of the iris may lose its connection, and may afterwards by process of adhesive inflammation become attached to some adjacent structure; or there may bo displacement of the crystalline lens, which may be driven into the vitreous humor, or it may fall forward into the anterior chamber. When the blow is so violent 
that the cornea is lacerated and penetrated, there is but little chance of a cure, because the retractor oculi muscle acts so strongly, that the lens is usually forced out.

Common Ophthalmia, that is, inflammation of the conjunctival membrane, often accompanies catarrh and influenza and also dentition. In these cases however the affection is only sympathetic and subsides with the primary disease. The inflammation of the membrane is only an extension of the inflammation previously existing in the neighbouring mucous membrane of the nose or gums.

- Inflammation of the conjunctival membrane seldom appears as a separate disease. When it cannot be traced either to some external injury or to sympathy with a previously existing affection, such as catarrh or influenza, it should be looked upon with great suspicion lest it should be the prelude of specific ophthalmia.

In common ophthalmia the cornea from the effect of the inflammation sometimes appears blue, but in other cases it remains clear and bright. The size of the pupil, it is to be particularly remarked, is seldom diminished, whilst in the specific disease this symptom is always present. Again, in common ophthalmia there is a state of general suffusion and redness about the cornea; whilst in the specific disease the vessels which traverse the palpebral portion of the conjunctival membrane investing the cornea take a circular direction round it with ramifications proceeding towards its centre.

\section{Treatment of common ophthalmia.}

The treatment of common ophthalmia, when it arises from slight external injuries, is simple. If due to the presence of a foreign agent this must be removed in the manner before directed. The patient should be placed in a diminished light, and his head should be tied up to the rack to prevent his rubbing his eye against the manger. This position also will accelerate the return of the blood from the part affected, and retard its upward flow. In the early stage fomentations of warm water are desirable, but as soon as the active inflammation has subsided, cold water dressings should be substituted. The parts will need bracing up in order to restore their usual healthy tone. The eye should be shaded by a single fold of softest linen suspended from the brow band, and kept constantly wet with cold water. It should be taken off at night, or it will get dry and irritate the eye. If feverish symptoms appear, an alterative or cathartic dose will be advisable. These simple remedies will generally be found sufficient.

For severe injuries, such as those mentioned in the preceding paragraph, little more can be done than to place nature in the most favourable condition to exert her restorative powers. It is sometimes desirable to abstract blood from the angular vein. The treatment of the external laceration or injury, as distinct from its effect on the eye, is the same as that of any other laceration or injury.

Any very severe injury of the cornea or parts in its neighbourhood, whether arising from a blow or from irritation produced by a foreign 
body, occasionally results in partial or even in complete, though generally only temporary, opacity of that structure. This opacity is caused by the deposit left on the part by the results of inflammation. The deposit is indicated by a white fleecy appearance, and is usually situated between the conjunctival membrane and the cornea, or in severe cases between the layers of the cornea.

Under favorable circumstances the deposit will be removed in time by the ordinary operations of nature, but in aggravated cases it will probably be in some degree permanent.

The best chance of removing it consists in the use of stimulants and astringents, with view of exciting the absorbents to increased action; but these agents must be used with great caution.

The after deposit must not be confounded with the general opacity of the cornea, which often accompanies the inflammation and generally subsides with it.

In cases of redness of the eye, such as may occur from various causes, a lotion of one third of a grain of cocaine in six ounces of water will be found very beneficial.

For exceedingly severe injuries, such as concussion of the retina, rupture of the internal blood-vessels, loss of proper connection of the iris, and displacement of the lens nothing can really be done. It will of course be advisable to use the remedies recommended above for reducing the inflammation and placing the parts in as favorable a condition as possible. Partial or complete opacity will however be the result. Loss of the lens necessarily produces total blindness in the horse, though in man its loss may be partially supplied by glasses.

These very severe accidental injuries are happily rare, because the violence is generally mitigated, as regards the eye, by the projection of the supra-orbital process and by the power which the horse possesses of drawing the eye far back into its orbit.

For common ophthalmia, arising from or rather connected with catarrh and influenza, no treatment is necessary beyond cooling lotions and diminished light, as the disease is only sympathetic and usually subsides with the primary affection.

In treating diseases of the eye we must always remember the great sympathy which exists between double organs, such as the eyes. Nothingr is more common than to find that the eye, which was not at first affected, also becomes involved.

\section{Specific Ophthalmia.}

Specific, otherwise variously termed Periodical, Constitutional, Hereditary ophthalmia, or moon blindness, is inflammation of the deep-seated tissues of the eye.

In the very early stage many of the symptoms are the same as those of common ophthalmia. If, however, on examination we can discover no sufficient cause for the closing of the eye, such as an external wound or a catarrhal affection, there is always some reason to fear that the attack may be the Specific disease. As the treatment in the early stage is the 
same in either disease, we may wait patiently for the development of further symptoms.

Sometimes the disease comes on slowly, at other times it gains ground rapidly. There is turgescence of the lids, a flow of tears, intolerance of light, and an inflamed state of the conjunctiva investing the outer margins of the cornea. As the above symptoms increase, the eye becomes somewhat sunk in its socket by the action of the retractor oculi muscle, and at the same time the membrana nictitans is brought partly forward over the eye. Then, there is a great redness of the conjunctival membrane, and blood-vessels appear in it, some of them running in a circular direction and others radiating to a central point; there is also general dimness of the surface, and a copious flow of hot tears. These symptoms will soon be followed by the aqueous humour appearing thick and muddy, and by the iris losing its brilliancy. In very acute cases there soon occurs a deposit of lymph often tinged with blood, which fills up the anterior chamber of the eye, so that the state of the interior can no longer be seen. The lymph is the result of exudation from the inflamed vessels of the internal structures.

When amendment is about to take place, the curtain of lymph gradually falls down from the superior border of the anterior chamber, if it has been attached there, and we are then enabled to see what mischief has been going on within the eye. These changes, both for better and for worse, take place in a remarkably short space of time.

We may find even after the first attack, that the iris is adherent to the capsule of the lens, or that cataract has commenced to form in the lens or in its capsule. But these marked effects do not usually appear until after several attacks. More generally we find no other trace of the attack than that the iris has lost in a very slight degree the brilliancy of its colour, the lens a little of its clearness, and that the pupil of the eye attacked is somewhat smaller than that of the other. A little opacity, varying more or less according to the virulence of the attack, is also left in the cornea, particularly round its margins. The iris also does not act quite so freely in the diseased as in the other eye, and hence the pupil is not kept quite so dilated as it ought to be. All these effects are due to the effused products of inflammation not being completely absorbed and carried away. In a first attack the patient usually recovers quickly after the disease begins to decline.

These symptoms show clearly enough that the malady affects the deepseated tissues. In common ophthalmia, on the contrary, the interior of the eye, except when the cornea itself is injured, seldom shows any alteration.

The great peculiarity of Specific ophthalmia lies in its frequent remissions of intensity, as described above, and the almost certainty of future attacks. It is very common for the second attack to take place in the eye not first affected. This also shows plainly that the disease is constitutional, not local. The first, second, and third attacks may last from about ten days to a fortnight; but as they become more frequent, their period of intensity is shorter. After each attack the structures within the 
eye will be found to have become more disorganised, until at last cataract, adhesion of the iris, or other disorganisation ensues, and the disease is then at an end.

After the second attack there will be more or less haziness of the cornea, the iris will have lost its bright colour, and the pupil will be contracted. The corpora nigra will be more pendulous, and will not show the usual jetty blackness; or they may exhibit slight specks of opacity. After further attacks, the cornea will become so opaque that all within will appear cloudy and confused, except when the lymph clears away to a certain degree at each periodical intermission of the attack. We may then find the iris changed into a dark-looking: substance, and the structures visible through the pupil may have assumed a glassy green colour, or cataract may have commenced. The lids will become corrugated, and the eye generally will have a sunken "three-cornered look."

The disease generally affects each eye alternately; but occasionally, when the primary attack is very virulent, cataract forms at once in the eye affected and the disease then ceases, while the other eye remains sound. Usually only one eye is affected at a time. It is very rare that both eyes are attacked simultaneously.

Specific ophthalmia usually ends in cataract. As soon-as that process is well established, the inflammation generally leaves the eye and does not return. The force of the disease appears to have expended itself, but the formation of cataract nevertheless goes on. Occasionally the disease terminates even more destructively. The crystalline lens may escape from its capsule, and full forward and become attached to the cornea. Sometimes the margin of the iris is torn, and the iris may then hang ragged or may become adherent to the neighbouring structures.

During the attacks the usual symptoms of fever as indicated by the pulse, by dryness of the mouth, and by constipation of the bowels and scantiness of urine, are present; but the appetite singularly enough is seldom affected.

The period of intermission between the first and second attacks varies from three weeks to three months or longer; but succeeding attacks often follow more rapidly, until the sight is destroyed.

Though after the first attack the eye may recover so completely that an ordinary person would not notice anything wrong, yet an experienced observer can always detect some trace, such as an unusual degree of pendulosity of the upper eyelid, a somewhat prominent haw, a little contraction of the pupil, a slight appearance of gloom and sunkenness about the globe, and an increase of the depth of the white margin encircling the cornea, with loss of pellucidity immediately round it. The animal is also shy about the head and suspicious of all around, especially on the side of the diseased eyc. Each succeeding attack leaves increased traces of mischief.

As soon as cataract has fully formed, the pupil, instead of being contracted as heretofore, becomes dilated, because the eye is less sensitive or in severe cases wholly insensitive to light. The nature of cataract will be treated of hereafter. 
Such are the usual symptoms and course of the attacks. But the disease does not always progress in the violent way described. Specific ophthalmia may run its course and lenticular cataract may form without any outward or noticeable symptoms. The author has known several such cases among troop horses. It may seem, and it is undoubtedly very strange that a disease producing such destructive ehanges in an organ ean occur without at some time or other giving rise to any noticeable outward local or constitutional symptoms; but it is beyond question sometimes the case.

Iritis or inflammation of the iris seldom occurs as a separate disease. It is usually combined with inflammation of the other structures.

\section{Nature of specific Ophthalmia.}

The disease, it will be seen, is inflammation of the internal structures of the eye. The opacity, which ensues whether in the lens itself or in its capsule, or in the aqueous humour, or in the cornea, is simply the result of the deposit of the exudations from the inflamed blood-vessels. This part of the subject will be referred to again under the head of Cataract.

\section{Causes.}

Specific ophthalmia is commonly regarded as an hereditary disease. The author is not inclined to deny that it may arise directly from hereditary taint. Like begets like in most points of conformation, and the progeny of animals with constitutionally diseased eyes are likely enough to inherit the failing. There are also probably many animals with a slight, or very slight, hereditary taint, in which the active disease will be developed with a less amount of stable mismanagement than would produce it in other horses. But in such cases he believes that the predisposition is comparatively rarely developed except under the influence of some exciting cause. In support of this opinion he would urge, that in many years' experience he has but rarely known a case of specific ophthalmia among the troop horses. It is difficult to believe that all those horses can have been free from any taint or hereditary predisposition.

Whether derived from hereditary taint or otherwise, Specific Ophthalmia is clearly a constitutional rather than a local disease. In most cases the exciting cause seems to be a vitiated state of the blood produced by any or many causes acting on the organ, especially if it be naturally weak, defective, or predisposed to disease. The ordinary causes of such deterioration of the blood are no doubt foul air, sewer gas, neglect, and general bad stable maniagement. Dark stables are also a predisposing cause. The structures of the eye become weakened by want of their natural stimulus, namely, light.

Such are, in the author's opiniou, the usual causes of specific ophthalmia, where it prevails as an epizooty or even affects a small number of animals. This opinion is borne out by the fact that cases of specific ophthalmia are rare in comparison to what they were in past years, when 
sanitary laws were indifferently applied to stable management. But isolated cases occurring where the stable management is undoubtedly good, he thinks may probably depend on minor causes acting on the organ, which is, either from hereditary predisposition or from defective structure, abnormally susceptible. For instance, high feeding causing fever and slight inflammatory symptoms, or excessive or deficient light, or other such minor causes may in horses so predisposed bring on a disease in the Eyes.

An opinion has gained ground of late years, that the malady is allied to rheumatic inflammation in many, if not in all cases; and that it owes its origin to the same or similar causes as that disease. Hence some modern scientific Veterinarians have designated it rheumatic ophthalmia. The iris is the chief seat of disease, - a circumstance which, under the above supposition as to its origin, might be explained not only by the high vascularity of that organ, but also by its structure being almost entirely muscular. Cold damp stables in which other rheumatic affections are most apt to occur, yield more cases of Specific Ophthalmia than perhaps any others.

\section{Treatment.}

Active treatment is practically useless. The best chance is to turn the horse out to grass. If eataract begins to form, the disease will run its course.

As the disease, whether it arises from hereditary taint, or from any of the other causes mentioned above, is constitutional, the treatment must be mainly constitutional, though of course local remedies must not be neglected. Treatment, however, though every sort and kind of experiment has been tried, has not as yet often proved very successful in preventing a recurrence of the attacks. A laxative followed by calomel and opium in large doses (60 grains of the former and half a drachm of the latter) twice a day for several days in succession as soon as effusion has taken place, is now generally recommended.

Special regard should, in all cases, be paid to the causes from which it seems probable that the disease may have arisen. When an isolated case of disease is clearly traceable to hereditary taint, not much hope of relief can be held out. But where the disease is general among the horses, or frequent in any particular establishment, we may be pretty sure that some gross mismanagement exists, and it will be necessary entirely to reform the stable arrangements. Stable management is too large a question to be discussed incidentally, and the author must refer the reader to the chapter bearing on that subject. The best grooming, the best feeding, the utmost care, carefully regulated exercise, good ventilation, attention to the due and proper admission of light, and the administration of tonics, afford the best chance of enabling nature to throw off the present and to resist future attacks of the disease.

No very great results can be expected from local treatment; but still no item, which can give relief, should be neglected. The patient should be placed in a cool rentilated loose box, and a diminished light only 
should be admitted; the body should be kept warm by clothing; a linen shade kept constantly wet should be applied over the eyes by day, as the organ is intolerant of light.

When the attack is an isolated one, a diligent search should be made for the causes which may have induced it; and any such causes, if discovered, should if possible be removed or reversed. Thus, if the horse is fat and in high condition, depletives may be beneficial; whilst on the other hand, if the animal is low, good feeding and tonics will be appropriate. If the horse has been standing in a dark stable, and the eyes on that account perhaps have become weak, it is probable that the tone of the part will be benefited by the stimulus of a little more light during the periods of intermission of the attacks. If, on the other hand, the eyes have been affected by excess of light, relief may be given by decreasing it.

Such measures may not perhaps have very much effect, but still they ought not to be neglected. Their benefit consists not so much in reducing any existing attack-for that will abate under almost any or indeed without any treatment; but in the chance they afford, that by careful avoidance of all predisposing causes, added to careful attention to the general health and to good stable management in every detail, they may ward off the recurrence, or at least mitigate the violence of future attacks. By such care, with time, age, and increasing strength, there is some little reason to hope that kind nature may enable the system to wear out the disease and resist its occurrence. In most cases, however, Specific Ophthalmia in spite of all treatment runs its course, sometimes unobtrusively and with scarcely noticeable force, and at other times with acute symptoms.

Bleeding, however, as a general depletive, may be useful in some cases, where the pulse and other symptoms indicate the need of such a remedy. Setons under the eye, or preferably, rowels in the space between the jaws, or blisters to the face and between the jaws, have been frequently tried, but generally without producing any beneficial result.

\section{Cataracts.}

Cataracts are divided into true and spurious. The seat of true cataract is in the crystalline lens, in its capsule, or in both, or even between the lens and its capsule. Any opacity in the lens must seriously interfere with the vision. So likewise, though in a lesser degree, any opacity in the capsule or between the capsule and the lens will affect the power of sight. There are three classes of true cataract, distinguished as to name by the position they occupy, namely Lenticular, Capsular, and Capsulolenticular or Interstitial.

The colour of a cataract depends on various circumstances, and especially on the length of time that has elapsed since its formation. In the very early stage the lens may show only a slight nebulosity; later there may be seen in it streaky lines radiating to a centre, and at last cataract may be fully developed as a circumscribed white spot gradually increasing in size. 
As a general rule, after several attacks of ophthalmia the pupil dilates and clears, and cataract forms. But in special cases the pupil may remain constantly contracted, because adhesion has taken place between the capsule of the lens and the iris ; or, on the other hand, the pupil may remain abnormally open, if there is paralysis of the optic nerve or a tendency to amaurosis. In such a case the eye is more tolerant of light, because less susceptible of its effect.

In rare cases a portion of the capsule of the lens may be partially clouded, as a result of any injury or blow on the eye. Such cloudiness is usually only temporary, though sometimes it may be persistent.

Spurious cataracts consist of an effusion of lymph into the posterior chamber of the eye, perhaps adherent against or upon the anterior surface of the lens. The lens itself is not really affected. Flakes of white lymph are also sometimes seen in the aqueous humour in the anterior chamber. These, if they do not become adherent, are usually soon absorbed.

\section{Examination of the Eye for Cataract.}

The state of the pupil is best seen in a diminished light. The existence or otherwise of cataract, the proper motion of the iris, and the state of the structures of the eye generally, are then as a rule very easily observed. But in some cases it is advisable to take the horse into a darkened stable and to examine his eye by the light of a candle, when the pupil will be found to be fully expanded.

In health, when a candle is moved before the fully expanded pupil, three images of it will be seen. First an erect image moving upwards and downwards, according as the candle is moved. This image is produced by reflection from the surface of the cornea. Secondly, another erect image produced from the anterior surface of the lens;-this also moves upwards and downwards, according as the candle is moved. Thirdly, a small inverted image reflected from the posterior surface of the lens ; - this moves downwards when the candle is moved upwards.

In lenticular cataract, in the early stage, the inverted image is indistinct. In its later stage it cannot be seen at all. When the cataract has fully formed, the deep erect image is invisible. In capsular cataract only the front image is visible.

\section{Lenticular Cataract.}

Lenticular cataract, or in other words partial or complete opacity of the lens, is the result of the deposits left by repeated attacks of inflammation. The effusion is at first interspersed through the substance of the lens, but gradually, as the more watery parts of the effusion are taken up, the deposit concentrates to one spot and forms the opaque speck known as cataract. Cataracts are generally of very gradual formation. The first attack of inflammation, though it probably leaves some, yet generally gives rise to no perceptible deposit or opacity; but after several attacks the deposit or speck becomes apparent.

In old horses similar changes sometimes go on insensibly, ending in 
cataract without any perceptible periodical attacks of inflammation. The Author has also known the same to occur in a young troop horse. He recollects the case of a troop horse purchased in a sound state at five years old, and which was found to be affected at eight years old with lenticular cataract in both eyes, though it had never shown outwardly the slightest sign of disease in those organs.

\section{Capsular Cataract.}

Capsular cataract proceeds from the same causes and is formed in much the same way as lenticular; but for some reason not very easy to explain the deposit fixes itself on the inner surface of the capsule instead of in the lens. If the lens be examined by a good reflected light, it will be found to be clear behind its capsule.

In some cases capsular cataracts form from causes other than attacks of specific ophthalmia. In such, it is probable that the deposit on the capsule may be absorbed, and the eye restored to its pristine state.

\section{Capsulo-lenticular or Interstitial Cataract.}

The third variety of true cataract, known as Capsulo-lenticular or Interstitial cataract, is found in the form of an opaque fluid between the lens and its capsule.

By taking a side view of the eye, these cataracts are easily distinguished from lenticular, because the transparency of the lens can then be seen behind the opaque deposit.

\section{Absorption of Cataracts.}

True lenticular cataract is very rarely, if indeed it is ever absorbed. Capsulo-lenticular are occasionally, and capsular cataracts are somewhat more frequently absorbed in time.

\section{Degree of injury to vision caused by true Cataract.}

The degree of injury to vision caused by true cataract is very uncertain. Probably it depends more on its position than on its size. A small speck, for instance, in the centre of the lens will obviously be more injurious than a larger opacity on the side. The best plan in each case is to test the horse's vision by taking him up to an obstacle, and then to notice how far his sight is imperfect.

Horses which see imperfectly are very apt to shy, and on this account many horsemen prefer an animal totally to one partially blind. Again it may be remarked that blind horses generally step high, so as to enable them to clear unseen obstacles. They instinctively select the hard road, and are afraid of soft ground. The sense of hearing also becomes more acute, and is shown by the almost constant movement of the ears.

\section{No cure for true Cataract.}

Veterinary science knows no cure for true cataract. We cannot arail ourselves of those operations which in the human subject are so valuable, 
not incleed for the cure, but for the relief of this disease. The horse, as previously stated, possesses a very peculiar power of withdrawing at will the eye into its socket, which would much increase the difficulty of performing any operation; but even if this difficulty be got over, the operations common in human surgery, such as couching the crystalline lens, would not be of any use, as it is obviously impossible to supply the horse with glasses.

\section{Spurious Cataracts.}

Spurious cataracts are opaque specks on the cornea, or flocculi of lymph in the anterior chamber of the aqueous humour, generally adherent to the anterior surface of the capsule of the lens or to the posterior surface of the cornea. They are generally the result of an effusion of lymph arising from the inflammation of common ophthalmia, into the aqueous humour. They are also occasionally found as a result of the specific disease.

The amount of detriment which they occasion to vision depends on their size and position. If on the cornea, they will not interfere much, but on the capsule they become a more serious evil.

Spurious cataracts are frequently absorbed after a time. Sometimes they appear quite suddenly and without any apparent cause, and disappear as suddenly.

\section{Amaurosis.}

Amaurosis, partial or complete, results from paralysis of a part or of the whole of the optic nerve. According to the degree of the affection, the blindness may be total or partial. The eye is generally in all other respects perfect. On account of the insensibility of the retina to the effects of light, the pupillary opening remains unnaturally large, the pupil possesses more than ordinary brilliancy, and the eye has a ghastly stare. This appearance of the pupil at once points out the cause of blindness. Again, in his action the animal has all the appearance of a blind horse. In partial amaurosis the movement of the iris may not be wholly lost. It may be only sluggish.

\section{Causes.}

Disease of the optic nerve may proceed from various causes-either peculiar to that one nerve, such as excess of glare or heat, or from pressure on it, such as that induced by the formation of a tumour, by extravasation of blood, or any morbid effusion; or it may proceed from some abnormal condition of the brain generally, induced by causes such as those last named. Disease of the optic nerve may also proceed from some abnormal condition of the body, such as an overloaded stomach, which affects the nervous system generally, and with it the nerve of the eye.

Amaurosis is also occasionally, though but rarely, the result of the violent inflammatory action of specific ophthalmia; and it occasionally arises from extreme debility of the whole system or from excessive loss 
of blood. Pressure from a fall backwards or a blow on the head may also bring on the disease.

\section{Treatment.}

The treatment of Amaurosis must depend on the cause from which it arises or is supposed to arise. When originating in atrophy or wasting away of the optic nerve, it is incurable. There is more hope of cases resulting from some affection of the brain.

Tumours and morbid effusions on the brain are sometimes removed by kind nature, and with their removal the optic nerve may recover its tone. Art can do but little to assist in promoting this change.

In oppression of the brain induced by an overloaded or disordered condition of the stomach, a dose of purgative medicine will be useful. On the other hand, if the disease is connected with general debility, generous diet and tonics will be of service.

In all cases, as topical remedies, cold applications to the head and diminished light are to be recommended.

\section{Glaucoma.}

Glaucoma is indicated by a yellowish or sea-green appearance of the eyes, which comes on gradually in old age. This appearance is due to opacity or cloudiness of the vitreous humour. It terminates in total blindness, and is incurable. Its cause is not yet understood.

\section{Minor diseases of the Eye and its appendages.}

We now pass on to the consideration of some minor diseases of the eye and its appendages.

\section{Lacerations of the Eyelids.}

Most common among minor injuries is laceration of the eyelid arising from a bite or other accidental injury. The treatment usually consists in bringing together the lacerated parts and maintaining them in proper apposition by pins or silver-wire sutures. Great care is needed to prevent the patient from rubbing his eye against the manger. A wet linen rag should be hung loosely from above over the eye, and the animal should be reversed in his stall.

No part of the injured structure should be cut away, unless it is so hopelessly lacerated as to make reunion very improbable. The horse has need of the protection of all his eyelid, as a guard against the admission of too much light as well as against accidental injuries and the admission of foreign bodies.

There is always a strong natural tendency to reunion of these parts; and therefore with judicious management a successful result need not be despaired of, even in very severe injuries. If the parts have dried up, they should be pared enough to make the edges slightly raw, and then when skilfully pinned together they will adhere at once. Let them 
hleed a little before pinning them together, i.e. until bleeding stops, which it does in a very few minutes. By that time a coating of lymph will have formed, and will cause the part to adhere when the pins are withdrawn or have fallen out:

\section{Diseases of the Iachrymal passages.}

When a weeping or flow of tears over the cheeks is permanent, the cause will usually be found in some obstruction of the lachrymal ducts or canals, which lead from the eyes to the nose, and by which in a healthy state the tears are discharged. The obstruction is generally due to a thickening of the membrane of the duct, arising from inflammation. We are not acquainted with any remedy for this affection. It is unsightly, but not serious. A similar effect may be produced by loss of the lower eyelid.

A trickling unconnected with disease may arise from an excessive secretion of tears caused by some external irritation, by inflammation of the conjunctival membrane, or from swelling of the eyelids, which then obstruct the entrance of the tears into the lachrymal duct. Slightly warm foments may be useful. In these cases the effect will cease with the removal or cessation of the cause.

\section{Shying.}

When a horse has a trick of shying, it is always well to have its eyes examined by a Veterinary surgeon. Defective vision or incipient disease of the eyes is a common cause of this unpleasant habit. If however examination fails to detect anything wrong with the eyes, and especially if the horse is in other respects quiet and tractable, we are inclined to think that the habit may arise from the animal being short-sighted, or slow of sight. There is no anatomical reason why these defects should not exist in horses as well as in men. Indeed, modern experience has demonstrated its not infrequent occurrence, though it has as yet failed to furnish a remedy. The adoption of glasses is impracticable.

\section{3a. Blind Horses.}

A blind horse at once betrays its malady even to the casual observer by the one-sided carriage of its head, and the pricked though constant moving of the ears, as they intently listen for every sound. These peculiarities are as obvious with blinkers as without them.

\section{3b. Worm in the Eye.}

Worm in the eye, a disease not very unfrequent in some parts of India, has been treated of above in Chapter 54 . 
CHAPTER 58.

DENTITION, OR AGE AS INDICATED BY THE TEETH.

864. Introduction. 865. Structural alterations in the Teeth. 866. Back Teeth, otherwise called Molars or Grinders. 867. Anterior Teeth or Incisors. 868. Distinction between the Temporary and Permanent Incisors. 869. Temporary or mill Incisors. 870. Development of the Permanent Tteth. 8i0a. Drawing of Milk Teeth. 871. The Mark. 872. Bishop-ing. 873. The Fang-hole or Secondary Mark. 874. Further changes indicating thy Age-Lateral breadth-Triangularity - Length-Slope-loss of circularite in form of the jaw, etc. 875. The Tusks. 876. Collateral circumstances to be taken into consideration.

\section{Introduction.}

The principal guide to the age of the horse consists in the indications given by the Teeth.

We shall proceed to explain the changes which take place, more with the view of enabling the reader to form a correct judgment in regard to age, than of giving a general dissertation on the nature and structure of the Teeth.

\section{Structural alterations in the Teeth.}

Structural alterations take place in the teeth every year from birth up to the sixth year. Hence there can rarely be any question as to the real age of a horse up to that date, though dealers often try to deceive the unwary by various tricks. Such tricks are, however, easily detected.

After the mouth is fully completed, the age can only be approximately determined by the effect of wear in altering the shape of the teeth, by the receding of the gums, and by other such signs.

Many circumstances, however, often contribute to modify the effect of wear on the teeth, and also to increase or decrease the action of time in other respects. Hence, after six years old, a correct opinion can only be formed by those who have given to the subject some time, thought, and trouble.

866. Of the Back teeth, otherwise called Molars or Grinders.

The foal is born usually with two, sometimes with three, temporary molars in each jaw. About twelve months old another molar, a permanent tooth, appears, and before the completion of the second year a fifth molar, also a permanent tooth, shows itself.

About two and a half years old the two anterior temporary molars are replaced by permanent teeth, and between three and four the remaining 
or third temporary molar is similarly replaced; and about the same time the last or sixth permanent molar begins to appear. Thus when the mouth is completed, there are six permanent molars in each jaw, or twenty-four in all.

These structural changes afford a very good index of the age of the horse up to the period when they are completed, namely four years old. The Molars, however, are seldom referred to, because their position at the back of the mouth renders their examination inconvenient and often very difficult. Nevertheless, it is useful to be acquainted with the structural changes of these teeth in cases where there may be a doubt as to the true age as indicated by the incisors. After four years old, the molars are not often taken into consideration in determining the age of the horse.

We may mention in passing, that a supplementary molar known as a "Wolf's tooth," sometimes appears in either jaw. Such teeth seldom cause any inconvenience. If they do so, they can easily be removed by the pincers, as they are only of a rudimentary character.

\section{Of the Anterior teeth or Incisors.}

The Anterior teeth, or Incisors, are six in number in each jaw, when the mouth is complete; and in the immediate rear of these in males, there is usually added one very peculiar pointed tooth on each side in each jaw, called a tusk. Though there are two crops of incisors, yet there is but one of tusks. In fact, these teeth, though they begin to appear about four years old, are not usually fully developed until the last permanent incisor is more or less up.

For the sake of brevity we shall confine our remarks to the lower jaw, as the structural changes, which take place in the upper, are nearly similar. In passing, however, we may remark that the upper incisors are considerably longer and larger than the lower.

\section{Distinction between Temporary and Permanent Incisors.}

Temporary, otherwise called Milk (Plate 39), are easily distinguished from Permanent incisors by the following well-marked signs, namely, they are smaller, whiter, and have more distinct necks. They are smooth externally, and grooved on the inside,-probably in order to enable the foal more easily to grip the teats of the dam. Their fangs are small and have but little attachment to the gutns. The jaws are plump, fleshy and round, and the teeth are arranged in something like a semicircle.

Permanent teeth, on the other hand, are larger, broader, wider in their necks, grooved externally and smooth internally, and more discoloured than milk teeth. The discoloration is due to the lodgment of the juices and other matters connected with the food in the grooves. The object of the external grooving probably is to enable the animal to get a better grip on grass and such like food. The plumpness and circularity of the jaw is less than in the younger animal, and it gradually decreases, until in very old age the teeth are arranged in a nearly straight line. 


\section{Of the Temporary or Milk Incisors.}

The foal is born with his teeth in a rudimentary state in the gums. At various periods during the first ten months the different temporary incisors appear (Plate 39, figure 0). Under one year old the foal is also clearly distinguished by a woolly tail.

The yearling is complete in all six incisors, but several well-marked signs distinguish his mouth from that of the two-year-old. The teeth at this period show but little signs of wear. The corner teeth are mere shells, having no inner walls, and all the teeth are in close juxtaposition. (Figure 1.)

At two years old, the inner wall of the corner teeth has grown up level with the outer wall. The centre teeth show considerable signs of wear, and indeed all the teeth appear somewhat smaller than they did in the yearling. They also stand somewhat wide apart at their necks on account of the gradual growth of the jaw in width. (Figure 2.)

Inexperienced persons have been known to mistake a two-year-old for a five-year-old mouth. But the difference in the conformation of the animal, as well as of milk and permanent teeth (see par. 868), ought to make such a mistake impossible.

\section{Development of the Permanent Teeth.}

A few months before three years old, the horse sheds the two centre milk teeth, which are replaced by permanent. Thus the jaw contains at three years old two centre permanent teeth and two milk teeth on each side. (Figure 3.)

A few months before four, the horse sheds the two next milk teeth, which are replaced by permanent. Thus the jaw now contains four permanent and one milk tooth on each side. (Figure 4.) The appearance of the mouth when closed, and also the mode in which the teeth meet, are shown in figure $4 a$. This figure will be presently contrasted with figures 26 and 27 , which show the mode in which the mouth closes and the teeth meet in extreme old age.

A few months before five, the horse sheds the two remaining milk teeth, which are replaced by permanent. Thus the jaw is now furnished with six permanent incisors, but the corner teeth are mere shells, having no internal wall. The absence of this wall distinguishes the five from the six-year-old mouth: (Figure 5.)

A few months before six, the inner wall of the corner teeth has grown up level with the outer wall. (Figure 6.)

The mouth is now fully complete in incisors, and no further structural changes take place in them. As a general rule, we may add that the upper temporary teeth fall out a little before those in the lower jaw.

Up to six years old, therefore, inasmuch as we have structural changes to guide us, there can seldom be any doubt as to the age of the animal. There are, however, some well-authenticated instances of abnormal development of the permanent incisors, but they are rare.

Thoroughbred horses date their age from the 1st of January, whilst 
other horses are reckoned from the 1st of May. Thoroughbred mares are covered so as to throw their foals as soon as possible after the 1st of January; whilst in regard to other mares the owner does not wish to have their progeny born before the spring grass is available for the sustenance of the dam and her foal.

High feeding encourages the growth of the teeth in common with the rest of the frame. Hence thoroughbreds (independently of their earlier date of foaling) are somewhat more forward in their mouths than halfbred animals, though on the other hand it increases the wear and so hurries the obliteration of the marks.

\section{0a. Drawing of Milk Teeth.}

A practice prevails of tampering with the milk teeth, in order to make the animals appear of more mature ages than they really are.

In horses rising four years old the corner temporary incisors are pulled or punched out, in order to hasten the growth of the permanent teeth, which would in the process of nature take their place at a later period, and thereby give the horse the appearance of rising five years old.

More rarely attempts are made to give the three-year-old mouth the appearance of four by drawing the outer milk tooth on each side.

In the foreign horses now largely imported it is common to find both milk teeth drawn on each side in three-year-old animals.

No doubt in all these cases nature does to a certain degree hasten the development of the permanent teeth, in order to supply the vacuum.

There is, however, no need for anyone to be deceived as to the real age of an animal which has been subjected to such treatment. The upcoming permanent tooth is usually displaced in its alveolus or socket by the violence used in punching out the milk tooth. Again, the removal of the milk tooth before its time deprives the upcoming permanent tooth of its natural guide to the surface of the jaw, and causes it to make its appearance slightly diagonally to the curve of the jaw, thus leaving a space between it and the neighbouring tooth, which is quite abnormal.

Again, the enamel of the crown of the new tooth, from having been brought into use before its natural time, is not properly consolidated, and hence presents an irregular appearance, quite different from that of the naturally developed tooth.

In males this trick may be at once detected by the absence of the tusk, which will not come up before its proper time; but in mares we have not this assistance.

\section{Of the Mark.}

Hitherto we have taken no notice of the "Mark," or Infundibulum. We have abstained from doing so, not because the marks in the young mouth do not afford some indication of the age, but because fuller and more satisfactory evidence up to six years old is afforded by the structural changes detailed above. At and after six, however, we are compelled to have recourse to the indications given by the marks and other slight, but 
gradual, alterations which take place in the form of the teeth and their position-these latter, however, are more reliable than the marks.

A satisfactory explanation of the mark cannot, we are afraid, be given without entering at some length into the structure and organisation of the teeth. The Mark or Infundibulum is a very peculiar hollow extending, when the tooth first comes up, about half an inch down the temporary and rather deeper down the permanent incisors. (Figure 18.)

Teeth practically may be said to consist of two materials, namely, enamel and dentine. Enamel, which is very hard, sharp, and originally of pearly whiteness, covers the outside of the teeth, and also lines the sides and bottom of the hollow or infundibulum. Thus in the tooth, as it originally appears, there are four walls of enamel. The remainder of the tooth consists chiefly of dentine, a substance of considerable, but less hardness than enamel, and more like ivory. A small quantity of crusta petrosa is also found on the outside of the fang extending upwards and overlapping the enamel covering the crown.

When an incisor first comes up, the hollow affords lodgment for the débris of the food and the juices expressed from it, and therefore soon looks black. As the tooth wears down, the hollow of course disappears; but the surface of the dentine immediately below the original hollow, being a somewhat soft material, has become stained for some distance down. Thus there is still a black mark. With the further wear of the tooth the stained portion of the dentine wears away, and the "mark" is then said to be out. The mark, as the reader will easily see from this description, is in a constantly changing condition.

Premising that the time, which the mark will take to wear out, will vary to a greater or less degree according to certain circumstances detailed hereafter, we shall now endeavour to give some general rules for guidance.

Between three and five years old all the marks are very plain in all the permanent incisors. (Figs. 3, 4, 5.) At six, the marks are wearing out of the two centre teeth, which came up at three years old. They are plain in the two next, and perfectly fresh in the two corner teeth. (Fig. 6.)

At seven, the marks have disappeared from the centre teeth, are wearing out of the two next, and are distinct and plain only in the corner teeth. (Fig. 7.)

At eight, the marks have disappeared from all but the corner teeth, in which they are becoming indistinct. (Fig. 8.)

At nine, the marks are not usually found in any of the teeth. (Fig. 9.)

For about two years after the mark has disappeared in each tooth, there may still be seen in the form of a star a trace of the enamel which lined the bottom of the original hollow, and which underlies it for some depth. This star of course decreases in size with the wear of the teeth. About twelve or thirteen the last traces of the enamel have usually disappeared even from the corner teeth, but it may remain some time longer.

Many casual circumstances, however, cause a certain degree of devia- 
tion from these general rules. The time, which the mark takes to wear out, will vary in different horses according to the hardness or otherwise of the teeth and according to the nature of the food on which the animal is kept. In grass-fed horses the marks usually remain at least a year and sometimes two years longer than in those fed on hard food. Again in parrot-mouthed horses, that is, where the upper overlaps the lower jaw, the marks may remain for many years. (Fig. 29.)

On the other hand, some horses, which have a trick of biting the manger, wear down their teeth very rapidly, and therefore lose their marks very early. Horses fed on salt marshes where the sea sand is washed up among the grass, or on sandy plains or meadows, are affected by the increased friction on the teeth caused by the sand. Occasionally a projecting tooth in the upper jaw may cause unusual friction on the corresponding tooth of the lower jaw, and so may hasten obliteration of the mark.

Most of these and other causes of irregularity of wear, which might be mentioned, are at once apparent to a careful and accurate observer, and will scarcely prevent his forming a pretty correct opinion of the age.

The upper incisors, as previously stated, are considerably longer and larger than the lower, and the infundibulum is nearly twice as deep. The marks therefore remain longer than in the lower teeth. We mention this in passing, lest the reader should be misled, if he should by chance refer to the indications given by the upper teeth to corroborate or correct any opinion as to age, about which he may be in doubt from the appearance of the lower jaw.

Occasionally the dentine on the side of the infundibulum may become stained and even black, and in such cases something like a double mark may be observed.

The mouth taken as a whole is broader at seven years old than at any other period. After this it gradually narrows with age. In this respect the drawings, taken as a consecutive series, are in some degree at fault, as the Author found it impossible to get mouths of the required ages to form a perfect ideal series. For instance, the mouth represented in figure 16 (extreme age) obviously has belonged to a very different animal from that shown in the preceding figure. Again, figures 16 and 17 are fair specimens, though very diverse, of what may be expected in extreme age.

872. Bishop-ing.

Marks on the incisors are occasionally simulated by means of caustic or the hot iron by low dealers with the view of deceiving the unwary.

The fraud is readily detected, because though it is easy to make a black mark on the crowns of the teeth, yet it is impossible to restore the wall of pearly enamel, which surrounds the natural mark. (Figs. 19, 19a.)

\section{The Fang-hole or Secondary Mark.}

About nine years old, in consequence of the wearing down of the teeth, a slight trace of the fang-hole usually appears in the centre teeth, and 
somewhat later in the other teeth. It is indicated by a slight discoloration of the tooth at the above point. There is, however, no actual hole, because with advancing years the upper part of the original cavity has become filled up with a sort of spurious dentine, which is more yellow than the true material, of which the body of the tooth consists. As age increases, this indication of the fang-hole, which is sometimes called the "Secondary mark," becomes rather more plain. It, however, affords no reliable data by which to judge of the age, and is only mentioned in this place lest the reader should mistake it for the remains of the infundibulum. The enamel, it will be remembered, is pearly white, whilst the mark of the fang-hole is brownish yellow. The position of the fang-hole is shown, fig. $18 \mathrm{~B}$.

\section{Further changes indicating the age.}

It will be seen that about nine the "marks," never very reliable, entirely fail us, and indeed after seven or eight they can hardly be said to afford any very reliable data. Veterinary surgeons and horsemen prefer to judge the age mainly by the changes which gradually take place in the shape of the teeth. But the public always rely a good deal on the marks.

From eight years old and upwards the best indications of the age are given by the gradual alterations, which take place in the shape of the teeth from wear and in the closing of the mouth.

Lateral breadth, \&c.-The teeth originally are broad laterally at their upper surfaces, otherwise called their crowns or "tables," and thin from front to rear. (Figures 4, 5, and 6.) They narrow gradually towards their necks and fangs. Hence as their upper surfaces wear off, the teeth become narrower year by year. In very old horses there is often a positive interval between the teeth (figures 16 and 17), and they appear like sticks in the jaw.

The gradual effect of wear in producing this alteration is shown in figure 20, where successive portions of the upper surface of the tooth are represented as having been removed by the saw. The original form of the tooth is shown in fig. 21.

The amount of wear on the upper surface of the teeth is greater in the young mouth than it is afterwards, because in youth the teeth meet more fairly than they do in after years. (Compare Figs. $4 a$ and 27.) The rate of wear gradually decreases as years increase, because the teeth do not meet so directly, but on the contrary project more and more forward in something like two parallel lines. For example, a quarter of an inch will usually be worn off the surface between five and six years old, whilst probably not more than that quantity will be worn off between twenty-and twenty-five years old.

Triangularity.-A further very well-marked indication of increasing age is given by the increasing depth from front to rear in the upper surfaces or crowus of the teeth. This increase of depth will be noticed if figs. 7 and 8 are carefully compared with figs. 4, 5, and 6 . Further wear causes the crowns of the teeth to assume a triangular form. The cause of 
this will be clearly seen on reference to fig. 20 . The teeth, though they diminish in lateral breadth, increase in thickness from front to rear all the way from the crown to the fang. (Figs. 20 and 21.)

At six and up to eight years old, the teeth are all broad laterally at their upper surfaces. (Figs. 6, 7, and 8.) Up to this time the exact year, as the reader will recollect, is pretty well known by the "marks."

At nine, when the marks fail, the alterations in the crown surface or table come to our aid. The two centre teeth, which came up at three, become somewhat triangular. (Fig. 9.) At ten, the two next teeth show similar signs. (Fig. 10.) At eleven, the corner teeth have become somewhat triangular. (Fig. 11.) At twelve the triangularity has increased in all the teeth. (Fig. 12.) This alteration continues to increase in all the teeth, until in very old horses the depth from front to rear exceeds the lateral width of the teeth. Figure 13 shows an average mouth of sixteen years old. Figure 14 represents the appearance at twenty. Figure 15 shows twenty-four; whilst figs. 16 and 17 may serve as specimens of the teeth in extreme age.

Length.-Again, as age increases, the teeth, notwithstanding they really wear down, become apparently longer. This effect is due to the fleshy parts of the gums receding faster than the teeth wear down. In extreme age, however, when the guns have receded as far as they can, the effect of wear causes the teeth to become visibly as well as really shorter.

Slope.-An alteration also takes place in the position or "slope" of the teeth, as regards their closing. This is due to the effect of wear. The original form of the tooth is shown in fig. 21. Its upper portion, it will be seen, is nearly perpendicular, whilst the lower part lies in a more horizontal position. Hence in youth the teeth meet directly, whilst in extreme age they can scarcely be said to meet at all. Their stumps project forward in two almost parallel lines. (Figs. 26 and 27.)

The various changes which take place in the position of the teeth in reference to their position or "slope" are shown in figs. 2 to 27 . At two years old (fig. 2) the gums are full, fleshy, and prominent, and the teeth are nearly perpendicular. The gradual changes, which take place in the slope with increasing years, are shown perhaps more clearly in the plates than could be explained in words.

Up to twelve years old, there can scarcely be much difficulty in forming a pretty correct judgment as to the age. After that time it requires more time, practice, and opportunity than most people have at disposal to obtain the requisite knowledge.

It would probably scarcely interest the non-professional reader to trace very minutely the changes which take place after twelve years old. Suffice it to say, that the gums continue year by year to recede, the teeth become apparently longer and longer and really narrower, and consequently the intervals between them increase, and they project forward more and more in a straight line.

About twenty or twenty-two, and in some instances a good deal sooner, the teeth, which up to this period have apparently increased in length, begin to grow visibly shorter, because the gums are so far alusorbed that 
they can recede no further. Hence all further wear shows its effects by diminishing the length of the teeth.

Loss of circularity.-In the very young horse the teeth are arranged almost in the form of a semicircle. Year by year this form decreases, until in old horses the teeth are arranged in something like a straight line. Compare figs. 0, 1, 2, 3, and 4 with figs. 14, 15, 16, and 17 .

If the reader should happen to be in the neighbourhood of a cavalry barrack, he will have the best possible opportunity of studying the age of living horses, because in every regiment an accurate register is kept of the age of every horse. As all the horses are bought at four or five years old, it is almost impossible that any mistake can occur.

Memorandum. - The drawings of the teeth have all been made from nature ; and hence, although pretty normal specimens have been selected, yet in various ways they present in some instances irregularities and deviations from a positively regular rule of wear. Perfect regularity in wear and in the effect of wear is seldom found in nature. In some instances it will be observed that the enamel is higher and more prominent than in others. This difference does not indicate or in any degree depend on age, but simply on the comparative hardness or softness of the enamel and dentine.

\section{The Tusks.}

In horses, as distinguished from mares, great assistance in determining the age is derived from the presence of the Tusks, which are generally wanting in the latter. The tusks usually begin to appear in a very slight degree about three and a half or four years old. Their sharp points then just pierce the gums, and they continue to grow until fully developed about five or five and a half years old. They do not meet like other teeth, and thercfore do not suffer from wear from that cause. They suffer however from wear in the course of mastication, and in fact undergo greater changes than any other teeth, and so form a valuable guide as to age.

The tusk is a very peculiar-shaped elongated tooth. Internally it consists of dentine, and is protected on the outside only by enamel. The enamel however overlaps the dentine, and hence arises the sharp edge or hook of the newly developed tusk, which may be felt if the finger be brought round it from behind.

This sharpness gradually wears off. After seven it has disappeared, and in each succeeding year the tusk becomes not only rounder and blunter, but its upper portion wears off. It also appears yellow, on account of the dentine becoming exposed by reason of the enamel wearing off its exterior surface. The tusks, unlike other teeth, do not apparently increase in length with-years, but become shorter and shorter. In fact the effect of wear is greater on them than on other teeth, and it is also greater than the process of the receding of the gum. In very old horses the tusk is very little above the level of the gum. Mares sometimes have four small rudimentary tusks.

The alterations, which gradually take place in the form of the tusks, are shown in a series in fig. 28. 


\section{Collateral circumstances to be taken into consideration.}

In judging of the age of the horse by the teeth, every collateral circumstance requires to be taken into consideration, such as the form of the mouth, the way in which the teeth meet and close on each other, the food on which the animal has been kept, any irregularity in the upper teeth which may cause increased or diminished wear on the lower teeth, and also the habits of the horse in the stable. The teeth of animals, which bite at the rack or manger whilst being cleaned, invariably present appearances of wear beyond their real age.

The body also presents many indications of the age which may assist us in forming an accurate opinion, and sometimes may enable us to correct an erroneous impression produced by some abnormal appearance of the teeth. The young horse is fleshy about the gums and head, and the hollow over the eye is shallow. Year by year, as age increases, the gums lose their fleshiness, the head becomes more lean, and the hollow over the eye deepens. The shoulders lose much of their thickness and become finer, and assume an appearance of greater length. The hind quarters in like manner lose some of their roundness, and the animal generally gains an appearance of more breeding than he had in his younger days. The back becomes more or less hollow, a result partly due to the effect of weight, especially in long-backed animals, and partly to loss of fleshiness of the muscles which run along the spine.

Again, as the horse becomes old, the fulness of the chin under the mouth disappears. The inferior margin of the branches of the bone of the lower jaw also becomes thin. Lastly, the general appearance of the aged horse is much influenced by the work he has done and the treatment he has received.

Age must not be judged by any one sign, but by a mean judiciously struck between all the signs, and by a careful consideration of all collateral circumstances. It never happens that all the signs combine together to deceive a careful and well-informed observer.

From these pages the reader will perceive that after six years old, i.e. after the structural changes in the mouth are completed, it is impossible to lay down any one single definite rule by which the age can be ascertained. Still, with a little trouble and attention there is no real difficulty in acquiring a knowledge of the horse's age up to a comparatively late period of his life.

Such a knowledge is always valuable to an intending purchaser. Horses of eight or nine years old are still in their prime; but from want of knowledge of the means of ascertaining the real age, and from very natural distrust of what the owner may tell them, the public are very shy of buying such horses; and consequently they may generally be obtained at prices far below their real value.

The Author is well aware of the popular feeling in favour of young horses ; but in his own opinion a moderately fresh "aged" horse is generally a much more useful, presently available, and therefore more really valuable animal, than a young untried horse with all troubles, ailments, diseases and liability to disease before him. 


\section{CHAPTER 59.}

\section{LAMPAS.}

\section{Lampas. 877a. Dentistry. 877b. Stomatitis. 877c. Glossitis.}

\section{Lampas.}

Lampas is congestion of the blood-vessels in the lining membrane of the Palate. It is most common in young animals from irritation set up by the growth of or changes in the teeth. It may also occur in horses at work from inflammation set up by bit injuries, and in old horses from irregularity of the teeth. The soreness so caused will prevent the horse from masticating his corn, and the inflammation may give rise to feverish symptoms.

Where the inflammation and soreness is due to the processes of dentition, no treatment is necessary except to put the animal on wet bran and soft food for a few days, by which time the inflammation will have subsided and the soreness passed away, and the horse will again feed.

Where the inflammation is due to injuries from the bit, the remedy of course is to remove the cause and treat as above.

When Lampas occurs in old horses, the cause will be found in some irregularity of the teeth, generally of the molars. The irregularity must be carefully removed by the rasp (see infra, Dentistry). Other treatment as above.

In cases where the congestion is excessive, and causes the palate to project on a level with or below the tables of the Incisors, free scarification, which consists of superficial incisions with a lancet, will afford immediate relief.

A brutal practice was in fashion some years ago of burning the palate with a hot iron. This barbarous and useless custom is now happily extinct.

\section{7a. Dentistry.}

In young horses some febrile diseases, which are commonly attributed to atmospheric or other causes, are often due to Teething, especially in blood stock, which are forced and artificially developed from the moment of weaning to prepare them for their turf engagements. It is therefore always wise to examine and be guided by the state of the gums before adopting any treatment. The mischief is generally caused by some irregularity in the development of the permanent molars, especially when their growth is interfered with by retarded removal of the crowns of the temporary ones. The gums will show considerable irritation and inflammation.

The treatment consists in keeping the animal on soft diet and grass if obtainable, with slight scarification, lancing of the congested membrane, or the surgical aid indicated. 
In aged horses the attention of the equine dentist is, however, most needed to the molars. As age increases the permanent molars in many cases require periodical rasping to prevent their sharp points from wounding the inside of the cheeks, and thereby causing the horse to bolt his food instead of properly masticating it, and thereby gives rise to indigestion; and in some instances the pain so caused will altogether prevent the animal from feeding. Another commoner cause is irregularity in the height of the molars. One or more may be so much higher than the others as to interfere with mastication. The remedy is the rasp in the hands of a skilful operator.

When the Molars have to be smoothed or shortened, each tooth should be rasped singly, not collectively, as was formerly the practice. Horse tooth rasps have been very much improved of late years. Those of one or not more than two inches in length in the rasp with ridge guards are the best.

A careful servant, who watches his horse while feeding, will readily detect dental trouble by the Slobbering or "Salivation" that attends painful or difficult mastication. In many cases the animal will eat with his head on one side, whilst in worse cases the food after imperfect mastication will be quidded or ejected from the mouth.

\section{7b. Stomatitis.}

In addition to the febrile conditions produced by Dentition, there are some other diseases of the tongue and mouth, of which a short description may be useful.

Stomatitis, or inflammation of the mouth, more frequent in old than in young horses, is due to various causes, but most commonly to mechanical violence or to bàrbed grasses, especially Squirrel-tail or Meadow barley. The treatment is removal of the cause. Occasionally it occurs in foals, whilst yet with their dam.

Stomatitis usually takes the form of vesicles, which rupture suddenly, leaving ulcers, which sometimes run into each other, and if occurring in horses of bad habit of body they are tardy of healing.

General treatinent-ordinary eare of health and surroundings. The local treatment consists in pulping the food, which should be given in boiled linseed jelly. Gargling the mouth after feeding is also needed. After gargling the excoriation may be painted with chlorate of potash, half an ounce to a pint of water. Where fotor is present, a solution of Sanitas, one part to six of water, will quickly subdue the smell. If the ulcers become chronic, they may be rendered healthy by being dressed with lunar caustic.

\section{7c. Glossitis.}

Glossitis or inflammation of the Tongue is a rare affection in the horse. It is indicated by tenseness and protrusion of the tongue from tumefaction. The dorsum or upper surface of the tongue becomes brown in colour. There is difficulty in swallowing and an accumulation of glairy saliva which, if not carefully removed, gives rise to foctor. 
The treatment must for obvious reasons be per anum and laxative in its nature. A clyster of linseed oil four ounces, warm water one pint (well shaken), may be injected occasionally to keep the bowels open. The patient should be encouraged to suck linseed tea or thin gruel, either of which can be medicated with chlorate of potass, half an ounce to a pint of water. The tongue should be scarified and then gargled with warm water. The head should be freely steamed. A larger bucket or nosebag than usual should be used, so as to permit free respiration.

The causes of both Stomatitis and Glossitis are often obscure.

\section{CHAPTER 60.}

\section{CONFORMATION.}

878. Conformation to be studied. 879. Idea of a good-shaped Horse. 880. Mechanical reasons for good and bud shapes. 881. Defects, dependent on the use required. 882. Special points needed for some sorts of work. 883. Of the bony frame. 884 Head. 885. Forehead. 886. Nose. 887. Nostrils and Muzzle 888. Mouth. 889. Eye. 890. Ears. 891. Mane. 892 Neck. 893 Setting on of the Head. 894. Withers. 895. Shoulders. 896. Scapula. 897. Humerus. 898. Chest. 899. Radius. 900. Ulna. 9u1. Knee. 902. Metacarpal Bones. 903. Fetlocks. 904. Sesamoid bones. 905. Coffin bone or Os pedis. 906. Navicular bone. 907. Forefeet. 908. Soles. 909. Frog. 910. Ltg below the Knee. 911. Back. 912. Ribs. 913. Pelvis. 914. Loins. 915. Hind quarters generally. 916. Femur, Tibia, and Stifle. 917. Hock. 918. Great and.Small Metatarsal Bones. 919. Sesamoid and Navicular bones of the Hind leg. 920. Hind feet. 921. Tail. 922. Sheath. 923. Dock. 924. Belly. 925. Body. 926. Bone in different breeds. 927. Muscles. 928. Tendons and Ligaments. 929. General Remarks. 930. Action: 831. Defects in Action. 931a. Stumbling. 932. Position in standing. 933. Colour. 934. Constitution. 935. Breeding. 936. Distinctive Marks and Colour. 937. Sulkiness. 937a. Conclusion.

878. Conformation to be studied.

Whilst with some men a knowledge of the shape of the horse appears to be almost intuitive, with others and indeed with the great majority it is not so. Many acquire it only by continued experience of losses and disappointments. Even with those who are naturally pretty good judges of horse-flesh, a better knowledge of the leading points would probably assist them, especially at the commencement of their dealings. 
Conformation in good truth requires to be studied and learnt in the same way as any other item of knowledge. Some may learn it quickly, some slowly, but all may learn.

The drawing of the skeleton is reduced from a large print by Professor Varnell, late of the Royal Veterinary College. (Plate 39.)

\section{Idea of a good-shaped Horse.}

A good horse is an animal with many good, few indifferent, and no bad points. Any one radically bad point neutralizes any number of good points. As in a chain any one really defective link will destroy its power of holding, so in a horse any one radically bad point will render useless the aptitude and compactness of the conformation in other respects. The greatest strength of a chain is limited by its weakest link. Similarly in a horse, his strength is limited by his weakest point.

But this is not all. In addition to the absence of weak links, in the horse it is needed that all the links should be of proportionate strength. Though in a chain it would not signifiy much if one link were stronger or heavier than the rest; yet in the horse, whose primary value is his power of locomotion, in whom every limb or part has to be moved or carried in the process of locomotion, it is essential that no one limb or structure should be disproportionately heavy or strong, or in other words cumbersome in comparison to another. Excess of power or development in one part in a horse may not be merely useless,--because the strength of the animal is limited by the weakest point;-but it may be and often is a positive source of evil, and, if we may use the expression, of weakness. For example, a well-developed carcass with good deep back ribs on the top of weak legs will by its disproportionate weight and substance cause the under-structures to fail sooner than they would otherwise do. Similarly a strong powerful fore-hand is not an advantage if the hind quarters are light; because the stress on the propelling agents will be unduly great, and they will in consequence be more liable to fail. Similarly, if the fore-legs are weak, they may suffer from excessive propulsion communicated to them by powerful hind quarters; whilst they might perhaps have lasted for years if the propelling power had been less good. These examples, which might easily be multiplied, will probably be suffcient to illustrate our meaning. In a well-formed horse there must be no weak point; neither must there be any part disproportionately powerful to the other parts.

We cannot, however, expect to find in a horse, or indeed in any animal, our ideal of perfection. The Author wishes to be careful not to lead the reader to look for perfection. A good horse is an animal "with many good, few indifferent, and no bad points."

Minor deficiencies are often lessened, though never quite compensated for, by other points of conformation. For instance, a horse may have short back ribs, and may therefore appear hollow in the flank; but if he has wide hips and strong loins, it affords some compensation for the defect. It may even happen, that points in themselves somewhat objec- 
tionable may to a certain degree remedy other faults. For instance, a horse deficient in bone below the knee will be less likely to fail at that point, if also somewhat light in his carcass.

\section{Mechanical reasons for good and bad shapes.}

Good points in a horse are not mere matters of ideal beauty; but shapes, which on principles of mechanics, are likely to answer the required ends. For every so-called good shape a sensible reason can be given; and so likewise a mechanical objection can be shown to every bad shape.

\section{Defects, dependent on the use required.}

But shapes, which may be decidedly objectionable for one class of work, are not necessarily equally objectionable for another description of work. Thus a hollow back, which would be very objectionable in a troop horse, an animal especially required to carry a heavy weight on its back, is not equally objectionable in a draught horse. Again good feet, which are essential in hackneys, are not equally essential in harness horses. Good feet, however, are valuable in any horse, and any defect in this organ always leads to trouble,--though perhaps with care and attention the animal may continue to go sound for years under favorable circumstances.

\section{Special points needed for some sorts of work.}

It is nearly impossible to obtain perfection of shape, except perhaps occasionally at a very long figure. The intending purchaser should therefore pay special regard to those points which are essential for the class of work, for which he needs the animal ; whilst in other points he may be content with something short of the ideal standard.

Again, each class of horse, the racer, the hunter, the hackney, the cob, the draught horse, \&c., has some particular points in his best conformation which would be absolutely faulty in another.class. For instance, in the dray horse we look for circularity of the ribs, breadth of chest, and fore-legs wide apart,- points which would be absolutely ruinous in a racehorse, whose special vocation requires a deep chest, and legs closer together. In the one animal we want all that contributes to strength and weight and aptitude to put on flesh; whilst in the other we need those shapes which are most likely to give speed combined with endurance. The respective conformations of the bull-dog and the greyhound will perhaps illustrate our meaning.

The remarks on Conformation, which follow, are chiefly directed to the better class of horse, used for racing, hunting, riding, and light-harness work.

\section{Of the Bony frame.}

As outward forms are mainly dependent on the formation of the bony skeleton, we shall at once proceed to the consideration of that structure. 
In a well-bred horse the tendons, ligaments, and muscles are generally in keeping with the bones, i.e. large bones usually give attachment to large powerful muscles, tendons, \&c. Again the processes of the bones are much more developed, and thereby give a great mechanical advantage to the muscles. In the underbred horse, on the other hand, we frequently find large, coarse bones accompanied by small tendons and ligaments and deficient muscular development.

The bone of a thorough-bred horse, we may remark, is relatively stronger in proportion to its size that that of a coarse animal. Its structure is more dense and firm. It is said to be an ascertained fact, that an inch cut from the metacarpal bone of a thorough-bred horse will weigh more, when dried, than the same quantity cut from the metacarpal bone of a low-bred animal when similarly dried, although the latter may be much thicker. The difference between them is the same as that which exists between "ivory" and "bone."

The power and value of a horse increases with his size, provided the relative proportion of the parts and the general compactness are maintained. This, however, is but rarely the case. A good big horse, it is true, will always beat a good little horse; but then good big horses are, for the reason given above, few compared with the number of good little horses.

Very large horses are seldom good for much. There is a certain size beyond which the parts do not seem to grow in due proportion to each other. Again, size and development must not be made up of or be largely interspersed with fat; but it must arise from natural development of bone, muscle, and tendon.

Without good structural formation we cannot expect strength; but it by no means follows that even with it we get the desired qualities.

\section{The Head.}

In considering the various bony structures, we shall commence with the Head.

The head should be small. A large head acts like a heavy weight at the end of a long lever. It has a tendency to make the horse heavy in hand,though this also much depends on its setting on, and on the obliquity or otherwise of the shoulders. It also operates unfavorably on the progression, is apt to make the horse stumble, and, if he does stumble, may help to over-balance him. A silly remark is sometimes made in favour of big heads, viz. that horses do not go on their heads. This is no doubt true; but a heavy weight at the end of a long lever like the neck is likely enough to cause a horse to come on his head.

For riding horses large heads are very objectionable; but for harness work this point is not of much consequence, except as a matter of appearance. A small head is a marked sign of breeding, whilst a large head denotes an underbred animal. A long, lean head is, however, often found in well-bred horses.

The well-bred head, though usually small, is wide across the forehead, 
lean, unencumbered with flesh, finely chiselled, and terminates rather wide at the nostrils. The base of the skull is wide. The distance from the eye to the angle of the jaw is great. It is also wide under the jaw, or as it is sometimes called in the jowl or channel, in order to allow ample room for the larynx and respiratory passages. In high-bred horses we often have a prominence in the forehead with a sinking in just above the nose.

Fig. 1 represents a very good, fig. $1 a$ a common, and fig. 16 a very coarse underbred head. (Plates 32 and 33.)

\section{The Forehead.}

Whilst the head should be small, the Forehead and base of the skull should be not only relatively, but absolutely broad, in order to give due capacity to the cavity containing the brain and great nervous centres. Energy and resolution largely depend on the development of the nervous system. Pluck and endurance will assuredly be wanting if the nerrous power is deficient.

It is rather a curious fact that small well-bred heads are actually wider between the eyes than large coarse underbred heads; or in other words the brain region is larger in high than in underbred animals. Figs. 2 and 3 represents the forehead of a well-bred horse, fig. $2 a$ that of a common animal, and figs. $1 b$ and $2 b$ that of very coarse brutes.

\section{The Nose.}

In fig. 1 , and 3 and $3 b$, a very good nose is shown. A projecting or Roman nose (figs. $1 b$ and $2 b$ ) usually indicates want of breeding. A tendency however towards that form in a rather long, lean, and otherwise well-bred head is occasionaly found even among some of our best thorough-bred stock.

\section{Nostrils and Muzzle.}

Breeding or its absence is very plainly indicated in the Muzzle. In the well-bred horse every part is boldly marked. The borders of the nostrils are scanty and end abruptly. The Nostrils themselves should be large and wide and unencumbered with hairs in the entrances, and they should occupy nearly the whole of the lower part of the facial structure (Plate 32, fig. 1, and Plate 33, fig. 3). The horse, unlike man, who breathes chiefly through his.mouth, breathes entirely through his nostrils. Hence in all horses required for fast work and endurance, well-developed large nostrils are of great importance.

In the low-bred horse the entrances of the nostrils are contracted by the overlapping of their borders, and the entrances are small and beset with long bristly hairs. Plate 32 , figs. $1 b$ and $2 b$. 


\section{The Mouth.}

The Mouth of the well-bred horse is small and the lips are small and thin and yet firm. Fig. 1. The mouth of the underbred horse is large, and the lips are large and flabby. Fig. 1b. Also fig. $2 b$.

\section{The Eye.}

The Eye should be large, prominent, and mild, with a well-developed brow and fine eyelids. The weapons of defence in the horse consist of his power of flight and in his heels. Nature has made the eye of the well-bred horse prominent, by means of which he is enabled to command a great range of vision. Fig. 1. Such horses are generally fearless and bold; whilst an animal with a sunken eye is nearly always suspicious, perhaps because he cannot see so well around him, and he is often also sulky. Fig. 16 . Also fig. 26.

An eye which is unduly round in the anterior portion of its globe, and on this account over-prominent, is objectionable. It is believed in some cases to be productive of short-sight, and, as a consequence, of shying. The prominence in the formation of the eyeball itself must not be confounded with the prominent setting on of the socket mentioned above.

There is much to be gathered of the character of the horse from the expression of his eye. The rather sunken sour, or "pig" eye is allied to vice, whilst a mild expression generally indicates good temper. Horses which show the white of the eye, when looking askance, are said to be vicious; but the Author has not been able to verify this tradition in his experience.

\section{The Ears.}

The Ears should be thin, delicate, small, and pointed, that is, directed forwards. The points should be nearer to each other than the roots. Horses with their ears close at their base are generally nervous. When the horse is at work, the ears should be kept firm. Figs. 1 and 3 . If they hang loosely, it indicates want of tone and of muscular development. Large flabby ears mark an underbred horse. Figs. 16 and 2b. Lop ears are ugly, but are found in all classes of horses.

\section{The Mane.}

In the well-bred horse the hair of the Mane is fine, silky, and generally rather scanty. In the underbred animal it is coarse, curly, and generally thick and abundant.

\section{The Neck.}

The neck should be light, moderately long, and taper off towards its upper end in order that the head may be set on at a suitable angle. It should be "long in the rein," i.e. longer at its upper than at its under side. Unless it is so formed, the neck cannot be properly arched, nor can the head be well set on. Fig. 3. Also fig. 1.

The upper line of the neck from the withers to the head should form 
an elegant curve ; whilst its lower surface should be gracefully incurvated as it approaches the jowl, and it should join the ehest by an easy flowing line rather above the point of the shoulder. In stallions, however, thickness of the neck is to be looked upon as a distinetive sexual mark.

The Crest should feel firm under the grasp of the hand.

The Throttle or commencement of the larynx should stand out boldly, and the lower branches of the jaw-bone, adjoining the neck, should be wide apart, so as to give ample room for the respiratory passages.

If the neck be short and thick, fig. $3 a$, the horse will be unhandy and awkward in turning. If the neck be thick, and especially if the thickness be continued to its junction with the head (even though the neck be long enough) the horse will carry his nose poked out, and no bit ean make him do otherwise. Fig. $3 b$. If the rein be short, and the lower part of the neck be long, and especially if it be also thick at its junction with the head, the horse will probably be a "Star gazer." Fig. $3 c$.

Ewe necks are unsightly, and the formation has a tendeney to cause the horse to carry his head too high with his nose poked out. Fig. $3 c$.

Nature has made the neck in many pieces as regards its bony structure in order that the horse may be able to turn it easily. A moderately thin neck will assist its pliability. It may however be too thin, deficient in strength or over-pliable. Fig. $3 d$. Horses with such necks are difficult to control.

Fig. $3 e$ represents a neck so formed that the animal gets his head into his chest. Horses so made are very unpleasant to ride and difficult to hold if headstrong.

\section{Setting on of the Head.}

The setting on of the head is mainly dependent on the shape of the neck. - The head should be naturally set on at that angle at which we all wish to have it in riding. If it is set on too straight, the horse will be unpleasant to ride and difficult to control; whilst if it is set on at too great a bend, the animal will be apt to get his head into his chest.

Much may be done by good riding to control the position of the head and neck; but horses badly formed in this particular are apt very soon to lose their breaking, especially in the hands of an indifferent rider.

(For illustrations see figs. $3,3 a, 3 b, 3 c, 3 d, 3 e$. See also remarks in preceding paragraph.) Plates 32 and 33.

\section{The Withers.}

The Withers (A, fig. 4) are formed by the spinous processes of the anterior dorsal vertebra, which in this region are more fully developed, or in other words rise higher than in other parts of the back. To these processes are attached many. of the muscles, ligaments, and tendons which control the motion of the fore-hand. A considerable degree of elevation is necessary in order to afford good leverage to the above controlling agents. Well-developed withers are also needed to give due length to the shoulder. Horses with somewhat high withers are generally pleasant and safe to ride. llate 31 , tig. 1. 
When the spinous processes of the anterior vertebræ are very long, we have what is termed a "fine" wither; but this formation is frequently deficient in muscle. The withers must be supplied with a due amount of muscular power, and therefore should not be unduly fine. Horses with very fine high withers, though the formation is handsome and perhaps suitable for a charger, will not, as a general rule, stand severe work as well as those a little coarser at this point. A moderately fine high wither is however almost essential in a hackney, and in all horses adds much to beauty of conformation.

Low withers (A, fig. 4a) do not afford sufficient leverage for the muscles, ligaments, and tendons of the fore-hand. They are generally combined with rather straight shoulders.

It may perhaps be necessary to remind the reader that the withers are not the shoulder. (B, fig. 4.) The withers may be high and fine at the same time that the shoulder is narrow, straight, and altogether badly formed. Much error often arises from losing sight of this distinction.

\section{The Shoulder.}

The shoulder (fig. 5) must not be confounded with the withers. The latter are, as explained in the preceding paragraph, elevations of the anterior vertebræ of the back-bone. The bones, which compose the shoulder, are separate and distinct from the withers. The shoulder is commonly spoken of as if it were one bone; but it really consists of two bones articulating together, viz. the scapula (A) and the humerus (B). For the purpose of proper description it will be necessary to treat of these two separately.

\section{The Scapula.}

The Scapula or upper bone of the shoulder (A, fig. 5) extends obliquely forward from a little below the withers to what is among horsemen termed the point of the shoulder, but which point is in reality formed by the articulation of the scapula with the humerus. (B, fig. 5.) The position of the scapula should be oblique, and the bone itself should be long and broad. This formation is most favorable for the mechanical working of the muscles and tendons which elevate the fore-hand in action. Fig. 5.

If the scapula be straight, i.e. upright (fig. $5 a$ ) the handle of the crank, if we may use the simile as applicable to the motion of the scapula and humerus, is placed in a disadvantageous position for raising weight. Again if the scapula is short, although it may be oblique (fig. 5b), there is a mechanical deficiency of power, as in the case of a crank with a short handle. When from either or from both these causes (fig. 5c) combined the mechanical power is deficient, the action will be defective.

A thick heavy shoulder always produces lumbering unpleasant action. On the other hand a very light fine high shoulder may be wanting in proper muscular development. Horses however, with such shoulders, though they may be deficient in muscular power for very hard work, such as hunting, are pleasant to ride and generally have good action. 
A long oblique scapula (A, fig. 5) gives what is termed "plenty before the rider," and thus, in addition to the action gained by the formation, the horse is pleasant to sit upon. On the other hand, if the scapula is straight (fig. 5a) or short (fig. 5b), or both straight and short (fig. $5 c$ ), the rider is placed too far forwards; and if the horse stumbles, as from defective action entailed by such conformation he is very likely to do, he may probably overbalance himself and come down.

Again, if the scapula is well thrown back and sufficiently high, the saddle will generally sit well in its place; whilst if it is straight or short, or both straight and short, it is likely to work forward. The fitting of saddles however is also dependent on depth of girth, as will be explained hereafter.

For hunters and saddle horses a good oblique scapula is very essential. For harness horses and especially for heavy draught animals this point, though desirable, is not of much consequence. In race-horses the shoulder is not much, if at all, thought of. Speed is the one great requisite. All propelling power comes from behind: Powerful hind quarters are the great desideratum, and the fore-hand is little cared for, as long as the fore-legs can move freely out of the way of the hind legs. In racehorses we often find the fore-hand on a level with the croup. A high wither and scapula producing much "up knee" action would militate against speed.

\section{The Humerus.}

The Humerus or lower bone of the shoulder (B, fig, 5$)$ should be rather short. If very short, the mechanical action of the shoulder is placed at a disadvantage; whilst, if over-long, it has the effect of placing the forelegs too much under the horse, and the weight of the animal is thereby thrown too much forward. Such formation is unsuitable for riding.

It is to be observed that, whilst it is desirable the shoulder should be long, it is requisite the length should be in the scapula or handle of the crank instead of in the lower bone or humerus. In a well-made horse a plumb-line let fall from the point of the shoulder will nearly touch the toe.

The angle formed by the scapula and humerus is, we may remark, nearly the same in all horses. If the scapula is upright the humerus is more horizontal, and the fore-legs consequently are more under the body. Figs. $5 a$ and $5 c$.

Finally a good shoulder consists of a long scapula with a proportionate liumerus; and it is on this due proportion that freedom of stride, safety in action, and comfort to the rider generally depend.

\section{The Chest.}

The Chest should be deep, moderately broad, and plump in front. Both breadth and depth are absolutely necessary in order to give due capacity to the cavity of the chest, in which are situated those important organs, the lungs and the heart. 
It is essential that the chest should be moderately broad, not merely at its inferior part, but also up to the back-bone. This formation does not necessarily interfere with a fine high wither, because the withers, as explained above, are only the spinous processes of the dorsal vertebræ. On the other hand undue or excessive breadth and circularity of the chest is objectionable, because it has the effect of placing the fore-legs too far apart, and thereby causes a rolling motion in the gait. In cart horses however, in whom speed is not required, a wide circular chest is an advantage.

The chest cannot well be too deep. Depth increases the capacity of the chest without producing any disadvantage, such as that occasioned by excessive breadth. Again a deep-chested horse always carries his saddle well if the shoulder be proportionately good, whilst with a shallow chest it is pretty sure to run forward. Narrow horses, even though with deep chests, generally lack endurance. They are however pleasant to ride. Fig. 6 shows a deep, and fig. $6 a$ a shallow chest.

\section{The Radius.}

The Radius or upper bone of the leg (A, fig. 7) should be long in proportion to the length of the leg, or in other words the greater the proportion of the leg above the knee the better. This bone cannot be too thick and big, nor can it be too fully supplied with muscles. Muscular development in the arm, and in the corresponding portion of the thigh just above the hock, are points of primary importance. Fig. 7 represents a leg, in which the radius (A) is long, whilst the bones below the knee, marked B, are short. In Fig. $7 a$ the total length of the leg is the same, but the greater part of the length is in the bones below instead of in the bone above the knee.

\section{The Ulna.}

The Ulna or upper portion of the radius, to which in the adult horse it is inseparably united, should be large, long, and prominent. It gives strength to the upper portion of the radius, and when well developed affords a powerful attachment to the muscles and tendons. In a wellmade horse the point of the elbow should be full, and clear of the chest. It should not incline inwards, and it should not appear to " dig " into the chest at every step. Nothing looks worse than a horse "tied in" at the elbows, as this defect is called, and animals of this conformation have almost always cramped action. To detect it, the horse must be carefully observed as he walks slowly past, and away from, the spectator.

\section{The Knee.}

The Knee (Plate 35, fig. 8) in common with all joints should be large and prominent. A greater degree of wear and stress comes on the joints than on most parts of the frame. Hence the formation and size of joints are matters of great importance.

The Knee should be wide laterally, and although prominent, should appear nearly flat when viewed from the front, and small when seen from 
behind. The knee appenrs small as seen from behind, when the trapezium or posterior bone (marked $\mathrm{N}$ in skeleton) is well dereloped and long, and therefore capable of giving good attachment to the muscles and ligaments. A well-developed trapezium is a point of great importance. This will be referred to again under the head of the Leg below the Kinee.

Calf or buck knees are very objectionable. (See supra, Fig. 8a.) The formation causes undue strain to come on the ligaments and tendons. The opposite formation, if natural, is not oljectionable. It has a tendency to prevent undue stress coming on the tendons and ligaments. As a rule, however, this formation is not natural. Horses, which stand over at the knees, generally do so from effect of severe and constant work, on account of which the ligaments, which ought to brace up the joints, have become strained and weakened.

Large boned joints, we may remark, are usually accompanied by large and well-developed ligaments and tendons. Small knees (Fig. 8b) are obviously very objectionable.

For drawing of the bones of the knee see Plate 27.

\section{The Metacarpal Bones.}

The Metacarpals or bones between the knee and fetlock are three in number. The centre or great metacarpal bone, otherwise called the cannon or shank, cannot be too short or strong (Plate 25). It is a bone which often suffers from overwork, and therefore it is very important to have it short and strong. Shortness is a material item in its strength.

This bone should be quite straight in its course from the knee to the fetlock,-neither bowed backwards nor forwards, nor curved laterally. Any deviation from a straight line is both a cause and sign of weakness.

The small metacarpals or splint bones, which lie on each side of the great bone, but do not extend down to the pasterns, play only a very subordinate part in sustaining the weight. Their chief use appears to be to give support to the outer bones of the knee-joint. The breadth of the knee, which is greater than that of the cannon bone, seems to be an arrangement made by nature to diffuse and thereby obviate concussion in that important joint. See Chapter 39 on Splint.

\section{The Fetlock.}

The Fetlock, under which term we include the large or upper pastern bone or os suffraginis, and the small or lower pastern bone or os coronæ, should be of moderate length (Plate 37, figs. 14, 14a, 14b).

If the fetlocks are very long, fig. $14 a$, they are necessarily weak, and there will be undue strain on the ligaments and tendons. From the effect of such strain we may expect exostoses or windgalls. If on the other hand the fetlocks are short, fig. 14b, they must be also upright, and the horse will be unpleasant to ride on account of the concussion to which this formation gives rise. From such increased concussion we may expect exostoses or windgalls about the part, if the work is at all severe. 
Errata.-Page 438, par. 903.

Line 3. For " $14 a, 14 b$ " read " and 15." Line 7. For " $14 b$ " read " $15 a$." 

The eminences and the repressions of the inferior hear of the upper pastern bone should be well developed, so as to dip well into the corresponding parts of the lower or eoronet bone. This formation gives strength to the articulation, and eases the strain on the ligaments and tendons.

\section{The Sesamoid Bones.}

The Sesamoid bones (marked 9 in skeleton) are situated at the upper back part of the fetlock. Into them is inserted the superior sesamoideal, commonly called the Suspensory ligament. It is important that these two bones should be large and well developed in order to give proper attachment to that important ligament. They also act as rollers for the great flexor tendons of the leg, which pass over them.

The sesamoid bones are occasionally subject to ulceration, but the disease does not usually originate in them. The tendons, when overtaxed, often become inflamed, and then the bones, over which they pass, become secondarily involved in the neighbouring inflammatory action. (See Plates 25 and 26 on Splint and Plate 27 on Sprains of the Tendons and Ligaments of the Fore-leg.)

\section{The Coffin bone or Os pedis.}

The Coffin bone or os pedis or bone of the foot ( $k$. Fig. 10, Plate 35) varies somewhat in size in different horses. But the size of the foot does not depend so much on the size of the bone, as on the quality and condition of the crust or horn which encloses the bone. The crust, as the reader is aware, frequently alters in size according to many varying circumstances; but the bone, we need scarcely say, does not alter in size except in cases of very serious disease. The coffin bone rests on innumerable springs. Concussion is thereby so expended, as to be greatly lessened in the frame above:

In the disease, known as Founder, the attachment of the laminæ $(b b$. $c c$. Fig. 10) to this bone becomes loosened, and the toe of the bone then comes on the sole; and the peculiar condition recognised as "pumice" foot is produced. See Plate 56, Figs. 23 and 24, for Laminitis, also par. 1027 .

\section{The Navicular Bone.}

The Navicular is a small bone placed at the inferior and posterior part of the coffin bone $(l$ Fig. 10). It acts chiefly as a roller for the flexor perforans tendon (m.m. Fig. 10), where it makes its bend prior to insertion into the lower part of the coffin bone.

It is somewhat frequently the seat of disease, especially of earies. The disease appears to originate in the bone from the effect of concussion or other such causes. (See Chapter 65, par. 1021, Navicular Disease.) The tendon, which passes under and round this bone, is very apt to become secondarily involved in the disease affecting the bone; or it may become sprained at the point marked $X$ in Fig. 10, section of a foot, where it makes its bend round the navicular bone, prior to its insertion into the coffin bone. 


\section{The Fore feet.}

The Feet (Plate 35, Fig. 10), regard being had to the make and shape of the horse, should be of medium dimensions. A foot rather below the -standard size is preferable to one above it. Both, however, are objectionable.

In large feet the crust is generally weak, the animal on account of the size of his feet may probably brush, the action is rendered heary and lumbering, and the horse soon becomes fatigued. In small feet on the other hand the crust is generally brittle, the basis of support is insufficient, and the animal is apt to stumble or stand over.

The above remarks apply to natural conformations. Large wide flat ieet which have become so as the result of disease, or feet which have become contracted, are of course very objectionable. Any difference in the size of the feet should be regarded with the greatest suspicion, as it is a sure indication of disease either past or present in the feet or in some portion of the frame connected, though perhaps only indirectly, with the feet.

The slope of the crust of the fore-feet should form an angle of between 50 and 52 degrees with the ground. If the feet are more upright, they will generally be found to be contracted. If more flat, they are usually weak and predisposed to many diseases, especially to corns. The hind feet are generally more upright than the fore-feet.

The horn should be tough and sound. A ringy condition of the horn is very objectionable. It indicates weakness and want of tone in the secreting organs. It frequently follows inflammation of the feet or any debilitating disease. Rings however are common on feet of horses at grass. They are not serious. They are often due to alterations in the succulence in grass at varying seasons. If the horn shows signs of much chipping or breaking away at the nail-holes, it indicates undue brittleness. White feet are more predisposed to disease than dark-coloured feet. Some reasons for this peculiarity will be found under head of Colour, par. 933.

\section{The Soles.}

In the well-formed foot the Sole is moderately concare. When so formed, its margins receive a fair amount of wear and pressure, just sufficient to ensure the health of its tissues. In upright feet the sole is often unduly concave, and is then apt to become very hard. In flat feet on the other hand the sole is always unduly flat, and sometimes even convex. In this position it is liable to become injured and inflamed by excessive wear and pressure, or by bruises from stones, \&c.

\section{The Frog.}

The Frog ( $f$, fig. 10, Plate 35) should be moderately large, bold and clean. The frog is an elastic cushion, placed at the back of the foot in order to lessen concussion in the animal's frame, and also to act as a stay against slipping. If the frog be removed from the healthy influence of wear and pressure by thick shoes or calkins, or by allowing the crust to become unduly long, it will surely become small and probably diseased. 
Again, if the heels are narrow and the sole is unduly concave, the frog will surely be small and probably diseased, because that conformation removes it from the healthy influence of wear and pressure. If the foot is flat and the sole convex, the frog often grows very large, because such conformation induces the horse to put much weight on his heels. In such a case a large frog cannot be regarded as a good sign. The organ has enlarged and developed on account of malformation elsewhere.

For further and more detailed information on the structure of the foot, its frog and sole, the reader is referred to Chapter 62.

\section{The Leg below the knee.}

The Leg from the knee to the fetlock should be straight, flat and broad. The tendons should stand out from the bone, and should feel tense, distinct, and hard, and the interspace between the tendon and the bone should give to sight and feel a "hollow" (Plate 27). If this space is filled up with soft substances, the leg will appear "gummy." Also Chapter 44.

The leg from the knee to the pastern (Plates 27, 35, and 37) should be straight. If the bone deviates from the straight line, it will be weak, and we shall probably find splint or some other indication of weakness at the point of deviation, if the horse is put to hard work. Again, if the bones incline outwards, we shall probably find the toes turned out; whilst if the bones incline inwards, the horse will probably be "pigeon" or in-toed. (Figs. 14a, 14b, 15a, 15b, 16a, 16b, 17, and $17 a$, Plate 37.$)$

Prominence of the trapezium or bone at the back of the knee is a most important point. If this bone is small and undefined, the ligaments and tendons will also be small and undefined, and the leg will be small immediately below the knee. No horse will stand real hard work with so radically defective a formation. (Fig. $8 b$, Plate 35. )

For drawings of the bones of the leg below the knee and some further illustrations of good and bad conformations, see Plates 26 and 35, 37, and 38, also Chapter 39, on Splint.

\section{The Back.}

The Back should be straight and not over-long. It is strongest when straight and short, and weakest when both long and hollow. A certain amount of length in the back is however essential to speed. Though shortness of back is an item of strength, as regards carrying weight, yet the reader must remember that too much must not be sacrificed to any one point. The chief use and value of a horse is his power of locomotion. Again, a horse with a very short back is apt to over-reach, unless his shoulders are very oblique and his action good. Moreover he cannot get his hind legs sufficiently under him.

Backs, which are in their original formation hollow, invariably give way and become more hollow under the influence of weight and age. Horses however with hollow backs have usually good shoulders and crests, and one weak curre is to a certain degree compensated for by the 
counter-curve. Hollow-backed horses are generally pleasant to ride, but this formation diminishes the capacity of the thorax and abdomen; and this deficiency militates against endurance and power of staying. All hacks, we may mention, though originally straight, become moro or less hollow with age. This effect is due partly to the ordinary mechanical effect of weight on a given line, and partly to wasting away of the muscles with age. In young horses the muscles along the line of the back should stand as high as or higher than the spinous processes of the vertcbra of the back bone.

A horse with a roach back is generally rough and uncasy in his paces and apt to over-reach, and the saddle may slip forward. But the formation is favorable to strength, and if his shoulders and quarters are good and he is well-bred, the animal will generally be found to be valuable as regards power and endurance.

A good back is shown in fig. 11, a hollow back in fig. 11a, and a roach back in fig. $11 b$, Plate 36 .

\section{The Ribs.}

The Ribs should be deep and oval throughout, and especially behind the saddle (Plate 36, fig. 12). This formation is essential in order to give due capacity to the cavity of the chest and that of the stomach. Flat-sided horses are very objectionable.

The ribs should be continued well back towards the pelvis. If therc is an undue interval, that is, an interval exceeding a hand's breadth between the last rib and the point of the hips ( $a$ to $b$, Fig. 12a), the horse will be certain to run up light, if subjected to work. A similar incapacity to stand hard work will be found in horses whose posterior ribs are wanting in due length and in sufficient arch $(c$ to $d$, Fig. 12b). In the former case the animal is said to be slack, and in the latter case light in the ribs.

A slight deficiency in the ribs may not be very objectionable in horses intended for light work; but for all horses required for hard usage and certainly for troop horses, which on service are often subject to short rations, this formation is very detrimental. Horses which are light in the loins and also narrow in the chest are predisposed to scour, and are often in addition delicate feeders.

Condition, though it does not really affect the structural formation, has a good deal to do with the appearance of the posterior ribs and the " coupling up." Many an animal, when poor, appears to an inexperienced person to be slack or light in the ribs, which will look well enough, when "furnished." On the other hand, many a horse is turned out of a dealer's stables so fat and weli-covered, that the purchaser does not find out the real defect until he has had the animal in work for some weeks.

If a horse, when out of condition, appears somewhat light or loose in the ribs, the intending purchaser should look well to his width across the loins. If he has width there, any slight defect in the ribs will not be of much consequence; but if he is narrow across the loins, and especially if 
this formation is continued to the chest, the animal probably will not do work.

Figures 12, 12a, and $12 b$ respectively represent good, slack, and light ribs.

\section{The Pelvis.}

The Pelvis (No. 4 in Skeleton, Plate 31) should be broad, deep, and oblique, and its spinous processes ealled the hips should be moderately wide; but they need not be so wide as to be unsightly or to give the appearance known as "ragged hipped." Breadth and depth are needed in order to give space for and attachment to the muscles of the hind quarters. All propelling power in the horse is derived from these muscles. They should therefore be large and well developed; and it is essential to appearance that they should be laid on smoothly and evenly. Obliquity in the pelvis is needed in order to give due length to the quarters.

Many horses with great jumping power often have very broad " ragged" hips. This breadth in the Irish hunter is frequently combined with a sudden drooping of the quarters and great length of hock. These conformations give great leverage for the muscles; and although the formation is not handsome, yet when it is combined with powerful muscles, it often produces a horse valuable for hunting and steeplechasing.

The question of power however is one which must always be considered relatively to the other points of the conformation. As a general rule, an over-broad pelvis is not desirable in riding horses. It causes the hind legs to be set on too wide apart, and is therefore apt to produce an unpleasant rolling motion in the gait. Similarly the hips should not be too wide or too prominent. On the other hand, a narrow pelvis and a flat thigh invariably indicate a worthless animal. If the pelvis is deficient in width, the horse will be "split up," and the muscles on the inside of the thigh will be deficient.

\section{The Loins.}

The loins should be large, long, well arched, and fully furnished with muscle. The muscle should be evenly supplied, so that the outward appearance may be smooth and round. Any great prominence on either side of the loins with a depression in the centre indicates want of breeding. In race-horses the muscular development of the loins is a point of the utmost importance.

The thighs should be deep and full. There should, however, be suffieient interval between them to prevent friction. Horses with heary thick thighs set closely together will not answer for fast work. On the other hand a want of muscular development, such as is indicated by the animal being "split up behind," is most objectionable. Most of these points are illustrated in the drawings given in Plate 24.

\section{The Hind quarters generally.}

The Hind quarters, taken as a whole, should be long, deep, full, rounded externally, and placed well under the centre of gravity. 
The well-made thorough-bred horse is straight and long in the portion of the back from the pelvis to the tail (see Skeleton). Due length in this part is essential both to power and to appearance, Fig. 18. Want of length is found in horses of all breeds, Fig. 18a; but short round rather drooping quarters are essentially an under-bred formation, Fig. $18 b$. Very drooping or "goose" rumps are unsightly, and (except sometimes in Irish hunters) are only found in low-class animals, Fig. 18c, Plate 37.

Length from the pelvis to the hock is also essential for speed and power. Although a race-horse, hunter, or riding horse may be disadvantageously broad across his hips, yet he can never be too long or too much "let down" in his quarters. The muscles will be thereby increased in length and volume, and the animal will gain in power and speed. Due proportion is, however, necessary between the strength or development of fore and hind quarters. Very great propelling power behind, if the fore-hand is not equally good, will cause failure in the structure. For example, in the hunting field horses with abnormally developed hind quarters are apt to over-jump themselves and to come on their heads, especially over "drop" fences. This applies in a greater degree to Steeplechasers of similar build. For more detailed information and illustrations, see Chapter on Conformation of the Hock, and Plates 22, 23 , and 24.

\section{The Femur, Tibia, and Stifle.}

The Femur (No. 6) and Tibia (No. 7 in Skeleton) jointly form the upper part of the hind quarters. The femur should lie obliquely forward in order to bring the hind leg well under the horse. The tibia on the other hand should lie obliquely back, so as to bring the hocks under the direct line of the incidence of weight. In addition to lying obliquely forward the femur should be strong and long, so as to give due length to the quarters. The tibia should be strong and cannot be too long, having due regard to the general proportions of the horse. It is essential that it should be well let down into the hock.

The muscles of the femur and tibia should be very well developed. They should appear especially prominent immediately above the hocks. This swelling out, or what are sometimes called "second thighs," is a formation essential to excellence in the racer or hunter. (Plates 22, 23, and 24.)

The Stifle, in which the Patella is situated, marked No. 5 in Skeleton, should appear prominent and well defined. This will always be the case when the two bones, namely the femur and tibia, which articulate at this joint, are respectively properly placed, that is one obliquely forward and the other obliquely back.

\section{The Hock.}

The outline of the Hock should be clean, rigid, and well defined. Puffiness or swelling in any part is a sign of weakness or disease. The bones should be large and prominent. Size is essential to strength, and prominence is necessary in order to afford due leverage and attachment to the ligaments and tendons. Large and prominent bones are usually 
accompanied by large and well-developed tendons and ligaments. The hock as seen laterally should be wide both above and below. Strength and size of bones and ligaments are both indicated by lateral width.

The leg from the point of the hock down should incline a little under the body. This conformation is best adapted both for jumping and speed, because it allows the legs to be brought well forward in action. If the leg is inclined very much forward, the formation becomes weak, because the great bend made at the hock will occasion strain on the ligaments and tendons of that important structure. (Plates 22, 23, and 24.)

On the other hand, if the leg be placed perpendicularly under the hock there will be excessive concussion and great strain, especially in halting and turning, and consequent liability to diseases such as spavin, bogspavin, and thorough-pin. If the leg inclines backwards, the horse cannot draw it well under his body, and there will then be want of propelling power. The hock, too, will be liable to sprain, and to become affected with bog-spavin, \&c. In short, the angle formed at the hock by the tibia and metatarsal bones should be neither very great nor unduly small. In itself, as distinct from the angle just spoken of, the leg should be perfectly straight from the point of the hock to the fetlock.

Any deviation laterally from the perpendicular line, as is the case when the hocks are inclined either too much out or too much in, is a source of weakness and therefore of disease. By the public, hocks which bow out are generally considered less objectionable than those which incline towards each other. The author very much questions the correctness of this opinion. In the former case horses are said to go "wide behind," whilst in the latter they are called "cow-hocked." (Plate 24.)

The os calcis or prominent bone at the posterior point of the hock, No. 21 in Skeleton, should be very well developed, very prominent, and isolated as it were from the substance of the thigh, in order to give due leverage to the tendons passing over it and attached to it, and also attachment to the ligaments belonging to it. This formation is essential to power and speed.

More detailed information in regard to the conformation of the hock will be found in the Chapter specially deroted to that subject, No. 37. (Plates 22, 23, and 24.)

\section{Great and small Metatarsul bones.}

The remarks made in the earlier portion of this Chapter on the bones of the fore-leg below the knee apply equally to the bones of the hind leg below the hock. Briefly however we may say that the portion of the leg below the hock cannot be too short. The greater length should be in the bones above the hock. The metatarsal bones, though their position should be slightly obliquely forward, must be in themselves perfectly straight.

\section{Sesamoid and Navicular bones. Hind legs.}

The Sesamoid and Navicular bones, though their functions are similar to those of the corresponding bones in the fore-leg, are less often diseused, 
because from a slight differenee in the position of the leg, less concussion and strain comes on them than on those of the fore-leg. (See Skeleton.)

\section{The Hind Feet.}

The same remarks apply generally to the hind as to the fore-feet. But from various circumstances, into which it is not necessary now to enter, the hind feet are much less subject to disease than the fore-feet.

We may remark however that the hind foot is generally more upright than the fore-foot and also narrower, and its lower surface or sole is more recessed. On account of this formation its frogs are less subject to pressure and wear, and hence in the shod horse, at least, they are generally less well developed. The frogs are also somewhat liable to suffer from thrush, probably because the hind feet usually stand in the dirtiest and wettest part of the stall. In the fore-foot the toe and outer quarter are the strongest parts, whilst in the hind foot the greatest strength is in the quarters.

\section{The Tail.}

The hair of the tail in the well-bred horse is distinguished by its fineness and straightness. Figs. 13 and $13 a$. A thick, coarse, or eurly tail generally indicates want of breeding. Fig. 13b, Plate 37.

In the well-bred horse the tail is carried firm and well away from the hind quarters. There is an appearance of force and muscularity about its root. It is set on almost in a line with the back-bone. When so placed, it is capable of affording great leverage to the hind quarters.

A tail well set on is a great ornament to a horse. The Arab (Fig. 13) carries it almost straight out in a line from the spine. Fig. $13 a$ represents an ordinary well-bred tail. In the under-bred animal the tail is usually set on low down, possesses no muscular power, clings to the hind quarters, and altogether looks mean. Fig. $13 b$.

Fine curly hair is occasionally, though not very often, found in the tails of even thorough-bred horses.

\section{The Sheath.}

The Sheath ought to be large and well developed. Horses with small sheaths are seldom lasting or strong.

\section{The Dock.}

The Dock should be large and muscular. Horses with small docks are seldom good for much.

\section{The Belly.}

The Belly is mainly supported by the back ribs. Horses which are short in the chest, or long and loose loined, and at the same time great feeders, often distend their bellies, so that they "hang down." Such animals are unpleasant to ride, because the saddle has a tendency to work forward on the shoulder. The same unpleasant result is produced when 
the sides of the ehest are narrow, and the ribs just behind the saddle are unduly circular.

There is also an opposite evil. If from want of proper length and due convexity of the middle ribs the circumferent measurement decreases from the fore-hand to the rear, the girths and with them the saddle will slip back, and in the stable the same result will happen with the roller and the clothes.

\section{The Body.}

The Body should be long and low, that is, it should stand over a good deal of ground, and yet be deep and broad in all parts. The length should be due to a large, long, and oblique scapula, and long quartersnot to long and badly coupled loins. Such conformation is calculated to give both speed and endurance. Length is essential to speed, and breadth to endurance. Neither the one nor the other, however, must be disproportionate. In the body as in every other part of the frame we need to combine, in their just relative proportion, opposite qualities, namely, those which give speed and those which give endurance.

\section{Of Bone in Different breeds.}

Bone must not be measured solely by reference to size. Bone varies very much in quality in different breeds. That of the under-bred horse is coarse, porous, and light, being what is in common parlance termed " bone" as opposed to ivory; whilst that of the thorough-bred horse is dense and heavy and more nearly resembles ivory, and the projections for the attachment of muscles and tendons are well and boldly developed.

\section{The Muscles.}

The Muscles throughout require to be well developed. Those of the arm, thigh, and back are of especial importance. No horse is fit for hunting or racing if these are in any degree deficient. Again, if they are at all deficient, it is more than probable that the tendons and ligaments, which join on to their extremities, will also be weak.

A full round hard firm appearance of the muscles of the thigh is an indication of strength in those parts. The muscles of the back should completely fill up the space between the ribs and the upper portion of the spinous processes of the backbone. (See Skeleton, Plate 31.) Any hollow, or in other words any deficiency in the muscles on the sides of that bone is an indication of weakness.

\section{Tendons and Ligaments.}

The Tendons, which are most frequently sprained, are those of the legs. They should be hard, clean, free from any gumminess, broad, and flat. Breadth and flatness are the chief elements in the conformation of a grood tendon. The same remarks apply to the superior sesamoideal ligament, commonly called the suspensory ligament.

All the other many Liganents which keef in apposition the bones of the various joints likewise need to be strong and well dereloped; but out- 
wardly their conformation is not actually visible. Their size, however, as a rule, is pretty correctly indicated by the size of the bones at the joints. Large well-formed joints are accompanied and knit together by large well-developed ligaments, whilst small joints are usually held together by small ligaments.

In examining the tendons, the eye alone should not be trusted to. They should also be carefully examined by pressure with the forefinger and thumb along their course,-namely, the more flattened perforatus, which is situated posteriorly, the corded perforans immediately in front of it, and the suspensory ligament in front of the last named. See Plate 27. After examining the leg with the weight on it, it should be lifted up, and the tendons and ligaments (being then relaxed) should be again examined and compared with those of the other leg. The inside of the knee should also be noticed to see if there is any mark of speedy-cut. (See X Plate 25.)

\section{General Remarks.}

We stated in the beginning of this Chapter, that like as the strength of a chain is measured by its weakest link, so is the power and endurance of a horse limited by the weakest point in his structure.

It does not, however, necessarily follow that a horse will eventually fail at that point, which was originally the weakest. For example, in a chain cable with a weak link no storm may occur for years to test its utmost strength, and under such circumistances the weak link may last as long as the rest of the chain. Similarly in a horse which is moderately worked and well cared for, the particular defect may never go against him, before age has worn him out altogether.

Again circumstances may cause an excessive strain on a part which is not weak, and that part may yield, whilst weaker points, which are not subjected to strain in the particular animal may continue sound. For instance, a horse may have good hocks and bad feet. From the peculiar nature of the work, such as hunting, to which he may be subjected, it is very possible that he may fail in the hocks; whilst the feet, to whose health soft ground is favorable, may stand scund. Again a horse may have a defective chest, and yet die of some disease totally unconnected with that weak point.

Nevertheless our comparison with the chain holds good in the main; and a horse with defective conformation at any given point is especially liable, if pushed, to fail at that point. In estimating, however, the comparative degree of importance to be attached to the various points, constant reference must be made to the special use for which the intending purchaser requires the horse; and also to the price at which the animal with certain defects can be obtained.

Certain defects will not go much against a horse for some sorts of work, whilst they may be most objectionable for other déscriptions of work. For example, a somewhat hollow back is not of much detriment to a horse intended solely for harness; whilst it would be most objectionable in an animal intended to carry a heavy weight on his back. Again, 
certain sorts of work require special strength or features in particular parts of the frame. For instance, good hocks are especially ess_ntial in a hunter, good feet in a hackney, high courage and the best blood in a race-horse.

Furthermore, circumstances in a great measure modify or increase the importance of particular points even in horses intended for the same class of work. Thus good ribs and chest or an aptitude to carry flesh even under short rations and hard work are essential in a troop horse ; whilst in a well fed, well cared for, moderately worked riding horse, no ill effect from slack or short ribs may ever become apparent, even though the owner rides eighteen stone. Again, length, especially in the hind quarters, is essential, where pace is required, whilst in animals not required for fast work, it is not equally material. A blind horse is inconvenient and dangerous to ride, but yet may go very well and safely in double harness.

These instances and remarks might easily be multiplied to any extent. Our object, however, is only to impress on the reader, that instead of looking for perfection, which either cannot be obtained or can only be oltained at a very long price, he should look out for a horse suitable and good for the purposes for which he wants him.

If the purchaser finds that he has made a mistake in the animal he has bought, the author would recommend him to get rid of him at a sacrifice, rather than persist in putting him to a class of work for which he is physically unfit.

\section{Action.}

Good true action generally, but not always accompanies a well-formed outline. Action is greatly dependent on the muscular power and on the tendons and ligaments, though these again depend on the bony conformation. Strength of muscle and leverage derived from the conformation of the bones must go together. If the muscle is strong, but the leverage is weak, it is of no avail. On the other hand, the position of the bones, however favorable it may be, will be of no use unless there are muscles powerful enough to work them.

We must not forget that the bone in the well-bred horse is stronger, heavier in proportion to size, and more solid than in the under-bred animal. The muscles partake of the same character, being clean, fibrous, and free from adipose tissue. When the muscles are in the state fittest for exertion, the horse is said to be "in condition."

The thorough-bred horse owes his speed to the mechanical arrangement of his frame; whilst the cart horse for his particular work requires solidity and squareness of make. These are the two extremes. Between them lie those structural formations which are most suitable for ordinary riding purposes and light harness work.

Again, the well-bred horse is endowed with much greater nerrous energy than the cart horse. The quality of blood, as is generally supposed, but more probably greater brain power and generally increased nervous development, give this mysterious vital stanina-the will and the endurance. 
When horses grow over-large, they seldom increase in good points in due proportion. Hence so many overgrown horses are of little value. A good big horse with all his parts in proportion will always beat a good little horse. The very best shape, however, we may remark, will generally be found in small horses and ponies, especially in the latter.

Action should be true, that is, level and straight, and above all it must be free. If a horse performs his walking pace freely, he generally does his other paces equally so. If he moves cramped or short at a walk, the other paces are usually bad. In a hack or charger a good free independent walk is indispensable. A horse that stands well, that is, with his limbs in a proper position, will probably walk well. A naturally bad shuffling walker should be refused.

The lift of the foot in the walk should be sufficient to clear all ordinary obstacles in the road, and the action should be collected and perfectly within the animal's control. The foot should be well flexed in the air without any great deviation laterally, and the toes should not be much turned either in or out. In a hackney we desire to have a horse with a quick walk rather than with the long pace of the thoroughbred.

A horse should place his foot firmly and flatly down. Still his action should be so light and nimble, that there should be but little noise from his tread. A clumsy-going horse is at once known by the noise of his tread. The shoe should be fairly worn at all parts. Any undue wear at the toe is an indication that the horse may probably be a stumbler. Horses that stick their toes in the ground are easily thrown off their balance, and may come down. On the other hand the knee should not be raised too much, nor should the horse "wind" his foot when raised. Such action takes off from the speed and security of the walk.

In trotting, the hind and fore-legs must act truly and correctly and in unity with each other. The hocks should be well flexed and brought well under the body, the fore-legs should be lifted quickly and lightly, and all the movements must be in harmony.

High action in walking and trotting, though fashionable, is not really good. A horse loses in progression, all that he steps unnecessarily high. For this reason high-stepping horses generally tire soon, and are then apt to stumble. Besides they are uncomfortable to ride, and moreover they knock their legs to pieces, and are likely to suffer from the effects of excessive concussion. It is essential that the action should be high enough to be perfectly safe, but all beyond that the Author thinks an evil. The action should suggest the idea that it commences from the top of the shoulder. Good action does not consist merely in the flexion of the knee.

Dealers are great adepts at temporarily improving and developing walking and trotting action; or if we may be allowed the expression, in producing action artificially. The trick is simple enough. One man with good hands leads the horse with a sharp bit in his mouth, whilst another cracks a whip behind him. As the horse attempts to go forward, he is sharply checked by the bit. The result is that his knees go up', because progress is checked, when the impulse is given from behind. After a few lessons the horse begins to step high, and will continue to do 
so, for fear of the bit and the whip, whilst in the yard and perhaps during a short ride, such as the intending purchaser may wish to take. Very heavy shoes have been used with same object, and with more permanent effect. But the plan fails, because the heavy shoes must be removed before the horse can be shown to a customer.

More lately and more ingeniously, the same object has been gained by shot-bags, weighing from $4 \mathrm{lb}$. to $6 \mathrm{lb}$, round the front fetlock. These can be removed in two or three minutes. But the action is not natural, and the purchaser will generally find that after a few days the animal reverts to the action appropriate to his conformation. Defective action may however undoubtedly be improved by good riding and suppling of the shoulders. But it is not the intention of the Author in this treatise to enter into the question of horse-breaking.

In galloping, the hind legs must be brought well under the body, and the animal must go low and near the ground.

\section{Defects in Action.}

The Author is afraid that he would render this chapter too long if he were to enter into a detail of the innumerable defects which occur in action. Any and every deviation from light, springy, easy, quick, straight action is in some degree a defect.

The more prominent defects however are rolling, dishing, cutting, and stumbling. Want of harmony between the fore and hind legs is also very objectionable. If a horse, for instance, has powerful hind quarters and straight shoulders, the extra propelling power is an evil; or conversely the best shoulders are of no avail without good hind quarters. Pitching action, i.e. the fore-foot being darted straight out, is very unpleasant to the rider. Winding of the fore-foot is also very objectionable. Any action of the hind legs, which is performed by or accompanied with swaying of the loins, is unpleasant in a riding horse and unsightly.

\section{1 a. Stumbling.}

Stumbling is more often due to the way in which a horse puts his foot down on the ground than to want of height in raising the foot in action.

It is rare that a horse strikes an obstacle in transitu. He generally strikes the obstacle as he puts his foot down on the ground. Hence high action is not itself a bar to stumbling - though it is probable that a horse with light easy action will put his foot more nimbly down on the ground than a sluggish goer.

Stumbling however in the Author's opinion far more often arises from want of nervous appreciation of the obstacle, or, in other words, want of delicate sensibility of touch, than from defect either in the manner of raising or putting down the foot. Such want of nervous appreciation of obstacles of course constitutes the worst class of bad action.

Some horses appear to have an intuitive appreciation of all obstacles, inequalities of ground, hollows, elevations, $f(.$, , whilst others with appurently good action blunder against everything. 


\section{Position in Standing.}

The horse should so stand, that the weight may be evenly distributed on the legs without interfering with their free motion. No precise rules can be laid down as to exact position, because as soon as the animal is put into motion, so much will depend on the kind of action he may have. The eye must principally guide us. Still some general rules may be given.

1st. A vertical line let fall from the point of the shoulder should meet the ground nearly at the point of the toe, Fig. 14, Plate 37. If the foot is removed much behind that point, the equilibrium is imperfect and the horse is unsafe, Fig. 14a. If on the other hand the line falls much behind the foot, the horse is probably long in the fetlock and with low heels, and he will in consequence be very liable to sprain of the ligaments of the fetlock, Fig. $14 b$.

2nd. A vertical line let fall from the middle and back part of the arm should equally divide the knee, cannon, and pastern, and should reach the ground a little behind the heels, Fig. 15. If the line falls within the heels, the horse must have an upright pastern; Fig. 15a; whilst if it falls at a considerable distance behind that point, the pastern is unduly long, Fig. $15 b$.

3rd. A vertical line let fall from the middle of the fore-arm ought to divide equally all the inferior parts, Fig. 16. If the said line falls more exteriorly, the legs are too close, Fig. $16 a$; whilst if it falls within, the legs are too wide apart, Fig. 16b, Plate 38.

4 th. If the said line divides equally the knee and leg as far as the fetlock, but afterwards falls on the inside, the toes will be unduly turned out, Fig. 17 ; whilst if the line falls more exteriorly, the horse will be pigeontoed, Fig. $17 a$.

5th. The lines applicable to the position of the hock were given in Chapter 37, Conformation of the Hock.

\section{Colour.}

It is often said that a good horse cannot be a bad colour. This saying is scarcely true. It would be more like the truth to say that a good horse never is a bad colour.

There is but little choice in regard to colour provided only that the colour be good of the sort. All colours which are light of the sort are bad; whilst all are good which are decided of the sort. For example, a rich brown is good-so also is a bright bay with dark legrs; whilst a common brown running to bay about the legs and flanks, or a bay with light mealy legs is objectionable. Chestnuts, both dark and bright, are good if the richriess of the hue be maintained to the extremities; but both are objectionable if the tail and legs are lighter than the body. The same remarks are applicable to other colours or shades of colour.

Colour, if wanting in depth, alnost always fails towards the extremities. The explanation of this peculiarity is said to be, that all colour is dependent on light and heat. Now the heat of the body is greatly dependent 
on the circulation, which again is dependent on the vigour of the constitution. If the circulation be weak there will be a want of tone throughout the body producing the weakness or washiness of colour to which we object. This weakness will of course be felt especially in the extremities, which are furthest removed from the centre of the circulation.

Whether this explanation be correct or not, it is certain that horses, whose colour fails in the extremities, are generally weak in constitution. Hence the common saying, "Washy in colour, washy in constitution."

\section{Constitution.}

A good Constitution generally accompanies a powerful frame; but this is not invariably the case either in horses or men; and a powerful frame we need scarcely say is not of much use without a good constitution.

Some horses apparently well made are yet so highly nervous, that they will never carry flesh. Others, again, with the best appearance sometimes deceive us from want of spirit and pluck. We cannot always explain these things.

Many a horse, however, may be dull and sluggish, when in poor condition, which may be a very different animal when well fed and cared for. As a general rule, unless a horse is naturally a good feeder, we cannot make much of him.

\section{Breeding.}

Breeding or "blood" exercises a mysterious influence in the horse: Closely allied with it is nervous organisation. It may be, perhaps, that the well-recognised effects of breeding are really more dependent on the latter than on blood. In the high-bred animal the thought almost of the rider, the slight feeling of the hand or leg is conveyed to the horse ; whilst the under-bred animal is very slow in receiving any such impressions. Endurance and courage are also notable characteristics of the well-bred horse ; whilst a lazy sluggish feeling and a desire to save himself mark the under-bred animal. A good thorough-bred horse will go till he drops. A low-bred animal will always stop in good time. The rider may think that he has urged him by whip and spur to the utmost extent of his power; but on a visit to his stable a few hours after, he will probably find that the brute shows no great signs of having over-exerted himself. A high-bred horse fights against difficulties, whilst the other yields to them. A high-couraged horse, when he comes to a hill, will face it and pull harder than on level ground. On a downward slope he will probably not care to exert himself. The low-bred animal may perhaps show a disposition to increase his pace downhill, but will "shut up" at a stiff ascent. The well-bred horse will go as pleasantly and gaily at the end as at the beginning of a long day; whilst the other, though he may very likely be troublesome and fractious at the onset, will probably require both whip and spur to keep him to his work.

Our best-bred horses are derived from an admixture of Arab blond. The English "thorough-bred" is not of pure Arabian stock. Arab sires 
only were imported at the date at which our stud book commences, and their produce out of certain mares, called the Royal mares, which had been collected by the King during the latter half of the seventeenth century, both from home and from foreign countries, constitute what is now called our "thorough-bred" stock. It will be seen, therefore, that the name is in some degree a misnomer.

Careful breeding and high feeding have, however, developed a race of horses, with which the real thorough-bred, i.e. the produce of the Arabian sire and dam, cannot at present compete on the turf. On the other hand, it must be remembered that the pure high caste Arab does not measure over 14.3 hands. What might be the result if the Arab were in the course of years by careful breeding and early good feeding developed to the size of the English thorough-bred the Author cannot say.

This experiment is now being tried by Mr Wilfrid Scawen Blunt, of Crabbet Park, Three Bridges, Sussex. Mr. Blunt has imported the very best Arab sires and dams ; and every lover of the horse will rejoice if his spirited endeavour results in increasing the bone, stamina, and endurance of our English breed of horses. Mr. Blunt's experience so far has been that it is difficult to increase greatly the height of the English-bred Arab without losing something of the original type and quality. $\mathrm{He}$ is of opinion that 14.3 or 15 hands will long remain the maximum height in pure-bred English Arabs, though their power and endurance may be indefinitely improved by selection and better feeding.

Best Arab time 1 mile-1874, Madras, Lucifer, 10 st. 2 lb., 1 minute 52 seconds. 1877, Calcutta, Saracen, 9 st., 1 minute $50 \frac{1}{2}$ seconds. For 2 miles, Calcutta, Sherwood, 10 st. 2 lb., 3 minutes 49 seconds.

Best Derby time, 1887, Merry Hampton, 2 minutes 43 seconds ; 1888, Ayrshire, 2 minutes 43 seconds. Best Oaks time, 1892, La Flêche, 2 minutes $431-5$ seconds. Course, $1 \frac{1}{2}$ miles and 29 yards. Hilly and not good for time.

Sandown Eclipse Stakes, 1893, Orme, 10 st. 2 lb., $1 \frac{1}{4}$ miles, 2 m. 10 s.

Time is not often taken on the English turf for 1 mile races. The Author has not been able to get any thoroughly reliable statistics, but as far as he can ascertain $1 \mathrm{~m} .43 \mathrm{~s}$. is the best time on record for 1 mile.

Best Steeplechase time is probably 1893, Cloister, 12 st. 7 lb., Grand National, Liverpool, $4 \frac{1}{2}$ miles, 9 minutes 8 seconds.

The best Waler (Australian) time, 2 miles, 3 minutes 54 seconds.

It will be seen from the above that there is not much difference between English and Arab time. But "time" comparison is not altogether fair to the English horse. Arab races are run at full speed throughout. This is not the case on the English turf. Something is always reserved for the final struggle. What would be the best possible time of the English horse the Author has not been able to ascertain. The custom of running Arabs at full speed throughout is doubtless due to their great staying power.

But when the English and Arab horses meet, the former can give the Arab 4 st. or more. The explanation of this curious fact is that the N.B.-For latest best English and Indian time see Postscript. 
English horse has a longer stride and can outpace the Arab for the first $\frac{1}{4}$ mile. The Arab will struggle to keep up to the pace of his competitor, and in this hopeless struggle will exhaust himself; and then the English horse canters in an easy winner.

As regards English thorough-bred horses, there is some reason to fear lest the present system of very short races should lead to the breeding of horses more with a view to speed than endurance. It is, however, a mistake to suppose that very worthless animals will ever be used on the turf. No horse can be trained at all, not even for the very shortest race, unless he has considerable strength of bone, tendon and ligament. The misfortune rather is that in the endeavour to produce a speedy animal, so many horses worthless for any purpose are brought into existence.

Whilst the Author yields to no one in his appreciation of the value of blood, yet he must remind the reader that high-bred horses do not answer so well for some purposes as those of a lower caste. For many sorts of work involving slow, patient drudgery, the sluggish nature and broader and heavier build of the under-bred horse is far more suitable than the eager exertions and slighter frame of the thorough-bred. In the mean between these two lies the horse most useful for ordinary purposes.

\section{Distinctive Marks and Colour.}

In taking the description of a horse, after detailing of course the colour, age, and sex, it is usual to specify any Marks, whether natural or acquired, which the horse may have about him.

A Star is a round or roundish white spot on the forehead. A Race is a narrow white streak down the face. It may be a continuation of a star or it may be separate and distinct from it. It may be straight or crooked. A. Snip is a white mark on a nostril or side of a nostril, running down to the mouth. It is sometimes continued to the lower lip. The part is often almost devoid of hair, and in such case has a flesh-coloured appearance. All these marks may be separate or they may be combined. A Blaze consists in the whole or half of the face being marked by a broad white streak extending to the mouth. White legs or heels, spots of any colour, grey hairs in the mane or tail or about the body, are also always recorded in the description.

Blemishes, if any, such as saddle marks, scars, broken knees, permanent enlargements about any part, \&c., should also be detailed.

The Color of a horse in doubtful cases is decided by the color of the muzzle. Thus, if it be a question whether a horse is black or brown, the muzzle would determine the point. An almost black horse, for instance, with a brown muzzle is counted as brown; whilst a horse of similar color of body with a.black muzzle would be reckoned as black.

\section{Vice and Sulkiness.}

Awkward-shaped horses are often vicious or sulky, probably because from awkward shape they cannot readily comply with the indications of the hand and leg, and the wishes of the rider ; and hence they are often harshly treated, and in consequence become vicious or sulky. 
Again, many ligh-couraged sensitive horses become vicious from rough or awkward usage. The original fault more often lies in the usage than in the animal. A bad rider or an ill-tempered man had better get an under-bred slug.

\section{7a. Conclusion.}

We shall conclude these remarks by observing that neither frame nor constitution is of much use without good condition. This latter great essential can only be obtained by good grooming, careful and regular feeding on the best forage, strong and regular exercise, fresh wholesome air in the stables, and general good management.

\section{HINTS ON PURCHASE OF RIDING HORSES.}

A horse should be rejected for any one really bad fault. The greatest strength of a horse is limited by his worst point. Horses are often bought because they possess one or more very good points. This is a wrong principle in buying. The selection of horses should begin by rejection for bad points. Bad points are of course, in a great measure, a question of degree. Discretion is needed in rejecting as well as buying.

1. In measuring a horse or judging of his height and size by sight, take care that he stands on a level with yourself. Dealers generally stand a horse, if under-sized, on higher ground, or if over-sized on lower ground than the intending purchaser.

2. Want of a fair amount of breeding should be an absolute bar.

3. Reject a horse with a big coarse head.

4 . ............... with a small sunken eye. They are generally obstinate and sulky.

5. ............... of a colour light of the sort.

6. ............... with a long slack back. It will not carry weight.

7. ............... with a hollow back. The formation is weak.

8. ............... with flat sides. They will not do work or look well.

9. ............... with a slack loin, i.e. undue length between the last ribs and hind quarters (sacrum). They are often bad feeders and will run up light with work.

10. with a light loin, i.e. want of breadth over the loins. . They run up light with work.

11. with scraggy hips. They never do credit to feeding, particularly if also slack in the loins.

12. with a bad girth, i.e. "light through the heart." This formation will always cause trouble in saddling.

13. with a thick or short neck.

14 , unless it has a good Rein. With a clumsy neck the head is in consequence badly set on. Without 
a good rein a horse will never break well, or be pleasant to ride.

15. Reject a horse with very low withers. The saddle will be apt to work forwards, and the "rein" will probably be deficient, and the leverage for the muscles of the fore-hand is defective.

$15 a$.............. a slug always a nuisance.

16. To see the above points stand on the side and form your opinion before the horse moves off.

17. Reject a horse with a narrow or shallow chest. There is not sufficient capacity for the Lungs.

18. ................ with fore-legs very close together. This and the former defect generally go together. To see these points stand in front.

19. ................ whose fore-legs are not straight. They will not stand wear. Stand behind the horse as he walks away from you, and you will be able to notice these defects, if they exist.

20. which is light below the knee, especially if light immediately below the knee. The conformation is essentially weak.

21. with long, or with short, or with upright pasterns. Long pasterns are subject to sprains. Short or upright pasterns make a horse unpleasant to ride, and on acount of extra concussion are apt to cause ossific deposits.

22.

with toes turned in or out. The twist generally occurs at the Fetlock. Toes turned "out" are more oljectionable than toes turned " in." When toes are turned out, the fetlocks are generally turned in, and animals so formed are very apt to cut or brush. Both, however, are weak formations.

23. whose hind legs are too far behind. Good propelling power will be wanting, and disease as a result may be expected in the hocks.

24 . ................ which goes either very wide or very close behind.

25 . .............. with very straight or very bent hocks. The former cause undue concussion, the latter are apt to give way.

26.

which is "split up," i.e. shows much daylight between his thighs. Propelling power comes from behind, and must be deficient in horses without due muscular development between the thighs.

$27 . . . . . . . . . . . .$. with flat feet or over-large feet, also with very small feet. Medium size are the best.

$28 . \ldots \ldots \ldots \ldots \ldots$ with one foot smaller than another.

29. A goose rump is not objectionable as a mechanical formation, but it is ugly. 
Action must be light, easy, free, and straight. Reject a horse that crosses his legs in walking or trotting. He will be unsafe. Freedom, power to move easily along, is the great point.

A good walk is absolutely essential. Reject a horse that does not walk well ; he is never pleasant to ride. If a horse walks well, he will probably trot well ; but a horse may trot well without walking well.

To ascertain whether the action is true and straight, stand behind the horse as he walks and trots away from you. You cannot ascertain this important point by standing on the side.

Never omit to stand behind a horse as he walks away.

A good sloping shoulder is an important item in a riding horse, but bad action may co-exist with a good shoulder; and, vice versâ, good free action may co-exist with a somewhat straight shoulder.

Reject a horse which is straight in the shoulder and long from the point of the shoulder to the upper part of the forearm. This formation places fore-legs too much under the horse, and makes him unsafe to ride.

You may have a plain horse, even if all the above very apparent defects are absent, but you will, at least, have a serviceable one if in addition found sound on veterinary examination.

Having first of all kept clear of all absolute defects such as the above, then select your horses for the presence of good, serviceable, and handsome points, and easy, free, graceful carriage.

But, I repeat, begin by rejection for any one positively bad defect. The greatest strength of a chain is limited by the strength of its weakest link.

In purchasing Horses, it is a great point not to lose time. If you see any one radical defect, reject the Horse at once. The Dealer will, of course, try and persuade you to do otherwise, and will call your attention to some very good point or points in the really defective animal.

Do not lose time. A dealer, if you are a stranger to him, will probably bring out and try and palm off on you his inferior horses. But if you are quick in seeing bad points, and at once reject defective animals, he will soon find it necessary to show you his best horses.

\section{CHAPTER 61:}

\section{THE LAW OF WARRANTY.}

\section{Uncertainty of the Law.}

The English law of Warranty is in a very unsettled and unsatisfactory state. No man, who gives a warranty, is safe. The seeds of disease or lameness may be legally traced back almost any length of time. On the other hand, a bonâ fide purchaser even in cases of downright fraud often finds the greatest difficulty in recovering his money from an unscrupulous dealer.

In almost every case some Veterinary Surgeon may be found to give his professional opinion that the cause of unsoundness may have been and 
probably was antecedent to the sale; whilst on the other side an equally eminent practitioner may be found to give a directly opposite opinion. Hence arise tedious lawsuits and conflicting decisions. The jury are puzzled by contradictory professional evidence. The judge explains to them the law of the case, namely, that if in their opinion the cause of unsoundness was antecedent to the sale, the horse can legally be returned; but if they think that the cause was not antecedent, the animal cannot be returned. He then reads over his notes and tells them that they must be judges of the question of fact.

The state of the law is also made in many cases a means of oppression and injustice, even where the matter does not come to trial. Take a very ordinary case. A farmer sells a young horse to a dealer for $£ 70$, and warrants him sound. Ten days after the purchase the dealer writes to say that the colt has turned a roarer, and that he must return him. The farmer lives at a distance from - , and has no means of investigating the truth or otherwise of the statement. An angry correspondence ensues, and the dealer threatens an action. Rather than have the trouble, expense, and uncertainty of a lawsuit, the farmer eventually returns half the money; whilst the horse may be all the time perfectly sound, or may have become diseased from want of due care in bringing him suddenly into the confined atmosphere of a town stable.

Or take another case. A dealer sells a horse to a customer. The animal's legs by judicious management, laxative diet, moderate exercise, and bandages have been got pretty fine, and he passes muster on the day of sale. After a few days' work the horse goes lame. The purchaser then takes the animal to a veterinary surgeon, who tells him the unpleasant truth, namely, that he has made a bad bargain, or in other words has been "done." The buyer threatens an action, but the dealer laughs at him, and says that he can produce evidence, plenty of evidence, that the horse has been in regular work for six months previous and has always been sound. The purchaser is deterred by the probability that the seller will produce the required evidence-whether the jury will believe or not may be doubtful - but he is afraid of the uncertainties and expense of the law, and so he puts up with the loss.

An excellent custom-not law, for there is no law on the subject-prevails in Ireland, namely, that the purchaser may take the horse to a veterinary surgeon of his own selection any time within forty-eight hours after the purchase; and that both parties are finally bound by his decision. If the purchaser neglects to do so, the bargain is nevertheless complete at the end of the above time. Of late years this has also become customary in England.

As regards soundness, the Author would earnestly recommend the seller only to give a warranty of the above description, namely, "sound, subject to the opinion, to be taken within forty-eight hours, of a veterinary surgeon selected by the purchaser;" and on the other hand he would advise a purchaser not to ask for anything more.

It may however occur, that the veterinary surgeon may recommend that a special warranty be given for a specified time on some particular 
points which he thinks suspicious. To such special warranty on any one point for a given time the Author sees no objection-either on the part of the buyer or of the seller.

Warranties are also given as to freedom from vice. These are very apt to lead to difficulty. A horse may be quiet with one person and troublesome with another. A horse may be quiet if properly exercised, and fractions if left in the stable and over-fed. Again, a horse with a really beautiful mouth will often show temper and perhaps rear, if the rider has bad hands.

As regards the temper or vice, the intending purchaser ought to protect himself by riding or driving the animal, and ascertaining by such trial that he suits his hands and seat. If he is too timid to do it himself, he can always find a friend who will not object to make the trial; though for the reason given above such trial is very inferior to that made by the intending purchaser personally. Seeing a horse ridden by the dealer or his man is worth nothing. Horse dealers, though they make a point of abusing their men and declaring that they have no "hands," in reality always provide themselves with good riders for the purpose of showing off their cattle to the best advantage.

In trying a horse, the animal should always be ridden in front of, alone, and in company. Many vicious horses go quietly along with another horse, especially with one to which they are accustomed; whilst others go quietly alone, which are excessively unpleasant to ride along with other horses. The horse, when tried in company, should always be ridden a little behind as well as in front of and alongside others. Some animals fidget all day unless they are in front, whilst others start and shy when in front, though quiet when ridden behind or with others.

\section{Purchase of aged horses.}

The advisability of buying a mature horse of six or seven years old should never be lost sight of, notwithstanding a few lumps or bumps, the result of work, in preference to an absolutely clean-legged animal of that age. The chances are that perfectly clean legs at that age are due to a delicate constitution, a bad temper, or an attack of serious disease, which has kept the animal out of the influences likely to cause these signs of "honest work."

An unbroken technically, i.e. absolutely sound six-year-old horse, is an object of grave suspicion to all practical horsemen, who know that no ordinary reason would induce the breeder to keep the animal till that age, when it was as marketable at four years old.

Moreover Conformation-must play a very important part in expressing an opinion regarding the unsoundness of Legs, which may presumably be the result of work or accident.

\section{9a. Responsibility of Veterinary Surgcons.}

As in the human subject specialists are often mistaken in the views they take of the patient's constitutional ailments, so it may occur that 
Veterinary Surgeons, even the most skilled, with the greatest possible care may fail to detect latent defects, and it seems unreasonable that juries should hold them pecuniarily responsible. The medical man who makes a mistake with the patient who consults him is not so held responsible; or take another case, which is perhaps more closely allied to the exanination of horses for soundness. An insurance office employs a medical man to report on the constitutional and probable longevity of a person wishing to be insured. The medical man is not held by the insurance office to be pecuniarily responsible, if he makes a mistake in his diagnosis and the person insured dies shortly afterwards.

\section{CHAPTER 62.}

\section{PRINCIPLES OF SHOEING.}

Plates 47 to 57 . The figures are consecutive throughout these Plates.

940. General principles. 941. Structure of the Foot. 942. The outer case of the Foot. 943. The Crust or Wall. 944. Effect of rasping on the Crust. 945. Why then do farriers rasp? 946. Of lowering the Crust versus rasping its external surface. 947. Prevention of splitting of the Crust after being lowered. 918. The Bars. 919. The Sole. 950. Of undue pressure on the sensitive Sole, as a result of paring. 951. Of undue pressure on the sensitive Sole from mutilation of the Crust. 952. The Frog. 953. Cleanliness. 954. Shape of the Foot. 955. Size of the Feet. 956. Feet to be pairs. 957. Contraction and expansion of the Foot. 958. Conclusion.

\section{Principles of Shoeing.}

I sIIALL dismiss for the present all questions of particular patterns of Shoes,-though I have my own preference. At the outset I shall treat only of that which is essential to all good shoeing, namely, the preservation of the foot in a sound and healthy state.

Certain sorts of shoes mina be adjuncts to good shoeing, but they are not absolutely essential to it. Without a healthy foot any sort of shoe will more or less fail. With a healthy foot, most sorts of shoes will answer tolerably well. I attach far more importance to the treatment of the foot than I do to the shoe.

One great principle runs through all good shoeing, namely, the preservation of the outer case of the foot; this includes-

1st. The preservation of the Crust and Bars whole and entire.

2 nd. The preservation of the Sole.

3rd. The preservation of the Frog.

\section{Structure of the Foot.}

'The Foot is a sensitive vascular structure with a bone, or rather two bones and a portion of a third, enclosed within its outer case. 
All that we need do-or perhaps I-should rather say, all that we can do in shoeing-is to preserve the outer case whole and entire; namely, the Crust and Bars, the Sole and the Frog. Nature in most cases takes care of the interior structures, if we preserve the outer case. The exceptions to this rule are diseases resulting from constitutional or accidental causes.

But if we do not preserve the outer case whole and entire, the interior structures will certainly suffer in various ways, to be described hereafter.

\section{Of the outer case of the Foot.}

The outer case consists of three parts, viz. 1st, the Crust, otherwise called the Wall (Plate 47, A, fig. 1), and the Bars; 2nd, the Sole (B, fig. 2) ; 3rd, the Frog (c, fig. 1). The Bars are not shown in this drawing. See 1 , fig. 6 .

\section{Of the Crust or Wall.}

The Crust or Wall (A, fig. 1) will suffer if it be rasped outside. It consists of a number of fibres (containing a soft cellular nutritive material), running down longitudinally from the coronet. In technical language the crust is said to be secreted by the plexus of blood-vessels round the coronet, called the coronary band or cushion. In plainer words, it grows from the thickened skin round the coronet ( $\mathrm{E}$, fig. 1). In the human fingers the nails grow in a similar way from the skin. The crust is overlaid externally by a gluey glazed superficial layer-of which hereafter.

The fibres of the crust contain the above-mentioned soft cellular material in an organised form for a considerable, perhaps two thirds of the distance down. In their lower portion the crust becomes dry and hard; and the fibres are then in a condition, first, to stand wear and pressure without sensation; and, secondly, they are in a state almost ready, and in their lowest portions quite ready, not exactly to be cast off, but to be worn off by friction with the ground. The fibres are constantly being renewed by growth from above.

No doubt under the wise laws of nature the renewal or rate of growth is exactly proportioned to that amount of wear which would be incidental to a horse in a state of nature, such as would be required for obtaining food and water. I am aware that when horses are turned out in this country in a field with no distance to go in search of food or water, this natural wear does not sufficiently take place, and in consequence the feet become long. But it must be remembered that this is a semi-artificial condition. A horse really in a state of nature would probably have to travel many miles a day in search of food and water.

I may here remark, if the reader will pardon a short digression, that nature appears to furnish horses with feet suitable to the locality in which they are bred. The low-bred horse, which is a native of rich wet pastures, where he would not have far to travel in search of food and water, has usually large, wide, somewhat Hat, "Hleshy" feet. Such feet are more convenient to the animal in such pastures than narrow and more 
upright feet, which would sink deep at every step. But certuinly they would not stand much wear.

The high-bred horse, which is a native of the arid sandy plains of Arabia, must in a state of nature travel many miles every day in search of food and water. Nature has accordingly furnished him with feet more capable of withstanding wear. Hill ponies often have feet almost like those of donkeys. Such feet are suitable for rough rocky hills.

\section{14. Effect of Rasping the Crust.}

1st. Of rasping the crust high up, where the fibres are vitalised (A, fig. 2).

Rasping produces two evils: 1st, the outer and strongest layers of fibres are destroyed; and 2nd, the gluey superficial layer which overlies the outside of the crust is destroyed, and then the moisture of the horn, which is essential to its toughness, escapes. In consequence, the horn becomes brittle and then shrinks and contracts. Again, the moisture having escaped, the horn becomes hard.

Having become hard and contracted, the horn then presses unduly on the vascular and sensitive parts within, especially on the sensitive laminæ, and causes them to become hot, inflamed, and ultimately diseased. We recognise the earlier of these effects in the foot being hot. I do not say that the permanent and more injurious results above mentioned will ensue in a day or in a month, or even perceptibly in a year, but surely and slowly the maltreatment produces and must produce an ill effect on the vascular and sensitive structures of the foot.

2 nd. Of rasping the crust below the point to which vitality extends (A, fig. 3, Plate 48).

What harm is there in that? it may be said. Well, two evils resultthe one mechanical, the other vital-through injury to the mechanical arrangements of the foot.

The width of the crust "proper," taken by itself, is about half an inch. But including the fibres, which interlace it with the laminæ, it may be said to be about three quarters of an inch in width. These latter fibres are not so strong as those of the crust, but they are capable of sustaining some weight.

On this three quarters of an inch has to be borne the greater portion of the weight of the horse and his rider, and the pounding and concussion occasioned by fast riding on hard roads. Now three quarters of an inch is not a great width on which to sustain all this weight and concussion.

Two evils, the one mechanical, the other vital, as I said above, result from rasping the crust. Its width is probably diminished to half an inch; and moreover, the strongest fibres have been destroyed. This reduced width is one third less than nature intended. And nature is always right. In consequence of diminished width and strength, the crust becomes insufficient to carry the weight of the horse. Hence undue concussion, heat, inflammation, and disease. The first portion of the injury is mechanical; the second, a result of the mechanical injury, is vital. The sensitive internal structures are injured. Moreover, the strongest 
horn fibres having been destroyed, the nails have a less firm hold and consequently the shoe is more easily pulled off, and probably a considerable portion of the weakened crust will come away with it.

\section{Why then do farriers rasp the Crust?}

First, because an apparently good fit of the shoe to the foot is essential. Secondly, because it is easier to produce to the eye of an inexperienced person the appearance of a good fit by rasping down the foot to a shoe rather too small for it than to fit the iron to the real size and shape of the foot.

The primary essential of all good shoeing is that the outside of the crust be not rasped.

\section{Of lowering the crust versus rasping its exterior surface.}

The crust or wall having been protected by the shoe from that natural friction and wear against the ground to which it would have been subjected if it had not been so protected, it is necessary each month to lower the crust as much as will represent what would have been the natural detrition by wear.

How much this will be must vary in different horses. In some feet the growth is much more rapid than in others. In some hoofs of soft material the crust wears away considerably, even though protected by a shoe. This question must be left to the practical and practised eye of the farrier.

But it will be asked, How is the crust to be lowered without causing the injuries described above to its structure?

Simply by removing all that requires to be removed from the inferior or ground surface of the crust, without touching the superior part. This will be best done by the rasp from underneath, though, if the crust be very long, the knife may be used (A, fig. 4).

After a sufficient quantity has been removed, the inferior or ground surface must be made perfectly level, for the reception of the shoe, by the use of the rasp.

The strength of the fibres of the crust will not be in any degree lessened by shortening them. On the contrary, it will be rather increased. Let me illustrate what I mean by an ordinary quill or pencil. If I shave it longitudinally it will be weakened as regards its power of sustaining weight on its top; but if I cut half an inch or an inch off its lower end it will practically be strengthened. For illustration see A, figs. 2 and 3, as compared with $\mathrm{A}$, fig. 4. -

\section{Prevention of splitting of the Crust after leing lowered. Feather edge.}

When the crust has been sufficiently lowered and made level by the rasp, as above described, it will be sharp all round its exterior circle. This sharp or feather edge must be removed by the rasp before the shoe 
is applied, in a way which I will endeavour to describe, but which can be much more easily shown practically. The foot being held up, the rasp must be applied from below to the under edge of the erust, and must be drawn round it so as to produce a blunt edge. If properly done no mark of the rasp will be visible above the rounding off ( $A_{A} A_{\text {, fig. }}$ 5, Plate 49).

Again, this rounding off must be done before the shoe is applied. It cannot be done afterwards. Try and do it after the shoe is nailed on, and then take off the shoe and you will find a sharp edge.

MLemo.- If a sharp edge be left the crust will be liable to split and chip, which is a great evil. All splitting and chipping may be obviated in ordinary feet by rounding off the crust in the way described before the shoe is applied, provided always that the exterior of the crust has not been previously injured by rasping.

Farriers almost always-I think I might say always-rasp the lower edge of the crust after the shoe has been nailed on, and thereby produce a sharp edge. They use the rasp at this time in order to produce the appearance of a good neat fit of the shoe to the foot.

\section{The Bars.}

The bars (B, fig. 6) are a reduplication inwards of the crust at the heels. In addition to other uses the bars are the stays provided by nature to the back part of the foot against contraction. The continuity of the circle of the crust is broken at the heels by the intervention of the frog. Here some stay or buttress is needed to prevent a wiring in of the crust at the heels.

The bars demand no special treatment, except to be let alone. If let alone, they will perform their duties efficiently and well. It is, however, the common practice of farriers to cut them away, because their absence gives a wider and more open appearance to the foot at the heels. But the result, the inevitable result, except perhaps in very strong feet, is contraction at the heels, and in many cases corns.

It is also the common practice to pare out the sole from the angle between the crust and the bars. This angle is the seat of corn. It is pared out under the impression that this operation will relieve the part from that pressure which is the cause of corn. This idea, as preventive of corn, is a fallacy. Nature has filled up the angle with sole, and nature is never wrong. The portion of the sole between the crust and the bars acts beneficially in sustaining the bars in their proper position. When it is removed, the bars from want of its due and natural support are apt to wire in towards the crust. This wiring in produces undue pressure on the seat of eorn, and may ultimately induce corn. Corns, however, are also due to other causes, of which hereafter.

Bars, which have been eut away for a number of years, almost cease to exist. Pressure and weight are essential to their development, and in common with other parts, which are deprived of that duty for which nature intended them, they will dwindle away, and nothing but the germ will remain. In most cases, however, they may be again developed and 
brought into their natural prominence by use and pressure, especially if the horse be shod with tips.

\section{The Sule.}

Supposing the crust to have been properly treated and cared for in the manner above described, the sole necds nothing except to be let alone (A, fig. 6, also B, fig. 1). This is a very simple and easy mode of treatment, and anyone can follow it.

But, before going further, I must earnestly eaution my readers that this natural treatment of the sole is only applicable to feet in which the crust is good and has not been mutilated or otherwise abused. If the crust be mutilated, the sole must also be mutilated, as otherwise lameness will ensue. The reason for this will be explained hereafter.

Having given this caution, I now proceed to consider the structure of the sole and the reasons arising therefrom, which under the circumstances of a naturally good and well-preserved crust render advisable the negative treatment recommended above.

The sole is not constructed for sustaining weight except at its junction with the crust or wall, where it is thickest and strongest. Its fibres are composed of softer horn cells than those of the crust. Nor is it intended for sustaining pressure, except at this particular part. It is a recessed surface; recessed surfaces are never intended to be exposed to pressure. Whilst the erust is worn away by friction with the ground, the solewhich from its recessed position is not exposed to any such wear-of its own accord, from some peculiarity in the material composing its fibres, exfoliates in flakes, when its outer surface becomes effete.

The sole consists of two layers, an outer and insensitive, and an upper and sensitive layer. Immediately above the upper sensitive layer is the coffin bone or os pedis. Hence it will be seen that the sensitive sole is placed between two hard substances, namely, the lower insensitive layer and the bone of the foot (D, fig. 1). Hence, if undue pressure comes on the lower layer, the upper and sensitive layer will be crushed between the two hard substances, and great pain and perhaps inflammation will ensuc.

Undue pressure may come on the sensitive sole from two causes:1st, from paring away the outer or insensitive layer, which renders it incapable of duly protecting the seusitive sole; and 2 ndly, from mutilation of the crust and frog.

\section{Of undue pressure on the Sensitive Sole as a result of paring.}

A fallacy exists among many horsemen and farriers, namely, that the insensitive sole, if not pared away, will unduly accumulate, and so cause pressure on the sensitive sole. Hence farriers eut it away-with good intent, no doubt, but in ignorance of its structure. For reasons given above, connected with its structure, the sole will never, except in disease, unduly accumulate. At the proper time it will exfoliate in flakes.

Another fallacy also conmmonly exists, namely that the outer or ground surface of the sole will, if not pared unt, become very hard, and will then 
be liable to cause injury to the sensitive sole. Therefore the farrier cuts it away. In fact, the direction usually given is to pare out the sole at each shoeing, until it will yield to the strong pressure of the thumb, with a view of giving relief to the sensitive sole from undue pressure.

In truth, however, the sole will never become unduly hard unless it be pared out. Its hardness or its softness is mainly dependent on its thinness or its thickness, except in certain diseases.

If left in a state of nature, the thickness of the healthy sole is sufficient to preserve its own inherent moisture; but if it be made artificially thin by paring the whole remaining substance will dry up and become hard. On the other hand, the outer flakes, if allowed to remain, though they. may be apparently hard, will preserve the moisture of the inner flakes. If, however, the outer flake be removed, the next flake becomes hard, and so on; and if by constant and premature removal of successive outer flakes by the knife, the insensitive sole is made very thin, the whole remaining substance will become very hard. Let me take an illustration. If I take a quire of paper and soak it in water, the underneath sheets will remain soft for a long time; but if I take off each upper sheet as it becomes dry and hard, the next sheet will soon become dry and hard; and if I continue the process of removal as each sheet becomes dry, the lowest sheet of all will become dry and hard.

\section{Of undue pressure on the Sensitive Sole from mutilation of the Crust and Frog.}

The effect of rasping the crust was pretty fully described in the carly part of this Chapter. The crust or wall of the foot, with the aid of the frog, is intended by nature to sustain the greater part of the whole weight of the frame. If the crust be weakened by rasping and thereby rendered insufficient to sustain the weight, a portion of the weight will come on the sole at the part not intended by nature to bear weight or pressure (B, fir. 2, also $\mathrm{B}$, fig. 3). A similar effect is produced by mutilation of the from. The fror is intended by nature to sustain a large portion of the weight of the animal.

\section{The Frog.}

The Frogr (c, fig. 1, also c, fig. 6, Plate 49), except in disense, needs only the same treatment as the sole, namely, to be let alone. The frog is an elastic pad placed on the back of the foot. It exfoliates in flakes in due time in much the same way as the sole. Therefore it does not need to be pared. The structural reasons against paring it are much the same as those detailed above in regard to the sole.

There is, however, another reason against paring it. Unlike the solo the frog is prominent and convex. It is therefore obviously intended by nature for pressure and friction. Under the influence of its natural use viz. pressure and friction, it will thrive, develop, and become strong. Without pressure and friction, it will shrink up and dwindle away and 
almost cease to exist. There is no fear of the frog wearing away, if exposed to wear. The contrary is the invariable result.

The frog has three principal uses, which it will only fulfil well if it be large and prominent. The frog is an elastic pad intended first to receive on itself a large portion of the jar and concussion which results from the movement of so large carcassed an animal as the horse; and again, by receiving it on itself, it diminishes concussion in other parts of the frame, such as the bones and joints, which are not by nature adapted for sustaining jar and concussion. Secondly, the frog being elastic and wedgeshaped, acts as a stay to the ground against slipping. Hence its maintenance and developnent are objects of great importance. Thirdly, the frog, when properly developed, acts as a support to the coffin-joint, especially to the centre of the navicular bone.

Memo.- I have said above that the frog ought not to be pared at all. This is true in theory and correct in practice as regards a sound, healthy frog. But all frogs are not sound and healthy. Disease, most commonly thrush, is very soon set up in the frog by any carelessness, such as not carefully and frequently washing out the feet, and especially by allowing the horse to stand in his own dung or urine. Disease commences in the frog, not in the outer layer, but under it, i.e. in the interior layer. Hence it is often not discovered until it has run to a considerable extent. Therefore it is a wise precaution in all eases, where there is any doubt, as indicated by raggedness or unpleasant smell, to remove the ragged parts with a view of ascertaining whether any disease is latent underneath. Such removal of the ragged parts ought not, however, to be made an excuse for paring down the frog; nor is any such removal allowable, unless there are at least some indications of latent disease. The frog especially requires to be kept not only clean but dry.

\section{Cleanliness.}

One other point remains to be considered, namely, cleanliness. Cleanliness is essential to the health of the foot. The foot must be kept clean, not only by washing and picking it out, but more especially by keeping the stall clean and free from dung and urine. Stalls cannot be kept clean unless the paving and drainage are good. Stables, I may add, are seldom kept clean and sweet, unless in addition to good paving and drainage there is also ample light and ventilation.

\section{Shape of the Foot.}

The shape of a good Foot (fig. 6) at its lower or ground surface approaches that of the circle. The crust should grow down at an angle of between 50 and 52 degrees (A, fig. 1).

The ground surface has doubtless been made circular, because that form affords within a given circumference a greater weight-bearing space than any other. Other circumstances, however, require a slight modification of the circular form. The continuity of the circle is somewhat broken at the heels by the insertion of the wedge-like frog, and anteriorly 
it is somewhat squared off by the wearing away of the toes. Again the circular form is less perfect on the inner than on the outer side, because the crust is thinner on the inside than on the outside, and more upright (fig. 6).

Two advantages are gained by the diminution of the thickness of the crust on the inside, and by its uprightness. 1st, the chance of interference of one foot with the other is lessened; 2nd, greater elasticity is afforded. Greater elasticity is required on the inside than on the outside, in order to obviate the greater concussion which, as is well known, falls on the inside. Greater concussion falls on the inside because greater weight falls on it than on the outside. It may perhaps seem strange to the reader that less thickness of crust should be given on that side on which the greater weight falls. But a similar formation with a similar view, namely, elasticity and the lessening thereby of concussion, is found throughout on the inside of the limb up to the knee.

In considering, however, the strength required on the inside, it is important to bear in mind three points. 1st. Although greater weight falls on the inside, yet it falls more perpendicularly than it does on the outside ; and the two inside crusts are more directly under the centre of gravity than the two outside crusts. 2nd. The two inside crusts are nearer each other than the two outside crusts, and therefore each requires less strength-a principle well known to all builders. 3rd. The fibres of the crusts on the inside are more perpendicular than those of the outside, and are thereby better placed for sustaining weight."

The crust is placed by nature on the outer edge of the circle of the foot, because in that position it affords the greatest circumference for sustaining weight. The shoes will be found to be most worn on their outer circumference, because they there rest on the portion of the crust best adapted for sustaining weight.

\section{Size of Feet.}

Feet of a medium size, in proportion to the size and breed of the horse, are the best. In large feet the horn is generally of a coarse inferior quality, deficient in toughness and strength, and slow in growth. In small feet the horn is generally tough and sound, though sometimes it may be brittle. Small feet, if equally so all round are, as a rule, preferable to wide spreading feet. Small feet, when of a natural formation, are easily distinguished from contracted feet by the fact that they are correspondingly small all round. Contraction rarely, if ever, affects all the feet, and never affects all the feet equally. One foot smaller than another is rarely, if ever, a natural formation.

Small feet are common in the well-bred horse, who is a native of dry, sandy plains, whilst the under-bred horse, living in low wet pastures and fed on succulent diet, has a tendency to laige coarse feet.

956. Feet to be pairs.

Whether feet are large, medium, or small, it is essential that they should he pairs. Any difference in size between the two fore-feet or 
between the two hind feet is the almost sure and certain sign of disease, either past or present, in the foot or in some part of the limb directly or indirectly connected with it, or of some irregularity of action.

There are, however, some few families of thorough-bred horses which are notorious for having odd fore-feet, and yet seldom go lame on them.

\section{6a. Malformed Feet.}

Malformed feet, if congenital, such as "Fleshy" feet, which have abnormally thin walls and thick soles; or in some cases "Club" feet, i. e. one more upright than the other, are not necessarily unsound, though under certain conditions they may speedily become so. "Mule" feet, which are the result of rearing on very dry or rocky soils, will stancl wear, but are objectionable in horses, such as hunters, which are required to go in deep ground.

\section{Contraction and Expansion of the Foot.}

The question of the contraction and expansion of the foot has long been a subject of keen discussion among Veterinarians. Three different views are held.

1st. That the foot expands on coming to the ground by reason of the weight and pressure imposed on it; and contracts when it is raised off the ground.

2nd. That the foot contracts on coming to the ground by reason of the weight and pressure imposed on it; and expands when raised off tho ground.

3rd. That the foot neither expands nor contracts to any perceptible degree.

This latter view I believe to be correct. No doubt there is a certain degree of elasticity in the horn, as in all living structures, but not sufficient to constitute expansion or contraction.

It has been often remarked that there is in general a bright mark on the upper surface of the shoe towards the heels, which is by many supposed to be due to the effeet of contraction and expansion at that part. These marks, however, it may be noticed, run along the web of the shoe and not from side to side, as would be the case if they were due to expansion and contraction. They are in reality caused by the backwards and forwards motion of the heels of the shoe, which is produced by the leverage at the toe when the horse is in motion. There are no such bright marks on the quarters of the shoe where the effect of contraction and expansion, if it existed, would surely show itself, inasmuch as the greatest weight and pressure falls on that part of the foot.

\section{Conclusion.}

I have now said all that I conceive to be necessary for maintaining the health of the foot in the shod horse.

Other cognate subjects remain which are of much interest, such as the 
hest kind of shoe; but these, though important, are not so immediately concerned in the health of the foot.

The treatment of feet not in a state of perfect health is also important, as is also the treatment of feet in a state of disease. Again, there may be feet of delicate structure or of indifferent conformation, which, though free from positive disease, require special treatment.

But if a person buys a horse with good sound feet, and if in the treatment of the feet and in shoeing he complies with the requirements of nature, he will probably find that he is never troubled with any foot disease. Feet do not wear out with age as do many other parts of the frame. The foot of an old horse is generally just as good as that of a young horse.

\section{CHAPTER 63.}

\section{SHOEING-DETAILS OF.}

Plates $47-57$. Figures are consecutive throughout.

959. Shoeing. 960. Breadth of Fore-Shoe. 961. How thick should the Shoe be? 962. How often should horses be shod? 963. Of removing Shoes. 964. Upper surface of Shoes. 965. Under or ground surface of Shoe. 966. Length of the Shoe. Heels of the Shoe. 967. Fitting of the Shoe. 968. Objections to close-fitting Shoes. 969. Removal of the old Shoes. 970. How many Nails are required. 971. Nails to be frequently examined. 972. Form and materials of Nails. 973. Position of Nails. 974. Punching of nail-holes and Driving of nails. 975. Nail-heads. Countersunk Nail-holes. 976. Rose-headed Nails. 977. Nail-heads not to project below the Shoe. 978. Clenching of Nails. 879. Nail-bound. Tight nailing. 980. Importance of Nails and nailing. 981. Fullered Shoes. 982. Loss of Shoes. 983. Tips. 983a. Charlier Shoes. $983 b$. Bar Shoes. 983c. Rocking Shoes. 984. Hind foot and Shoe. 985. Form of the Hind Shoe. 986. Calkins. 987. Shoes to be level. 988. Directions to Farrier for Shoeing ordinary Fore-feet. 989. Directions to Farrier for Shoeing ordinary Hind feet. 990. To Shoe a troublesome horse. 991. Roughing.

\section{Shoeing.}

In the present chapter I shall endeavour to avoid all crotchets, and shall treat only of the broad principles of the art of shoeing, viz. those which are-

1st. Fissential to the health of the foot. 
2nd. Necessary to maintain the shoe on the foot, especially in deep ground.

The directions given as regards the weight, width, and thickness of shoes will be those applicable to ordinary riding horses. Heavy draught and cart horses will need heavier shoes, whilst race horses will require lighter. For very heavy horses, see Calkins, par. 986.

In the succeeding chapter I shall advance some reasons in favour of a change in the ordinary form of the toe of the fore-shoe. But this change, though I believe it to have many advantages, both as regards the comfort of the horse in progression, and as regards the safety of the rider, is not essential to the health of the foot or to the security of the shoe.

\section{Breadth of the Fore-Shoe.}

For ordinary riding horses, hunters and carriage horses, it is usual to make the shoe about one inch wide. I believe that three quarters of an inch is sufficient. The crust or wall of the foot, including the substance intervening between the crust "proper" and the sensitive laminæ, is about three quarters of an inch in width. This, as explained in the previous chapter, Par. 944, is the proper weight-bearing structure of the foot.

The shoe must be as wide as the weight-bearing structure. It must rest not on a part, but on the whole of this structure. To enable it to do so the shoe must, contrary to the usual practice, be made flat towards the foot (Plate 50, AA, Fig. 7) (see also Par. 964).

The shoe must not be wider than the weight-bearing structure. Any greater width than this must be useless, and moreover, will be the means of allowing dirt and gravel to lodge between the shoe and the recessed sole, and will also render the shoe liable to be sucked off in deep ground.

The shoe should be of even width until it approaches the heels. Towards the heels, where the crust gradually comes to a point at its junction with the bars, the shoe must also come to a point, the inner edge of its heels exactly following and resting on the bars (Plate 50, B, fig. 7).

The narrowing of the web of the fore-shoe at the heels may seem unnatural to those who are not accustomed to it. But if it is the shape, as it undoubtedly is, which nature has chosen for the crust at its junction with the bars, can it be either unnatural or unsuitable? On the other hand, the ordinary square or rounded heels are objectionable, because that part, which overlaps either the crust or the bars, rests on nothing, and is therefore useless; and moreover affords a handle, as it were, by which to wrench off the shoe in deep ground.

\section{How thick should the Shoe be?}

The growth of the foot renders it necessary that the shoe should be refitted at the end of a month. It is obviously undesirable to burden a horse with a greater weight of iron on his feet than is absolutely necessary. Weight tells much more (on the well-known principle of the steelyard) at the end of a long lever, such as the leg practically is, than it does 
on the back. I am not aware of any means of showing practically what is the difference of weight carried on the back and on the feet, but it is certainly very considerable.

Prima facie, therefore, shoes should be as thin as is compatible with their wearing for a month. But practically there should be a week's wear to spare at the end of the month; both because it is not always convenient to send a horse to be shod on any particular day, and because it would be inconvenient to be liable to the risk of a shoe breaking, if the owner happened to take an extra long ride towards the end of the month.

No absolute rule can be laid down as regards the weight of shoes, 1st, because horses' feet vary very much in size; 2nd, because some horses, from peculiarity of action, wear out their shoes much quicker than others ; 3rd, because some horses are called upon to do much more work than other horses; and lastly, much will depend on the nature of the ground or roads on which the horses are worked.

However, nine ounces may be taken as the minimum, and fourteen ounces as the maximum for ordinary riding horses. On very large cart horses in London I have seen shoes which weighed as much as seven pounds each; four pounds is a common weight for the shoes of such horses. I cannot say from my own experience whether such weights are really necessary.

\section{How often should a Horse be shod?}

The growth of the foot renders it necessary to refit every shoe at the end of the month. For reasons given above, it is undesirable to burden a horse with heavier shoes than necessary. Therefore the horse should be shod with new shoes every month.

\section{Of removing Shoes.}

Shoes, if properly fitted, and if resting on a sound unrasped crust, should not require to be removed during a month. The nails, however, should be frequently examined, and any that are faulty should be replaced.

\section{Upper: surface of the Shoe.}

The upper surface of the shoe should be flat, so that it may rest on the whole surface of the crust. Nature has intended the whole of this width to be employed in sustaining the weight of the horse; and in moulding a shoe we should endeavour to follow as nearly as possible the arrangements and structures of nature (Plate 50, A, Fig. 7).

Shoes, however, are generally "seated out" on their upper surface in such a manner that only one half of their width rests on the crust. At first sight it may seem curious, that an arrangement so obviously incorrect and opposed to nature should so extensively, indeed almost universally prevail in our forges. There is, however, a good reason for it. The crust is usually weakened by rasping, and then it gives way under 
the weight of the horse; and a shoe of the usunl width (one inch) flat towards the sole would press unduly on the sole, unless the pressure was ohviated "loy seating out" (A, Fig. 8).

"Seating out" is a practice wrong in itself, but generally rendered necessary by another bad practice. There need, however, be no fear of undue pressure on the sole, if the crust be preserved whole, sound, and tough.

Again, it is obvious that the superincumbent weight is more diffused by gaining a wider bearing for the shoe; and hence those diseases which arise from undue concussion are less likely to occur.

\section{Under or ground surface of the Shoe.}

The under or ground surface of the shoe should be concave (A, Fig. 9). This is the form in which nature has moulded the horse's foot, and wo cannot do wrong in following it. I am not aware of any objection which can be urged against it. This form, it is true, is not adopted in the shoe in ordinary use; but this arises not from any objection in theory, so far as I am aware, but from the simple fact that inasmuch as, for the reasons given above, it is usual to seat out the upper surface, it is impossible also to seat out the lower surface. A double seating out would render the shoe so thin that it would be liable to break.

A concave ground-surface has a great practical advantage, inasmuch as the shoe gets a much greater hold on the ground, and the horse is therefore less liable to slip, or pick up stones.

\section{Length of the Shoe. Heels of the Shoe.}

The length of the shoe is determined by the length of the crust. The shoe must-be the exact and full length of the crust. Nature, in fact, in all cases points out the proper length of the shoe by the termination of the crust. If shoes are made shorter than the crust, their heels or "ends of their branches" will be apt to press upon and dig into the seat of the corn. If, on the other hand, the shoes are longer than the crust, toe hind shoes may catch in the heels of the fore-shoes and pull them off.

An objection is sometimes raised to fore-shoes being made the full length of the crust, on account of a fear lest the hind shoes should catch in them. This accident, however, is not likely to occur where the shoes are not longer than the crust. The possibility of it will be prevented by sloping off the heels of the fore-shoes in the direction of the fibres of the crust (fig. 9), and again by sloping off the inner or posterior edge of the toe of the hind shoes. (See Over-reach, Chap. 65, par. 1002.)

\section{Fitting of the Shoe.}

The crust having been lowered by the rasp, aided as little as possible by the knife, and rendered smooth by the rasp, and its sharp edge having been rounded off, the shoe must then be so fitted that its outer edge corresponds exactly with the crust. It must not be smaller than the 
crust, nor overlap it in the slightest degree. If a shoe be applied smaller than the crust-and such is the usual practice - the crust must be rasped down to it. If, on the other hand, the shoe be larger than the crust, treads and other injuries may be the result, and in deep ground the shoe may be pulled off.

Though the above directions may seem very simple and reasonable, yet practically there is great difficulty in getting them carried out. The accurate fitting of the shoe must be produced by the troublesome process of moulding the shoe to the foot-not by the easy process of rasping the foot down to the shoe. Any mark of the rasp on the crust is the sure sign that the farrier has not taken the trouble to fit the shoe to the foot.

The shoe may be tried on warm enough to mark the crust. It is diffi- . cult to fit the shoe accurately without such marking. There is no real objection to the practice, as the horn is quite insensitive. But this permission must not be made an excuse for burning down the crust.

\section{Of objections to close-fitting Shoes.}

It is often objected to close-fitting shoes that they do not allow room for the expansion of the foot, and will therefore be liable to cause contraction. It may be sufficient to observe that all shoes are, for fear of treads and interfering, fitted close on the inside, where contraction almost invariably occurs, and that they are left wide on the outside, where contraction is seldom or never found. It is needless to say that a shoe left wide on the outside can have no effect in preventing contraction on the inside.

The question of the contraction and expansion of the foot was discussed above in Par. 957.

\section{Removal of the old Shoes.}

The clenches should be cut carefully without injury to the crust, and then each nail should be drawn separately. Much damage is often done to the crust by neglect of these simple precautions. It takes very little time to remove an old shoe properly, and there is really no excuse for the hurried and violent manner in which this operation is too often performed.

\section{How many Nails are needed?}

The fewest which will retain the shoe securely in its place is, of course, the theoretical answer. The practical answer will, however, depend on various considerations - with the size of the foot, the soundness and toughness of the crust, the accuracy of the fitting of the shoe, and the nature of the ground on which the horse is to be worked.

For ordinary riding horses and for hunters, if the crust be sound and good, and if the fitting of the shoe be also good, five nails, namely, three on the outside and two on the inside, are sufficient for the fore-shoe, provided that the heads of the clenches are not rasped.

If, however, the crust be rendered thin and brittle by rasping, or if the 
shoe projects beyond the crust, or if the clenches are filed away after turning down, or if the nails are bad, no number of nails will retain a shoe under circumstances favorable for pulling it off.

N.B.-If the shoe be what is called " back punched," i.e. the upper end of the nail holes opened out too much, the shoe may drop off, leaving all the nails in the foot.

\section{Nails to be frequently examined.}

Where few nails are used, it is absolutely necessary that the farrier or groom should frequently examine them and see that each nail and clench is good. A broken nail, or one with its head or clench gone, is obviously useless, and must be replaced.

The necessity of replacing a damaged nail is often urged as a serious objection to the use of few nails by persons whose horses are seldom seen by the farrier, except at the end of the month. This objection may, however, be easily obviated by making the groom responsible for looking to the nails, and taking the horse to the forge whenever necessary.

\section{Form and material of nails.}

Nails must be made of the best and toughest iron, for none other can stand the strain and jar of fast work. The quality of a nail may be easily tested by fastening it in a vice. It should not break before pointing under five bendings. The operation of "pointing" renders nails more brittle, and they will then generally break at the third bending. A great improvement has taken place of late years in the manufacture of machine-made nails, and some competent judges think them as good as the best hand-made nails.

The size of the nail must be varied according to the size of the foot and the weight of the shoe. The dimensions of the head must of course be proportionate to the size of the nail. The point should be hammered out fine and sharp. A nail larger than necessary is objectionable, because it needlessly damages the crust, and besides requires a larger hole, which obviously must weaken the shoe.

When a nail breaks in a shoe, the seat of fracture is generally at the neck. The ordinary cause of its breaking at that point arises from the neck having been made too thick for the upper part of the hole. When this is the case, there is a difficulty in driving the nail home, and the neck is frequently so injured in the operation that it breaks off when subjected to the strain and jar of work. Whenever the head requires to be much battered in the operation of driving the nail home, the farrier may be pretty sure that it has become injured in the neck, and he should draw it and substitute another. On the other hand, if a nail be too small for the hole, it gets but little hold, becomes loose, and by working about soon breaks. When the neck is sound, the nail seldom breaks during a month's wear. 


\section{Position of Nails.}

The position of nails in the fore-shoe is a matter of great importance. There is greater wear on the toe of the shoe in ordinary use than on any other part. If the anterior nails are placed so far forward as to be subject to this extra wear, their heads will soon be worn off and the nails will then lose their hold. The anterior nail on each side should therefore be placed just posterior to this extra wear (Figs. 7 and 9). The two remaining nails on the outside should evenly divide the distance to the heels. On the inside, on which there should be only two nails, the second nail should be placed exactly opposite the second nail on the outside. It is a practical fact, that nails placed exactly, opposite to each other have a greater holding power than if placed irregularly.

Five nails, as stated above, are sufficient. Therefore there must be threc on one side and two on the other. The inside is chosen for the omission of the third nail, because the crust on that side is thinner and more elastic, and therefore affords less hold; and because contraction, when it occurs, is generally found on the inside. I do not think that nailing is a real cause of contraction. But as there is an opportunity of omitting a nail, I prefer to leave it out on the inside.

\section{Punching of Nail-holes, and driving of Nails.}

The Nail-holes should be punched rather nearer the outside than the inside of the web of the shoe, and should be brought out on the upper side with a very slight inclination outwards, so as to diminish the risk of pricking.

The practice of punching nail-holes almost on the outer edge of the web is, in my opinion, objectionable, as the nails do not get a sufficient hold in the crust. When however the crust has been reduced in thickness by constant rasping, the nails must of course be driven very "fine ;" but where the crust is sound and unrasped, the punching may be placed as directed above, and certainly with great advantage to the holding power of the nails. (Figs. 7 and 9.)

The nails should be brought out in the hoof about an inch above the shoe. If brought out higher, there will be risk of injury to the sensitive part of the horn. If lower, they will not get sufficient hold. But in feet which have been maltreated, it will be safer to bring the nails out somewhat lower. The heel nails may be brought out somewhat lower than the toe and quarter nails.

\section{Nail heads. Countersunk Nail-holes.}

A great advantage is gained in the form of nails by making use of countersunk holes (Fig. 9, Plate 51). With them the heads of the nails can never wear out, if they fit the holes, until the shoe itself is worn through. With these nails (Fig. 10) the heads should exactly occupy and completely fill the holes. No portion of the thin part of the nail should be in the shoe, nor any portion of the thick part in the crust. 
The thin part should berin where the nail quits the shoe to enter the crust.

\section{Rose-hcaded Nails.}

liose-headed nails cannot exactly fit and fill the nail-holes. A portion of the neek of the nail must be in the shoe, and at that point it will be apt to break. Again, a portion of the head generally projects below the shoe, and that portion must soon be lost by frietion with the ground. (Fig. 11.)

\section{Nail.heads not to project below the shoe.}

The heads of the nails should be driven down very nearly but not quite flush with the under surface of the shoe. A very little projection, however, is necessary in order that the pincers may be held firm against the heads of the nails, whilst the elenches are being turned down, otherwise it is difficult to get a good firm elench. The needed accuracy in punching the countersinks of the proper size, and selecting the nails to fit them will give the farrier a little extra trouble.

The objections to nails projecting below the shoe are that the exposed portion of the head will be very soon worn off by friction with the ground; and, again, with the further wear of the shoe the remaining portion of the head will be worn away. A nail without its head or without its clench is useless. The shoe is held on by the head of the nail and its clench.

\section{Clenching of Nails.}

Clenching is the technical term for turning down the end of the nail after it has been driven through the crust. The nail should be broken off as short as possible, and turned down and flattened by the hammer. The rasp should not be applied to the clench. Any filing will weaken it and may cause it to break off. Farriers often say that they cannot turn down and flatten the clench properly with the hammer; but they can do so with safety if the crust be sound.

But where the crust has been rasped, and thereby rendered thin and brittle, it is probable enough that the hammering down of the elenches may cause pain and pressure on the underlying sensitive layer of the crust. In such cases it may be advisable slightly to file the under side of the clench, so as to make it bend easier. There is no sense whatever in filing the upper side of a clench after turning it down.

\section{Näil-bound. Tight Nailing.}

These are terms applied to irritation of the feet, occasioning slight limmeness, from the nails having been driven too near the quick. The injury is of the same nature, but less serious, than that known as "pricking." (See Chapter 65, Par. 1006.) The remedy consists in carcfully drawing the nails and replacing them by others driven more fine. 
To tight nailing, properly so called, $i$.e to driving well home the nails, there is no objection. On the contrary, it is essential to the security of the shoe.

\section{Importance of Nails and Nailing.}

I have dwelt at length on this sulject, because it is really one of importance, as the best made and best fitting shoes will not remuin on the best feet unless due attention is paid to nails and nailing. Without good nails and good nailing all the labour is thrown away. Again, I have entered more fully into detail, because I advocate the use of a smaller number of nails than usual, namely, five in the fore-feet, and six in the hind feet; and it is obvious that where few are used, the efficiency and right placing of each individual nail becomes of greater importance.

Before quitting this subject, it may be as well to repeat that no trouble should be spared to obtain nails of the very best quality.

\section{Fullered Shoes.}

By fullering is meant a groove extending round the web of the shoe. The advantages supposed to be gained by it are-1st, that the farrier is enabled to punch the nail-holes more easily and more accurately than he could do without the assistance of such an artificial line; 2nd, that the groove will prevent slipping; 3rd, that the nail-heads being in the groove will be thereby better protected from the effect of wear. (Fig. 12.)

None of these reasons have much force. A tolerably good workman ought not to need the assistance of a fuller-line to guide him in punching the nail-holes. Again, admitting that the groove may have some effect in preventing slipping when the shoe is new, yet this advantage will be lost as the shoe wears, and the horse, being deprived of this artificial assistance, will be more prone to slip during the last fortnight's wear of the shoes than if he had not had such assistance during the first fortnight. Lastly, the groove does not protect the nail-heads any more or even as much as counter-sinks.

Fullering, moreover, is objectionable because the groove weakens the shoe; and, again, nails never fit so well or so tightly into the groove of the fuller as into countersunk holes.

\section{Loss of Shoes'}

The ordinary causes of the loss of shoes are-1st, the use of bad nails ; 2nd, the non-removal of broken or defective nails; $3 \mathrm{rd}$, rasping and mutilation of the crust; 4th, filing of the clenches; 5th, wearing out the head of the nails; 6th, shoes wider or longer than the crust; and lastly from the toe of the hind shoe eatching in the heel of the fore-shoe. All these causes are, as a generil rule, preventable. Accidents, no doubt, will occur, but it can be safely said that shoes ought very seldom to be lust off grood sound feet. 


\section{Tips.}

Some reasons were given above, why closely fitted shoes, such as recommended, are not more likely to cause contraction than the shoes in ordinary use. If, however, it be desired especially to guard against contraction, let the horse be shod with tips. (Plate 52, fig. 13.)

A tip should cover the toe and anterior portion only of the quarter, whilst the heels and bars are left uncovered or unprotected, as some call it. The length of the tip should be about half that of the ordinary shoe. Tips are generally made much too long; so much so that they are little else than short shoes, and of course produce the many evils of such shoes. Tips should be turned up at the toe. Tips should be sloped from the first nail-hole to prevent undue strain on the fetlock.

The advantages gained by the use of tips may be summed up as under, viz.-1st. Freedom is secured to the heels, which are the the most common seat of contraction. Whatever a shoe may do, a tip cannot cause contraction at the heels. 2nd. Concussion, and the diseases which arise from it, must be greatly diminished by substituting the natural action of the heels and frog for the jar of the iron shoe against the ground. 3rd. The heels and frog are strengthened and developed by being brought more actively and prominently into work and wear. 4th. The liability to slip is much less in horses shod with tips than with any kind of shoe, because the heels perform their functions more perfectly when brought into contact with the ground than when elevated from it by a shoe. The frog and bars are, from their structure, the natural stays of the foot against slipping.

The principal objections urged against tips are-1st. That they do not afford sufficient protection for the foot; that a horse, for instance, cannot travel safely over stones. This is a question which can only be settled by the test of experience. The Author has tried them for years, and is satisfied that they do afford sufficient protection. 2nd. It is urged that with our hard roads and hard work the heels and frogs will wear away. This, again, is a question of experience. The Author has found that both heels and frogs strengthen and develop under use.

Time is, of course, necessary after substituting tips for shoes, to allow the heels and frogs to grow strong. It will not do to take the shoes off a horse to-day and to rattle him in tips over stones to-morrow. In shoeing with tips it is necessary to shorten the toe rather more than for the ordinary shoe to make up for the absence of iron at the heels and to maintain the natural obliquity of the foot and pastern. 'Tips ought to be removed every fortnight.

\section{3a. "Charlier Shoes.}

The Charlier shoe consists in fitting a narrow rim of iron into a groove cut round the lower margin of the crust of the hoof by means of a special knife protected by a moveable guide.

The appearance of a horse's foot shod in this fashion is very similar to the iron heel of a man's boot. 
This method of shoeing is well calculated to preserve the natural condition and functions of the foot, and is valuable in cases where, from previous mutilation or other causes, it would bo difficult, if not impossible to bring the frog to the ground.

For upright blocky feet with contracted heels and shrunken frogs it acts admirably, and the majority of cases of this sort will be permanently benefited by the frog and posterior parts of the hoof being allowed to perform their proper functions.

The Charlier shoe may also be applied with benefit in special cases, the result of previous defective shoeing or other causes, such as contracted feet, weak heels, ossified cartilages, brushing, speedy cutting, \&c.-provided that the hoof is strong, but it must be remembered that it is unsuited to flat feet with weak soles.

This fact, combined with the amount of skill required to make it fit the Charlier shoe properly, has prevented its being brought into general use.

The shoe should be made less than half an inch in width at the toe, narrowing gradually and becoming thinner as it approaches the heels, and it should be rather shorter than the ordinary shoe. The inner upper edge must be rounded off to prevent inconvenience arising from pressure against the adjacent sensitive structures.

Ordinary iron does not answer well for the Charlier shoe, because, when worn somewhat thin, it is apt to spread. A mixture of equal parts of iron and steel well welded together, or Bessemer steel rod answers admirably.

The nail-holes should be oval to prevent splitting or spreading out of the narrow rim of metal. The heads of the nails must be of the same shape, and should fit well into the holes. For ordinary feet four nails are sufficient. No clip is required.

Previously to applying the Charlier shoe for the first time, it is advisable to work the horse for a few weeks in ordinary tips, so as to accustom him gradually to frog and heel pressure.

At the first shoeing the groove in the crust should be made rather shallow, and the shoe should be let in only half its (the shoe's) depth. At each shoeing the groove may be cut deeper, until eventually the under surface of the shoe is flush with the sole. The shoe must be fitted hot, as it is important that it should have a level bed to rest on, and it must fit the groove perfectly.

Charlier shoes are not well adapted to hind feet.

\section{3b. Bar Shoes.}

A Bar shoe simply consists of a bar or band of iron connecting the heels, and thereby gives a considerably increased bearing surface, especially on the frog.

They are very valuable in cases where it is necessary to relieve some part of the crust of the hoof from pressure, such as in corn or sanderack, or when it is advisable to apply pressure to the frog.

They are not suited for ordinary use. 


\section{3c. Rocking Shoes.}

Rocking shoes are made of very stout iron about twice the thickness of the ordinary shoe in the centre, becoming gradually thin at the toe and heels. In form they are somewhat like the rocker of a cradle. They are made wider in the web than the ordinary shoe, so that the sole may take its share in bearing the weight, and thus relieve the crust and sensitive laminæe to a great extent.

The advantage of llocking shoes is that the animal can throw his weight at his will either on the anterior or posterior part of the foot. They are valuable in some cases of foot disease, and especially in laminitis (see Par. 1027).

\section{Hind Foot and Shoe.}

The general principles are the same as those which regulate the shoeing of the fore-foot. The crust must not be rasped, the sole must not be pared out, the frog must not be mutilated, and the shoe must be accurately fitted.

There are, however, some points of difference between the hind and fore feet. The crust or wall of the hind foot is more upright than that of the fore-foot. It is also thinner. As it is thinner, i.e. narrower, the web of the shoe must also be narrower. It should not much exceed half an inch, which is the width of the crust. (Plate 53, fig. 14.)

\section{Form of the Hind Shoe.}

There is no objection to the form of the hind shoe in ordinary use. Two or three points, however, require to be noted. In ordinary cases the shoe should be of the same thickness all throughout; especially the height of the shoe should be the same at both heels. I lay stress on this, because where calkins are used it is very common to make the outside heel, to which the calkin is usually applied, higher than the inside heel. Nature has made the two heels of the same height, and any deviation from this arrangement of Nature will be liable to cause disease especially in the hocks.

In order to prevent over-reach, the under inner posterior edge of the hind shoe should be rounded off (fig. 14) in a way which is more particularly explained in the article on "Over-reach," Par. 1002, Chapter 65.

\section{Calkins.}

Calkins are used generally as a stay to the foot, which may be needed in heavy draught work or on slippery ground, and sometimes for the purpose of effecting an alteration in the action, and also in certain diseases.

Calkins, though sometimes necessary, are in all cases more or less of an evil. They are not really required for ordinary riding or driving. They cannot be as much needed as is often supposed, because, although they are usually worn away long before the horse is re-shod, the. public 
seldom complain that their horses go worse towards the end of a set of shoes than at the beginning.

Calkins are an evil, because they interfere with the natural bearing of the foot on the ground; ; because they deprive the hinder portion of the foot of its fair share of work and pressure; because they unduly raise the hind quarter and thereby tend to increase the risk of sprain so common in the hock; because they are a frequent cause of injury from treads and kicks, and because they make both treads and kicks, when they occur, more severe than they would otherwise be. Calkins on the inside are especially apt to cause injuries from treads.

If, however, it is thought necessary to use calkins, the better plan is to apply them to the outside heels only, and the heels of the shoe on the inside should be proportionately thickened, so as to give a level bearing to the foot on the ground.

iA calkin should be turned up wide (A, fig. 15) and made of steel. If made, as is often the case, narrow or little more than a spike, it soon wears down, and ceases to be of any use (B, fig. 15).

Calkins are utterly inadmissible on the fore-feet. (For Calkins on very heavy horses, see 633 .)

\section{Shoes to be level.}

A natural and level bearing of the shoe on the foot, and a natural and level tread, are matters of primary importance. All that interferes with such natural and level tread is an evil, except in special cases of disease or malformation. In a succeeding chapter, No. 65, in regard to the treatment of injuries and disease, frequent reference will be made to the advantages gained by the use of three-quarter shoes or of shoes raised at both heels or at one heel only. But all such deviations from a natural tread are an evil, except in special cases. As soon as the injury or disease ceases to require such artificial bearing, the horse should be again shod level.

\section{Directions to the Farrier for shoeing ordinary Fore-feet.}

1. With your rasp remove from the ground surface of the crust, as much as may represent a month's growth. Remember, that there is usually a more rapid growth of horn at the toe than at the heels or quarters. More, therefore, will require to be taken off the toe than from other parts-in other words, shorten the toe. Having lowered the crust to the necessary extent, make the under or ground surface perfectly level with the rasp.

2. Round off the lowèr edge of the crust with the rasp in the manner explained in Par. 947. Do this carefully and thoroughly with the fine side of the rasp. If a sharp edge be left, the crust will be apt to split and chip.

The preparation of the foot is now complete. It remains to fit the shoe to the foot.

3. Make a shoe with $\frac{3}{4}$-inch web, of even width all round except to- 
wards the heels (see Direction No. 7), flat towards the sole, concave towards the ground.

4. Make the anterior portion, $i . e$. the toe of the shoe, somewhat square from quarter to quarter, so as to fit and correspond with the shortened toe.

5. Make five countersunk holes in each shoe, viz. three on the outside and two on the inside. Make the anterior hole on each side in the anterior portion of the quarter (not in the toe), just behind where the shoe begins to be squared off in front. In this position it will be just behind the line of greatest wear. Let the second and third nails on the outside evenly divide the remaining distance to the heels. Let the second nail on the inside be exactly opposite the second nail on the outside.

6. Fit the shoe accurately to the foot. It must be as large as the crust, but no part must project beyond it. The shoe must be as long as the crust at the heels, but not longer.

7. The web of the shoe must be narrowed at the heels, so that its inner edge may rest on and cover the line of the bars, but no more.

8. Slope off the heels of the shoe in the same direction as the fibres of the crust, so as to prevent the possibility of their catching in the toe of the hind shoe. (Plate 51, fig. 9, в в.)

9. Select nails which will fit exactly into and completely fill the nailholes.

10. Twist off the clenches as short as possible, re-hammer the nailheads, then turn the clenches down with the hammer, and let the pincers during this time be firmly pressed against the heads of the nails. The clenches must not be filed either before or after turning down, nor is a ledge to be made in the crust to receive them.

\section{Directions for shoeing horses with ordinary Hind feet.}

1. For ordinary Hind feet the pattern of shoe in common use is recommended, but with a clip on each side instead of a single clip at the toe.

2. The web should be made somewhat wider at the toe than in the other parts, in order to allow space for the thorough sloping off of its inner edge, as recommended under the head of over-reach (Par. 1002).

3. Six nails, viz. three on each side, are needed to hold a hind shoe securely in its place. From the peculiar action of the hind quarters and the greater length of the hind leg, the hind is more liable to get twisted than the fore shoe; and, again, it is more apt to be displaced by stamping and kicking.

4. The other directions given above, as regards lowering the crust, rounding off its inferior edge, accurate fitting, clenching, \&c., apply equally to hind as to fore feet.

989a. What to look for in a newly shod horse.

1. No mark of the Rasp on the hoof.

2. That the Nailing is regular, i.e. with equal distance hetween the clenches, if at least the state of the wall admits of regularity. 
3. That in a fairly normal hoof the nails are brought out - the centre nail one inch above the shoe, and the anterior and posterior nails slightly less. Allowance however must be made according to circumstances in very flat and in very upright hoofs.

4. That the Shoe is not wider than the natural edge of the wall.

5. That the Feet are the same length-i.e. that one has not been lowered more than the other.

6. That the Nail heads fit accurately into the nail holes or fullering.

7. That the Sole of the foot is not pared out.

8. That the Frog has not been pared, unless from unhealthy action it has become ragged.

9. That the Wall has not been cut into too deep to seat the Clips.

10: That the Clenches have not been rasped after being turned down.

These instructions are for Riding horses and for the lighter class of Harness horses.

Such horses require to be shod "close," as any Projection of the shoes beyond the wall or any Length of the shoes at the heels greater than the heels of the hoof, will render the shoes liable to be pulled up in fast work or in deep ground.

Heavy Draught horses with their wide fleshy heels and not unfrequently weak walls to their feet, need the amount of cover afforded by a greater width of shoe and consequent projection both on the sides and at the heels.

Practically there is no fear of brushing in the heavy breeds, as the legs are by nature placed much further apart than in well-bred horses; and the slower pace of work renders the heels of the shoes of the horse in front less liable to be pulied off by the horse behind.

Weight of shoes. - For riding and light draught horses $14 \mathrm{oz}$. to $1 \mathrm{lb}$. is a fair average weight. For heavy draught horses the weight of the shoes will require to be increased according to the side and weight of the horse. In London the weight of the shoes of railway van horses is generally about $2 \mathrm{lbs}$. to $23 \mathrm{lbs}$. ; whilst in the very large heavy "trolley" liorses used, in the docks $4 \mathrm{lbs}$. is quite common, and $7 \mathrm{lbs}$. per shoe is occasionally found.

\section{To shoe a troublesome Horse.}

The chief difficulty generally occurs with the hind feet. I hare tried the following plan with success.

1st. To prevent the possibility of the horse getting loose, put a rope about ten yards long on the ring of the snaffle. The horse may start backwards or forwards, but a rope of the above length.will be sufficient to hold him without any undue or violent check. Practically horses do not run backwards or forwards above a few yards.

2nd. Put a stout, well-padded shank with a strong ring round one fetlock. Attach a long rope to the ring of the shank.

3rd. Pull up the leg of the foot, which you desire to shoe, from before. The lorse will resist this at first and try to get his foot to the ground. 
If he succeeds in doing so, pull up the leg again immediately. Never let his foot rest on the ground for a moment. It will probably require three or four men at the rope to prevent his getting his foot down. But in time, in half an hour or more, he will be tired, and glad to rest his leg on the farrier who comes to shoe him.

It will be observed that in this mode of treatment the horse is compäratively free. There is nothing in it to alarm, him or make him nervous, or more difficult to shoe on any succeeding occasion. My experience has been that horses so treated in time get over their dislike of being shod. The contrary is the case where side lines, violence, or casting are resorted to. I admit that there may be horses more vicious than I happen to have met with, and perhaps it may be necessary to cast such animals.

For horses difficult to shoe on the fore-feet, I recommend strapping up the fore-leg with a "Rarey" strap for a few hours. At the end of that time the chances are that the horse will be glad enough to lean on the farrier who comes to shoe him.

Another very simple mode is often very effectual. Give the horse a very long and very hard day's work, and shoe him immediately on his return. The chances are that he will stand quiet.

\section{Temporary Roughing.}

The old plan of roughing, though it gives a good foothold, is open to some serious objections, namely, 1st, that it entails removal of the shoes and re-nailing; 2nd, that the roughing soon wears smooth, and if the frost continues, the shoes must again be taken off, re-roughed, and nailed on again, this of course damages the hoofs; 3 rd, that this plan cannot be carried on without the services of a farrier.

Another and better plan is to make 2 screw-holes in each shoe-not when a frost comes, but in all shoes put on after 1st October. It takes very little time or trouble to make the holes with a proper tool; and when a frost occurs, the screws can be put in without trouble and without the services of a farrier. No injury is done to the foot, and the screws can be withdrawn and renewed as often as necessary. This plan answers very well with harness horses. N.B.-Screws can be used on both sides of the feet, but on the outer side of the hind shoes, for fear of tread, where somewhat heavy shoes are used, which will carry a screw with a strong worm; but it does not answer so well with light shoes.

The third plan is that known as the cabman's nail. It has been in use in London for a good many years, and it certainly answers as an antidote to slipping. But it has a serious defect. The shoe must be considerably wider at the heels than the crust. On this projection a hole is punched perpendicularly, through which a nail with a special large head is driven, and the shank is battened down on the outside. The hoof is not penetrated by the nail-and therefore the nail can be reinoved and replaced as soon as its head is worn down, without injury to the hoof. So far good. But the extra width of the shoes at the heels is 
apt to cause the horse to cut or brush or interfere, as it is variously called. These three terms all mean the same.

4th. The plan now proposed is a modification of the cabman's nail. It has been introduced into the Army after careful trial for some years in the Royal Horse Guards under Vet. Lt.-Col. Mathews. The shoes are made only of the usual width, and the hole for the frost-nail is made obliquely from the centre of the under or ground surface of the shoe, and brought out on the outer edge of the upper surface of the shoe, so as just to clear the crust at the heels. (Plate 56, fig. 20.)

In the cabman's plan the full length of the shank of the nail is battened down outside. This projection of the nail increases the liability to brushing, and the long shank is apt to get loose, and this again increases the liability to brush.

In the improved plan the shank, after being battened down, is nicked by the edge of the fine side of the rasp just one eighth of an inch below the upper surface of the side of the shoe, and it must be well and firmly battened down. When so shortened it is not liable to spread out and thereby cause brushing. It also gets a better and firmer hold than the lengthened shank in use by the cabman. This may seem somewhat contrary to what might be expected, but it is a practical fact. The leverage is less.

The services of a farrier are not required to put in frost-nails or draw them. Any fairly intelligent stable servant, if he is provided with a hammer and a file, can put them in, and he can draw them out if he is provided with pincers. He should also have a hollow cap to put on the head of the nail which is driving.

Frost-nails ought to be of the best hard temper as regards the head, but the shank should not be tempered. Frost-nails and frost-screws can in the present day be obtained in almost any town, but to prevent inconvenience and delay on the occurrence of a frost, some two or three dozen should be kept in stock in every stable. The "life" of a frost nail or screw of course depends much on the material of the road, but twenty miles may be taken as an average.

All roughing, whether the old plan or screws or nails, is liable to cause treads, both on the road and in the stable. In this respect there is not much difference between screws and nails. But both have the advantage over the old system, because they can be drawn when the journey is finished. And as after a journey they will probably be pretty well worn, and therefore not fit for another journey, it is as well to draw them on return to the stable.

The fourth or improved plan of temporary roughing is applicable only to riding and the lighter classes of horses used for draught.

For heavy draught horses it will be better to adopt the permanent methods in ordinary use.

The tools necessary for screws are a spanner, of required size, a driving hanmer with a buffer to clear the holes in the shoes.

For frost nails - a pair of pincers, a driving hammer, a buffer, a hoof 
rasp, a hollow cap for finally fitting nail head to hole without injury to sharpened or projecting portion. Plate 20, A.

Hardening, i.e. tempering frost nails.-Ordinary frost nails are readily hardened by being dipped while at a black heat into water. Great care is necessary that only the "frosting" portion of head is so treated; if the shank be hardened it will be rendered brittle and useless. The vendor should be made to exchange all found to be so hardened in the shank.

In these nails the wearing or frosting face of nail should at least project $\frac{3}{8}$ inch.

\section{1a. Slippery pavements.}

The pavements in use in London and other large towns are-1st. Macadam, i.e. broken granite stones. This pavement is safe in all weathers, except of course in frost. 2nd. Wood, which is safe when dry and also when thoroughly wet. It is dangerous in the intermediate stage, especially when greasy, which it becomes when there is rain enough to turn the dust into mud, and not rain enough to wash away the mud. The same applies to artificial watering. 3rd. Asphalte, which is more dangerous. It is least dangerous when quite dry or very wet, and most dangerous in the intermediate stage, as in the case of wood.

Various patent pads and shoes have been brought out to obviate these dangers. Pads over the sole may be used for a day or two, as in frost. But their constant use will produce lameness, as the sole is a recessed surface, and therefore not intended to bear pressure. Frog pads are better, but expensive.

Anti-slipping shoes of many various patterns have been brought out. Those in most common use are Rodway's and Rowley's. Rodway's answer well enough for a time, but the edges will not stand a month's wear; and when the edges are worn away, they necessarily lose their effect. Martin's shoes, 30, Olding Place, Marylebone, and Chelsea, will stand the month, and the author has no hesitation whatever, both as to durability and safety, in recommending them.

Tips answer far the best; but coachmen are generally prejudiced against them. The Frog, which is nature's wedge against slipping, is brought more thoroughly into use than with any kind of shoe. See Tips, par. 983, especially the last sentence, regarding the time necessary after substituting tips for shoes to allow the frogs and heels to grow strong.

But after all, habit is the great point. Horses get used to travelling on slippery surfaces. Horses fresh from the country, where the roads are made of gravel, must 'be gradually accustomed to the streets. A " eountry" horse on coming to London should be driven first on macadam, then on granite stone pavement, next on wood, and last on asphalte.

\section{Ice shoes for winter wear in cold countries.}

Fig. 21 represents Russian, and fig. 22 American trotting shoes, i.c. for fast work in winter. They are of value as showing the systems found 
to answer best in the two countries, whose climatic conditions are identical, and which necessitate auxiliary aid to foothold in the shape of projections for half the year.

The Russian shoe is provided with a steel toe wedge and a longitudinal sharpened wedge at each heel, whilst the American is provided with a wider toe steel wedge and a transverse wedge at each heel.

For ordinary carriage work however screws are generally used in Russia.

\section{CHAPTER 64.}

\section{SHOEING OF THE FORE-FEET.}

Plates 47 to 57. Figures consecutive throughout.

992. Of Fore-shoes. 993. Wear of the Fore-shoes. 994. Form of the toe of the Fore-shoe. 995. Fitting of turned-up fore-shoes. 996. Action of the fore-leg.

\section{Of Fore-shoes.}

In the two previous chapters I have stated all that I believe to be necessary to the health of the foot and the security of the shoe on the foot.

The following remarks in regard to the best form of the toe of the fore-shoe do not concern the health of the foot, nor is the system recommended in these remarks essential to good shoeing. I advocate the turning up of the toe of the fore-shoe because I believe it gives ease and comfort to the horse and safety to the rider. But $I$ admit at once that it is not essential to good shoeing or to the health of the foot. I must ask the reader not to regard it as a cardinal point in the system $I$ have recommended, but simply as a valuable adjunct. (Plate 51, figs. 16 and 17.)

\section{Wiar of the Fore-shoes.}

Every person accustomed to horses must have remarked the very uneven mamner in which the wear is distributed over the fore-shoe in ordinary use. At the end of the month the toe is the only part worn out. It is inconsistent with the general structure of the foot, and with the beautiful economy of space and material shown by Nature in all her works, to suppose that such unequal wear can be natural. 'The structure of the weight-bearing portion of the foot sufficiently indicates that the weight, and consequently the wear, is intended to be pretty evenly distributed over the foot.

In our adaptation of a shoe to the foot we should endearour not to 
interfere with the natural bearing of the weight on the foot or with the natural tread of the animal. Any artificial interference with the natural distribution of weight and wear over the surface of the foot, such as that produced by the straight shoe in ordinary use, must induce many evils, much inconvenience to the animal, and, in some cases, disease.

\section{Form of the toe of the Fore-shoe.}

If it be desired to maintain in the shod horse the natural and really level bearing and tread of the foot, it will be necessary to turn up the toe of the shoe in the same manner as the toe of the unshod foot would be naturally worn away and turned up by friction with the ground.

The reader will probably ask at this point how much should be taken off the toe of the foot in order to represent the effect of natural wear. The answer is simple. As much as is necessary in each case to give the horse a level bearing on his foot and a natural tread, or, in other words, as much as is necessary to make the wear nearly even all over the shoe. The wear is never completely even all over the shoe, because, when horses are shod according to the natural formation of the foot, the greatest weight will fall on the quarters, which are the broadest part of the foot, and are therefore most capable of sustaining weight; here also will be the greatest wear.

Most persons must have noticed how badly many horses go when newly shod, and how apt they are to stumble, and that it is not until the shoes have been worn some days that they seem again to go at their ease. The reason of this is simple enough. The horse has neither ease, comfort, nor safety in travelling, until by friction with the ground he has worn off some portion of the projecting toe of the straight shoe. But the relief gained by wearing away the toe of the shoe is only comparative, and is very inferior to that gained by the use of turned-up shoes, adjusted to fit the crust, previously shortened and lowered to represent the natural rounding off of the toe by wear in the unshod horse.

The evils occasioned by the ordinary straight shoe may be summed up briefly as follows:-1st, stumbling and inconvenience to the horse in action; 2nd, a tendency to contraction of the heels and shrivelling up of the frog from absence of a due and natural proportion of wear at the back part of the foot; 3rd, loss of speed from resistance of the toe against the ground; 4th, undue strain on the flexor tendons, whose office is to raise and flex the leg; 5th, undue stress on the suspensory ligament. In action when the foot is brought to the ground, a great portion of the weight falls on this ligament.

Straight toes have a tendency to produce these results, but they do not produce them to the extent which might be expected, because the animal frame has been so beautifully and aptly constituted by nature that it will stand a good deal of mismanagement without, for a time at least, sustaining perceptible injury.

Many objections have been raised to the turned-up shoes now recommended. Among the most prominent are-1st. That the horse when so shod cannot get a fair, level, and natural bearing on the ground with 
his foot. This objection, if well founded, would be fatal to the proposed plan, but the even wear of the shoe disproves it. 2nd. That horses will be liable to fall and come on their heads when deprived of the fulcrum of the toe against the ground. This objection will not stand inquiry. Horses generally stumble from striking their toes against the ground. They are certainly not saved from falling by the length of the toe. On the contrary, it is usually the length of the toe which first causes the horse to stumble, and afterwards prevents him from recovering himself, the toe forming the lever which overbalances him. 3rd. It is urged that a horse must be much more liable to slip in turned-up than in ordinary shoes. This objection, though at first sight it may. seem formidable, arises from misconception of the functions of the different parts of the frame. The frog and bars are, from their structure, the stays of the foot against the ground. Turned-up shoes, by causing the weight and wear to be evenly distributed over the foot, develop the frogs and bars, and therefore, instead of facilitating, must have a tendency to prevent slipping. 4th. It is alleged that turned-up shoes are unsightly, and make a horse looks as if he wanted shoeing. The first of these two objections is a matter of opinion; the second is a matter of habit. Lastly, it is urged that the toes in the new-born foal are not turned up. Assuredly not, for the feet have not yet been subjected to wear.

\section{Fitting of turned-up Shoes.}

Both skill and practice are necessary in fitting a shoe to the natural tread. A farrier seldom succeeds well in his earlier attempts. The following hints may assist the workman. The turn up of the shoe is niade on the horn of the anvil by beating out the toe of the shoe. The process of beating out the web at the toe will necessarily make it wider. This extra width must be removed by the file, for, as has been recommended above, the web should be of even width all round. The breadth of the turn up must be from the anterior part of the quarter on one side to the corresponding part on the other side. The degree of turn up is, of course, greater at the toe than at the sides. A very common error is committed by merely turning up the point of the toe. This may be of some use in preventing stumbling, but it is not sufficient to restore the natural tread, nor to make the wear nearly even all over the shoe. To effect this object the turn up must be broad, namely, from the anterior part of each quarter. The farrier has always a simple guide in the old shoe. Where he finds undue friction going on he must ease off the part, and not attempt to fight against Nature by thickening it or by inserting a bit of steel.

\section{Action of the Froreleg.}

With reference to the tread of the lorse, it is a mistake to suppose that in action he merely lifts up and puts down his feet. If he did so there would be no objection to straight shoes, for such shoes would perfectly suit such a movement, but then there would be no progression. 
Progression is gained by a semicircular movement of the fore-leg, aided by impulse from behind.

To assist the movement it is necessary that the soe should be shortened and rounded off. The horse, when shod with straight shoes, has every time he lifts his foot to overcome the resistance of the straight toe against the ground by extra exertion of the flexor tendons.

Simple rule to begin with. Turn up the toe of the new shoe, if the horse has been shod with straight shoes, as much as the old shoe is worn away at the toe; and at each successive shoeing increase the turn up until the wear is nearly level all over the shoe.

CHAPTER 65.

DISEASES OF, THE FOO'T.

Plates 47 to 57 .

997. General sketch. 998. Of Horses which stick their toes into the ground, and thereby stumble. 999. Brushing, Cutting, and Interfering. 1000. Speedy-cut. 1001. Clicking or Forging. 1002. Over-reach. 1003. Leather. 1004. Stopping. 1005. Treads. 1006. Pricking, Picking up a nail, and Punctures. 1007. Treatment. 1008. Punctures of the Frog. 1009. Corns. 1010. Treatment. 1011. Quittor. 1012. Sand-crack. 1013. False Quarter. 1014. Seedy Toe. 1015. Thrush. '1016. Treatment. 1017. Chronic Thrush. 1018. Neglected Thrushes. 1019. Canker. 1020. Treatment. 1021. Navicular disease. 1022. Causes. 1023. Nature of the Disease. 1024. Symptoms. 1025. Treatment. 1026. Neurotomy. 1027. Laminitis. 1028. Causes. 1029. Symptoms. 1030. Trealment. 1031. Results. 1032. Chronic Laminitis. 1033. Blistering round the Coronet.

\section{General sketch.}

In this chapter I propose to treat-1st, of horses which, from peculiarity of action, or from defective action, or from abnormal conformation of the feet, require special shoes; and 2 nd, of the various diseases which affect the feet.

998. Of Horses which stick their toes in the ground, and thereby stumble.

The owner will do well to have the toes of the fore-feet shortened by lowering the anterior portion of the crust by the rasp from underneath - not by rasping the crust in front. The new shoe should then be turned up to correspond with the toe so shortened. It will be observed 
in all horses, which "toe," that the shoe is much worn in front. Now take the old shoe for your guide, and make the new shoe like it in form. Probably at the end of the month you will find that the toe of the shoe is still unduly worn. Well, make the new shoe again like the now old shoe, and so again in the succeeding month. At the end of a few months you will have found out how much that particular horse requires to have his toes shortened and his shoes turned up, in order to enable him to travel safely and comfortably.

It has been often noticed that horses which "toe," do so much more when newly shod, than afterwards. The reason is obvious enough. My attention was first called to the need of shortening the toe and turning up the shoe by noticing this fact.

\section{Brushing, Cutting, and Interfering.}

The above are different names given to an injury of the fetlock, either fore or hind, from its being struck by the opposite foot.

In the outset it is important to ascertain the exact part which comes into collision with the fetlock. It will then enable us at once to detect and remedy the cause. With this view a wet pipe-clayed bandage should be put round the part struck, and a mark will be left on the part which strikes it. As a general rule, the part which strikes the opposite fetlock is the anterior portion of the quarter, about half-way up. It is very generally supposed that the contact is with the side of the foot; but such is not usually the case.

Having ascertained the exact part which comes in collision with the fetlock, we have still to ascertain the cause in each particular case.

The cause of collision may arise from carelessness in shoeing, such as the clenches not being properly turned down, or from the shoes being too wide. Such cases admit of easy remedy.

More difficulty occur's where the collision is due to some peculiarity in the shape of the foot or leg, especially if combined with peculiarity of action or from the toes being turned out. In these cases the best plan is to try the effect of increasing the height of the shoe on the inside, or, what amounts to much the same thing, to apply a $\frac{3}{4}$-shoe on the outside; and in severe cases both remedies may be tried. The result of this change will be to slightly alter the action, and by throwing the parts outward to cause avoidance of collision. If this fails, the opposite remedy, viz. raising the outer side of the shoe, may be tried. The application of Charlier shoes will frequently prevent brushing from this cause.

But there is yet another cause, namely weakness and want of condition. As a temporary measure, alterations in the shoeing are useful. The real remedy, however, in these cases will be found in good feeding, in better grooming, and in increasing the constitutional stamina. When the horse acquires a more lively or more steady gait, collision will often cease. Most owners of horses must have noticed that brushing and cutting are common when a horse gets tired and leg-weary in a long day's work, although at other times the injury does not occur.

Young horses sometimes brush or cut from throwing their legs about. 
Steady work, careful riding, and more practice in carrying weight on their backs will often in due time remedy the defect.

It is very seldom advisable, though there may be cases in which it may be necessary, to remove the prominence of the hoof by the rasp.

As soon as the horse is observed to brush, it is advisable, unless the cause is obvious and at once removable, such as a projecting clench, to put on a boot, until it is ascertained that the remedy applied has been effectual. If this precaution is neglected, the fetlocks may become permanently enlarged. In all cases, where the fetlocks have become sore or enlarged, the horse should be rested until the parts have regained their natural size. If, however, all these remedies fuil, a boot must be worn permanently.

\section{Speedy-cut.}

Speedy-cut is a far more serious evil than brushing. It is an injury caused by collision of one or other foot with the leg immediately below the knee. It is due to peculiarity of action, but it may be aggravated or possibly caused by any or some of the causes mentioned above in regard to brushing. It is, however, generally incurable. It is most common in impetuous horses with exaggerated action and which carry their heads high. A boot may be tried, but the pain caused by the collision is often so severe that this shield fails to afford the necessary protection, and then the horse comes down suddenly.

A horse with a mark on the seat of speedy-cut should not be purchased. Such a horse is unsafe to ride. At best he is only fit for slow harness work in a four-wheeled carriage, when the nuisance of his coming down will not be very serious. The animal should be driven very quietly and in a snaffle. For seat of Speedy-cut see Plate $25 \mathrm{X}$.

\section{Clicking or Forging.}

The noise known as Clicking or Forging is produced by the toe of the hind shoe striking against the under inner or posterior edge of the toe of the fore-shoe, when the feet are raised in action. Primarily it arises from a quicker action of the hind quarters than the corresponding motion of the fore-quarters. The remedy as regards shoeing is to shorten the toes of the hind feet, and to bevel off the posterior edge of the toe of the fore-shoe. Shortening the toes of the fore-feet and turning up the shoes will also assist in decreasing the evil, because these measures will enable the horse to raise his fore-hand more easily and more quickly, and so avoid collision with the hind feet. The noise, though not the actual collision, will be decreased by setting back the toe of the hind shoe behind the toe of the foot. The noise is also greatly diminished and frequently is entirely stopped by the application of Charlier shoes. Good riding, holding the horse together, and making him step out quickly and lively are, however, the truer remedies. Again, many horses which 
click when in low condition and over-worked do not do so when they gain strength.

\section{Over-reach.}

Over-reach is the result of a blow struck by the under inner posterior edge of the toe of the hind shoe. The injury is not occasioned by the anterior, but by the under inner posterior edge of the hind shoe. It usually occurs in deep ground, when the raising of the fore-hand is somewhat delayed; or it may occur in the act of springing for a leap, when the hind quarters are very suddenly advanced.

The remedy is easy, and in almost all cases effectual. It consists in thoroughly rounding off the under inner posterior edge of the toe of the hind shoe. This edge should be completely sloped off from front to rear or made "half round" on the anvil before the shoe is put on. It cannot be effectually done afterwards. The edge can be cut off by the rasp in the anvil, but it is more easily and completely done by a little tool made for the purpose. Round-toed hind shoes should always be used for hunting.

When this precaution is taken, a blow may notwithstanding be struck on the heel of the fore-foot by the hind shoe; but it will not be of so severe a nature as to amount to the injury known as over-reach. (Plate 53, fig. 14, under inner posterior edge rounded off ; fig. 15, edge left sharp.)

\section{Leather.}

Leather is not needed as a protection to the sole in a healthy foot, unless Nature's leather, i.e. the sole itself, has been removed by paring.

There are, however, cases in which, for a time at least, leather is useful. In cases of pricks or picking up a nail, it is necessary to remove a considerable portion of the sole, in order to allow a free exit for the matter which will form under the sole in consequence of the injury. Here leather will be useful as a protection against sharp stones in lieu of the portion of the sole removed. A horse so protected can be put to work some days sooner than he could otherwise be worked.

\section{Stopping.}

The non-paring of the sole obviates the necessity of the old-fashioned practice of stopping the feet. The supposed object of stopping is to keep, or rather to make the sole moist and soft. Nature will do this better than art, if the natural outer covering of the sole be not removed.

\section{Treads.}

Treads are injuries of the coronary band or coronet, generally inflicted by the shoe of the other foot in turning, backing, or shying, and rery rarely by a tramp from another horse.

Treads are most common in the hind feet, especially when horses are 
shod, as is often the case with heavy draught horses, with calkins on the inside as well as on the outside. In these cases the best remedy is to substitute a raised heel well bevelled off for the inside calkin. If, however, it is considered absolutely necessary to use a calkin on the inside, the liability to injury will be decreased by making it long and broad (Plate 53, fig. 15A) instead of short and narrow (fig. 158). Shoes projecting beyond the crust are also a common cause both in hind and fore feet. A little attention to properly fitting and rounding off carefully the edges of the shoe, will render treads less frequent as well as less serious when they do occur. Young horses are more prone than others to injure themselves in this way.

The treatment of a tread is the same as that of common wounds. But when lameness is present, a poultice may be beneficially applied and a dose of laxative medicine may be given. Treads, if neglected, especially when they occur towards the heels, are apt to run into quittor. When such is the case, the treatment recommended under the head of that disease should be followed (par. 1011).

\section{Pricking, picking up a nail, and puncture.}

Pricking is a technical name given to injuries of the foot caused by the misdirection of a nail in shoeing. Punctures may arise from the above or any similar cause. Picking up a nail is a somewhat similar injury, and may occur at any time at exercise.

When the sensitive sole is injured by any such cause, inflammation is necessarily set up in it. The inflammation, unless very slight, produces a secretion of pus, or what is commonly termed matter.

The pus, which forms in the internal structure, i.e. in the sensitive sole, must have an exit. The processes of suppuration and ulceration are the means by which Nature provides an exit for the pus thus produced. These processes, however, can only take place in organised structures. The insensitive sole is of too inorganic a nature to be capable of suppuration and ulceration. Hence the pus which forms in the sensitive sole is unable to gain an exit through the insensitive sole, and will collect, or as it is termed "under-run" the horny sole. Therefore, not being able to escape below, it must, unless relieved by treatment, work its way upwards through the soft vascular parts of the interior of the foot, which are capable of suppuration and ulceration, and will gain an exit for itself immediately above the coronet. The fistulous sore so formed is known as Quittor.

\section{$\because$ 1007. Treatment.}

In all cases it is essential to pare out freely, not merely the seat of the puncture, but the whole of the surrounding insensitive sole for a considerable distance with the view of affording an easy exit for any matter or pus, which may form in the sensitive sole, as a result of the inflammatory action caused by the wound. The font should then be hathed in hot water for an hour. 
Having taken these precautionary measures, it is, in general, safe in cases which are treated immediately after the recurrence of the injury, i.e. before inflammation has set in (but not otherwise), to close the puncture at once by the application of tow and tar placed over the wound, with a view of excluding the air and thereby decreasing the chance of the occurrence of inflammation. The shoe must be nailed on lightly in order to secure the stopping in its place. A dose of physic in most cases is advisable. Perfect rest is essential. In favorable cases the horse will be fit for work in a few days. Very few cases, however, are taken suffciently early to render the closing of the wound advisable.

As a general rule, inflammation will have set in and the formation of matter begun before the injury is noticed. The evil with which we have then to deal is the confinement of the pus in the interior of the foot. In addition to paring out the sole, recourse must be had to fomentations and poultices of linseed meal and bran, with the view of modifying the inflammation and relieving the pain.

When these measures are efficiently taken, injuries of the sensitive sole seldom prove either serious or tedious. A portion of the insensitive sole, however, having been freely removed, the horse will not be fit for work until Nature has re-supplied a sufficient quantity of horn for the protection of the foot, or until an artificial covering, such as leather, is provided. When suppuration has ceased, the part should be dréssed with tar, covered with a pad of tow, and the application kept in its place by. means of a leather sole retained by crossed pieces of thin hoop iron slipped under the edge of the shoe. This can easily be removed and the foot re-dressed as required.

For treatment of neglected cases, see "Quittor," par. 1011.

\section{Punctures of the Frog.}

Punctures of the Frog are similar in nature and require similar treatment to those of the sole. They nearly always arise from picking up a nail. When taken in time, they are not serious and yield to treatment even more readily than injuries of the sole, inasmuch as the insensitive frog is more permeable than the insensitive sole.

If neglected, however, they are apt to lead to extensive disease of the frog, and canker may be the probable result (see "Canker," par. 1019). In some cases the inflammation caused by the puncture may involve the neighbouring navicular joint, and serious and tedious disease may ensue. In still rarer cases a nail may even penetrate the joint. (See par. 727, "Wounds of the navicular joint.")

\section{Corns.}

The seat of corn is in the angle between the crust and the bars (see Plate 49 , fig. $6 \mathrm{D}$ ), usually on the inside heel, because greater weight and therefore greater pressure falls on the inside than on the outside. In horses, however, which turn their toes in, and thereby throw the greater weight on the other side, corns will not unfrequently be found on the outer heel. 
The presence of a corn is easily recognised by a reddened appearance of the sole in the angle above mentioned. The redness arises from extravasation of the blood of the part. A similar appearance is found in other parts of the sole when bruised or subjected to undue pressure.

Corn is an injury produced by pressure, generally by continued pressure on a sensitive part, $i . e$. on the sole of the above-mentioned angle, which is not intended to bear any great pressure. Corn may also be the result of a bruise. With good shoeing, corns ought never to occur in good feet. When the shoe is so fitted, that it rests fairly on the crust and on the bars, no undue pressure can come on the seat of corn.

Of direct causes of pressure on the sole at the seat of corn the most common are short shoes, the ends of which press on the seat of corn; and the shifting of shoes from bad fitting or from over-time.

The indirect, but equally real and more common causes of this disease will be found--1st, in the ordinary practice of rasping the crust, by which it is rendered thin and insufficient to carry the superincumbent weight; 2nd, in the removal of the bars, which jointly with the crust ought to sustain the shoe at the heels; 3rd, in the practice of paring out the seat of corn, by which the sensitive sole becomes exposed to injury from bruises and from the accumulation of dirt and gravel under the shoe in the hollow so made; and lastly, from lateral pressure on the seat of corn from wiring in of the crust and bars, when the insensitive sole in the angle between the crust and the bars is pared out.

There is a predisposition to corns in flat feet and in feet where the heels wire in, because with either of these conformations undue pressure is liable to come on the seat of corn. Great care is needed in the shoeing of such feet, and in some such cases it may not be possible to avoid the occurrence of corns.

\section{Treatment of Corns.}

The treatment of a corn in its early stage consists simply in removing the cause, namely, undue pressure. In very slight cases, not causing lameness, it will be sufficient to apply shoes somewhat longer than the crust, and somewhat broad in the web at the heels, i.e. slightly projecting over the crust and bars.

But when lameness is present, the seat of the corn should be pared out carefully and without injury to the crust or bars. After which a $\frac{3}{4}$-shoe, or a shoe so narrow in the web at the heel that it may rest only on the crust, should be applied. Either of these measures will remove the cause, viz. pressure. The first-named remedy ( $\frac{3}{4}$-shoe) is very easy to apply. A farrier can scarcely be so clumsy as to make a mistake. The latter, which is perhaps the best, requires some skill and attention on the part of the farrier.

The common practice of applying a complete bar shoe with the view of protecting the seat of the disease from bruises is objectionable, because dirt and gravel are apt to lodge under the shoe in the hollow made by the paring out; and great and increased irritation may be thereby occasioned. 
In good-shaped feet, the cause, namely pressure, being removed, the corn will soon cease to exist. It is, however, essential to bear in mind that though, as a temporary measure, undue pressure may be prevented by paring out and by the use of special shoes, yet the only real means of preventing a recurrence of the disease consists in the maintenance of a good sound unrasped crust and unpared bars, on which a well-fitted shoe of the proper length can rest firmly and securely without undue pressure on the seat of corn. Corns, when treated only by paring out, even though they may by such means be got rid of for a time, generally reappear. Their permanent removal can only be effected by careful preservation of the crust and bars and by attention to the proper length and fitting of the shoes.

If, however, the cause of the corn, namely pressure, be not removed, the inflammation of the sensitive sole in the above-mentioned angle will increase, and the suppuration or, in other words, the formation of matter will ensue. In such cases it will be necessary to rest the horse and to apply poultices in addition to adopting the treatment recommended above.

If further neglect takes place, the disease may run into quittor, of which the appropriate treatment will be found in the succeeding part (par. 1011).

It is a common practice to pare out the seat of corn even in sound feet with the view of preventing pressure on it. Nature, however, in this, as in other cases, is our safest guide. A certain amount of insensitive sole is supplied to this part of the foot, and is useful to it as a protection against bruises, \&c. As in other parts of the sole it will shell off in due time, and therefore should not be removed artificially. Again, the paring out of the seat of corn weakens the crust and bars by depriving them of that lateral support which they would otherwise derive from the presence of the insensitive sole in the angle; and in so far paring out has a tendency to produce rather than prevent the evil.

As mentioned in the last sentence, par. 1009, there is a predisposition to corn in flat feet and in feet where the heels wire in. Special care will be needed in shoeing such feet.

Corns are seldom or never found in the hind feet-probably from the greater degree to which the sole is recessed; and also because the hind feet are rarely, if ever, shod with too short toes.

\section{Quittor.}

Quittor is a fistulous sore at the coronet. The most common cause is a severe tread on the coronet. It may also arise from a neglected corn or from a bruise or prick of the sole.

Whatever may have been the cause, the great mischief arises not so much from the original injury as from the tendency of pus or matter generated by the inflammatory action to burrow and form sinuses in the interior of the foot.

Therefore in all cases our primary aim must be to afford an easy and depending exit to the pus. With this view the crust below the coronet should be rasped very thin. Great care must be taken to arcid injuring 
the coronary band. In cases where the disease has originated in a corn or in injury to the sole, the sole should also be pared out thin. In cases which are taken early, these measures will give immediate and sufficient relief.

But when the disease has been neglected, it becomes formidable. The fistulæ or sinuses caused by the pent-up pus will be found to be numerous, extensive, and ramifying in various directions. In such cases it will be best to pass a red-hot probe directly through the sinuses. Care must be taken to secure a depending orifice, and also to avoid injury to the coronary band or rim of the crust. This treatment may seem severe, but it probably causes less pain to the animal than the old-fashioned practice of inserting pledgets of caustic into the sinuses. The actual cautery will cause almost immediate removal of the core or tough membrane which lines the sinuses. No cure can be complete until this membrane is destroyed. In two or three weeks the horse ought to be again fit for work. When the quittor arises from a neglected corn the horn must be pared away, a depending orifice secured, and a seton may be passed through the sinus.

When the internal disease is removed, the treatment of the mere sore at the coronet is easy. In fact, beyond keeping it clean, applying a simple cold water dressing, and occasionally caustic lotion, little more need be done. Sometimes, however, there is a great tendency to the growth of unhealthy granulations round the sore, which will require to be checked by pressure or caustics, or removed by the knife.

Great care must in all cases be taken to prevent the external sore from healing over before the internal disease is thoroughly eradicated. From the great vascularity of the parts in the neighbourhood of the coronet there is always an over-tendency to the healing action.

In cases of quittor a $\frac{3}{4}$-shoe or a $\frac{3}{4}$-bar shoe should be used in order to lessen the pressure and concussion on the part of the foot affected by the disease. In some cases it may be desirable to apply a complete barshoe. It may be necessary to apply a blister to the coronet after the healing process has been completed, especially if any part of the crust has been injured.

\section{Sandcracks.}

A Sandcrack is a fissure in the crust. It is usually found on the inside in the fore-feet, and in front in the hind feet. In most cases the fissure is due to brittleness of the crust. This brittleness may be constitutional, but it is more often due to the evil practice of rasping the crust. The fissure may also be due to contraction at the heels. Such contraction may be due to natural causes, but it is certain to be aggravated, if not caused, by the practice of cutting away the bars and so-called "opening" the heels. Sandcracks are also found in flat or sprawling feet, and in these cases seem to arise from want of tone in the secretions of the crust, and to want of quality in the horn.

A sanderack does not ordinarily cause lameness until it has become 
sufficiently deep to expose the sensitive laminæ, or until it has extended to the coronary band.

In treatment we have to reckon with the fact that a fracture or division of the horn or wall has taken place. The horn will never re-unite. Our object must be to produce as speedily as possible a new growth of horn from the coronet. This is the first point in treatment. The next point is to prevent the further splitting upwards of the wall. For this purpose a transverse nick should be made with the rasp in the undivided horn above the split, if at least the split has not extended to the coronet. The shoe must be removed, and an "arch" about one or one and a half inches wide must be made on the wearing or ground surface of the wall, and about an inch or more in height. The shoe must then be replaced. The object of this is to take all bearing or weight off the part of the crust affected by the split. The further treatment consists in promoting a new growth of horn from the coronet. With this object the coronet must be sharply blistered with ointment composed of equal parts of biniodide of mercury and cantharides, one part of each to eight of lard, which will speedily give rise to increased secretion of horn. The horn will usually grow down with a projection or "knob" which gives extra strength at the end of the new growth. A day or two after the blistering, the horn should be immersed in hot water three or four times a day, and a wet swab should be kept on the hoof between the immersions, but great care must be taken that the swab does not come in contact with the blistered coronct. As soon as the skin which has been blistered is well, which will generally be in about a fortnight, the horse may be put to work, but should be shod with tips for a time at least, if not permanently.

In cases where the split in the horn has extended to the coronet the treatment will in the main be the same, but the horse must not be put to work until the new horn has grown down at least an inch and a half.

In the cases of horses subject to sandcrack or shelly feet, the coronet should be periodically stimulated with a weak blister in order to increase the growth of the horn.

Sandcracks being more or less constitutional are apt to recur.

\section{False Quarter.}

When any part of the coronary band is involved in serious inflamniation, its ordinary secretions are necessarily arrested. If the inflammation is long continued, the portion of the band affected becomes wholly disorganised and its vitality is destroyed. As the crust is secreted from the coronary band, it necessarily follows that there must be a break or separation of the crust immediately below the place where the injury to the secreting surface has occurred. This separation is called False Quarter.

The disease in the coronary band is usually the result of a tread or of quittor, or sandcrack, or of any external injury sufficient to produce violent inflammation in the secreting substance, and consequent arrest of its secretion. 
As the secreting surface, when once destroyed, cannot be restored, there is no cure, properly so called, for False Quarter. The treatment will consist in restricting the disease within the narrowest possible limits, and in adopting such measures of relief as may enable us most speedily to work the animal again.

As the treatment of those diseases, which terminate in False Quarter, has been already given, we have now only to deal with the result, namely, the permanent separation in the crust. The earlier stage is usually accompanied with lameness, and the horse must be rested; and if not in very low condition may be given a dose of physic, which will allay any irritability. The detached portion of the horn on the side of the fissure must be removed, and the fissure itself kept scrupulously clean, for the admission of dirt or gravel will produce irritation and delay the cure. If much pain is present, it is advisable to apply a poultice.

As soon as the acute symptoms have subsided, a plaster of tow and tar should be applied to the fissure with a view of keeping out the dirt and of stimulating the parts to throw out new material. A blister may also be applied to the coronet at this part. In a few weeks the lameness will probably subside, and with the assistance of a $\frac{3}{4}$-shoe, which will prevent undue pressure and concussion on the seat of the disease, the horse may be worked again.

In course of time, though the legitimate secretion of the coronary band is not restored, nature will from the surrounding part throw out a species of spurious horn, which will sufficiently protect the sensitive parts immediately under the seat of injury, and the horse will be again sound for all practical purposes, and eventually the aid of a $\frac{3}{4}$-shoe may be dispensed with. Especial care must be taken that the deposit of horn in the neighbourhood of the False Quarter be not injured by rasping.

\section{Seedy Toe.}

The disease known as Seedy Toe consists in a separation of the crust from the laminæ. It is caused by an irregular and unhealthy secretion of the lower portion of the laminæ, which is incapable of maintaining the union between the above-named structures. The disease always commences in the lower portion of the laminæ, and extends upwards and laterally. Though known as seedy toe, the disease frequently affects the quarters, and more rarely other parts of the circumference of the foot.

Seedy toe is often a result of Laminitis. More often it may be caused by the pressure of the clip of the shoe. In some cases it is due to constitutional causes. After the separation has taken place the disease is easily aggravated by dirt or gravel getting into the hollow so formed.

Lameness is not usually present until the disease has run to a very considerable extent upwards. But the farrier, when shoeing the horse, ought to detect it in its earlier stages. When any considerable degree of separation has taken place, a hollow sound will be emitted on percussion.

In treatment our first endeavour must be to limit the extent of the disease, and secondly, to promote a more vigorous and healthier secretion of horn. All that portion of the crust which has become detached from 
the laminæ must be cut away with the knife; and if the disease shows signs of extending, such further portions as may be necessary must be cut away. The hollow so made in the crust should be filled up with artificial horn made of gum arabic and gutta percha poured in liquid. It will soon become hard and may be secured by a nail driven through and clenched. A ledge may be made in the upper part of the sound crust, which will assist in retaining it in its place. A bar shoe should be applied with the view of relieving the anterior portion of the foot. The shoe must not have a clip at the toe. Lastly, with a view of promoting a healthier action of the parts, the coronet must be frequently blistered. A long rest without shoes will in general cure Seedy Toe without any treatment.

\section{Thrush.}

The structures and functions of the frog and the treatment needed to maintain it in health were described in Chapter 62, par. 952.

Thrush is, to the discredit of our stable management, a common disease. It shows itself under the form of an acrid, strong-smelling, unhealthy secretion issuing from the sensitive frog through the cleft of the external or insensitive frog. The causes of the altered secretion of the internal structure may be summed up under two heads, viz.-1st, wet and dirt, or, in other words, neglect; and 2 nd, want of use.

To maintain the frog in health, it should be washed scrupulously clean every day with a hard water-brush, and the feet picked out at each stable hour. The mere fact-of dung being allowed to remain in the feet is often sufficient in a few days to induce thrush. Again, the ammonia and other gases generated by dirty or decaying litter act most injuriously on the structures of the frog. Hence it is essential that the floor of the stable should be well paved, thoroughly drained and kept clean. The litter should also be dried and aired every day. Continued wet, such as may occur to horses in camp, has likewise a mischievous effect in softening the external structure, which then ceases to afford due protection to the sensitive parts within. But it is from the effect of dirt, combined with wet, that the frog suffers most rapidly.

Disease in the frog is also readily induced by paring, contraction, highheeled shoes, or any other causes which bring it into disuse.

Work, wear, and pressure are natural to the frog and essential to its health and development. If, however, by being constantly pared away at each shoeing, or by any of the above-mentioned causes, the frog is deprived of pressure and wear, it soon becomes unhealthy and diseased. In feet which have been for some time affected with navicular disease, a similar effect is produced on the frog; because the horse, on account of the disease, the seat of which is immediately above the frog, saves as much as possible that portion of his feet and treads on his toes. It is, however, a singular fact that this effect on the frog is often not found in the earlier stage of navicular disease. (See par. 1021.) Again, in contracted feet the sole is generally so much recessed that the frog hardly ever comes to the ground, and hence from want of use it becones diseased. 
Paring the frog, independent of its injurious effect in removing the frog from pressure, has also a further tendency to produce disease. It will be remembered that the structure of the frog is such that its external coat shells off itself in due time. When, however, this coat is artificially removed, the surface, which is then freshly exposed, is not adapted at that time by nature to resist the effect of wet and dirt, and is therefore very susceptible of injury.

Thrush is more common in the hind than in the fore feet, probably because the former usually stand in the dirtiest and wettest part of the stable.

\section{Treatment.}

In the treatment of those cases which originate in dirt and wet, our first care must be to remove the cause and keep the frog scrupulously clean and dry. The removal of any ragged or partially detached parts will lessen the difficulty of keeping it clean.

Having removed the cause, our next endeavour must be to clean the part thoroughly and then to absorb the discharge. This is essential, because the discharge is of an acrid nature, and has in itself a tendency to cause disintegration of the structure. The cleft of the frog should be thoroughly washed out from the bottom by means of a thin flat piece of wood and some soft tow and hot water. If the case is a bad one, poultices will be beneficial.

After the part has been thoroughly cleansed a piece of fine tow well saturated with a lotion composed of one part of carbolic acid to twenty parts of water must be gently thrust to the bottom of the cleft and covered with dry tow. This dressing may be repeated night and morning for a few days, and the thrush then dressed over with calomel and dry tow. Care must be taken to keep the frog free from dirt and moisture.

Further, with a view of restoring the parts to healthy action, pressure must be applied. This will be best effected by lowering the crust at the heels every fortnight, by shortening the toes, so as to throw more pressure and work on the heels, or still more effectually by the use of tips instead of shoes.

When the disease in the frog has arisen from deprivation of its natural functions by paring or by the use of high-heeled shoes, the treatment will be first to dry up the discharge by the means recommended above, and secondly to remove the causes, viz. want of work and pressure (see preceding paragraph).

When the disease has its origin in navicular disease, little more can be done than to keep the frog scrupulously clean and to dry up the discharge as soon as it appears.

\section{Chronic Thrush.}

For Chronic Thrush, when not arising from navicular disease, it will be advisable in addition to the treatment recommended above to shoe the horse with tips. This remedy will bring wear and pressure on the 
frog. Nature has made the frog as a cushion or elastic pad, on which to receive concussion and to lessen it in other parts of the frame. If the frog be subjected to a fair amount of wear and pressure before the disease has run too great a length, it will probably again become sound and strong.

\section{Neglected Thrush.}

If Thrush is long neglected, the neighbouring parts become affected, and in bad cases the whole of the sensitive sole is involved. The sole is then said to be "under-run;" or in other words the unhealthy secretions, being greatly increased and unable to find sufficient exit through the insensitive frog, burrow between the sensitive and insensitive sole. The disease, if still further neglected, may run into canker. The treatment of serious cases of neglected thrush is nearly similar to that required in canker, which will be described in the succeeding paragraph.

\section{Canker.}

Canker is a morbid secretion of the sensitive frog and sole, involving of course the corresponding insensitive parts. This formidable disease usually has its origin in neglected thrust, but it may be due to constitutional causes. It is most common in heavy cart horses.

The discharge, which issues from the frog, is more or less copious, foetid, and colourless. The frog itself becomes large, spongy, and covered with pallid stringy prominences of a fungoid nature, intermixed with offensively-smelling, semi-dried, cheesy masses of matter composed of imperfect horn-cells. "The smell is disgusting.

\section{Treatment.}

The treatment of Canker consists 1st, in the complete exposure of the diseased surface; 2 nd, in the application of pressure; $3 \mathrm{rd}$, in thorough dryness.

The whole, not merely the diseased portion, but the whole of the insensitive sole must be removed. When this has been thoroughly and effectively done, the whole of the exposed surface must be dressed with nitric acid. The sole must then be firmly packed with dry tow secured with a bandage, and the foot enclosed in a leathern boot. This will give the necessary pressure. To prevent excessive bleeding from the removal of the sole a tourniquet should be applied to the fetlock. The foot, bedding, and sole must be kept scrupulously dry.

After two days the dressing should be removed. In favorable cases the whole of the exposed surface of the foot will present a healthy appearance, and will gradually become covered with good horn, and no further treatment will be required beyond cleanliness, dryness, mild astringents, and moderately firm pressure and bandages. For at least a week after the operation the horse should stand without shoes. But as soon as the feet are able to bear shoes, they should be applied, as it is much easier to dress the feet with shoes on. 
But the more aggravated cases will continue to present fungoid elevations and morbid secretions, and will require repeated dressings with powerful caustics. The dressing should be changed every day or nearly every day, as after a few applications the same remedy seems to lose its effect. Chromic, sulphuric, and other acids may be used in turn.

Care, however, must be taken not to continue for too long the use of strong caustics, or the whole sensitive sole will be destroyed and necrosis of the bone induced, followed by great sloughing and perhaps death of the patient. After a time therefore, in lieu of the above, burnt alum, sulphate of copper, terchloride of iron, chloride of zinc, and other astringents may be tried. Carbolic acid may also be used. Most cases inprove under firm pressure, but in others, long-continued pressure seems to stimulate the diseased action and the growth of fungus. It is scarcely possible to lay down a positive rulc. The symptoms of each case must be carefully watched and treatment applied accordingly. In all cases, except for the first two days, the dressing should be removed daily.

The general health must be carefully attended to. A purgative will probably be beneficial in the first instance, followed after a time by tonics. Good dry food, fresh air, great cleanliness, and a dry stable and bedding are essential.

\section{Navicular Disease.}

Navicular disease in its primary stage is inflammation of the navicular bone, which lies at the back of the coffin bone, or bone of the foot. Plate 47 , fig. 0 .

After a time the neighbouring parts, viz. the tendon, which passes under the bone, as a rope under a pulley (Fig. k), and its cartilagre and bursa, become inflamed.

\section{Further changes.}

The inflammation which has been set up in the bone, leads to a variety of changes both in its external and internal structures. In some cases the bone gradually wastes away, until at last it becomes liable to fracture from any trivial cause. In other cases an ossified deposit takes place on the outside of the bone. This deposit limits the free play of the tendon, and it gradually becomes adherent to the bone, and its bursa becomes absorbed. In other cases the fibres of the tendon split up, partly from friction against the roughened surface of the diseased bone, but more often from degeneration of its structure from the inflammatory action, which extends to it from the bone. In the end the tendon may give way altogether.

As the disease goes on the concavity of the foot increases, and the frog becomes either hardened and elevated from the ground, or softened by it discharge from its cleft and surface. These changes however, are not due to the disease, but to the decreased use which the horse makes of the heel on account of the disease existing in the foot. 


\section{Symptoms.}

The lameness may appear suddenly. No cause can be found for it. It may probably disappear, and after a time reappear either in the same or in the other foot, and these appearances and disappearances may occur for some time. Such is usually the case when the disease is due to rheumatic affection. In time the symptoms become more marked.

Or the first sign may be pointing of the foot in the stable, followed after a time by shortness in the step and perhaps by lameness. The foot and the horse may be examined, and nothing wrong can be found. Probably the next day the animal may be sound. But in the course of a few days the symptoms become more marked.

Pointing in the stable is common with many horses as an act of rest or as a mere matter of habit. When, however, pointing arises from habit, or as an act of rest, the animal stands with one fore-foot and then with the other, in a semi-flexed position, in a careless lounging way; but he points two limbs simultaneously, namely, one fore and the hind leg of the opposite side of his body. In navicular disease, however, a fore-foot or feet only are pointed. There is no corresponding resting of the hind limb.

The above signs may lead us to suspect navicular disease as the cause of lameness. But the strongest indication of the disease lies in the absence of any cause, such as external injury or heat sufficient otherwise to account for the lameness. The fact of intermittent lameness in the carlier stage, and of persistent lameness in the later stage, without any external symptoms sufficient to account for it, is the strongest indication that the disease lies in the navicular bone.

The symptoms of lameness are evidently those of foot lameness (see Chapter 42, Par. 654). If laminitis be present, there will be heat and tenderness, and the animal will go more or less on its heels. If a corn be the cause, its presence is easily detected. In fact, in nearly every other form of disease there are external signs, which will at once point to the cause of disease. But in navicular disease, if we except occasional heat and tenderness in the hollow of the heel, or redness of the frog and sole immediately below the navicular bursa, there is no external sign. Even the redness of the frog and sole, now and then met with, is not always to be depended on as a sign of navicular disease, as it may arise from external injury, such as treading on a stone, and may be superficial only.

In navicular disease, pressure on the hollow of the heel will very often give pain ; and the pain so evinced is no doubt symptomatic of the existence of the disease. But it is necessary to remark, that any great pressure on the heel and violent flexing of the pastern will often cause even a sound horse to show signs of pain. Therefore this symptom cannot be absolutely relied on.

In the more advanced stage, the horse will often come out of his stable lame after an interval of rest. He may scarcely be able to put his foot to the ground, but after he has been exercised a short time the great 
lameness will disappear, especially if the ground be soft. This is very characteristic of the disease.

A marked feature in navicular lameness is that the animal invariably goes upon his toes in progression and is more lame in going downhill. If lame in both fore-feet he will have a short pottering action.

From the above it will be seen that the symptoms of navicular disease are negative rather than positive. If the signs of the lameness are those of foot lameness, and if after due examination no other adequate cause can be discovered, we have reason to suspect navicular disease.

In all cases of long standing the foot or feet become contracted. In some cases the atrophy extends to the muscles of the shoulders and forearm. This wasting away is due simply to the decreased use which the horse makes of his fore-hand in action on account of the disease existing in his fore-feet.

\section{Cause.}

My attention was drawn some years ago to the very marked decrease of cases of Navicular disease; and about the same time to the very great decrease of the practice of paring out the Sole and mutilating the Frog.

The symptoms of Navicular disease, as given in par. 1023, are those which must occur in the interior of the foot by the concussion and friction caused by the paring out of the sole, and the mutilation of that "everlasting" pad known as the Frog. I have used a strong word, because the Frog grows stronger and stronger the more it is thumped about. Please turn to par. 952 (the Frog), and 1015 (latter part).

The symptoms of Navicular disease in the interior of the foot are exactly those which must occur from concussion and friction, when kind nature's protection against concussion and friction is taken away.

\section{Treatment.}

If the reader will turn to Plate 47 , Fig. 10 , he will at once see that the mischief is in the very centre of the foot, and that outward application, such as blistering or firing, can have no effect on the tendon runningr under the navicular bone; nor can any external treatment arrest the erosion of a bone in the centre of the foot.

It has been suggested to pass a seton through the Frog. But it is not easy to see in what way a seton could strengthen the tendon, or stop the decay of the navicular bone.

\section{Neurotomy.}

It has been suggested to unnerve the foot. Of course this would give relief for some limited time, and cause apparent soundness. But as greater force in action would be thrown on the already broken structure in the interior of the foot, the apparent relief could not last long.

There are cases on record where horses after being unnerved have done excellent work for years. The answer is simple, viz. that the horse was not affected by Navicular disease.

Horses, which have been unnerved, are obviously unsafe off a level turnpike road. 


\section{6a. Of Remedies.}

In good truth there is no remedy. Long experience has proved that. But though there is no remedy, the disease can be averted: The Cause is jar and concussion. That can be averted by maintaining in full strength and vigor the Sole and Frog.

Of course there may be here and there cases of weakness of the navicular ligament or caries of the sole. And possibly a case of navicular disease may occur.

\section{Laminitis.}

Laminitis or inflammation of the sensitive laminx is the disease popularly known as Fever in the Feet, or Founder. The original attack is always acute. It may be entirely relieved, and no ill effects remain. But often a change of structure results from the effects of the acute attack. This after result is known as Chronic Laminitis. Horses suffering from it are subject to recurrence of the acute disease.

Laminitis is very painful, and the lameness is excessive. The pain is due to confinement of the products effused by the inflammation within the outer hard unyielding case of the foot, and the pressure thereby caused on the sensitive structures of the interior. The seat of the disease is in the anterior and lateral portions of the foot. (Plate 56.)

\section{Causes.}

A predisposition to this disease is often traceable to hereditary tendency and to defective conformation of the feet. But the immediate cause most frequently is concussion. The fore-feet are more often affected than the hind, because concussion is most severely felt in them. Rasping of the crust, and paring of the sole and frog are the more usual causeschiefly because by impairment of the structure they increase concussion. Excitement, over-exertion, and indigestion are also frequent causes. The disease, however, in many cases is due to metastasis or a sudden shifting of inflammation existing in some other organ of the body to the feet. Confinement on board ship is frequently a cause of laminitis from longcontinued strain on the sensitive laminæ.

Horses with flat, weak feet are predisposed to this disease.

Both feet, either hind or fore, are usually affected. Similar causes generally affect both feet, and therefore produce similar results. Sometimes all four feet are affected. When one foot only is affected, the cause is generally some injury of the opposite foot, which has caused the horse to throw all the weight on the previously sound foot.

1029. Symptoms.

The symptoms of Laminitis are very marked. The attack is very sudden in its occurrence. The horse can hardly be got to move. $\mathrm{He}$ seems as if all his body were cramped.

There is heat in the feet affected. As the seat of the disease is in the anterior portion of the feet, the animal will save that portion of his feet as much as possible, and will throw his weight on his heels. The disease is intensely painful. On account of the pain the pulse is always accele- 
rated. Frequently general febrile symptoms are present, and throhbing of the plantar arteries is a marked feature in this disease.

If the two fore-feet only are affected, the hind legs will be drawn under the belly, and the fore-feet advanced, so as to take the weight off them as much as possible. If the two hind feet only are affected, he will stand with his fore-feet back under his body, and his hind feet brought forwards, so as to throw the weight upon the heels. If all four feet are affected, the symptoms will be a combination of the above.

\section{Treatment.}

Our first endeavour must be to relieve the local inflammation existing within the feet. Mild purgatives should be given, and if the bowels are torpid, clysters should be administered. But a full dose of medicine may do serious mischief on account of the irritability of the system in this disease.

The shoes should be at once removed, and the crust of the hoof rasped down so that the animal may be able to throw some of his weight upon a portion of the sole.

Owing to the intensity of the pain it is sometimes a difficult matter to remove the shoes, and occasionally the animal has to be cast or slung before this can be accomplished.

As soon as the action of the laxative medicine has ceased, the patient should be placed upon cooling diet, mashes, green food-if procurablecarrots, etc. A pail of fresh water should be left within reach. If any febrile symptoms are present, half an ounce of nitre may be dissolved in the water.

The local treatment should consist of cold applications.

Hot fomentations and poultices are inadmissible in this disease as they tend to relax and distend the overloaded blood-vessels, and by encouraging swelling of the inflamed sensitive structures, which are closely confined in that unyielding horny box, viz. the hoof, produce an increase of the pain which is already excessive, and favour the approach of those structural lesions which we are anxious to prevent.

Bleeding from the coronet, either by scarifying with a lancet or by means of leeches, with a view of relieving the congestion and diminishing the pain, is a practice frequently employed with benefit.

The animal should be made to stand in a wet clay bath during the day, and at night may be sllowed to occupy a well-littered loose box or stall, and encouraged to lie down. Or the feet may be kept cool by the application of wet swabs round the coronet.

As soon as the most acute symptoms have been relieved, and the animal is able to bear weight upon the feet, no time should be lost in applying the special "rocking bar shoe" described in paragraph $983 c$, and getting the horse out to exercise, as soon as possible, on wet soft ground.

If the disease progresses favorably, ordinary shoes may be applied in the course of a few days, and it may be necessary to blister the coronet. See paragraph 1033 . 


\section{Results.}

In favorable cases, that is, where the inflammation is not very severe, and its effused products are taken up by the absorbents and blood-vessels, there will be no structural alteration, and in due course the horse will be sound again, though always more or less liable to recurrence of the disease.

But in unfavorable cases there will be an alteration of structure, and the result will be Chronic Jaminitis.

\section{Chronic Laminitis.}

The alteration of structure caused by the inflammation (Plate 56) usually consists of a separation between the sensitive and insensitive laminæ. In consequence of this loosening of attachment, the anterior point of the coffin bone descends and presses on the sole. The sole being pressed upon also descends and loses its concave shape, and becomes convex and weak. The anterior portion of the crust having in some measure lost its attachment, becomes weak and bulges out anteriorly. There is a large mass of imperfectly formed horn at the toe.

When these alterations of structure have taken place, the horse must be considered radically unsound; but with good care and good shoeing may be useful for years.

The shoe must be adapted to the altered form of the foot. A very wide web, seated out, so as not to press on the sole, will be needed. As recommended above, the heels of the shoe must be very thin, so as to throw up the toe by letting down the heels, and thereby relieve the anterior part of the foot from pressure. Leather under the shoe, but not over the sole, is useful both in diminishing concussion, and in raising the sole off the ground. Leather over the sole will cause increased pressure. Great care must be taken in the nailing.

\section{Blistering round the Coronet.}

A few words may be necessary in regard to blistering round the coronet, which has been repeatedly referred to above.

The object is of course to excite an increased growth of horn by stimulating the action of the coronary substance or protuberant band of thickened vascular skin, which extends for about a finger's breadth above the hoof, and from which the crust is secreted. The vesicant should be applied only to this protuberant band, and may be repeated every nine days, until the desired effect, viz. increased growth of horn, has been produced. The horse may be worked throughout.

It is necessary to explain this, because, simple and obvious as it seems, the object of blistering this part appears often to be misunderstood, and 
the vesicant is applied over half or even the whole of the pastern, and the horse is in consequence obliged to be thrown out of work.

\section{CHAPTER 66.}

\section{THE PROGRESS OF VETERINARY SCIENCE.}

\section{A Lecture delivered to the Portsmouth Literary and Scientific Societr.}

1034. In addressing an unprofessional audience on a professional subject, I shall endeavour to deal only with the general aspect of Veterinary science. If I should be able to excite a general interest in the treatment, the wants, and ailments of the lower creation, perhaps some of my hearers may be induced to follow out the subject to practical results.

There are impostors and quacks in the medical profession. There are more, there must be more, impostors and quacks in the veterinary profession because the sufferers-those rudely or ignorantly treated-have no means of making known their sufferings. Nature has not vouchsafed to them the organ of speech, by means of which they could make known their grievances and their sufferings.

\section{Veterinary Science.}

The progress of civilisation in man has been marked by a greater degree of care for human life, by an increased desire to gain a more accurate knowledge of the laws of health, and especially of late years by what is known as sanitary science.

The progress of civilisation has also been marked by the greater value which man sets upon those animals which are needed for his existence, for his use, or for his comfort. In the savage, or semi-savage state of man, animals were simply hunted down or destroyed. In the civilised state of man the welfare of animals useful to man is carefully studied. Their increase in number, in individual value, and in the perfection of their respective species, as, for example, in the horse, cow, and sheep, are questions of social wealth and of vital importance to the community at large.

In the increasing value of domesticated animals useful to man, and in the greater ravages of disease, as must be the case where animals, more or less intended to roam at large, are crowded together; as must be the case where land increases in value, and where also population increases in numbers, and daily requires larger supplies of food; in the increasing value and need of domestic animals, and in their increasing ailments arising from domestication, modern Veterinary Science has had its rise.

The Veterinary art, however, was not unknown to the ancients, but, 
like the kindred art of human medicine, it was studied in a very rude and unsatisfactory way.

The first attempt to teach in England veterinary medicine on scientific principles was made by Sainbel, a Frenchman, about a hundred years ago, in the school now known as the Royal Veterinary College of London. Since that time three other schools have been established. In 1844 a Charter of Incorporation was granted to the Veterinary profession under the name of the Royal College of Veterinary Surgeons. Into this body are now affiliated the four teaching schools above alluded to.

A licence to practise cannot be given by any teaching school, but all the students are sent up for examination before the board of the Royal College of Veterinary Surgeons, and from that board alone the student can receive his diploma.

In the hundred years which have elapsed since the days of Sainbel the veterinary profession has made rapid, very rapid strides towards the attainment of that position to which its claims and its aims entitle it. This progress has been chiefly due to the enlightened views and striking abilities of those who were appointed as the earlier professors of the veterinary art-men who devoted their lives to its development and perfection. The public, on the other hand, have been slow to recognise the claims of Veterinary science, and it was not until the recent enormous losses, produced by ignorance of the true origin of disease, called greater attention to the subject, that the Veterinary art has been recognised as second only in its usefulness to the care of human life.

Under the head of Veterinary Science is included the art of healing, as applied to all animals useful to man. But modern ideas in veterinary as in medical practice now regard the prevention of disease as more important than its cure. In the human race this change of ideas is fairly realised. In veterinary practice it is more fully realised, inasmuch as animals, unlike human beings, cease to be of any value, unless they are sound and healthy, except in special cases, such as brood mares. The cure of sick animals is not practically so important as their maintenance in health. No doubt the cure of disease is an important object, but it is only one, and certainly not the chief object of the many duties appertaining to Veterinary science.

\section{Veterinary Sanitary Science.}

Veterinary Sanitary science is also closely allied to human sanitary science. A great many of the diseases which affect animals are communicable to man, and are of a most serious character. Again, the flesh of animals in disease, as well as their milk, may be a prolific source of disease in man. Again, wide-spread animal plagues, such as rinderpest, foot-and-mouth disease, pleuro-pneumonia, and others, may render meat - that article of food which is so important to all classes-both scarce and dear.

Animals of the higher class suffer from much the same diseases as man, and these generally arise from much the same causes. For example, fevers of various kinds, diseases of the lungs, liver, kidneys, nervous and 
muscular systems. The circulation of blood in animals, though the pulse may be somewhat quicker or somewhat slower, is the same as in man. In fact, almost all that is known of the circulation of the blood is derived from observation on the circulation in the frog's foot. The respiratory organs, the heart, liver, spleen, kidneys, nervous system, and all the more important organs of the body, have, in the higher class of animals, the same functions as in man, and in disease require the same treatment.

As regards treatment, and as regards the diseases themselves, there is but little distinction between the veterinary and the human medical art. It is not meant that the medicines used are exactly the same in quantity, or perhaps in quality, but the principles on which they are applied are the same. Animals, as a general rule, are acted on through the same organs and in the same way as human beings, though the medicines used are not always the same, nor do all medicines produce the same effects on all animals. Purgatives, for instance, produce the same effect on the horse as on man. But the medicine given is not the same. Aloes is the best and safest aperient in the horse, whilst in man it has a drastic effect. Again, aloes is not suitable to cows. Salts produce in them the safest effects. The tonics and depressants used are the same in horses and men, and produce the same effects. Blisters act similarly in both, but probably on account of the greater thickness of the skin they require to be applied more freely in the horse than in man. For the same reason actual cautery can be applied to horses, whilst it is generally inapplicable to man. In liver disease, so common among stud-bred horses, $i . e$. half English, half native horses, in India, calomel is used as in man; but from some peculiarity of the system the dose in the horse is usually a scruple, i.e. twenty grains. On the other hand, in the canine species, a dose which might be given to a child will produce salivation.

Some animals can absorb into their stomachs what are deadly poisons in man. The white ant of India can eat strychnia; the toucan feeds on the seeds of nux vomica; the goat eats tobacco.

Again, though the organs are the same and perform the same functions, yet similar organs vary very much in size in various animals, according to the use for which Nature has designed the animal. In the horse the stomach is small. He is evidently intended to feed frequently and sparingly, to be fit at all times to seek safety in flight; for Nature has given him no horns, only heels to use in flight. The $\mathrm{ox}$, on the contrary, has a very capacious stomach, is incapable of rapid motion, but is provided with horns for defence. The camel has a very peculiar arrangement for retaining water in the stomach, and is therefore well fitted for traversing large sandy plains, where water can be obtained only at somewhat rare intervals.

Still these differences do not affect the general question, namely, that in the higher class of animals, and to a certain extent in the lowest, the organs of life are the same and require somewhat similar treatment as in the human being.

From some diseases common to human beings some animals are exempt. For example, the horse rarely suffers from toothache; the 
nerve does not approach so near the crown of the tooth as in man. Again, animals are generally exempt from those numerous diseases which man produces in himself by vice; for example, those resulting from the use of ardent spirits. On the other hand, fat and over-pampered animals suffer from liver disease as readily as man.

\section{Veterinary and Human Medical Science-distinctions between.}

The Veterinary medical art, however, differs from the Human medical art in several very distinct ways.

1st. Animals can give but very little assistance to the practitioner in detecting the seat and nature of the disease under which they are suffering. Information can only be gleaned from the symptoms. Herein the Veterinarian is placed at a disadvantage compared with a medical man, and hence greater skill in the diagnosis of disease is needed in the Veterinarian than in the Medical man.

$2 n d$. In regard to the effect of medicine and treatment, the Veterinarian must rely wholly on his skill in discerning their effects. $\mathrm{He}$ cannot ask questions to the sufferer as to the effect which his medicine is producing. For instance, we give an animal iron and other tonics. We are obliged to wait until some decided result, either for good or for worse," is produced. In the human subject the medical man would ascertain day by day from his patient what result was being produced. Herein, again, greater skill is needed in the Veterinarian than in the Medical man.

3rd. It is seldom worth while to treat serious injuries-not sicknesses, but injuries in animals. For instance, a horse breaks his leg. Bones will re-unite in an animal as easily as in man, but complete restoration to soundness can hardly be expected in either one or the other. A medical man is often well enough pleased if, in case of fracture of the leg, he can make his patient sufficiently well to walk about. But a horse will not repay the cost of cure unless he can be restored to perfect, soundness at the walk, trot, and gallop. Hence serious fractures are seldom treated.

But fractures of the less important bones, and especially of non-weightbearing bones, may be, and frequently are treated with success. But all such cases demand especial care and skill on the part of the Veterinarian; as the animal, from ignorance of the nature of the treatment adopted, and from impatience, and, perhaps, irritation is apt, unless great care is taken and the restraints most accurately adjusted, to destroy in a few seconds all the results of the care and treatment of weeks.

4th. The hindrances with which the Veterinary surgeon has to contend in the treatment of disease are greater than those of the medical man. $\mathrm{He}$ is seldom called in in the earliest stage of the disease. This is due partly to the ignorance and to the incapacity of those in charge of animals to recognise the earlier signs of the disease; partly to a stupid desire to save a fee, to wait and see if the animal will get well of itself; and, lastly, to the inability of the unfortunate sufferer to speak for itself. Animals cannot, except by silent expression, tell their grievances or explain their sensations. Again, in stables and farms generally there is an absence of those accessories of comfort which are as absolutcly essen- 
tial to the successful treatment of disease in animals as in man. Good nursing is quite as essential in the treatment of animals as of man.

Lastly, the Veterinary surgeon, in order to be successful, must be a man of very acute observation among those to whose ailments he may be called to minister. He must be devoted to his art; he must live much among his patients. It is only by knowing the habits and expression of the various animals in health that he can hope to detect, as it is most important to do, the earlier signs of disease.

Veterinary science is said by many to be in its infancy. This is hardly correct. The relations between veterinary and human medicine are so close that most of the great strides which have been made in the medical art of late years are applicable to, and have been adopted in veterinary treatment. It is true that the most improved modes of treatment have been worked out by the labour of medical men; but it is also true that veterinary science has profited as much by those discoveries as the other branch of the healing art. For instance, the violent remedies of bloodletting and depletion, which were common a few years ago in both the medical and veterinary art, have given place to more reasonable treatment in both sciences. I shall not elaborate the subject; it would hardly be interesting to a non-professional audience.

\section{Prevention of Disease. Sanitary Veterinary Legislation.}

With regard to the prevention of disease Veterinary sanitary science has already done much. It has taught the laws of health concerning domesticated animals; it has insisted on ventilation, on drainage, on cleanliness, on purity of water, on food adapted to the stomach of each individual animal; it has, for instance, in our cavalry regiments reduced the looss of horses to the lowest possible scale; it has reduced the annual casting of horses in a cavalry regiment to 10 per cent., giving an average service of seven to eight years to each horse carrying eighteen stone on his back at a rapid pace over rough ground-a result which may stimulate the cupidity, if not the humanity, of the very large class who use up horses in about two and a half years.

\section{Cattle Plague or Rinderpest.}

Veterinary sanitary science has done much, and hopes to do more in future, in suppressing or combating those dreadful maladies, such as Cattle Plague, which have caused such heavy losses to the community, and greatly embarrassed the trade in food. But the value of this branch of veterinary science is not yet appreciated as it ought to be. It has often been made a subject of reproach to Veterinary surgeons, that at the time of the cattle plague, otherwise known as Rinderpest, they utterly failed to cure it; that their only remedy was brutal and unscientific, namely, slaughter. This objection, so commonly made, was, I think, founded on a misconception of the real facts of the case, or, in other words, in ignorance on the part of those who b'amed the Veterinary profession. 
Contagious and infectious diseases may, I think, be divided into two great classes, viz. those which are indigenous in a country, which are inherent in its climate and soil, or have become acclimatised in it; and, secondly, those which are of foreign origin and which do not become acclimatised, which can only be reproduced to a limited extent, and for a linited time, by virus freshly imported from those countries in which the disease is indigenous. In the human subject we in England recognise yellow fever as a foreign disease. Ships arrive at Southampton from the West Indies with yellow fever on board; but it spreads only to a very limited extent in English climate and soil. The climate and soil do not suit its development, and the virus dies out. Cholera is another somewhat similar disease. It is of foreign origin, and can be reproduced in this country only so long as the strength of the imported virus sustains itself. Gradually it weakens and dies out in English soil and climate.

Now cattle plague was, and still is, essentially a foreign disease. If sufficiently stringent regulations had been at once adopted, as the Veterinary profession recommended, the disease might have been stamped out at once, and the lives of many hundreds of thousands of animals, valuable to man, might have been saved. The Veterinary profession had long before realised this important distinction, and, therefore, recommended slaughter. They were right; but they were and are abused for that recommendation. It may, however, be said that this was a new disease, and that there was no reason to expect such dreadful ravages. But this observation is untenable. The disease had long been known to veterinary surgeons, and had been studied by several of them on the steppes of Russia ; and they were therefore fully justified in their recommendation of slaughter. In cholera in human beings it would be impossible to adopt the same stringent course. But if it could be applied on its first appearance in a country which is not its natural habitat, I doubt not but that it could be stamped out, and many thousands of lives might be saved.

\section{Home-bred Diseases.}

Whilst I am strongly of opinion that diseases of foreign origin, such as cattle plague, may be stamped out by preventive measures, I look upon the attempt to stamp out diseases natural to, or acclimatised in our climate and soil, as useless and idle. For those diseases which are natural to or acclimatised in our country, such as pleuro-pneumonia, foot-andnouth disease, etc., the germs of which exist throughout the length and breadth of our land, I believe the measure restricting locomotion to be more costly and irksome than successful in result.

If these diseases, which are always in the country, can be spread, as alleged, by so many causes, by air, by water, by passage of cattle over ground, by flies, by birds, by hares and rabbits, etc., what can be the use of restriction? Can you bind the wind? Can you stop the flow of water? Can you limit the flight of flies and of birds?

Further, I look on the now prevalent idea that these diseases are usually due to infection or contagion as a source of great evil. I believe 
that they are nearly always due to local causes (see Chapter 67, "Origin of Diseases") aided by bad sanitary arrangements. I believe that socalled infectious and contagious diseases will rarely, if ever, spread under good sanitary arrangements, and under circumstances favorable to health. I have had a good deal to do with horses all my life. In cleanly, wellventilated stables, and with horses properly cared for, I have never known a case of so-called infectious or contagious disease spreading to any serious extent. I have seen on several occasions cases of glanders, farcy, ınange, and other such like diseases, isolated cases, but in my own experience $I$ have never seen any of these diseases spread where the conditions have been favorable to health, and where the stable management has been good.

\section{The Cost of Ignorance.}

Of the losses suffered by the community from neglect or ignorance of the laws of health as affecting animals, it is impossible to give any estimate. But I will give a few examples which happen to be within my own knowledge. I was asked a few years ago to go over the accounts of the horse department of a large coal and iron company. I found that their horses cost on an average $£ 50$, and lasted about three years. Shortly afterwards I went over the accounts of another large company, doing similar work, but managed by a competent Veterinary surgeon. In this case the horses cost an average of $£ 40$, and lasted about six years. Both establishments had about four hundred horses. The total difference of cost between the two establishments for renewal of horse stock, food, ctc., was over $£ 6000$ per annum, but the real difference was much greater, because in the first-mentioned establishment a considerable proportion of horses were constantly sick, and therefore unfit for work. A few weeks ago I was asked to go over the stables of a large London brewery. They were admirably managed. Their horses lasted on an average ten years. I believe five to six years is common in that class of work. The London cab horse lasts about three years.

\section{Animal Pain.}

The question of animal pain and suffering is, perhaps, more interesting than any other subject connected with the lower creation. That the higher class of animals suffer from pain as acutely as man is, I think, quite susceptible of proof. That their diseases are much the same, assume the same types, and require the same treatment as those of man, is known to every Veterinarian. For instance, the phenomena of inflammation are exactly the same as in man. We believe the pain to be the same. We can hardly doubt but that the desire of the animal to get well is the same as in man. But here we meet in our investigation with a difficult obstacle, which I do not attempt to solve. I merely mean to state it and the facts connected with it.

Animals suffer from pain, from disease, from accidents. Such is the law of Providence, the law of creation, so far as we can see. Man also 
suffers from pain, disease and accidents. In man we are taught to believe these trials are sent by an all-wise Creator for purposes ultimately beneficial to man-an immortal, imperishable creature-though we may not be able to see the immediate good results. We look forward to a future world as giving compensation, and in a Christian sense, utilising the pains and trials of this passing life in a future state. But this solution of these uses of pain and suffering in man will not solve the question of animal pain and suffering, unless-here I pause for a moment. It would seem to be inconsistent with the ways of an all-wise and merciful Creator to bring into existence these countless millions of the animal creation, all suffering pain and disease, very many suffering from cruelty to each other, very many suffering great evils from man-unless in some way or other there is a future before those animals.

\section{Animal Soul.}

Man has, we believe, a Divine soul, an emanation of the Deity. May not animals have, in some way of which we have no idea (for it has not been revealed to us), what I may term an animal soul-some future existence, some compensation for pain and suffering here on earth, some reward in some future state? It is impossible to limit the ways of the Almighty; His ways are past finding out. It seems to me that we, as Christians, should be guilty of wrong ideas towards the Creator unless we believe-not that God has created myriads of creatures for constant pain and suffering, but rather that we should believe that in some way past our finding out, animals have, must have some future existence.

It may be said that animals have no sense, no perception of moral right and wrong; that even their kindnesses are mere instinct; that certuinly, whether they have any perception of right or wrong, they have no means of developing any ideas of right or wrong beyond mere instinct. I think all such ideas unduly limit the power of the Creator. For myself I cannot but believe that there is in every one of the lower creation an animal soul, of what nature I know not, but an animal soul appropriate to and suited to the instinct of each creature brought into the world by the will of the Great Creator.

It may be said that in the Books of Moses, where power is given to man over all animals, power to slay and eat, no vestige of an idea of a future state for animals is given in those writings. To this I reply that in the Books of Moses only a faint, certainly not a distinct, idea of a future state is vouchsafed to the Israelites; and we know from the New Testament that even as late as the time of our Saviour, a large proportion even of the priests, the Sadducees, had not even up to that time deduced from the Mosaic writings any idea of a future state.

Is it possible to believe the Saviour's words, that not a sparrow shall fall to the ground without His Heavenly Father's knowledge, is it possible to believe those words, unless we also believe that God Almighty exercises far greater care, and takes far greater interest in animals, than man in his selfish pride is perhaps willing to admit?

Animal suffering and a future in prospect for animals must always, I 
think, be present to those who make Veterinary science their life's study. It is almost impossible for a man of average sensibility to observe closely and to note the painful expression and the intelligence of those creatures, whose structure and organisation he has to investigate before he can minister to their ailments, - it is impossible for him to witness their sufferings, to witness the brutal treatment which they too often meet with from ignorant and cruel men; it is impossible for him to see these things without sorrow, without endeavouring to alleviate their agony, and endeavouring to ameliorate their hard fate.

It is said to be, and justly said to be, the type of the highest Christian virtue to do good to those who cannot repay you, who cannot or who will not even thank you. If this be so, and it is so, then there can be no higher virtue than the alleviation of animal pain and suffering. I know of no more leal satisfaction than to relieve an animal of pain, or to cure him of a disease from which he suffers as acutely as we do ourselves. Animals do appreciate our help. Of that I have no doubt. Some show their gratitude more visibly than others. Dogs, for instance, and some other animals, show it outwardly and plainly enough; but doubtless all animals made by the same Creator feel it, not in our, but in their own way.

\section{Horses.}

Veterinary science and Veterinary surgeons can and should do much to lighten the hard lot of animals which toil incessantly for man; and surely no creature stands more in need of this aid than the horse. His life is often one of continual slavery, and in many instances of perpetual discomfort. He ulone, or almost alone, of all creatures is doomed to never-ceasing labour. The life of the ox, the cow, and the sheep, is one of comparative, if not absolute happiness, whilst the life of the dog is generally happy.

But the horse seems to be haunted by the demon of labour and fatigue almost from his earliest years, and generally increasing to the hour of his death-to be haunted by a demon whose power to torment seems to increase as the horse becomes older and more worn.

If any animal deserves, as a reward for services to man, and as a compensation for days, weeks, and years of abuse ; if any animal deserves a tranquil future, a glorious pasturage traversed by never-failing crystal streams of water, surely that animal must be the horse.

These views of animal pain and suffering, and the doctrine of an animal soul, are deeply mingled with that of future retribution to man for cruelty to the lower creation. Ruskin has eloquently said, "Can any man account for all that happens to a cab horse? Has he ever fairly looked at the fate of one of those beasts as he is dying? Has he measured the work it has done, and the reward it has got? Has he ever put his hands on the bloody sores through which its bones are piercing, and so looked to Heaven with an entire understanding of Heaven's ways about the horse? Yet the fate of the horse is no dream; no revelation among the myrtle trees by night. The dust it lies upon, and the dogs that eat it 
are facts. And yonder happy person who owned the horse until its knees were broken over the hurdles; who sold it to a cab owner as soon as it was blemished; yonder happy person with an immortal soul, with peace and wealth on earth, shall this happy person have no stripes? If other things are, indeed, reserved for him, Heaven's kindness or justice might be in question therefrom."

The Christian religion is closely allied to the science of medicine, whether human or veterinary; and its brightest, its most hallowed feature is the humanity which it inculcates to man andd beast. But the Christian religion does not vouchsafe to us any guarantee for a future state even to those animals next to man in intelligence. The words of the Saviour in regard to the humble sparrow are too often lost sight of, whilst the expression "of the beasts that perish" too often gives the key-note to the dealings of man with the dumb creation. But whether animals have a future or not, it is certain that they feel pain and suffering as keenly as we do ourselves; it is certain that they appreciate kindness or cruelty; above all, it is certain, because it is consistent with the Christian religion, to believe that cruelty by man to animals will be rewarded with many stripes in that future world to which man, whether for his virtues or for his vices, whether for his weal or woe, is heir immortal.

CHAPTER 67.

ORIGIN OF DISEASES.

A Lecture delivered before the National Veterinary Medical Association at Birmingham, 1885.

1045. Classification of Diseases. 1046. Of Specific Diseases. 1047. Of Germs of Disease. 1048. Of Foreign and Home "Germs of Specific Diseases. 1049. Of Home Germs of Specific Disease. 1049 a. Contagious Disease. 1050. Of Home Specific Diseases. 1051. Of the growth of Germs. 1052. Where do Germs of Disease come from? 1053. Of the Spreading of Specific Discases. 1054. Conclusion-Specific Diseases. 1055. Origin of Non-Specific, otherwise termed Spontaneous Diseases. 1056. Bacteriology.

1045. Classification of Diseases.

Diseases may be broadly divided into two classes-e. $g$.

1st. Specific diseases. - Each Specific disease is marked by certain fixed and unchangeable features, which clearly distinguish it from any other disease, and which can only arise by propagation from the original source. 
The only recognised specific diseases affecting the horse are Anthrax, Influenza, Glanders, Farcy, and Pink Eye. Ophthalmia, sometimes called "specific" in contradistinction to other less serious affections of the eye, is a true specific disease.

2nd. Non-specific diseases, $i$.e. diseases of spontaneous growth, such as constitutional disturbance in the lungs, liver, stomach, and other organs.

\section{Of Specific Diseases.}

So far as we can surmise, for positive knowledge has not been rouchsafed to us, the germs or organisms, from which Specific diseases are developed, are aboriginal creations.

It will probably be admitted that each seed or herb bearing seed after its kind is an aboriginal creation. No wheat can grow except from a wheat seed. No oak can grow unless there is an acorn.

Similarly no Specific disease can be reproduced, unless there is a gerın of that disease present.

No amount of suitable manure mixed with suitable soil will produce an oak, unless the germ of an oak exists in that soil.

Similarly no amount of malaria or "nidus" suitable for the development of a specific disease will produce that disease, unless the germ of the disease is in the nidus.

If the germ of an oak is in suitable soil, it will under favorable climatic influences develop into an oak. If the climatic conditions are unfavorable it will not develop into an oak, even though the soil is suitable.

Similarly, if the germ of a specific disease is present in a suitable malarious nidus, it will under circumstances favorable to its germination develop into that Specific disease. If, on the other hand, circumstances are unsuitable to its development, it will lie dormant.

To take a well-known instance. Let us substitute "seed" for "germ." The Wheat seed found among the mummies of Egypt germinated freely after a lapse of 3000 years, when placed in a suitable soil and under favorable climatic influences; but its vitality had lain dormant until it found a suitable seed bed.

Similarly germs of disease may lie dormant for any number of years; and, so far as we know, or rather can surmise, their vitality is not destroyed by any lapse of years.

\section{Of Germs of Disease.}

What is the germ of each specific disease? We do not know. Wherein lies the scent of flowers? We do not know. In regard to seeds and their produce it is somewhat different. We can see and handle seeds. We cannot handle the germs of disease, but in one or two instances it is possible to see them, and even to watch their growth with the aid of the inicroscope. We only know or at least believe from the reproduction of specific disease that the germs of those diseases must exist.

Seeds may lie dormant and produce no crop for any length of time, 
as in the case of the nummy wheat above mentioned, unless the accessory causes needed to produce germination are present. What are those causes?

In regard to seeds we know the accessories needed to produce germination. Any gardener, any agriculturist can tell you the accessories needed to produce germination in any particular seed.

It is probable, only probable, for we are treading on the unknown, that the germs of specific diseases, like the seeds of the fruits of the earth, exist-some almost everywhere-some only in particular countries - some only in restricted areas. But the germ of each disease needs certain special accessories to cause it to germinate. Germs of disease partake of the nature of fungi, and as a general rule require warmth, moisture, and a close confined atmosphere to ensure germination.

\section{Of Foreign and Home Germs of Specific Diseases.}

Germs of a specific disease, like seeds, can only grow in a climate and soil suitable for their reproduction-at least only to a certain extent. Some English seeds, for instance, will germinate and produce a crop for one or two seasons in a tropical climate. But the climate does not suit them, they dwindle and die out. Similarly some foreign germs of disease niay reproduce themselves for a year or two in this climate, $e . g$. cholera, but they soon die out. Others cannot germinate at all in this climate, e.g. yellow fever.

\section{Of Home Germs of Specific Disease.}

Some people talk of "stamping out" diseases. Doubtless it may be done as regards foreign diseases, both in man and beast, e. $y$. cholera among men, rinderpest among cattle.

But as regards those diseases, the germs of which have their habitat established in this country, e.g. smallpox among men, glanders, farcy, etc., among the animal creation, it is not probable that it can ever be done.

You may keep a garden clean, you may pull up all the weeds; but if the garden is neglected only for a short time, the weeds natural to the soil, i.e. those whose germs or seeds are in the soil, will soon reappear and grow again.

Similarly, germs of disease indigenous to, and thoroughly suited to germinate in this climate, will never die out. They will reproduce themselves, whenever and wherever the accessories needed for their reproduction are present.

\section{9a. Contagious Disease.}

At the present time (1901) some of our great scientists are confident, that by care, cleanliness, and early segregation, Contagious diseases can be eliminated. But the Author doubts any very early arrival of Utopia. 


\section{Of Home Specific Diseases.}

The Author believes that the germs of all home diseases are present almost everywhere, and will develop themselves wherever causes favorable for their development are present. Noxious weeds suited to the climate are present almost everywhere, and will infest any garden or field which is not kept clean by good horticulture or agriculture. So also the germs of home diseases will develop and infest any house or stable which is not kept clean and well ventilated. But noxious weeds, though indigenous to the soil and suitable to the climate, will not prevail where the husbandry is good; nor will the germs of specific diseases develop to any great extent where proper sanitary precautions are adopted.

\section{Of the growth of Germs.}

What are the conditions necessary to produce development in the germs of specific and contagious diseases? Seeds reproduce themselves by germination in the earth. There is visible outgrowth. We do not know, we cannot understand the processes, of growth. But we can see and easily recognise the result.

In the few cases, in which germs of disease can be actually seen and their growth watched under the microscope, it has been found that they reproduce themselves in two ways-by division, the rod lengthening and dividing into two-and endogenously by the formation of spores within the cells, their development and growth being attended by various kinds of fermentation.

Yeast is probably the best known germ, the reproduction of which is attended with fermentation. It will therefore serve well for the purpose of illustration. We know the conditions necessary to cause the fermentation and development of yeast.

1st. There must be a nidus or soil suitable for its development, such as dough.

2 nd. There must be warmth.

3rd. There must be moisture.

4th. There must be a confined atmosphere.

If any one of these conditions is wanting, the yeast will not germinate, or will do so imperfectly. It will be more or less inactive-the dough will not be affected by it - the bread will be as "heavy as lead."

Now the process of the growth or development of the germs of a specific disease is much the same. Before the germs of disease will develop in a house or stable, there nust be a suitable nidus or seed bed. There must also be a foul and confined atmosphere. The germs of disease are generally of the nature of fungi. They thrive in a foul atmosphere. They require warmth. They require a confined as well as a foul atmosphere. Draught hinders their germination. A plentiful supply of fresh air will after a time render their reproductive powers inert.

\section{Where do Germs of Disease come from?}

More or lesk it is probable that the germs of disease are present almost everywhere in a dormant, i.c. undeveloped state. The foul confined 
atmosphere of an unventilated drain is very suitable to their growth. If the air of an unventilated drain is admitted into a house or stable the germs of disease may come with it. Water, into which sewage has percolated, is also very favorable to the development and growth of germs of disease. If water, tainted by sewage, is drunk by man or beast, the germs of disease will probably very soon make their presence felt.

\section{Of the Spreading of Specific Diseases.}

The question is often asked, why, if specific disease be due to local causes, are not all the men or all the animals subject to those causes affected? A similar question with equal reason might be asked why certain seeds germinate readily in certain soils under certain climatic influences; and why, in similar soils under different climatic influences they do not germinate. A similar question might also be asked of the advocates of the theory of the propagation of disease by infection and contagion.

The answer to these questions is the same. Different systems are not equally liable to be affected. Nay more, the state of the system may vary from day to day, even from hour to hour. A man or animal in good health, and with a good constitution, may long resist malarial influence. A delicate ailing susceptible system may soon be affected. Again, a man may be strong and hearty in the morning. His system may be able to resist noxious influences. He may return home hungry and fatigued. He may become susceptible. Again, he may resist malaria for days or weeks. His system may become lowered from a variety of causes, rendering him susceptible to malarious influence. A seed bed may be dry and hard. Seeds will not germinate. A shower of rain may come, followed by a warm sun, and soon the seeds will germinate.

A simple illustration may perhaps help to explain what we mean. Take half a dozen sheets of paper, - one of the best glazed, another of inferior quality, another rough, another of whited brown paper. Hang them up in a draught in a London fog for a few hours. Note the amount of "blacks" which have adhered to each. To the best glazed few, if any, "blacks" will be found adhering, and these will be easily blown off. More blacks will be found adhering to the inferior paper; still more to the rough paper, and it will not be easy to dislodge them; whilst to the poor whited brown paper almost every black will be adhering.

Now let us reduce the state of "health." Suppose the day changes from dry to damp. Examine the papers. Even the best glazed paper will have become somewhat moist, and many blacks will be adhering to it and will not be easily blown off ; and so in increasing proportion, until we come to the whited brown paper, which has absorbed all the moisture, and in which every black will be sticking fast, and cannot be dislodged.

All however have suffered from lowering of tone. And so it is in regard to men and animals subjected to noxious influences.

The germs or particles may find a suitable nidus in one system, which they do not find in another; and the conditions of the system in which 
they find a nidus may, and do, vary from day to day and from hour to hour.

\section{Conclusion-Specific Diseases.}

From the above it will be seen that though specific diseases are not of spontaneous origin, yet they prevail mainly from causes which may fairly be termed preventable, $i$. e. from neglect of good sanitary precautions.

Specific diseases are generally regarded as infectious or contagious.

But the prevalence and the virulence of these affections depend in a great measure upon the sanitary arrangements of the house or stable. Bad ventilation, bad drainage, improper and indifferent food and water, want of cleanliness, etc., all tend to lower the system of man or animal, and render it susceptible to the invasion and development of disease germs ; while on the other hand, by the observance of due sanitary and dietetic precautions, the tone, vigour, and general health of the body are maintained, and the system is thus placed in the best possible condition for resisting the influence of the contagium. No doubt specific diseases may be and are propagated by infection or contagion. But such is more rarely the case than is generally supposed. Similar causes produce similar effects, and are liable to produce disease among all the men or animals subjected to their influence: It is but seldom that such diseases are "caught," to use a conventional expression, from one man or animal to another, if the sanitary arrangements in the house or stable are good.

\section{Origin of Non-Specific, otherwise termed Spontaneous Diseases.}

Non-specific, otherwise termed spontaneous diseases, are those which cannot be transferred from one living subject to another by inoculation or infection, such as coughs, colds, fevers, affections of the lungs, liver, kidneys, and stomach. There may be, and often is, great similarity in cases of spontancous growth, but there is no absolute identity as in specific diseases.

It is generally admitted that such diseases arise from causes peculiar to the individual affected. They are generally due to bad stable management, such as want of ventilation, bad food, over-feeding, want of exercise, and neglect in grooming, especially in allowing a horse, when wet or heated, to stand in the stable without being cleaned and dried. All such causes produce ill-health, and so-called spontaneous diseases.

\section{CHAPTER 67 A.}

\section{.BACTERIOLOGY.}

\section{Science and the Microbe.}

Science, aided by the microscope, has within recent years opened to us the knowledge of a numerous class of very minute creatures called Germs, Microbes, or Bacteria, which belong to the vegetable kingdom, and are at the very bottom of the scale among Living things. For all practical purposes, these three may be classed under the same head. 
The great majority may be said to lead harmless and even useful existence, living and multiplying in dead organic matter at the earth's surface.

A few, however, habitually or occasionally live as parasites in the blood or tissues of living animals, and cause disease.

With regard to the disease-producing microbes, it is a fact, that some of them, such as those of Glanders and Tuberculosis, are always at work; but others, such as the tetanus bacillus, are only occasionally, and in a measure accidentally, the cause of disease.

In this connection much depends on the circumstances in which men and horses are kept, as the opportunities for infection vary with circumstances.

It is also probable that some classes of Bacteria may remain dormant for untold ages, and may (we cannot tell How or Why) be called into active organisation, and generate some new type or types of disease, or renovate types of disease which we hoped had died.

\section{CHAPTER 68.}

\section{POISON.}

\section{Poisons and their Antidotes.}

In the treatment of Horses in case of Poisoning, it must be remembered that the Horse is unable to vomit, and we are therefore denied the valuable aid of emetics.

\section{Arsenic Symptoms, Antidotes, and Treatment.}

Symptoms.-Thirst, irregular pulse, colicky pains, purging, difficulty in breathing, and cold sweats.

Antidotes and Treatment.-A drench of $5 \mathrm{oz}$. Sulphate of Magnesia in a quart of Milk; followed in a quarter of an hour by a pint of water in which a table-spoonful of Rust (hydrated peroxide of iron) has been well shaken up. This is most easily obtained by taking the water from the trough for cooling shoes by the side of the forge fires. Mucilaginous drinks, such as gum and water mixed with white of eggs, or Linseed tea may be frequently given. If there is much prostration a dose of Whiskey $4 \mathrm{oz}$. may be added thereto.

\section{Arsenic as a Tonic.}

Arsenic, as a Medicinal Agent is a good tonic, when required by a low state of system, under Professional advice. But its use by grooms should be absolutely prohibited. The symptoms of excessive or continued use as a tonic are the same as those noted above, but of course in a very modified degree.

Treatment.-Discontinue its use. 


\section{Antimony. Antidotes and Treatment.}

Symptoms.-Thirst, dribbling of saliva from the mouth, sometimes peeling off of the mucous membrane lining the mouth, cramps and tetanic symptoms, followed by loss of muscular power, cold legs, weak pulse and convulsions.

Antidotes.-A drench of $2 \mathrm{dr}$. of Oak Galls, finely powdered, mixed with the white of eggs in a quart of milk. Hot wet cloths to abdomen, but care must be taken to prevent the water dripping down the limbs or other exposed parts for fear of causing a chill. Brisk, though not too violent friction to limbs from shoulder and hips downwards, especially where loss of muscular control is shown, is beneficial. Occasional drinks of mucilage (gum and water) will sheathe the corroded membranes. In the absence of oak galls, strong tea or coffee should be given in quart doses, by drench, if the horse will not drink it otherwise. If much exhaustion is present with symptoms of sinking, give $4 \mathrm{oz}$. of Whiskey in a pint of milk.

\section{Lead Poisoning. Antidotes and Treatment.}

Lead poisoning is always accidental. It is generally the result of drinking soft water from a cistern lined with Lead, or which is supplied by Leaden pipes, or from drinking water from streams polluted by certain factories.

Symptoms.-Colic, constipation, cramps, pulse slow and feeble, emaciation, foetor of breath, excreta highly coloured. If of long standing, a blue line will be observed around the gums.

Antidotes.-Remove the cause. Give 5 oz. Sulphate of Magnesia, well powdered, in a quart of milk with 3 or 4 raw eggs added. In a quarter of an hour give one and a half drachms of dilute Sulphuric Acid in a quart of water. Fomen't the abdomen with very hot cloths, taking care to avoid chills. If there is much pain Morphine may be subcutaneously injected, but this must be done by the veterinary surgeon.

For chronic cases (having of course removed the cause) give repeated doses of Sulphuric Acid half a drachm with Sulphate of Magnesia one ounce in a quart of water.

. CHAPTER 69.

EMERGENT CASES.

1062. In places remote from Professional Assistance it may be useful to keep on hand the medicines in ordinary use, and in the quantities set against each. 


\section{In bottles with glass stoppers.}

Aconite, Fleming's tincture of $3 \mathrm{oz}$. Liniment of Ammonia, ComArnica . . . $3 \mathrm{oz}$. *Ammonia, aromatic spirits of $6 \mathrm{oz}$. Aloes, best Barbadoes . . 2 oz. *Camphor . . . . $3 \mathrm{uz}$. pound Magnesia, sulphate of . $8 \mathrm{oz}$ Mucilige (gum and water) . $8 \mathrm{oz}$. *Nitıic Ether . . . 6 oz. Opium, tincture of . $\quad .6 \mathrm{oz}$. Carbol c Acid for external use $8 \mathrm{oz}$. * Collodion, extremely volatile $2 \mathrm{oz}$. Honey or Treacle . $5 \mathrm{oz}$. Physic balls, each $4 \mathrm{dr}$. aloes and $1 \frac{1}{2} \mathrm{dr}$. ginger . . 6 Friar's Balsam . a small bottle. Gentian $.8 \mathrm{oz}$. Potass, chlorate of . . $4 \mathrm{oz}$. Ginger, powdered $\quad .8 \mathrm{oz}$. Lins:ed Oil . . . . 1 qt. , nitrate of . . $1 \mathrm{lb}$. Sulphur, best quality . . 3 oz. Turpentine Oil, very best $\cdot \frac{1}{2} \mathrm{pt}$.

\section{In tin boxes.}

Ginger Powders, 2 dr. each, No. . . . . 12 Linseed Meal . . . $1 \mathrm{lb}$.
Lint, pieces of, 8 in. $\times 6$, No. 12 Medicated Wood-wool . . $4 \mathrm{oz}$. Fine Tow . . . $\quad 1 \mathrm{lb}$.

In addition to the above, two colic draughts to be kept ready made up for emergencies at night, each consisting of Linseed Oil $16 \mathrm{oz}$. (about a pint), Oil of Turpentine $2 \mathrm{oz}$, Tincture of Opium $1 \frac{1}{2} \mathrm{oz}$. This prescription is recommended for stock not because it is better than others, but because it will keep well. The stock should be renewed as often as used. To be well shaken up before use. This prescription will answer well for both Spasmodic and Flatulent Colic. But when there is time and opportunity to make up a draught, the first prescription recommended in par. 540 is to be preferred.

List of appliances necessary for unaking up prescriptions, where no chemist's shop is near at hand.

1 minim glass, graduated.

1 4-oz. glass, graduated.

1 pint measure, zinc.

1 set of scales, $1 \mathrm{gr}$. to $4 \mathrm{oz}$.
1 2-oz. syringe.

1 4-oz. syringe.

1 metal fuunel.

1 metal enema funuel.

To prevent mistakes, the following are the symbols used by chemists: Weight.

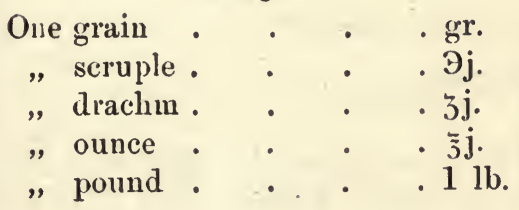

Measures of Capacity.

One minim .

" fluid drachm.

" $"$ ounce . . . H. $\mathrm{z} j$.

" pint . . . Oj.

" quart $\quad \cdot \quad \cdot \quad \cdot \quad \cdot \quad \cdot$ Q

, gallon . . . $\mathrm{Cj}$. 
But it must always be borne in mind that almost all Medicines deteriorate by keeping, and the more volatile soon lose their power altogether. Those which are marked * should be renewed annually, and especial care should be taken at all times to keep them carefully stoppered and excluded from light. All medicines, however, should be kept in a closed box, and the stoppers at once replaced after use.

Again, those who have no experience in making up prescriptions are very liable to make mistakes, possibly fatal ones. Therefore it is always advisable, in the absence of a professional man, to send the prescription to a chemist to make up.

N.B.-In the absence of a V.S., great care should be taken to give medicine time to act before repeating the dose or giving other drugs. Though such mistakes may not be fatal, yet they often impede recovery. The most common mistake, and one liable to end fatally, is to administer a second aloetic ball when the previous one has been broken in delivery, or delay occurs in purgation. Their united action may not improbably cause superpurgation, which is very difficult to check in the horse.

The Author does not recommend the owner to lean too much on himself when he can get professional assistance in time. But in out-of-theway places, and especially in the Colonies, where this work has some circulation, advice often cannot be got, and under such circumstances this Addendum to the previous Edition may be found useful.

\section{2a. Useful Stable Appliances.}

In addition to the ordinary.stable utensils, the undermentioned appliances, though not indispensable, will be found useful.

(1) Leather knee bucket, 36 inches deep by 12 diameter; for fomentations. (2) Eight feet india-rubber half-inch hose, with stopcock and female screw to fit stable yard tap. (3) Leather muzzle. (4) Leather poultice boot. (5) Neck cradle. (6) Side lines with plaited loop. (7) Pillar reins for each horse. (8) Set of three short tooth rasps (Arnold, West Smithfield). (9) Leather blocks to fit heels with strap and buckle, to prevent kicking in stable. (10) Hock caps to prevent capped hocks. (11) "Pudding" boots to prevent capped elbow. Metal enema funnel.

\section{CHAPTER 70.}

GENERAL SURVEY OF A HORSE.

\section{General Survey.}

It is of great importance that this survey should be made in a systematic manner, otherwise defects are easily missed. The following routine is suggested: 
1. Take note how the horse stands in the stable. Whether he stands fairly on all four legs, or "points," or favours one.

2. Whether he Cribs or Wind-sucks, par. 195.

3 . Note carefully how he turns in the stable. Stiffness, especially in the hock, is more noticeable in the act of turning short than at any other time, par. 606.

4. Bring him near the door, about a foot or two inside the stable, and examine his eyes, pars. $839-863$.

5. Bring him out, and let the groom at once trot him in hand with a very slack rein, at the rate of about five and a half miles an hour, about twenty-five yards in a straight line away from you. Take care that the groom does not hold short or catch at his head. You can then best see whether he goes Level, i.e. sound, par. 651 .

6. Then let the horse stand square and firm on his legs. Stand yourself about eight feet directly in front of the horse. Carefully look at him from that distance, beginning from between the ears, and let your glance come gradually down to the fore-feet, noting any defects en route and especially observing whether the feet are pairs.

7. Next, keeping the same distance from the horse, go to the near side of the neck, and observe whether there is any mark of his having been bled.

8. Then move to opposite the chest, and you will see any defect, such as an enlarged knee or any enlargements on either side of his front.

9. Move along the near side (keeping the same distance, eight feet), and note the conformation of the Ribs and Loins, pars. 912-914. Also any double action of the Flanks, indicative of Broken Wind, par. 465. In case of doubt a guarantee should be exacted.

10. Keeping the same distance off, stand behind the horse. You will at once see if there is any defect about the quarters, par. 915. And especially if the Hips are of equal height, i.e. not one "let down," that is no fracture of the point of the hip-bone, par. 588.

11. Follow the same course on the off side, finishing off at the front of the horse. This General Survey need not take more than three minutes.

12. This general survey finished, then begin again at the Head.

a. Standing on the near side, look into the Mouth for Age. Chap. 68.

$b$. Open the mouth wide, and see that the Tongue is perfect, and also the Molar Teeth, par. $877 a$.

c. Examine the near Nostril for any suspicious discharge, par. 414, Common Cold, and par. 525, Glanders; also par. 887.

d. Look in his Face. A good deal as regards Temper is to be gleaned from the Face.

$e$. Feel the Poll and raise the Fore-lock, especially of a harness horse, par. 710 .

$f$. Pass the hand along the channel of the Jaw to the throttle, par. 892 .

$g$. Cough the horse.

13. Still standing on the near side, pass your right hand down the front of the near fore Limb, particularly feeling the front of the Knee, 
roughing up the hair thereon to see if there is any scar or "broken knee." In case of doubt a wet sponge passed over the knee may reveal the unevenness of a cicatrix.

14. Pass your hand down the front of the Shank bone, grasping it lightly, and pass it on to the fetlock and coronet bone, when any enlargement, splint, Chap. 33, or ringbone, par. 628, or side-bones, otherwise termed ossified cartilages, par. 633 , ought to be felt, $i . e$. detected.

15. Then turn round, and with the left hand examine the back part of the same near fore-leg for sprains of Tendons and Ligaments, Chap. 44 ; mark of Speedy cut, pars. 618 and 1000 ; Brushing, par. 999 ; Windgalls, par. 644 , etc. 65 .

16. Pick up the near foot, and see that it is all right, Chaps. 62 and

17. Ascertain whether the horse has been Neurotomised, par. 1026. The operation is performed in the hollow just above the fetlock, and at the side of the pastern. If so, a scar will be left and detected, if the hair is roughed up.

18. Bend back the knee to see if the point of the fetlock will touch the forearm, as it ought to do if the knee is all right.

19. Give the foot to the groom to hold, and stoop down and see if the abdomen and groin are clear of any swelling or fistula, and in case of a horse examine the sheath.

20. Go through the same process in the hind as you have done in the fore-leg. Commence by standing, as before, eight feet from the horse at a right angle to the rear line of the hock. In this position you will best detect curb, if any (par. 702), also thoroughpins (par. 641). Then carefully feel for spavin, Chapter 38. N.B.-The best position from which to detect, i.e. see any enlargement on the seat of spavin is to stand in front of the horse and look between his fore-legs; but it must also be felt and ascertained to be bone. There may be enlargement such as a thickening of the integuments, resulting from a blow or a distended vein which may not be bone. The worst class, however, of spavins are those between the bones, which can neither be seen nor felt; and their existence can only be surmised by the nature of the stiffness in the action of the hock which they produce, par. 604 .

Thoroughpins are allso easily seen on the side of the hock, par. 641.

21. Pass your hand down the front of the shank bone, lightly grasping it, when any defects, enlargements, ringbone, etc., will be at once detected.

22. Pass your hand down the rear part of the near hind leg to the foot and note any enlargements, such as windgalls and callous thickening from a blow.

23. Lift up the tail and see if that region is perfect, especially if a mare.

24. Then go to the horse's head on the off side and proceed as directed for the near side, again finishing at the tail.

25. This manual survey need take very little time, not more than ten minutes. 
26. The above course having been completed, then try the horse's wind, and see if he is a grunter or thick in the wind, or whistler, or roarer, par. 454-469. For these give him a thorough good bustling, at a fast pace if a horse in work, or lounge him if unbroken or a stallion.

27. Next have the fore-shoes taken off and carefully examine the feet for corns, false quarter, sandcrack, seedy thrush, pumice sole, bad frogs, etc., Chapter 65, Diseases of the Foot, and Chapter 62, on Conformation of the Foot; and then have them replaced.

28. After this (the horse having been galloped), allow time enough for him to cool down, and then give him a final trot in the manner described in No. 5, and note whether he moves freely and level.

29. Lastly let the horse be pressed backward, "backed" to see whether he can do that well ; and then let him be turned short and quickly round both ways to see that he is not chinked in the back or paralysed, par. 569.

1064. If with these directions, "Where to look for defects," you miss seeing anything wrong, it will not be because you did not look for it, but because you failed to see or feel it when you were looking or feeling for it.

\section{CHAPTER 71 .}

\section{NOTES ON DENIISTRY.}

By Lieut.-Colonel Matthews, Royal Horse Guards.

1065. Development of the Teeth-Birth to five years old.

The science of equine dentistry has been of late prominently brought before the minds of owners of thoroughbred stock by the mishaps of Friar's Balsam and Orme on the eve of valuable engagements.

Throughout the period of racing life, i. e. from two to five years old, dentition is actively progressing with its attendant irritability of temper on account of the often acutely painful condition of the membrane of the mouth accompanying the development of the teeth.

In the human subject, the by no means distant prototype of the horse, the child is thought fortunate if he pulls through this period, though no attempt is made to force muscular development. It is always a period attended with querulousness and a strong predisposition to febrile disease and derangement of the bowels, the follicular structure of which is undergoing similar and extremely sympathetic development.

During the earlier years of the horse, soft food, such as grass, is more natural and less irritating to the membrane and gums, which are being 
pierced by the upcoming teeth, and the teeth themselves are not at this period fully adapted to the mastication of hard food.

But for the purpose of training it is necessary to force on the muscular development of the young race-horse. Hence he is, and practically must be, kept mainly on corn. The tender mouth and teeth are called upon to prepare this hard food for digestion, and constant irritation of the gums and teeth is the result, and this irritation and pressure is of course aggravated by the snaffle; hence the young animal often becomes fractious in his gallops.

Reports of horses in training frequently note that such and such a colt has taken to pulling, or is no longer a boy's horse, or has displayed unusual temper at the post.

'These signs should be an unerring guide to what is occurring in the mouth.

No branch of veterinary surgery demands closer attention than this, and trainers, experts as they undoubtedly are in the management and care of growing horses under the critical conditions of early life, will derive the greatest assistance by frequent consultations with their veterinary advisers.

At the present day the great majority of dental specialists are unqualified practitioners, unacquainted with the usual phenomena attendant on disease affecting parts other than the teeth. They are no doubt extremely skilful in manipulation of the teeth, but too often treat the symptoms they see, and not the causes which produce those symptoms. As a matter of fact dental disorders are usually concurrent with affections of the mucous linings and intestines, and therefore the assistance of a Veterinary surgeon is necessary.

Irregularities in early dentition, short of deformity and other than those caused by clumsy dentistry, are simple and generally easily removed by skilled aid with slight incisions and gentle extraction. Nature if given a fair chance, and unimpeded in the horse by syphilis or other hereditary disease, produces a regular set of teeth. See Dentition for the earlier ages, par. 868, also Plates 39, 40, and 41.

\section{Of the Molars or Grinders.}

As age progresses, after the completion of dentition no less than during the development of the teeth, the attendance of the veterinary surgeon is necessitated by irregularities produced in the teeth by wear or disease, which frequently seriously hinder mastication and produce indigestion and loss of condition. Frequent instances are on record of horses sold as useless, the result of irregular or diseased teeth, completely recovering their condition and original value on mechanical removal of the cause by surgical operation. It should never be forgotten that where dental irregularity interferes with mastication the horse may be ravenously hungry, loses condition, and therefore after relief.has been given by dentistry, great care must be taken to prevent his overgorging himself with food, which may result in rupture of the stomach. 


\section{How to examine Molars.}

1st. Make the "acquaintance" of the horse, i.e. handle and convince him that no harm is intended.

2nd. Loosen or remove the head collar. The groom should hold the horse.

3rd. Open the mouth, and gently, but firmly, take hold of the free portion of the tongue, turning it upwards but always keeping it inside the mouth, as if about to give a ball.

Then pass the free hand along the surface of the teeth, when any sharpness of their edges, or any irregularity in the line of wear, or any sign of caries will be at once perceptible. Especial care should be taken to examine the posterior molars on either side, in which in many cases the mischief lies.

In all cases of examination of the molars each tooth should be examined individually.

\section{Signs of Disorder in the Molars.}

1st. The horse is observed to feed slowly, mouthing his food, and probably holding his head on one side with streams of saliva trickling from his mouth. This is popularly known as slobbering. In some cases fairly masticated pellets of food are ejected from the mouth. This is known as quidding.

In advanced cases there is a very foetid smell. Congestion of the blood-vessels of the mucous membrane of the mouth, commonly known as lampas, is also present. The fourth, fifth, and sixth molars are developed up between three and four years old, and therefore between these periods there is a special liability to an accumulation of partially chewed food between them, which rapidly becomes foitid.

\section{Causes of Quidding.}

The ejection of partially masticated food arises from several causes, i.e. from impaction of food between the molars, from defective or deformed teeth, from sore throat or abscesses in the mouth. It may also arise from causes apart from disease of the teeth, e.g. barbed seed in hay or grass will produce a painful disease of the membrane and, as a result, quidding.

\section{Deformities.}

It would be idle to attempt a description of the various freaks of nature, which must be dealt with as they arise. Some of them are capable of being relieved by surgical aid or by extraction. Occasionally they render the animal useless on account of the loss of condition, which they entail by mechanical interference with mastication. 


\section{Size of Molars.}

Plate 46, fig: 2, delineates the third molar taken from upper jaw of a seven-year-old horse. Drawn exactly the natural size, it shows at a glance the difficulty presented to the removal of a mature molar, surrounded as it is by thin plates of easily frangible bone which compose its socket.

With age the fang becomes considerably shortened, and extraction an easier matter. So with temporary or deciduous teeth, which are easily removed as Nature absorbs their fangs before the growth of the permanent teeth.

\section{Irregularities in Growth.}

These are many and various, from the Parrot Mouth, in which the upper incisors overlap like the beak of the parrot; or the contrary, where the lower jaw projects, and the horse is said to be underhung. Or in other cases from excessive development of one molar from disease of its opposing tooth. Plate 46, fig. 1, A.

Not unfrequently one or more temporary teeth become permanent and overcrowd the jaw.

An interesting case occurred in my' own experience with a four-yearold, which failed to develop the lower tusks, and extreme poverty of condition resulted till nearly five and a half years old, when one tusk appeared very close to the centre of the jaw, and with it a rapid improvement in condition, which he has since maintained; but there is no sign of the missing tusk.

From irregularities of wear, probably produced by disease of one or other of the teeth, the end molars, both in front and rear, are peculiarly apt to overlap their opposing teeth, Fig. 1, B. Extra molars sometimes appear, and do but little harm if opposed by corresponding teeth in the other jaw.

Premature removal of the milk teeth with the intention of hurrying on the growth of the permanent teeth, sometimes results in non-appearance of the latter. Thus perhaps there may be four incisors only in the lower jaw, while there are six in the upper jaw.

The treatment of these irregularities is the work of a man intimately acquainted with the anatomy of the head. Surgical relief is alone of any use.

Projecting molars sometimes occur from want of uniformity in width or length of jaw, and in other cases from disease in crown of opposing tooth, which ceases to present the customary attrition from wear. Where far advanced, the hypertrophied tooth may attain such a size as to partially lock the jaw when mastication is attempted. See Fig. 1, A.

Or the projection arising from first-named cause takes place either at first or last grinder as shown at $\mathbf{B}$.

Surgical aid in skilled hands is the only remedy. 


\section{Caries of the Teeth.}

Caries or decay consists in the destruction by progressive softening and wearing away of the hard tissues of the tooth, originating always from without and usually affording a cavity for the lodgment of saliva or food. It usually occurs in the molars and generally at their crowns.

Caries is due to loss of vitality in the structure known as Dentine, which renders it unable to resist the chemical action of the saliva. Caries may also arise from injuries or from masticating pebbles in the food; but more frequently from constitutional causes.

\section{Sharp Edges of Molars.}

In aged horses, especially where the inferior jaw-bone is proportionally narrower than the upper, the outer edges of molar teeth become extremely sharp, and by their needle-like points so seriously lacerate the cheeks as to hinder mastication. Thousands of these cases exist all unsuspected by owners or attendants, and it is in the periodical reduction of these growths that the equine dentist is especially needed. Indeed, it is necessary in all unaccountable cases of loss of condition to examine the molar teeth.

\section{Dental Cough.}

The sound of Dental Cough is of a sonorous hacking character. It arises from sympathetic inflammation of the throat, and is most frequent in third and fourth year, i.e. during the growth of the permanent teeth. It disappears with maturity.

\section{Dental Fever.}

During the active stage of dentition, some horses suffer from constitutional disturbance accompanied by loss of appetite, debility, unthriftiness, a tendency to diarrhœa, quickened pulse; but without cough or other symptoms indicating that the fever is due to disease of any internal organs. On examining the mouth, the gums are heightened in colour, swollen and tender, with increase of saliva. Horses from three to four years of age are more subject to this form of dental irritation than those of a more tender age; and it is perhaps for this reason that horses between two and three years old often stand work better than those between three and four.

The treatment consists in giving relief to the immediate local cause, and complete rest and suitable diet, till recovery takes place. Surgical aid may be required.

It will be readily seen from the foregoing enumeration of dental ills, especially affecting the molars, what an important part dentition plays in the physical capacity of the horse during its development, and the great relief which the skilful operator is enabled to afford. It also clearly shows how carefully the molars should be examined for soundness. 
1071. Hernia. (Omitted in its proper place.)

Hernia (ruptiure) is the protruding of any organ from its natural cavity. Such ruptures most often occur (1) in the wall of the abdomen; and (2) between the hind legs, viz. ventral or scrotal.

The former generally results from accidental violence, such as the prod of a cow's horn. The latter is congenital.

As regards the first a truss would be the obvious remedy, but is not available in horses. A horse, however, with abdominal rupture may do slow steady work for years. But strangulation of the protruded gut is liable to occur at any moment from any sudden or severe effort, and the result will probably be fatal.

As regards the second the treatment is essentially surgical, and can only be attempted by a veterinary surgeon. 


\section{ADDENDA.}

The Author appends a more complete table of the value of Oats from 34. lbs. up to $44 \mathrm{lbs}$.

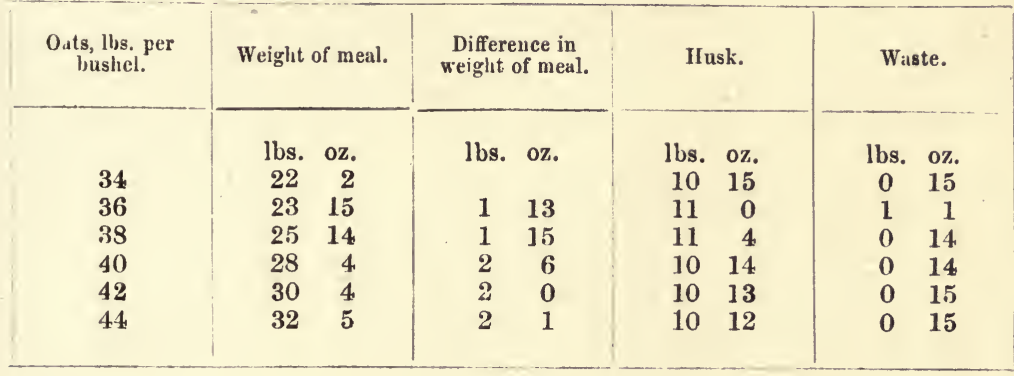

(Omitted.)

Erysipelas is a febrile, inflammatory, superficial disease, which, from its starting-point, spreads very rapidly.

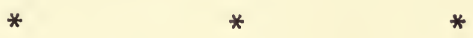

Par. 903. For "Fetlock," read Pastern et infra.

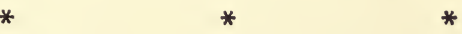

Of gauging the age of Horses at and after 9 years old.

A friend of mine has asked me to bring forward his crotchet for judging the age of horses of 9 years old and upwards.

He pleads as follows.

"The public generally are afraid to buy a horse over 8 years old,i.e. after the marks are out; whilst many horses are almost in their prime at 9 , and often do good service for many years longer."

"Horsemen, of course, can gauge the age by the changes which take place in the form of the teeth after the marks are worn out."

My friend wishes to introduce a system which, though not so accurate as the changes in the form of the teeth, yet may enable an outsider to get a pretty good knowledge of age after the marks are worn out. 
His system, though not really new, is very simple, and for outsiders very useful.

"Sometimes at 9, always at 10 years old, a dark yellow streak begins to appear at the upper end of the groove in the centre of the upper corner tooth."

This streak at first is not more than $\frac{1}{8}$ inch in breadth or length, but increases in length each year about $\frac{1}{8}$, until it reaches the lower end of the tooth about the age of 20 . 


\section{POSTSCRIPT.}

Mr Wilfrid Scawen Blunt has kindly allowed me to print his very interesting letter to me, regarding his Arab breeding in the country.

Newbuildings Place,

HoRSHAM,

Sussix ;

April 11th, 1901.

Dear General Fitzwygram,

Since the first edition of your book appeared, I have somewhat altered my ideas on Arab breeding in England. I have found by experience that nothing of value is to be gained by attempting to increase the height of pure bred Arabs beyond what seems to be its natural point, 14 hands 2 inches.

There is no difficulty, by selection and high feeding, in so increasing it, and both on the Continent and in America, Arabs are bred in this way up to 15.2 and even 15.3 ; but the result is unsatisfactory. The horse loses his compactness, and becomes leggy and less enduring, and his type little by little disappears. I have consequently for the last twelve or fifteen years made it a rule to weed out of my stud everything over $14 \cdot 3$, and to content myself with a selection for strength and beauty within that limit of height. I weed out also everything under $14 \cdot 1$, and have now got my breeding stock to a nearly uniform height of $14: 2$, which I find the best. In this way I have been able to preserve the type unaltered, and with it the best qualities of the breed. The Arab horse at his best is so good a horse that he does not need improving.

With regard to cross breeding, I have but a limited experience. The late Lord Bradford crossed Arab mares he got from me with first-class thoroughbred "stallions, and with fair racing results, even in the first generation; and I still believe that the reintroduction of the best Arab blood would improve the thoroughbred stock of the country for turf purposes. But I have not been rich enough to try the experiment myself. My only cross breeding has been with Suffolk mares put to Arab stallions. In this cross I entirely believe, as producing a most serviceable animal for carriage work. Indeed, I am convinced that, in breeding from cart mares of any kind, a really good Arab stallion of 14.2 can be trusted to get a better average of foals than a big thoroughbred stallion of equal apparent quality. His produce with cart mares will run up to $15 \cdot 2$ and $15 \cdot 3$.

It is as sires for half-bred stock that I consider the Arab of most practical use in this country.

With regard to your last question, I have no recent statistics as to the racing speed of Arabs, and, indeed, I have ceased to interest myself in this branch of the Arab question.

Yours very truly,

Wilfred Blunt. 
DIRECTIONS FOR SHOEING HORSES WI'TH ORDINARY FEE'I.

Reprinted from a Pamphlet, 1896. For use in the forge.

1.-Before removing the Old Shoe, each Clench should be carefully and fully raised. Note 1.

2.-The Crust or Wall is not to be rasped. Note 2 .

3.-The Sole is not to be pared out. Note 3.

4. - The Frog, if healthy, is not to be pared, or even trimmed. Note 4.

5. - The Bars are not to be cut away. Note 5.

6.-The seat of Corn is not to be pared out. Note 6 .

7.-The Crust or wall is to be lowered as much as may represent what would be worn away if the foot were not shod. Remember that there is a greater growth of horn at the toe than in other parts of the foot. Therefore more will require to be taken off at the toe than elsewhere. Therefore shorten the toe. Especial care must also be taken that the feet are made the same length.

8.-When the Crust has been lowered all round, then make the ground surface quite level all round with the Rasp.

9.-To ascertain whether the surface is level, the Shoe may be applied sufficiently warm to mark any inequalities, but not hotter than is necessary for this purpose.

10.-When the surface has been made level, take off the sharp Edge of the Crust with the Rasp,-in other words, blunt it. This is necessary to prevent its splitting.

11.-All Shoes should be Flat to the sole, not seated-out.

For Riding and Light Draught horses make a shoe to fit the foot, neither longer nor smaller, nor larger than the crust, except at the heels, where it may be not more than one-eighth inch wider than the crust. Note 11.

For Heavy Draught horses in towns where the streets are paved, it is found necessary to make the shoes wider and longer at the heels than the crust. Unless this assistance is given, the horse cannot get a firm hold, and therefore he will be liable to slip and roll, and soon become lame.

For Heavy Draught horses, employed on farms, etc., it is necessary 
to shoe at the heels according to the nature of the ground and the work to be done. On deep ploughed lands it is found advantageous to make the shoes longer and wider at the heels, in order to prevent the feet from sinking deep into the ground.

12.- "Dumping." It is the common practice of incompetent and careless Shoers to put on a shoe smaller than the crust, and then in order to make an apparent fit, to rasp the outside of the crust down to the shoe. This serious fault is commonly called "Dumping," and is most injurious. It is wrong to rasp the outside of the crust, as this hurtful practice produces two evils. 1st.-The outer and strongest horn-fibres are destroyed; and 2nd-The gluey superficial layer which covers the outside of the crust is destroyed, and then the natural moisture of the horn, which is essential to toughness, escapes, and the horn itself becomes brittle and unsound. This and "Dumping" are the very greatest causes of brittle and broken feet.

13. - The width of the shoe should vary according to the breed of the horse. For light horses, $\frac{3}{4}$ inch is sufficient, if the shoe really fits and the crust is sound. One inch is the width in common use. For Heavy horses the width must be increased to $1 \frac{1}{2}$ or 2 inches. Flat feet require wider shoes, i.e. more cover than natural and upright feet.

14.-Weight of Shoes. For light horses, 14 or $16 \mathrm{oz}$. will, in general, be sufficient. But some horses wear their shoes more than others; and, again, the material used on the roads makes a difference, often a great difference, and much will also depend on the amount of work. For heavy horses, $1 \frac{3}{4} \mathrm{lbs}$. to $2 \frac{1}{2} \mathrm{lbs}$., or even more is common.

15.-Duration of Shoes. One month is a fair average time, but the amount of work, and material used on the roads, affect the wear.

16. - Removal of Shoes. Whether Shoes are worn out or not worn out, they should be removed at the end of a month and refitted. The growth of the horn renders this necessary. See Note 6 (par. 5).

17.-Shoes. "Countersunk" shoes are better than fullered, as they are stronger, and the nails get a better hold.

18.-Nails. Countersunk nails should be used. They get a better hold than those rose-headed nails. Nail heads should not project below the shoe, as friction with the ground will soon wear off the heads, and then the nails lose their holding power.

19.-Nailing. For nag and carriage horses, with fairly good feet, the nails should be brought out about one inch on the crust. If the feet are all flat, they should be brought out somewhat lower. For cart horses, whose feet are larger and generally flatter than in better bred horses, 1 inch would be a fair average height. But regard must be had to the state of the feet. Nails get a better hold when high, but as serious evils result from too high nailing, it is safer to err on the side of too low rather than too high.

20.-Five or six nails are sufficient for light horses. Seven or eight, and sometimes more, are used for heavy horses.

21. - Position of Nails. The front nail on each side should be in the anterior portion of the quarter, and the remaining nails should 
evenly divide the distance to the heels. Nails at the toe are not of much use, as the leverage at the toe often breaks them; and, further, the wear at the toe wears off their heads, and they become useless.

22.-Calkins for Heavy Draught Horses. In London Calkins are not generally used. In Manchester, Liverpool, Dublin, and many other large towns, where the streets are paved with granite blocks, calkins are used both on the inside and outside heel; and in some towns Toe pieces also are in use.

If one Calkin only is used on the outside heel, the inside heel of the shoe should be raised to the same height. This is necessary in order to give a level bearing to the tread. Calkins have the disadvantage of raising the frog above the ground, and thereby preventing its development. The frog, if large and sound, is Nature's stay against slipping. See Note 4.

23.-Clenches should not be rasped after being turned down. They should be carefully flattened by the hammer. Any filing lessens their power of holding.

24.-Clips. If the crust is sound, and if the fitting of the shoe is accurate, and the narling is good, toe clips on the fore-feet are not absolutely necessary. If clips are used, the crust should not be pared out more than the depth of one-eighth of an inch to receive the clip.

On the Hind feet, two clips, one on each side, are generally needed to strengthen the hold of the nails. Toe clips are commonly used on the feet of heavy horses; but in the case of riding or harness horses doing fast work, they would be apt to cause over-reaches. For horses that kick against the stall posts, quarter clips are necessary.

\section{Explanatory Notes.}

1.-Clenches. The careful and complete raising of each clench separately is necessary in order to avoid injury to the crust; and each nail should be drawn separately, or a large piece of the crust may be dragged away.

2.-The Crust or outer Wall of the hoof sustains the whole weight of the body. The crust is only about half an inch in thickness. Any rasping outside materially weakens it.

3.- The Horny sole protects the sensitive parts of the foot above it from the ground, stones, etc. It is not thicker than is necessary for this purpose or "duty." It is, therefore, a grave mistake to pare it, as it will not grow too thick. It flakes off or "exfoliates" of its own accord in due time.

4.- The Frog, like the sole, only requires to be let alone. It is Nature's pad or cushion to lessen concussion in the upper structures when the foot comes to the ground. It can never grow too big. It thrives on concussion. If pared, and thereby deprived of use, it will dwindle away. 
The Frog, when well developed, also acts as a stay against slipping. A good sound frog is a better stay than calkins.

The Frog, if sound, should not be trimmed. But if it has become ragged (generally from having, by paring, been deprived of concussion with the ground, or in other cases from standing in wet dirty litter in the stable) the ragged parts should be carefully cut off. From either of the above causes, the frog may become affected with "Thrush."

5.-The Bars are Nature's support against contraction at the heels, and must on no acount be cut away. Nor must the sole in the interspace between the bars and the crust be pared out. This filling up of the interspace acts as a support to the bars and the crust against contraction at the heels. The practice of so-called "opening the heels" is strictly forbidden.

6.-Corns are due to pressure on the seat of "corn." Corns generally occur on the inside, because the greater weight falls on that side. The seat of corn is the angle between the crust and the bars. The ordinary causes of pressure on the seat of corn, are-1st. The cutting away of the bars and the paring out of the sole between the crust and the bars. $2 n d$. From the shoe at the heels not having a fair bearing both on the crust and the bars. 3rd. From short shoes, that is, shoes less than the full length of the crust. The ends of the shoe then come on and dig into the seat of corn. 4th. From shifting of the bearing of the shoes due to bad fitting and bad nailing. This occurs most frequently when the crust has been weakened by rasping its outside. 5th. From the nonremoval of the shoes every month. The growth at the toes, which is greater than at other parts of the foot, carries the shoe with it, and then the shoe becomes shorter than the foot, and in consequence its end presses on and digs into the seat of corn.

7.-If the fit and nailing are thoroughly good, an increased width of the shoe at the heels is not needed. But as the best fit and nailing cannot always be expected, a slightly increased width at the heel will be useful in preventing the ends of the shoe from coming down on the seat of corn, if in the course of wear it becomes somewhat displaced.

\section{What to Look for in a Newly-shod Horse}

1.-No mark of the rasp on the hoof.

2.-Sole has not been pared out.

3.-Frog has not been pared unless ragged.

4.-Bars have not been cut åway.

5.-Nailing as regular as the state of crust admits of.

6.-Nails in a normal hoof brought out one inch above the shoe, and in flat feet a little lower.

7.- Shoe neither larger nor smaller than the crust, or longer than the hoof, except in heavy draught horses. 
8.-Feet the same length.

9.-Nails fitted accurately into the nail holes.

10.-Clenches not rasped after being turned down.

[Copies of this Article, printed as a single sheet in large type, for the use of the Forge, can be obtained, price 3d. Longmans, Green \& Co., Paternoster Row, London.] 


\section{GLOSSARY OF SOME MEDICAL TERMS.}

Abscess, Purdennt.-An accumulation of pus in some tissue or organ of the body.

AbSCESS, Serous.-An accumulation of fluid in some tissue or organ of the body. A BSORBENTS. - (1) A term applied to inedicines which possess the power of sucking or drawing off morbid matters in the system. (2) Vessels which absorb or take up various fluid elements of the body.

AcUTr.-A term applied to diseases with violent symptoms, which terminate in a few days in relief, cure, or death.

Adnesion.-The means by which parts, naturally or artificially separated, become united.

Alteratives.-Medicines which induce change or correct morbid conditions, without producing marked effects.

ANAMIA.-A state of body arising from deficiency or impoverishment of the blood.

Anaesthetics.-Remedies applied to prevent pain by temporarily destroying sensation.

ANCHYLOSIs.-Stiffness or fixture of a joint.

ANEURISM. - A pulsating tumour containing blood. Dilatation of an artery.

Animalcola.-Very minute animals, invisible to the naked eye.

ANODYNes.-Medicines which assuage pain.

ANTISEPTICs.-Chemical agents which prevent decomposition of tissues by forming a chemical combination with one or more of their constituents.

Arteries.- Vessels which convey the blood from the heart to all parts of the body.

ASPHXXIA.-Suspended animation. Suffocation.

Asthenic.-(1) A type of disease marked by great debility - the opposite to sthenic. (2) Loss of strength.

Astringents.-Medicines which have the power of contracting muscular fibre, and of coagulating certain fluids. They thus restore tone and check morbid discharges. ATroPHY.-(1) Wasting away of the body. (2) General debility arising from want of nourishment.

Auscultation.-A method of distinguish ing disease by listening to sonnds within the chest either by direct application of the ear or by means of a stethoscope.

BrLE.-A thick, yellow bitter fluid secreted from the blood by the liver.

Capiluaries.-'The hair-like extremity of a vein or artery.

CARIES.-Ulceration or rottenness of a bone.

Catheter.-An instrument introduced into the bladder through the urethra.

Chancre.-An ulcer.

Chronic.-A term applied to diseases of long duration-the opposite of acute.

Cicatrix. - The scar left after a wound is bealed. Scab.

CoAGULUM.- (1) The fibrin and corpuscles of blood when separated from the serum or watery part. (2) A clot.

Congestion.-Abnormal accumulation of blood in any part.

Contagion.-Communication of disease by contact.

Convolsioss. - Violent and involuntary contraction of the muscles.

Crassamentum.-The fibrin and corpuscles of the blood when separated from the serum or watery part.

Crst.-A bag or sac containing matter or fiuid.

Cxstriss.-Inflammation of the bladder.

Drcoctrons.-Medicines procured by boiling in water.

DEODORIzERs.-Agents which disguise odours, acting mechanically.

DIAGNOSIs.-The forming of an opinion as to the nature and seat of a disease.

DIGEstion.-The process by which a portion of the food is reudered fit for $a b$ sorption into the venous blood.

Disinf ECTANTs.-Agents which chemically decompose noxious matters.

Drastics.-Powerful purgatives.

DRENCH.-Medicine given in a fluid form.

DYsentery. - Inflammation of the mucous lining of the bowels with bloody evacuations. 
Erfusion.-The outpouring of the watery part of blood through the coats of over. loaded blood-vessels.

EMULSION.-A milky substance, produced by uniting oil and water through the intervention of some alkaline or mucilaginous substance.

ERYSipelas. - See Addenda.

Exostosis.-An abrorinal deposit of bone.

Feverish SYMPtoms.-Increased lieat, quickened pulse, languor and thirst.

Functional Disease.-Disease due to improper working of an organ, as distinguished from structural disease of the organ itself.

Gangrane.-A term applied to the first stage of mortification.

HYGIFNE. - The branch of medicine appertaining to health.

IDIOPATHIC.-A term applied to a disease which is not dependent on, or produced by, any other complaint.

INCUBATION OF DISEASE.-The period between the generation of a disease and its full development.

INFECTION.-Communication of disense by the air.

In FLAMMATION.-See Chapter 18.

INFUSION.-Medicine produced by pouring water of any temperature over plants, herbs, etc.

INOCULATION.--The communication of disease by inserting infectious matter under the skin or into the system.

LESION.-Any kind of wound or bodily injury.

MACERATION.-The infusion of substances in cold liquids.

MaLignant.-A serious disease tending to a fatal issue.

Miliary.-A term applied to small tubercles like millet seeds.

MucrLaes. - (1) A term applied to slimy, gummy substances, such as linseed tea, gum and water, etc. (2) The fluids which lubricate certain parts of the body.

Mucus.-A fluid substance secreted by the mucous inembranes.

MUscles. - A mass of fleshy fibres capable of contraction and relaxation.

Narcotics. - Agents which first stimulate and afterwards depress vital power.

NondLes. - Little hard tumours on a bone or other tissue.

EDEMA.-Watery swellings in any part of the body.

Organic DISEASE.-Disease of an organ itself, as opposed to improper working of the organ.
Panacea.-A medicine pretending to cure all diseases.

Pathology. - T'he science of treatment of diseases.

PERCUssion.-The striking of a part of the body in order to determine by the sound the condition of a near inlying organ.

Penistaltic.-The worm-like motion of the intestines by which their contents are constantly carried forwards.

Plethora.- (1) A redundancy of blood. (2) A full habit of body.

Purolent.-Relating to pus.

PUs. - A cream-like fluid secreted in sores or abscesses. It may be healthy or unhealthy.

PUstule.-A small conical swelling or pimple containing pus.

Putrefaction.-1)ecomposition of flesh.

RAMIFY.-The separating and dividing into numerous branches.

REFLEX ACTION.-Action or motion directed back to a state of rest. Reflex action is involuntary.

REgURGITATION OF BLOOD.-A throwing or pouring back of blood.

RIGORS OR SHIVERING.-A symptom of a severe chill, the result of a flow of blood from the surface of the body on to some internal vital organ. A sym. ptom of serious disease.

SeCretion.-A component part of the fluid separated from the fluid itself, e.g. saliva separated from the blood.

Segregation.-A separation of animals to prevent the spread of contagious disease.

SkrRated.-Indented, jagged like a saw.

Soldtion.-A dissolving, e.g. salt dissolved in water becomes a solution of salt.

Specific.-(1) A medicine supposed to ensure a certain result. (2) Peculiar to itself, e.g. a specific disease.

SPORADIC. - A disease, dependent on causes common to all animals, but affecting only a few.

Sthenic. - Strength. As affecting a robust animal, as opposed to asthenic (see Asthenic).

Structural DIsease.-Disease of an organ itself, as opposed to functional derangement.

STYPTICS.-Agents which stop bleeding.

SYNCOPE. - Fainting.

Traumatic.-Applied to wounds.

TXPноID.-Low, subacute.

VeINs.-Vessels which convey the blood back to the heart.

VESICLES.-Small blisters or vessels containing fluid. 


\section{IN DE X.}

Abscesses, nature and treatinent of -Chap. 20

- formation of, in diseases of respiratory organs

- formation of, in stringles $\quad 497-8$

— mode of opening _ . 397

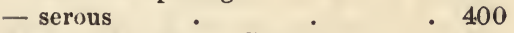

Absorbent system-Chap. $12 \quad$. 218

- lacteals . . . 221

- lymphatics : $\quad . \quad 222$

Absorption of new growths and deposits . $\quad 391,602,622$

Accidents and diseases, ordinary causes of . .

- erroneous ideas as to : $\quad .268$

Aconite

Action in walking, trotting, and galloping

— in walking, defects in :

- 930

- of fore-leg

Adhesion and organis atiou of lymph in inflammatory diseases

— in diseases of respiratory organs .

- healing by .

Adipose tissue or fat

735,744

Aftermath, or second crop of grass .

Age, as indicated by the teethChap. 58 .

- to be considered in regulating amount of work

Air, importance of pure.

- effects of breath on .

- composition of

- circulation of

- amount of, required by horses in stables

- change of, bencficial to sick horses

238

$98 a$

864

- cool fresh, as tonic

- foul, escape of

Aloes .

Alteratives

Alım .

A inaurosis
Ammonia as diffusible stimulant

PAR.

- and mustard.

- as stimulant to skin .

- liniment of .

Aualyses, chemical, of food

Anæsthetics .

Anchylosis .

Animal pain .

- soul

Aniseed

Antimony, poisoning by-Chap. 68.1057

- tartarised . . . 298

Antiseptics . $\quad$. $\quad$. 324

Antispasmodics . $\quad$. 302

Apoplexy . $\quad 559$

Appendinges of the eye $\quad . \quad 833$

Applications, cold $\quad 316$

Aqueous humour $\quad$. $\quad 825$

Arab . . page 541

Areolar or cellular tissue . $\quad 235$

Arnica $\quad . \quad 690$

Aromatics as slight tonics $\quad$. 304

Arrangement of horses in stables . 191

$\begin{array}{lll}\text { Arsenic as caustic } & \text {. } & 306\end{array}$

- as tonic . . 304

- poisoning by-Chap. $68 \quad .1057$

Arteries, veius, and blnod-Chap. 10 . 200

Arterial and venous blood. $\quad 206$

— and venous systems . 2

Artificial exercising ground 148

- foods . . . $98 \mathrm{~m}$

- wirming of stables . $\quad$. 162

Arytenoid cartilage $\quad$. 455-7

Aspect of stables _ $\quad 21$

Astringents . $\quad . \quad 307$

Auscultation as regards the pulse . 216

- in acute diseases of respiratory organs-Chap. 22

- in chronic disenses of respiratory

organs-Chap. 23 . 450

Backs, conformation of . $\quad .911$

Back and loins, special precautions in drying .
4.07

117 
Bacteriology-Chap. $67 a$.

Bales, stables divided by .

Balls, aloetic

- alterative

- cordial

- cough

- fever

- mode of delivering

Bandages, flannel

- flannel, for sick horses .

- sweating

- fomenting .

- linen, wet

- linen, for sick horses.

- linen, in open joint .

- dry pressure.

- putting on of

— to joints

- in open joint

- to wounds

Bars of the foot

Baths, warın .

- Turkish

Bathing, cold, to legs

Beans

Bedding or litter

— for greedy horses

- for sick horses

- sand in lieu of moss litter

- sawdust in lieu of

- shed for

Belladonna

Belly, conformation of

Biniodide of Mercury in reduced strength

- in full strength

- as stimulant and absorbent

- as application to sprains

Bishop-ing of teeth

Bladder, diseases of-Chap. 55

Bleached oats .

Bleeding

Blemishes from wounds

Blisters-Chap. 19

Blistering round coronet .

Blood, arteries and veins-Chap. 10 . 200

- circulation of

- temperature in health and disease $217 a$

Blood-spavins . 648

Bloody urine . $\quad$. $\quad .800$

Blowers, high . $\quad$. $\quad$. 461

Bluestone $\quad$. $\quad-\quad 306$

Body, conformation of $\quad$. $\quad 879,925$

Bog-sparin

Boiled foods

Bolts or slides for doors

. ${ }^{-640}$

$\left.\begin{array}{c}\text { Bones, diseases of-Chap. } 35 \\ \text { - structure and nutrition of-Chap. } \\ 35\end{array}\right\} 571$

- exostoses on .
PAR.

35

319

304

322

325

252

254

186

253

$645 a$

187

721

751

172

293

75

179

263

180

182

924

384

385

689

785

72

$758 a$

372

33

2

.

Cartilage

— fibro-

- inter-articular fibro-

- the arytenoid

Cartilages, ossified

Castiug in stall .

Cataracts

- capsular

- capsulo-lenticular

- lenticular

- spurious

- absorption of

Catarrh, common
PAR.

584

883, 926

- 781

$283-91$

- 533

- 533

- 480

$27-38$

- 279

4) 241

) 547

- $98 i$

- 199

- 313

- 124

- 3

- 935

- 714

- 465

$428-31$

- 107

- 999

- 637

- 638

71

794-8

- 986

- 301

667, 1019

- 382

- 386

- 3

- 704

- 850

- 234

- 827

- 851

- 323

309,743

- 2,4

- 6

- 576

. 1069

- $98 g$

- 313

- 231

- 232

- 233

- 457

$633-6,665$

847

850

851

849

- 855

- 852

- 412 
Cattle plague or rinderpest

Caustics

Cautery, actual .

- thermo.

Ceilings of stables

Cellular or areolar membiane

Chaff .

Chains, collar

Chapped heels-Chap. 50 .

Chemical analysis of food

Chest, conformation of .

Chills.

Chloroform

Chopped hay

Chorvid cont of eye

Chronic cough .

- disenses of organs of respiration -Chap 23 .

- foot lameness

Chyle.

Cicatrix

Ciliary ligament

Circulation of blood

- of air

Clean $v$. dirty coat, how to distin. guish

Cleanliness

Clicking or forging

Clipping

Clot or crassamentum

Clothing

— of exercise in

- for sick horses

Clover

- hay

Clysters or enemata

- in colic

Coagulation of blood

Coats, artificial removal of

- glossy and short

- do., improper means used to produce

- shedding of :

Coffin bone, conformation of

- disease of

- joint, injuries to

Colchicum

Cold, common, or catarrh

- applications .

- extreme, produced by evaporation

- as tonic

- water, apparatus for applying stream of .

Coldness, persistent, of legs

Colic-Chap. 30

Collars, head

Collar ropes or chains

Collodion

Colour of blood.

— of horses

- and distinctive marks .
PAR.

. 1036

- 309

306,378

. $390 a$

- 14

- 235

77

42

761

67

- 898

$113-17$

. $303 a$

77

821

450

450

669

53

752

828

2

$5-8$

-

125

953

1001

175

202

183

157

251

$98 f$

$98 e$

$291,1062 a$

- 540

- 205

$173-6$

- 110

111

104

905

905

728

503

412

316

115

304

265

189

262

44

42

309

207

933

936
Colts, exercise of, to be gradual 130 PAR.

Coma-Chap. 31 . 547

Common cold or catarrh . $\quad 412$

—ophthalmia . $\quad$. $\quad 840$

Concentrated foods . $\quad 89 l$

Condition, essentials to produce $160,937 a$

- hard, to be antecedent to fast work

- in hunters.

$144-55$

Conformation-Chap. 60 .

Congestion of blood in inflammation

- of liver

$331-6$

- of lungs (see Acute diseases of respiratory organs, also other diseases-Chap. 22) . $\quad .407$

Conjunctival membrane . $\quad .823$

Constitution . $\quad$. 934

Construction of stables-Chap. 1 . 1

- fuulty plans of . 11

- good plans of $\quad . \quad 12$

- ceiling of . $\quad . \quad 14$

- cheap plans of . $\quad$ - 26

Consumption, pulmonary . $\quad 470$

Contagion and infection-Chap. 16. 267

- conveyed by water trough .273

Contracted feet . $\quad$. $\quad 670,957$

Contused wounds $\quad$. $\quad .756$

Cooling drinks. $\quad . \quad \quad 317$

Copper, salts of, as astringents $\quad .307$

- as caustics . $\quad . \quad 306$

- as tonics . $\quad 304$

Coronet, blistering round . $\quad .1033$

Corn (see Oats).

- other than oats $\quad$. $\quad 74$

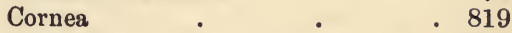

$\begin{array}{llll}\text { Corns . } & . & . & .1009\end{array}$

Corpora nigra . $\quad . \quad 829$

Corpuscles, red and white, of blood 203-4

Corrosive sublimate • • 306

Cost and dimensions of stables . 25

— cheap construction of do. - 26

Coughs, distinctive signs of various

- chronic, of .

410,411

Cough balls . $\quad$. 322

Counter-irritation $\quad$. 375

Counter-sunk nail-holes . $\quad$. 975

Cracked heel-Chap. 50 . 761.

Crassamentum . $\quad$. 202

Crib-biting . $\quad . \quad 195$

Croton farina . . . . $289 a$

- oil . $\quad . \quad 2896$

Crust or wall of foot, structure of $940-3$

- effects of rasping on . $\quad 944$

— of lowering and rasping $\quad$. 946

— prevention of splitting. $\quad 947$

Crystalline lens. $\quad . \quad 827$

Cubical space, amount required in stables

— in various stables 
Curb .

PAR.

Cuticle or scarf skin

702

Cutis or true skin

100

Cuts (see Flesh wounds-Chap. 48).

Cutting, interfering, or brushing

Cystitis

Daily exercise, amount of.

Damp stables

Dealers, horses from stables of

Demulcents

Dentistry-Chap. 71

Deutition

Deodorisers and disinfectants

Deposits, absorption of new $391,602,622$
Depressants

Diabetes

Diaphoretics

Diffusible stimulants

Digestion, process of-Chap. 4

Digestive ointments

Digitalis

Diluents

Dimensions and cost of strubles

Direct union, healing by .

Dirty $v$. clean coat, low to distinguish

- v. clean water

Diseases and accidents, ordinary causes of

- erroneous ideas as to.

Diseases, prevention of

- seldom transmitted by infection or contagion

- sequels of

- of foot-Chap. 65

- lome-bred and foreign

- origin of-Chap. 67 .

- specific

- spontaneous.

- germs of, growth of

Disinfectants and deodurisers

Disinfection of stables after malig. nant diseases

Diuresis or excessive staling

Diuretics

Dock, conformation of .

Doors for stables

- for loose boxes

- for sick boxes

Dorsal vertebre conformation of

Douche, water, for application to parts

Drainage

— in old stables

Draughts on horses in health

- on sick horses

Drenches, mode of giving .

- objections to

Dressings, exterual

- for flesh wounds

Drinks, cooling .

308

1065

$877 a$

300

53

310

298

311.

25

\section{-}

Dropsical swelling-Chap. 28

PAR.

Dust in hay

Dysentery

Ears, conformation of

Effusion of serum in inflammation

- in diseases of lungs and pleuræ . 445

- in formation of exostoses $\quad 391,580$

Elbow lameness.

- capped

- wounds of .

- 696

Electricity

Emergent cases-Chap. $6 \dot{9}$

- $400 a$

- 729

Emollients

Empliysema

$569 e$

- 1062

- 312

Enemata or clysters $\quad$ - 291, $1062 a$

- in colic

540

Enlargements, bursal-Chap. 41 $\quad 637$

734

125

64

269

268

267

- 272

276

. 997

$1038-41$

. 1045

. 1046

. 1055

1051

277,323

- 531

801

292

923

37

38

38

894

265

18

32

8

248

326

288

309,310

$743-5$

- 317
- nature and causes of

$637-9$

- boy-spavins .

- thorough-pins

- 640

- 74.1

— windgalls . $\quad 644$

Enteritis or inflammation of intestines

Epsom salts . $\quad . \quad 290$

Erysipelas (see Addenda).

Escharotics or caustics . $\quad 306$

Ether . $\quad 303$

Examination to detect seat of lameness-Chap. $42 \quad . \quad 649$

$\begin{array}{lll}\text { - of eye for cataract } \quad . \quad & 848\end{array}$

- of foot $\quad 661$

$\begin{array}{lll}\text { Excessive staling } & \text {. } & \text {. } 801\end{array}$

Exercise-Chap. $8 \quad$. $\quad 127$

- reason of need of $\quad . \quad 127$

- effect of, on various organs 128-33

- regularity in, desirable 133

- neglect of . $\quad . \quad 135$

- age, condition, etc., to be considered . . . 136

- of young horses $\quad$. 139-42

- of riding or harness horses $\quad 143$

- of hunters.

- in clothing . $\quad$. 157

— best time for $\quad$. $\quad 158$

- hard condition to be antccedent to work

155

- horses to be groomed immediately after

113,169

- summering of hunters . $\quad 145$

- best time for. $\quad$. 170

Exercising ground in summer $\quad 147$

— in frosty weather . . 149

\begin{tabular}{lll}
- artificiul & . &. \\
\hline
\end{tabular}

Exfoliation of bone $\quad \cdot \quad 579$

Exhaustion after work, treatment of 197

Exostoses, mode of formation $580-1$

- symptoms of lameness caused by . $\quad 655$

Extensor tendons, duties of $\quad 679$

- seldoin sprained $\quad$. 679

External form-Chap. 60 . $\quad .878$ 
Extremities, liable to chill.

PAR.

- to be dried first

Exudation and organisation of

\begin{tabular}{ll} 
lymph & \\
- in dise sses of respiratory organs: & 354 \\
\hline & 446
\end{tabular}

\section{Evacuants}

$283-91$

Evaporation, cold produced by $\quad 115$

- danger of leaving horses to dry by 120

Eye, the-Chap. 57

- structure of .

- diseases of .

- pink

- worm in

Eyelashes

Eyelids, lacerations of

$$
816-38,889
$$

$839-63$

. $473 a$

- 784

- 835

False quarter

Fang-hole or secondary mark

Farcy-Chap. 29.

- diseases mistaken for $\}$

Farrier, directions for shoeing

Fascia

Fat or adipose tissue

Febrifuges

Feeders, delicate

Feeding and watering-Chap. 4

Feet, diseases of-Chap. 65

- size of

- to be pairs.

- outer rase of

- crust or wall of

- shape of

- expausion or contraction of

- structure of .

- symptoms of lameness in-Chap. 43

. 861

.1013

- 873

- 524

- 988

- 236

$67 \alpha, 238$

- 320

66

53

997

955

956

942

943

954

957

941

- rings on

661

- do not wear out

- fore-, conformation of .

- hind, conformation of .

- contracted

Femur, conformation of :

- spriins of ligaments of

Fetlocks, conformation of .

Fetlock-joint (fore) sprains of
(hind)

- wounds of .

7,907

190-146

- 907

- 920

- 670

- 916

706

903

691

708

728

337

321

$767 a$
232

- balls

- mud

Fibro-cartilage .

Fibrous tissue, yellow and white

Fireplaces in stables

Firing

- by thermo-cautery

First intention, healing by

Fissures in wall of foot .

Fistulæ

Fistulous withers

Fittings of stables-Chap. 3

Flesh or muscle.
Flesh wounds - Chap. 48. PAR.

Flexor tendons, duties of . $\quad .676$

- sprains of . . $\quad 682$

Floor of stable (paving) . $\quad 16$

- to be higher than ground outside . 17

Fomentations . $\quad 255,312,314$

Food (watering and feeding)-Chap.

4 . 435

- (forage)-Chap. 5 . $\quad .67$

- artificial . . $98 k$

- boiled . $\quad . \quad 98 k$

- cliemical analyses of . $\quad .67$

- concentrated $\quad . \quad 98 n$

- course of . $\quad . \quad 53$

- witer $\quad . \quad 54$

$\begin{array}{lll}\text { - for sick horses } & \text {. } & \text {. } 259\end{array}$

- nitrogenous, non-nitrogenous $\quad .67 a$

- Thorley's, Henri's, etc. $\quad 98 m$

Foot lameness, symptoms of-Chap. 43

- chronic, symptoms of

- fastenings

- structure of-Chap. 62

- shape of

- size, etc.

- diseases of-Chap. 65 .

Forage-Chap. 5

654,661$$
\text { - oats . }
$$

- other grain .

- beans

- hay

- grcen

- stores

- carrots

Forehead, conformation of

Fore-leg, action of

Fore-shoes, form of toe of

- wear of

Forging or clicking .

Foxy oats

Fractures of bones-Chap. $36 \quad 584$

Priction of bones-Chap. 36

Friction

Frog, the

- puncture of .

Fro 1008

$\cdot 909$

- temporary ride during $\quad .149$

Fullered shoes . $\quad$. 981

Fumigated oats. $\quad$ - 72

Ganglia, nervous $\quad$. $\quad 241$

Gangrene or mortification $\quad$. 448

Gentian . $\quad 300,304$

- in combination with aloes $\quad 288$

Germs of diseases-Chap. $67 \quad .1045$

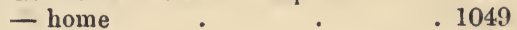

$\begin{array}{llll}\text { - foreign } & . & . & 049\end{array}$

Ginger . $\quad$. 304

Glanders and Farcy-Chap. $29 \quad 518$

- diseases sometimes mistaken for . 529

237 Glands, structure and uses of 240 
Glands of skin .

Glaucoma

Gleet, nasal-Chap. 25

Glossiness of coat

Goulard lotion .

Grain (oats)

- other than oats

Gram .

Granulations, healing by .

- excessive

Grass as food for sick horses

- horses brought into stables from . 168

- fed colt

- varieties of, in hay

Grease and cracked heels-Chap. 50

. 761

Green forage

Grey and white legs, cleaning of

Grinders or back teeth

Gripes or colic-Chap. 30

Grooming-Chap. 6

- reason of need of

- objects gained

- use of the brush

- methad

- subsidiary uses of

- neglect of

- time for

. 106

- 107

. 108

- 110

. 109

112-17

- time required to clean a horse . 123

- breaking out after cleaning . 124

- by machinery

- clean $v$. dirty coat

- impropir means used to obtain short and glossy coat

- washing the skin

- washing the legs

111

Glossitis

Gruel, mode of making

- for nutritive enemata .

Grunting

118

119,120

$.877 c$

- $98 h$

- 291

462

Gummy legs : . $\quad$. 197

Guts, entanglement of, or intussus. ception

Hæmorrhage, stoppage of

Hair, structure of

Hand-rubbing beneficial .

- to sick horses

Hard and solt water

Harness work, objectious made to $\quad 153$

Haw, or membraua nictitans 838

Hay.

$76-98 e$

- distinction between new and old. $98 b$

- new and old, as regards feeding . $98 c$

- quality and value of .

- Irish

- allowance of .

- waste of

- chopped

- clover

- loft
Hay racks

PAR.

48

- upland, lowland, and water meadow . 8 80-88

- time of cutting $\quad$. $\quad 93-96$

- mowburnt . . . 97

- dust in . $\quad .98$

- aftermath or second crop $\quad$. 98a

Head, conformation of . $\quad$. 884

- setting on of $\quad$. 893

- collars .

Healing-Chap. 48 . 731

- modes of . $\quad$. $\quad 733-40$

- dressings for wounds . $\quad 743-8$

Heart, action of $\quad$. 217

- as affected in influenza $\quad 482$

Heels, cracked-Chap. 50 . 761

Hepatitis, acute $\quad$. 812

Hepatisation of lungs . . 446

Herbage, varieties of . $\quad 89,90$

Hernia (see Postscript).

High blowers . • . 461

Hind quarters, conformation of $\quad .915$

Hinges . 41

Hips, conformation of $\quad . \quad .913$

— injuries to . . $\quad .588$

Hock, conformation of-Chap. 37 . 595

- (see also Spavin-Chap. 38) . 600

- (see also Sprains of hind legsClıap. 45).

699

- mode of examining $\quad . \quad 612$

- remarks on . $\quad . \quad 917$

- capped $\quad . \quad$. 704

— wounds to joint _ . 726

Home-bred diseases $\quad . \quad 1040$

Horses, working life of . $\quad .199 a$

Humerus, conformation of $\quad$. 897

Humors in legs . 292, 517

- (see also Dropsical swellingsChap. 28) . . $\quad 509$

- (see also Weed) . 226

— of eye $\quad$. $\quad 825-7$

Hunters, feeding of $\quad$. $\quad ~ \quad 68$

- exercise of . $\quad$. $\quad .144$

- summering of $\quad . \quad 145$

- to be exercised occasionally in deep ground in autumn 154

- exercise suitable to, in summer . 152

Hydrocyanic acid . $\quad 289$

Hydrothorax . . . 443

Ignorance, cost of . 1041

Improvement of old stables-Chap. 2

Incised wounds . $\quad . \quad 754$

Incisor teetl $\quad$. $\quad . \quad 867$

Indian corn . $\quad$. 74

Infection and contagion-Chap. 16 . 267

Infirmary stables, special precautious as to ventilation and cleanliness 278

Inflammation-Chap. 18 . $\quad 327$

- theory, nature, and causes of $327-30$ 
Inflammation, phenomena of

- fever

- effect on nutrition of part affected

- local, diffused, and specific

- acute, subacute, and chronic

- signs of

- symptoms indicating locality of . 349

- sthenic and asthenic types of . 350

- results of

- treatment

- after effects .

- treatment by depletives, etc.

- of bladder

- of bone and periosteum

- of eyes

- of intestines

$351-6$

$357-67$

- 368

. 369

. 792

. 580

$839-62$

$541-6$

— of joints (open joint)-Chap. $47 \quad 716$

— of joints, stiff (anchylosis) . 582

- of bursal enlargements-Chap.41 637

$\begin{array}{llll}\text { - specific . } & \text {. } 370\end{array}$

- curative . $\quad . \quad 371$

— of kidneys.

- of lungs and orgaus of respiration-Chap. 22

- of tendons and ligaments (sprains)-Chaps. 4.4 and 45673,699

- artificially induced-Chap. 19 . 372

- as supplemental to curative and reparative action 372 , also Chap. $34 \mathrm{~A}$,

- as stimulaut to parts deficient in vital energy

$570 a$

786

607

373

— as excitant to absorbent system . 376

- agents used to produce

- counter-irritation

$377-90$

- irritants used to produce artificial -Chap. 19

$377-91$

Influeuza-Chap. 24

471

Injuries to vital structures, repair of-Chap. 34A

$.570 b$

Inoculation 274

Inter-articular fibro-cartilage

Interfering or brushing .

Intestines, inflammation of

Intussusception .

Iodide of potassium

Iodine

Iodoform

Iris

Irish colts

Iron, salts of, as tonics

- as caustics.

- as astringents

Irritants - Chap. 19

- action and uses of

- firing

- blisters

- setons

- stimulants.

Itchiness of skin
PAR.

Jaws, fractures of $\quad$. 592

Joints, bandages to • 188

- conformation of $\quad$. 901

- open-Chap. $47 \quad$. 714

- strncture of . $\quad . \quad 714$

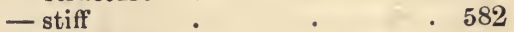

- synovial . $\quad . \quad 715$

- oil $\quad \therefore \quad$. 230

— shonlder, injuries to $\quad . \quad 729$

$\begin{array}{lll}\text { - stifle } \quad \text {. } & .730\end{array}$

- hock $\quad$ " $\quad . \quad 726$

- navicular " . $\quad .727$

— fetlock

— elbow " . $\quad .729$

Kicking in the stable . 192

Kidneys, diseases of-Chap. $55 \quad 785$

- (sce also Diuretics) . . 292

- as affected in influenza 481

Kilu-dried oats - $\quad 72$

Knee, broken-Chap. 47. . 714

- conformation of . $\quad 901$

- wounds of, not producing open joint

Lacerated wounds $\quad$. $\quad$. 755

Lacerations of eyelids . $\quad$. 861

Lachrymal duct $\quad$. $\quad 833,862$

- passages, diseases of . $\quad .862$

Lacteals, functions of $\quad . \quad 221$

- diseases of . $\quad . \quad 223$

Lameness, detection of seat and cause of-Chap. 42 . 649

Lameness in foot-Chap. 43 . 661

Laminitis . $\quad 1027$

- chronic $\quad . \quad 1032$

- symptoms of $\quad$. $\quad 663$

Lampas-Chap. $59 \quad$ a $\quad .877$

Laryngitis and sore throat $\quad 416$

Larynx, structure of . . 456

$\begin{array}{lll}\text { Latches } \quad \text {. } & & 39\end{array}$

Lead, acetate of $\quad . \quad 307$

- poisoning by-Chap. $68 \quad .1057$

Leather soles : $\quad$. 1003

Leg below the knec, conformatiou of 910

Legs, persistent coldness of $\quad 189$

- swelled . . 292, 517

- (see also Dropsical swellingsChap. 28) . . $\quad 509$

- (see also Weed) . $\quad .226$

Lens, crystalline $\quad$. 827

Lenticular cataract $\quad$. $\quad . \quad 849$

Lesions (see Wounds, Chaps. 34 and 48) . . 372,731

Lice . . . . $\quad$. $774 a$

Ligaments, sprains of, in fore-legChap. 44 . 673

- sprains of, in hind leg-Chap. 45694

- effect of exercise on $129,130,146$

- structure of . $\quad$. 234

- remarks on conformation of 928

- duties of . $673-79$ 
PAR.

Ligaments, metacarpal . $\quad$ - 683

- suspensory . . . 684

- sheaths of, injuries to . $\quad 692$

Light

- (see also Windows)

23, 33

- improvement of, in old stables

Liniments

- digestive do.

- of ammonia or turpentine

- soap

Linseed

- boiled

- oil

- for poultices

Lips, conformation of
Litter (see Bedding) sheds

Liver-Chap. 56

- as affected in influenza

Lockjaw-Chap. 33

Lofts for forage

Logs .

Loins, conformation of .

- strains of

- and back, special precautions for drying

Loose boxes

27, 38,24

- boxes for sick horses.

Lotions, cooling

Louvre boards.

Lowland hay

- 279

- 318

13

84

Lucern, as food for sick liorses . $98 f$

Lungs, acute diseases of - Chap. $22 \quad 407$

- chronic diseases of-Chap. 23 . 450

- effect of exercise on . 131

— structure . . . 424

- as affected in influenza

Lymph, formation of, and adhesion

- exudation and organisation of, in diseases of respiratory organs .

Lymphatics

Machinery, grooming by .

Manes

- and tails

Mange-Chap. 51

Mangers

Marks, distinctive, and colour

- in the teeth.

Mashes, bran, etc.

Medicines, action and uses ofChap. 17

- to be kept in stock-Chap. 69

Megrims or vertigo-Chap. 32 .

Melanosis

Membrana nictitans or haw

122

891

178

768

47

- 936

$871-4$

$98 i, 199$

Membranes, various-Chap. 13

- areolar or cellular 280

- conjunctival

- mucous

- serous

- synovial
Mercury, biniodide of, in reduced strength

— in full strength

- perchloride .

Metacarpal bones (see Splint-Chap. 39)

- bones, remarks on conformation of

- ligament, duties of

- 902

677

- sprains of . $\quad . \quad 683$

Metatarsal bones, conformation of . 918

Milk for sick horses $\quad$. 259

Molar teeth for extraction $\quad 866$

Mouth,age as indicated by-Chap. $58 \quad 864$

$\begin{array}{lll}\text { - conformation of } \quad . \quad & 888\end{array}$

$\begin{array}{lll}\text { Mortification . } & \text {. } & 356\end{array}$

- in disease of respiratory organs . 448

Moss litter . $\quad$. 180

Mucilage (see Glossary) . $\quad$ page 548

Mucous membrane $\quad$. 227

Mud fever . . . . . $\quad .767 a$

Muscles, structure and functions of 128,237

- developed by exercise . $\quad$. 128

$\begin{array}{lll}\text { - conformation of } & . & .927\end{array}$

\begin{tabular}{lll} 
Mustard &. &. \\
\hline
\end{tabular}

- and ammonia $\quad . \quad .383 b$

$\begin{array}{lll}\text { Muzzle and nose } & \text {. } & .887\end{array}$

$\begin{array}{lllll}\text { Muzzles } & \text {. } & & & \end{array}$

Nails, form and material of $\quad .972$

- how many required . $\quad .970$

- position of . . . 973

- to be frequently examined $\quad .971$

- driving of . . . 974

- clenching of $\quad$. $\quad .978$

- picking up of $\quad . \quad 1006$

- and nailing, importance of $\quad .980$

$\begin{array}{lll}\text { - rose-headed . } & .976\end{array}$

$\begin{array}{llll}\text { Nail-bound } \quad . \quad & . & . & 979\end{array}$

Nail-lieads $\quad$. $\quad$. $\quad 975-80$

- not to project $\quad$. $\quad .977$

Nail-holes, counter-sunk . $\quad .975$

- punching of $\quad . \quad$. 974

Nailing "tight" $\quad$. $\quad$. 979

Narcotics . . . 301

Nasal bones, fractures of . $\quad .591$

-gleet-Chap. 25 . . 487

Nauseants • $\quad$. 299

Navicular disease, cause and treatment . . 1021

- bone (fore-feet), conformation of 906

- (hind) conformation of $\quad 919$

- disease, symptoms of . $\quad$. 664

- joint, wounds of $\quad . \quad 727$

Neck, conformation of $\quad . \quad 892$

- of bladder, inflammation of $\quad 795$

- straps . . . 44

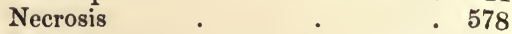

Nephritis . . . 786

Nervous system-Chap. $14 \quad 241-51$

- loose boxes and quiet . $\quad 247$ 
Nerve, optic PAR.

Neurotomy $\quad .1026$

Nitrate of silver

Nitre .

- sweet spirits of

Nitric ether

Nitrous ether

Nitrogenous and non-nitrogenous foods

Nose, confurmation of

- fracture of bones of

- running from, precautions as to 591

Nustrils, conformation of $886-7$

- discharge from

- to be sponged ont twice daily 121

Nursing, good-Chap. 15 . 246

Oak bark

. 304

$68-73$

Oats.

- allowance of, to horses.

68

- characteristics of good and bad .

- weight of

69

70

- mode of weighing a bushel

- various defects in, viz.-

Bleaching. Damp Dirt and stones. Foxy. Fumigating. Kiln drying. Mouldiness. Mustiness. Softness. Sprouting. Want of winnowing.

- crushed

$73 a$

- distinction between new and old

Edema-Chap. 28

73

500

Oil, linseed

289

- olive

- turpentine as diuretic .

- do., in liniments

- joint

Ointments, digestive

Open joint-Chap. 47

Ophthalmia, common

- specific

Opium, as narcotic

- as antispasmodic

-- as astringent

- in poultices.

Optic nerve

Origin of diseases-Chap. 67

- specific diseases

- spontaneous diseases.

Ossified cartilages

Over-reach

291, 313

- 292

- 310

- 230

. $313 a$

714

840

843

301

302

307

313

830

1045

1046

1055

633,655

.1002

Pain .

- animal

Paralysis-Chap. $33 a$

Partitions, height and length of

Pasterns, conformation of

- sprains of .

Pastern bones, fractures of

Patella, conformation of .

- displacement and sprains of

— injuries to

Pavements slippery in towns

- 342

. 1042

. $569 a$

35

- 903

691,708

589

- 916

- 707

- 730

. $991 a$
Paviug, and cost of variuus sorts 16,31

- improvement of, in old stables . 31

- to be higher than ground outside 17

Peas. . . $75 a$

Pedis, os $\quad$. $\quad . \quad 905$

Pelvis, conformation of . $\quad .913$

- fracture of . $\quad . \quad 588$

Periosteum, structure of . $\quad .575$

- inflammation of . $\quad .580$

Peritonitis or inflannmation of intestines

Permanent teeth $\quad$. $\quad 868-76$

Perspiration . $\quad .102$

Phrenitis (see Staggers-Chap. 31). 552

Physic, action and uses of-Chap. 17 ; also par. 198 . 280

- not to be given periodically . 198

Picking up a nail $\quad . \quad 1006$

$\begin{array}{llll}\text { Pigments } & \text {. } & \text {. } & \\ \text { P } & 239\end{array}$

Pink eye $\quad . \quad 543 a$

Pleuræ, structure of $\quad$. 425

$\left.\begin{array}{l}\text { Pleuritis } \\ \text { Pleuro-pneumonia-Chap. } 22\end{array}\right\} 423-49$

Pneumonia

Poisoned wounds

Poisons-Chap. 68

Poll evil

Polypi

Position in standing . $\quad$. 932

Potassium, iodide of $\quad$. $\quad 386,804$

Poultices . $\quad 312,313$

Prevention of disease $\quad . \quad \quad 267$

Pricking and picking up a nail $\quad 1006$

Pulmonary consumption . . 470

Pulse, the-Chap. 11 . 210

$\begin{array}{lll}\text { Punching } & \text {. } & 389\end{array}$

Punctured wounds $\quad . \quad 757$

Punctures of foot $\quad . \quad 1006$

一 of frog . . 1008

Purchase of horses - pages $466-8$

Purgatives . . 283-91

- not to be given to weak horses . 286

Pus, formation of . $\quad$. 355

- healthy $\quad 393$

- unhealthy . $\quad$. $\quad$. 394

Quarter, false . . . 1013

Quassia . . . 304

Quidding $\quad . \quad 1067$

Quinine, disulphate of . $\quad$. 304

Quittor . 1011
Race horses, training of .

Racing time, Arab and English

Radius, conformation of : $\quad: \quad 899$

Rasping the crust, effect of $\quad 944-7$

Red precipitate. $\quad$. 306

Refrigerant drinks $\quad$. $\quad$. 317

Removal of old shoes $\quad$. $\quad .969$

Repair of vitalstructures-Chap. $34 a \quad 570$

$\begin{array}{llll}\text { Resin . } & \text {. } & 292\end{array}$
Raks 1066 
Resolution in inflammation

PAR.

Respiration, acute diseases of organs of-Chap. 22

- chronic diseases of organs of -Chap. 23

Retention of urine

. 450

Retina .

Rheumatism-Chap. 27 .

- as cause of lameness.

Ribs, conformation of .

- broken

Rice water

Riding horses, amount of exercise for

Rigors or shivering

Rinderpest

Ringboue

Ringworm-Chap. 52

Roaring

Rose-lieaded nails

Ronghing for frost

796
822

- 837

- 503

659,697

. 912

- 590

. 291

r 143

- 348

. 1039

- 628

- 775

$454-60$

976

$991,991 b$

Sale of horses-Chap. 61 .

. 938

Saline medicine

- 290

53,240

Saliva

- 307

Salt, as astringent

Sanderack

Sand for bedding

Sawdust for bedding

Scabbing, bealing by

.1012

. 180

. 180

- 736

- 896

. $760 a$

Scirrhous cord .

Scouring

Secretions

Sedatives

Seedy toe

Sequels of disease

Serous membranes

- abscesses

Serum

Servants, instruction of, in nursing 266

Sesamoid bones, conformation of 904,919

- ligament, duties of . $\quad 678$

- sprains of . $\quad . \quad 684$

Setons . . 388

Shampooing . $\quad . \quad 107$

Sheath, the conformation of $\quad 922$

- to be kept 'lean

121

Sheaths of tendons and ligaments, injuries to .

692,725

- distinction between sprain of a sheath and sprain of a tendon or ligament

Shedding of coat

Shins, sore

Shivering or Rigors

348

\section{Shoeing-}

General principles of-Chap. 62

Details of-Chap. 63

940

Of fore-feet-Chap. 64

950

Directions for, fore-feet
Shoeing-

PAR.

Directions for, hind feet

989

Do., of a troublesome horse $\quad .990$

How of ten required . . 962

What to look for in newlyshod horse

Shoes-

Bar

Charlier .

Rocking .

Breadth of .

Thickness of

Removal of

$989 a$

Do., in sickness

Taking off, mode of .

Length of .

Fitting of .

Under or ground surface

Upper surface, fore-shoes

Form of toe of fore-shoe

Do., fitting of fore-shoe

Wear of toe of fore-shoe

Fullered.

Hind shoes

Form of

'To be level.

Loss of .

Frost shoes

Fore, turned up-Chap. 64

$983 b$

$983 a$

$983 c$

960

961

963

257

969

966

967

965

964

994

995

993

981

984

985

987

982

9913

992

895

729

594

695

863

279

278

633

Side bones

Sinews (see Tendons and ligaments).

Singeing

174

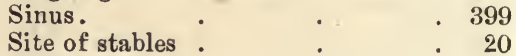

Sitfast $\quad . \quad 760$

Size of loose boxes $\quad$. $\quad 38$

— of stalls . $\quad . \quad 35$

$\begin{array}{lll}\text { Skeleton, the bony } & \text {. } & 883\end{array}$

Skin, structure of $\quad$. $\quad 100$

- cleaning of (see GroomingChap. 6)

- washing of .

- itchiness of .

- glands of.

101

- scarf and true $\quad . \quad 100$

Sleeping when standing . $\quad .193$

Slides or bolts for doors . . 40

Slings $\quad$. $\quad$. $\quad 52$

Slope of stalls . $\quad$. $\quad ~ 19$

Sloughing and ulceration-Chap. 21401

Do. do. . . 749

Soft $v$. hard water $\quad \cdot \quad 64$

Sole, the $\quad$. $\quad 949-951$

- sensitive, undue pressure on $\quad .950$

- do., as a result of paring $\quad 950$ 
Sole, the, as result of mutilation of crust

Soles of feet, conformation of

Sore shins

- throat

Soul, animal .

Soap liniment.

Soundness, as regards warrantyChap. 61

Spasins of intestines(colic) - Chap. $30^{\circ}$

Spavin bone-Chap. 38

- bog

- blood

Specific ophthalmia

Speedy cut (latter part).

Splint-Chap. 39

Spongiopiline

Sprains of tendons and ligaments (fore-leg)-Chap. 44 .

- of hind leg-Chap. 45 .

- degree of injury caused by

- of sheaths of tendons and ligaments

- of shoulder.

- of suspensory ligament

- of fetlock-joint

- of loins

Stahle fittings-Chap. 3 :

- management-Chap. 9

Stables, ventilation and construction of-Chaps. 1, 2

- appliances useful in .

- aspect of

- cheap construction of .

- artificial warming of .

- change of

- damp

- drains

- temperature of

- registering thermometer for

- in hot weather

- of horses brought into, from grass

- plans of-faulty

- do., good

- cubical contents of various

- - space required

- light

- loose boxes.

- dimensions and cost

- walls and foundations .

- windows

- site of

Staggers, mad and sleepy-Chap. 31

staling, excessive

Stalls, slope of .

- width of

- partitions between

Standing, position of horse in

Starch for astringent enema

- for stiffening bandages

Sthenic inflammation

Stiff joint
PAR.

951

908

626

416

1043

310

938

533

600

- 640

648

- 843

618,1000

614

315

673

694

698

692

695

684

708

709

35

160

. 1,20

$1062 a$

- 21

- 26

24, 162

- 167

- 166

18,32

- 161

164

163

168

11

12

10

- 9

$23-33$

27, 38

25

22, 36

51

20

547

801

19

35

35

932

291

587

350

582
Stifle, conformation of

PAR.

- joint, injuries to

916

dislocations of, and sprains of . 707

Stimulants, diffusible

- irritant

Stomach

$372-83$

Stomatitis

$53-8$

Stopping of feet

$.877 a$

1004

Strains (see Sprains)

409

Strangles-Chap. 26

Straw

- (see also Bedding)

493

- $98 l$

- 570

Stringhalt-Chap. 34 do. . $\quad$. 658

Stud, size of, for hunting .

Stumbling

151

Sulkiness and vice

Sulphuric acid .

- ether

Summering of hunters

Superpurgation .

Suppuration

$931 \alpha, 998$

- 937

. 306

. 540

. 145

- 285

Suspensory ligament $\quad$. $\quad 678-84$

Survey, general, of horse-Chap. 701063

Sutures

751

Sweat or perspiration $\quad . \quad 102$

Swelled legs . . $\quad .517$

Swellings, inflammatory . $\quad$. 345

- dropsical-Chap. 28 . $\quad .509$

Synovia . $\quad$. 230

Synovial membranes . $\quad 230,638$

$\begin{array}{llll}- \text { joints } & . & . & \end{array}$

Tail, conformation of $\quad . \quad \quad 921$

Tails and manes $\quad$. 178

Tartar emetic . $\quad . \quad 298$

\begin{tabular}{lll} 
Tears . &. &. \\
\hline & 836
\end{tabular}

Teeth-Chap. 58 . $\quad .864$

- mark in . . . 871

- bishop-ing . $\quad . \quad 872$

- structural alterations with $\quad .865$

- further changes and collateral circumstances indicating age . 874

Temperature, animal . $.217 a$

- in disease . $\quad . \quad 483$

- of stables . . . 161

Tendons and ligaments, conformation of . 1 129,928

- structure of . $\quad$ 234, 674

- of fore-leg, sprains of-Chap. 44 673

- of hind leg, sprains of-Chap. 45699

- extensor, duties of $\quad . \quad 679$

- flexor, duties of $\quad . \quad 676$

— strengthened by exercise $\quad 129$

- remarks on conformation of . 928

- and ligaments, distinction between

234, 674

- sheaths of . $\quad . \quad 692$

Tetanus or lockjaw-Chap. $33 \quad 563$

Thermo-cautery $\quad$. $390 a$

Thermoineter, registering . . . 164

- elinical $\quad .217 a$ 
PAR.

Thick wind . $\quad . \quad 452$

Thorough-pins . $\quad . \quad 641$

Throbbing of arteries . . 346

Thrush

666,1015

- chronic $\quad$. $\quad$. $\quad .1017$

- neglected $\quad . \quad 1018$

- symptoms of . $\quad . \quad 666$

Tibia, conformation of $\quad$. $\quad 916$

- firactures of . $\quad$. $\quad 593$

Time, best, for exercise $\quad$ - $\quad 158,170$

- for grooming

- required to clean a horse

112-17

- 123

- racing, English and Arab

- 935

Tips. . $\quad 983$

Tissues, structure of various-Chap.13 227

- cartilage . . 231

- fibro-cartilage $\quad . \quad 232$

- inter-articular fibro- . $\quad .233$

- fibrous, yellow and white $\quad 234$

- areolar or cellular . $\quad .235$

- fascia $\quad$. $\quad 236$

- muscular $\quad$. $\quad$. 237

\begin{tabular}{llll}
- adipose & . &. & \\
\hline
\end{tabular}

- ligamentous and tendinous $\quad .674$

Toe, seedy . . . 1014

Touics, inineral and vegetable $\quad . \quad 304$

Treads . 1005

Trephining • $\quad . \quad 492$

Trifolia, objectionable as food for sick horses .

Trotting action .

Tumours, slight, or warbles $\quad$ - 759

Turued-up shoes-Chap. 64 992

Turpentine, as diuretic . $\quad 292$

- as liniment . . $\quad 310$

Tusks .

875

Ulceration and sloughing-Chap. 21; also par. 356

Ulcers, varieties of

Ulna, conformation of $\quad . \quad 900$

Union, modes of, in flesh woundsChap. 48 .

Unmerving for spavin : $\quad$. 611

- for navicular disease . . $\quad .1026$

Upland hay

$80-83$

Urinary organs-Chap. 55

Urine, bloody .

785

- retention

-

Veins . $\quad . \quad 209$

Venous and arterial blood $\quad \therefore 206$

- system

Ventilation-Chaps. 1, 2.

— arguments against

- natural facilities for

- improvement of, in old stables Chap. 2.

- of infirmary stables

- boxes

- of stables with rooms over them.

Vermifuges

PAR.

Vertige or megr

Vesions-Chap. $32 \quad 561$

V • • • 385

Vetches . . $98 f$

Veterinary science, progress of Chap.66 . $\quad . \quad 1034$

- sanitary science, progress of $\quad .1036$

- and buman medical science, distinction between

1037

- sanitary legislation . $\quad .1038$

Vice and sulkiness $\quad . \quad$. 937

Villi . $\quad$. $\quad .0 \quad 228$

Vital structures, repairs of injuries to-Chap. $33 a$

569

$\begin{array}{lll}\text { Vitreous humour } & \text { • } & \text {. } 826\end{array}$

Walking action . $\quad$. 930

Wall or crust of foot $\quad \cdot \quad 943$

Walls and foundations of stables $\quad . \quad 22$

$\begin{array}{llll}\text { 一 inside of } & \text {. } & \text {. } & 36\end{array}$

Warbles . . $\quad .759$

Warming, artificial, of stables 24,162

Warmth of body in disease $\quad 250$

Warranty, law of-Chap. $61 \quad 938$

- responsibility of V.S. . $\quad .939 a$

Warts-Chap. 53 . $\quad$. 781

Washing of skin $\quad$. 118

Water, hard and soft $\quad . \quad 64$

- clean and dirty $\quad$. $\quad .64$

— for sick horses $\quad$. 258

- apparatus for applying cold stream 265

Watering and feeding-Chap. 4 . 53

Water-meadow hay $\quad 80,81$

Weaving . $\quad . \quad 194$

Weed . $\quad$ - $\quad 226,517$

Weeds in hay . $\quad \cdot \quad 92$

Weighing oats, mode of . $\quad 71$

Wheat . . . 75b

Whiskers $\quad . \quad 105$

Whistling . $\quad . \quad 463$

White fibrous tissue . $\quad$. 234

White and grey legs, cleaning of 121

Wind, broken . . 465-9

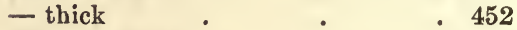

Wind-sucking . $\quad$. $\quad$. 196

Windgalls $\quad . \quad$. $\quad .644$

Windows $\quad \cdot \quad 51$

Withers, conformation of . $\quad 894$

— fistulous . $\quad 713$

Wood-wool, medicated $\quad . \quad 754$

Work (see Exercise).

$\begin{array}{ll}\text { Working life of horses } & \cdot \\ \text { - cab and job } & \cdot\end{array} 199 a$

Worms-Chap. 54 $\quad$. 781

Worm in the eye $\quad$. 784

Wounds, flesh-Chap. 48 . 731

— of joints-Chap. 47 . 714

Yellow fibrous tissue $\quad$. 234

Zinc, sulphate of $\quad$ • 307 
Bones of the Hock.

A

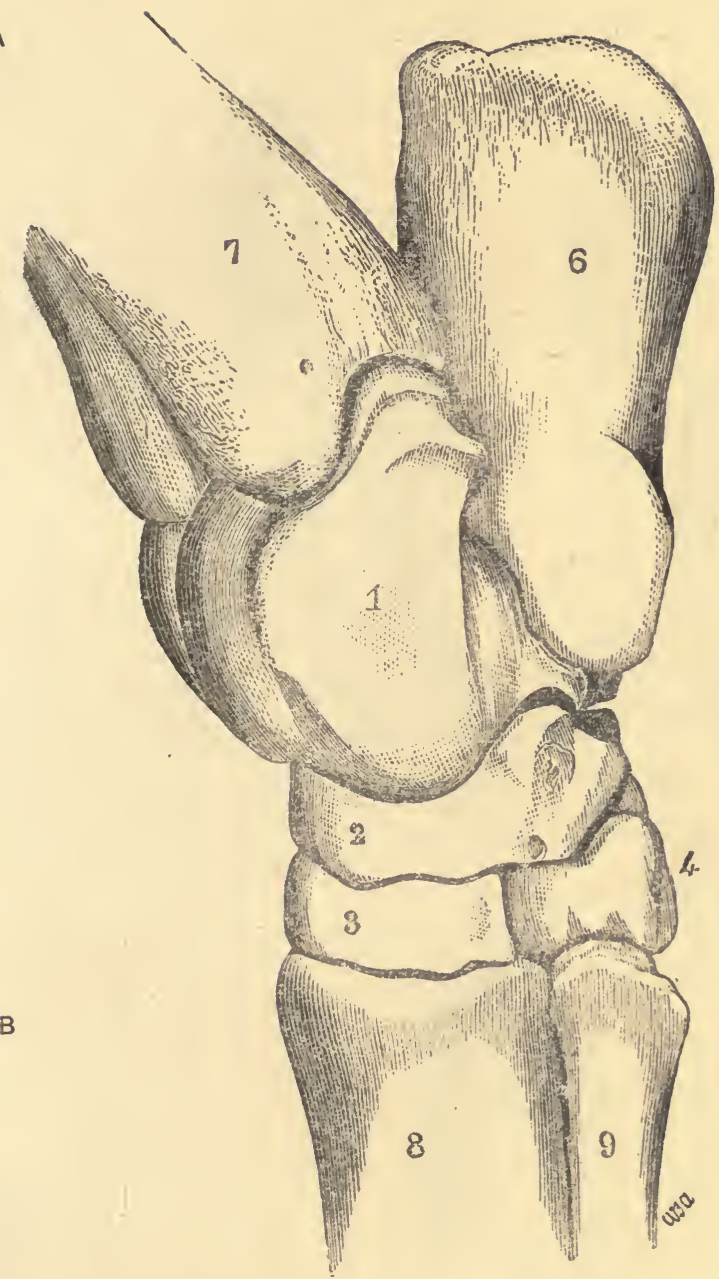

A

B

1. Astragalus.

2. Cuneiform magnum.

3. Cuneiform medium.

4. Cuneiform parvum.
6. Os calcis.

7. Tibia.

8. Great metatarsal, or cannon bone.

9. Inner small metatarsal.

N.B.-Cuboid is on outer side of cunciform bones, and therefore does not appear in above diagram. 

Plate 24.

Conformation of Hock.

Fig. 4.

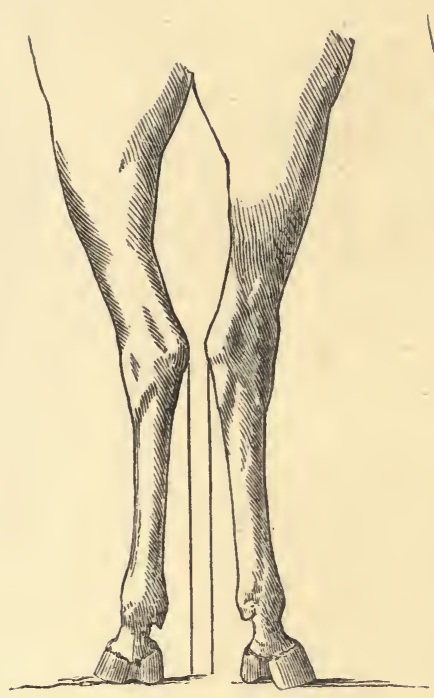

Hocks - Too close.

(Too much in.)
Fig. 5.

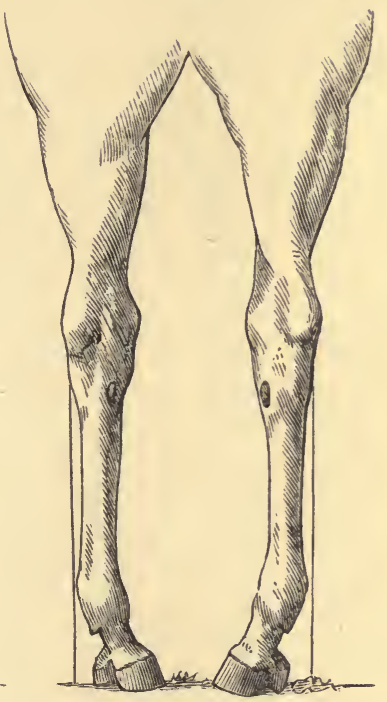

Hocks-Too wide.

(Too much out.)
Fig. 6.

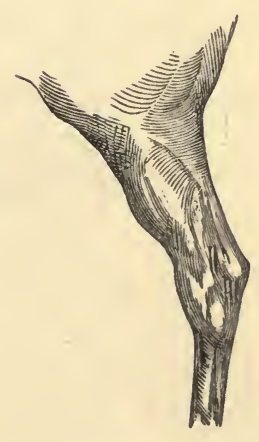

Prominent os calcis.
Fig. 7.

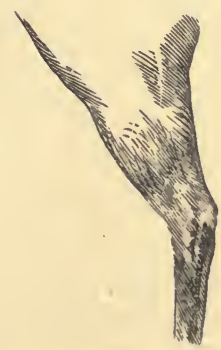

Badly developed os calcis.

"Weak" hock " not well let down." 
Bones of Fore-leg.

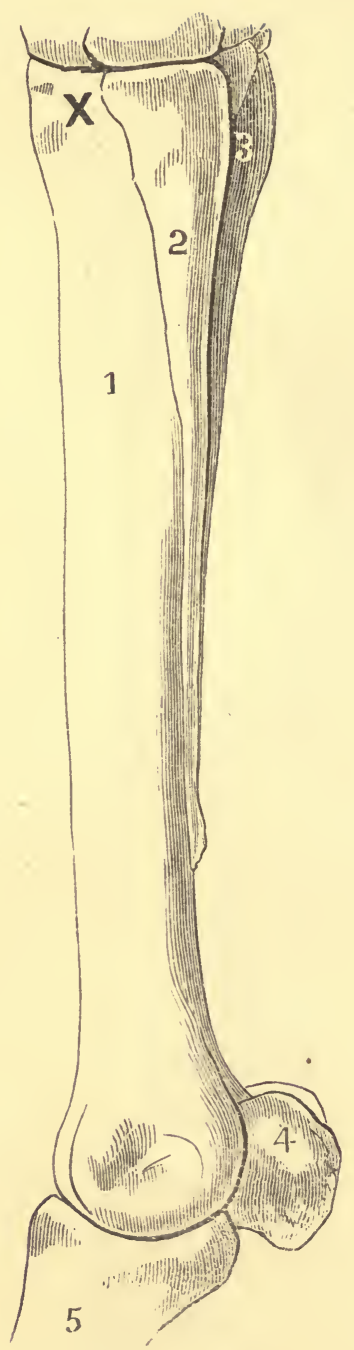

Inner-side Tiew.

1. Great metacarpal, otherwise called the cannon or shank bone.

2. Inner small metacarpal or splint bone.

3. Outer ditto.

4. Sesamoid bunes.

5. Upper pastern or os suffraginis.

$X$. Seat of speedy cut.

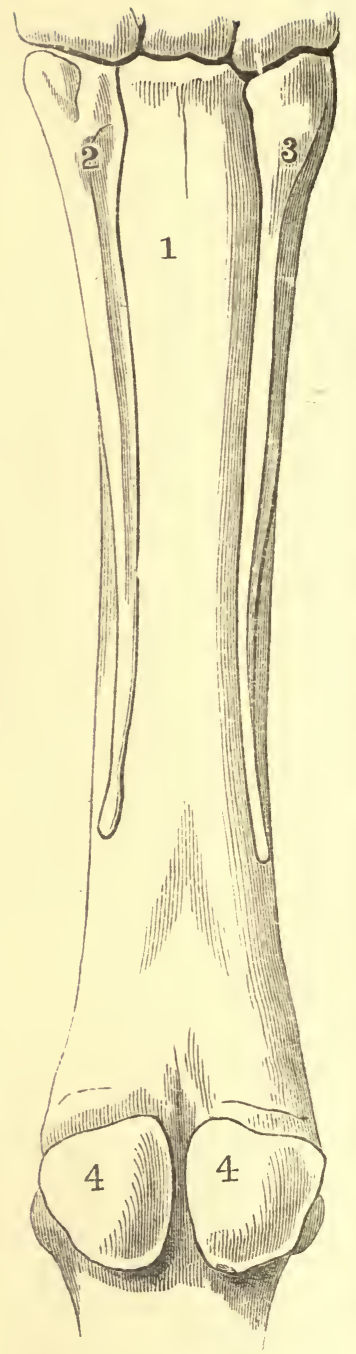

Posterior Viev.

1. Great metacarpal bone.

2. Outer small metacarpal or splint bone

3. Inuer ditto.

4. Sesamoid bones. 


$$
\begin{aligned}
& \text { VIII } \\
& \text { VII }
\end{aligned}
$$


Tendons and Ligaments of the Fore-leg.

S. Splint bone.

E. Extensor tendon.

M. Great metacarpal, or cannon or shank bonc.

E. Extensor tendon.

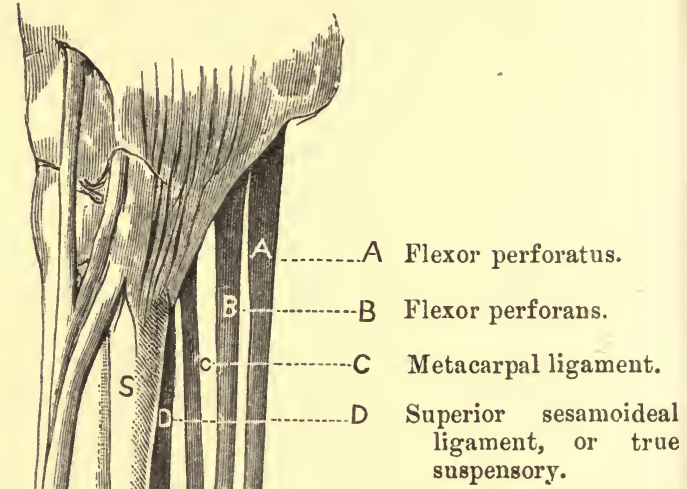

Insertion of Metacarpal ligament into Flexor perforans.

uperior sesamoideal ligament at bifurcation.

Flexor perforans.

Flexor perforatus.

Sesamoideal ligament at its insertion into fetlock (on both sides).

Continuation forward of branch of the sesamoideal ligament.

Continuation of the Flexor perforansafterwards inserted into the lower side of the os pedis.

Coffin bone. 
Plate 28.

View of the Bones of the Off Knee.

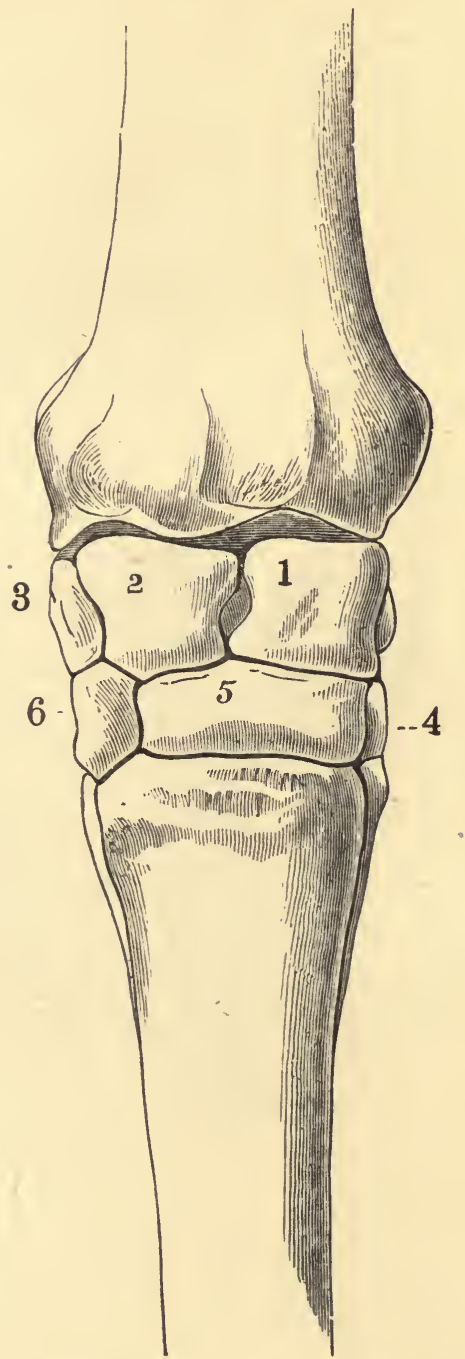
1. Cuneiform.
2. Lunar.
4. Unciform.
3. Scaphoid.
5. Magnum.
6. Trapezoid.

N.13.-The trapezium or bone at the back of the knee is not shown in this drawing. 
Plate 29.

Ligaments of Hock Joint.

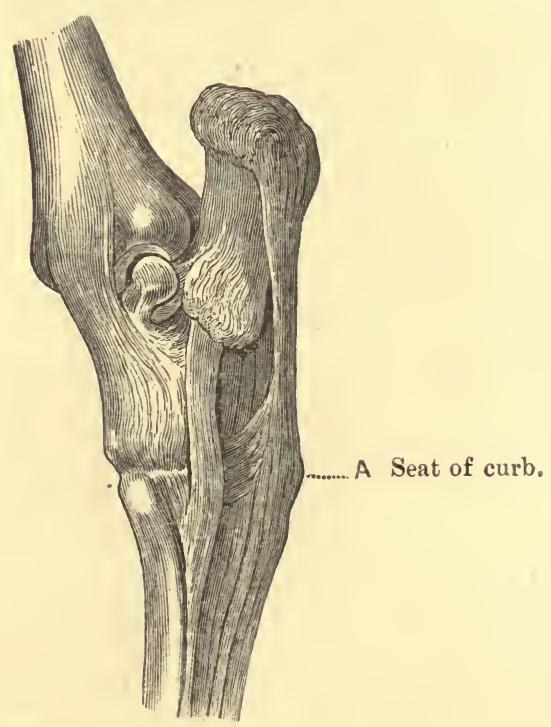


Prate 30.

The Eye.

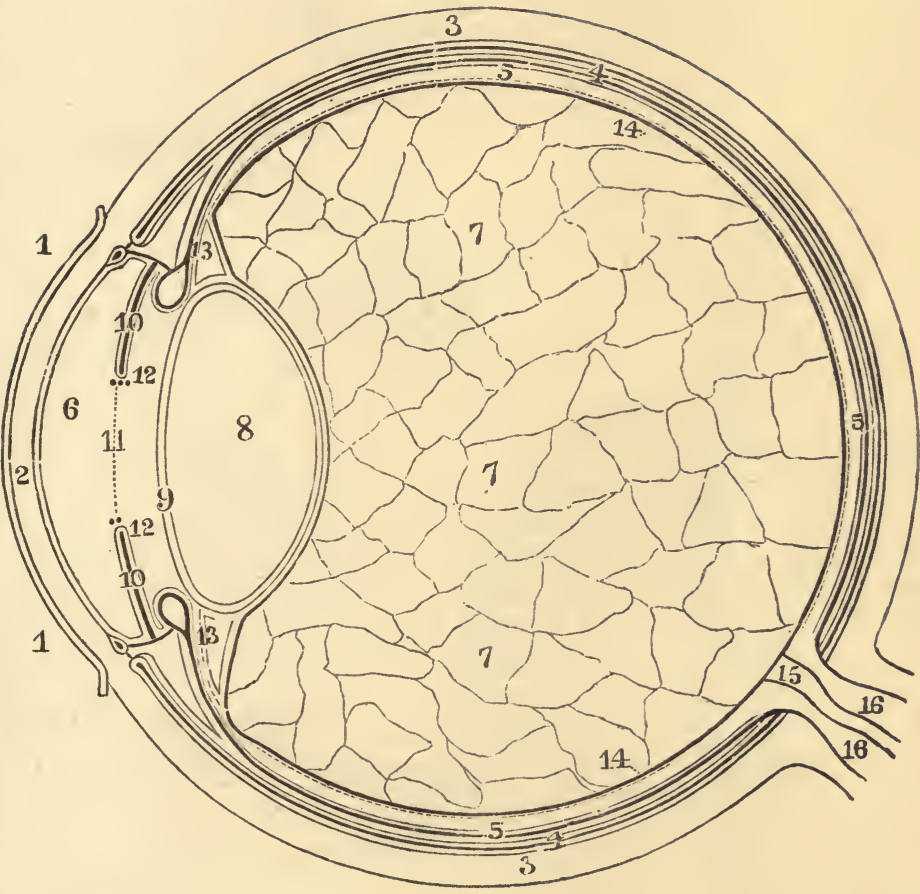

1. Conjunctiva.

2. Cornea.

3. Sclerotic coat.

4. Choroid coat.

5. Retina.

6. Aqueous humour.

7. Vitreous humour.

8. Crystalline lens.
9. Capsule of lens.

10. Iris.

11. Pupillary opening.

12. Corpora nigra.

13. Ciliary ligament.

14. Hyaloid membrane.

15. Optic nerve.

16. Arteries and veins. 
Plate 31.

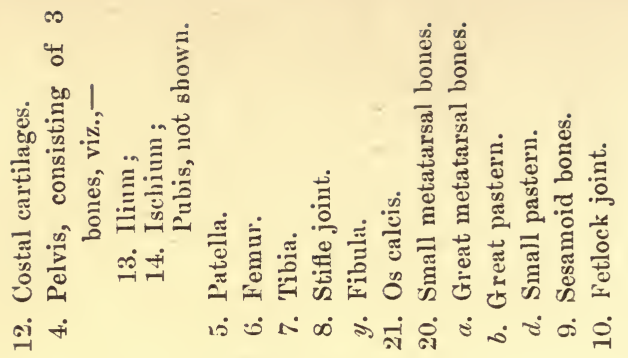

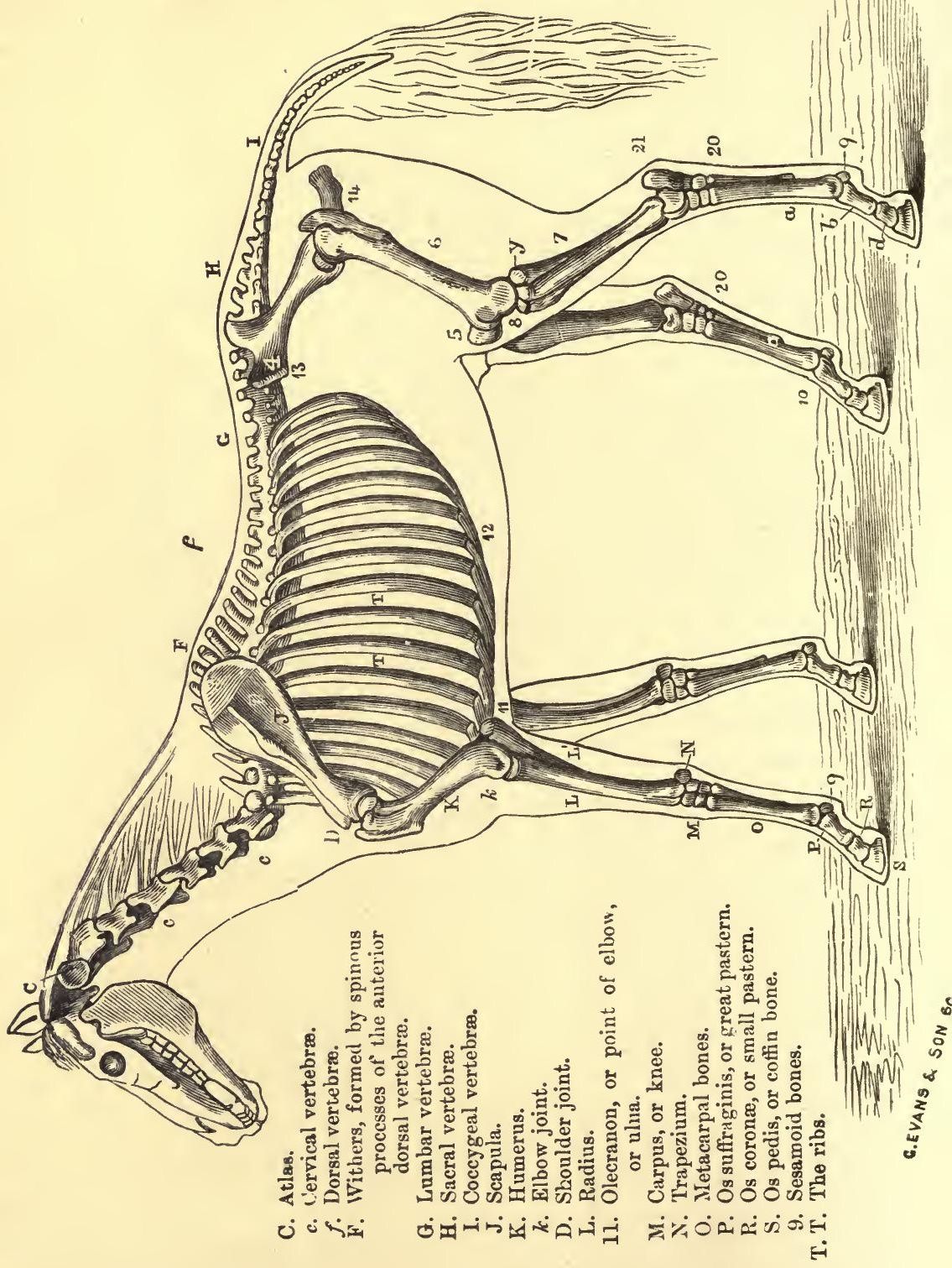


Fig. 1.

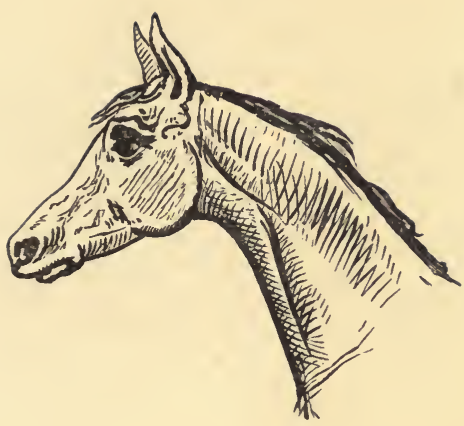

Fig. $1 a$.

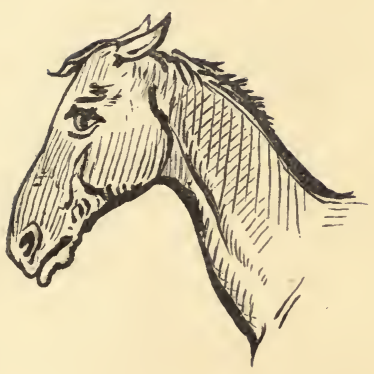

Fig. 16 .

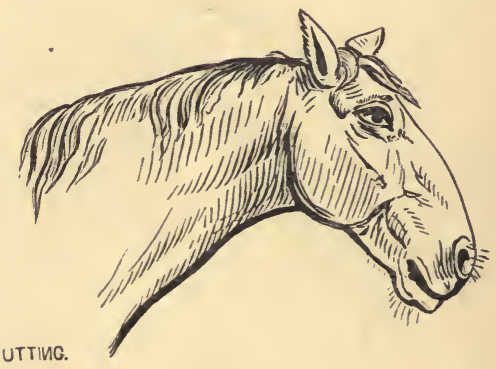

Fig. 2.

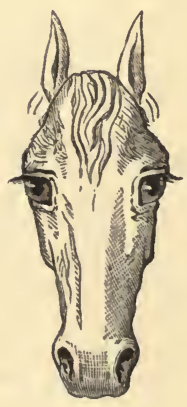

Fig. $2 a$.

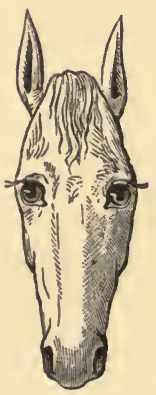

Fig. $2 b$.

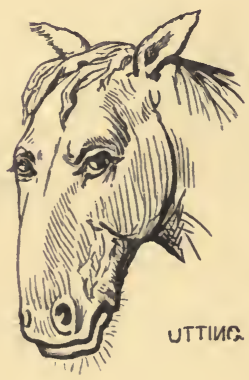


Piate 33.

Fig. 3.

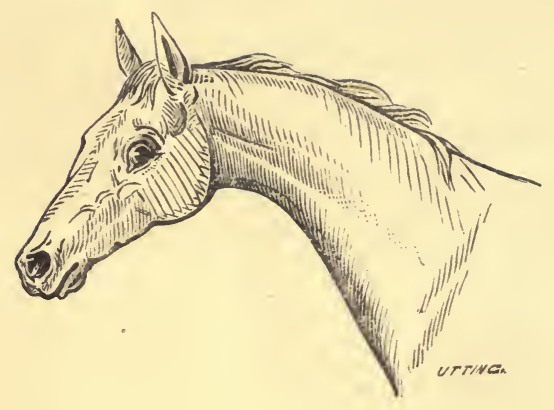

Fig. $3 b$.

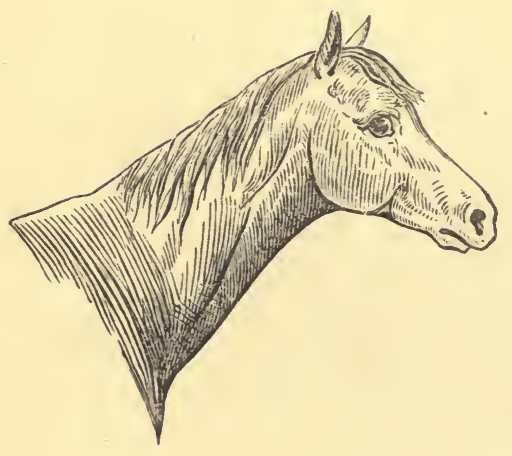

Fig. $3 d$.

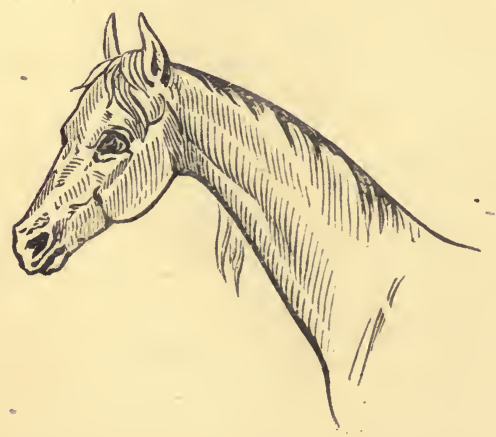

Fig. $3 \alpha$.

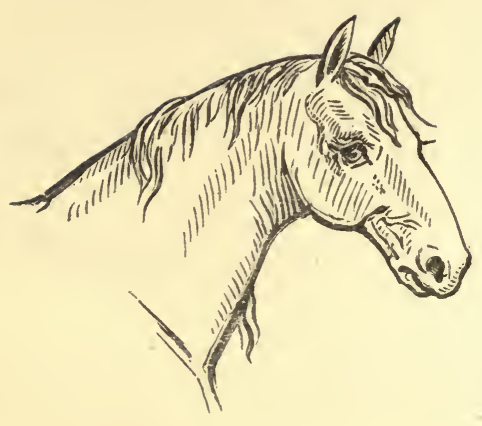

Fig. 3c.

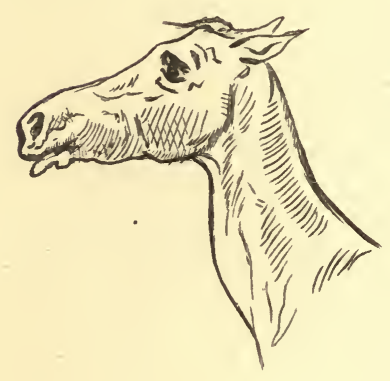

Fig. $3 e$.

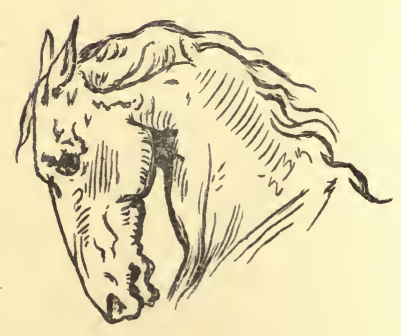


Fig. 4.

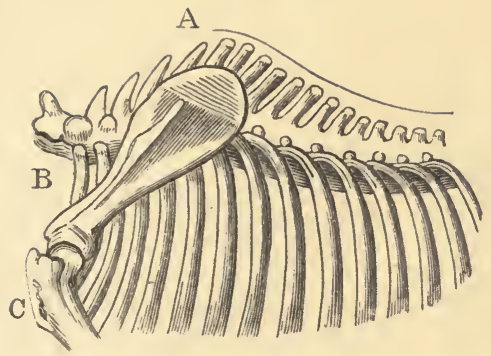

Fig. $4 a$.

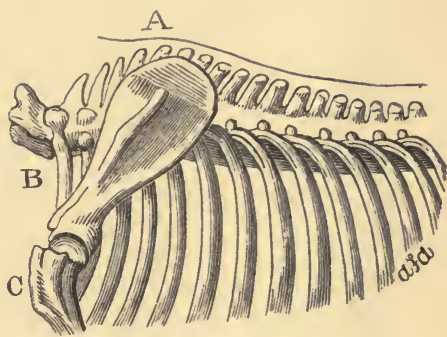

A-Withers; B-Scapula ; C-Humerus.

Fig. 5.

Fig. $5 a$.
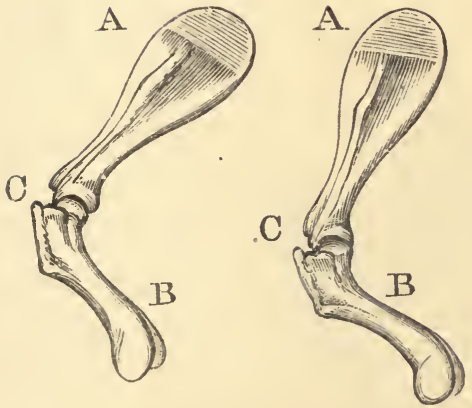

Fig. $5 b$.

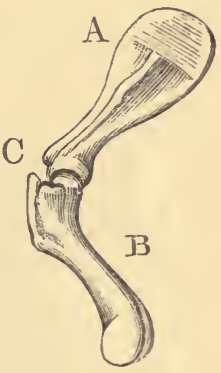

Fig. $5 c$.

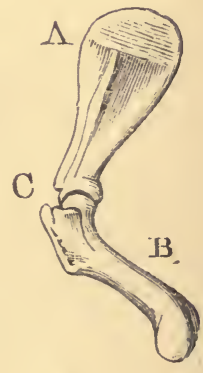

A-Scapula ; B-Humerus; C-Shoulder-joint.

Fig. 6.

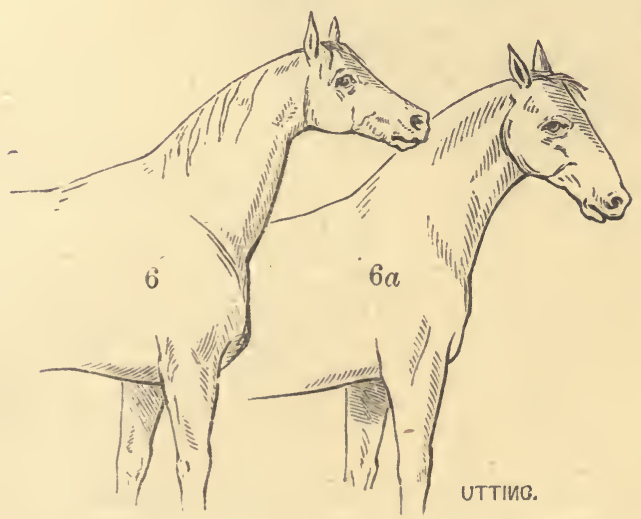

Fig. 7. Fig. $7 a$.
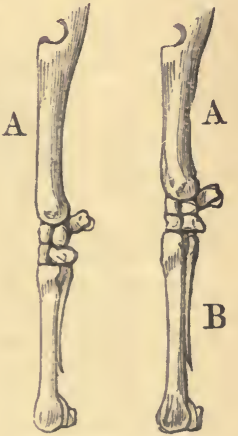
Plate 35.

Fig. 8.

Fig. $8 a$.

Fig. $8 b$.
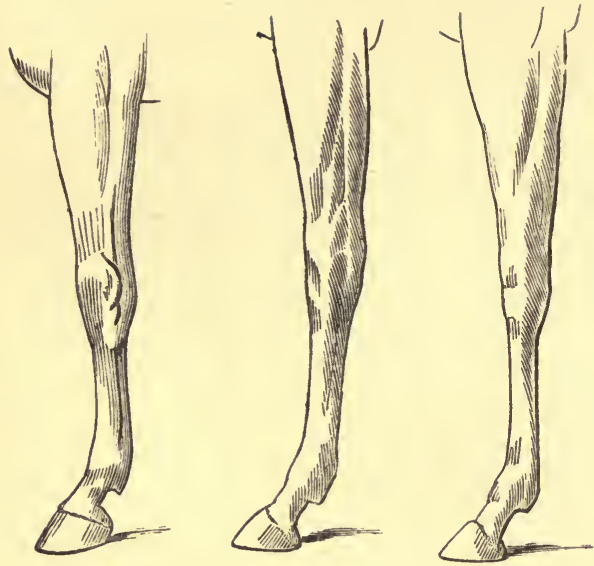

Fig. $9 a$.

Fig. 9.

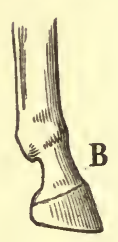

A. Long pastern.

B. Short pastern.

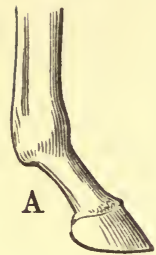

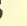
.

Good knee. Calf or buck knee. Small knee.

Fig. 10.-Section of a Foot.

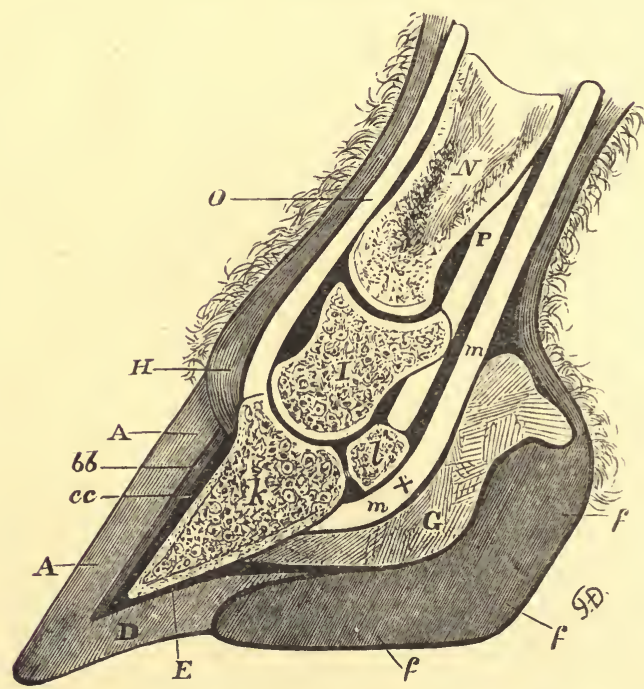

A A. Crust or wall.

$b b$. Insensitive laminæ.

c c. Sensitive laminæ.

D. Insensitive sole.

E. Sensitive sole.

$f f$. Insensitive frog.

G. Sensitive frog.

H. Coronary band.

I. Small pastern bone. 
Plate 36.

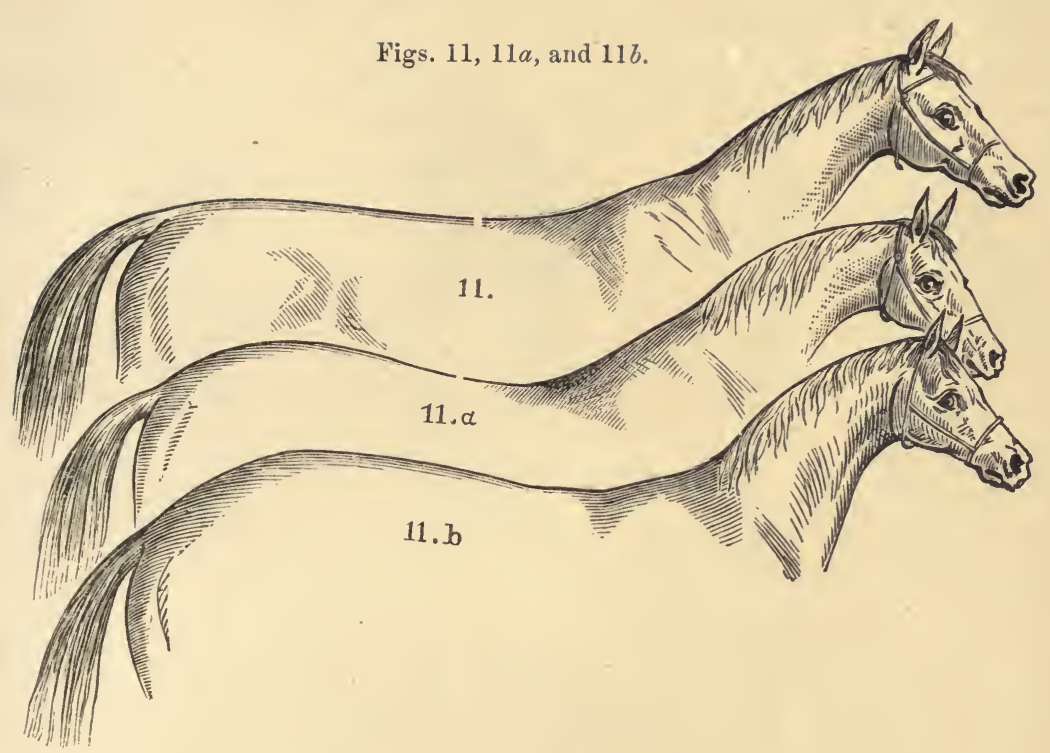

Fig. 12.

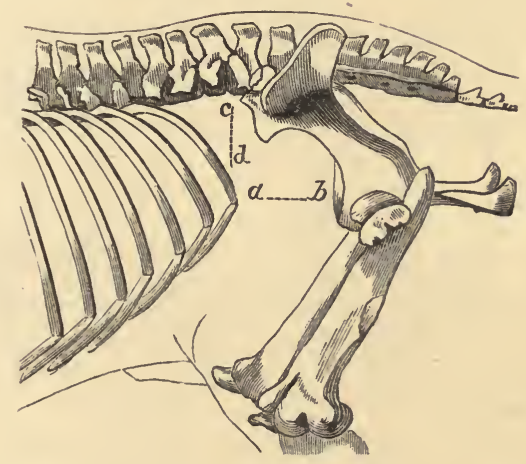

Fig. $12 a$.

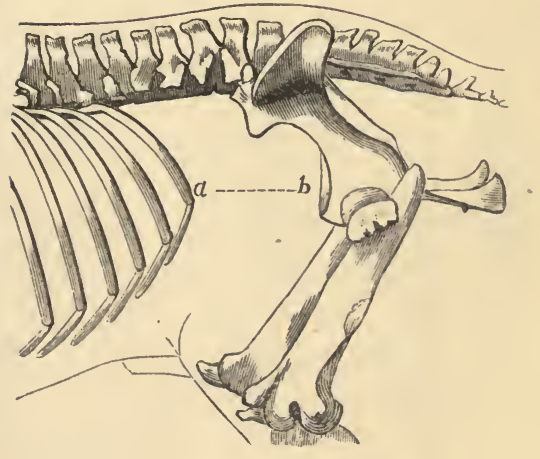

Fig. $12 b$.

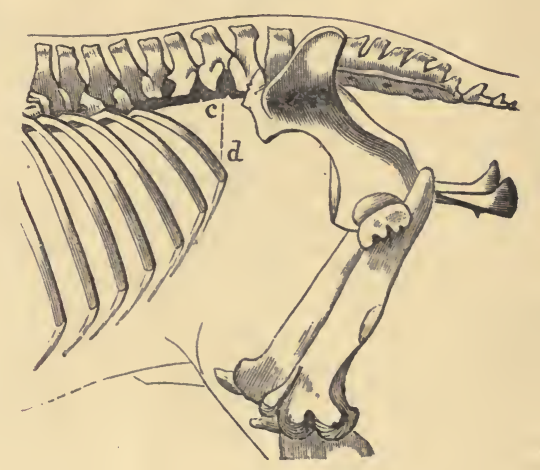


Plate 37.

Fig. 13.

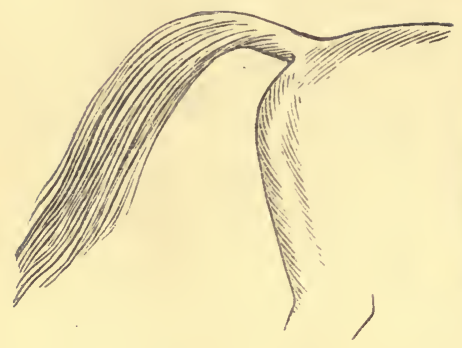

Fig. 14.

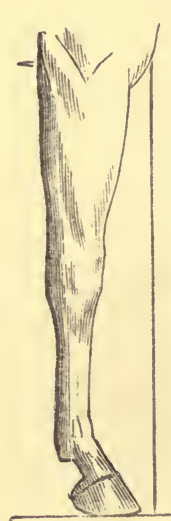

Fig. 15.

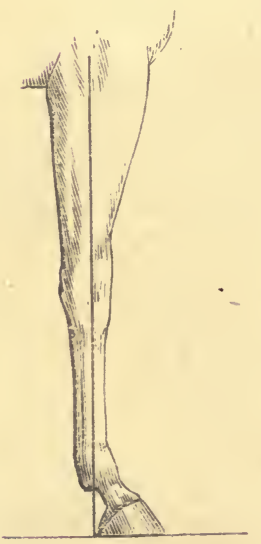

Fig. $13 a$.

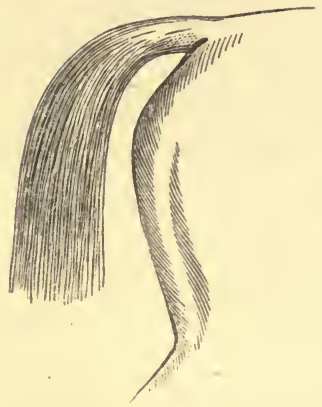

Fig. $14 a$.

Fig. $14 b$.

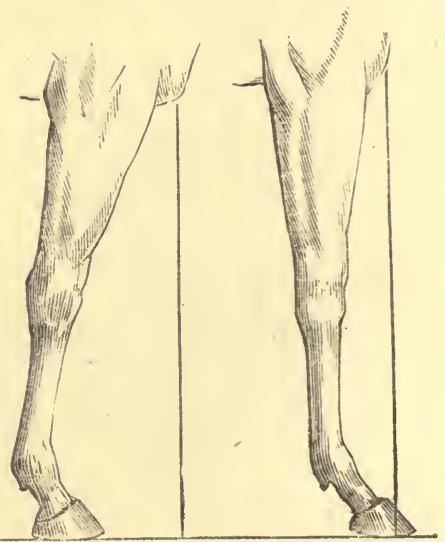

Fig. 15a. Fłg. $15 b$.

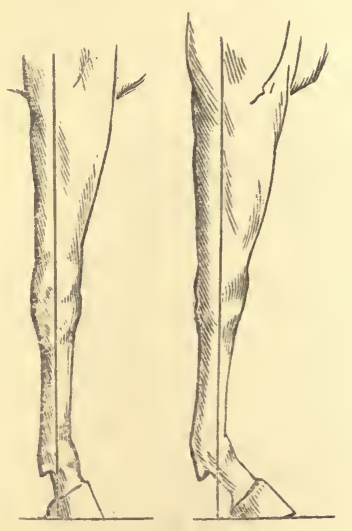

Fig. $13 b$.

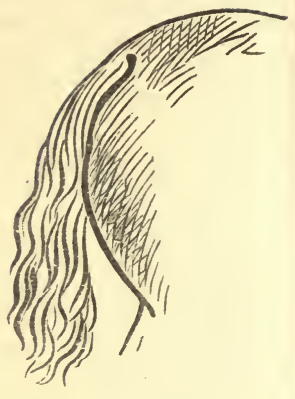


Fig. 16.

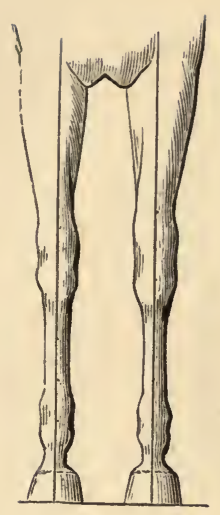

Fig. $16 a$.

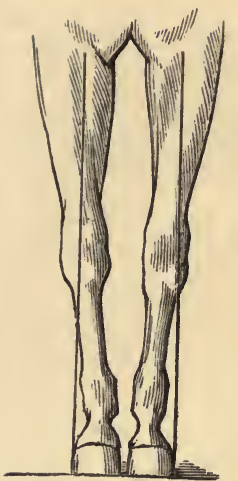

Plate 38.

Fig. $16 b$.

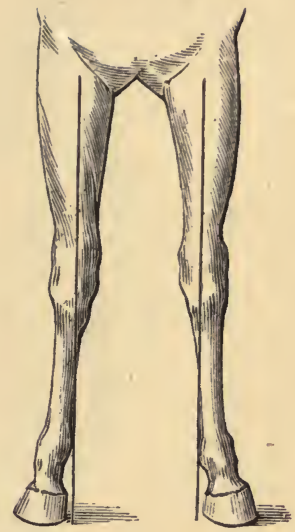

Fig. 17.

Fig. 17a.

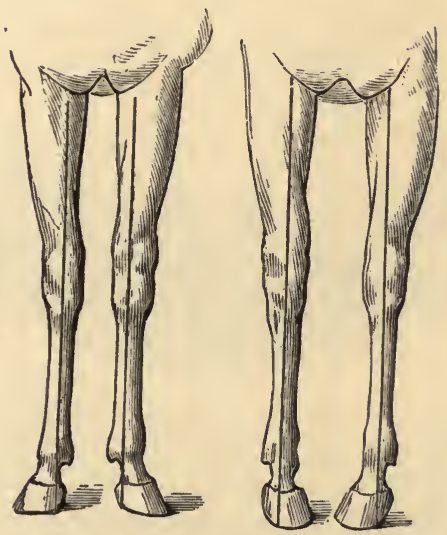

Fig. 18. Fig. 18a.

Fig. $18 b$.

Fig. 18c.

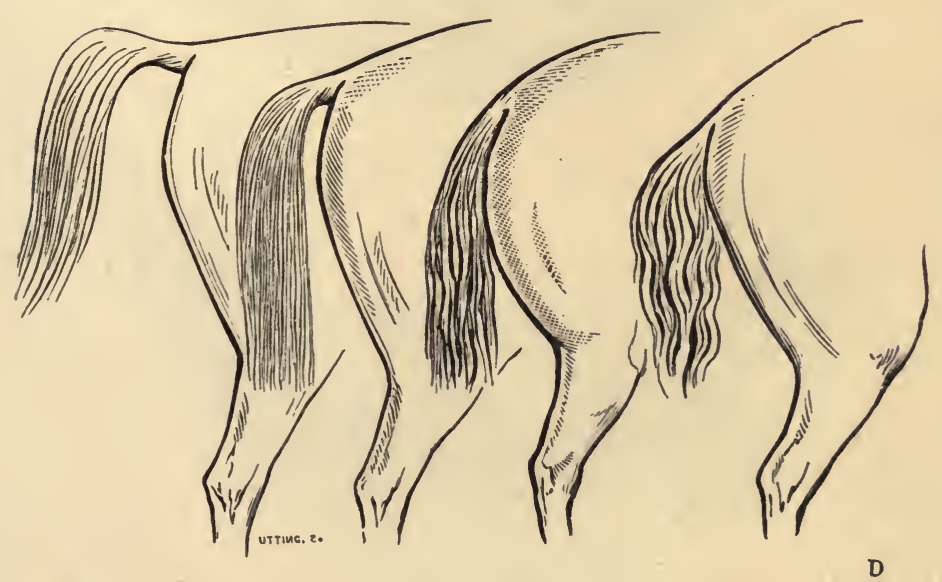


Plate 39.
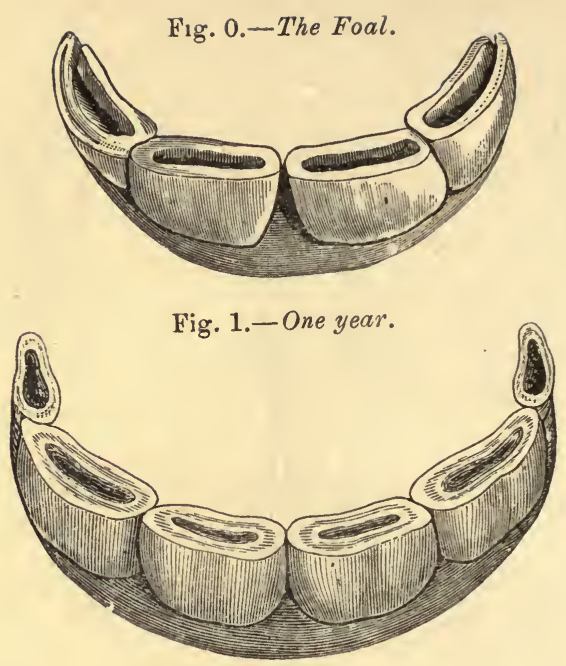

Fig. 2.-Two years.

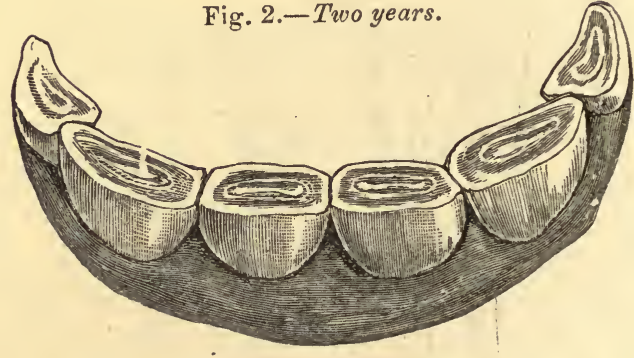

Fig. 3.-Three years.
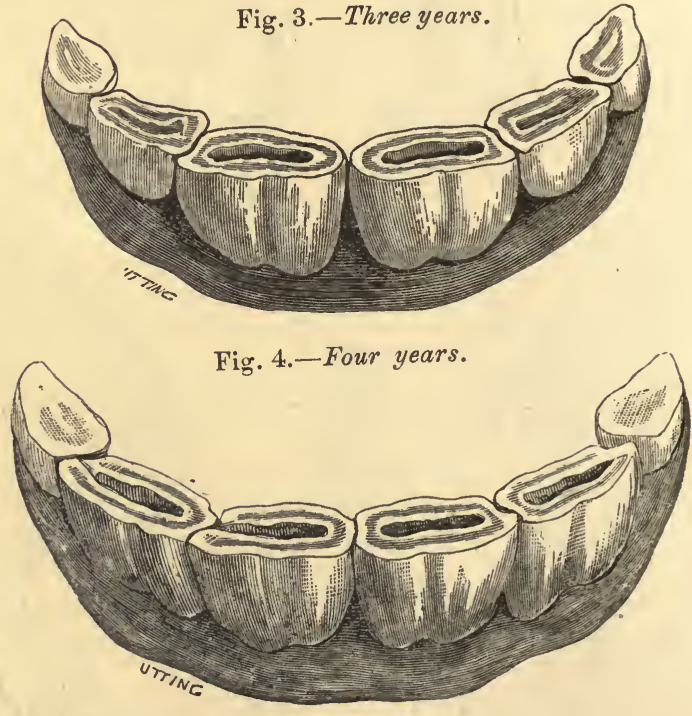

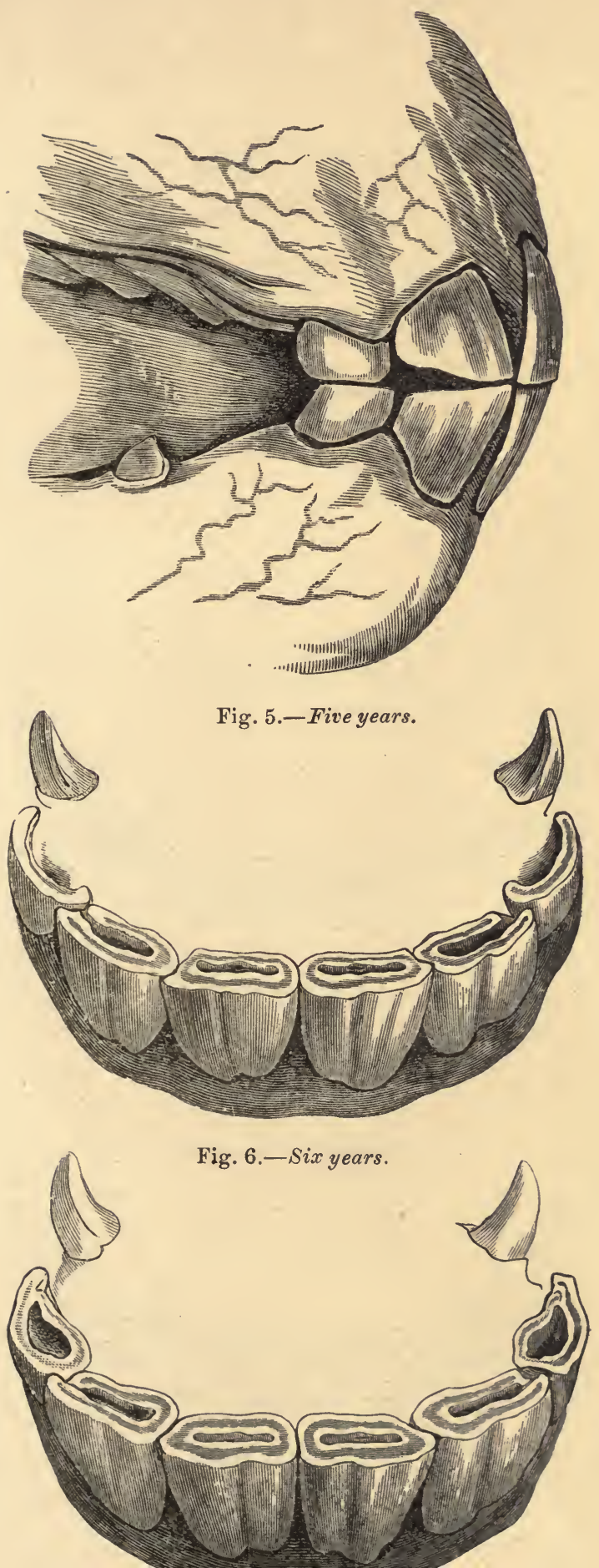
Plate 41.

Fig. 7.-Seven years.

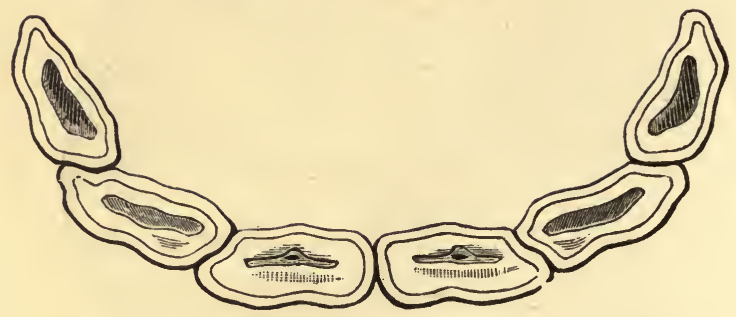

Fig. 8.-Eight years.

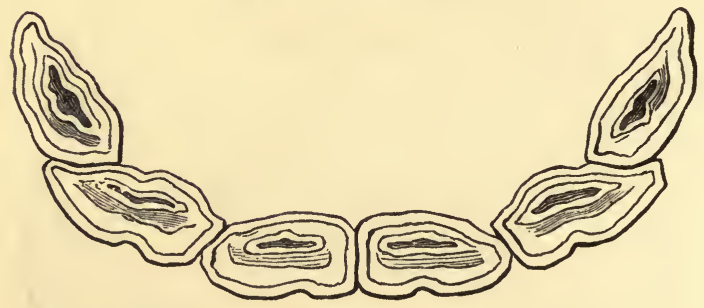

Fig. 9.-Nine years.

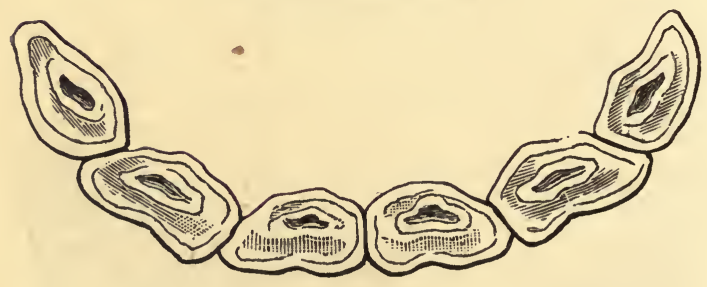


Fig. 10.-Ten years.

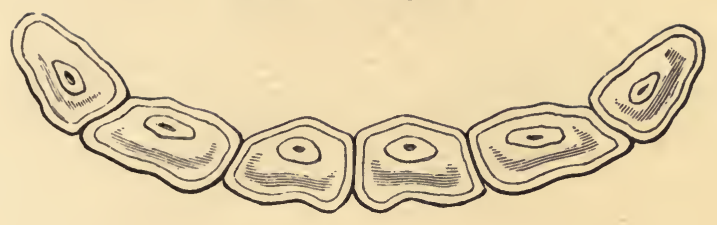

Fig. 11.--Eleven years.

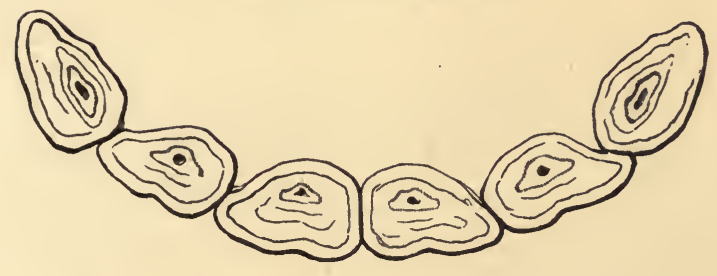

Fig. 12.-Twelve years.

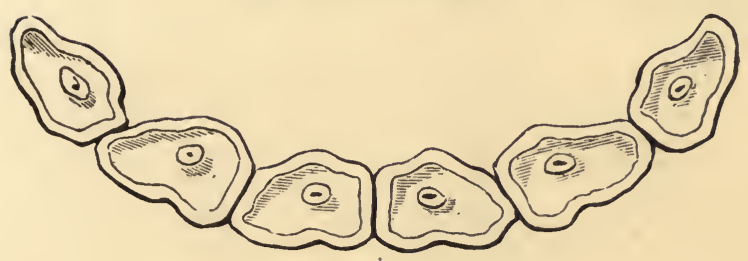

Fig. 13.-Sixteen years.

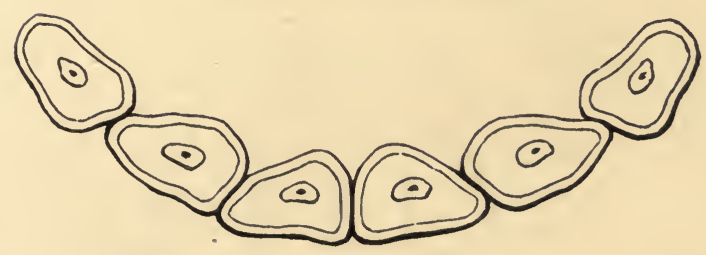


Plate 43.

Fig. 14.-Twenty years.

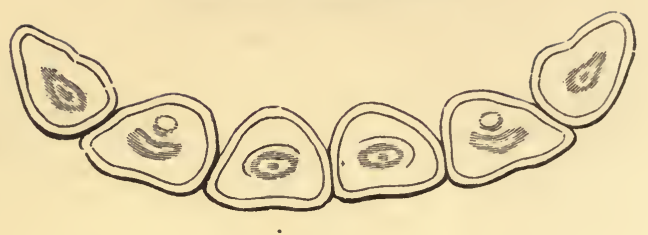

Fig. 15.-Twenty-four years.

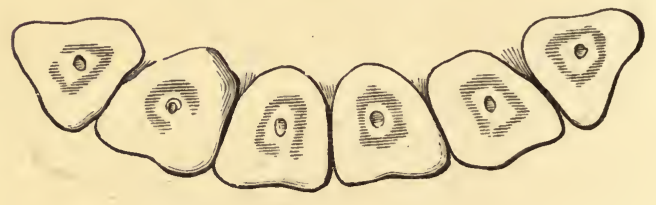

Fig. 16.-Extreme age.

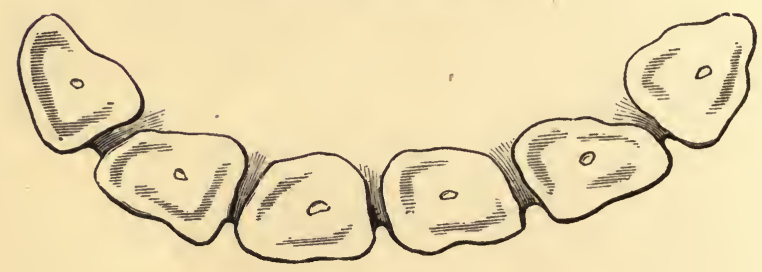

Fig. 17.-Extreme age.

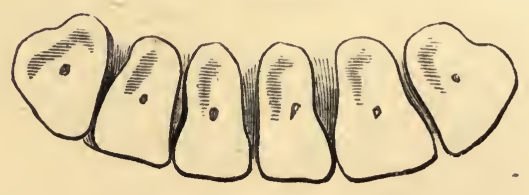


Fig. 18.-Section of a Tooth. A-Infundibulum. B-Fang Hole.

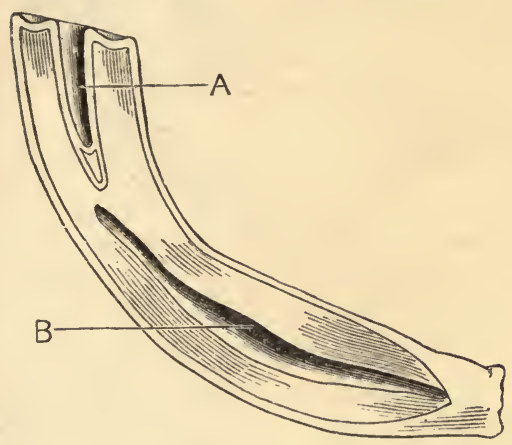

Fig. 20.-Removal by the saw of successive portions of a Tooth.
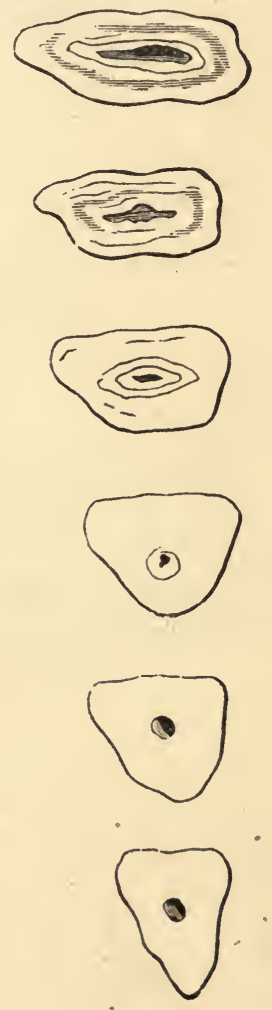

Fig. 19.--Real and simulated marks. Fig. $19 a$.
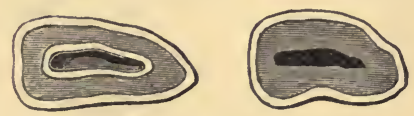

Fig. 29.-Parrot mouth.

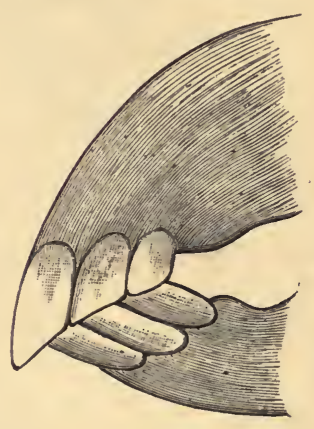

Fig. 21.-Original form of a Tooth.

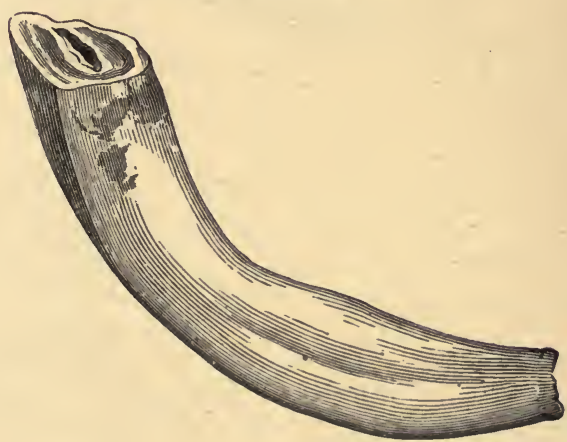


Plate 45. Slope of the Teeth at Different Ages.

Fig. 22.-Two years.

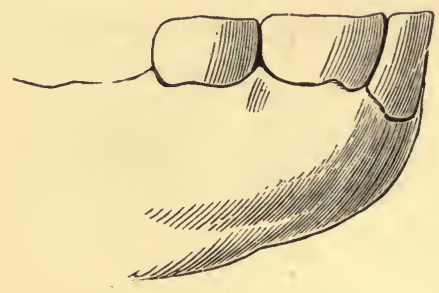

Fig. 24.-Twelve years.

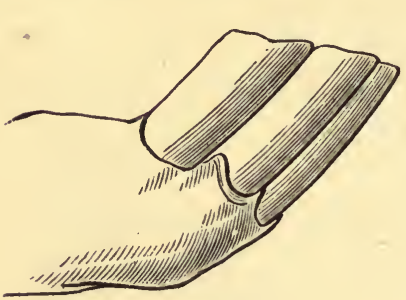

Fig. 26.-Extreme Age.

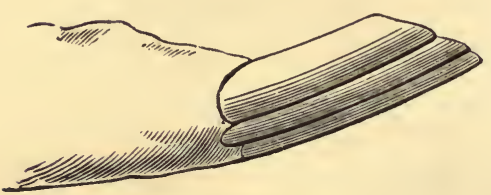

Fig. 23.-Six years.

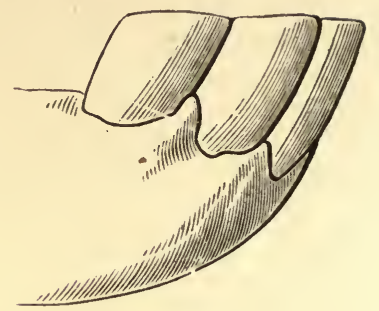

Fig. 25.-Eighteen years.

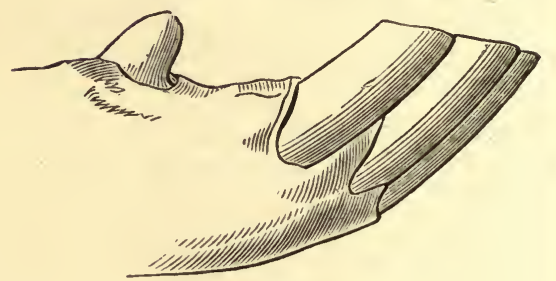

Fig. 27.-Closing of Mouth in Extreme Age

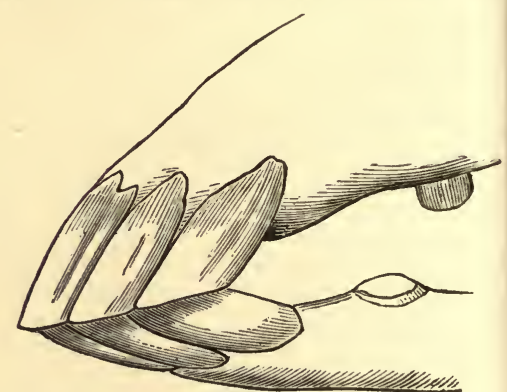

Fig. 28.-The Tusks.

Four years. Five years.
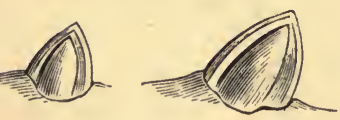

Six years.

Eight years. Twelve years.

old.
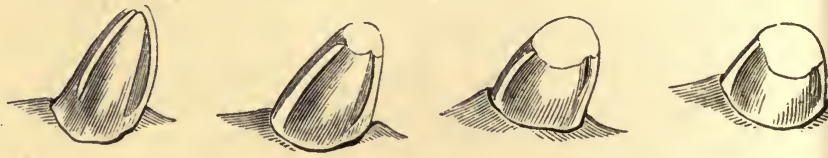
Plate 46.

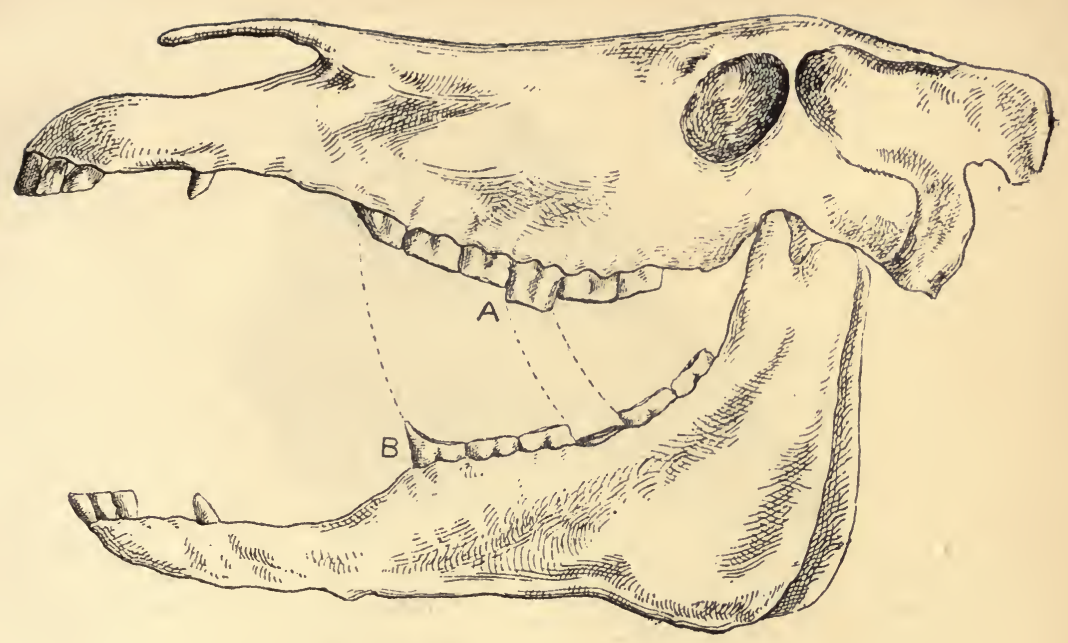

FIG.I

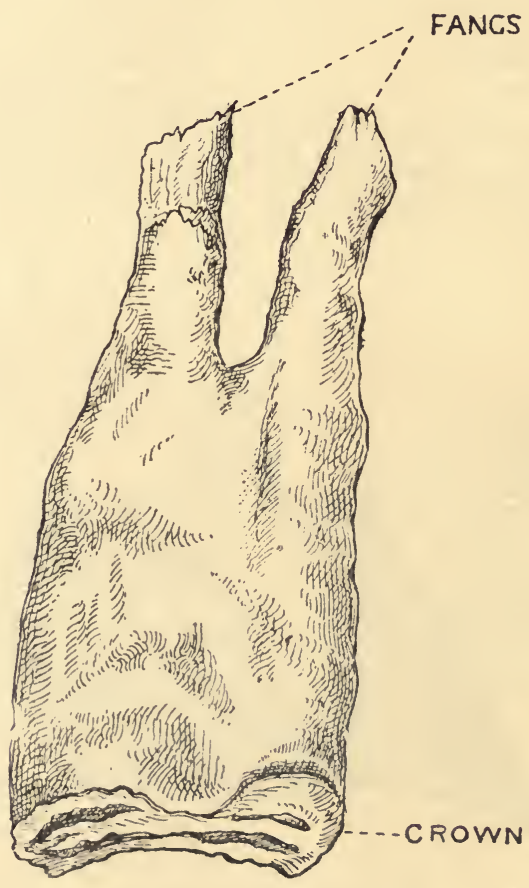

\section{Fic.?}

Molar Tooth-Upper Jaw. Natural size. 


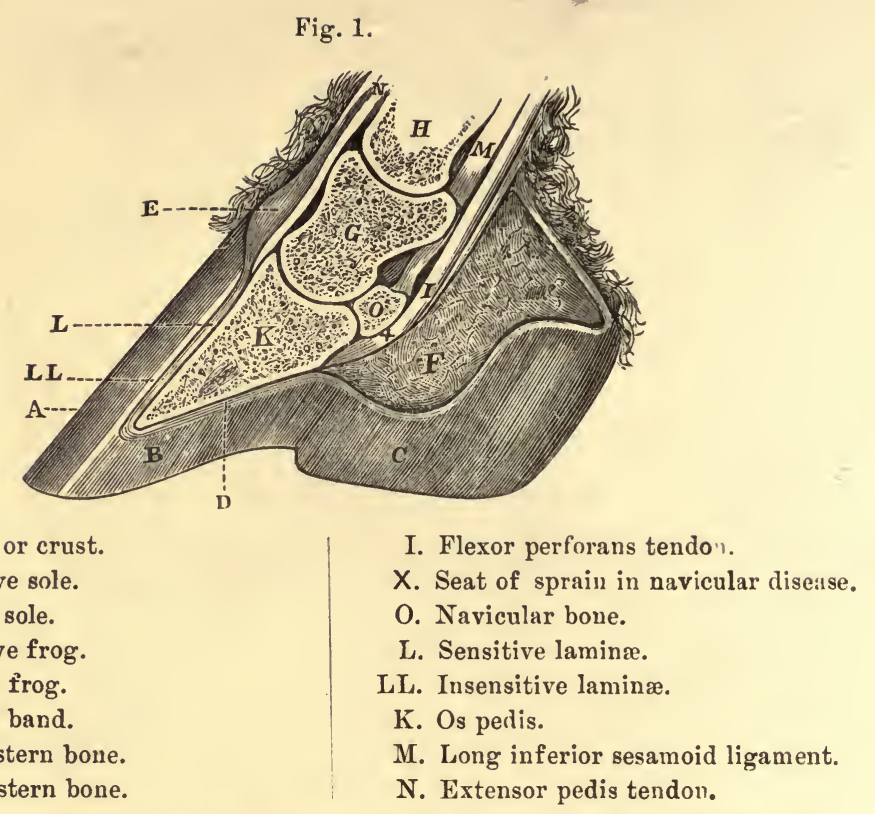
A. The wall or crust.
B. Insensitive sole.
D. Sensitive sole.
C. Insensitive frog.
F. Sensitive frog.
E. Coronary band.
G. Small pastern bone.
H. Great pastern bone.

I. Flexor perforans tendo'".

$X$. Seat of sprain in navicular disease.

O. Navicular bone.

L. Sensitive laminæ.

LL. Insensitive laminæ.

K. Os perlis.

M. Long inferior sesamoid ligament.

The appartnt position of the Os pedis pointing down so much at the toe is due to the section being made in the centre of the bone, where it is most concrve. The lateral appearance would be flat.

Fig. 2.

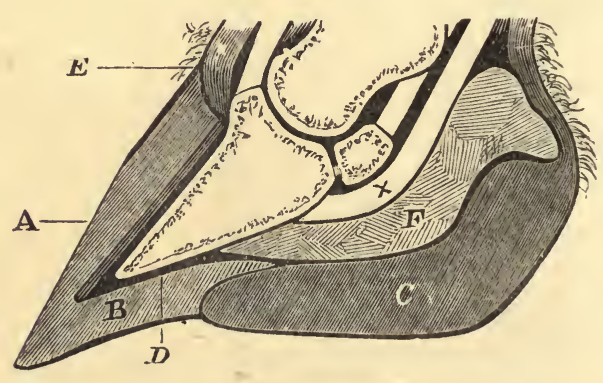

A-Crust rasped high up. 
Plate 48.

Fig. 3.

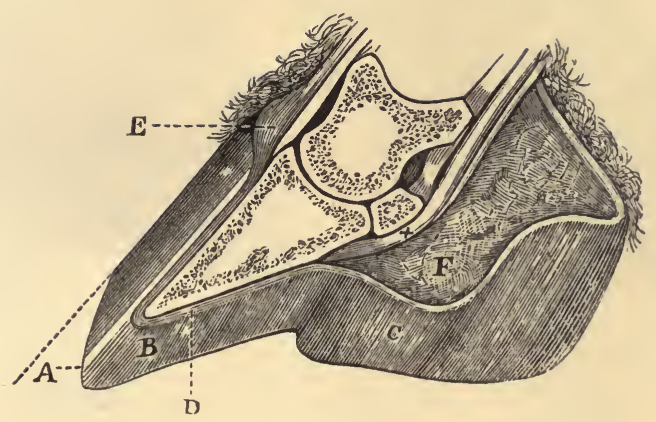

A-Crust rasped low down.

Fig. 4.

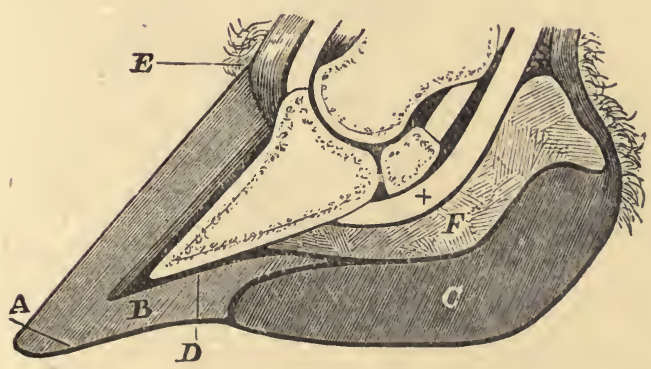

Crust lowered and shortened from underneath (par. 946). 
Plate 49.

Fig. 5.

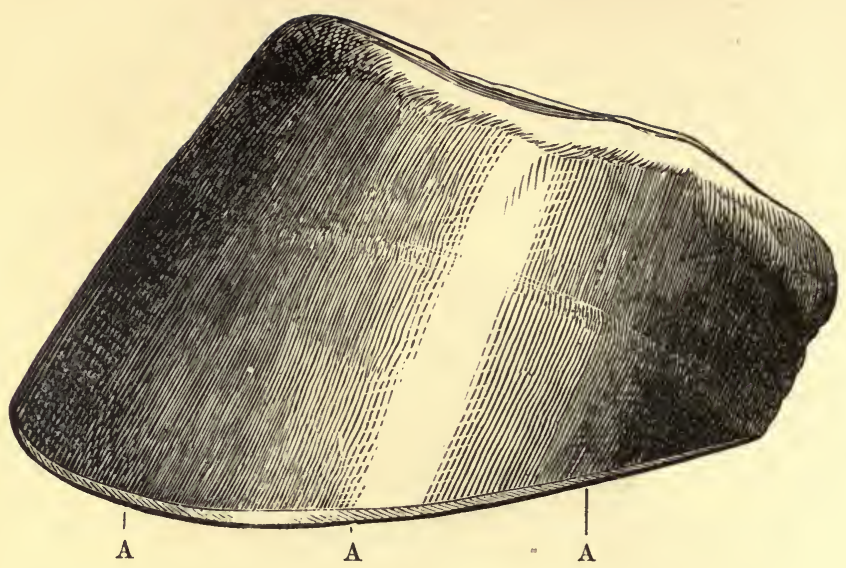

Fig. 6.

$b$-Cleft of frog. $\quad l \quad b$-Cleft of frog.

D-Seat of corn.

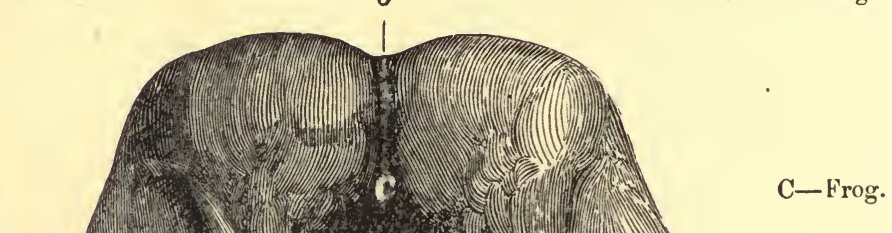

E-Crust or wall

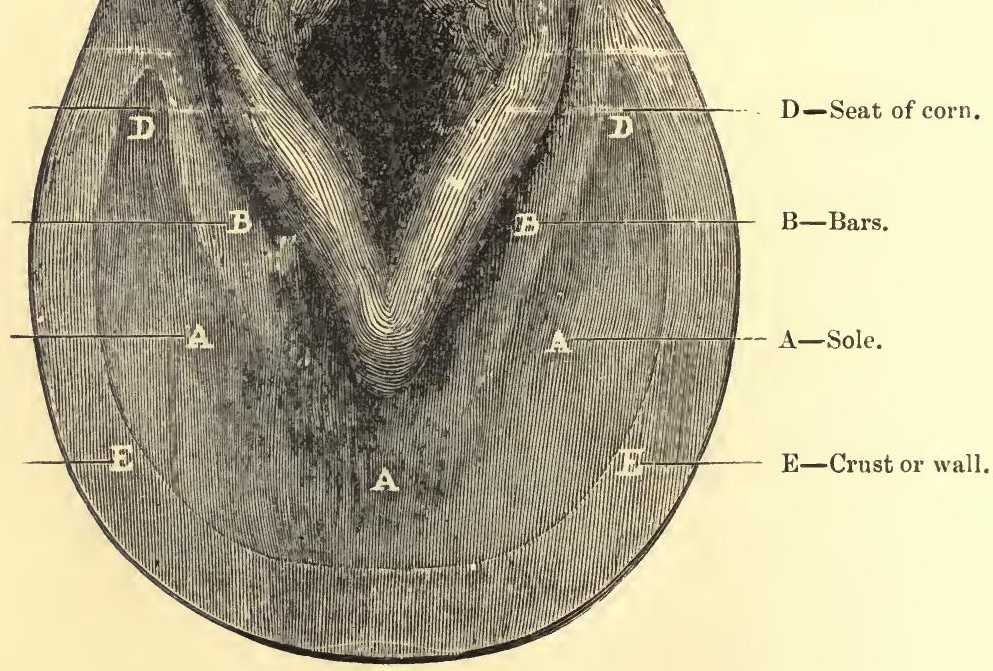

Ground surface of the foot. 
Fig. 7.

Plate 50.

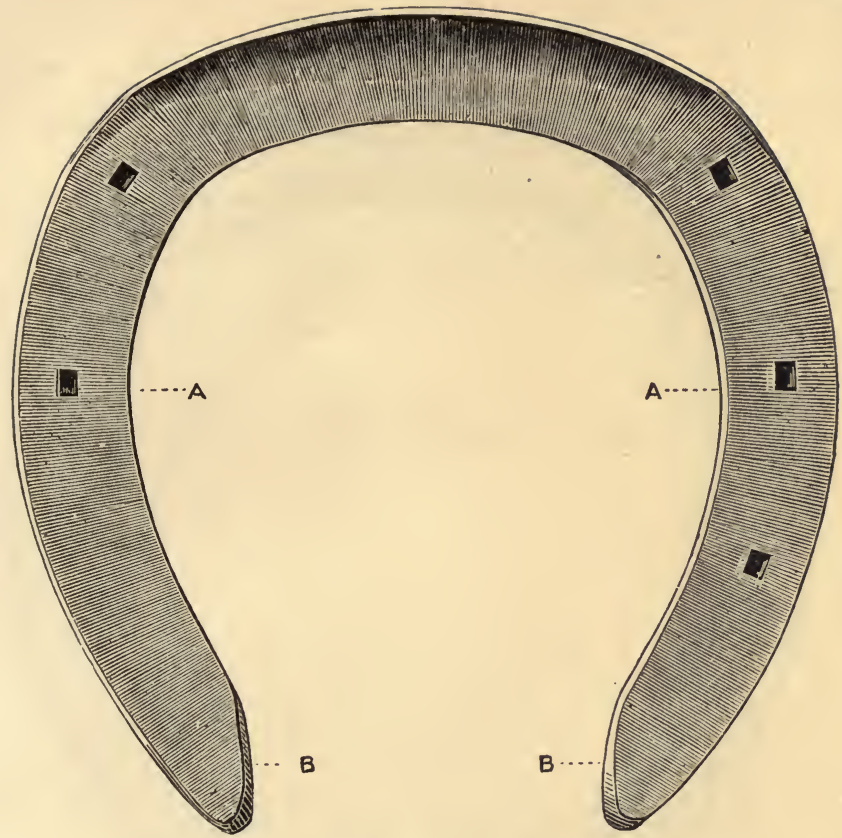

Shoe flat to the sole.

Fig. 8.

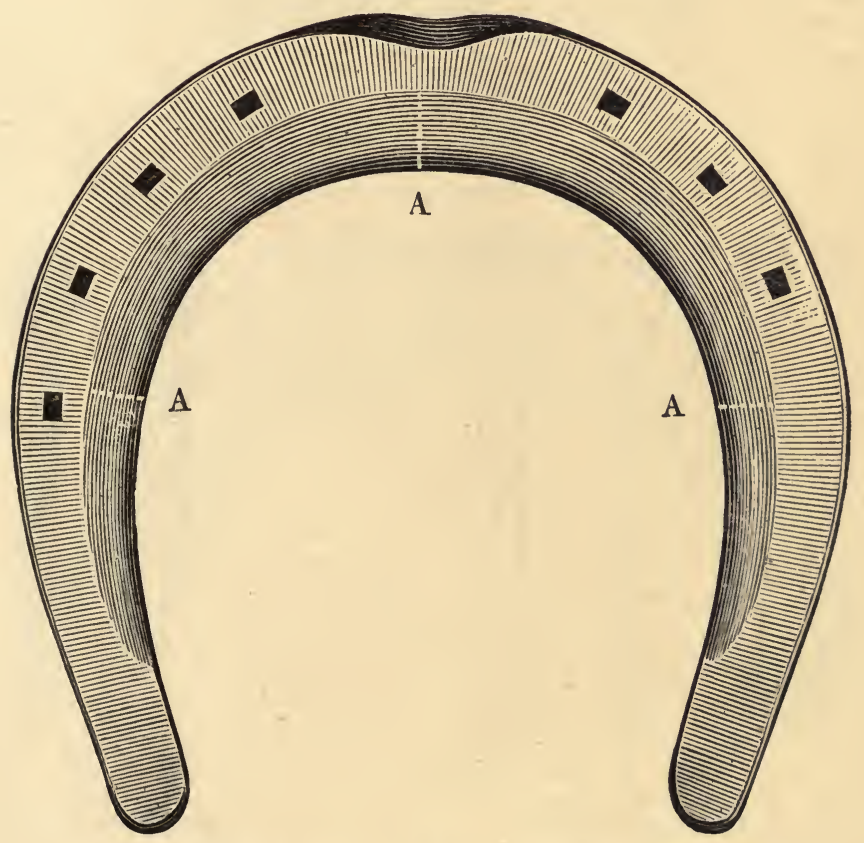

Seated-out Shoe. A A A-Seating-out. 
Plate 51.

Fig. 9.

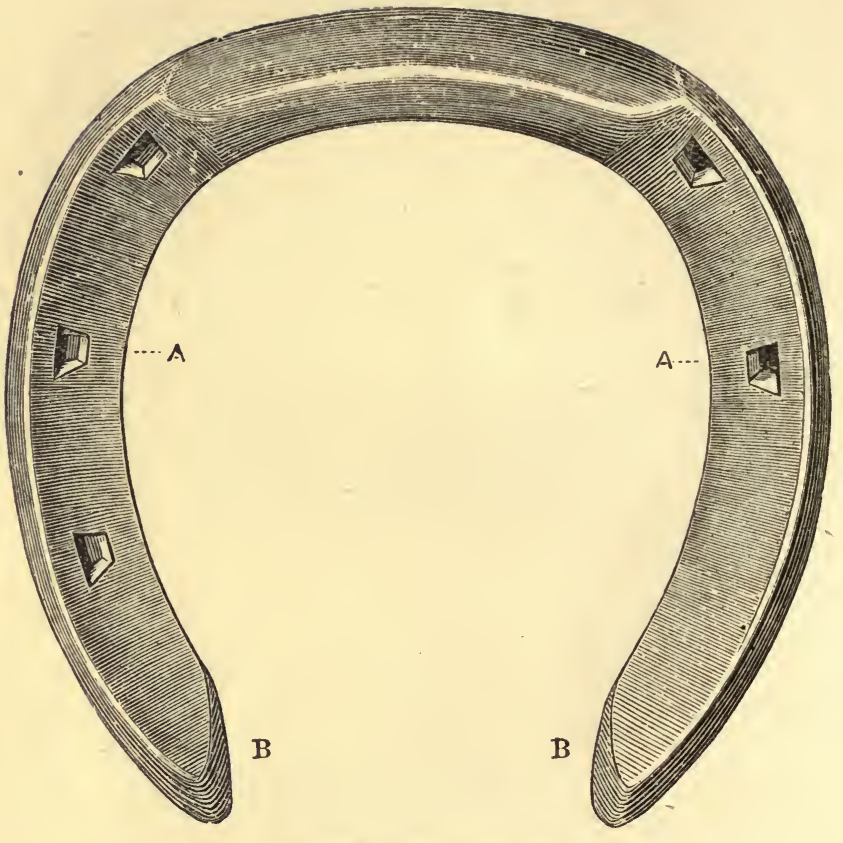

Concave ground surface.

Fig. 10.

Fig. 11.
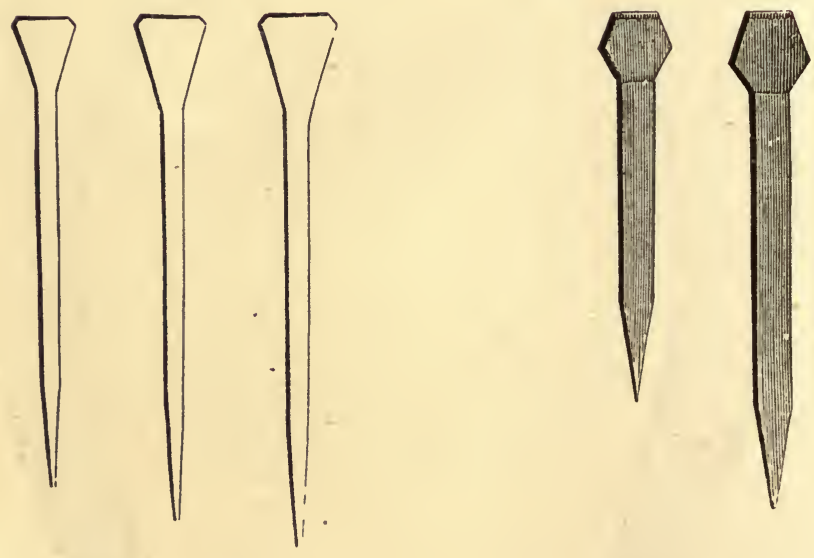

Countersunk nails.

Rose-headed nails. 
Plate 52.

Fig. 12.

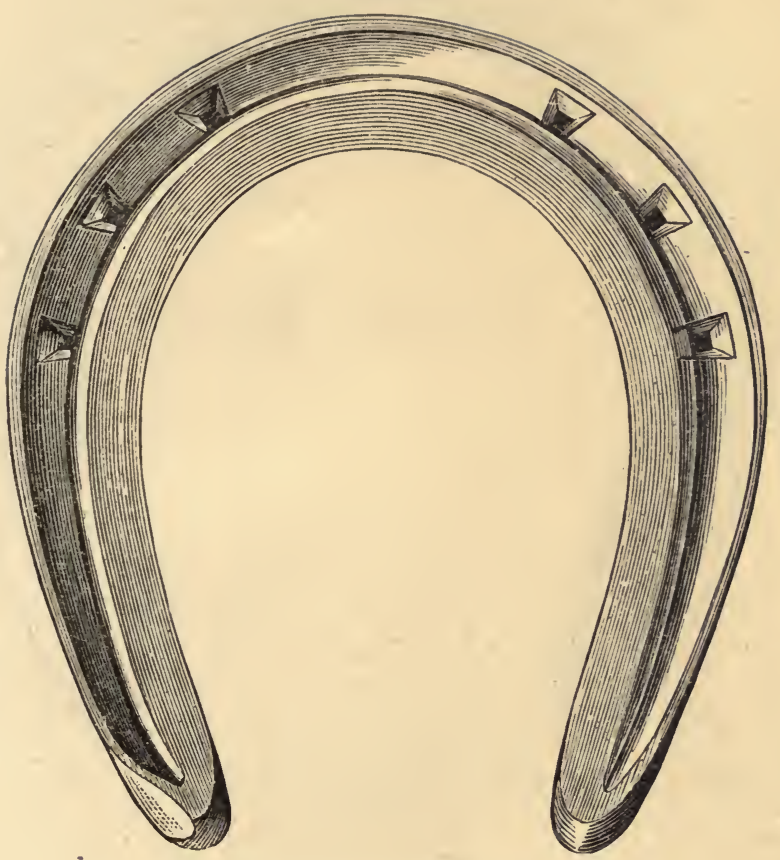

Fullered and seated-out shoe.

Fig. 13.

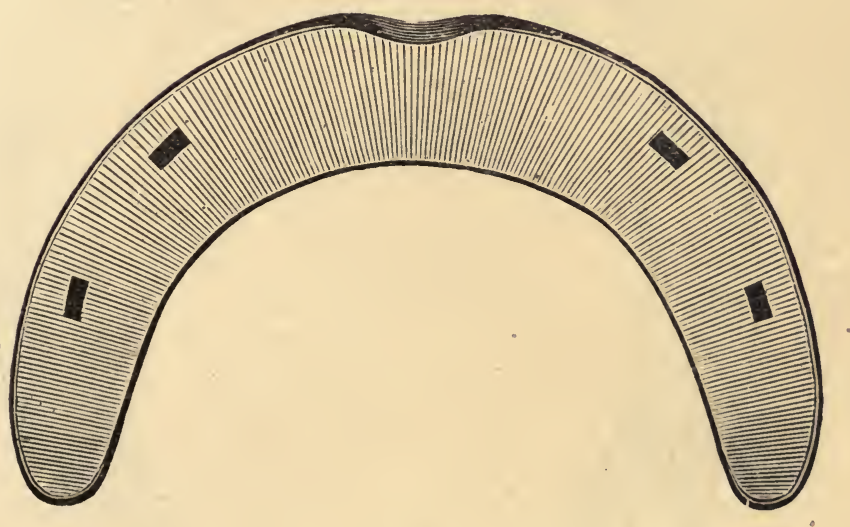

A Tip. 


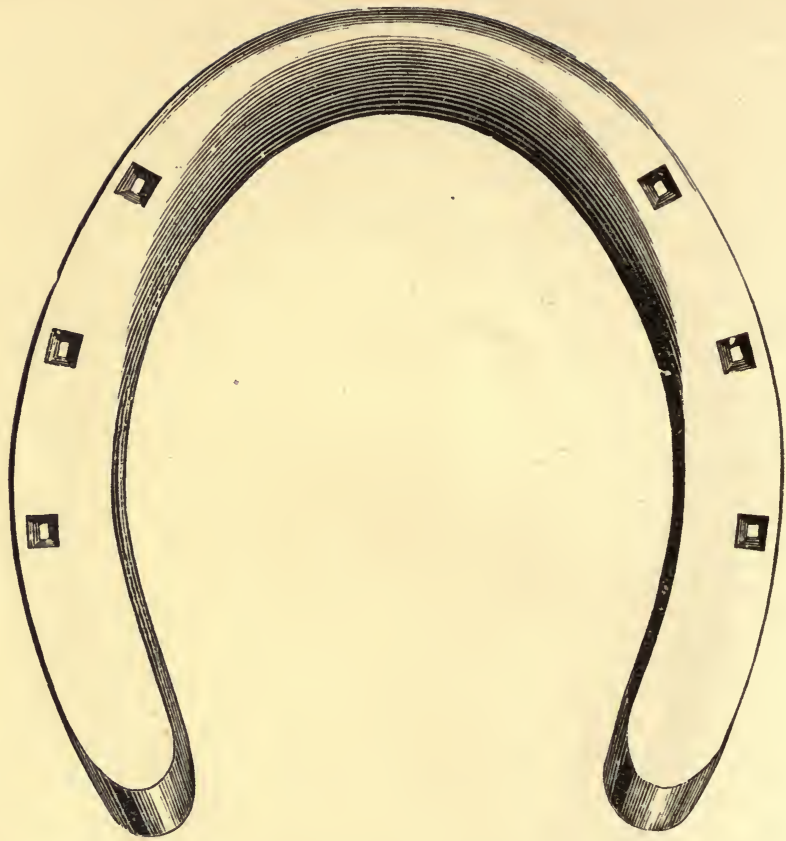

Hind Shoe. Under inner posterior edge of the toe rounded off. Fig. 15.

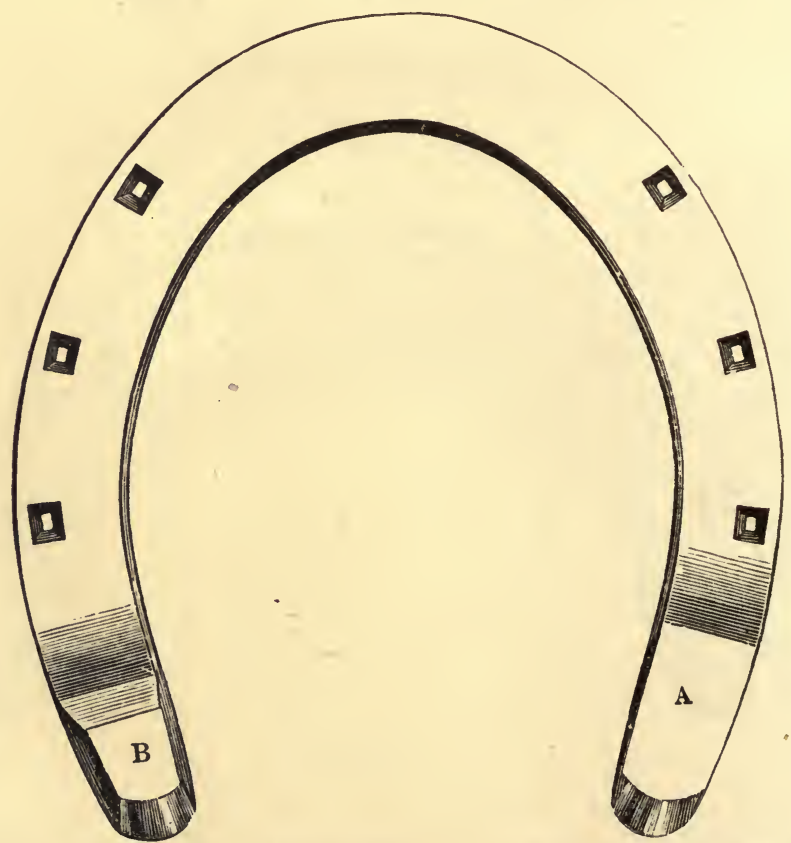

B -Calkin turned up narrow. Under inner. A-Calkin turned up wide. posterior edge of toe not rounded off. 
Fig. 16.

Plate 54.

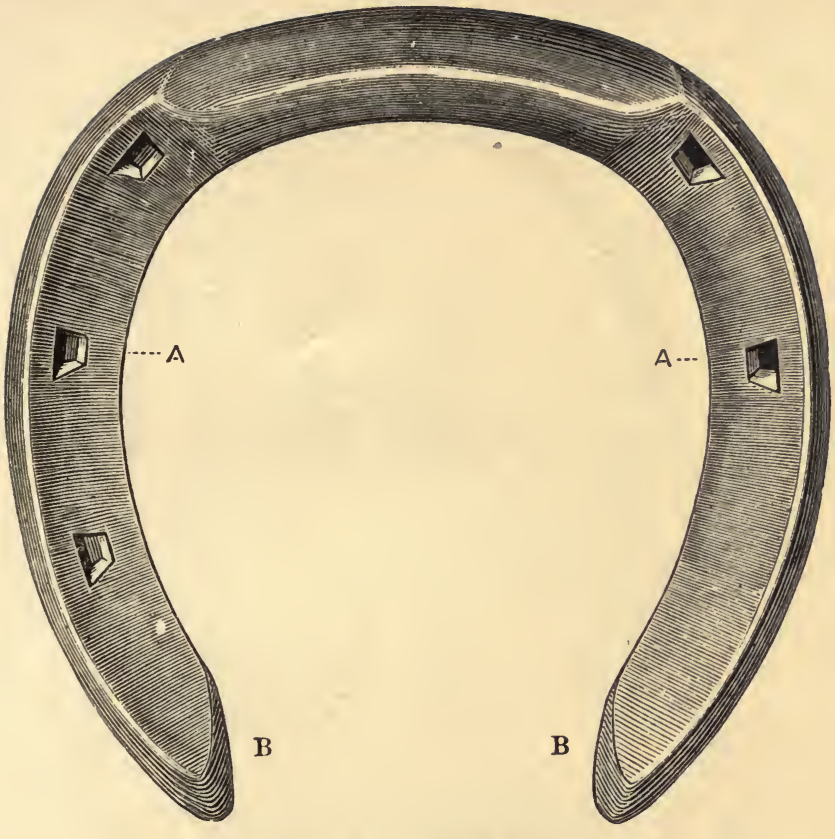

Turned-up toe-ground surface.

A A-Upper surface of shoe flat to sole. B B-Web narroved and sloped off at heels.

Fig. 17.

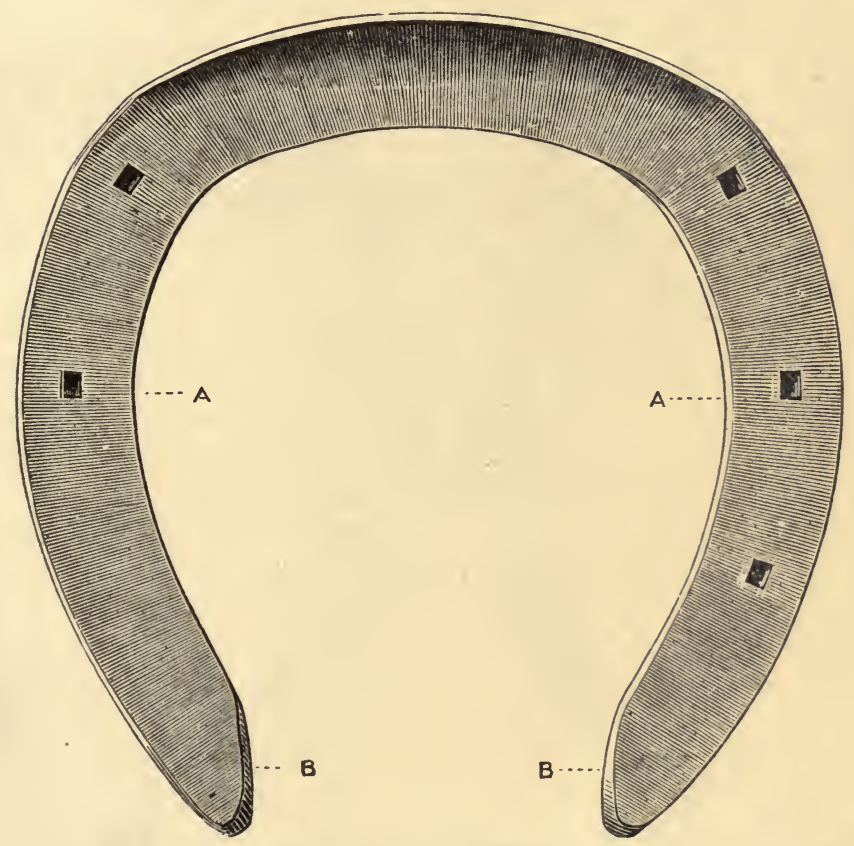

Turned-up toe-sole surface. 
Fig. 23.

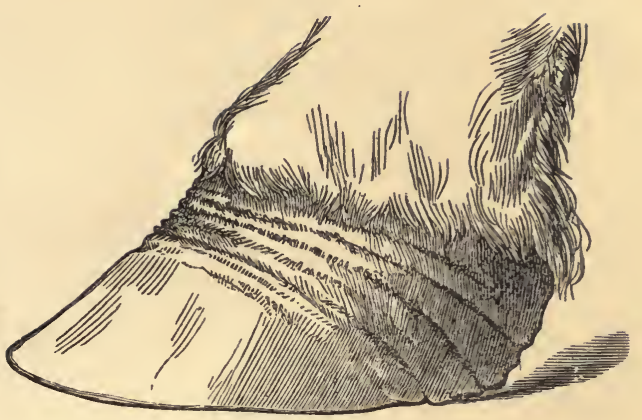

Outward appearance of Hoof in Laminitis.

Fig. 24.

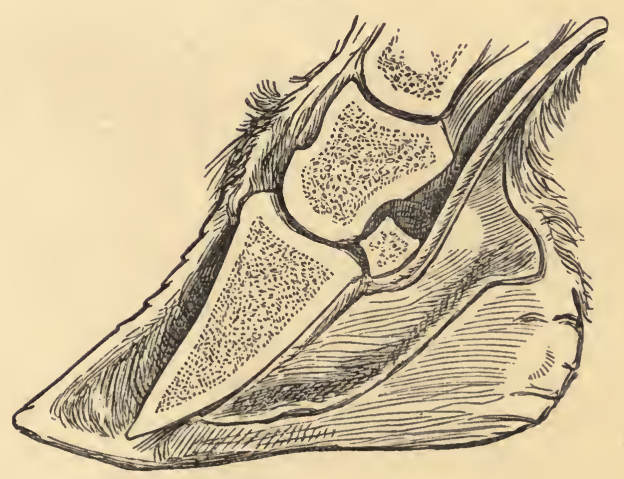

Section of Hoof in Laminitis. 


UNIVERSITY OF CALIFORNIA LIBP A T. - 

RETURN TO the circulation desk of any University of California Library

$$
\text { or to the }
$$

NORTHERN REGIONAL LIBRARY FACILITY

Bldg. 400, Richmond Field Station

University of California

Richmond, CA 94804-4698

ALL BOOKS MAY BE RECALLED AFTER 7 DAYS

- 2-month loans may be renewed by calling (510) 642-6753

- 1-year loans may be recharged by bringing books to NRLF

- Renewals and recharges may be made 4 days prior to due date.

DUE AS STAMPED BELOW

\section{FEB 171997}

\section{$12,000(11 / 95)$}

LD2 1 A $-60 m \cdot 8,70$

(N8837s10) 476 - A-32

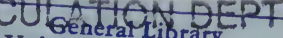

University of Caliry Berkeley 


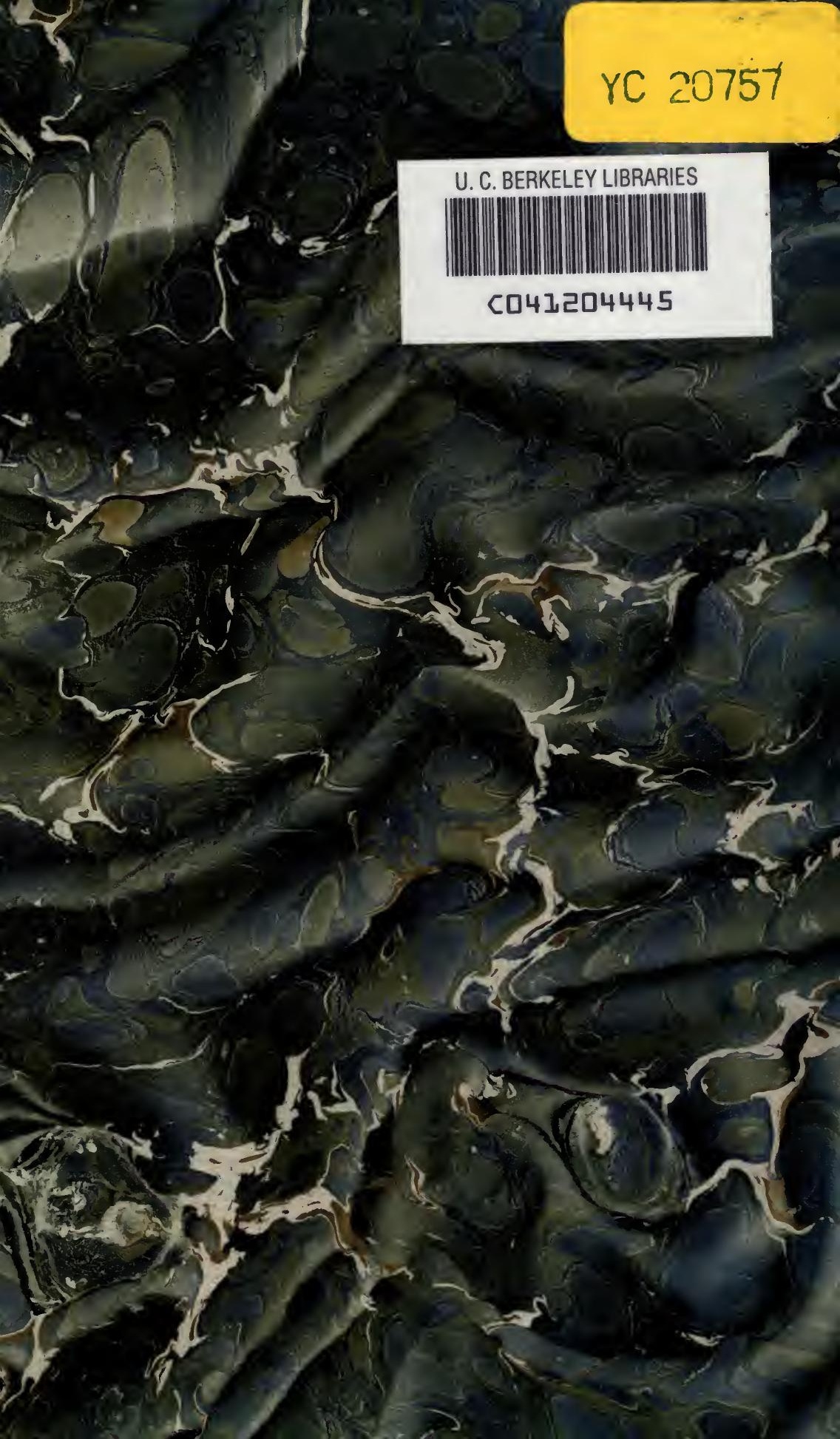


of

崩

3089

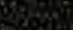

5.

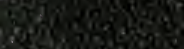

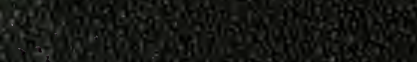
a.tig 3.

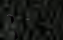

a 10.0

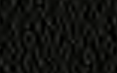

vicion

(1.2.

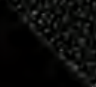

